
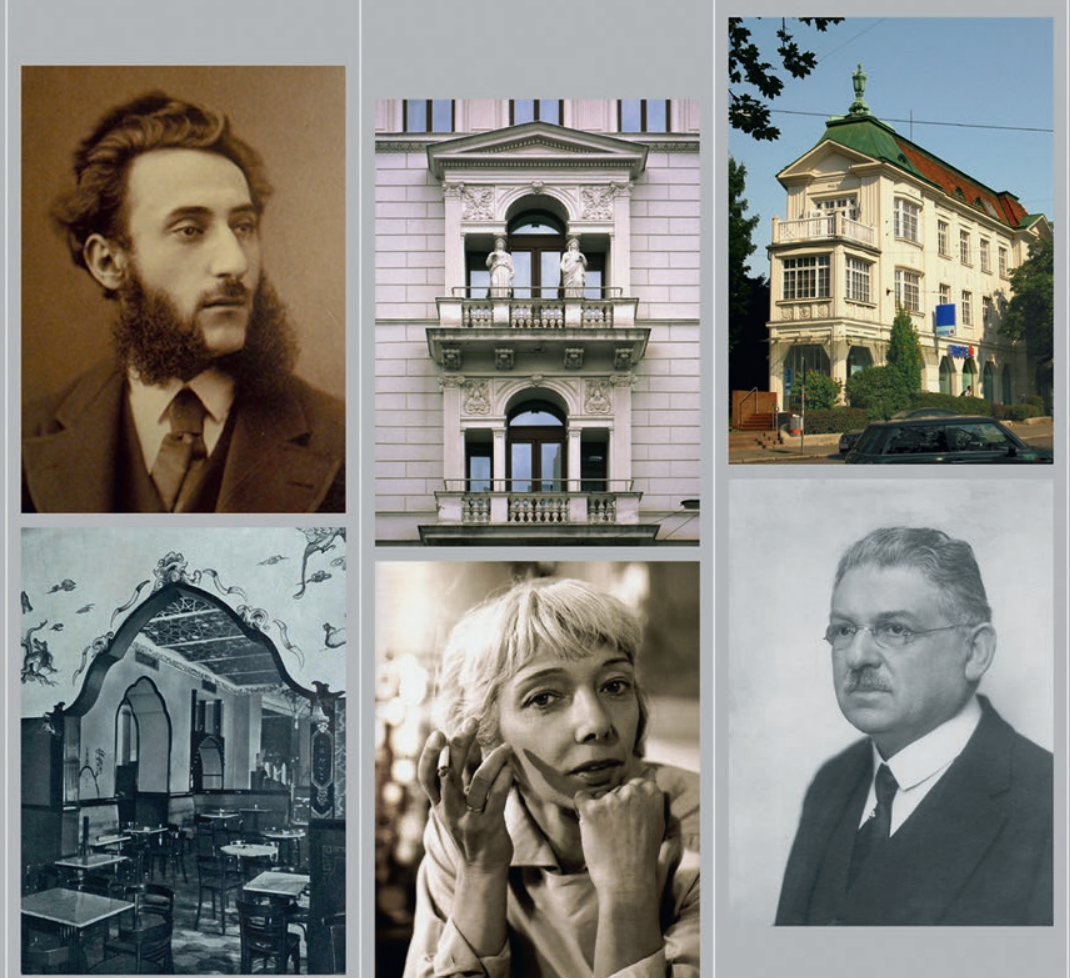

$\frac{\sqrt{10}}{2}$

\title{
ZUM JÜDISCHEN ERBE IN DER WIENER ARCHITEKTUR
}

Der Beitrag jüdischer

Architektlnnen am Wiener

Baugeschehen 1868-1938 
böhlau 


\author{
Ursula Prokop
}

\title{
ZUM JÜDISCHEN ERBE IN DER WIENER ARCHITEKTUR
}

Der Beitrag jüdischer ArchitektInnen am Wiener Baugeschehen I868- I938

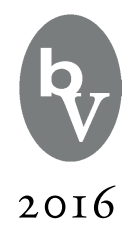

BÖHLAU VERLAG WIEN KÖLN WEIMAR 
Der Wissenschaftsfonds.

\section{Veröffentlicht mit der Unterstützug des Austrian Science Fund (FWF): PUB 269-G26}

Open Access: Wo nicht anders festgehalten, ist diese Publikation lizenziert unter der Creative-CommonsLizenz Namensnennung 4.0; siehe http://creativecommons.org/licenses/by/4.o/

Bibliografische Information der Deutschen Nationalbibliothek:

Die Deutsche Nationalbibliothek verzeichnet diese Publikation in der Deutschen Nationalbibliografie; detaillierte bibliografische Daten sind im Internet über http://dnb.d-nb.de abrufbar.

Umschlagabbildungen:

Wilhelm Fraenkl/Porträt (Österr. Ing. u. Architektenverein)

Jacqueline Groag/Porträt (privat)

Ignaz Reiser/Porträt (privat)

Julius Wohlmuth, Geschäftshaus, Wien 19, Grinzinger Allee 1 (Prokop)

Wilhelm Fraenkel, Miethaus Schlesinger, Schottenring (Prokop)

Renate Wiener, Café Tirolerhof (Moderne Welt 1929)

(C) 2016 by Böhlau Verlag GmbH \& Co. KG, Wien Köln Weimar

Wiesingerstraße 1, A-1010 Wien, www.boehlau-verlag.com

Alle Rechte vorbehalten. Dieses Werk ist urheberrechtlich geschützt.

Jede Verwertung außerhalb der engen Grenzen des Urheberrechtsgesetzes ist unzulässig.

Korrektorat: Volker Manz, Kenzingen

Satz: Michael Rauscher, Wien

Einbandgestaltung: Michael Haderer, Wien

Druck und Bindung: Finidr, Cesky Tesin

Gedruckt auf chlor- und säurefreiem Papier

Printed in the EU

ISBN 978-3-205-20265-3 


\section{Inhalt}

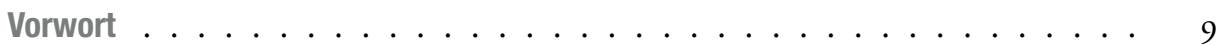

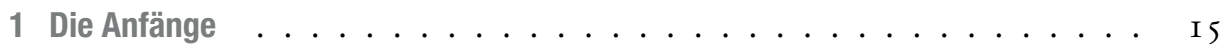

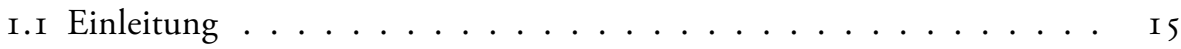

I.2 Die Einzelgänger: Wilhelm Fraenkel und Josef Unger - Adelspalais und Arbeiterwohnungen .................. I7

2 Die Schüler Friedrich von Schmidts … . . . . . . . . . . . 25

2.I Max Fleischer, Wilhelm Stiassny und deren Umfeld - die Kontroverse um das jüdische Selbstverständnis im Kontext des Synagogenbaus . . . 25

2.2 Karl König - ein jüdischer Professor . . . . . . . . . . . . . . . . 44

3 Die Schüler Karl Königs vor dem Ersten Weltkrieg . . . . . . . . . . . . 53

3.I Das Werden der modernen Großstadt - neue Bauaufgaben . . . . . . . 53

3.I.I Das Warenhaus . . . . . . . . . . . . . . . . 53

3.I.2 Das Wohn-Geschäftshaus . . . . . . . . . . . . . 56

3.I.3 Banken und Versicherungen . . . . . . . . . . . . . . 70

3.2 Neue Wege im Synagogenbau . . . . . . . . . . . . . . . . . 74

3.2.I Nicht realisierte Projekte und ihre Nachfolgebauten -

Ernst Lindner und Oskar Marmorek . . . . . . . . . . . . 74

3.2.2 Innovative Kultbauten auf dem Weg zur Moderne - Ignaz Reiser und Arthur Grünberger . . . . . . . . . . . . . . . . 84

3.3 Hartwig Fischel - ein Schüler Karl Königs im künstlerischintellektuellen Umfeld der Wiener Moderne . . . . . . . . . . . 92

4 Baumeister und nicht akademische Architekten - die Hochblüte des Miethausbaus. Drei Fallstudien: Leopold Fuchs, Neumann Tropp und Ernst Epstein ． . . . . . . . . . . . . . . . . . . . . . 97

5 Die Schüler Karl Königs in der Zwischenkriegszeit die "zweite Wiener Moderne" . . . . . . . . . . . . . . . . . . . . . . Io9

5.I Josef Frank und die Werkbundsiedlung . . . . . . . . . . . . . I09

5.2 Oskar Strnad - fließende Grenzen zu Theater und Film . . . . . . . . I 2 I

5.3 Oskar Wlach $-»$ Haus und Garten« . . . . . . . . . . . . . I26 
5.4 Walter Sobotka - der gute und billige Gegenstand . . . . . . . . . . I 29

6 Der Kreis um Adolf Loos . . . . . . . . . . . . . . . . . . . . . I33

6. I Jacques Groag und Paul Engelmann - das Projekt des »Wittgenstein-

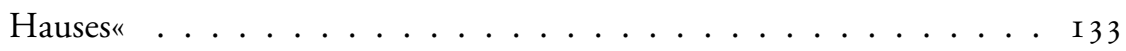

6.2 Felix Augenfeld und Ernst Schwadron - weitere Protagonisten der Wiener Wohnraumkultur . . . . . . . . . . . . . I46

6.3 Die Architektengemeinschaft Josef Berger und Martin Ziegler - Bauten des Roten Wien" . . . . . . . . . . . . . . I 55

6.4 Heinrich Kulka und seine Verdienste um die Loos-Rezeption . . . . . . I 59

7 Auflösungstendenzen der jüdischen Identität - Konvertiten und

Partnerschaften mit Nichtjuden . . . . . . . . . . . . . . . I63

7.I Ernst Lichtblau . . . . . . . . . . . . . . . . . . . . I63

7.2 Die Grenzfälle - Karl Jaray, Siegfried Drach, Felix Angelo Pollak und Gustav Schläfrig . . . . . . . . . . . . . . . . I70

7.3 Partnerschaften mit Nichtjuden . . . . . . . . . . . . . . I79

7.3.I Paul Fischel und Heinz Siller - traditionelle Tendenzen im

Wohnbau ................. I79

7.3.2 Fritz Judtmann und Egon Riss - die zeitgenössische Moderne . . $\quad$ I83

7.3.3 Wilhelm Baumgarten und Josef Hofbauer - der innovative Schulbau .................. . I 87

7.3.4 Rudolf Baumfeld und Norbert Schlesinger - Geschäftslokale prägen das Stadtbild . . . . . . . . . . . . . I9I

8 Frauen als Pioniere auf dem Gebiet der Architektur . . . . . . . . . . . . . . 193

8. I Ella Briggs und das Rote Wien . . . . . . . . . . . . . . . . I94

8.2 Liane Zimbler - Einrichtungen für die gehobene Mittelschicht . . . . . $\quad$ I97

8.3 Friedl Dicker und Franz Singer - die Einfachheit des Wohnens . . . . . 20 I

8.4 Kunstgewerblerinnen als Innenarchitektinnen . . . . . . . . . . 206

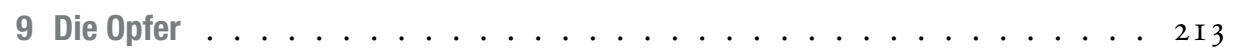

9. I Der direkte Transport in den Tod - Friedrich Schön, Stefan Fayans und Josef Sinnenberg . . . . . . . . . . . . . . . 2 I 3

9.2 Außergewöhnliche Schicksale im Inferno der NS-Zeit - Erich Ziffer, Jakob Reitzer, Leopold Schulz und Fritz Keller . . . . . . . . . . . . 22 I

9.3 Die Opfer von Theresienstadt - Heinrich Kestel und Leopold Steinitz . 226 
10 »Emigranten« mit Erfolgsgeschichte . . . . . . . . . . . . . . . . . . 23 I Io. I Friedrich Kiesler . . . . . . . . . . . . . . . 23 I ro.2 Richard Neutra . . . . . . . . . . . . . . . . . . . . . 234 I0.3 Victor Gruen . . . . . . . . . . . . . . . 237

11 Die endgültige Auslöschung . . . . . . . . . . . . . . . . . 24I

12 Schlussbetrachtung . . . . . . . . . . . . . . . . . 249

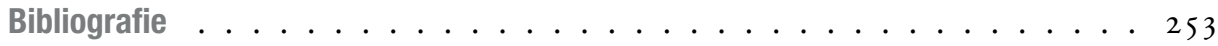

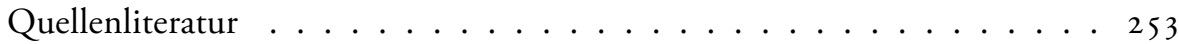

Forschungsliteratur . . . . . . . . . . . . . 255

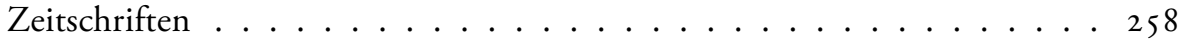

Internetlinks . . . . . . . . . . . . . . . . . . . 259

Archive und ihre Abkürzungen . . . . . . . . . . . . . 259

Abbildungsverzeichnis .................. 26 I

Dankadresse ....................... 267

Personenregister . . . . . . . . . . . . . . . . . . . . 269 


\section{Vorwort}

Dem Phänomen des großen, oftmals maßgeblichen Anteils jüdischer Künstler und Intellektueller an der Wiener Fin-de-siècle-Kultur wurde in den letzten Jahrzehnten allgemein große Aufmerksamkeit zuteil. Das Interesse an dieser Periode wurde insbesondere durch Carl Schorskes bahnbrechende Studie geleitet, die in der Folge zu zahlreichen Ausstellungen, Forschungsprojekten und Publikationen führte. ${ }^{1}$ Während dem Anteil der Juden auf dem Gebiet der Natur- und Geisteswissenschaften und im künstlerischen Bereich, insbesondere mit Blick auf Literatur, Theater, Film und Musik, bereits breiter Raum gewidmet wurde, ist das Gebiet der Architektur bislang nahezu überhaupt nicht beachtet worden. Jüdische Architekten wurden - wenn überhaupt - zumeist nur im Rahmen der Emigrationsforschung beachtet, während das Baugeschehen in Wien selbst eher marginalisiert wurde. In diesem Kontext fanden Juden vorwiegend als Finanziers oder Mäzene Erwähnung, kaum aber als Architekten und Baumeister, obwohl nicht wenige prominente und für das Stadtbild prägende Bauten jüdischen Österreichern zu verdanken sind. Von diesem Ansatz geht auch die bemerkenswerte Studie von Fredric Bedoire "The jewish contribution to modern architecture I 830-1930 aus, die sich in erster Linie mit den jüdischen Bauherren und den von ihnen in die Wege geleiteten Projekten befasst, auf die Architekten jedoch kaum eingeht. ${ }^{2}$

Bezeichnend für diese Nichtbeachtung - nicht zuletzt auch in jüdischen Kreisen selbst - ist die Haltung des Kunsthistorikers Hans Tietze, der seinerseits ein konvertierter Jude war, in seinem 1930 erschienen Überblick über die Geschichte der Juden Wiens, in dem er auf deren Anteil am Architekturgeschehen nur ganz nebenbei eingeht und es eher abschätzig als "epigonal « bezeichnet. ${ }^{3}$ Diese Bemerkung ist umso erstaunlicher, als sich Tietze selbst seine Villa 1907 von Hartwig Fischel errichten ließ, einem durchaus qualifizierten Mann, der seine Ausbildung an der Wiener Technischen Hochschule erhalten hatte, wo er - wie viele andere jüdische Architekten - die Vorlesungen von Karl König besucht hatte. Auf König, der eine ganz bedeutende Stellung als einer der wenigen jüdischen Professoren einnahm, wird noch einzugehen sein, da der Großteil der in Wien tätigen Architekten jüdischer Herkunft bei ihm studiert hatte. In ähnlicher Weise hat auch noch rund siebzig Jahre später Robert

I C. Schorske, Fin-de-siècle Vienna, Melbourne 1987.

2 F. Bedoire, The Jewish contribution to modern architecture I830-1930, Stockholm 2004.

3 H. Tietze, Die Juden Wiens, Wien 1933. 
Wistrich in seiner äußerst umfassenden und profunden Studie "Die Juden Wiens im Zeitalter Kaiser Franz Josephs« diesem Thema nahezu keine Beachtung geschenkt. ${ }^{4}$

Eine Erklärung für dieses Phänomen könnte der Umstand sein, dass zum Zeitpunkt der intensivsten Tätigkeit von jüdischen Baumeistern und Architekten sich bereits viele so weit assimiliert hatten, dass sie darauf bedacht waren, ihre jüdische Identität zu verbergen. So beklagt Adolph Kohut, der Autor des Lexikons » Berühmte israelitische Männer und Frauen", das um I905 publiziert wurde, dass viele Künstler sich weigerten, dem Autor Informationen zu liefern, »da sie davor zitterten, als Juden auch öffentlich zu figurieren. "5 Eine weitere Erklärung könnte auch sein, dass der Prozentsatz der Juden, die in der Baubranche tätig waren, mit ungefähr I 2 Prozent nur etwas mehr als dem generellen Anteil an der Wiener Bevölkerung entsprochen hatte, es hier also keinesfalls zu einer "Überrepräsentation" gekommen ist wie zum Beispiel auf dem Gebiet des Journalismus oder der Literatur. ${ }^{6}$ Des Weiteren kam es gerade in diesem Bereich späterhin zu einer relativ engen Verflechtung von Juden und Nichtjuden in mehrfacher Hinsicht, die als Indiz einer kulturhistorischen Symbiose gedeutet werden kann, wie sie besonders für Wien spezifisch war und die auch die Möglichkeit einer anderen - einer »normalen« - Weiterentwicklung in sich getragen hätte.

Die Nichtbeachtung dieses Themas wurde natürlich auch durch die spezifische politische Situation Österreichs im 20. Jahrhundert verstärkt. Bereits ab I938, dem Jahr des sogenannten "Anschlusses" Österreichs an NS-Deutschland, durfte nichts über Juden publiziert werden. Nach dem Ende des Krieges und noch Jahre danach wurde dieses Thema absolut verdrängt. Das Desinteresse war dermaßen profund, dass die längste Zeit auch über die bedeutendsten Persönlichkeiten nicht einmal die elementarsten Lebensdaten bekannt waren. Erst allmählich, Mitte der Achtzigerjahre, gab es einzelne Beiträge oder Ausstellungen wie "Die Vertreibung des Geistigen«, wo insbesondere Friedrich Achleitner in seinem Katalogbeitrag "Die geköpfte Architektur" auf den ungeheuren Aderlass hinwies, den die Vertreibung der jüdischen Österreicher nicht zuletzt auch auf dem Gebiet der Architektur bedeutet hatte. ${ }^{7}$ Bahnbrechend waren schließlich die beiden 1987 bzw. I992 erschienenen Publikationen Pierre Genées über die Synagogen in Österreich mit dem Schwerpunkt Wien. Erstmals wurde hier das Interesse auf ein bis dahin nahezu völlig ignoriertes Gebiet der Architektur gelenkt. In diesem Kontext erfolgte auch die Nennung diverser Architektennamen, die

4 R. S. Wistrich, Die Juden Wiens im Zeitalter Kaiser Franz Josephs, Wien/Köln/Weimar 1999.

5 A. Kohut, Berühmte israelitische Männer und Frauen, Leipzig o. J., I. Bd., S. 324.

6 Der generelle Anteil der Juden an der Bevölkerung Wiens betrug um I900 knapp 9 Prozent. Siehe dazu auch M. L. Rozenblit, Die Juden Wiens I867-1914, Wien/Köln I989.

7 F. Achleitner, Die geköpfte Architektur, in: Die Vertreibung des Geistigen (Kat.), Wien 1985. 
zu diesem Zeitpunkt noch weitgehend unbekannt waren. ${ }^{8}$ Damit eröffneten sich für die weitere Forschung völlig neue Perspektiven. Auf die Existenz der beiden Architekturschulen um Otto Wagner und Karl König, die neben fachlichen Auseinandersetzungen nicht zuletzt auch von antisemitischen Gegensätzen geprägt waren, wies Mitte der Neunzigerjahre die Studie "Wien, Aufbruch zur Metropole« hin. ${ }^{9}$ Nur kurze Zeit später beschäftigte sich die von Matthias Boeckl kuratierte Ausstellung "Visionäre \& Vertriebene« vor allem mit den in die USA ausgewanderten Architekten und erarbeitete erstmals auch genauere Biografien der betreffenden Persönlichkeiten. ${ }^{10}$

In kurzer Folge erschienen dann einige monografische Arbeiten, die sich zumindest mit den bedeutendsten Persönlichkeiten der Wiener jüdischen Architektenszene befassten. Markus Kristan publizierte seine Arbeiten über Oskar Marmorek und Karl König und Maria Welzig veröffentlichte ihre Dissertation über Josef Frank. ${ }^{11}$ Auch im Rahmen der Genderforschung wurde das Augenmerk nicht zuletzt auf jüdische Künstlerinnen gelenkt. Hier leistete insbesondere Sabine Plakolm-Forsthuber Bahnbrechendes. ${ }^{12}$ Das durch die Emigration bedingte Nichtvorhandensein von Nachlässen oder Nachkommen, die eventuell Auskunft geben könnten, erschwerte allerdings die Forschung ungemein.

Einen großen Sprung auf diesem Gebiet stellten das von Helmuth Weihsmann 2005 herausgegebene Lexikon "In Wien gebaut" und das vom FWF geförderte und seitens des "Architekturzentrum Wien" (AzW) über rund zehn Jahre (2003-2013) durchgeführte Projekt einer Datenbank »Architektenlexikon, Wien I770-1945 « dar. ${ }^{13}$ Erstmals wurde hier das Augenmerk nicht nur auf die wenigen bereits bekannten Persönlichkeiten gelenkt, sondern in der Breite geforscht und auch unbedeutendere Architekten abgehandelt. Dieser Umstand ermöglichte es dann, Querverbindungen herzustellen und das Bild der Wiener Architektenszene abzurunden. Obwohl in der Thematik sich teilweise überschneidend, waren die beiden Vorhaben doch ziemlich unterschiedlich strukturiert und haben sich schließlich sehr gut ergänzt. Insbesondere nach der Onlinestellung der Datenbank gab es darüber hinaus noch sehr viele Rückmeldungen von Angehörigen aus der ganzen Welt, die dabei halfen, die Puzzlestü-

8 P. Genée, Synagogen in Wien I825-1938, Wien 1987; ders., Synagogen in Österreich, Wien 1992.

9 U. Prokop, Wien. Aufbruch zur Metropole, Wien/Köln I 994.

ı $\mathrm{M}$. Boeckl (Hg.), Visionäre und Vertriebene (Kat.), Wien I995.

I I M. Kristan, Oskar Marmorek, Wien/Köln/Weimar 1996; ders., Carl König, Wien I999; M. Welzig, Josef Frank, Wien/Köln/Weimar 1998.

I2 S. Plakolm-Forsthuber, Künstlerinnen in Österreich I897-I938, Wien 1994.

I 3 H. Weihsmann, In Wien gebaut, Wien 2005 ; Datenbank des Architekturzentrums Wien (AzW) »Architektenlexikon Wien, 1770-1945", abrufbar unter www.architektenlexikon.at, hinfort zitiert als "Architektenlexikon«. 
cke zu einem Ganzen zusammenzufügen, auch wenn noch immer vieles offenbleiben muss.

Basierend auf der hier angeführten Literatur und insbesondere dem Projekt der Datenbank, dem eine intensive Archivrecherche vorangegangen ist, stellt diese Studie den Versuch dar, einen Überblick über das Thema zu geben, wobei sich allerdings einer Aufarbeitung die verschiedensten Probleme entgegenstellen. Vorweg steht die Kernfrage, wie sich der Begriff »Jude« definiert und ob es überhaupt legitim ist, Menschen nur unter dem Aspekt ihrer Religionszugehörigkeit oder Herkunft als eigene Gruppe zu besprechen. Generell würde man heute solche Fragestellungen eher verneinen und diese Fakten als reine Privatangelegenheit betrachten, wenn die Geschichte des 20. Jahrhunderts diese Einstellung nicht auf das Brutalste widerlegt hätte. Nicht wenige Geisteswissenschaftler, wie zum Beispiel Ernst Gombrich, haben sogar eine »jüdische Identität" generell abgelehnt und als ein »künstlich geschaffenes Konstrukt« bezeichnet. ${ }^{14}$ Bezeichnenderweise sieht Gombrich in seinem Essay - unter Hinweis auf die "Bilderfeindlichkeit der jüdischen Kultur" - auch keinen nennenswerten Anteil jüdischer Künstler an der bildenden Kunst und Architektur. Die antisemitischen Strategien der NS-Zeit, deren ideengeschichtliche Wurzeln allerdings weit in das I 9. Jahrhundert zurückreichen, waren für das Schicksal der - in der hier abgehandelten Periode - lebenden Personen jedoch so maßgeblich, dass man gezwungenermaßen den sehr weit gefassten NS-Begriff des »Juden« übernehmen muss. Dies insbesondere angesichts des Umstandes, dass sich in Wien sehr früh infolge von Konversionen und "Mischehen" eine Art von "Mischkultur" ausgeformt hatte, sodass nicht wenige der Wiener Juden gegen Ende der 3oer-Jahre des 20. Jahrhunderts so weit assimiliert waren, dass viele von ihnen sich gar nicht mehr bewusst waren, dass sie nach NSRassenkategorien als "Juden" galten. Generell hätte in diesem Kontext der Begriff »jüdische Österreicher« weit mehr Berechtigung. Hier ist auch der von Martha L. Rozenblit vertretenen These einer generellen Segregation der Wiener Juden von der nicht jüdischen Bevölkerung - insbesondere was die »bürgerliche« Mittelschicht betrifft - mit einer gewissen Skepsis zu begegnen. ${ }^{15}$

Ein weiteres Problem stellt die Strukturierung des Themas dar. Die Intention dieser Studie ist keinesfalls eine umfassende enzyklopädische Auflistung aller betreffenden Personen, sondern eine kulturhistorische Überschau mit bestimmten Schwerpunktsetzungen. Einer chronologischen Anordnung folgend werden vor allem Einzelpersönlichkeiten im Hinblick auf ihre Bedeutung beziehungsweise Gruppierungen nach

I 4 Sieh dazu E. H. Gombrich, Jüdische Identität und jüdische Schicksal, Wien I997.

I 5 Marsha L. Rozenblit, Segregation, Anpassung und Identitäten der Wiener Juden vor dem ersten Weltkrieg, in: Eine zerstörte Kultur (G. Botz u. a), Wien 2002. 
Schulen und deren Positionierungen oder Schicksal angeführt. Auch einzelne Themenschwerpunkte, etwa spezielle Bauaufgaben oder besonders markante Projekte, sollen hervorgehoben werden. In diesem Kontext kann hingegen die Geschichte der oftmals jüdischen Bauherren nur im Einzelfall und ansatzweise behandelt werden eine tiefer gehende Betrachtung dieses Themas würde zum Ausufern der Arbeit führen, ist aber als Hintergrundfolie für weitere Forschung durchaus angedacht. 


\section{Die Anfänge}

\subsection{Einleitung}

Der lange und schwierige Weg der Juden auf dem Weg zur Emanzipation, wie sie in den meisten europäischen Ländern im Laufe des 19. Jahrhunderts erreicht wurde, ist wohl hinlänglich bekannt, soll aber im Hinblick auf die konkrete Thematik noch einmal kurz zusammengefasst werden. Obwohl seit dem Toleranzpatent Josephs II. von 1782 Juden in Österreich theoretisch die Zulassung zu Hochschulen und Gewerbefreiheit zugesichert wurde, existierten weiterhin zahlreiche Beschränkungen, sodass von einer "normalen" Integration noch lange nicht die Rede sein konnte. Dementsprechend waren in der ersten Hälfte des I9. Jahrhunderts in den meisten Berufsgruppen - insbesondere in den zünftisch organisierten - nur äußerst selten Juden vertreten. Erst im Zuge der bürgerlichen Revolution von I 848 kam es allmählich zu Zugangserleichterungen, um schließlich 1867 im Rahmen des sogenannten "Ausgleichs" von Österreich-Ungarn endlich die völlige rechtliche Gleichstellung der Juden zu gewährleisten. Dies betraf insbesondere die Berufswahl und das Niederlassungsrecht, die bis dahin sehr restriktiv gehandhabt worden waren.

Diese Entwicklung spiegelt auch das Baugewerbe wider. Während in der Zeit des "Vormärz« praktisch keine jüdischen Baumeister und Architekten tätig waren, wobei auch die relativ schlechte Baukonjunktur dieser Periode eine gewisse Rolle gespielt haben könnte, kam es Mitte des 19. Jahrhunderts infolge des Zusammentreffens mehrerer Umstände zu einschneidenden Veränderungen. Das bedeutendste Ereignis im Rahmen der Wiener Stadtgeschichte war zweifellos die I857 erstellte Verfügung Kaiser Franz Josephs zur Schleifung der bis dahin bestehenden Basteien und Festungsmauern, um eine bauliche Verbindung mit den einige Jahre zuvor eingemeindeten Vororten herzustellen. Dieser kaiserliche Erlass bedeutete die Geburtsstunde des modernen Wien und ermöglichte einen der wachsenden Bevölkerungszahl Rechnung tragenden Ausbau der Stadt, der in der Folge in einem heute kaum mehr vorstellbaren Ausmaß vorangetrieben wurde. Insbesondere in den Siebziger- und Achtzigerjahren des I9. Jahrhunderts kam es infolge der zunehmenden Industrialisierung geradezu zu einer Bevölkerungsexplosion und einer intensiven Baukonjunktur. Ihren Höhepunkt erreichte diese Entwicklung I89I, als es zur Eingemeindung der außerhalb des Gürtels gelegenen Bezirke, der sogenannten »Vororte«, kam. I 904 wurde Wien schließlich nach der Eingliederung von Floridsdorf mit rund 27.I26 ha und fast zwei Millionen Einwohnern (die Bevölkerung hatte sich innerhalb von rund fünfzig Jahren nahezu 
verdreifacht) zur zweitgrößten Stadt Europas. Wenn es auch zwischendurch Einbrüche in der Konjunktur gab, setzte sich dieser Wachstumsprozess bis zum Ausbruch des Ersten Weltkrieges fort. Im Rahmen dieser Entwicklung spielte die bereits oben erwähnte völlige bürgerliche Gleichstellung der Juden, die insbesondere einen Großteil des liberalen Bürgertums stellten und weitgehend zum Träger dieses Aufschwunges und Modernisierungsschubes wurden, eine wichtige Rolle. Nicht zuletzt geriet das ehrgeizige städtebauliche Projekt der Wiener Ringstraße, die anstelle der alten Basteien erstand, zur repräsentativen Selbstdarstellung dieser Schicht und wurde zum Symbol dieser Ära. Viele der großen jüdischen Familien, wie die Epsteins, Todescos und Ephrussis, ließen sich ihre luxuriösen Palais am neuen Wiener Prachtboulevard errichten. Ungeachtet dieser liberalen Ära wurden in diesen Jahren aber auch bereits zunehmend antisemitische Pamphlete publiziert, die sich mit diesem Phänomen befassten, wobei die üblichen Klischees, dass Juden unter anderem nur zu epigonenhaften Arbeiten fähig wären, strapaziert wurden. ${ }^{16}$ Ein Vorurteil, das insbesondere seit Richard Wagners I 850 publiziertem Aufsatz "Das Judenthum in der Musik» Allgemeingut geworden war und in der Folge auch auf andere Bereiche übertragen wurde.

In die Anfänge der sogenannten "Ringstraßenära" fällt auch das Auftreten der ersten jüdischen Architekten in Wien, wobei sowohl die soziale Herkunft als auch die architektonische Positionierung sehr heterogen waren. Die wenigsten stammten aus alten Wiener jüdischen Familien, die weitgehend dem »jüdischen Adel « angehörten und die die längste Zeit nur Dank kaiserlichen Privilegs in der Reichshauptstadt wohnen durften, sondern sie selber - oder ihre Eltern - waren kurz zuvor aus den verschiedensten Kronländern der Donaumonarchie in die Reichshauptstadt gezogen. Von großer Bedeutung waren hier insbesondere Regionen wie das Umland von Pressburg (Poszony oder Bratislava, damals noch zu Ungarn gehörend), Böhmen, Mähren und nicht zuletzt Galizien. Die ersten dieser Zuwanderer hatten daher ihre Ausbildung oft noch auswärts erhalten (ein Umstand, der aber durchaus auch auf Angehörige anderer zugewanderter Volksgruppen zutraf). Dementsprechend zählen zu den bedeutendsten Persönlichkeiten der »ersten Generation" vor allem Einzelgänger, wenngleich sich schon bald die ersten Ansätze zur Ausbildung spezifischer Gruppen von Architekten beobachten lassen. Sie alle werden zum integralen Bestandteil der Wiener Architekturszene und zu Protagonisten des Überganges vom Späthistorismus zur Moderne, wobei bemerkenswerterweise Juden sowohl auf der Seite der Traditionalisten als auch auf der der Neuerer zu finden waren.

I6 Anonymus, Das Judentum in der Baukunst, in: Zeitschrift für praktische Baukunst 38.I878, S. 3 If. 
I. Wilhelm Fraenkel, Porträt/ÖIAV

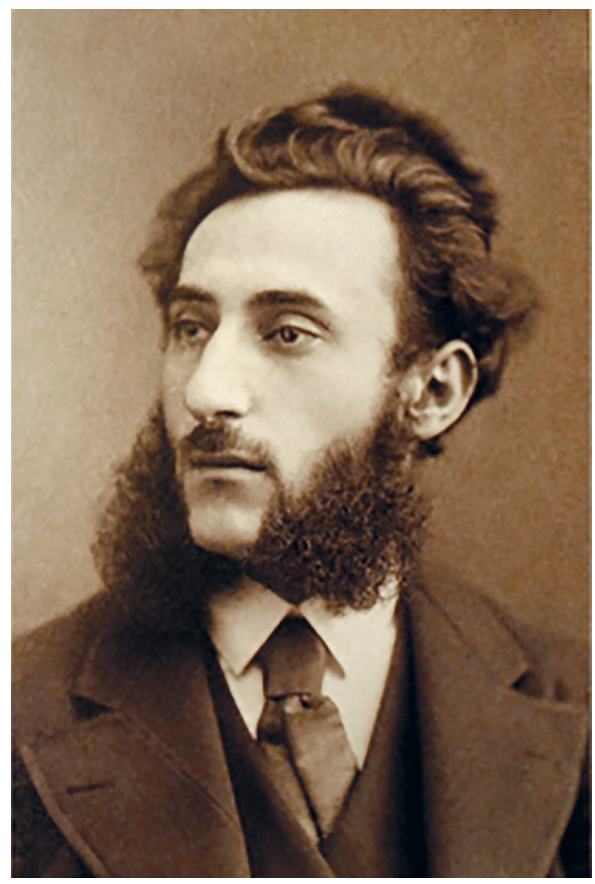

\subsection{Die Einzelgänger: Wilhelm Fraenkel und Josef Unger - Adelspalais und Arbeiterwohnungen}

$\mathrm{Zu}$ den ersten in Wien tätigen Architekten ist Wilhelm Fraenkel (I844-I9I6) zu zählen, der noch an der Frühzeit des Ringstraßenausbaus Teil hatte. Aus einer jüdischen Kaufmannsfamilie stammend, wurde er I 844 in Oberglogau in Oberschlesien (heute Glogowek in Polen) geboren. Er erhielt seine Ausbildung in Breslau/Wroclaw und später in Berlin an der Bauakademie, damals die renommierteste Institution im deutschen Sprachraum überhaupt, zumal die Ausbildungsstätten in Berlin Juden viel früher offenstanden als in der Habsburgermonarchie. Schon bald nach Abschluss seines Studiums ist Fraenkel Mitte der Sechzigerjahre nach Wien gekommen, wo er in das Büro von Karl Tietz (I 832-I874) eintrat, der gleichfalls in Berlin an der Bauakademie studiert hatte. ${ }^{17}$ Es ist anzunehmen, dass sie einander von ihren Berliner Jahren her kannten. Tietz, der mehrfach eng mit Theophil Hansen zusammengearbeitet hatte, gehörte noch zu den großen Ringstraßenarchitekten und hatte neben einigen

I7 I. Scheidl, Wilhelm Fraenkel, in: Architektenlexikon, zit. Anm. I3. 
adeligen Palais insbesondere mit dem Bau des "Grand Hotels« I86I an der Wiener Ringstraße eines der ersten großen Hotels in Wien errichtet. Fraenkel widmete sich als Mitarbeiter von Tietz in seiner späteren Laufbahn bezeichnenderweise sehr ähnlichen Bauaufgaben. Insbesondere als Tietz sich infolge psychischer Probleme Anfang der Siebzigerjahre sehr früh aus dem Berufsleben zurückziehen musste, wurde Fraenkel gewissermaßen sein Nachfolger. Bereits einige Jahre zuvor, I 868, hatte er noch nicht fünfundzwanzigjährig - die Baumeisterkonzession erworben und sich selbstständig gemacht. Fraenkel gehörte damit zu den ersten Juden überhaupt, der als Baumeister zugelassen war, da das Baugewerbe - wie alle zünftisch organisierten Institutionen - sich bis dahin der Aufnahme von Juden weitgehend entgegengestellt hatte. Ein Foto Fraenkels aus dieser Zeit zeigt uns einen modisch frisierten und elegant gekleideten jungen Mann, der durchaus in den oberen Kreisen zu reüssieren verstand (Abbildung I).

Einer seiner ersten Aufträge war um I 870 die Errichtung einer Gruppe von hochherrschaftlichen Miethäusern in prominenter Lage in der Inneren Stadt, Schottenbastei 4-8 (Abbildung 2). Diese Stadtwohnhäuser in der Formensprache einer dezent eleganten Neorenaissance, der Tradition Theophil Hansens folgend, brachten dem jungen Architekten breite Anerkennung ein und führten bald zu weiteren Aufträgen. Fraenkel realisierte in der Folge sowohl für den alten Adel als auch für den neuen Geldadel zahlreiche Mietpalais und Villen. Insbesondere war er für den Freiherrn Reitzes von Marienwerth tätig, der als Industrieller und Bankier zu großem Reichtum gekommen war. Nachdem er für die Familie Reitzes bereits I 878 ein Mietpalais (Wien I, Universitätsstraße 5) gebaut hatte, plante er nur kurze Zeit später für denselben Auftraggeber eine feudale Villa im damaligen Vorort Döbling (Wien I9, Sieveringer Straße 245). Fraenkel konzipierte den aufwendigen Bau noch ganz nach den Kriterien der Schlossarchitektur, wobei er mittels architektonischer Details, etwa eines klassizierenden Portikus und einer zweiarmigen Freitreppe, den feudalen Anspruch der Villa unterstrich. Nach dem sogenannten "Anschluss« Österreichs an NSDeutschland 1938 wurde die Villa, wie auch das Stadtpalais, seitens der NS-Behörden "arisiert" und dort eine Außenstelle der deutschen Reichspost installiert. Nach dem Ende des Zweiten Weltkrieges erhielt die Familie Reitzes im Rahmen der sehr zögerlich durchgeführten Restitutionen nur das Stadtpalais zurück, während die Villa weiterhin lange Zeit als Fernmeldezentrale diente. ${ }^{18}$

Neben der Errichtung von feudalen Wohnbauten für die Oberschicht war aber Wilhelm Fraenkel - in der Nachfolge von Karl Tietz - insbesondere auch auf dem relativ neuen Gebiet des Hotelbaus tätig. Es waren der sich allmählich herausfor-

I 8 Siehe dazu P. Melichar, Neuordnung im Bankwesen, Wien 2004, S. $368 \mathrm{ff}$. 
2. Wilhelm Fraenkel, Miethaus Wien I, Schottenbastei 4, erbaut um I870/Kulturgut

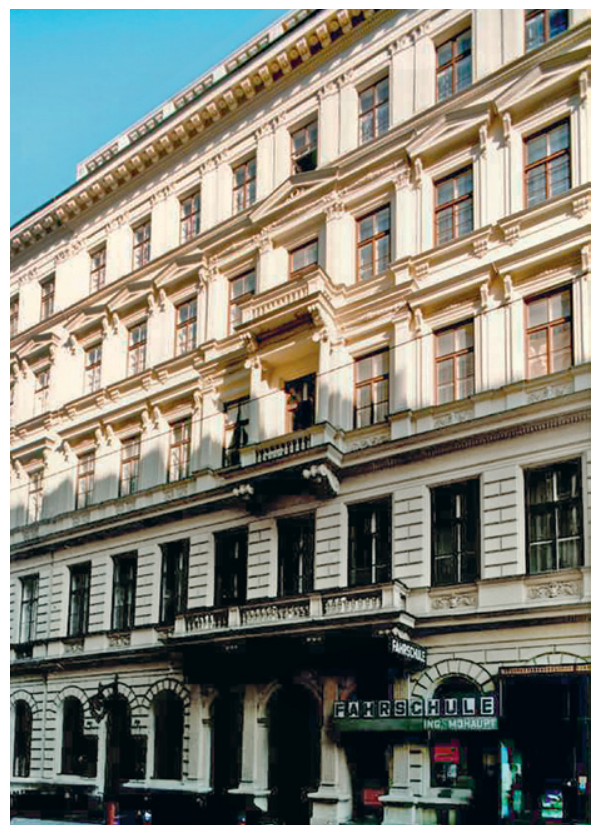

mende Tourismus und vor allem die großen Weltausstellungen des späten I9. Jahrhunderts, die den Bedarf an modernen Hotels forcierten. Im Zuge der Planungen für die Weltausstellung von 1873 in Wien errichtete Fraenkel unter anderen das »Hotel Austria" am Schottenring, dessen Bestand jedoch unter keinem guten Stern stand und das schon bald - möglicherweise infolge des Börsenkrachs - vom Innenministerium aufgekauft wurde und als Polizeidirektionsgebäude diente. ${ }^{19}$ Während des Zweiten Weltkrieges fiel das Gebäude den Bomben zum Opfer.

Wesentlich glücklicher verlief hingegen die Geschichte eines weiteren Hotelbaus von Fraenkel, den er I875 für den Gastronomen Eduard Sacher in der damaligen Augustinerstraße (jetzt Philharmoniker Straße) entwarf. Das in »italienischer Renaissance» gestaltete Gebäude sollte bald als »Hotel Sacher» (Abbildung 3) zu einem unverzichtbarer Bestandteil des Wiener Kulturlebens werden. Insbesondere unter der Leitung von Eduards Witwe Anna Sacher, die als Zigarren rauchendes Original in die Annalen einging, florierte das "Etablissement « und wurde durch seine Lage hinter der Oper legendär als Zufluchtsstätte für gelangweilte Opernbesucher und frustrierte Mitglieder des Kaiserhauses, die nach dem steifen Zeremoniell der Hoftafel hier Abwechslung suchten. Bis heute ist das "Sacher« eines der renommiertesten Wiener

I9 Wiener Bauindustriezeitung 8.1890, S. 170, T. 27. 


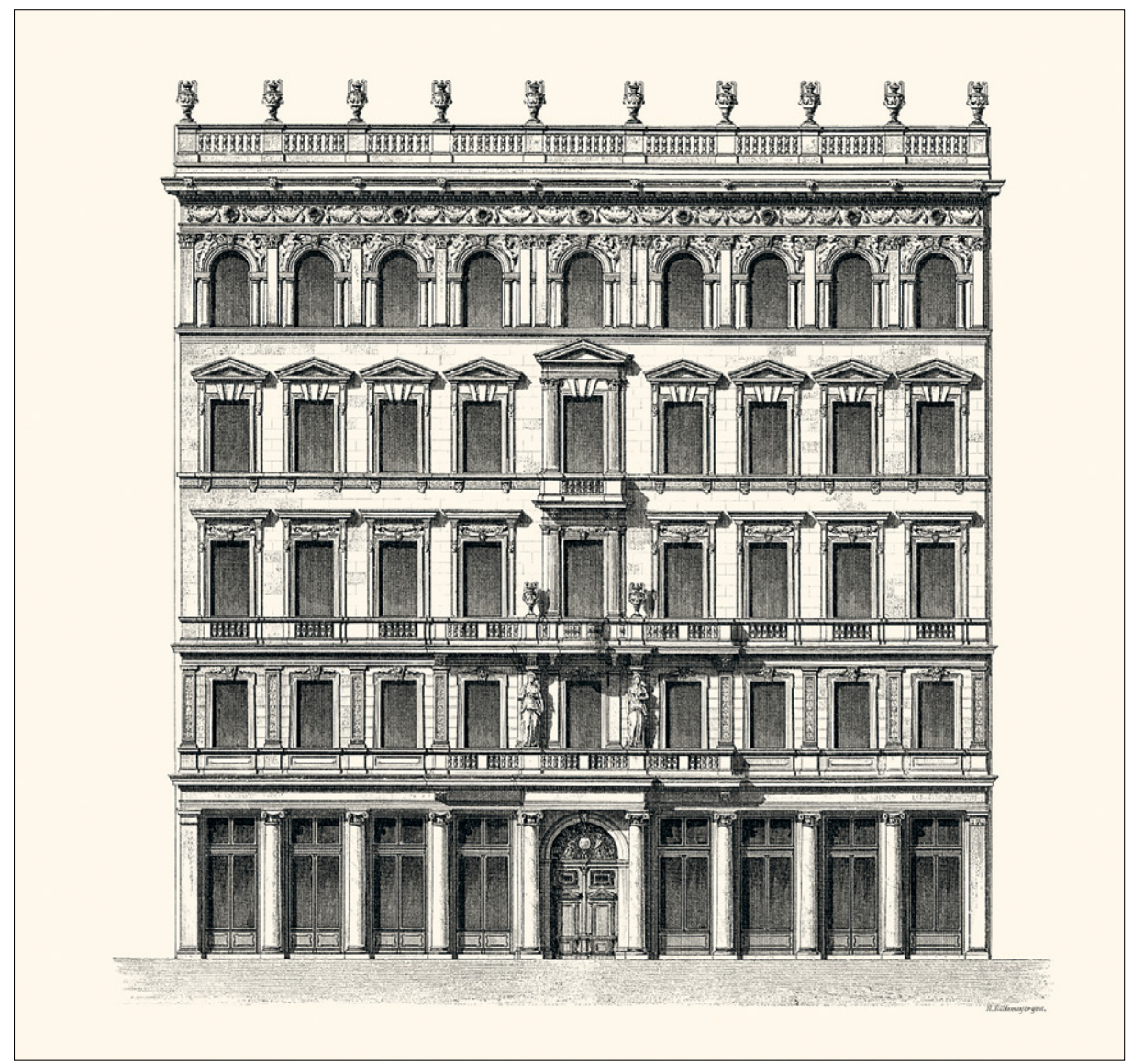

3. Wilhelm Fraenkel, Hotel Sacher, Wien I, Philharmonikerstraße 4, erbaut I 876/Allg. BZ

Nobelhotels, das auch durch den Vertrieb der gleichnamigen Torte Weltberühmtheit erlangt hat. Das Gebäude ist - zumindest im Äußeren - bis heute weitgehend erhalten und reflektiert die Noblesse der damaligen Ringstraßenarchitektur. Einzig das elegante, von Vasen bekrönte Flachdach, das einen italienischen Palazzo evozierte, musste einem modernen Dachaufbau weichen. Wie die zeitgenössische Literatur verrät, war der ursprüngliche Bau interessanterweise in seinen funktionellen Anforderungen relativ bescheiden. Neben den Speise- und Gesellschaftsräumen im Erdgeschoß befanden sich nur im I. Stock Hotelzimmer, während die oberen Stockwerke normalen Mietwohnungen vorbehalten waren. ${ }^{20}$ Selbstverständlich wurden im Laufe

20 Allgemeine Bauzeitung 42.1877, S. 76, T. 69 ff. 
der Jahrzehnte mehrere umfassende Adaptionen und Erweiterungen durchgeführt, um einen modernen Hotelbetrieb zu gewährleisten.

Fraenkel, der 1916 in Wien starb, war bis kurz vor dem Ersten Weltkrieg sehr erfolgreich tätig. Neben seiner Arbeit als Architekt in Wien hat er auch die - offenbar aus seiner Studienzeit herrührenden - Verbindungen nach Berlin nie ganz aufgegeben und für die dortige Oberschicht, etwa die Familie Arnheim, elegante Wohnsitze gebaut. ${ }^{21}$

Nicht für die gehobene Ringstraßengesellschaft, sondern für eine ganz andere Klientel arbeitete ein anderer Vertreter der ersten Generation jüdischer Architekten in Wien. Die fortschreitende Industrialisierung und das schnelle Wachstum der Stadt stellten die Architekten in der zweiten Hälfte des I9. Jahrhunderts teilweise vor völlig neue Probleme und Bauaufgaben, die sie sich erst erarbeiten mussten. Neben Warenhäusern, Bahnhöfen, Hotels und anderem mehr wurde zunehmend auch die Errichtung von Wohnbauten für die neu erstehende Arbeiterklasse zu einer wichtigen Aufgabenstellung. Lange wurde dieses Thema von den alteingesessenen akademisch ausgebildeten Architekten nicht beachtet, da es nach damaligem Verständnis nicht den Kategorien der "Baukunst" entsprach. $\mathrm{Zu}$ den frühen Pionieren auf diesem Gebiet gehört der heute völlig vergessene Josef Unger (I846-I922). Als Sohn des Kaufmanns Isidor Unger in dem kleinen Ort Kunarowitzl in der Nähe von Bielsko-Biała (damals Galzien ) geboren, kam er über eine Zwischenstation in Brünn, wo er die Oberrealschule besuchte, um I 864 mit seiner Familie nach Wien. ${ }^{22}$ Als einer der ersten jüdischen Studenten überhaupt besuchte er das damalige Wiener Polytechnikum (Vorläuferinstitution der heutigen Technischen Universität), wo er unter anderen den renommierten Ringstraßenarchitekten Heinrich von Ferstel zu seinem Lehrer hatte. Mehrere Indizien weisen darauf hin, dass die Familie damals in sehr bescheidenen Verhältnissen lebte. Wie viele der weniger begüterten Juden, die zumeist aus Galizien kamen, wohnte man in der Leopoldstadt, und Josef Unger war vom Schulgeld befreit.

Nach der Beendigung seines Architekturstudiums I 868 erhielt er eine Anstellung bei der Österreichischen Nordwestbahn, arbeitete aber - vor allem in seinen späteren Jahren - nebenbei auch als freiberuflicher Architekt. Die damals gerade neu gegründete Eisenbahnlinie war eine wichtige Verbindung zu den schnell an Bedeutung gewinnenden Industriegebieten in Böhmen und Mähren. In seiner Funktion als Inspektor war Josef Unger - neben der Planung von Hochbauten für den unmittelbaren Bahnbetrieb - insbesondere auch mit dem Bau von Wohnhausanlagen für die Bahnangestellten befasst, die im Zuge der Errichtung von neuen Bahnstrecken erforderlich wurden. Diese Bauaufgabe, die damals noch relatives Neuland war, veranlasste Unger,

2I Berliner Architekturwelt I9I2, II. Sonderheft, S. $73 \mathrm{ff}$.

22 Siehe dazu U. Prokop, Josef Unger, in: David, jüdische Kulturzeitschrift, 20.2008, Nr. 79, S. $38 \mathrm{ff}$. 
zahlreiche Studienreisen insbesondere nach Westeuropa zu unternehmen, um sich mit dem Arbeiterwohnbau und dem Einfamilienhaus zu beschäftigen. Unger, der seine Erfahrung auch in diversen Fachartikeln publizierte, wurde in der Folge zu einem der anerkanntesten Experten auf diesem Gebiet. Insbesondere der Ankauf seiner I 895 erschienenen Studie über dänische und deutsche Arbeitersiedlungen seitens der kaiserlichen Fideikomissbibliothek verdeutlicht sein hohes fachliches Prestige. ${ }^{23}$

Wenn es auch auf den ersten Blick erstaunlich sein mag, dass Probleme des sozialen Wohnbaus, die für eine bis dahin weitgehend in agrarischen Strukturen verhaftete Gesellschaft neu waren, im Zusammenhang mit dem Bahnwesen thematisiert worden sind, so sei darauf hingewiesen, dass die Bahn und alles, was damit zusammenhing, einer der wichtigsten Faktoren des Modernisierungsschubes im I9. Jahrhundert waren. Nicht nur, dass die Errichtung der neuen Bahnlinien zahlreiche technische Innovationen, wie zum Beispiel neue Konstruktionsverfahren, Brückenbautechniken und die Rationalisierung des Bauwesens, zur Folge hatte, sie ermöglichte darüber hinaus den Menschen eine bis dahin nie gekannte Mobilität. Dieser Umstand veränderte nicht nur die gesellschaftlichen Strukturen - verwiesen sei auf den Zuzug der Landbevölkerung in die Städte und die bessere Nutzung der Rohstoffe für die neu entstehende Industrie -, sondern auch die Alltagskultur, insbesondere durch die Entstehung eines neuen Tourismus mit all seinen Folgen. Nicht zuletzt fand das Phänomen "Bahn« auch seinen künstlerischen Niederschlag in den Bildern der Impressionisten, für die die dampfenden Lokomotiven und die flirrende Atmosphäre der großen Bahnhöfe immer wieder ein beliebtes Sujet war.

Nicht zufällig spielten Juden, die aus den bis dahin bestehenden wirtschaftlichen Strukturen weitgehend ausgeschlossen waren, auf dem neuen Gebiet des Bahnwesens von Anfang an eine bedeutende Rolle. Insbesondere waren es die großen Familien Pereira und Rothschild, die als Initiatoren und Finanziers den Aufbau des österreichischen Eisenbahnnetzes vorantrieben. Weniger beachtet wurde hingegen die Bedeutung der auf einer Ebene tiefer arbeitenden jüdischen Ingenieure und Techniker, die sich in diesem gänzlich neuen Bereich engagierten und vielfach Pionierleistungen vollbrachten. Entsprechend groß war die Zahl der Technikstudenten, und viele Mitglieder des damals äußerst renommierten »Österreichischen Ingenieur- und Architektenvereins« waren Juden. ${ }^{24}$ Auch Josef Unger war diesem wichtigen Fachverband

23 J. Unger, Der Arbeiterbauverein in Copenhagen und die Spar- und Bauvereine in Deutschland, in: Zeitschrift des österreichischen Ingenieur- und Architektenvereines 47.1 895, S. $545 \mathrm{ff} ., 556 \mathrm{ff}$.

24 Dieser Umstand führte nach der Auflösung 1938 zu einem erheblichen ideellen und materiellen Aderlass, von dem sich der Verein auch nach seiner Neukonstituierung 1945 nie mehr so recht erholen konnte. Siehe dazu G. Widtmann, Ein Blick zurück, Abriss der Geschichte des ÖIAV, in: ÖIAV I 43.1998, H. 7 (Festschrift I 50 Jahre Österreichischer Ingenieur- und Architektenverein). 


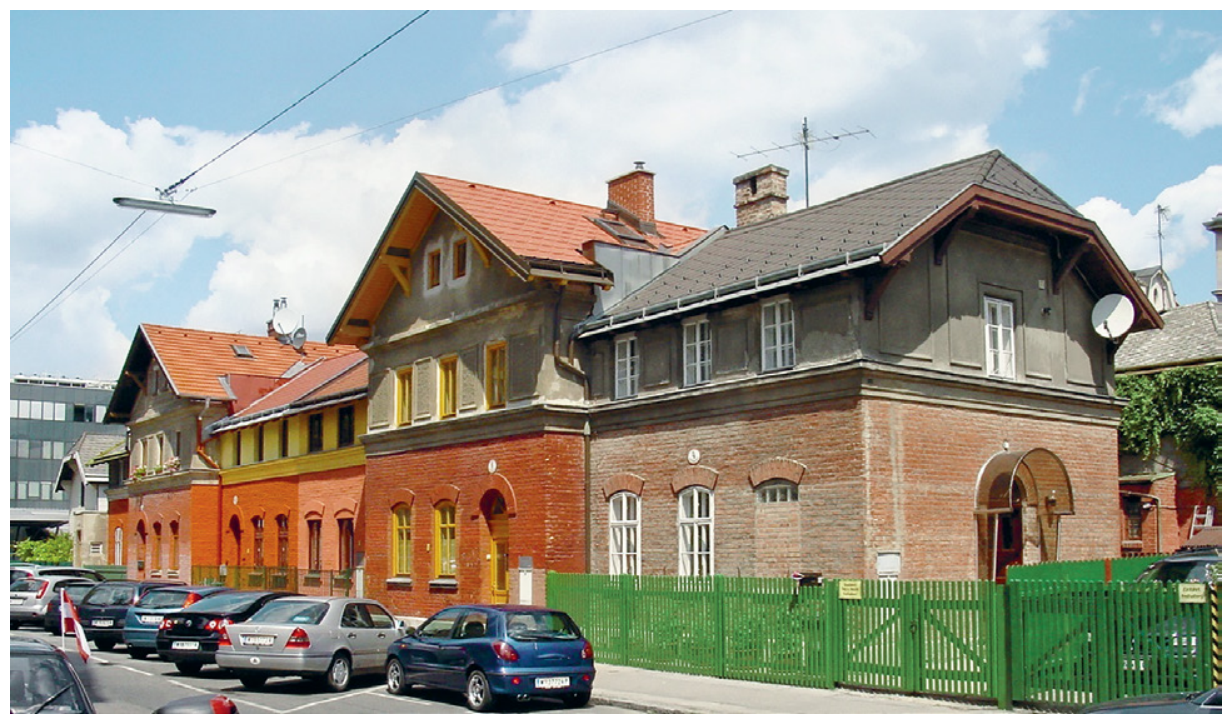

4. Josef Unger, Arbeiterwohnhäuser, Wien ı, Kiesewettergasse 3-I 5, erbaut um I886/Prokop

schon bald nach seinem Studienabschluss beigetreten und hatte den Großteil seiner Schriften in den Organen des Vereines publiziert.

Seine fundierten Kenntnisse auf dem Gebiet des Arbeiterwohnbaus brachten Unger schließlich in Kontakt mit dem Philanthropen Dr. Maximilian Steiner, unter dessen Leitung sich I 886 der sozial engagierte »Verein für Arbeiterhäuser« konstituiert hatte. ${ }^{25}$ In der Folge wurde noch im selben Jahr Unger mit der Planung einer Mustersiedlung beauftragt. In den nächsten Jahren entstand auf den damals billigen Gründen in WienFavoriten (Wien Io, Kiesewettergasse 3-15, Abbildung 4) eine kleine Gruppe von Arbeiterwohnhäusern, die zum Teil noch erhalten ist und das älteste Beispiel sozialen Wohnbaus in Wien darstellt. Unger konzipierte nach englischem Vorbild einstöckige Reihenhäuser mit Vorgärten oder Höfen. Die kleinen Häuser mit Giebeldächern waren teils in Sichtziegelweise, teils in Putz ausgeführt und lehnten sich formal sehr eng an die damals übliche Gestaltungsweise von Bahnstationsgebäuden an. Die Wohnfläche schwankte zwischen 67 und $97 \mathrm{~m}^{2}$, die Gärten waren bis maximal $68 \mathrm{~m}^{2}$ dimensioniert. Alle Wohnungen verfügten bereits über einen direkten Wasseranschluss in der Küche und einen Abort, der im Haus situiert war und nicht wie bis dahin üblich außerhalb lag. Die relativ große Anzahl von Räumen (eine Wohnstube und zwei bis drei

25 J. Unger: Die Arbeiterwohnhäuser in Wien Favoriten, in: Wochenschrift des Österreichischen Ingenieur- und Architektenvereines I I. I 886, S. $329 \mathrm{ff}$. 
Schlafräume) sollte den Bewohnern Zuverdienstmöglichkeiten durch die Betreibung eines Gewerbes oder Untervermietung bieten. Mittels jährlicher Zahlungen sollte innerhalb von 25 Jahren das Haus ins Eigentum übergehen. ${ }^{26}$ Von dem ursprünglich viel umfassender geplanten Projekt kam allerdings nur die Hälfte der Häuser zur Realisation. Die kleine Siedlung existiert bis heute und hat sich einen gewissen nostalgischen Charme erhalten, auch wenn sie nahezu erdrückt von den umgebenden Hochbauten ein Relikt aus vergangenen Zeiten ist. Generell erwies sich dieses Konzept, das im angelsächsischen Raum mit seinem Pachtsystem durchaus üblich war, für Wien mit seinem starren römisch-rechtlichen Eigentumsbegriff an Grund und Boden nicht sehr geeignet. Mitte der Neunzigerjahre löste sich daher der Verein auf und übergab sein Vermögen der »Stiftung für Volkswohnungen«.

Als anlässlich des Kaiser-Jubiläums von I 898 diese Stiftung unter großem publizistischen Aufwand einen Bewerb für ein Volkswohnprojekt in Wien-Ottakring ausschrieb, beteiligte sich daher auch Unger daran. Nach seinen Erfahrungen mit dem Favoritener Projekt und dem Scheitern der Reihenhausidee basierte Ungers Wettbewerbsentwurf diesmal auf dem Konzept der Geschoßbauweise, wobei er vierstöckige Häusergruppen um einen zentralen Innenhof, von dem auch die Treppenhäuser zugänglich waren, situierte. Erstmals waren auch Gemeinschaftseinrichtungen wie Waschküchen und Baderäume vorgesehen. Dieses Konzept Ungers nahm bereits wesentliche Kriterien des sozialen Wohnbaus der Zwischenkriegszeit - des sogenannten »Roten Wien« - vorweg. Allerdings konnte Unger aufgrund von Zeitmangel seinen Entwurf nicht näher ausführen, sodass er nur den 2. Preis und daher auch nicht den Auftrag für das Projekt der »Kaiser-Jubiläums-Volkswohnbauten « erhielt. ${ }^{27}$ Unger griff jedoch noch im selben Jahr auf diesen Entwurf zurück, als er für die Landarbeiter des Chorherrenstiftes von Klosterneuburg das sogenannte "Jubiläums-Arbeiterwohnhaus" errichtete. Allerdings war die Anlage wesentlich kleiner dimensioniert, und es mussten auch einige Modifikationen vorgenommen werden, insbesondere bei den hygienischen Einrichtungen, da Klosterneuburg damals noch nicht über eine Wasserleitung verfügte. Auch dieses frühe Beispiel sozialen Wohnbaus besteht bis heute (Klosterneuburg, NÖ, Wiener Straße 68). Als Josef Unger nach rund fünfunddreißig Jahre währender Tätigkeit für die Österreichische Nordwestbahn 1904 hochgeehrt in Pension gegangen war, arbeitete er noch einige Zeit weiterhin als freier Architekt, wobei der Wohnbau seine Domäne blieb. 1922 verstarb er im sechsundsiebzigsten Lebensjahr in Wien.

26 Siehe oben und F. Achleitner, Österreichische Architektur im 20. Jahrhundert, Bd. III/I, Wien/Salzburg I990, S. 265.

27 Das Projekt wurde schließlich nach den Plänen von Leopold Simony und Theodor Bach realisiert. 


\section{Die Schüler Friedrich von Schmidts}

\subsection{Max Fleischer, Wilhelm Stiassny und deren Umfeld - die Kontroverse um das jüdische Selbstverständnis im Kontext des Synagogenbaus}

Während die oben Angeführten sozusagen »Einzelgänger« in der Wiener Architekturszene waren und auch keine Nachfolger hatten, formte sich jedoch bald eine relativ homogene Gruppe aus, die aufgrund ihrer gemeinsamen Ausbildung an der Akademie der bildenden Künste bei Friedrich von Schmidt einer "Schule« zuzuordnen ist und die in der Folge auch die "Ahnherren" einer kontinuierlichen Reihe von Wiener jüdischen Architekten stellten. Der aus Württemberg stammende Friedrich von Schmidt (I825-I89I), einer der bedeutendsten Ringstraßenarchitekten, hatte sich selber seine Stellung im Wiener Kulturbetrieb erst erkämpfen müssen. Ursprünglich protestantisch, musste er zum Katholizismus übertreten, um in Wien eine Professur an der Akademie und später auch die wichtige Stellung eines Dombaumeisters zu erhalten. Dieser pragmatische Umgang mit Religion sowie eine generell sehr liberale Einstellung - man munkelte sogar, dass er Freimaurer gewesen wäre - und ein sehr offenes integratives Naturell prädestinierten ihn dazu, zum Lehrer der ersten Generation von jüdischen Studenten zu werden, die an die Akademie kamen. Nicht zufällig widmeten ihm zwei seiner bedeutendsten jüdischen Schüler, Wilhelm Stiassny und Max Fleischer, die warmherzigsten Nachrufe. ${ }^{28}$ Insbesondere Fleischer, der über seine Studienzeit hinaus noch rund zwanzig Jahre im Büro von Schmidt arbeitete und zu seinen engsten Mitarbeitern zählte, gibt ein anschauliches Bild von der Persönlichkeit Schmidts, der Geselligkeit liebte und einem Glas Wein in fröhlicher Runde nicht abgeneigt war. Von besonderem Interesse ist der Abschnitt über das private Verhältnis Schmidts zu seinen Schülern: "So wie Schmidt seinen Mitarbeitern zu geachteten und gesicherten Lebensstellungen zu verhelfen trachtete, so war es ihm eine besondere Befriedigung, sie unter die Haube zu bringen. Und nur Wenige dürften sein, bei denen er nicht bei der Vermälung (sic) Beistand gewesen wäre. Eine derartige Einladung nahm er stets gerne und bereitwillig an [...] und so sahen wir ihn auch eines Tages im Tempel in der Seitenstettengasse als Trauungsbeistand fungiren. ${ }^{29}$

28 M. Fleischer, Friedrich Freiherr v. Schmidt, Wien I 89I; W. Stiassny, Freiherr v. Schmidt als Künstler und Lehrer, Wien I 89i.

29 Fleischer, zit. Anm. 28. Die Schilderung der Trauungszeremonie bezieht sich auf Fleischer selbst. 
Friedrich von Schmidt hatte sich im Spektrum des Späthistorismus insbesondere einen Namen als »Gotiker" gemacht. Ausgebildet an der Kölner Dombauhütte, hatte er diese - bis dahin in Wien nicht sehr populäre - Richtung in die Reichshauptstadt gebracht, wo er als Professor an der Akademie im Rahmen seiner Meisterschule eine Wiederbelebung dieses mittelalterlichen Formenrepertoires initiierte. Auch in seinem eigenen architektonischen Werk konzentrierte sich Schmidt demgemäß vor allem auf den Kirchenbau und die Restaurierung von alten Burgen und Schlössern und wurde in der Folge zum einflussreichsten Architekten seiner Zeit auf diesem Gebiet. Dessen ungeachtet gilt ein Profanbau - das Wiener Rathaus - als Schmidts Hauptwerk und Paradigma der neugotischen Richtung. Im Rahmen aller dieser weitreichenden Tätigkeiten - Akademieprofessor, Dombaumeister und freischaffender Architekt - etablierte sich rund um Schmidt eine große Zahl von Schülern und Mitarbeitern, die als die sogenannte "Schmidt-Schule« maßgeblich am Architekturgeschehen der späten Donaumonarchie Anteil hatten. ${ }^{30}$ Insbesondere auf dem Gebiet des christlichen Sakralbaus führten viele seiner Schüler bis in den Anfang des 20. Jahrhunderts sein Erbe weiter. Weniger beachtet wurde bislang, dass auch im Kontext des damals florierenden Synagogenbaus, der infolge der stark wachsenden jüdischen Gemeinden notwendig wurde, seine Theorien und ästhetischen Kategorien nicht ohne Einfluss waren.

Das Thema der Synagoge hatte im Rahmen der Ausformung einer eigenständigen jüdischen Architektengruppe natürlich eine große Bedeutung. Die längste Zeit war es der kleinen jüdischen Gemeinde in Wien verboten, öffentliche Gottesdienste abzuhalten oder Immobilien zu erwerben, sodass man zu diesem Zweck nur bescheidene Räumlichkeiten anmietete und daher dieses Thema keinerlei Aktualität hatte. ${ }^{31}$ Erst zu Beginn des I9. Jahrhunderts wurde der Gemeinde erlaubt, den Dempfinger Hof in der Seitenstettengasse zu erwerben, wo schließlich eine Betstube und eine Schule eingerichtet wurden. Als das Gebäude Anfang der Zwanzigerjahre baufällig und ein Neubau erforderlich wurde mit der Intention, erstmals eine große, repräsentative Synagoge zu errichten (die allerdings straßenseitig noch immer kaschiert sein musste), stand noch kein jüdischer Architekt zur Verfügung. Man beauftragte einen der damals führenden Baukünstler Josef Kornhäusel, der insbesondere für den Hochadel zahlreiche Projekte ausgeführt hatte. ${ }^{32}$ Der Stadttempel (obwohl es nach

30 Siehe u. a. Friedrich v. Schmidt. Ein gotischer Rationalist (hg. v. Historischen Museum der Stadt Wien), Wien I99I; I. Scheidl, Schöner Schein und Experiment. Katholischer Kirchenbau im Wien der Jahrhundertwende, Wien/Köln/Weimar 2003.

3 I S. Husserl, Gründungsgeschichte des Stadttempels, Wien 1906.

32 Josef Kornhäusel (I782-I 860) war einer der meistbeschäftigten Architekten seiner Zeit. Er arbeitete insbesondere für den Fürsten Liechtenstein und Erzherzog Karl (Weilburg bei Baden, Umbau der Albertina). 
jüdischer Auffassung nur den Tempel in Jerusalem gibt, waren dennoch die Begriffe "Tempel" oder auch "Gotteshaus" damals üblich- nicht zuletzt auch Ausdruck der zunehmenden Assimilation - und werden daher auch im Text verwendet) mit seiner wunderschönen Innenausstattung, der aufgrund seiner engen Verbauung vom Novemberpogrom 1938 verschont worden war, zählt bis heute zu einem der bedeutendsten kulturhistorischen Gebäude seiner Zeit. Auch als man I853 den Bau des großen Leopoldstädter Tempels in Angriff nahm, der bezeichnenderweise erstmals nach außen als Gotteshaus erkennbar war, gab es noch keine jüdischen Fachleute. Nach der Ausschreibung eines Wettbewerbes wurde der Bau nach Plänen von Ludwig Förster errichtet, der gleichfalls damals einer der maßgeblichen Architekten war und zur selben Zeit auch in Budapest eine prachtvolle Synagoge erbaute. ${ }^{33}$ Neben dem Problem der Beauftragung von nichtjüdischen Architekten für die ersten repräsentativen Kultbauten war es auch bezeichnend, dass man in formaler Hinsicht völlig offen war. Während der von Kornhäusel errichtete Stadttempel - offenbar als Ausdruck der Aufklärung - im Stil des Revolutionsklassizismus gehalten war, orientierten sich die beiden Synagogen Försters an maurisch-orientalischen Vorbildern, die vor allem seitens der sephardischen Juden als identitätsstiftend angesehen wurden.

Als in den Siebzigerjahren des I9. Jahrhunderts schließlich die jüdischen Gemeinden schnell anwuchsen und ein umfassender Bedarf an Kultbauten aktuell wurde, konnte erstmals eine neu ausgebildete Generation von jüdischen Architekten sich dieser Thematik annehmen, die jede Menge Problematik und Diskussionsstoff in sich barg. Nicht zufällig waren es dann die aus der Schule Friedrich von Schmidts hervorgegangenen Schüler, die in Wien und den Ländern der Donaumonarchie Wesentliches auf diesem Gebiet leisten sollten.

Eine bedeutende Rolle spielte in diesem Kontext der bereits zuvor erwähnte Max Fleischer (I84I-1905). Aus Prossnitz/Prostejov in Mähren kommend, hatte er nach Abschluss der Oberrealschule das damalige Wiener Polytechnikum besucht, um im Anschluss daran an die Akademie der bildenden Künste zu gehen, wo er anfangs bei Eduard van der Nüll und Karl Rösner studierte. Bereits in diesen frühen Jahren holte er sich seine ersten Erfahrungen als Mitarbeiter bei der Errichtung der Altlerchenfelder Pfarrkirche und des Wiener Arsenals. ${ }^{34}$ Erst gegen Ende seines Studiums wechselte er zu Friedrich von Schmidt und trat schließlich auch in dessen Büro ein. Im Rahmen

33 Ludwig Förster (I787-I 863) gilt als einer der bedeutendsten Architekten des Frühhistorismus. Insbesondere als Herausgeber der »Allgemeinen Bauzeitung« trug er viel zur Erneuerung der Architektur bei. $\mathrm{Zu}$ seinen Auftraggebern gehörten viele große jüdische Familien, wie die Pereiras und die Todescos.

34 Siehe dazu B. Martens, Virtuelle Rekonstruktion dreier Synagogen von Max Fleischer in Wien, in: David 9.2007, H. 74; E. M. Faber, Max Fleischer und die Synagoge in der Neudeggergasse, in: K. Kratz, Verlorene Nachbarschaft, Wien 1999. 


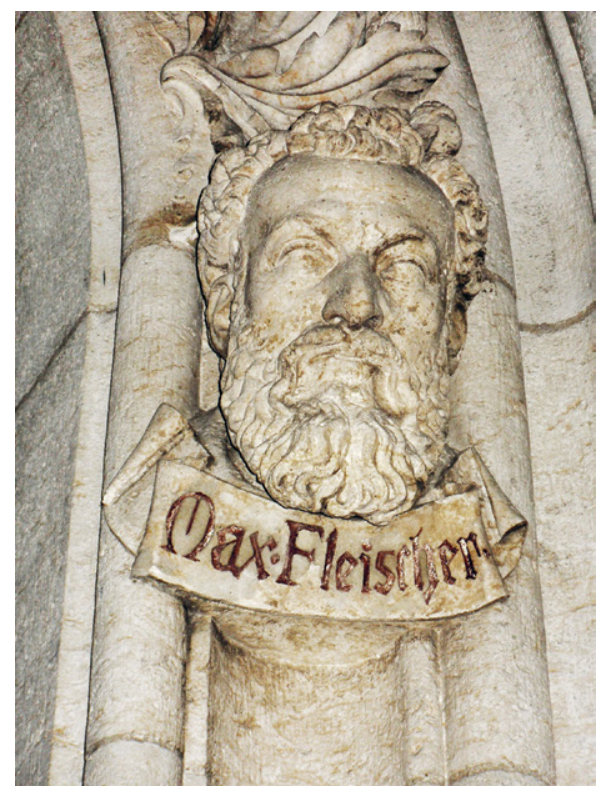

5. Max Fleischer, Büste über dem Eingang des

Wiener Rathauses/Prokop

dieser Tätigkeit war er als einer der Bauleiter maßgeblich an der Errichtung des Wiener Rathauses beteiligt, das einer der teuersten und aufwendigsten aller Ringstraßenbauten war und dessen Bauzeit insgesamt rund zwanzig Jahre währen sollte (I 868-I888). Demgemäß wurde, als in der Vorhalle des Rathauses nach mittelalterlicher Baumeistertradition Büsten der Mitarbeiter angebracht wurden, auch Fleischers Porträt an prominenter Stelle am Eingang in der Hauptachse platziert (Abbildung 5). ${ }^{35}$

Fleischer, der in großer Loyalität dem Atelier von Schmidt bis zu dessen Auflösung Ende der Achtzigerjahre angehörte, war dadurch in seiner eigenständigen Tätigkeit etwas eingeschränkt und konnte sich erst danach seinem eigenen Werk intensiver widmen. Neben einer Reihe von Miethäusern, Industriebauten, Fabriken und Geschäftshäusern, die nach seinen Entwürfen errichtet wurden, machte er sich vor allem einen Namen als Architekt von Synagogen. Als er Anfang der Achtzigerjahre im 6. Wiener Bezirk, wo er selber Vorstand des dortigen »Tempelvereines" war, in der Schmalzhofgasse einen Tempel in Anlehnung an die zeitgenössischen neugotischen Kirchenbauten errichtet hatte, wurde dieser Bau von vielen Wiener Juden äußerst positiv aufgenommen. Dabei lehnte sich Fleischer nicht nur formal an christliche Sakralbauten an, sondern führte auch in den Organisationsstrukturen Neuerungen

35 Auch auf seinem Grabstein wird Fleischer ausdrücklich als Mitarbeiter des Wiener Rathauses gewürdigt. 
6. Max Fleischer, Synagoge Wien 8, Neudeggergasse I2, erbaut 1903 (nicht erhalten)/Bautechniker

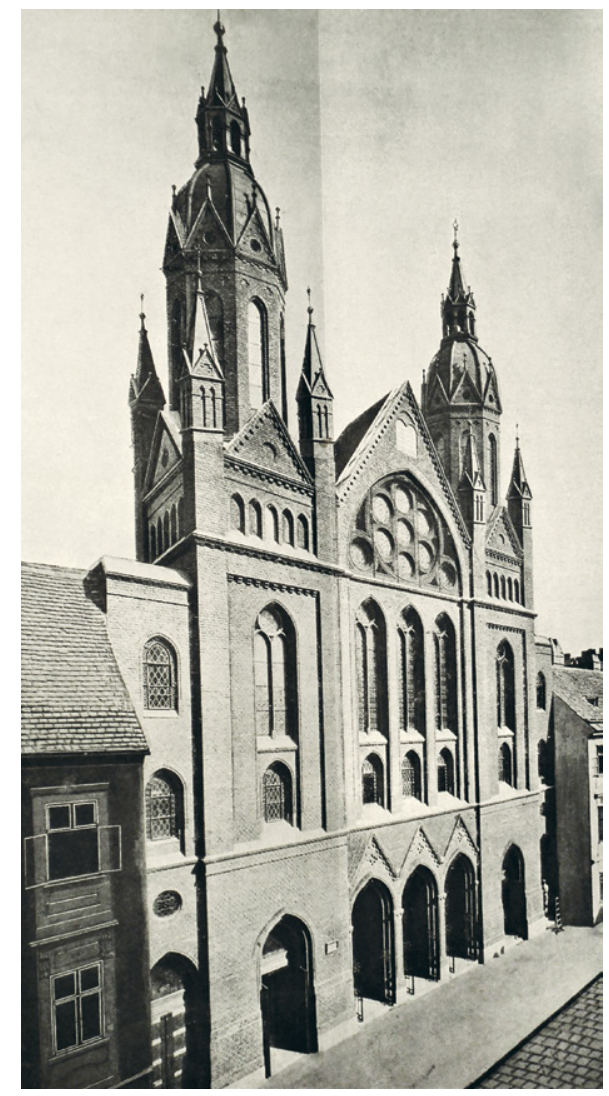

ein. Neben seiner Ablehnung der Frauengalerie war er vor allem darauf bedacht, Zweckmäßigkeit und Funktionalität in den Vordergrund zu stellen. Fleischer, der sich auch als Maler verstand und selber im weitläufigen Baukomplex wohnte, wo die Synagoge situiert war, hatte dort auch ein kleines "Fleischer-Museum « eingerichtet, wo er seine Entwürfe und Aquarelle untergebracht hatte. ${ }^{36}$

Er erhielt in schneller Folge zahlreiche weitere Aufträge, darunter für die Synagogen in Wien 9, Müllnergasse (1888/89), und Wien 8, Neudeggergasse (1903, Abbildung 6), aber auch für viele jüdische Gemeinden in den Kronländern der Donaumonarchie. ${ }^{37}$ Insbesondere der I 888 errichtete monumentale Tempelbau in Budweis/

36 Neue Freie Presse 20.I 2. I905, Nachruf auf Max Fleischer.

37 Insbesondere im Raum Niederösterreich und Mähren (u. a. Budweis, Lundenburg, Nikolsburg, Krems und Hohenau). 
Budejovice, der auch durch seine rundum frei stehende Situierung einen besonderen städtebaulichen Akzent setzte, gehörte zu seinen bedeutendsten Aufträgen. ${ }^{38}$ Der neugotische Charakter seiner jüdischen Kultbauten wurde von Fleischer, der sich auf wissenschaftlicher Basis mit dem Synagogenbau im historischen Verlauf befasst hatte, mit dem Argument begründet, dass die Tempelbauten immer an den jeweiligen Zeitstil und die lokalen Gegebenheit gebunden gewesen seien. Apodiktisch kam er zu dem Schluss: "[E]inen speciell jüdischen Stil gibt es nicht. " ${ }^{39}$ Fleischer, dem es grundsätzlich mehr um Funktion und Ökonomie als um Stilsymbolik ging, verteidigte auch die in der "Schmidt-Schule" gängige Sichtziegelbauweise, weil sie schlichtweg preiswerter sei als eine Steinfassade. Inwieweit dieses Streben nach Eingebundenheit in die Gesellschaft - symbolisiert in der Gestaltung der jüdischen Gotteshäuser - eine Folge des bereits sehr starken antisemitischen Druckes dieser Jahre war oder aber tatsächlich Fleischers Überzeugung aufgrund seiner historischen Studien entsprach, sei dahingestellt. ${ }^{40}$ Möglicherweise war es ein wenig von beidem.

Der bescheidene Wohlstand, den er im Laufe seiner Berufstätigkeit erreicht hatte, ermöglichte es ihm auch, zwei wohltätige Stiftungen ins Leben zu rufen. Fleischers jüdischem Selbstverständnis entsprechend engagierte er sich in der Kultusgemeinde, deren Vorstand er über Jahre angehörte und wo er als Friedhofsreferent für den Entwurf zahlreicher äußerst repräsentativer Grabmäler verantwortlich war. Wie sein Studienkollege Wilhelm Stiassny war er außerdem einer der Mitinitiatoren der "Gesellschaft zur Sammlung jüdischer Kulturgüter«, die I 895 zur Gründung des Jüdischen Museums führte. Dort brachte er auch bei zahlreichen Vorträgen sein kunsthistorisches Fachwissen ein, das er während des Studiums erworben hatte. Fleischer, der zahlreiche Ehrungen erhalten hatte - insbesondere für seine Verdienste um das Wiener Rathaus -, starb in seinem vierundsechzigsten Lebensjahr in Wien.

Einen anderen Weg im Synagogenbau beschritt sein Studienkollege Wilhelm Stiassny (I842-1910, Abbildung 7). Dieser lehnte Fleischers Theorie ab und forderte ganz im Gegensatz dazu eine bewusst "jüdische» Selbstdarstellung. Stiassny, der aus Pressburg stammte, war nahezu gleich alt wie Fleischer, mit dem ihn vieles verband, ungeachtet ihres divergierenden Zuganges zum Synagogenbau. Nicht nur dass sie als Studenten die gleiche Ausbildung erhalten hatten, waren sie auch beide sehr fromme Juden, die sich viel mit der Geschichte des Judentums befassten und Judaica sammelten. Im Kontext dieses Engagements beteiligte er sich gleichfalls an der oben erwähn-

\footnotetext{
38 M. Fleischer, Über Synagogen-Bauten, Wien I894, in: Zeitschrift des Österreichischen Ingenieurund Architektenvereines 46.I 894, H. I 8, S. Iff., T. 9.

39 Ebenda.

40 Siehe dazu auch Genée, zit. Anm. 8.
} 
7. Wilhelm Stiassny, Porträt/ÖIAV

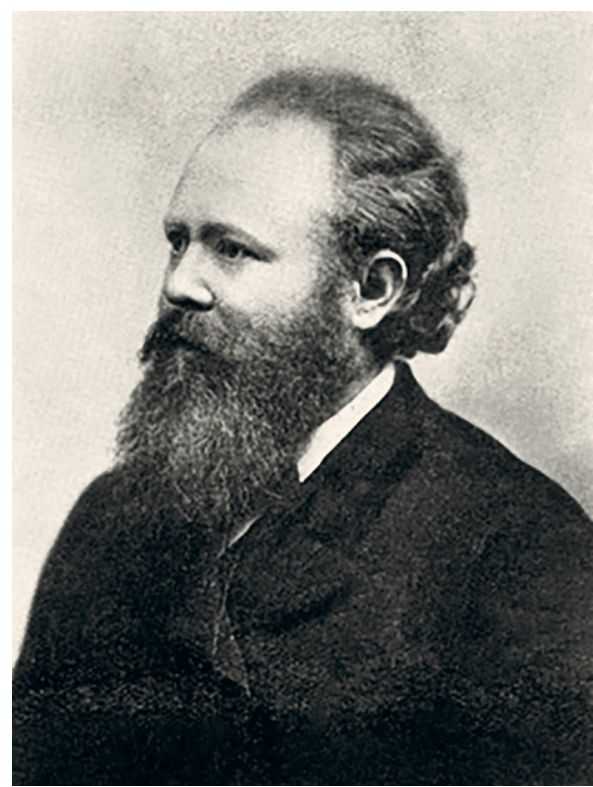

ten "Gesellschaft zur Sammlung jüdischen Kulturgutes«, die schließlich I 895 zur Gründung des Jüdischen Museums führte, das erste seiner Art in Europa überhaupt. Über Jahre hinweg waren auch beide im Vorstand der Wiener Kultusgemeinde und sozusagen Teil des Wiener jüdischen Establishments - nicht zuletzt auch aufgrund ihrer erfolgreichen Karriere als Architekten.

Im Gegensatz zu Fleischer hatte sich Stiassny jedoch schon bald nach seinem Studium selbstständig gemacht und wurde in Kürze einer der erfolgreichsten Architekten und Bauunternehmer in Wien. Darüber hinaus befasste er sich auch mit dem jüdischen Kultbau und errichtete zahlreiche Synagogen, Zeremonienhallen und Grabmäler. Um I 875 - schon einige Jahr vor den ersten Synagogen Fleischers in Wien - entwarf Stiassny für die wohlhabende jüdische Gemeinde in Teplitz-Schönau/Teplice ein Gotteshaus, das in einer raffinierten Synthese Elemente der italienischen Renaissance mit "maurischen « Bauformen verband, wobei der Architekt mit diesem orientalisierenden Vokabular eine spezifisch »jüdische« Selbstdarstellung anstrebte. In diesem Kontext bedeutete die zitathafte Übernahme einer maurischen Formensprache - wie sie schon seinerzeit von Ludwig Förster eingesetzt worden war - insbesondere für die sephardischen Juden, aber auch für die Aschkenasim, eine Anspielung auf die aus dem I 4. Jahrhundert stammende Synagoge »El Tránsito« in Toledo, der im »jüdischen Gedächtnis« eine besondere Bedeutung zukam. Dieser höchst spektakuläre Teplitzer Bau - damals die größte Synagoge in Europa überhaupt - stieß zwar auf großes 


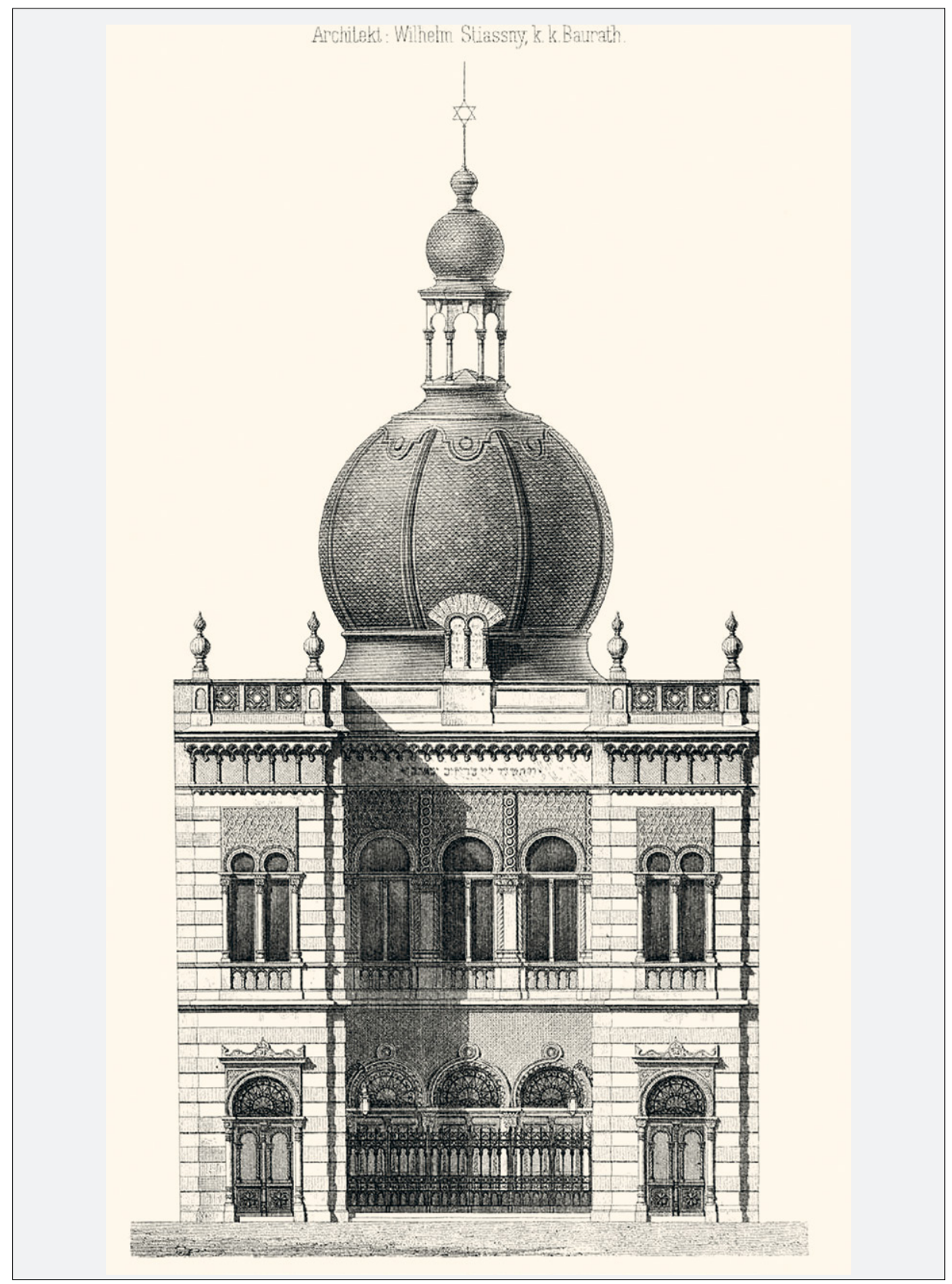

8. Wilhelm Stiassny, Synagoge »Poln. Schul«, Wien 2, Leopoldsgasse 29 erbaut I 893 (nicht erhalten)/ Allg. BZ 
9. Wilhelm Stiassny, Jubiläumssynagoge Prag, Nove Mesto, Jeruzalemska 7, erbaut 1906/Prokop

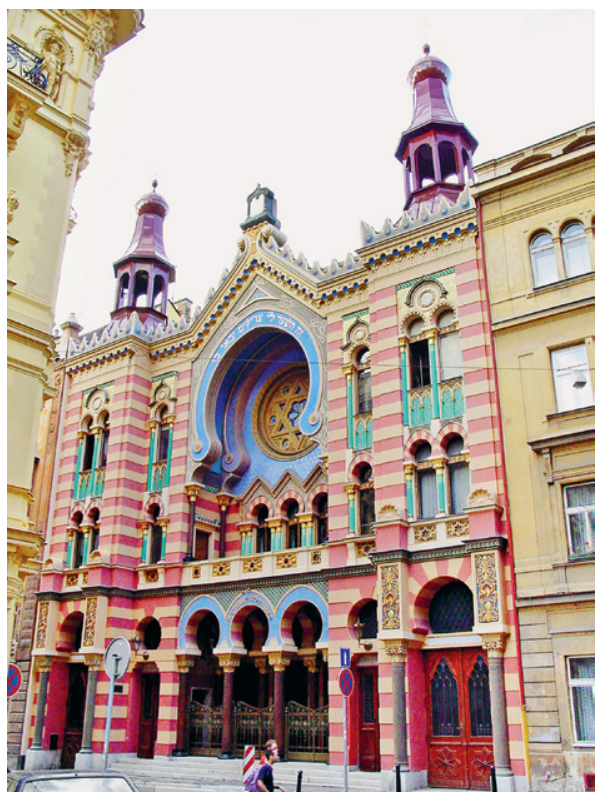

Interesse, dennoch erhielt Stiassny vorerst keinen Auftrag in Wien für einen jüdischen Kultbau, bevorzugte man dort doch eher die angepassten Tempel von Max Fleischer. Dessen ungeachtet setzte Stiassny seine Linie von Tempelbauten in einem maurischorientalischen Stil - wie die Synagogen in Malacka ( I 887) oder in Gablonz/Jablonec (1892) - fort, was ihm jedoch nicht zuletzt herbe Kritik seitens der Wiener Fachleute einbrachte, die seine Gotteshäuser unter anderem als "total missglückt « ablehnten. ${ }^{41}$

In Wien war es ihm daher nur vergönnt, eine einzige Synagoge zu errichten, und dies bezeichnenderweise für die polnisch-jüdische Gemeinde: die sogenannte »Polnische Schul « im Jahr I 893 (Wien 2, Leopoldsgasse 29, Abbildung 8), auf die seitens der alteingesessenen Wiener Juden ein wenig herabgesehen wurde. ${ }^{42}$ Auch hier gestaltete Stiassny den Bau in einem farbkräftigen orientalisierenden Vokabular und krönte ihn mit einer Zwiebelkuppel, die auf die osteuropäische Herkunft der Gemeinde verweisen sollte. ${ }^{43}$ Generell reflektiert diese Diskussion um den Synagogenbau zwischen Stiassny und Fleischer die Gespaltenheit der Wiener Juden in dieser Zeit, die zwischen Assimilierung und selbstbewusster Abgrenzung schwankten. Andererseits zeigt

4I Wiener Bauindustriezeitung 5.I 887, S. 604.

42 In seiner Frühzeit errichtete Stiassny noch I 879 die Zeremonienhalle der alten israelitischen Abteilung des Zentralfriedhofes im Stil der Neorenaissance - das Gebäude ist heute nicht mehr erhalten.

43 Allgemeine Bauzeitung I 894, S. 7 of. u. T. 55 ff. 
sie aber auch, wie sehr die beiden Architekten Kinder ihrer Zeit waren, die in den Kategorien des Späthistorismus dachten, wo die Frage nach dem "Stil« und dessen Symbolik große Priorität hatte. Nicht zuletzt kursierte auch in christlich-kirchlichen Kreisen damals die große Frage »In welchem Stil sollen wir bauen?«, wobei die Bandbreite von Romanik über Gotik bis zur Moderne reichte. ${ }^{44}$ Ungeachtet der betont unterschiedlichen Gestaltungsweise der Synagogen Fleischers und Stiassnys wurden in der NS-Zeit jedoch nahezu alle vernichtet - insbesondere in Wien. Eine der wenigen erhalten gebliebenen ist die aufwendige Jubiläumssynagoge in Prag, die Stiassny in seinen letzten Jahren (1905) errichtet hatte und die in ihrer farbigen Pracht den Ideenreichtum der späthistoristischen Architektur vermittelt (Abbildung 9). ${ }^{45}$

Abgesehen von seiner Bedeutung für den Synagogenbau, ist Stiassny noch in mehrfacher Hinsicht eine bemerkenswerte Persönlichkeit gewesen. Wie bereits erwähnt, zählte er schon bald nach Abschluss seines Studiums zu den meistbeschäftigten Architekten Wiens, der eine nahezu unüberschaubare Zahl von Wohnhäusern und anderem mehr errichtete, die bis heute das Stadtbild von Wien prägen. Insbesondere ist neben einigen eleganten Ringstraßenpalais und einer stilvollen Villensiedlung in Wien-Döbling (Reithlegasse I-3), Stiassnys Anteil am Ausbau des sogenannten "Textilviertels« hervorzuheben, das nach der Stadterweiterung rund um die Börse und den Rudolfsplatz im I. Bezirk entstand, als sich dort die weitgehend jüdischen Textilhändler im Zuge des gründerzeitlichen Baubooms ihre Firmenniederlassungen und Wohnbauten errichteten. Das Viertel, dessen Ausbau gegen Ende der Sechzigerjahre des I9. Jahrhunderts begonnen wurde und weitgehend in den Achtzigerjahren abgeschlossen war, besticht bis heute durch die große Homogenität seiner Bausubstanz. Bemerkenswert ist vor allem, dass hier weitgehend sehr repräsentative Miethäuser des gehobenen Wohnbedarfs in Kombination mit Geschäften, Magazinen und Produktionsstätten entstanden, die zu einem für das Viertel charakteristischen Mischtypus führten. Während sich im Souterrain die Magazine befanden, waren Parterre und Mezzanin den Geschäftslokalen vorbehalten, die zumeist um einen glasüberdachten Innenhof gruppiert waren. Die großzügig angelegten Wohnungen in den Obergeschoßen erstreckten sich über das ganze Stockwerk und umfassten neben den straßenseitig gelegenen Gesellschaftsräumen die rückseitigen Privatzimmer und Wirtschaftsräume. Nicht selten gab es bereits Badezimmer - eine Einrichtung, über die die Hofburg damals noch nicht verfügte. Zur Trennung der unterschiedlichen Funktionen verfügten diese Häuser zumeist über zwei Hauseingänge (z. B. Wohn-Geschäfts-

44 Sieh dazu Scheidl, zit. Anm. 30.

45 Siehe dazu T. Satoko, Wilhelm Stiassny. Synagogenbau, Orientalismus und jüdische Identität, Phil. Diss. Wien 2009. 
ı. Wilhelm Stiassny, Miethaus Wien I, Rudolfsplatz Io, erbaut I 88 I/Wr. Bauindustriezeitung

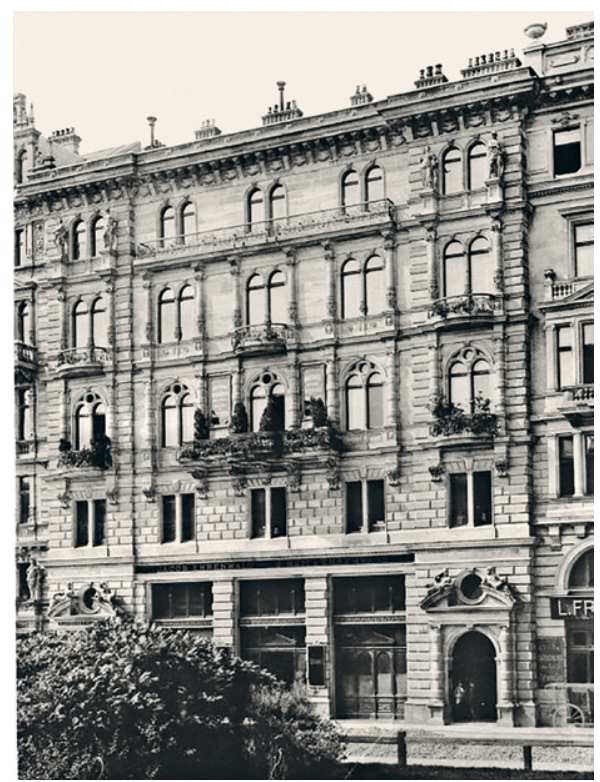

haus Wien I, Rudolfsplatz Io, I 88 I, Abbildung Io). ${ }^{46}$ In diesem Kontext ist es bemerkenswert, dass es höchstwahrscheinlich Wilhelm Stiassny war, der - als um I 900 eine Diskussion innerhalb der Wiener jüdischen Gemeinde über den Neubau eines Tempels in der Inneren Stadt ausbrach, da der alte Bau in der Seitenstettengasse für die ständig wachsende jüdische Gemeinde viel zu klein geworden war - eine Synagoge auf dem im Zentrum des Textilviertels gelegenen Rudolfplatz plante. Ein schlecht erhaltenes Aquarell gibt eine Vogelperspektive des Platzes wieder, der an der Schmalseite von einer mächtigen Synagoge abgeschlossen wird. ${ }^{47}$ Inwieweit diese Skizze auf Stiassny zurückgeht, ist nicht geklärt, aber es wäre höchst unwahrscheinlich, wenn er nicht in irgendeiner Weise an diesem Projekt, das jedoch nie zur Realisation gelangte, beteiligt gewesen wäre.

Darüber hinaus engagierte sich Stiassny in der Kultusgemeinde vor allem auch in karitativer Hinsicht und erbaute im Auftrag der großen jüdischen Familien zahlreiche Fürsorgeeinrichtungen, unter anderen das Blindeninstitut auf der Hohen Warte (Stiftung Königswarter) oder das Rothschild-Spital in Währing (Währinger Gürtel 97), das noch bis 1942 in Funktion war, nach dem Krieg als wichtiges Durchgangslager für jüdische Flüchtlinge diente und erst 1955 abgerissen wurde. In diesem Kontext

46 Allgemeine Bauzeitung I 885 , S. 84 , T. $56 f$.

47 T. Sakoto, zit. Anm. 45. 
befasste sich Stiassny in mehreren Publikationen auch intensiv mit dem Spitalswesen und der Volksgesundheit, die er in einem engen Zusammenhang mit dem Wohnungsproblem sah. Infolge seiner großen Kompetenz auf zahlreichen Gebieten des Bauwesens wurde Stiassny schließlich auch I 878 als Vertreter der Liberalen und einer der ganz wenigen Juden in den Gemeinderat entsendet (die jüdische Bevölkerung, die damals ca. Io Prozent betrug, war mit knapp 3 Prozent jüdischer Gemeinderäte kommunalpolitisch völlig unterrepräsentiert), dem er mit kurzer Unterbrechung bis zu seinem Tode angehörte. Kurzfristig war er I 894/95 als Stadtrat sogar Mitglied der Wiener Stadtregierung, musste dieses Mandat aber nach dem Sieg der antisemitischen Christlichsozialen unter Bürgermeister Karl Lueger niederlegen. ${ }^{48}$ Im Rahmen seiner langjährigen Funktionstätigkeit hielt er rund I.500 Referate und war in zahlreichen Kommissionen mit dem Ausbau der städtischen Infrastruktur, die damals in bahnbrechenderweise in die Wege geleitet wurde, befasst. Sogar Gustav Klimt hat Wilhelm Stiassny verewigt, als er I 898 anlässlich des Abrisses des alten Burgtheaters die Wiener Gesellschaft quasi als Gruppenporträt im Zuschauerraum des alten Burgtheaters abbildete. Stiassny ist schließlich nach längerer Krankheit während eines Sommeraufenthaltes I9 Io in Bad Ischl gestorben. Eine Gedenktafel an dem Haus Wien I, Krugerstraße 8, das von ihm errichtet wurde und in dem er die letzten Jahre wohnte, erinnert bis heute an diese große Persönlichkeit.

In Zusammenhang mit Wilhelm Stiassny und seiner Tätigkeit als Gemeinderat ist ein kurzer Exkurs auf Donat Zifferer (I 845-1909) gerechtfertigt, der gleichfalls einer der wenigen jüdischen Gemeinderäte war und eine nicht unwesentliche Rolle im Wiener Baugeschehen spielte. Ungefähr der gleichen Generation angehörig wie Stiassny und Fleischer, gehörte Zifferer - der jedoch nur fallweise als Architekt tätig war und auch keine akademische Ausbildung hatte - zu den bedeutendsten Baumeistern und Bauunternehmern der vorigen Jahrhundertwende. Aus Bistritz/Bystrice in Mähren stammend, hatte er in Brünn/Brno und dann in Wien am Polytechnikum studiert. Nach längerer Baupraxis bei der Österreichischen Baugesellschaft machte er sich I 875 selbstständig und kaufte als Bauunternehmer zahlreiche durch den Abriss der Basteien frei gewordene Baulose des Stadterweiterungsprojektes an, die er späterhin verbaute. Zifferer soll in der Folge mehr als zweihundertfünfzig Bauten ausgeführt haben. ${ }^{49}$ In Zusammenarbeit mit den bedeutendsten Architekten dieser Zeit hat er als ausführender Baumeister auch eine Reihe von noblen Mietpalais in der Inneren Stadt, im 4. und im 9. Bezirk (darunter einige prestigeträchtige Projekte

48 Dessen ungeachtet soll Stiassny ein gutes persönliches Verhältnis zu Lueger gehabt haben.

49 Neue Freie Presse ir.or.1905, Donat Zifferer zum 6o. Geburtstag; Dr. Bloch's Wochenschrift 8.I0.1909, H. 4I, S. 704f. (Nachruf). 
für die Familie Rothschild) errichtet. Darüber hinaus war er als frommer Jude auch mit der Ausführung diverser jüdischer Einrichtungen, wie des Rothschildspitals und einiger bemerkenswerter Synagogen, befasst. ${ }^{50}$ Zifferer, der es im Zuge seiner unternehmerischen Tätigkeit zu einem beachtlichen Vermögen gebracht hatte, unterstützte insbesondere zahlreiche humanitäre Institutionen. Neben seinem Engagement in der Wohlfahrt und der Armenfürsorge trat er auch anderweitig als großzügiger Spender auf. Unter anderem beteiligte er sich an der Finanzierung eines Spitals in seinem Heimatort Bistritz oder verzichtete beim Bau der Synagoge in der Hubergasse (Wien I6) als ausführender Baumeister auf sein Honorar. Als engagierter Freimaurer war er auch Ehrenmitglied zahlreicher in- und ausländischer Logen. ${ }^{51}$

Bemerkenswert ist vor allem auch das gesellschaftliche Umfeld Zifferers. Seine Frau Rosa (geb. Schüler, I 8 5 I-I9I I) war eine bedeutende Frauenrechtlerin und Präsidentin des Vereines "Wiener Frauenhort", sein Neffe Paul war ein bekannter Schriftsteller. Die Tochter Elisabeth (I874-1950) war mit dem Architekten Alexander Gotthilf verheiratet, mit dem Zifferer insbesondere in seinen letzten Jahren auch öfters zusammenarbeitete und von dem später noch die Rede sein wird. Freundschaftlich verbunden war Zifferer auch mit Max Fleischer, der der Pate seiner Kinder war. Gemeinsam waren sie unter anderem um I890 beim Projekt des israelitischen Mädchenwaisenhauses in Wien 19, Ruthgasse 19, sowie beim Bau der Synagoge in der Müllnergasse und 1903 an der Spitalssynagoge des Allgemeinen Krankenhauses tätig. Zifferer musste sich um 1905 krankheitsbedingt aus dem Berufsleben zurückziehen und ist 1909 in Wien verstorben.

Im Kontext der Synagogenarchitekten aus der Schule Friedrich von Schmidts steht Jakob Modern (I838-I9I2, Abbildung II) ein wenig im Schatten von Fleischer und Stiassny. Das könnte sich auch aus dem Umstand erklären, dass der Bau von jüdischen Gotteshäusern nur ein Nebengebiet dieses Architekten war. Wie Stiassny stammte auch Modern aus Pressburg, ist aber gleichfalls schon in sehr jungen Jahren nach Wien gekommen, um sich hier am damaligen Polytechnikum ausbilden zu lassen und im Anschluss daran an der Akademie bei August von Sicardsburg und späterhin bei Friedrich von Schmidt zu studieren. Schon bald nach seinem Studium trat er in die Allgemeine Österreichische Baugesellschaft ein und fungierte dort als Bauleiter, wo er in zahlreiche große Projekte eingebunden war, die allerdings nicht namentlich dokumentiert sind. ${ }^{52}$ Nach rund zwölffähriger Tätigkeit bei der

5o Zifferer fungierte u. a. als ausführender Baumeister bei den Synagogen in Wien 9, Müllnergasse (Entwurf Max Fleischer), und Wien I6, Hubergasse (Entwurf Ludwig Tischler).

5 I U. Prokop, Donat Zifferer, in: Architektenlexikon, zit. Anm. I3.

52 L. Eisenberg, Das geistige Wien, Wien I 893. 


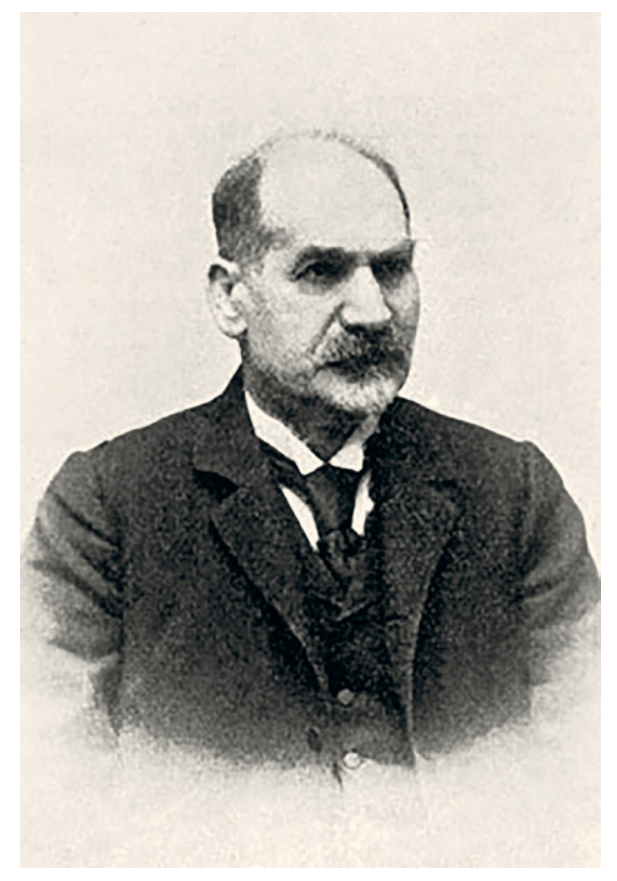

Baugesellschaft wagte er den Sprung in die Selbstständigkeit und war in der Folge auch weiterhin mit der Errichtung von Wohnbauten befasst. Erst Ende der Achtzigerjahre erhielt er seinen ersten Auftrag für eine Synagoge in Währing, das damals noch ein Vorort von Wien war und aufgrund des raschen Bevölkerungszuwachses ein Gotteshaus für die dort ansässige jüdische Gemeinde benötigte. Der relativ bescheidene Bau für rund 500 Gläubige, dessen Grundsteinlegung im Dezember I 888 erfolgte, wurde mit geringen Mitteln in der kurzen Zeit von nur zehn Monaten errichtet. Bei dem im Straßenverbund situierten Gebäude in der Schopenhauerstraße (damals noch Wiener Straße) gestaltete Jakob Modern die in Sichtziegelbauweise errichtete Fassade in einer Formensprache, die an die Neoromanik angelehnt war und ein wenig von den evangelischen Kultbauten Försters und Hansens beeinflusst war (Abbildung I 2). ${ }^{53}$ Damit vermied Modern eine allzu enge Anlehnung an den katholischen Kirchenbau. Der Dekor des dreischiffigen Innenraums war hingegen im »arabischen Style« gehalten. ${ }^{54}$ Weitere Projekte Moderns für jüdische Gotteshäuser gelangten jedoch entweder nicht zur Realisation oder sind nicht genau zu orten.

53 B. Martens, Die zerstörten Synagogen Wiens, Wien 2009.

54 Allgemeine Bauzeitung 57.1892, S. 39, T. $32 \mathrm{f}$. 


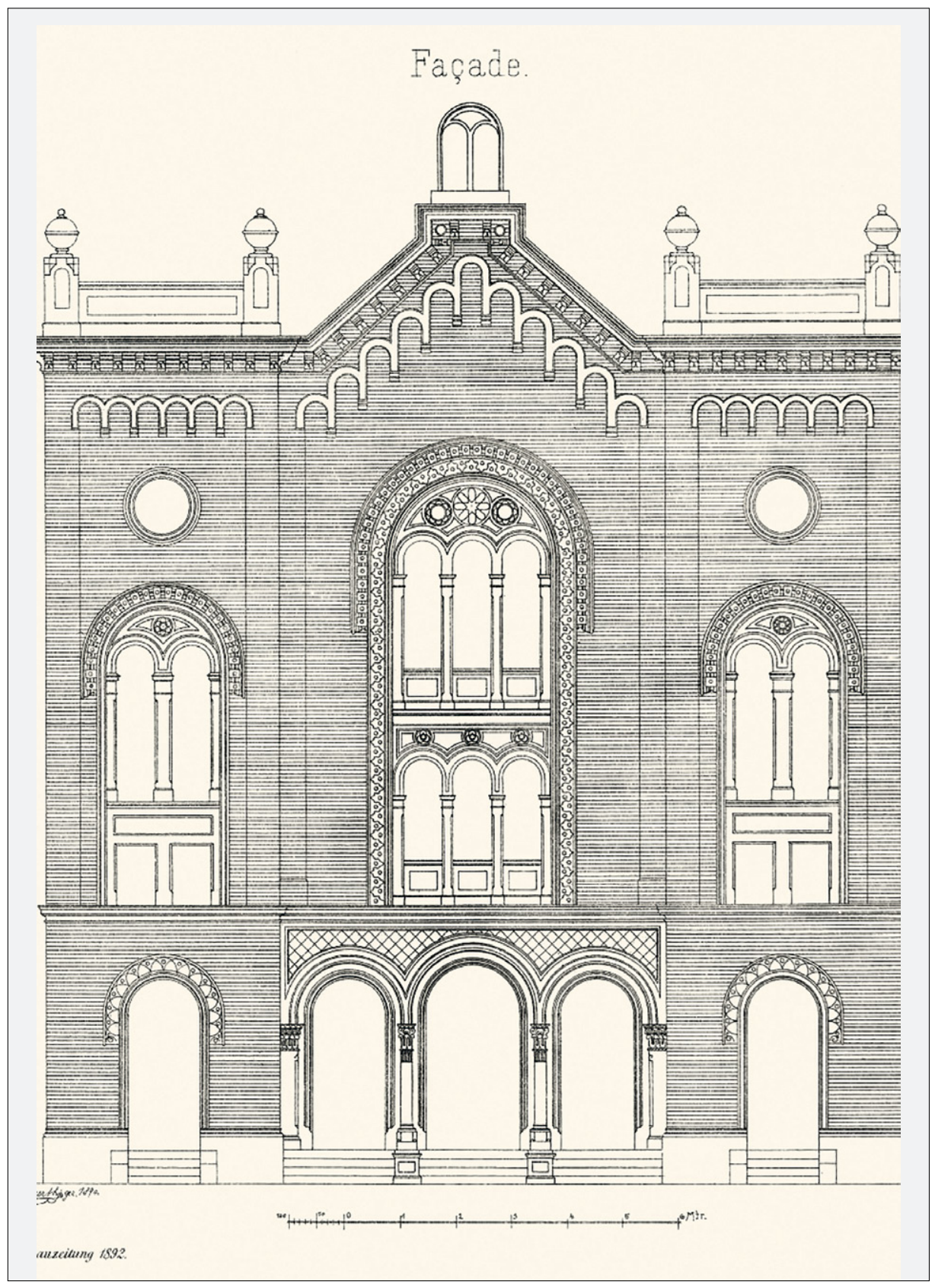

I2. Jakob Modern, Synagoge Wien I8, Schopenhauerstraße 39,erbaut I889 (nicht erhalten)/Allg. Bauzeitung I 892 


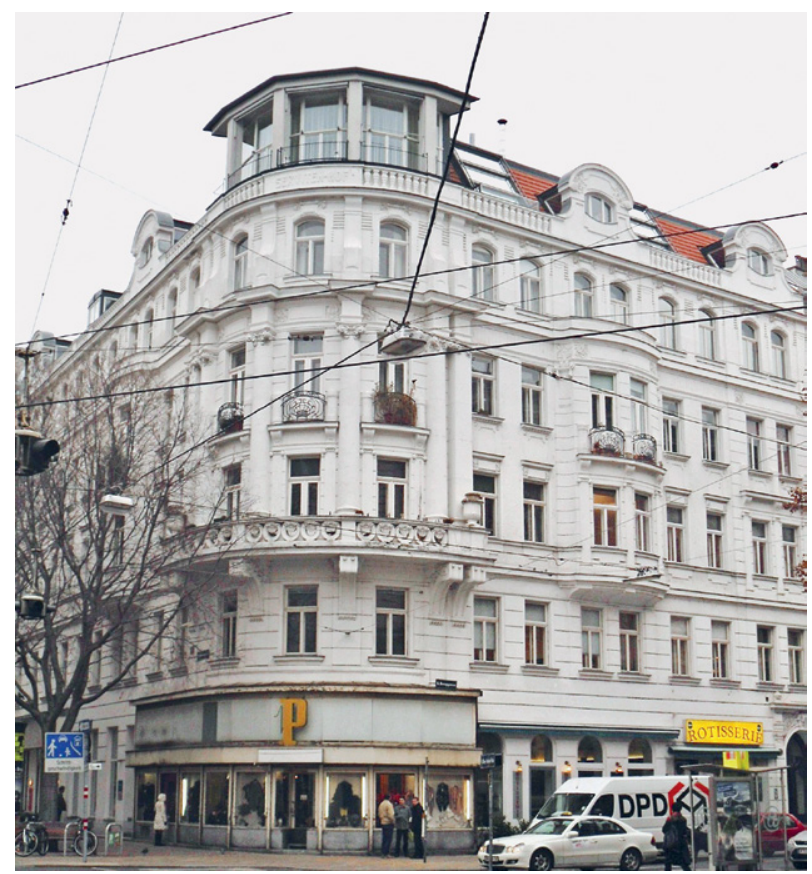

I 3. Jakob Modern, "Servitenhof «, Wien 9, Berggasse 25, erbaut I904/Prokop

Jakob Moderns Schaffen, das sich bis ins frühe 20. Jahrhundert erstreckte, geriet noch in die Turbulenzen der frühen Wiener Moderne, sodass das Spätwerk des von einem ausgeprägten Historismus beeinflussten Architekten zuletzt Übernahmen von Secessionismus und Jugendstil aufweist. Dies manifestierte sich ganz besonderes bei seinen Miethausbauten, von denen er eine erkleckliche Zahl im 9. Bezirk in der Gegend der Rossau errichtete. Dieses ruhige gutbürgerliche Viertel wurde auch von nicht wenigen Juden bewohnt, die sich rund um den alten "Oberen Werd« - bereits seit dem Spätmittelalter jüdisches Siedlungsgebiet - hier niedergelassen hatten. Insbesondere Künstler und Intellektuelle aus der Mittelschicht - beispielgebend sei Sigmund Freud genannt - bevorzugten diese Gegend. Als nun im Zuge der Modernisierung der Stadt und der Schleifung der alten niederen Verbauung in den Jahren vor dem Ersten Weltkrieg ganze neue Viertel entstanden, errichtete um 1904/05 Modern insbesondere auch im sogenannten "Servitenviertel« eine Reihe von bemerkenswerten Wohnhäusern, die bis heute der Gegend den Charme des Jugendstils verleihen (Abbildung I 3 , Servitenhof). Jakob Modern ist nur einige Jahre später I9 I 2 verstorben.

Sein Sohn Richard Modern (1872-1957), der entgegen allen Usancen im Gegensatz zu seinem Vater keine akademische Ausbildung erhalten hatte, war schon bald nach Abschluss der Gewerbeschule ins väterliche Büro eingetreten und arbeitete auch 
I4. Jakob Gartner, Porträt/ÖIAV

späterhin bei verschiedenen Baugesellschaften. Auch er konnte noch kurz den Bauboom der Jahre vor dem Ersten Weltkrieg lukrieren und eine Reihe von Miethäusern errichten. ${ }^{55}$ In der Zwischenkriegszeit sind kaum Bauten von ihm dokumentiert, sodass anzunehmen ist, dass er aufgrund der schlechten Wirtschaftslage kaum selbstständig gearbeitet hat. Richard Modern geriet noch in die Wirren des "Anschlusses" von 1938 und schaffte es - damals bereits hoch in den Sechzigern - nur mit Mühe, gerade noch im Jänner 1940 in die USA zu entkommen. Nach einer kurzen Zwischenstation in New York gelangte er schließlich nach San Francisco, wo er Ende der Fünfzigerjahre verstarb.

Eine Sonderstellung im Rahmen dieses Kapitels nimmt Jakob Gartner (I 86 I-I92 I, Abbildung I4) ein, der allerdings kein Schüler Friedrich Schmidts war und deshalb auch formal etwas andere Wege beschritt. Da seine umfassende Tätigkeit auf dem Gebiet des Synagogenbaus jedoch in diese Periode fällt und vom Geist des Historismus geprägt ist, erscheint es legitim, ihn in diesen Abschnitt aufzunehmen. Nahezu eine Generation jünger als Fleischer und Stiassny, hatte der aus Prossnitz/Prostejov in Mähren stammende Gartner seine Ausbildung an der Wiener Akademie der bildenden Künste in der Meisterschule Carl Hasenauers erhalten. ${ }^{56}$ Gartners Interesse galt offenbar von Anfang an dem Synagogenbau, denn noch während seines Studiums

55 J. Brandstetter, Richard Modern, in: Architektenlexikon, zit. Anm. I 3.

56 Siehe dazu: I. Scheidl, Jakob Gartner, in: Architektenlexikon, zit. Anm. I 3. 


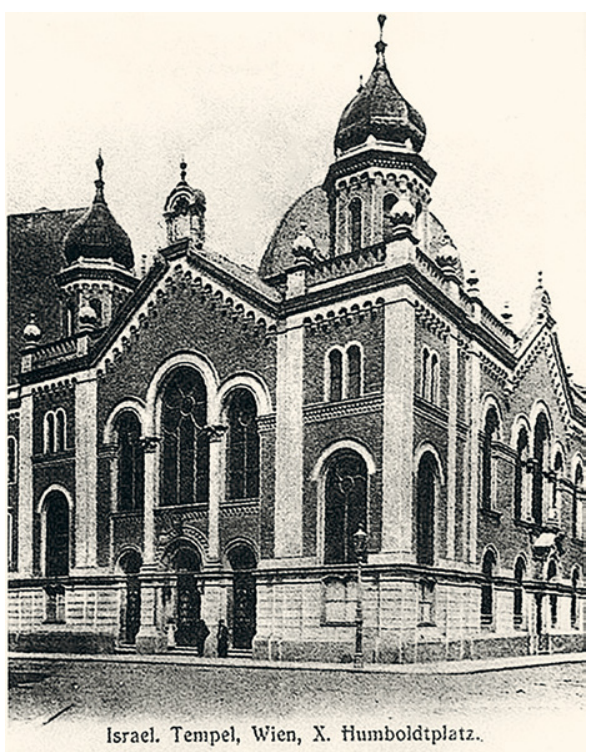

I5. Jakob Gartner, Synagoge Wien ro, Humboldtgasse 27, erbaut 896 (nicht erhalten)/Wikipedia

praktizierte er bei Hugo von Wiedenfeld, der damals mit dem Bau des prestigeträchtigen türkischen Tempels in der Zirkusgasse befasst war. ${ }^{57}$ Mit dieser spezifischen Ausbildung wurde er bald zu einem der meistbeschäftigten Architekten auf dem Gebiet des Synagogenbaus in der Zeit um I900, der infolge der stark wachsenden jüdischen Gemeinden damals geradezu boomte. ${ }^{58}$ Schon bald nachdem er sich um i 888 selbstständig gemacht hatte, konnte Gartner einige kleinere Kultbauten in der Provinz errichten. Die Zuerkennung des I. Preises und in der Folge die Realisierung einer großen Synagoge in Troppau/Opava, die er in einem prächtig-byzantinischen Stil - in der Art Theophil Hansens - errichtete, bedeuteten dann den großen Durchbruch.

In schneller Folge erhielt Gartner weitere Aufträge für einen Tempel in Olmütz/ Olomouc und schon bald auch in Wien, wo er schließlich vier Synagogen innerhalb von rund zehn Jahren bauen konnte. Ähnlich wie Max Fleischer gestaltete er seine Bauten in Anlehnung an den christlichen Kirchenbau, in dem er z. B. Zweiturmfassaden und Radfenster als architektonische Details verwendete. Andererseits scheute er sich aber auch nicht, farbkräftige orientalisierende Elemente zum Einsatz zu bringen. Das markanteste Beispiel dafür war der Favoritener Tempel, der, I 896 in der

57 Aufnahmeformular Jakob Gartners in den Österreichischen Ingenieur- und Architektenverein, I 894. 58 Gartner soll insgesamt rund 25 Synagogen errichtet haben (Dr. Blochs Wochenschrift, 29.4.1910, H. 17, S. 298). 


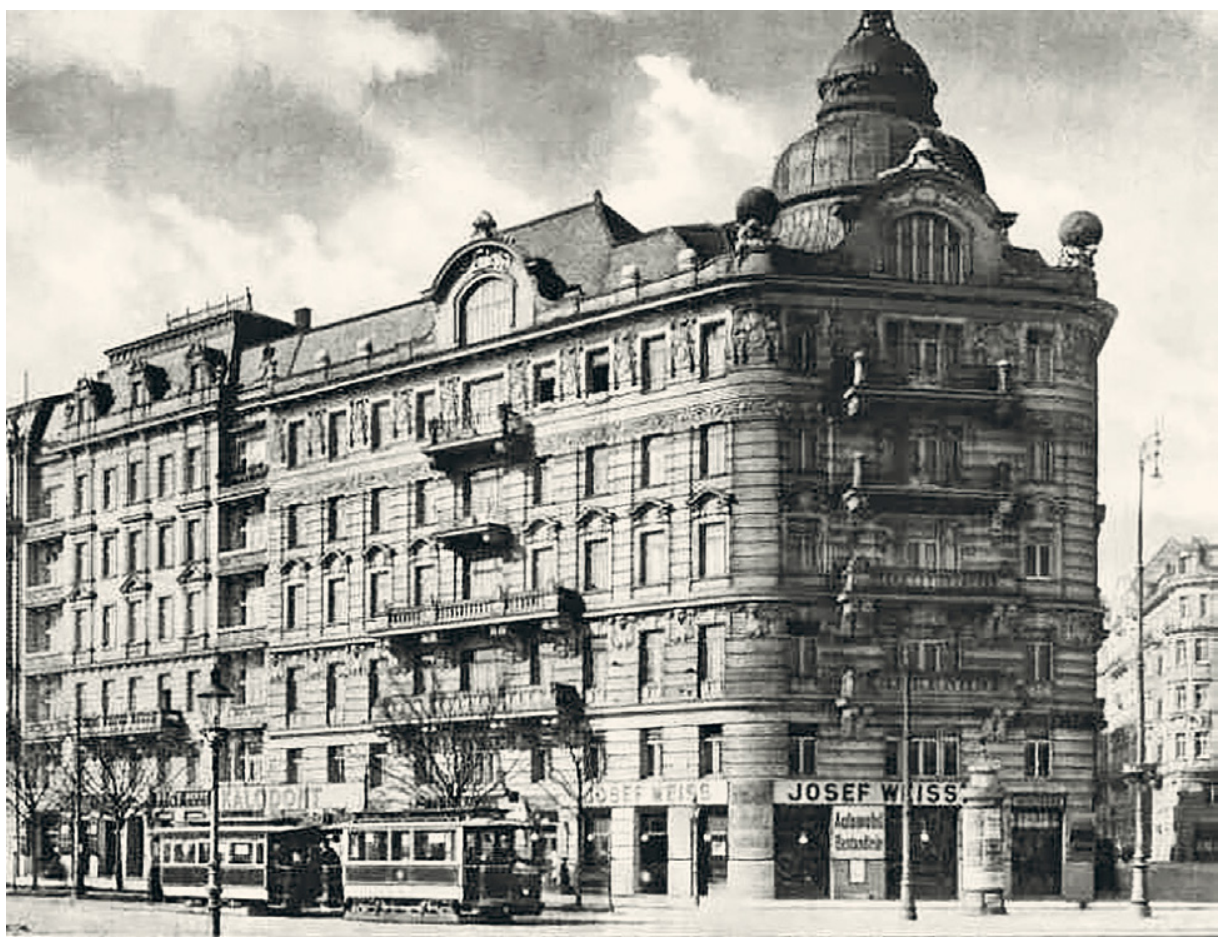

I6. Jakob Gartner, Miethaus Wien I, Stubenring 2, erbaut I905, Wr. Bauindustriezeitg. I907

Humboldtgasse (Abbildung I 5) errichtet, der damals stark wachsenden jüdischen Gemeinde im zehnten Bezirk als Vereinssynagoge diente.

Neben den zahlreichen Kultbauten plante Gartner aber auch eine Reihe von sehr repräsentativen Miethäusern in noblen Wiener Wohnvierteln. Insbesondere im sogenannten Stubenviertel, wo durch den Abriss der Franz-Josephs-Kaserne ein großes Bauareal frei wurde, das die Vollendung des letzten Abschnittes der Wiener Ringstraße ermöglichte, konnte er einige bemerkenswerte Wohnbauten errichten. Ähnlich wie bei seinen Synagogenbauten vertrat Gartner auch hier keine avantgardistische Linie, sondern bemüßigte sich des Kompromisses einer historistisch-neobarocken Gestaltung, die nur mit einzelnen secessionistischen Details angereichert war. Auch wenn sich Adolf Loos über diesen Abschnitt der Ringstraße abfällig äußerte und ihn als »fünfstöckiges MährischOstrau « bezeichnete (für Loos offensichtlich der Inbegriff von Provinzialismus), ${ }^{59}$ erfreute sich diese gemäßigte Ausrichtung bei den Bauherren großer Beliebtheit. Bis heute

59 A. Loos, Heimatkunst, I9 14, in: Trotzdem, Wien I982, S. I23. 
haben sich diese Gebäude eine gewisse Eleganz bewahrt, die den Glanz der Fin-de-siècleKultur widerspiegelt (z. B. Miethaus Stubenring 2, Abbildung I6).

Ungeachtet seiner großen Verdienste für den jüdischen Kultbau wurde Gartner erst I9I I - bereits in fortgeschritteneren Jahren - als Vorstandsmitglied der Israelitischen Kultusgemeinde in der Nachfolge von Wilhelm Stiassny aufgenommen. Während des Ersten Weltkrieges noch mit dem provisorischen Ausbau der neuen israelitischen Abteilung des Zentralfriedhofes befasst (die Anfang der Zwanzigerjahre von Ignaz Reiser ausgebaut wurde), starb Gartner bald nach dem Zusammenbruch der Monarchie im 6o. Lebensjahr in Wien. Nahezu alle seine Kultbauten wurden in der NS-Zeit zerstört, geblieben sind weitgehend nur seine eleganten Miethäuser, die heute noch insbesondere das Viertel um den Stubenring prägen.

\subsection{Karl König - ein jüdischer Professor}

Ein weiterer bedeutender Schüler Friedrich von Schmidts war Karl König (I 84II 9 I 5, Abbildung I7), einer der ersten jüdischen Professoren auf dem Gebiet der Architektur überhaupt, der infolge seiner langjährigen, nahezu fünfzig Jahre währenden Lehrtätigkeit von einem nicht zu überschätzenden Einfluss für die Wiener Architekturszene war. König, dessen Familie aus Pressburg (ungarisch Poszony, slowakisch Bratislava) stammte, kam allerdings bereits in Wien zur Welt, wo er als Sohn eines Sekretärs in bescheidenen, bürgerlichen Verhältnissen aufwuchs. Praktisch gleich alt wie Stiassny und Fleischer, war er sowohl am Polytechnikum als auch später an der Akademie ein Studienkollege der beiden. Nach dem Studium und einer kurzfristigen Mitarbeit bei Friedrich von Schmidt ging er allerdings bald einen völlig anderen Weg. Infolge seiner eingeschränkten wirtschaftlichen Verhältnisse arbeitete König vorerst in verschiedenen Baubüros, bis schließlich der bekannte Ringstraßenarchitekt Heinrich von Ferstel auf den brillanten Zeichner aufmerksam wurde und ihn I 866 als Assistent ans Polytechnikum holte, wo König in der Folge bis zu seiner Pensionierung blieb und langsam, aber stetig die Karriereleiter erklomm.

Gleichzeitig fand in dieser Periode auch die sukzessive Wandlung von einem ausschließlich auf das Ingenieurswesen und technische Konstruktion ausgerichteten Unterricht des Institutes zu einer vollgültigen Architekturschule statt - ein Umstand, der für Königs berufliche Entwicklung von großer Bedeutung sein sollte. I 873 wurde er zum außerordentlichen Professor für architektonische Formenlehre ernannt, daneben begann er in dieser Zeit auch als freiberuflicher Architekt zu arbeiten, wobei sein Euvre in diesen frühen Jahren infolge seines intensiven Engagements an der Hochschule jedoch eher schmal blieb. Eines seiner ersten Projekte war die Errichtung der 
I7. Karl König, Porträt,/Wr. Bauhütte I9ı 2

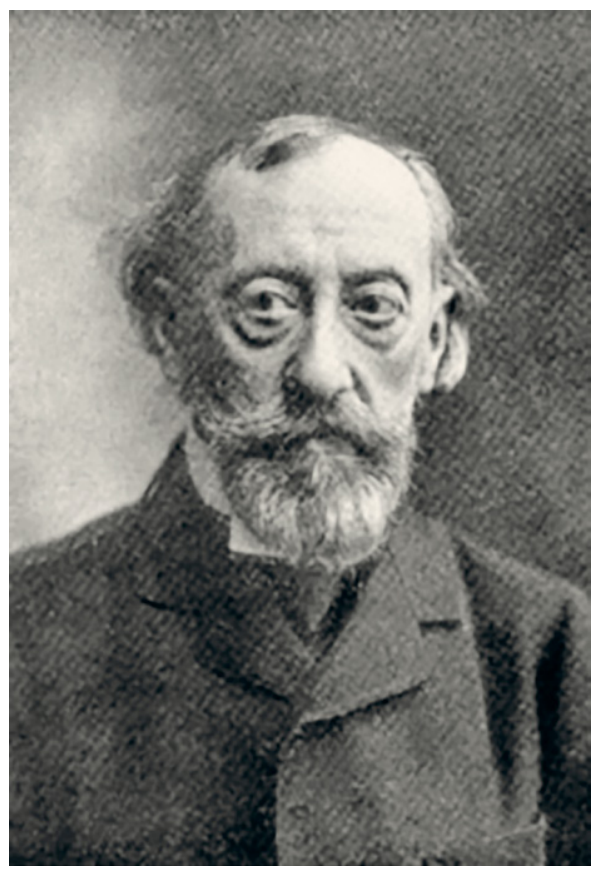

Synagoge in Wien I5, Turnergasse (1870-187I), die sich formal an der Renaissance orientierte und damit die Eingebundenheit der jüdischen Kultur in der hellenistischklassischen Tradition hervorhob, der er sich auch persönlich sehr verbunden fühlte (Abbildung I 8). ${ }^{60}$ Zwei Jahre später, I 875, wurde er im Kontext der oben erwähnten Umwandlung des alten Polytechnikums in eine Technische Hochschule zum Vorstand der Lehrkanzel für Propädeutik ernannt, hatte aber weiterhin noch keinen eigenen Lehrstuhl. Aufgrund seines Beamtenstatus erhielt König auch das Wiener Heimatrecht, auf das er bis dahin als Sohn zugewanderter Eltern kein Anrecht hatte. Um seine weitere Karriere nicht zu gefährden, trat er Mitte der Siebzigerjahre aus der Kultusgemeinde aus, ließ sich aber bemerkenswerterweise nie taufen, sondern blieb konfessionslos. ${ }^{61}$ Wie man aus seinem späteren Werk (z. B. I 889 Bau der Synagoge in Reichenberg/Liberec oder mehrere Grabmäler für jüdische Honoratioren) und diversen Funktionen (so war er u. a. Mitglied der Rothschildstiftung) ablesen kann, blieb

6o Auch dieser Bau wurde zerstört. Zur Biografie von Karl König siehe auch J. Brandstetter, Dipl.-Arb. Wien I996; Kristan, zit. Anm. I I.

6I Das exakte Austrittsdatum Königs ist strittig. Während Kristan angibt, dass König bereits I 876 anlässlich der Ausstellung des Heimatscheines als konfessionslos ausgewiesen worden sei, führt Brandstetter als Austrittsdatum I 878 an (basierend auf den Matriken der IKG). 


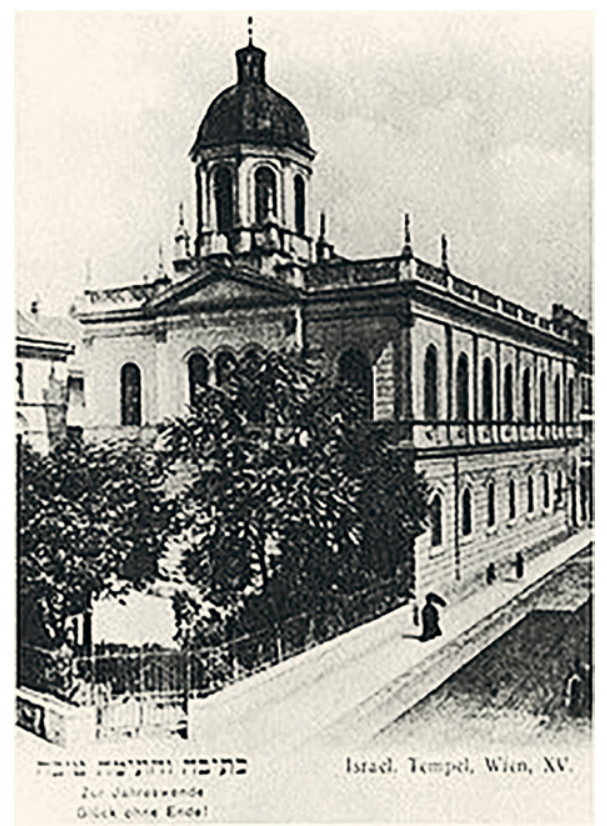

I8. Karl König, Synagoge Wien I5, Turnergasse 22, erbaut 19872 (nicht erhalten)/Wikipedia

er aber ungeachtet seiner weitgehenden Assimilierung weiterhin in engem Kontakt mit jüdischen Kreisen.

Tatsächlich konnte König I885 nach dem Tod Heinrich Ferstels, der auch eine Umstrukturierung der Lehrkanzeln mit sich brachte, dessen Nachfolge als Ordinarius für die Baukunst der Antike und Renaissance antreten, wobei jedoch zu bedenken ist, dass er zu diesem Zeitpunkt schon fast zwanzig Jahre an der Hochschule lehrte, also eine unverhältnismäßig lange Wartezeit hinter sich hatte. Etwas entlastet von der Alltagsarbeit an der Hochschule, da ihm jetzt Assistenten zur Seite standen, konnte König auch seine Tätigkeit als Architekt intensivieren. Kurz zuvor hatte er sich mit der Errichtung des repräsentativen Wohn-Geschäftshauses des »Philipp-Hofes« (Wien I, Albertinaplatz I, Abbildung I9) große Anerkennung bei einer breiteren Öffentlichkeit verschafft. Vor allem durch den Einsatz des Formenrepertoires des Neobarock, insbesondere einer Kuppel - bis dahin ein absolutes Novum im bürgerlichen Wohnbau -, wurde der Philipp-Hof zu einem Paradigma der späthistoristischen Barockrezeption. ${ }^{62}$ Im Kontext der sich verstärkenden Nationalitätendiskussion dieser Jahre

62 Der Philipp-Hof wurde gegen Ende des Zweiten Weltkrieges im Frühjahr I945 durch einen Bombenangriff zerstört, zahlreiche Verschüttete blieben unter dem Mauerwerk begraben. An seiner Stelle steht jetzt das Denkmal für die Opfer des Faschismus von Alfred Hrdlicka. 


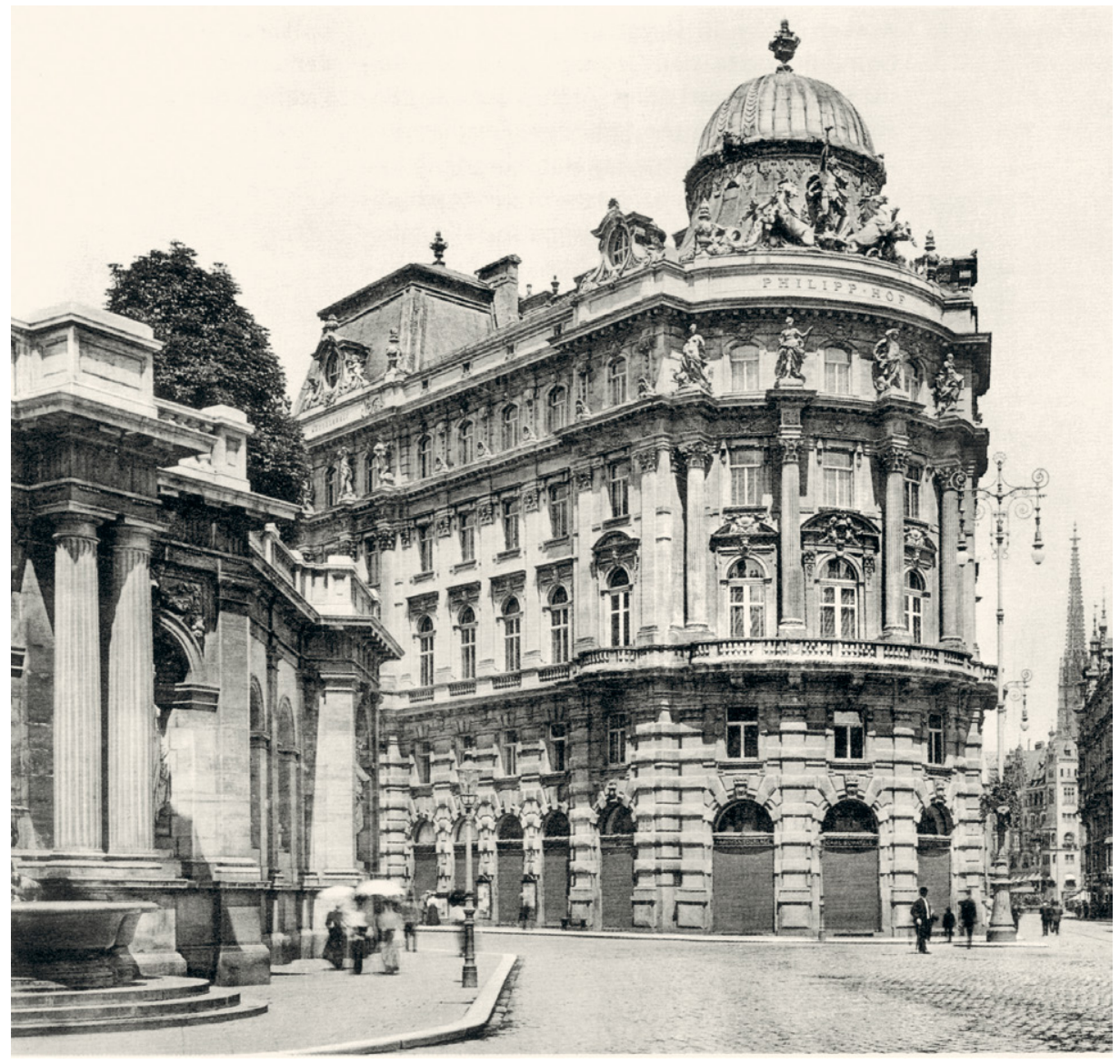

I9. Karl König, Philipp-Hof, Wien I, Augustinerstraße 8, erbaut um I 884 (nicht erhalten)/Architekton. Rundschau

wurde das Barock, vor allem durch die Schriften des Kunsthistorikers Albert Ilg, der als Lehrer des späteren Thronfolgers Franz Ferdinand nicht ohne Einfluss war, als genuin »österreichischer Stil« interpretiert und löste zunehmend den bis dahin in der Architektur so beliebten Formenapparat der Neorenaissance ab. ${ }^{63}$ Die ideelle Nähe des Werks Karl Königs zur "österreichischen« Identität und zum Hause Habsburg eine Haltung, die damals keineswegs selbstverständlich war und von deutschnationalen Kreisen heftigst abgelehnt wurde - wird auch bei dem Ende der Neunzigerjahre errichteten »Palais Herberstein» (Wien I, Herrengasse I) deutlich. Die formale Ge-

63 Albert Ilg, Die Zukunft des Barockstils, Wien I 880. 
staltung des Baus war hier als Weiterführung des kurz zuvor errichteten Hofburgtraktes am Michaelerplatz konzipiert, der sich seinerseits weitgehend an alte Pläne Fischer von Erlachs anlehnte. Wiederum ist es vor allem die überkuppelte Ecklösung des Palais Herberstein, die Aufmerksamkeit und Diskussionen auslöste und - je nach der persönlichen Positionierung - als Anmaßung (da es sich um ein unmittelbares Zitat eines Motivs Fischer von Erlachs handelte) oder als Hommage interpretiert wurde. Bezeichnenderweise war es diese Kuppel, die offenbar noch Jahre hinaus von einigen als Stachel im Fleisch empfunden und in einem viel diskutierten Umbau bereits in den Dreißigerjahren des 20. Jahrhunderts abgetragen wurde. ${ }^{64}$

Einer der letzten großen Aufträge Königs war das Haus der Industrie (Abbildung 20), das in den Jahren I 906/09 in prominenter Lage am Schwarzenbergplatz errichtet wurde und als durchaus repräsentative Selbstdarstellung der im gesamteuropäischen Kontext zwar etwas verspäteten, aber dennoch erfolgreichen österreichischen Industrie dienen sollte. Ungeachtet der aufkommenden Moderne, wie sie in diesen Jahren insbesondere von Otto Wagner und dessen Umfeld in Wien initiiert wurde, bediente sich König auch bei diesem Bau weiterhin eines späthistoristischen neobarocken Formenvokabulars, wobei anzunehmen ist, dass er auch den konservativen Geschmack seiner Auftraggeber berücksichtigen musste. Konsequenterweise gestaltete König auch das nahezu gleichzeitig errichtete Palais Kuffner im Döblinger Cottage (Wien I9, Peter-Jordan-Straße I), das er für den jüngeren Sohn der berühmten Ottakringer Braudynastie in der Art eines französischen Renaissanceschlosses entwarf. Ungeachtet dieser damals schon etwas "altmodischen « Auffassung, zeugen die harmonischen Proportionen der Villa Kuffner von der Könnerschaft Karl Königs. Von der weiteren, beschämenden Geschichte des Palais wird noch im letzten Kapitel die Rede sein.

Otto Wagner hatte einige Jahre zuvor I 896 mit seiner theoretischen Schrift »Moderne Architektur «, in der er eine Synthese von Technik und Baukunst anstrebte und als Konsequenz eine »Naissance« der Architektur forderte, deren Ästhetik den neuen Konstruktionen und Funktionen angemessen sein sollte, eine große Fachdebatte in Wien ausgelöst. ${ }^{65}$ König, der selbst relativ wenig publizierte und sich eher selten zu theoretischen Fragen äußerte, hatte I 90 I anlässlich seiner Antrittsrede als Rektor der Technischen Universität zwar gleichfalls die enge Verbundenheit der »Kunst der Architektur und der Wissenschaft des Ingenieurs« bejaht, seine traditionsverbundene Position jedoch unter anderem damit begründet, dass »[d]as Studium der Vorbilder, die uns die Vergangenheit liefert, eine Hauptquelle der architektonischen Erfindung

\footnotetext{
64 Als "unverfroren" wurde die Kuppel sogar noch in der jüngeren Literatur bezeichnet (R. Bösel, Der Michaelerplatz in Wien, Wien I991, S. I38).

65 O. Wagner, Moderne Architektur, Wien 1896.
} 


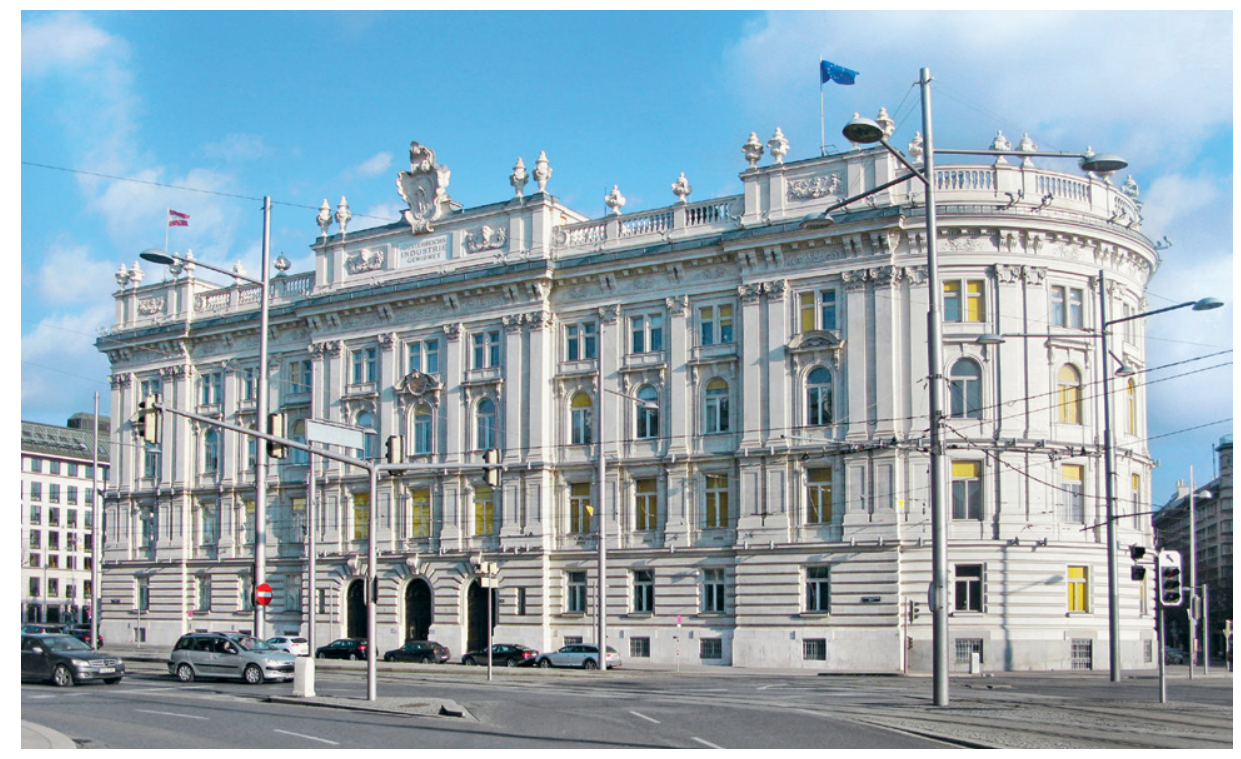

20. Karl König, Haus d. Industrie, Wien 3, Schwarzenbergplatz 4, erbaut um I 906/Prokop

ist«. ${ }^{66}$ Im Gegensatz zu Otto Wagner spielte die Stilfrage für König eher eine untergeordnete Rolle. Auf der Basis der Kenntnis der klassischen Tradition standen für ihn technische Aspekte, wie Konstruktion, funktionelle Anforderungen und Raumorganisation, im Vordergrund. ${ }^{67}$

Die in formaler Hinsicht traditionsverbundene Haltung Karl Königs, der es bis zu höchsten Funktionen im Hochschulbereich gebracht hatte und mit Titeln und Orden ausgezeichnet worden war, erklärt sich möglicherweise durch den Umstand, dass er als typischer Vertreter des assimilierten Judentums der historistischen Tradition insofern besonders verpflichtet war, als das Judentum seit dem Ausbruch aus der Welt des Ghettos endlich in der Gesellschaft der Ringstraßenkultur Fuß gefasst hatte. In den Palais der Todesco, Ephrussi, Epstein und anderen glaubte man den Traum von Assimilation und Emanzipation verwirklicht zu sehen. Insbesondere die ältere Generation der jüdischen Bourgeoisie stand daher verändernden Tendenzen nicht selten eher misstrauisch gegenüber.

66 Zitiert nach Kristan, siehe Anm. I I, S. 4I.

67 Siehe dazu Chr. Long, An Alternative Path to Modernism: Carl König and the architectural Education at the Vienna Technische Hochschule I 890-19I3, in: Journal of Architectural Education, Sept. 200I, S. 2 Iff. 
Diese Kontroverse zwischen Karl König und Otto Wagner im architekturtheoretischen Diskurs dieser Jahre fand insbesondere auch im Rahmen ihrer Lehrtätigkeit ihren Niederschlag. Der konservativen Ausrichtung Karl Königs an der Technischen Hochschule standen die progressiven Tendenzen der sogenannten "Wagner-Schule» (wie die Schüler Otto Wagners landläufig bezeichnet wurden) an der Akademie der bildenden Künste entgegen, wobei sich allerdings die Organisation des Unterrichtes an den beiden Instituten sehr voneinander unterschied. Während es an der Akademie der bildenden Künste die sogenannte »Meisterschule« gab, die von einem Professor geleitet wurde, mussten die Studenten an der Technischen Hochschule die unterschiedlichsten Vorlesungen bei verschiedenen Professoren besuchen. König, der »architektonische Formenlehre unterrichtete, hatte im Rahmen dieser Organisation allerdings ein besonders wichtiges Fach inne. Auch in quantitativer Hinsicht war seine Lehrtätigkeit beachtlich, insofern er es infolge seiner langen Dienstzeit auf rund fünfhundert Schüler brachte. Außerdem erfuhr die Technische Hochschule zu der Zeit, als Karl König unterrichtete, durch die Einführung eines Doktoratsstudiums Ende der Neunzigerjahre des I9. Jahrhunderts eine erhebliche Aufwertung, und man kam daher zunehmend von dem Usus ab, nach dem Studium an der Technischen Hochschule noch an die Akademie zu gehen, um sich dort in »künstlerischer" Hinsicht zu vervollkommnen.

Bezeichnenderweise legten die meisten der ersten Doktoranden, wie Max Fabiani, Alfred Teller, Oskar Strnad, Oskar Wlach, Josef Frank und andere mehr, wobei die meisten von ihnen Juden waren, ihre Dissertation bei Karl König ab und wurden ihrerseits bedeutende Architekten - es wird in späteren Kapiteln noch davon die Rede sein. Angesichts dieser Umstände ist es sicherlich gerechtfertigt, von einer »KönigSchule« zu sprechen.

Der Antagonismus der beiden »Schulen« von Otto Wagner und Karl König wurde über die fachliche Diskussion hinaus noch durch gesellschaftspolitische Konflikte, vor allem durch den sich zunehmend radikalisierenden Antisemitismus, verschärft. Während an der Technischen Hochschule bis zu 30 Prozent der inskribierten Studenten dem »mosaischen Bekenntnis « ${ }^{68}$ angehörten, besuchten jüdische Studenten - insbesondere nach dem Ende der liberalen Ära - die Akademie der bildenden Künste eher selten, schon gar nicht die Meisterschule Otto Wagners, der in einem Naheverhältnis zu Bürgermeister Karl Lueger stand und dem eine eher antisemitische Gesinnung nachgesagt wurde. ${ }^{69}$ Wenn jüdische Studenten an die Akademie gingen, dann

68 Der amtliche Begriff für die Religionszugehörigkeit war in der Monarchie »mosaisch«.

69 Unter den rund I90 Schülern Otto Wagners, die von I894 bis I9I4 dessen Meisterschule absolvierten, scheint Ernst Lichtblau, der aber kurz nach seinem Studium 1909 konvertierte, der einzige Jude gewesen zu sein. Siehe dazu Prokop, zit. Anm. 9, S. 65. 
bevorzugten sie eher die Meisterschule von Friedrich Ohmann, dem eine liberalere Gesinnung nachgesagt wurde und der als Ausbildner einer gewissen Anzahl jüdischer Architekten anzusehen ist. ${ }^{70}$ Diese Situation, die für die letzten zwei Jahrzehnte vor dem Ersten Weltkrieg prägend war, sollte in weiten Bereichen auch späterhin die Ausgangsbasis für die Wiener Architekturszene der Zwischenkriegszeit werden.

70 Siehe dazu I. Meder, Lebens- und Arbeitsbedingungen jüdischer Architekten in Österreich, in: A. Senarclens de Grancy/H. Zettelbauer (Hg.), Architektur. Vergessen - Jüdische Architekten in Graz, Wien U. a. 20 I I. 


\section{Die Schüler Karl Königs vor dem Ersten Weltkrieg}

Karl König hatte in seiner - wenn man seine Assistentenzeit mit berücksichtigt - nahezu fünfzigjährigen Lehrzeit (ca. I866-I9I3) eine Unzahl von Schüler, darunter ein gutes Drittel "mosaischen Glaubens" (der damals übliche amtliche Terminus). Es würde den Rahmen dieser Arbeit sprengen, auf alle einzugehen. Vorrangig werden solche Architekten erwähnt, die besonders markante Bauten in Wien errichtet oder eine bedeutende Rolle im kulturhistorischen Kontext gespielt haben, wobei auch nach diesen Kriterien die Zahl derer, die erwähnenswert wären, zu groß ist, um alle berücksichtigen zu können. Zur besseren Strukturierung dieses großen Gebietes werden die entsprechenden Architekten in thematische Zusammenhänge gestellt.

\subsection{Das Werden der modernen Großstadt - neue Bauaufgaben}

\section{I.I Das Warenhaus}

In zeitlicher Koinzidenz mit dem sprunghaften Ansteigen der Zahl jüdischer Architekturstudenten erfuhr auch Wien in den Achtziger/Neunzigerjahren des 19. Jahrhunderts einen dramatischen Wandel. Nach der Schleifung der Befestigungswälle und dem Ausbau der Ringstraße zu einem Prachtboulevard hatten auch die Vororte durch den stetigen Bevölkerungszuzug aufgrund des Arbeitskräftebedarfs der wachsenden Industrie ihren ländlichen Charakter verloren und wurden schließlich I 890 eingemeindet. Die zunehmende Konzentration von Menschen und Kapital lösten den Wandel Wiens zu einer modernen Metropole aus. Neue, bis dahin - zumindest in Wien - kaum bekannte Bauaufgaben stellten daher Herausforderungen an die Architekten. Der Prozess der Industrialisierung erforderte Kapital, das zur Entstehung von Großbanken führte, die sich dementsprechend auch nach außen präsentieren wollten, und der Handel verlagerte sich zunehmend vom kleinen ebenerdigen »Gwölb» (Wiener Bezeichnung für Geschäft) zum professionell durchorganisierten Warenhaus. Wenn Wien sich in dieser Hinsicht auch nicht mit westeuropäischen Städten wie Paris oder London vergleichen konnte, so gab es doch bemerkenswerte Einzelleistungen. Im Rahmen dieses Modernisierungsschubes spielten vor allem auch jüdische Unternehmer eine wichtige Rolle, wobei sie bei manchen Branchen geradezu eine Monopolstellung innehatten. Dies traf, wie bereits erwähnt, vor allem auf den Textilhandel zu.

Zu der Gruppe dieser aufsteigenden Unternehmer zählte auch August Herzmansky, der - obwohl selbst nicht jüdischer Herkunft - bereits I 863 ein Textilgeschäft an 
der Mariahilfer Straße aufgemacht hatte und der in der Folge dermaßen erfolgreich expandierte, dass er schließlich zum größten Textilunternehmer der Monarchie aufstieg und eines der ersten Warenhäuser in Wien eröffnete, das im Laufe der Zeit immer wieder erweitert und umgebaut wurde. Ende der Neunzigerjahre beauftragte er den Architekten Maximilian Katscher (I 858-1917) mit einem großzügigen Neubau (Wien 7, Stiftgasse 3). Katscher, der ursprünglich aus Austerliz/Slavkov in Mähren stammte, hatte Mitte der Siebzigerjahre an der Technischen Hochschule in Wien bei Karl König, zu dessen ersten Schülern er zählte, studiert. Nachdem er sich selbstständig gemacht hatte, konnte er sich neben der Planung von Villen und Wohnhäusern insbesondere mit der Errichtung des Kurhauses (1885) in Baden bei Wien einen Namen machen, das in der Art eines italienischen Renaissancepalazzos gestaltet bis heute den Kurpark von Baden prägt. Ein weiterer prestigeträchtiger Auftrag Katschers war der Bau einer Synagoge in Graz (I 890), die er als imposanten Zentralkuppelbau in den Formen der Neoromanik realisierte. ${ }^{71}$

Für den Textilgroßhändler August Herzmansky und dessen Familie hatte Katscher bereits in den frühen Neunzigerjahren einige Villen und ein Kinderheim ausgeführt, als er den Auftrag zum Bau des Warenhauses erhielt, wobei dieser Bautypus, der damals noch relativ neu war, ganz bestimmten Anforderungen unterlag. Neben dem Umstand, dass das ganze Gebäude praktisch nur einen einzigen, alle Geschoße durchgehenden Hauptraum umfasste, der eine große repräsentative Treppe mit einschloss und damit eine Herausforderung an die damaligen Möglichkeiten der Statik stellte, musste auch die Fassade im Hinblick auf eine möglichst optimale Nutzung des Tageslichts mit großen Glasfenstern ausgestattet werden, die gleichzeitig auch der Präsentation der Waren dienten. Dies stand ganz im Gegensatz zu heute, wo das Kunstlicht jede natürliche Lichtquelle ersetzt und die Warenhäuser sich nach außen zumeist als hermetisch geschlossene Bauten präsentieren.

Bei dem schließlich I 898 vollendeten Gebäude des Warenhauses Herzmansky (der Auftraggeber erlebte die Fertigstellung nicht mehr) verstand es Katscher dann sehr geschickt, diesen Anforderungen an Funktion und Ästhetik gerecht zu werden. Mittels der Ständerbauweise konnte der glasüberdachte Innenraum äußerst weitläufig gestaltet werden, wobei die Marmorverkleidung der gusseisernen Stützen im $\mathrm{Zu}$ sammenspiel mit dem dekorativen Geländer der Galerien und der repräsentativen Hauptstiege die erwünschte Atmosphäre von Luxus vermittelte. ${ }^{72}$ Während der

\footnotetext{
7I Auch diese Synagoge mit einer eindrucksvollen Lage am Ufer der Mur (Grieskai 58) wurde von den Nazis zerstört. Ende der Neunzigerjahre des 20. Jahrhunderts wurde eine neue Synagoge errichtet, deren Strukturierung sich zum Teil an den Vorgängerbau anlehnt.

72 A. Lehne, Wiener Warenhäuser I 856-1914, Wien I990, S. I $70 f f$.
} 
2 I. Maximilian Katscher, Warenhaus Herzmansky, Wien 7, Stiftgasse 3, erbaut um I 898/Wr. Bauindustriezeitg. 1899

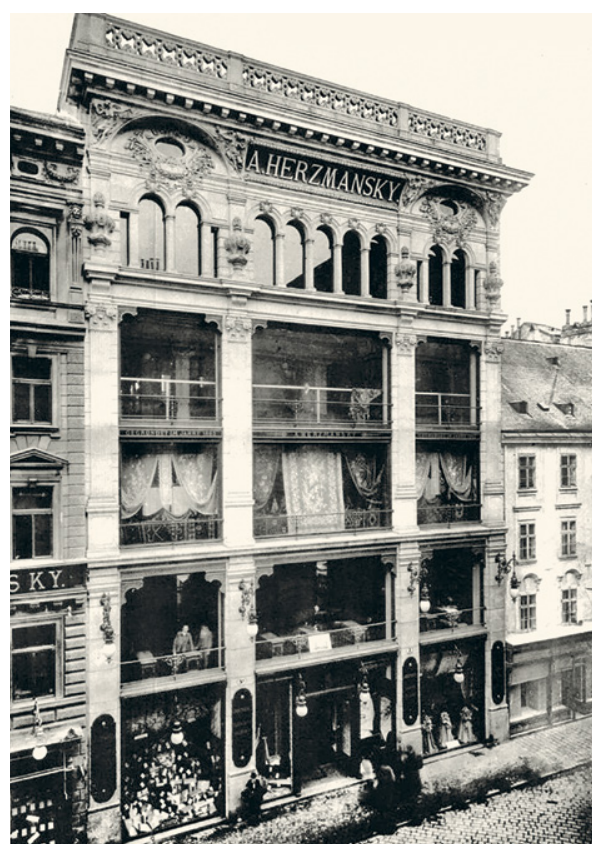

Innenraum heute nur mehr rudimentär erhalten ist - insbesondere die Treppenanlage fiel den diversen Umbauten zum Opfer -, ist die markante Fassade weitgehend intakt und ein bedeutendes Beispiel historistischer Architekturauffassung. In ihrer Synthese von einer damals hochmodernen Glasarchitektur und Neorenaissanceformen diente sie als repräsentativer Werbeträger des Unternehmens (Abbildung 2I). ${ }^{73}$ Die Firma Herzmansky selbst unterlag allerdings einer wechselvollen Geschichte; I938 wurde das in jüdischem Besitz befindliche Unternehmen arisiert und von der Vorarlberger Textilfirma Rhomberg übernommen, und schließlich gänzlich liquidiert. ${ }^{74}$ Das Gebäude nahe der Mariahilfer Straße (Stiftgasse I-3) gehört heute einer deutschen Textilkette.

Maximilian Katscher, der bis zum Ausbruch des I. Weltkrieges als Architekt tätig war, hatte in seiner Spätzeit vor allem noch einige größere Miethäuser in Wien realisiert. Bereits in etwas fortgeschritteneren Jahren war er I9I 4 eine Ehe eingegangen, die ihn veranlasste, zum Christentum zu konvertieren. Bereits drei Jahre später verstarb er neunundfünfzigjährig in Wien.

73 Wiener Bauindustriezeitung I6.I 899, Beil. S. I4, T. 42.

74 Siehe dazu T. Walzer/St. Templ, Unser Wien, Arisierung auf österreichisch, Berlin 200 I. 


\section{I.2 Das Wohn-Geschäftshaus}

Generell war der Typus des Warenhauses in Wien - im Gegensatz zu westeuropäischen Städten wie Paris oder London - jedoch eher spärlich vertreten. Weit häufiger setzte sich das sogenannte Wohn-Geschäftshaus durch, wo sich in den unteren Geschoßen Geschäftslokale befanden, während die oberen Stockwerke Wohnungen oder Büros vorbehalten waren. Infolge dieser gemischten Funktion - nicht selten waren auch Theater, Kinos und andere Lokalitäten in das Gebäude integriert - stellten sie oft große Anforderungen an die Architekten in Hinsicht auf Statik, Raumeinteilung, Erscheinungsbild und anderes mehr. Auch hier vollbrachten die Schüler Karl Königs Pionierleistungen, möglicherweise aufgrund des Umstandes, dass sie die bei ihrem Lehrer erworbenen Fähigkeit, klassische Proportionsprinzipien pragmatisch anzuwenden, befähigte, sowohl brauchbare als auch ästhetisch ansprechende Nutzbauten zu schaffen. Insbesondere in den letzten Jahren vor dem Ersten Weltkrieg entstanden infolge der guten Konjunkturlage eine Reihe bemerkenswerter Gebäude dieses Typus. Im Rahmen solcher multifunktionalen Großstadthäuser, die in dieser Periode entstanden, gehört auch der sogenannte "Nestroy-Hof» (Wien 2, Nestroyplatz I) zu den frühesten Realisationen dieser Art (Abbildung 23). I 898 von Oskar Marmorek (1 863-I909, Abbildung 22) errichtet, zeichnet sich der bis heute erhalten Bau, der in formaler Hinsicht typisch für den Übergang vom Späthistorismus zum Secessionismus ist, durch den Einsatz von bemerkenswert großen gläsernen Auslagen in der Geschäftszone aus, die dennoch mit dem Wohnbereich der oberen Geschoße harmonieren. Dem Architekten gelang es insbesondere auch, die hohen Anforderungen, die sich einerseits durch die schwierige städtebauliche Situierung auf einem äußerst unregelmäßigen Grundstück und andererseits durch den multifunktionalen Anspruch ergaben (nicht zuletzt galt es neben Wohnungen und Geschäften auch ein Kaffeehaus und ein kleines Theater unterzubringen), geschickt zu lösen. ${ }^{75}$

Marmorek war sozusagen in mehrfacher Hinsicht in die jüdisch wienerische Architekturszene eingebunden. Nicht nur dass er bei Karl König studiert hatte, er war auch über einige Zeit im Atelier von Wilhelm Stiassny tätig gewesen, dem er zeit seines Lebens freundschaftlich verbunden blieb. In Skala in Galizien als ältester Sohn eines Militärarztes geboren, wuchs er in bescheidenen bürgerlichen Verhältnissen auf. Während seine beiden Brüder Medizin und Jus studierten, schlug er die Architektenlaufbahn ein. ${ }^{76}$ Am Beginn seiner Karriere machte er sich vor allem als Ausstellungsarchitekt einen Namen. Insbesondere mit der großen Schau »Venedig in Wien«, die

75 F. Achleitner, zit. Anm. 26, S. 97.

76 Siehe dazu M. Kristan, Oskar Marmorek. Architekt und Zionist. I863-1909, Wien 1996. 
22. Oskar Marmorek, Porträt/Kristan, Central zionist., Archiv Jerusalem

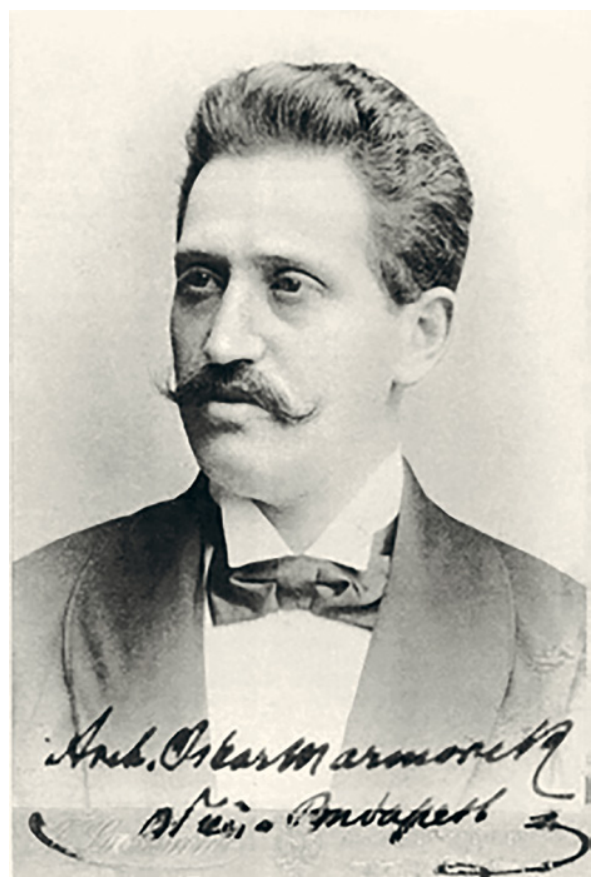

als eine Vorläuferinstitution der heutigen Disney-Land-Architektur zu sehen ist und I 895 auf dem Gelände des Wiener Praters errichtet wurde, erregte er großes Aufsehen.

Erst durch die Heirat mit einer Tochter eines wohlhabenden Bankiers erhielt er Aufträge für »seriöse Bauten«, darunter den bereits oben angeführten "Nestroy-Hof». Oskar Marmorek, der sich auch publizistisch betätigte und kurzfristig als Zeitschriftenherausgeber tätig war, stand in seiner architektonischen Positionierung der Schule Otto Wagners nahe. Dementsprechend zeichnet sich auch sein 1902 errichteter "Rüdiger-Hof" (Wien 5, Hamburger Straße 20, Abbildung 24) durch die Charakteristika der Wagner-Schule, etwa eine kubische Durchformung des Bauköpers und ein stark vorkragendes Dach, aus. Die persönliche Handschrift Marmoreks, der zweifellos als einer der originellsten "Jugendstilarchitekten " in Wien anzusehen ist, findet auch in der äußerst eigenwilligen farbigen Außengestaltung ihren Niederschlag. Der begabte Architekt beging jedoch knapp siebenundvierzigjährig einen spektakulären Selbstmord, in dem er sich am Grab seines Vaters erschoss, wobei nicht geklärt ist, ob die Ursache Depressionen oder finanzielle Schwierigkeiten waren. Marmorek ist auch insofern eine bemerkenswerte Persönlichkeit, als er sich schon früh für den Zionismus engagierte und mit Theodor Herzl persönlich befreundet war. Während es Marmorek als engagiertem Juden nicht vergönnt war, eine Synagoge zu realisieren - seine 


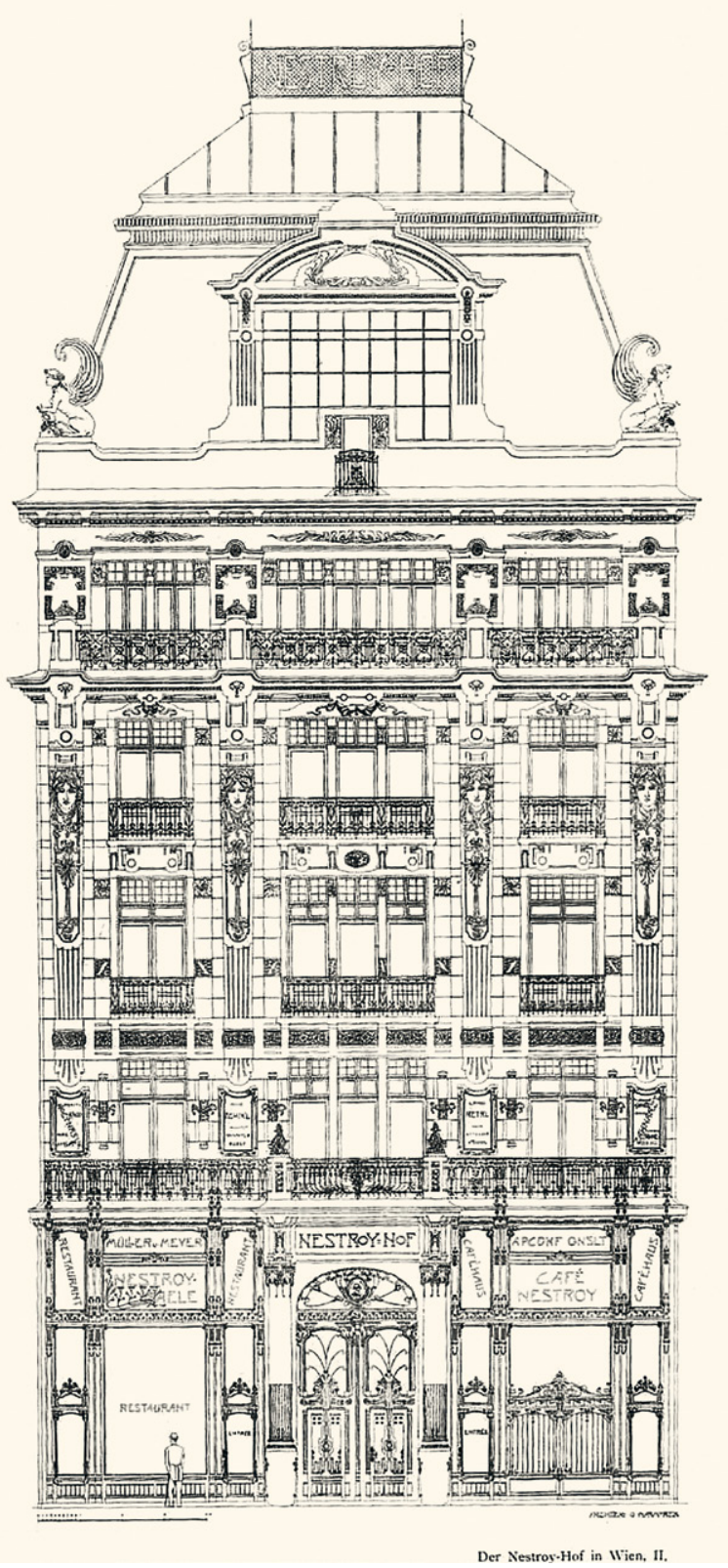

23. Oskar Marmorek, NestroyHof, Wien 2, Praterstraße 34, erbaut I 898/Der Architekt 1900 
24. Oskar Marmorek, Rüdiger-Hof, Wien 5 ,

Hamburgerstraße 20, erbaut 1902/Der Architekt 1903

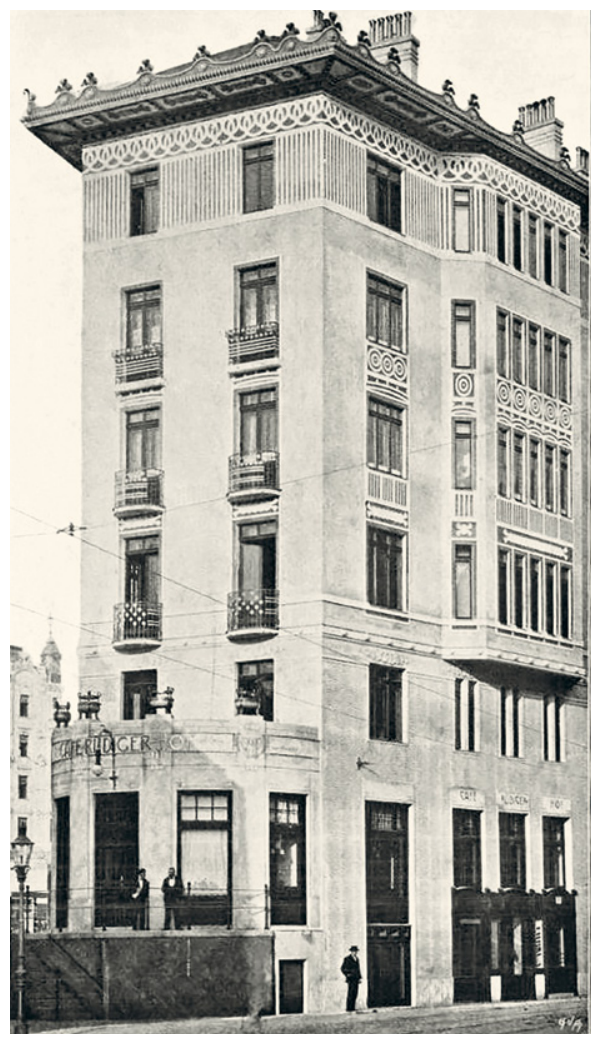

diversen Wettbewerbsentwürfe gelangten nicht zur Ausführung -, war er aber höchstwahrscheinlich der Autor des Grabmals Herzls auf dem Döblinger Friedhof. Herzl seinerseits hat in seinem Roman "Altneuland" in der Figur des Architekten Steineck Marmorek ein Denkmal gesetzt.

Eines der elegantesten Wohn-Geschäftshäuser dieser Periode überhaupt ist möglicherweise der sogenannte "Residenzpalast (Wien I, Fleischmarkt I/Rotenturmstraße, Abbildung 25), der in den Jahren I909/Io von Arthur Baron (I874-I944) errichtet wurde. ${ }^{77}$ Baron, der in Wien geboren wurde, stammte aus einer Kaufmannsfamilie, die ursprünglich ungarischer Herkunft war und in den Sechzigerjahren des I9. Jahrhunderts nach Wien gekommen war. Im Rahmen seines Studiums an der Technischen Hochschule bei Karl König gehörte er zu den ganz wenigen Studenten, die eine »strenge Prüfung« (eine Vorwegnahme der Diplomprüfung) abgelegt hatten. Aufgrund dieses

77 Siehe Prokop, Anm. 9, S. 65 ff. 


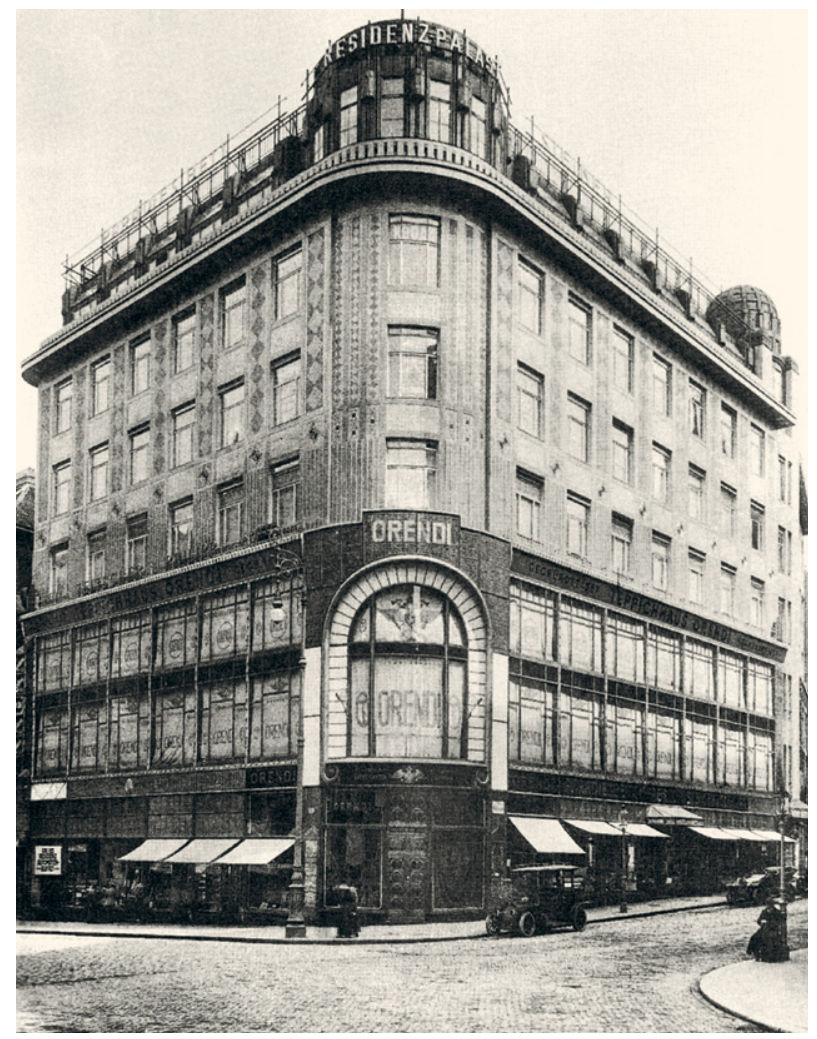

25. Arthur Baron, Residenzpalast, Wien I, Fleischmarkt I, erbaut I9Io/Der Bautechniker

erfolgreichen Studienabschlusses erhielt Arthur Baron das prestigeträchtige Ghega-Stipendium, das ihm eine längere Studienreise ins Ausland ermöglichte. Nachdem er kurze Zeit als Assistent an der Hochschule gearbeitet hatte, machte er sich schließlich um I900 selbstständig und gehörte in den nächsten Jahren zu den erfolgreichsten Architekten, die damals in Wien tätig waren, wobei sich seine Bauten durch maximale Zweckmäßigkeit und große ästhetische Qualität auszeichneten.

Zur Zeit der Errichtung des »Residenzpalastes«, der schon allein durch seine städtebauliche Situierung als Eckhaus mit zwei Straßenfronten einen imposanten Blickfang im Stadtbild darstellt, hatte Baron bereits eine große Zahl von Bauvorhaben ausgeführt, darunter den eleganten "Stadtparkhof« (Wien 3, Vordere Zollamtsstraße I I), und befand sich auf dem Höhepunkt seines Schaffens. Im Gegensatz zu seinen bis dahin realisierten Projekten, die einem gemäßigten Späthistorismus mit secessionistischen Einflüssen verpflichtetet waren, griff Baron beim »Residenzpalast " ganz aktuelle Tendenzen auf, die von den prominenten Mitarbeitern Otto Wagners, wie Max Fabi- 
ani und Josef Plečnik, kurz zuvor bei beispielgebenden Geschäftshäusern, etwa dem Haus Artaria am Kohlmarkt oder dem sogenannten "Zacherlhaus" am Wildpretmarkt, entwickelt worden waren. Neben dem Einsatz eines Stahlbetonskelettes, das höchstmögliche Flexibilität in der Raumeinteilung ermöglichte, betraf dies insbesondere auch die Fassadengestaltung des »Residenzpalastes», die schon rein optisch die unterschiedlichen Funktionsbereiche hervorhob. Während die drei unteren Geschoße für den Geschäftsbereich mittels einer Metall-Glas-Architektur zu einer diaphanen Wand gestaltet waren, wurden die kompakten Mauern der Obergeschoße mit Keramikfliesen verkleidet. ${ }^{78}$ Dieser Gegensatz der Funktionen wurde noch durch einen differenzierten Chromatismus hervorgehoben: die Fliesen der Obergeschoße, die mittels ihrer LilaBeige- und Violetttöne zu einem geometrischen Muster geformt sind, bilden einen effektvollen Kontrast zu der schwarzen, mit Goldrahmung versehenen Geschäftszone.

Neben diesen ästhetischen Qualitäten waren aber bei diesem relativ groß dimensionierten Bau, der durch drei Höfe gegliedert war, auch Multifunktionalität und optimale Ausnutzung ganz wesentliche Kriterien. Mehrere Aufzüge und ein sogenannter Paternoster (ein altes Liftsystem mit ständig umlaufenden Kabinen, die während der Fahrt zu betreten waren) führten zu den höher gelegenen Stockwerken. In den Souterrains, die durch die Anwendung eines ganz neuen Betonverfahrens große stützenlose Räume ermöglichten, waren das "Rotenturmkino" und das sogenannte "Residenztheater « untergebracht, das dem Gebäude seinem Namen gab. ${ }^{79}$ Das Theater wurde von dem bekannten Architektenbüro Krauss \& Tölk eingerichtet und besteht bis heute unter dem Namen »Kammerspiele«. Besitzer des »Rotenturmkinos« war Baron selber, der bei nicht wenigen seiner Miethäuser auch gleich Kinos einrichtete, die sich damals einer rasant zunehmenden Popularität erfreuten. Neben diversen Büroräumen und Wohnungen war im obersten Stockwerk noch die sogenannte "Schwedische Turnschule» untergebracht, einer der ersten Aufträge des jungen Josef Frank - von dem später noch die Rede sein wird -, die in einer Art von schwedischem Folklorestil eingerichtet war. ${ }^{80}$ Generell dürften Arthur Baron und Frank in einem Naheverhältnis gestanden sein, da auch Franks Wohnung sich in einem der von Baron errichteten Miethäuser befand (Wien 4, Wiedner Hauptstraße 64). Der »Residenzpalast « erlebte eine wechselvolle Geschichte und ging schließlich in das Eigentum der BAwAG über, die den Bau leider entkernte, sodass heute nur mehr die Außenerscheinung erhalten ist.

78 Die Fliesen stammten von der renommierten Firma Brüder Schwadron. Baron, der seine Bauten als Gesamtkunstwerke gestaltete, arbeitete generell mit den damals führenden Unternehmen bzw. Künstlern zusammen, etwa der Glasfirma Geyling oder dem Plastiker Michael Powolny.

79 Das Gebäude wird auch manchmal nach dem damals dort befindlichen Teppichgeschäft „OrendiPalast « genannt.

8o Welzig, zit. Anm. I I, S. 23 ff. 


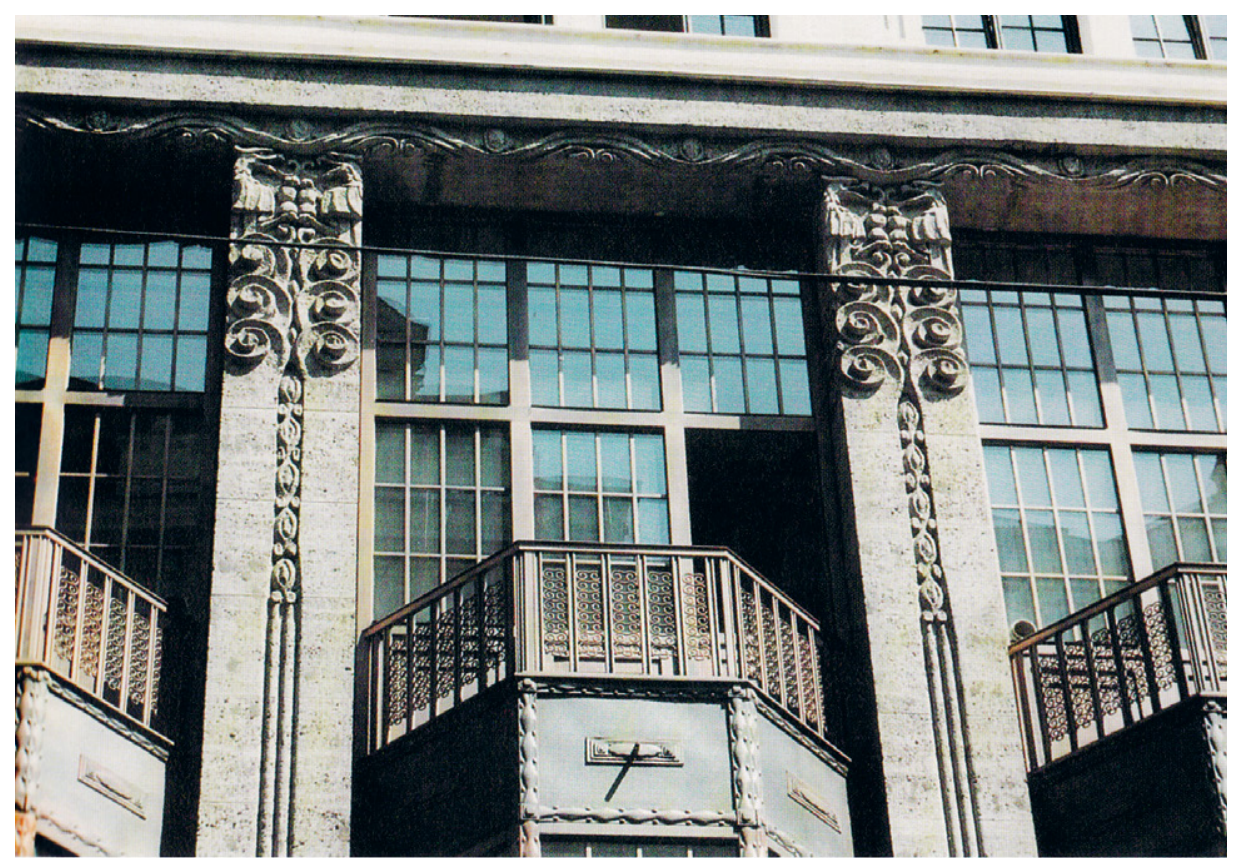

26. Arthur Baron, Druckereigebäude Steyrermühl, Wien I Fleischmarkt 3, erbaut 19I3/Prokop

Baron errichtete kurze Zeit später noch zwei höchst bemerkenswerte Druckereigebäude für die Verlagsgesellschaft Steyrermühl neben dem »Residenzpalast« (Wien I, Fleischmarkt 3 und 5), die wiederum technische Anforderungen und ästhetische Qualität auf höchstem Niveau vereinten und zu einem Musterbeispiel früher GlasEisen-Architektur gehören (Abbildung 26). Generell war der Architekt bis zum Ausbruch des Ersten Weltkriegs sehr erfolgreich tätig. Die schlechte Wirtschaftslage der Zwischenkriegszeit veranlasste ihn, sich weitgehend ins Privatleben zurückzuziehen. Nach dem »Anschluss" Österreichs an NS-Deutschland I 938 wurde er als Jude unter demütigenden Umständen zur Emigration gezwungen, wobei er auch seiner zahlreichen Immobilien und Kinos verlustig ging. Obwohl der 30. August I944 als Todesdatum gesichert ist, sind sowohl das Ziel seiner Emigration (das heißt sein Sterbeort) als auch die näheren Umstände seines Todes unklar. Seine Witwe, die Malerin Kitty Kassowitz, kehrte nach dem Krieg nach Wien zurück und erhielt einen Teil der Immobilien zurück. ${ }^{81}$

8I Auskunft Matrikenarchiv der IKG. 
27. Emmerich Spielmann u. Alfred Teller, Tuch-

laubenhof Wien I, Tuchlauben 7, erbaut I912/ Bautechniker I9 I 2

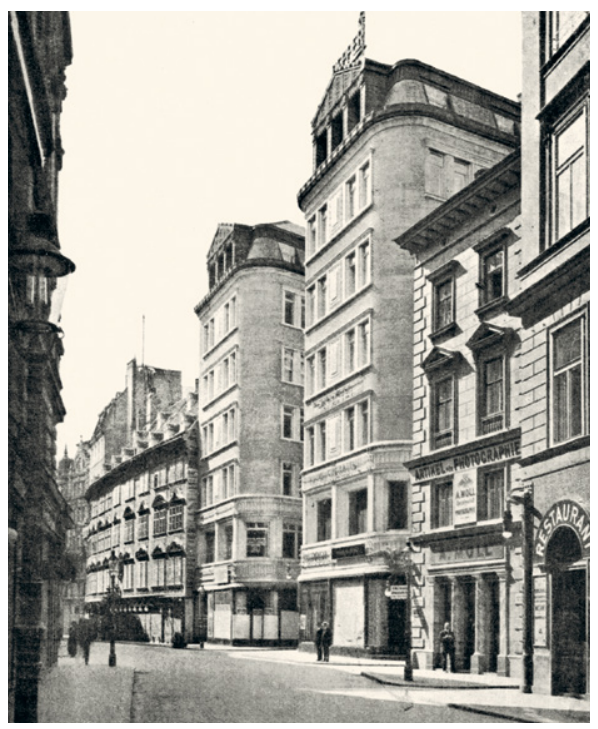

Ein weiteres bemerkenswertes Wohn-Geschäftshaus, das das Bild der Inneren Stadt prägt, ist der sogenannte "Tuchlaubenhof", der I9 I 2 von den zwei König-Schülern Emmerich Spielmann (I 872-?) und Alfred Teller (I 88 I-?) errichtet wurde (Wien I, Tuchlauben 7-7a, Abbildung 27), wobei sich der große Komplex über drei Bauparzellen erstreckte. ${ }^{82}$ Nach dem Vorbild des abgerissenen Vorgängerbaus aus der Zeit des Vormärz schloss auch der Neubau eine Verkaufspassage ein, die die Tuchlauben mit der Seitzergasse verband. In zeitgemäßer Weise zeichnete sich dieses Gebäude durch ein Maximum an Funktionalität aus. Neben den Wohnungen in den Obergeschoßen und den Geschäftslokalen im unteren Bereich waren im Souterrain noch diverse kleinere Säle, ein Kino und eine Galerie untergebracht. Der weitläufige Gebäudekomplex umfasste vier Stiegenhäuser, deren Eingänge alle von der Passage aus zugänglich waren. Dem Zeittrend entsprechend wurden der Wohn- bzw. der Geschäftsbereich auch nach außen sehr differenziert gestaltet. Während die untere Zone durchgehend mit weißen Fliesen verkleidet war, zeichneten sich die oberen Stockwerke durch eine geriffelte Putzfassade aus, nur die Fenster waren mittels einer keramischen Rahmung zusammengefasst. Ein tempelartiger, klassizierender Dachaufbau unterstrich den repräsentativen Anspruch des Baus. Die beiden Architekten dieses höchst fortschrittlichen Gebäudes, Emmerich Spielmann und Alfred Teller, hatten sich erst einige Jahre zuvor I $908 \mathrm{zu}$ einer Bürogemeinschaft zusammengeschlossen, wobei gleich eines ih-

82 Jetzt befindet sich hier die Luxusmeile »Goldenes Quartier«. 
rer ersten Projekte, ein Wettbewerbsentwurf für das Wiener Kriegsministerium, einen Preis erhalten hatte. In der Folge errichteten sie in den nächsten Jahren mehrere bemerkenswerte Villen und Geschäftshäuser. ${ }^{83}$

Emerich Spielmann, der Ältere der beiden, war in Wien geboren und hatte nach seinem Studium eine Zeitlang bei Wilhelm Stiassny praktiziert, bis er sich selbstständig machte, wobei er anfangs mit seinem Studienkollegen Ernst Lindner zusammenarbeitete. Alfred Teller, der aus Prag stammte und auch dort noch sein Studium begonnen hatte, gehörte zu den ersten Technikabsolventen, die ihr Studium mit einem Doktorat abgeschlossen hatten. Noch während seiner Dissertation beteiligte er sich I 903/o4 mit seinem Studienkollegen Oskar Strnad an dem großen Wettbewerb für eine Synagoge in Triest, ihr Entwurf gelangte allerdings nicht zur Realisation - es wird davon noch zu sprechen sein. Tellers Beschäftigung mit der römischen Barockarchitektur im Rahmen seiner Dissertation, insbesondere mit Pietro da Cortona, fand auch in gewisser Weise in seinem architektonischen Werk in manchen eigenwilligen Details seinen Niederschlag. Die beiden Architekten arbeiteten bis Anfang der Dreißigerjahre zusammen. Neben diversen Wohnbauten, darunter dem eleganten Miethaus Wien 3, Salesianergasse 29-33, das lange Zeit Josef Hoffmann zugeschrieben wurde, waren sie insbesondere auch mit der Errichtung von Fabrikbauten befasst. Die Gründe ihrer beruflichen Trennung sind nicht bekannt. I939 waren sie als Juden zur Emigration gezwungen. Während Spielmann sich nach London abgemeldet hatte, dürfte Teller in die USA gegangen sein. Nach ihrem Weggang von Wien verlieren sich jedoch ihre Spuren.

Gleichfalls auf dem Gebiet des Wohn-Geschäftshauses machte sich in diesen Jahren auch Arnold Karplus (I 877-1943) einen Namen. Aus Wigstadtl/Vitkov stammend (im damaligen Österreichisch-Schlesien gelegen), hatte er seine Schulzeit in Troppau/Opava absolviert, um dann von 1897 bis 1902 in Wien an der Technischen Hochschule zu studieren, wo er neben Karl König auch Max Ferstel und Karl Mayreder zu seinen Lehrern hatte. Karplus ging danach für einige Jahre an die Technische Hochschule in Prag, wo er während der Arbeit an seiner Dissertation als Assistent tätig war. Nach seiner Promotion zum Dr. tech. I903 kehrte er endgültig nach Wien zurück, um sich nach kurzer Praxiszeit bald selbstständig zu machen. ${ }^{84}$ In den Jahren bis zum Ersten Weltkrieg errichtete er dann neben einigen Heimen und Industriebauten, unter anderen die Anlage der Dambachwerke in Windisch-Garsten (OÖ), insbesondere eine Reihe von äußerst repräsentativen Wohn-Geschäftshäusern, die sich oftmals durch größte Multifunktionalität auszeichneten, in formaler Hin-

83 Siehe dazu Prokop, zit. Anm. 9.

84 Siehe dazu Weihsmann u. D. Herzner, Arnold Karplus in: Architektenlexikon, beide zit. Anm. I3. 


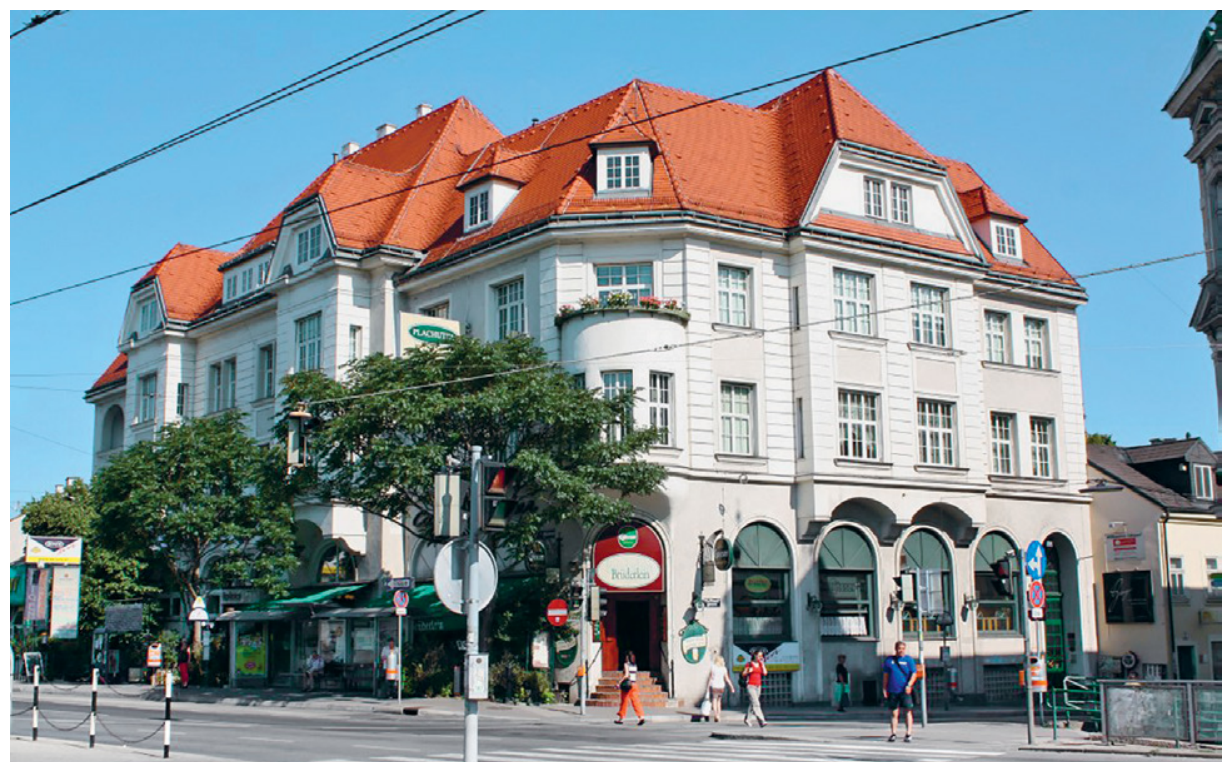

28. Arnold Karplus, Miethaus, Wien I4, Nisselgasse I, erbaut I9I 2/Kulturgut

sicht jedoch zumeist traditionsverbunden blieben, wie es für die Schüler Karl Königs charakteristisch war.

Neben Einflüssen der Wiener Werkstätte waren insbesondere Details im Heimatstil prägend, oftmals verbunden mit einer sehr betonten Durchformung des Baukörpers. Als Beispiel kann hier das Objekt in Wien I4, Nisselgasse I angeführt werden (Abbildung 28). Durch seine Situierung als Eckhaus im städtebaulichen Kontext hervorgehoben, war der Bau von einer außerordentlichen funktionellen Durchmischung geprägt. Während im Souterrain und im Erdgeschoß ein Kino und ein Kaffeehaus untergebracht waren, dienten die oberen Stockwerke Büro- und Wohnzwecken. Ungeachtet dessen war der Bau jedoch angesichts der eher peripheren Lage im I 4. Bezirk nicht allzu hoch, und die stark gegliederte Dachlandschaft im Heimatstil passte sich der eher beschaulichen Atmosphäre der Stadtrandsituation an.

Karplus' Schwerpunkt auf dem Gebiet des gehobenen Wohnbaus fand auch in seiner Publikation "Neue Landhäuser und Villen in Österreich" (I910) seinen Niederschlag, die bis heute eine wichtige Quelle für den Villenbau dieser Zeit ist. Kurz vor dem Ersten Weltkrieg wurde er Baudirektor der Wiener Baugesellschaft, der er bis zu deren Auflösung 1927 angehörte, sodass er seine Tätigkeit als freier Architekt etwas einschränken musste. Während des Ersten Weltkrieges eingerückt, diente er in einer der vielen Bauabteilungen der k. k. Armee, wo er mit der Errichtungen von 


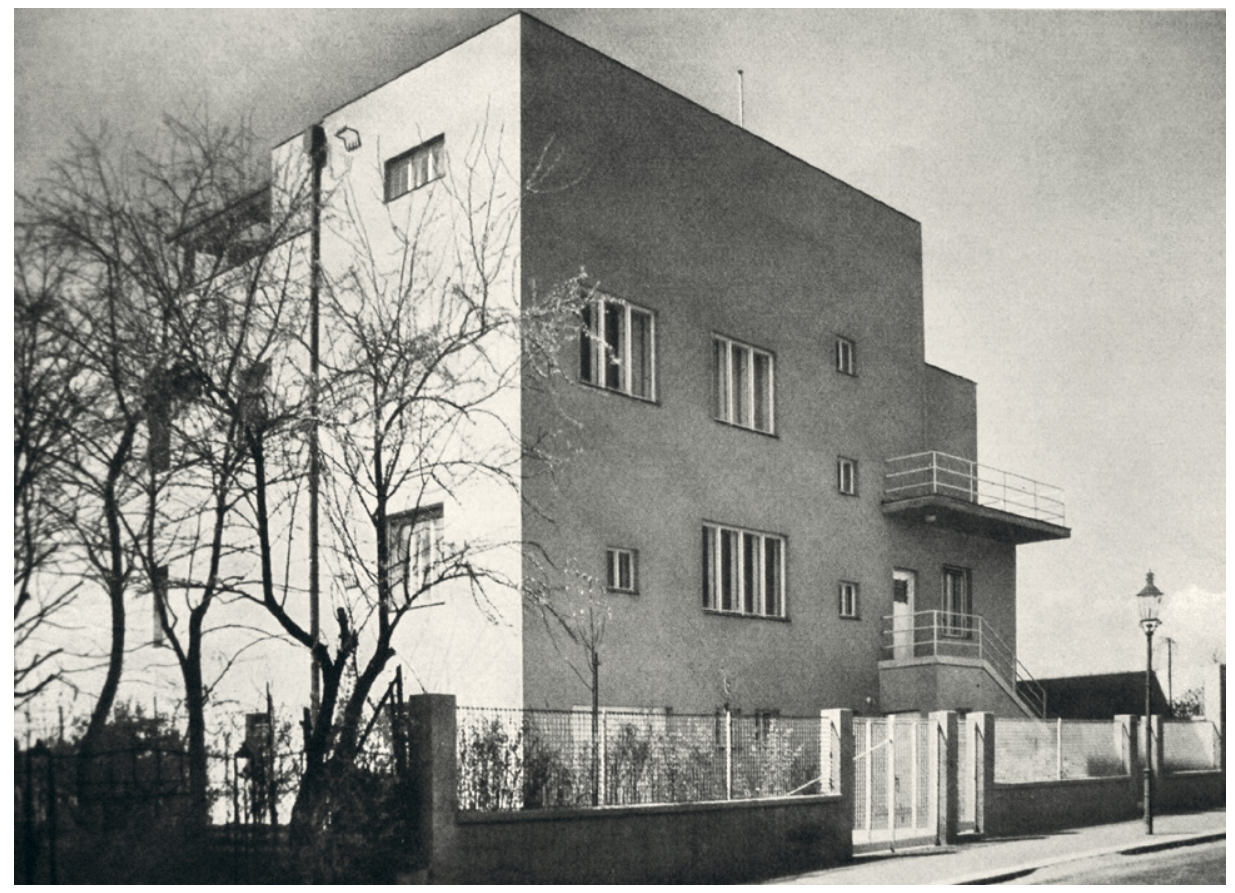

29. Arnold Karplus, Villa Krasny, Wien I9, Fürfanggasse 5, erbaut I928/Moderne Bauformen

militärischen Zweckbauten befasst war. Seine berufliche Laufbahn nach dem Ersten Weltkrieg reflektiert die enorm schwierige wirtschaftliche Situation dieser Jahre. Nach der Auflösung der Wiener Baugesellschaft versuchte er sich an weiteren Baufirmen zu beteiligen, deren Existenz jedoch zumeist nur von kurzer Dauer war. Diese Umstände führten dazu, dass er Ende der Zwanzigerjahre wieder seine Tätigkeit als freier Architekt intensivierte. Neben einer Wohnhausanlage für das "Rote Wien« (Dittes-Hof, Wien I9, Döblinger Gürtel I4) gehört vor allem die von ihm I928 errichtete Villa Krasny (Wien I9, Fürfanggasse 5, Abbildung 29) zu den qualitätvollsten Bauten der Zwischenkriegszeit. Seine eher traditionsverbundene Ausrichtung der Vorkriegszeit ablegend, orientierte sich Karplus, der das aktuelle Architekturgeschehen offenbar intensiv verfolgte, an der zeitgenössischen Avantgarde. Dies ist umso bemerkenswerter, als der Bau schon einige Jahre vor der Werkbundsiedlung errichtet wurde, die gemeinhin als ein Höhepunkt der Wiener Moderne angesehen wird. Neben den unübersehbaren Einflüssen von Adolf Loos, die sich in den schlichten kubischen Formen manifestieren, beruhen so manche Details der Villa Krasny insbesondere auf Ideen von Le Corbusier, wie die in unseren Breiten eher unübliche Außentreppe und 
der Garten auf dem Flachdach. Das von Friedrich Achleitner als »eines der schönsten Privathäuser Wiens« bezeichnete Wohnhaus ${ }^{85}$ wurde seinerzeit von der Firma »Haus und Garten « eingerichtet, die von Josef Frank und Oskar Wlach betrieben wurde und von der später noch die Rede sein wird.

Dass dieses Projekt im Schaffen von Arnold Karplus kein Einzelfall war, zeigt auch das um 1930 in seinem heimatlichen Wigstadtl errichtete Postgebäude, das mit seiner kurvig geschwungene Ecklösung in der Art von Erich Mendelsohn auf dem Höhepunkt der Zeit stand. ${ }^{86}$ Um 1934 trat sein Sohn Gerhard Karplus (1909-1995), der zu diesem Zeitpunkt sein Architekturstudium an der Technischen Hochschule gerade abgeschlossen hatte, in das väterliche Büro ein. ${ }^{87}$ Neben dem Umbau des Palais Kranz (das seinerzeit von Oskar Strnad adaptiert worden war) realisierten sie $1937 / 38$ ein Miethaus im 3. Bezirk, Am Modenapark I4. Dieses im Rahmen der Verbauung der Modenaparkgründe (neben der Verbauung des Freihausareals eines der größten städtebaulichen Projekte des "Ständestaates") errichtete Wohnhaus bestach durch seine klare Strukturierung und die Eleganz der Proportionen.

Ungeachtet dieses vielversprechenden Projektes brachen schon kurz danach die Geschehnisse des "Anschlusses" vom März 1938 über Vater und Sohn herein. Unmittelbar danach musste das Büro aufgelöst werden, und Gerhard Karplus konnte über Prag, Zürich und London nach New York fliehen. ${ }^{88}$ Erst ein Jahr später gelang es ihm, seine Eltern in die USA nachkommen zu lassen. Während der Vater noch während des Krieges verstarb, gelang es Gerhard Karplus, beruflich Fuß zu fassen. Anfangs arbeitete er als Mitarbeiter in einem Architekturbüro, nach dem Krieg als Selbstständiger, wobei er insbesondere mit großen Industriebauten befasst war. Das Schicksal von Gerhard Karplus ist eines der wenigen mit einem relativ versöhnlichen Ausgang. Nachdem er seitens der österreichischen Regierung Aufträge zur Einrichtung des österreichischen Kulturinstitutes und des Büros der Austrian Airlines in New York erhalten hatte, wurde ihm auch 1966 die Goldene Verdienstmedaille der Republik Österreich verliehen. Noch Ende der Achtzigerjahre trat er hochbetagt als Zeitzeuge der Ereignisse vom März 1938 in der Österreich-Dokumentation von Hugo Portisch im ORF auf.

Im Kontext der Wohn- Geschäftsbauten ist auch Ludwig Schmidl (I 863-I924) zu erwähnen, der den multifunktionellen Anforderungen der modernen Großstadtbau-

85 F. Achleitner, zit. Anm. 26, S. 68.

86 Die Tätigkeit von Arnold Karplus in Wigstadtl, die relativ schlecht dokumentiert ist, war offenbar ziemlich intensiv. Bereits I90 I war er an der Planung des dortigen Stadtparks beteiligt und hat auch späterhin immer wieder die unterschiedlichsten Projekte in dieser Gegend realisiert.

87 Dass Gerhard Karplus bereits an Projekten vor seinem Ateliereintritt Anteil hatte (wie sein Vater angibt), ist nicht auszuschließen, aber etwas strittig.

88 Siehe dazu Boeckl, zit. Anm. ıо; Weihsmann, zit. Anm. I3. 
ten mit seiner Schule des Israelitischen Mädchenunterstützungsvereines (Wien 9, Seegasse I6) gleichfall in ingeniöser Weise gerecht wurde. Aus einer gut situierten Wiener Familie stammend, hatte auch er die Technische Hochschule bei Karl König besucht und danach eine Anstellung bei der Nordwestbahn gefunden. Daneben arbeitete er gelegentlich als freier Architekt. Im Rahmen dieser Tätigkeit realisierte er zwei Schulgebäude, die sowohl in kulturgeschichtlicher als auch in architektonischer Hinsicht bemerkenswert sind. Beide Projekte entstanden vor dem Hintergrund feministischer Aktivitäten, die anfangs der vorigen Jahrhundertwende insbesondere seitens jüdischer Frauen in die Wege geleitet wurden, vor allem in Anbetracht der damals schlechten Ausbildungsmöglichkeiten für junge Mädchen. In einem Fall handelte es sich um ein privates Mädchenlyzeum in Wien-Döbling (Gymnasiumstraße 77), dessen Direktorin und möglicherweise Mitinitiatorin Salka Goldmann eine im »Wiener Frauenclub« sehr aktive Persönlichkeit war. Der "Wiener Frauenclub« war damals einer der wichtigsten Begegnungsstätten von intellektuell und künstlerisch engagierten Frauen, es wird später darüber noch zu sprechen sein. Das von Ludwig Schmidl I905/08 in den Formen des Wiener Secessionismus errichtete Schulgebäude entsprach in seiner äußeren Erscheinung - in Anbetracht seiner Lage am Rande des Cottage-Viertels in Währing - eher einer etwas groß dimensionierten Villa und war in seiner großzügigen Ausstattung offensichtlich für höhere Töchter aus gut situiertem Haus gedacht. ${ }^{89}$

Nur kurze Zeit später erhielt der Architekt den Auftrag, für den »Israelitischen Mädchenunterstützungsverein " gleichfalls ein Schulgebäude zu errichten. Es ist anzunehmen, dass die Mitbegründerin des Vereines und spätere Schuldirektorin Regine Ullmann, die als Mitglied des "Frauenclubs« in Kontakt mit Salka Goldmann stand, Schmidl von dieser Seite empfohlen wurde. Der Verein widmete sich vor allem der Ausbildung armer jüdischer Mädchen, denen die Erlernung eines der damaligen weiblichen Berufe ermöglicht werden sollte. ${ }^{90}$ In architektonischer Hinsicht lagen die Dinge jedoch etwas komplizierter, da das im 9. Bezirk in der Seegasse schräg gegenüber dem alten jüdischen Spital zu errichtende Gebäude nicht nur eine Schule, sondern in den oberen Stockwerken auch Mietwohnungen beherbergen sollte, um eine gewisse Rentabilität für den Verein zu gewährleisten. Außerdem mussten die Schulräume Werkstätten für die praktische Ausbildung und anderes mehr mit einschließen. Schmidl gelang es tatsächlich, durch eine äußerst geschickte räumliche Anordnung des Vereinshauses den unterschiedlichen Funktionen zu entsprechen. Insbesondere erzielte er mittels zweier getrennter straßenseitiger Eingänge, die jeweils

89 Heute Hans-Kelsen-Institut.

90 Siehe dazu E. Malleier, Regine Ullmann und der Mädchenunterstützungsverein in Wien, in: Ariadne (Almanach des Archivs der deutschen Frauenbewegung), H. 35, Mai 1999, S. $28 \mathrm{ff}$. 
30. Ludwig Schmidl, Schulhaus d. israelitischen Mädchenunterstützungsvereines, Wien 9, Seegasse I6, erbaut 1909/Prokop

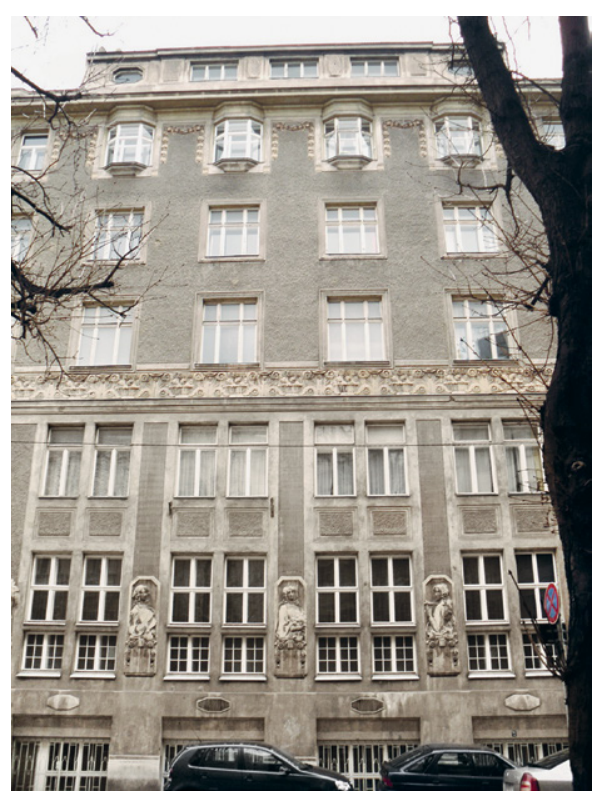

zur Schule und zu den Vereinsräumen beziehungsweise den Mietwohnungen in den oberen Stockwerken führten, eine Trennung der Bereiche. Dem Anspruch eines »öffentlichen Gebäudes« entsprechend wurde vor allem das Vestibül der Schule etwas repräsentativer ausgestaltet, wobei Wandverfliesung und Malerei der Ästhetik der Wiener Werkstätte verpflichtet war. Die unterschiedlichen Funktionen des Gebäudes waren auch an der Fassade ablesbar, insofern ein breiter Blumenfries optisch Wohnund Schulbereich voneinander trennte. Bis heute haben sich die Reliefs an den Wandpfeilern, die hübsche junge Mädchen mit ihren entsprechenden Lernbehelfen zeigen, erhalten (Abbildung 30). ${ }^{91}$ Der Verein musste jedoch das Gebäude bald nach dem Ersten Weltkrieg aufgrund der schlechten wirtschaftlichen Lage an die Schwedische Israelmission verkaufen, die sich in der NS-Zeit um die Auswanderung vieler - insbesondere getaufter - Juden verdient machte. Heute ist das Gebäude im Besitz der evangelischen Gemeinde. ${ }^{92}$

Ludwig Schmidl konnte neben der Planung einiger repräsentativer Villen in Hietzing und Währing noch ein weiteres sehr bemerkenswertes Objekt errichten, das

9I Heute dient das Gebäude als evangelisches Vereinshaus. Siehe auch U. Prokop, Spuren des jüdischen

Wien. Die Schule des israelitischen Mädchenunterstützungsvereines in der Rossau, in David 22.20I0, H. 85 , S. $32 \mathrm{ff}$.

92 Siehe dazu Chronik der Messiaskapelle, in www.meka.at/history. 
heute als Industriedenkmal unter Denkmalschutz gestellt ist. Als Ingenieur der Nordwestbahn insbesondere auch mit der Errichtung von technischen Nutzbauten vertraut, plante er 1906 eine Maschinenhalle für den Industriellen Maximilian Luzzatto (Wien ıo, Siccardsburggasse 36), die mit ihrem feingliedrigen Glasdach ein Musterbeispiel für die qualitätvolle Glas-Eisen-Architektur jener Jahre ist und deswegen auch bei einem umfassenden Umbau erhalten werden musste. ${ }^{93}$ Interessanterweise war die Ehefrau (Elisabeth, geborene Grünbaum) Maximilian Luzzattos, der seinerseits aus einer alten jüdischen Triester Familie stammte, gleichfalls in der Frauenbewegung aktiv und Vorstandsmitglied und Mitbegründerin des "Österreichischen Komitees für Frauenstimmrechte «. ${ }^{94}$ Die möglichen Gründe für den Umstand, dass viele der Projekte Ludwig Schmidls im Umfeld der damaligen Frauenbewegung standen, sind heute nicht mehr zu eruieren. Der Architekt selbst blieb Zeit seines Lebens unverheiratet, hinterließ jedoch, als er 1924 verstarb, seiner Lebensgefährtin ein nicht unbeträchtliches Vermögen.

\section{I.3 Banken und Versicherungen}

Der wirtschaftliche Aufschwung Wiens machte die Stadt auch zunehmend zu einem wichtigen Finanzzentrum und führte insbesondere in den letzten Jahren vor dem Ersten Weltkrieg zu dem Bau von zahlreichen äußerst repräsentativen Bankgebäuden, die bis heute das Stadtbild insbesondere des I. Bezirks prägen. Nahezu eine Monopolstellung auf diesem Gebiet hatte das Atelier von Ernst Gotthilf und Alexander Neumann, die als Studienkollegen an der Technischen Hochschule bei Karl König studiert und späterhin auch zur gleichen Zeit im Büro von Fellner \& Helmer, den Spezialisten für Theaterbau, gearbeitet hatten. Darüber hinaus verband sie ihre Herkunft aus wohlhabenden jüdischen Unternehmerfamilien - ein Umstand, der wahrscheinlich auch eine Erklärung für ihre guten Kontakte zur Finanzwelt sein könnte. Abgesehen von ihrem Studium an der Wiener Technik waren aber ihre weitere Ausbildung und auch ihre beruflichen Anfänge unterschiedlich. Der Ältere der beiden, Alexander Neumann (I 86I-I947), stammte aus Bielitz/Bielsko-Biała, das damals zu Österreichisch-Schlesien gehörte. Nach seinem Studium an der Technischen Hochschule arbeitete er in verschiedenen Ateliers, war aber nebenbei bereits selbstständig mit der Planung von diversen Miethäusern und Villen befasst. Um 1906 errichtete er für den Wiener Bankverein das Gebäude der Prager Niederlassung und machte sich damit offensichtlich einen Namen in Bankkreisen. Der fünf Jahre jüngere Ernst Gotthilf (I865-I950, ei-

93 Achleitner, zit. Anm. 26, S. 282.

94 www.onb.acat/ariadne 


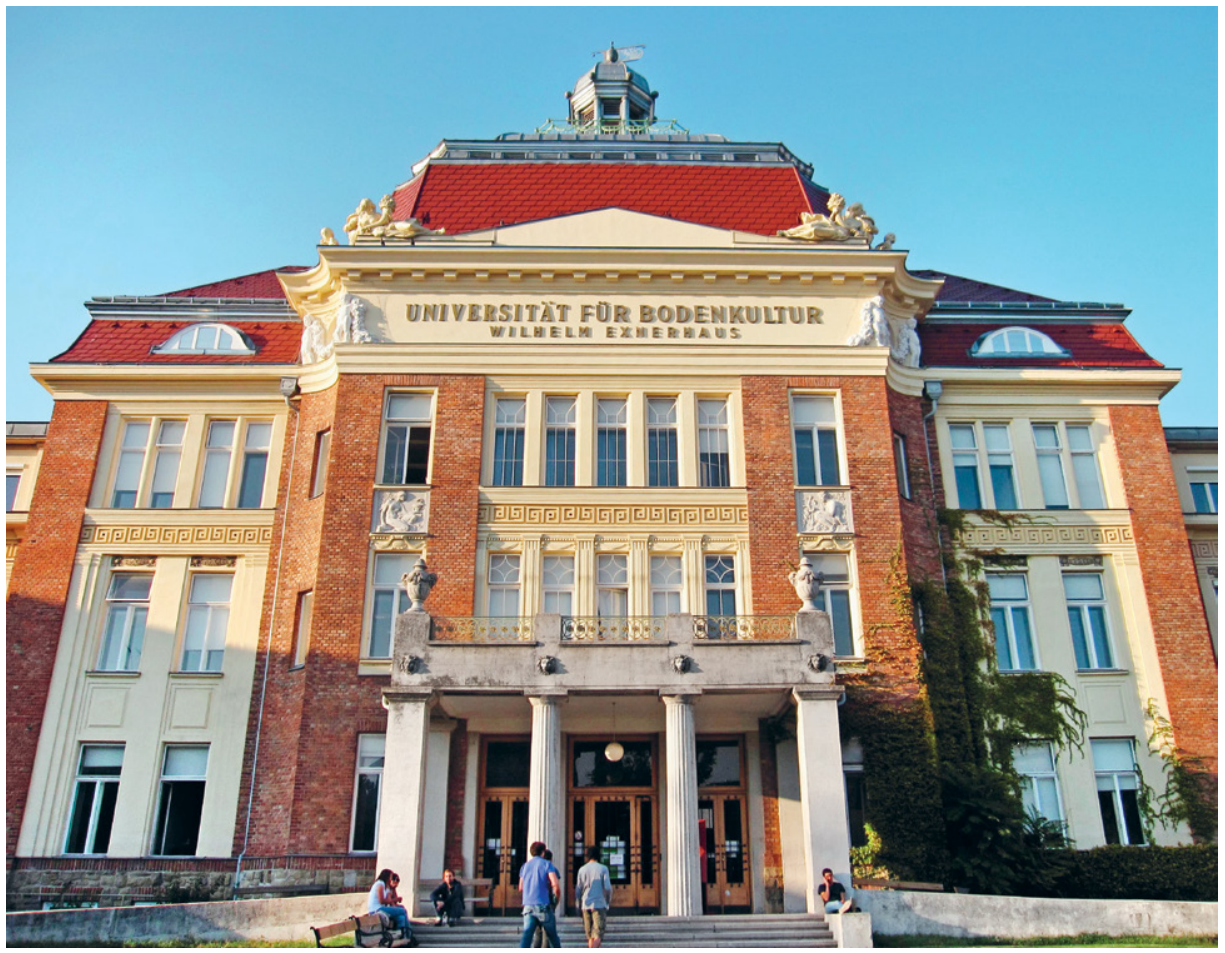

3r. Ernst Gotthilf, Krankenhaus d. Wiener Kaufmannschaft, Wien I9, Peter Jordan- Straße. 82, erbaut um I9 Iо (jetzt der Universität $f$. Bodenkultur zugehörig)/Kulturgut

gentlich von Gotthilf-Miskolczy) war der Sohn eines nobilitierten Großindustriellen aus Temesvar, das damals zu Ungarn gehörte (heute Rumänien). Im Gegensatz zu Neumann war seine Ausbildung jedoch weit umfassender. Neben einem Studium an der Technischen Hochschule in Zürich besuchte er auch noch die Akademie der bildenden Künste, wo er der Meisterschule Carl Hasenauers angehörte und aufgrund seiner Begabung auch einen Schulpreis erhielt. ${ }^{95}$ Nach einer kurzen Zeit des Praktikums machte er sich relativ jung selbstständig und erhielt bald mehrere größere Aufträge seitens der Wiener Kaufmannschaft, darunter einen so bedeutenden Bau wie das vereinseigene Krankenhaus (Wien I9, Peter-Jordan-Straße 82, heute der Universität für Bodenkultur zugehörig, Abbildung 3I). Das 1908 im noblen Cottage-Viertel errichtete Spital, das sich in seiner Außenerscheinung betont an die Schlossarchitektur

95 Siehe dazu J. Brandstetter, Alexander Neumann und Ernst Gotthilf, in: Architektenlexikon, zit. Anm. I3. 


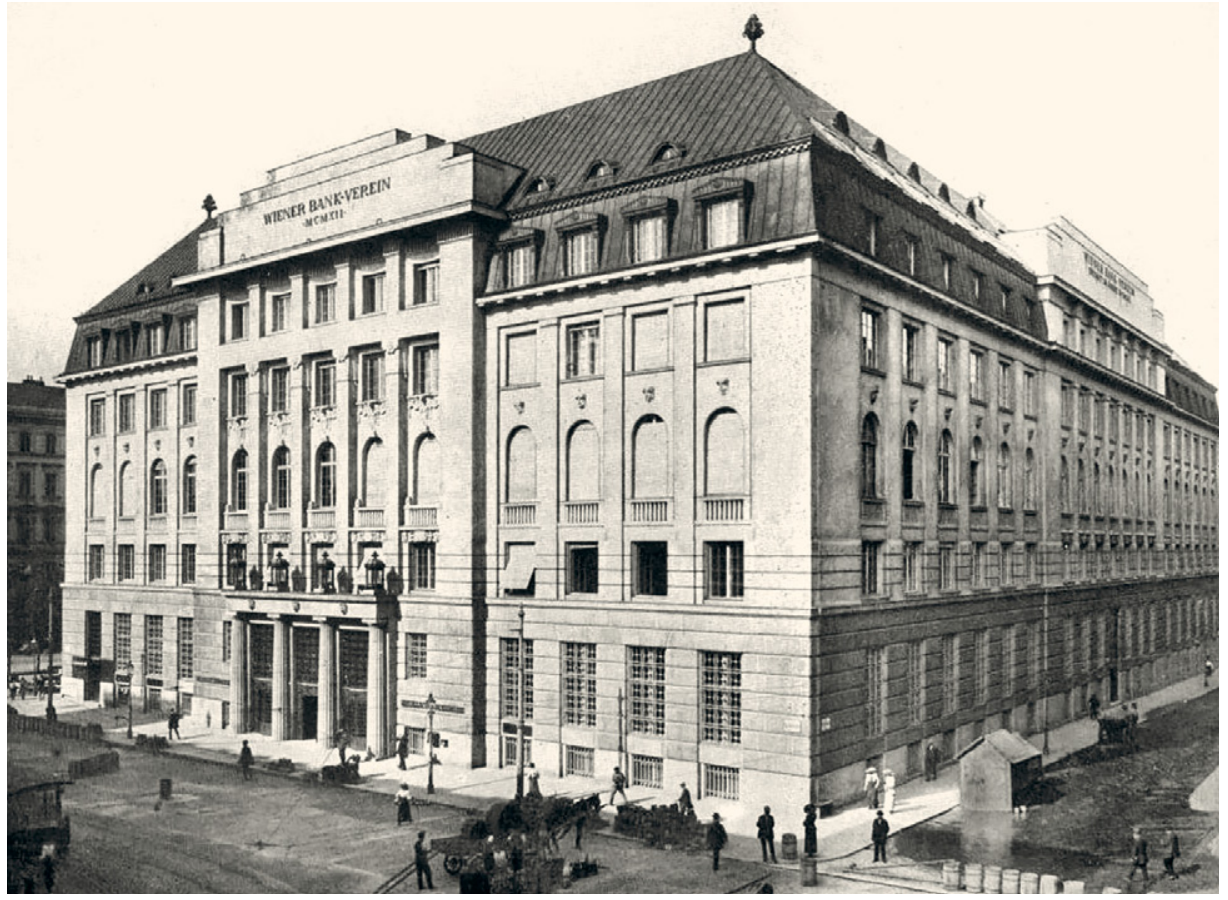

32. Alexander Neumann u. Ernst Gotthilf, Wiener Bankverein, Wien I, Schottengasse 6, erbaut um I9 Io (jetzt Bank Austria)/Der Architekt I9I9

anlehnte, visualisierte keineswegs einen Nutzbau, sondern entsprach offensichtlich dem gehobenen Anspruch der Auftraggeber.

Unter diesen günstigen Auspizien - sowohl im Hinblick auf ihre Ausbildung als auch angesichts der bisherigen Auftraggeber aus Bank- und Wirtschaftskreisen schlossen sich die beiden um I909 zu einer Bürogemeinschaft zusammen und errichteten dann allein in Wien innerhalb nur weniger Jahre vier große Bank- und Versicherungsgebäude. Als Markenzeichen diente ihnen eine äußerst repräsentative, fast feudal zu nennende Ausstattung, wobei sie jedoch sehr geschickt auch moderate Anlehnungen an die zeitgenössische Moderne einbrachten.

Das erste Projekt dieser Serie war das Gebäude für den Wiener Bankverein (eigentlich: Creditanstalt- Bankverein, I 855 von Anselm Rothschild gegründet) in Wien I, Schottengasse 6-8, errichtet zwischen 1909 und I9I2. Nahezu gleichzeitig folgten um I9I3 das Hauptgebäude der NÖ-Escompte-Gesellschaft (Wien I, Am Hof 2) ${ }^{96}$

96 Derzeit wird das Gebäude in ein Hotel umgebaut. 
33. Alexander Neumann u. Ernst Gotthilf, Palais Fanto, Wien 3, Schwarzenbergplatz. 6, erbaut I 9 I $7 /$ Prokop

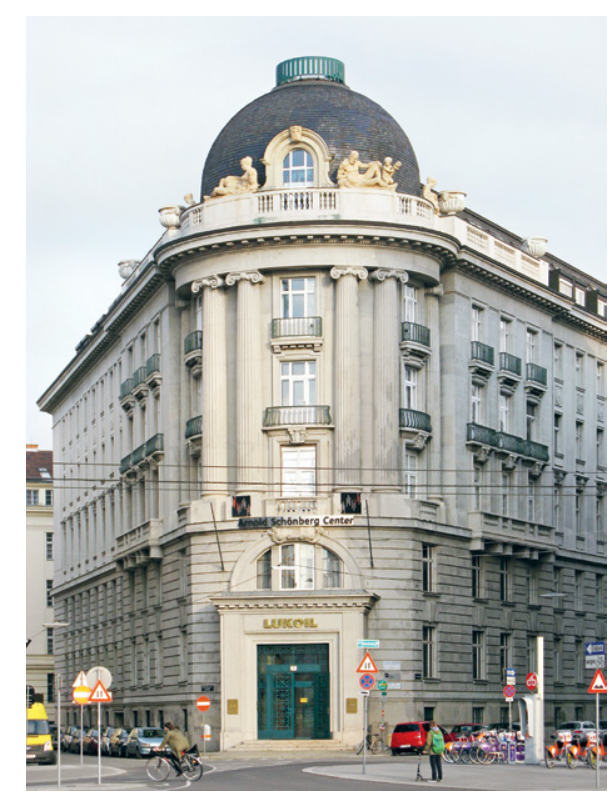

und das Haus der "Anker-Versicherung« (Wien I, Hoher Markt Io-I I), etwas später zwischen I9 5/I7 folgte der Bau der Österreichischen Creditanstalt (Wien I, Renngasse 2). Alle vier Gebäude, die auch örtlich relativ nahe beieinander liegen, zeichnen sich durch eine sehr prominente Situierung in der Inneren Stadt aus, und obwohl sie jeweils sehr individuell gestaltet waren, sind sie doch von der Handschrift des Architektenteams geprägt. Der vielleicht markanteste Bau in dieser Gruppe und ein bedeutendes Beispiel für den Neoklassizismus der Jahre kurz vor dem Ersten Weltkrieg ist das Gebäude des Wiener Bankvereins (Abbildung 32), das schon allein durch seine markante Ecklage am Wiener Schottenring den Anspruch erhebt, ein Teil der »Ringstraßenarchitektur" zu sein, obwohl die Eingangsseite und damit die Hauptfassade zur Schottengasse gerichtet ist. Generell ist die Strukturierung des Baus mit einem durch einen Stufengiebel und einen Säulenportikus hervorgehobenen Mittelrisalit noch ganz dem Kanon einer traditionsverbundenen, historisierenden Ausrichtung verpflichtet, dennoch haben sich die Architekten in der formalen Ausgestaltung auch an den damals aktuellsten Tendenzen der Wiener Moderne orientiert. Dem entsprechen der weitgehende Dekorverzicht und die Gliederung durch breite Pilaster ohne Kanneluren, die zu einer gewissen Nüchternheit der Fassade beitragen. Der relativ sparsame Einsatz von Dekor mittels vereinzelter Wandappliken könnte in seiner Methodik von Josef Hoffmann beeinflusst sein. Das Bankgebäude, das eine wechselvolle Geschichte erlebte und mehrmals den Besitzer wechselte, ist bis heute weitgehend 
unverändert erhalten. ${ }^{97}$ Auch die elegante Kassenhalle ist eines der wenigen Zeugnisse einer Innenraumgestaltung dieser Jahre, die auf uns gekommen ist.

Das Architektenteam konnte sich mit der Errichtung weiterer Bankgebäude und nobler Palais - unter anderem auch in Graz und Prag - erfolgreich behaupten. Sogar während des Ersten Weltkrieges, als die zivile Bautätigkeit nahezu zum Erliegen gekommen war, erhielten sie noch einen spektakulären Auftrag von dem Geschäftsmann Daniel Fanto, der mit dem Handel von Erdöl und Branntwein ein großes Vermögen erworben hatte. Bereits in den letzten Kriegsjahren I9I7/ I 8 realisierten sie für den Geschäftsmann das sogenannte "Palais Fanto« (Abbildung 33) in äußerst repräsentativer Lage am Schwarzenbergplatz 6. Im Gegensatz zu den einige Jahre zuvor errichteten Bankgebäuden bedienten sie sich hier einer sehr retardierenden, explizit neobarocken Formensprache, die in der Tradition ihres Lehrers Karl König stand und noch ganz dem Stil der großen Ringstraßenarchitektur verpflichtet war, wobei auch der Geschmack des Bauherrn eine Rolle gespielt haben könnte. Insbesondere der Eckrisalit des Gebäudes, dessen Grundriss einem spitzwinkeligen Dreieck entspricht, in Form eines überkuppelten Zylinders erinnert an den Philipp-Hof von Karl König. Das "Palais Fanto" ist trotz einiger späterer Umbauten weitgehend erhalten. Heute sind hier unter anderem die Räumlichkeiten des Arnold-Schönberg-Centers untergebracht.

Bedingt durch die schlechte wirtschaftliche Lage in der Zwischenkriegszeit konnte das Architektenteam späterhin nur mehr einige wenige Bauten realisieren. Nach dem sogenannten »Anschluss« Österreichs mussten beide, obwohl schon hochbetagt, I 939 emigrieren. Neumann wanderte über Australien nach Neuseeland aus und starb im achtundachtzigsten Lebensjahr. Gotthilf flüchtete nach England, wo er, allen Vermögens beraubt, I950 völlig verarmt verstarb.

\subsection{Neue Wege im Synagogenbau}

3.2. I Nicht realisierte Projekte und ihre Nachfolgebauten - Ernst Lindner und Oskar Marmorek

Während viele der Schüler Karl Königs sich bei neuen Bauaufgaben der Großstadt engagierten, blieb aber auch der Synagogenbau weiterhin eines der großen Themen, und dies vor allem vor dem Hintergrund eines allmählichen Abgehens vom historistischen Formenvokabular und der Suche nach neuen, zeitgemäßen Lösungen. Insbesondere als Otto Wagner I903 mit dem Bau der Kirche am Steinhof neue Wege im

97 Derzeit befindet sich der Bau im Besitz der Bank Austria. 


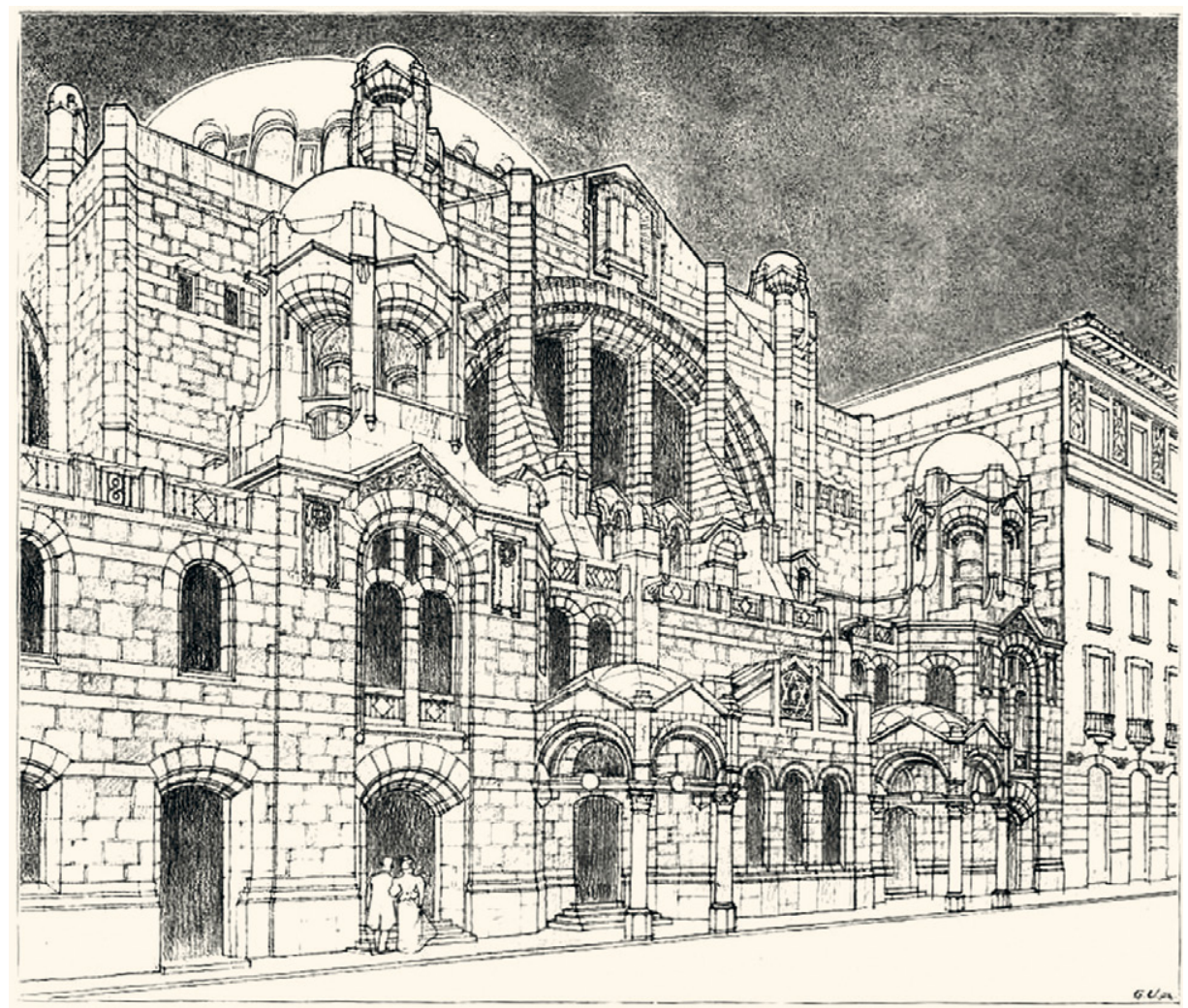

34. Theodor Schreier u. Ernst Lindner, Entwurf Synagoge Triest, I 904 (nicht realisiert)/Wr. Bauindustriezeitung

christlichen Sakralbau beschritt, setzte auch in der jüngeren jüdischen Architektengeneration ein Bemühen um eine Erneuerung des Synagogenbaus ein, wobei die Forderungen wie Funktionalität, gute Sichtbarkeit, bessere Eingebundenheit der Gläubigen in den Gottesdienst und anderes mehr durchaus ähnlich waren. Als daher gegen Ende I 903 die relativ große und wohlhabende jüdische Gemeinde von Triest - damals noch zur Donaumonarchie gehörend - einen Wettbewerb ausschrieb, beteiligten sich auch zahlreiche Wiener Architekten und nützten die Gelegenheit, neue Ideen einzubringen. ${ }^{98}$ Wie bereits erwähnt, nahmen unter anderen Oskar Marmorek und Alfred Teller (in Arbeitsgemeinschaft mit Oskar Strnad) an dem Bewerb teil. Bezeichnend für

98 Auch zahlreiche nicht jüdische Architekten nahmen an diesem Wettbewerb teil, siehe dazu E. Fuks, Der Synagogenwettbewerb von Triest, in: Oskar Strnad I 897-1935 (Kat.), Salzburg/München 2007. 


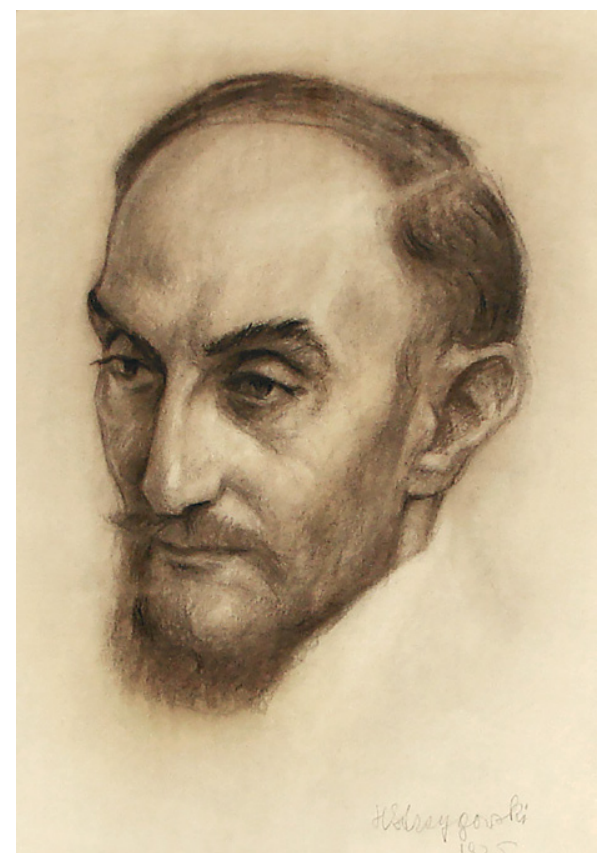

35. Ernst Lindner, Porträtzeichnung von Hertha Karasek 1925/privat

die Entwürfe ist der Umstand, dass man sich bemühte, von dem bis dahin geübten Schema eines maurisch-orientalisierenden oder neugotischen Stiles - verwiesen sei auf Wilhelm Stiassny oder Max Fleischer - abzugehen. Sicherlich nicht zufällig waren nicht wenige der Entwürfe von einer konkreten Auseinandersetzung mit Otto Wagners Kirche "Am Steinhof " geprägt, überwogen bei den Wettbewerbsprojekten doch Zentralkuppelbauten in einer reduzierten, "modernen« Formensprache.

Insbesondere das preisgekrönte Konkurrenzprojekt von Theodor Schreier (I873I943) und Ernst Lindner (1870-1965) bot eine kühne Synthese der oben angeführten Kriterien (Abbildung 34)..${ }^{99}$ Ernst Lindner (Abbildung 35) und Theodor Schreier waren gleichfalls Schüler Karl Königs, die sich ungefähr ab I900 zu einer Ateliergemeinschaft zusammengeschlossen hatten. Während Schreier aus Wien stammte, kam Lindner aus dem kleinen Städtchen Skotschau/Skoczow in ÖsterreichischSchlesien (heute Polen). Infolge dieses Umstandes war die Bürogemeinschaft nicht nur in Wien, sondern auch in dieser Region der Donaumonarchie tätig. Insbesondere in der Doppelstadt Bielitz-Biała/Bielsko-Biała, die zu dieser Zeit einen ungemeinen Aufschwung erfuhr, konnten sie neben diversen Wohnbauten auch einige

99 Ebenda; s. auch Wiener Bauindustriezeitung 9.I2.I904. 


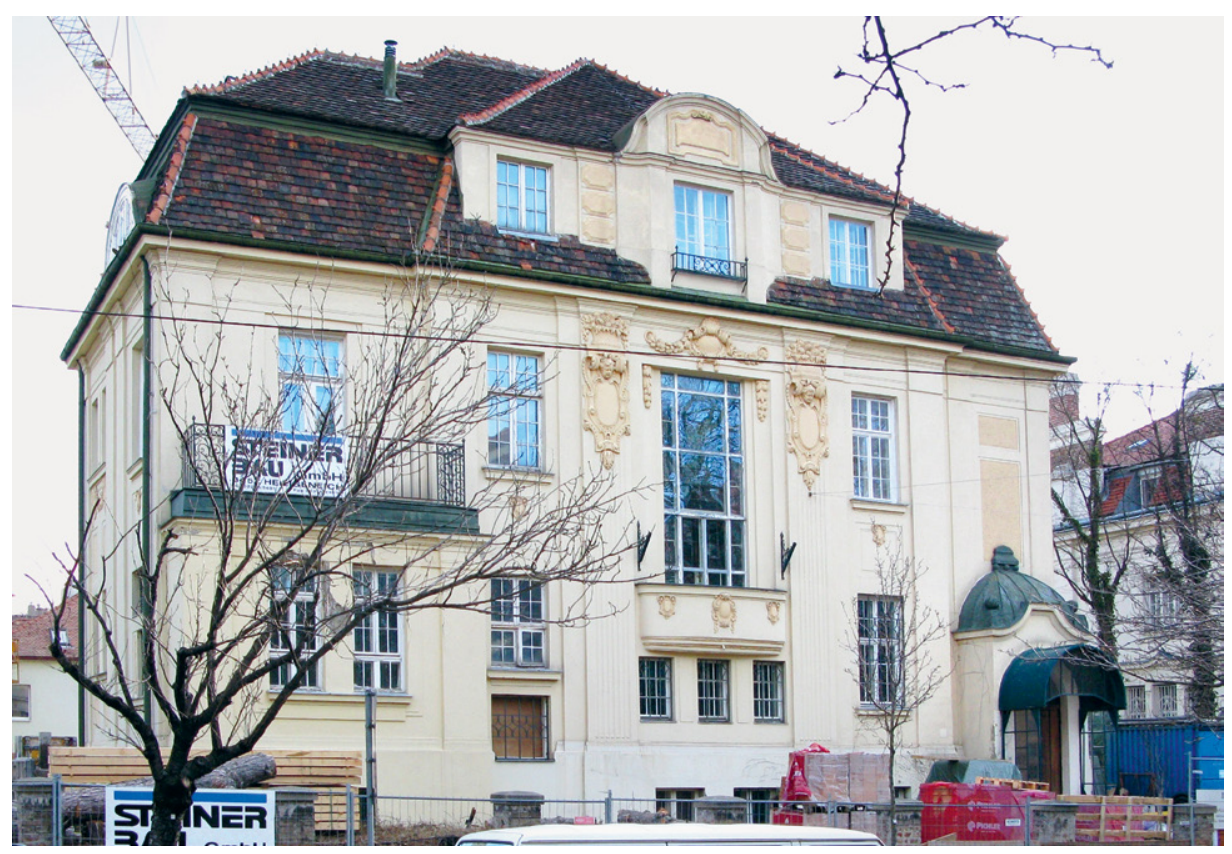

36. Theodor Schreier, Mietvilla Wien I9, Linnéplatz 3, erbaut I91o/Prokop

Amtshäuser und Schulen errichten. Darüber hinaus hatten sie sich auf den Bau von Synagogen spezialisiert. Bereits um I90 I/o2 hatten sie sowohl in Lindners Heimatstadt Skotschau als auch im nahe gelegenen Ustron Bethäuser errichtet. Während die größere Synagoge in Skotschau konventionell gehalten war, hatten sie bei dem relativ kleinen Gebäude in Ustron bereits mit einem zentralisierenden Baukörper experimentiert.

Bedauerlicherweise gelangte ihr preisgekrönter Entwurf für Triest, der eine interessante Weiterentwicklung des Synagogenbaus geboten hätte, nicht zur Ausführung, sondern es wurde schließlich ein lokales Triester Büro mit dem Vorhaben beauftragt. Dessen ungeachtet verhalf der Prestigeerfolg, der in der Fachwelt mit Aufmerksamkeit beobachtet wurde, dem Büro zu einem gewissen Renommee. Lindner und Schreier gingen jedoch bald getrennte Wege, die Gründe dafür sind nicht bekannt. Beide hatten späterhin noch die Möglichkeit, auf dem Gebiet des jüdischen Kultbaus tätig zu sein. Lindner konnte um 1908 einen Tempel in Neutitschein/Novy Jitschin errichten, der jedoch - möglicherweise auf Wunsch der Auftraggeber - eher konventionell gehalten war. Weitere interessante Synagogenentwürfe Lindners, die ein Abgehen von dem bis dahin üblichen Schema der historistischen Bauten intendierten und eine 


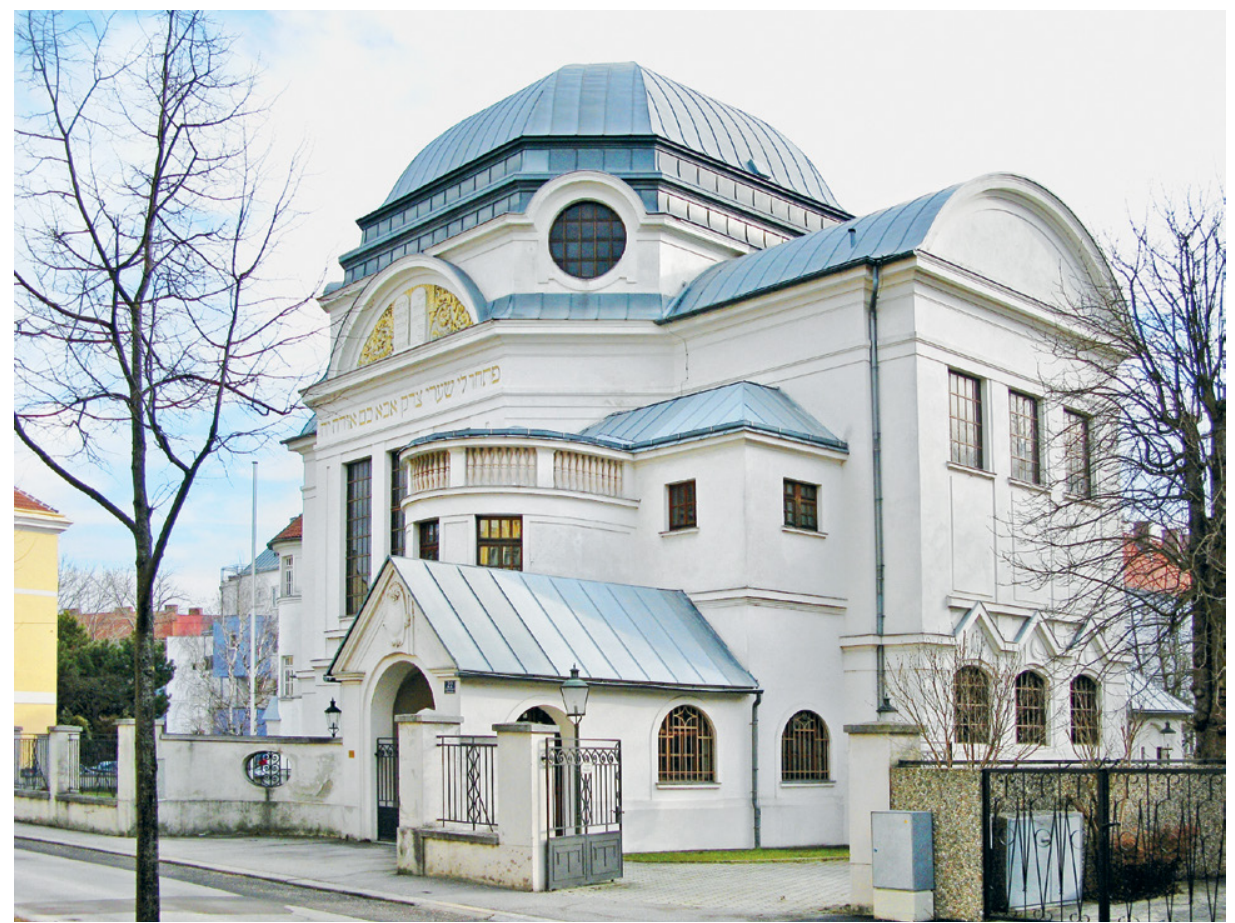

37. Theodor Schreier u. Viktor Postelberg, Synagoge St. Pölten, NÖ, Dr. Karl Renner-Promenade 22, erbaut I9I3/Prokop

Orientierung am Formenvokabular der »Wagnerschule« verrieten, mussten hingegen Papierarchitektur bleiben. ${ }^{100}$

Theodor Schreier hat in den letzten Jahren vor dem Ersten Weltkrieg insbesondere in den gehobenen Wiener Villenvierteln einige sehr qualitätvolle Wohnhäuser realisiert, wie die gegenüber der Hochschule für Bodenkultur gelegene Mietvilla am Linneplatz 3 (Abbildung 36). Darüber hinaus hat er I9I2 in Arbeitsgemeinschaft mit Viktor Postelberg (I 869-1920) einen in architekturhistorischer Sicht äußerst bemerkenswerten Tempel in St. Pölten/NÖ errichtet, der in seinen Strukturen eine vereinfachte Weiterführung des Triester Projektes war (Abbildung 37). ${ }^{101}$ Der Bau, der Ju-

I oo Wiener Bauindustriezeitung 26.1909, S. 339, T. 77.

IO I Viktor Postelberg (1869-I920), der in Wien geboren wurde und schon früh verstarb, war gleichfalls ein Schüler Karl Königs. Er hatte sich schon früh selbstständig gemacht und arbeitete vor allem auf dem Gebiet des Industriebaus. In Wien hatte er neben einigen Villen u. a. auch das Gymnasium in der Albertgasse und ein Entbindungsheim errichtet. Die Synagoge in St. Pölten war sein einziger jüdischer Sakralbau. 


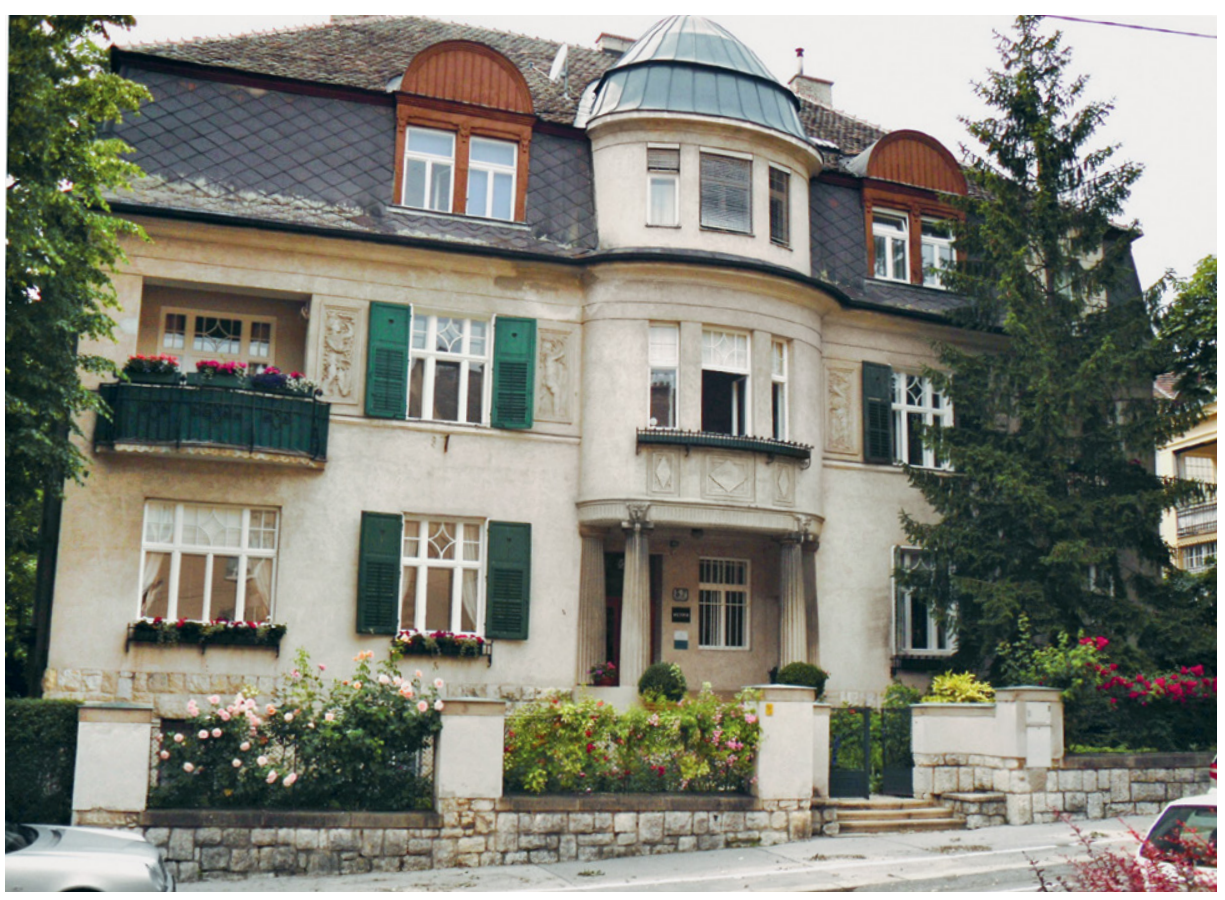

38. Ernst Lindner, Doppelhaus I9, Huleschgasse 57, erbaut I9 I 2/Prokop

gendstilelemente mit neobarocken Strukturen vereint, ist bis heute eine der wenigen erhaltenen Synagogen in Österreich, wird allerdings nicht mehr für Kultzwecke genutzt. Lindner hingegen hatte sich nach der Trennung von seinem Partner neben den bereits erwähnten Synagogenprojekten insbesondere auf seine Tätigkeit in Bielitz konzentriert, wo er zahlreiche Miethäuser, aber auch Schulen und anderes mehr errichtete. Ebenso wurden in Wien einige Bauten nach seinen Plänen realisiert, wie das äußerst dekorative Doppelhaus in Wien-Döbling (Huleschgasse 5-7, Abbildung 38).

Über die Tätigkeit von Lindner und Schreier in der Zwischenkriegszeit ist nur wenig bekannt. Lindner war nach Ende des Ersten Weltkrieges nicht mehr als freier Architekt tätig, sondern arbeitete als Leiter der technischen Abteilung der Wiener Kultusgemeinde. In dieser Funktion war er auch für die Renovierung des Tempels in der Seitenstettengasse I92 I verantwortlich. Nach dem sogenannten "Anschluss« gelang es Lindner, mit seiner Familie über England in die USA zu emigrieren, wo er hochbetagt 1956 in New York verstarb. ${ }^{102}$ Auch Theodor Schreier hatte aufgrund der

I02 Freundliche Auskunft Doris Baum, Bristol, USA (Tochter von Ernst Lindner). 
schlechten wirtschaftlichen Situation die freiberufliche Arbeit in den 2oer-Jahren aufgegeben und eine Anstellung im technischen Büro der Österreichischen Creditanstalt gefunden. Im Gegensatz zu Lindner ist er jedoch nach dem sogenannten "Anschluss" in Wien geblieben. Möglicherweise vermeinte er aufgrund seines fortgeschrittenen Alters und seines Fronteinsatzes im Ersten Weltkrieg nicht unmittelbar gefährdet zu sein. Dessen ungeachtet wurde er mit seiner Frau 1942 nach Theresienstadt deportiert, wo er im Jänner des folgenden Jahres elend verstarb. ${ }^{103}$

Obwohl die Teilnahme am Wettbewerb für die Triester Synagoge ein Fehlschlag gewesen war, brachte dieser Bewerb neue Impulse auf dem Gebiet des jüdischen Kultbaus, die auch bald in Wien ihren Niederschlag finden sollten. Bereits kurze Zeit später, I906, stand in Wien ein Synagogenprojekt zur Diskussion, das vom Tempelverein Döbling unter Leitung von Julius Lederer initiiert wurde. Der Verein wollte allerdings eine eher bescheidene Betstätte in einem bereits bestehenden Miethaus in Wien-Döbling, Dollinergasse 3 errichten. Die architektonische Aufgabe bestand darin, in den Innenräumen des Miethauses eine Synagoge einzurichten und auch die Außenerscheinung dementsprechend umzugestalten. ${ }^{104}$ Oskar Marmorek, der bereits oben erwähnt wurde, brachte Vorschläge für dieses Projekt ein und publizierte einen originellen Entwurf (Abbildung 39), der dem Gebäude in der Dollinergasse generell den Charakter eines Wohnhauses beließ, jedoch mittels architektonischer Details wie eines großzügigen Portals und einer reichen, dekorativen Ausgestaltung, darunter einige Davidsterne, auf seine religiöse Funktion hinwies. ${ }^{105}$ Bemerkenswert ist, dass Marmorek sich nicht scheute, das aktuelle "moderne» Formenrepertoire, wie es in der "Wagner-Schule» üblich war, hier einzubringen. Auch die auf dem Entwurf gezeigten "Flaneure«, die den Bau umgeben, entsprechen in ihrer Darstellung keineswegs orthodoxen Juden, sondern zeigen nach der damaligen Mode elegant gekleidete Personen aus dem gehobenen Bürgertum. Da dieses Projekt offensichtlich viel zu teuer gewesen wäre, gelangte es jedoch nicht zur Ausführung. Der Entwurf Marmoreks ist gemeinsam mit den nicht realisierten Projekten von Lindner und Schreier als bemerkenswertes Indiz anzusehen, dass seitens der Schüler Karl Königs versucht wurde, neue Wege auf dem Gebiet des Synagogenbaus in Auseinandersetzung mit der zeitgenössischen Moderne auszuloten. Der Ausbruch des Ersten Weltkrieges verhinderte jedoch eine Weiterentwicklung dieser Ideen.

Den Auftrag für das Tempelprojekt in der Dollinergasse, das schließlich in viel bescheidenerem Maße realisiert wurde, erhielt auch dann keiner der damaligen Größen,

I03 Chr. Gruber, Theodor Schreier, in: Österreichisches biografisches Lexikon, Bd. I I, 2003.

I04 Siehe dazu Genée, zit. Anm. 8, S. 73.

I05 Der Architekt I2.1906, T. 80. Es ist nicht geklärt, ob es sich im konkreten Fall um einen Wettbewerbsbeitrag oder um einen Vorschlag in Eigeninitiative handelt. 
39. Oskar Marmorek, Entwurf einer Synagoge in Döbling, I 9 I 2 (nicht realisiert)/Der Architekt

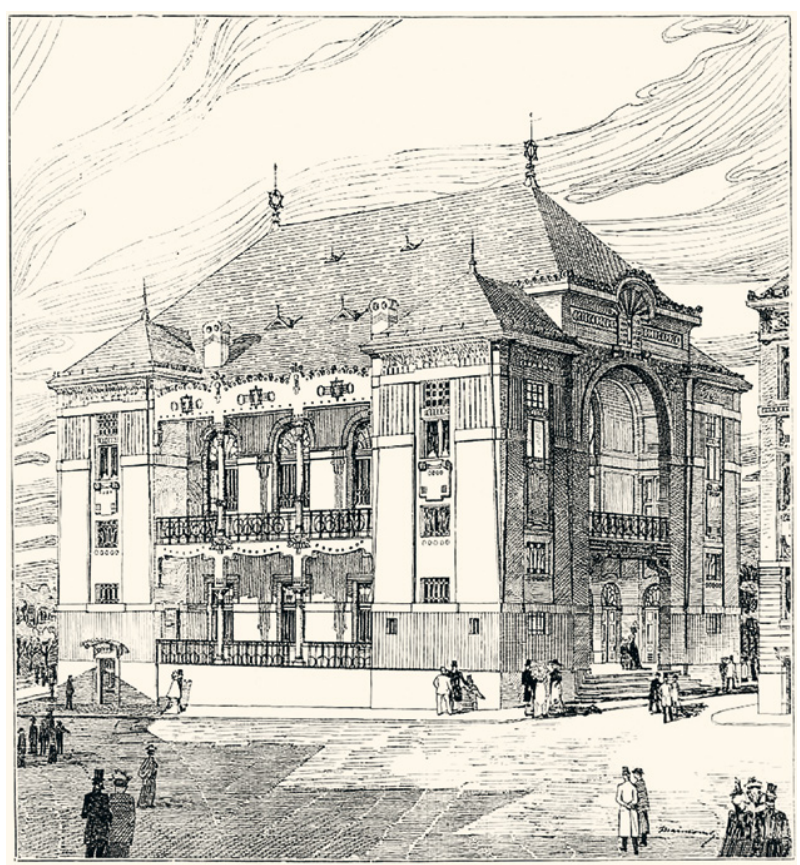

sondern der örtliche Architekt Julius Wohlmuth (1874-193I). Dieser hatte allerdings nur die Höhere Staatsgewerbeschule besucht, und es war unüblich, nicht akademisch geschulte Architekten mit der Planung von "Monumentalbauten« - eine Kategorie, unter die selbstverständlich auch Synagogen fielen - zu beauftragen. ${ }^{106} \mathrm{Da}$ es sich allerdings im konkreten Fall nur um den Umbau eines bereits bestehenden Miethauses handelte, war dieser Umstand offenbar ohne Relevanz. Möglicherweise spielte bei der Auftragsvergabe auch das Faktum eine Rolle, dass Wohlmuth selbst dem Döblinger Tempelverein angehörte und sich trotz seiner Jugend bereits mit dem Bau einiger spektakulärer Nobelvillen, die dem Kanon der damaligen Moderne entsprachen, einen Namen als Architekt gemacht hatte. Diese Qualität brachte er auch bei dem Projekt der Döblinger Synagoge zum Einsatz, deren Ausführung interessanterweise eine gewisse Übereinstimmung mit dem Entwurf Marmoreks zeigte, aber in den architektonischen Details wesentlich bescheidener blieb. Nicht zufällig lehnte sich der Bau mit einem prächtigen Davidstern im Mittelgiebel an die Monumentalarchitektur der »Wagner-

Io6 Siehe dazu U. Prokop, Von der Synagoge Dollinergasse zur »Riviera an der Donau«. Der Architekt Julius Wohlmuth, in: David 21.2009, H. 83, S. 44fff. 


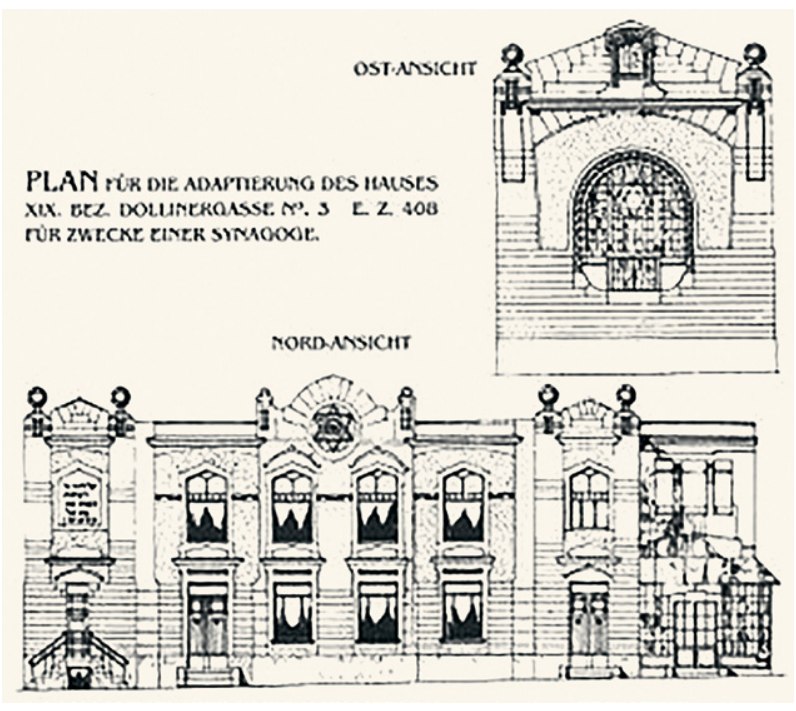

40. Julius Wohlmuth, Synagoge Wien I9, Dollinergasse 3 erbaut 1907 (nicht erhalten)/ Genee, Wr. Synagogen

Schule« an und war ein seltenes Beispiel einer Synagoge in der Formensprache der frühen Moderne (Abbildung 40).

Wohlmuth konnte noch bis zum Ausbruch des Ersten Weltkrieges einige bemerkenswerte Projekte realisieren, darunter das elegant klassizierende Wohn-Geschäftshaus Wien I9, Grinzinger Allee I (Abbildung 4I), das durch seine exponierte Ecklage bis heute ein markantes Gebäude im örtlichen Umfeld darstellt. Weniger glücklich verlief hingegen die Geschichte der Döblinger Synagoge, die wie alle jüdischen Einrichtungen 1938 in der sogenannten Reichspogromnacht zerstört wurde. Das neuerlich zu einem Miethaus umfunktionierte Gebäude wurde schließlich I995 zur Gänze abgerissen, sodass heute nicht die geringsten Spuren dieses bemerkenswerten Baus übrig geblieben sind. Auch Wohlmuths weitere Karriere verlief wenig glücklich.

Aufgrund der schlechten wirtschaftlichen Situation in der Zwischenkriegszeit musste er vorübergehend seine Tätigkeit als Architekt aufgeben und arbeitete als Versicherungsvertreter. Anfang der Zwanzigerjahre zog er nach Kritzendorf bei Klosterneuburg, NÖ, wo er bereits vor dem Krieg mit seiner Familie die Sommermonate verbracht hatte. Der Ort, der in diesen Jahren einen großen Aufschwung als Wiener Naherholungsgebiet erfuhr, erfreute sich insbesondere bei jüdischen Künstlern und Intellektuellen großer Beliebtheit. ${ }^{107}$ Auch Wohlmuth errichtete Mitte der

I07 Siehe dazu L. Fischer, Die Riviera an der Donau, Wien u.a. 2004. In diesem Kontext spielte der Wiener Rechtanwalt Dr. Marcel Halfon eine nicht zu unterschätzende Rolle, engagierte er sich doch 
4I. Julius Wohlmuth,

Geschäftshaus, Wien I9,

Grinzinger Allee I, erbaut I9 I 3 /Prokop

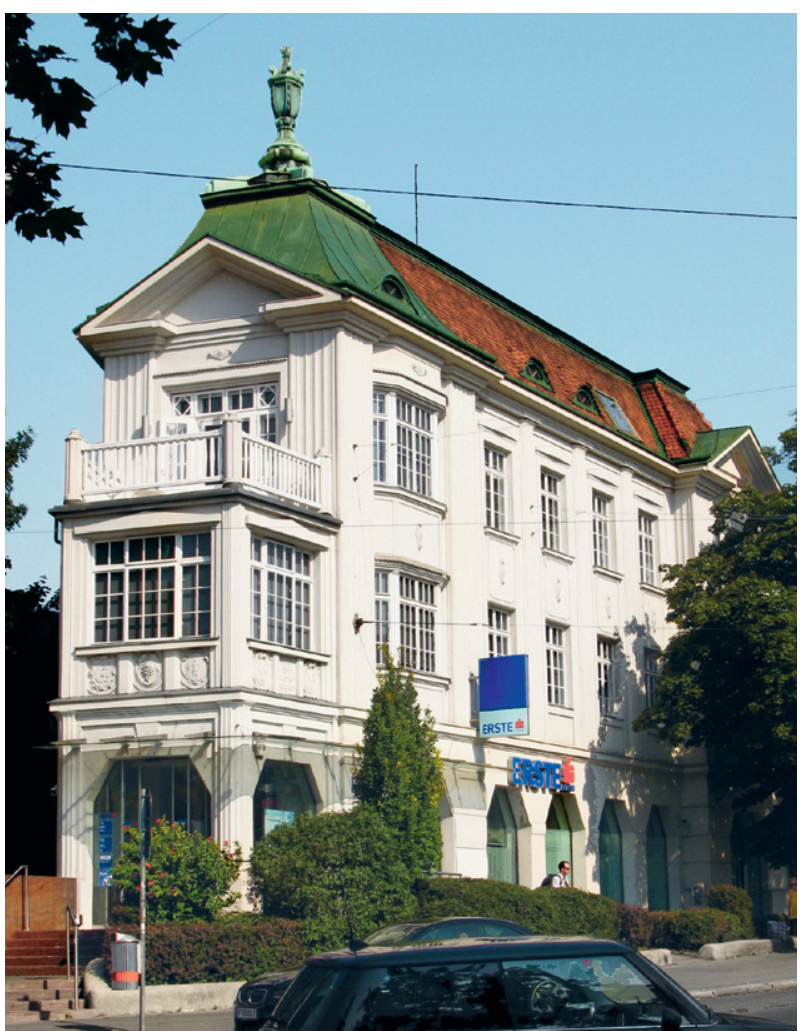

Zwanzigerjahre in der rasch wachsenden Strandkolonie mehrere Wochenendhäuser, darunter ein Strandhaus für den Zahnarzt Dr. Grünberg. ${ }^{108}$ Als daher 1926 der Neubau des inzwischen viel zu klein gewordenen Strombades in Angriff genommen wurde, war es nicht zuletzt Julius Wohlmuth, der ein diesbezügliches Ansuchen an die Niederösterreichische Landesregierung stellte und bei der Ausschreibung und Planung maßgeblich Anteil hatte. In Arbeitsgemeinschaft mit dem Wiener Architekten Heinz Rollig war er dann bis 1928 mit dem Ausbau des neuen Donaustrandbades befasst, wobei insbesondere die Hüttenzeilen und Kabinentrakte durch einen zentralen Platz architektonisch vereinheitlicht wurden und auch eine umfassende Infrastruktur errichtet wurde. ${ }^{109}$ Ein Großteil der Anlage besteht bis

als Obmann der dortigen Wochenendhausbesitzer immer wieder für Kritzendorf und publizierte auch mehrfach darüber (u. a. M. Halfon, Die Wochenendstadt, in: profil, 1933, S. 228).

I08 Das Haus befand sich in Kritzendorf, Donaulände I. Nach der "Arisierung« von 1938 erfuhr es mehrfache Umbauten. Publiziert in M. Halfon, Das Wochenendhaus, Wien 1928.

I09 Klosterneuburg, Sonderband 2 (die Architektur der Klosterneuburger Strandbäder), Klosterneuburg 


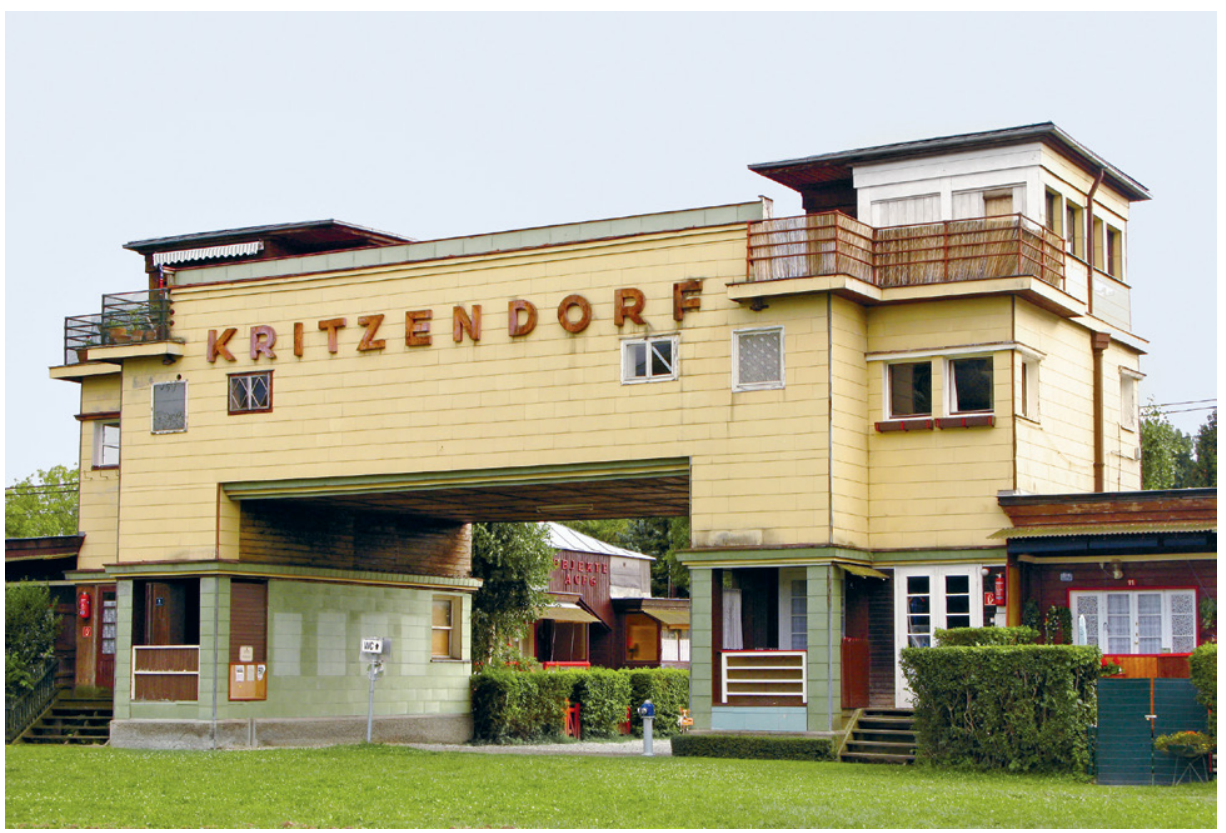

42. Julius Wohlmuth (mit Heinz Rollig), Strombad Kritzendorf, NÖ, erbaut 1926/28/Prokop

auf einige Modifikationen bis heute (Abbildung 42). Es sollte das letzte Projekt von Wohlmuth bleiben, der verhältnismäßig jung im siebenundfünfzigsten Lebensjahr I93 I Wien verstarb.

\subsubsection{Innovative Kultbauten auf dem Weg zur Moderne - Ignaz Reiser und Arthur Grünberger}

Im Hinblick auf die Geschichte des Synagogenbaus zu Beginn des 20. Jahrhunderts ging jedoch - ungeachtet des relativ bescheidenen, aber fortschrittlichen Kultbaus in der Dollinergasse - die Suche seitens der Schüler Karl Königs nach einer neuen Formensprache weiter. Es war Ignaz Reiser (I 863-I940, Abbildung 43), der schließlich bei der Errichtung des Kaiser-Jubiläumstempels in Wien 2, Pazmanitengasse 6, der I9 Iо anlässlich des 80. Geburtstages des Kaisers vom örtlichen Tempelverein in Auftrag gegeben wurde, sich von den bis dahin bestehenden Vorbildern zu lösen versuchte. Aufgrund des Umstandes, dass Reiser - ähnlich wie sein Studienkollege Mar- 


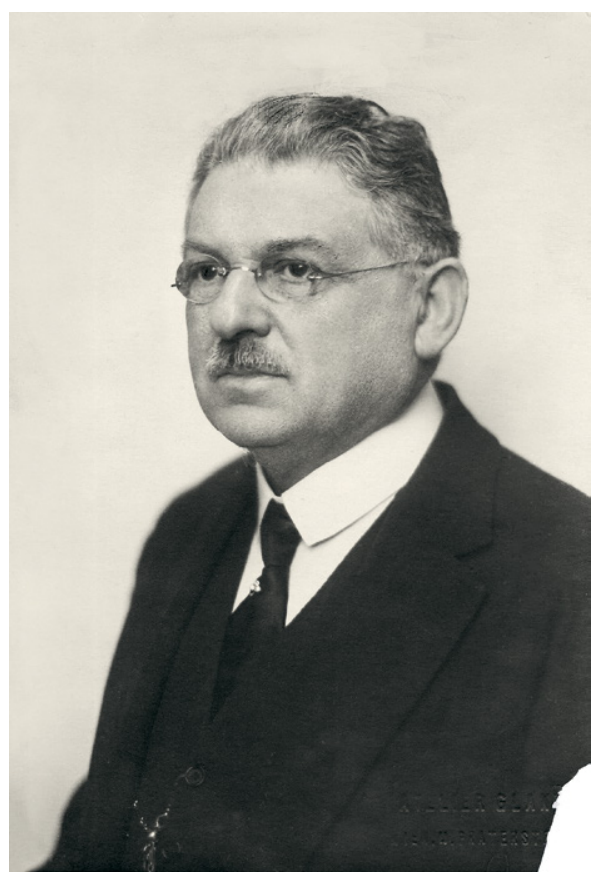

morek - sowohl bei Karl König studiert als auch im Anschluss daran im Atelier von Wilhelm Stiassny gearbeitet hatte, ist er zweifellos zum innersten Kreis der Wiener jüdischen Architekten zu zählen. Auf dem Gebiet des Synagogenbaus hatte er schon früh Erfahrungen gesammelt, als er Anfang der Neunzigerjahre die Bauleitung für den Gablonzer Tempel von Wilhelm Stiassny überhatte. Nach dessen Tod wurde er sozusagen sein Nachfolger und zu einem der wichtigsten Architekten auf dem Gebiet des jüdischen Kultbaus, wobei er jedoch durchaus eigenständige Wege ging.

Als Reiser I9 Iо mit dem Bau des Jubiläumstempels beauftragt wurde, war er zur gleichen Zeit auch mit der Errichtung einer Synagoge in Mödling, NÖ befasst - ein Hinweis darauf, wie sehr der Architekt damals geschätzt wurde. Die innovativen Ansätze, die Reiser beim Bau in der Pazmanitengasse einbrachte, betrafen sowohl den Einsatz von neuen Technologien und Konstruktionsweisen als auch neue Wege in der formalen Durchgestaltung, wobei zweifellos Erfahrungen, die Reiser kurz zuvor beim Bau einiger bemerkenswerter Wohn-Geschäftshäuser erworben hatte, eine Rolle gespielt haben dürften. ${ }^{10}$ Insbesondere der I9I I im Textilviertel von ihm

I I Siehe dazu Genée, zit. Anm. 8; B. Martens, Dreidimensionale Rekonstruktionen von Wiener Synagogen, in: David, H. 60, 2004. 


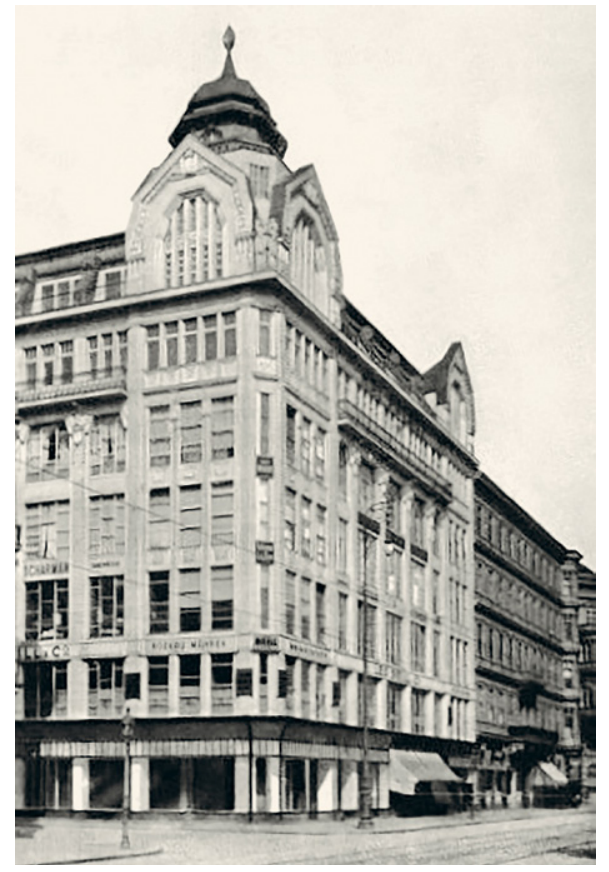

44. Ignaz Reiser, Kai-Palast, Wien I, Franz JosefsKai 57, erbaut I9I 2 (nicht erhalten)/Wr. Bauindustriezeitung

errichtete sogenannte "Kai-Palast« (Wien I, Franz-Josefs-Kai 47, Abbildung 44), dessen Ständerbauweise in Eisenbeton die sehr funktionalistische Außenerscheinung prägte, galt damals als einer der modernsten Bauten der Zeit. ${ }^{11}$ Es verwundert daher nicht, dass Reiser auch die Jubiläumssynagoge in Eisenbeton ausführen ließ und generell im Hinblick auf Brandschutz jeglichen Einsatz von Holz vermied. Ungeachtet dieser Vorsorgemaßnahmen wurde aber auch dieser Bau I 938 anlässlich der »Reichspogromnacht vom Mob angeblich "abgebrannt", was sich in Kenntnis dieser Umstände als zynische Lüge entlarvt. In formaler Hinsicht versuchte Reiser durch den Einsatz einer freien, nur sehr vage an die Romanik angelehnten Formensprache neue Wege zu gehen. Bemerkenswerterweise hatte das Gebäude, das im Bauverbund errichtet worden war, zwei Fassaden - eine zur Pazmanitengasse und eine zur Pillersdorfgasse -, die jeweils höchst unterschiedlich gestaltet waren (Abbildung 45). Insbesondere die mit einem hohen Giebel versehene Hauptfront, die von einem großen Korbfenster dominiert wurde, zeichnete sich durch einen sehr originären Umgang mit dem historischen Formenrepertoire aus, während an der Rückseite ein großes

I I I Der Bau wurde erst um 2004 abgerissen. 
45. Ignaz Reiser Synagoge Wien 2, Pazmanitengasse 6, erbaut I9013 (nicht erhalten)/Wr. Bauindustriezeitung

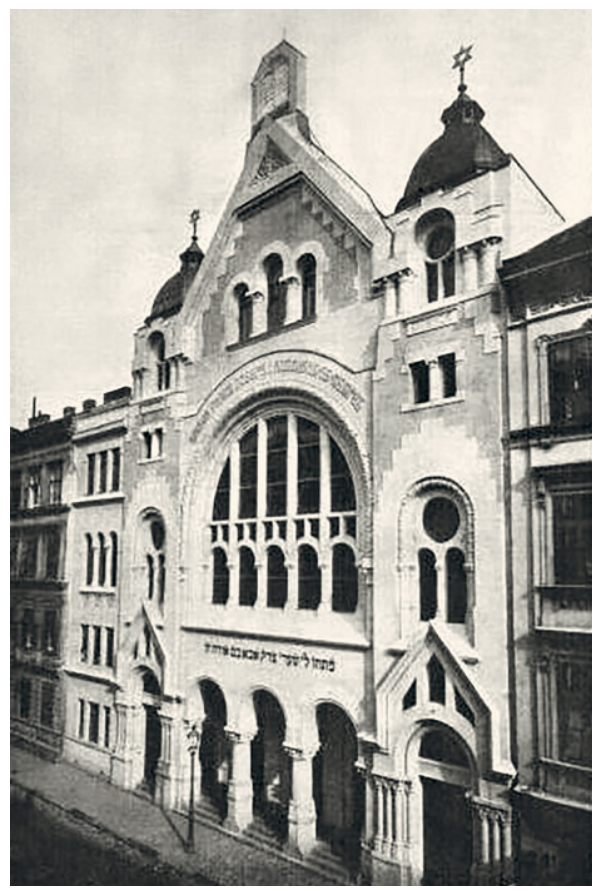

Rundfenster mit einem Davidstern angebracht war. Die Organisation des einseitig gerichteten Längsraumes war dem reformierten Ritus verpflichtet, Thora und Almemor befanden sich nahe nebeneinander. Der prachtvoll dekorierte Innenraum war mit einer Frauenempore ausgestattet. Besondere Aufmerksamkeit widmete Reiser den funktionellen Notwendigkeiten wie Beheizung, Lüftung, Zugänglichkeit der Ausgänge und anderem. ${ }^{112}$

Nach dem Ende des Ersten Weltkrieges erfuhr Ignaz Reisers Tätigkeit als Architekt erhebliche Einbußen. Die großen Aufträge - insbesondere auf dem Gebiet des Wohnbaus - blieben aus und viele Wettbewerbsentwürfe gelangten nicht zur Realisation. Weitgehend war die Kultusgemeinde sein einziger Auftraggeber in dieser Zeit. Mitte der Zwanzigerjahre konnte er sich jedoch im Rahmen eines Wettbewerbs durchsetzen und erhielt den Auftrag zum Bau der Zeremonienhalle der neuen israelitischen Abteilung auf dem Wiener Zentralfriedhof. Dieses Projekt war von der Kultusgemeinde bereits I9 I 4 in Angriff genommen, jedoch durch den Ausbruch des Krieges verzögert worden, sodass bis dahin nur ein von Jakob Gartner errichtetes Provisorium existierte.

I 2 Wiener Bauindustriezeitung 3I.I9I4/I 5, S. 88, T. 2 If. 
Reiser baute dann in den Jahren I926-1928 den Eingangsbereich mit der Zeremonienhalle und dahinter liegende Grabanlagen (Abbildung 46). Abermals kam es zum Einsatz neuester Konstruktionen, etwa eines Betonspritzverfahrens für die Schale der Kuppel, die die Halle bekrönte. Diese Technik ermöglichte die äußerst komplexe Gestaltung der originellen Kuppel, die sich nach innen über einen achtseitigen Grundriss erhob und außen vierundzwanzigseitig gefaltet war. Die leicht orientalisierende Außenerscheinung orientierte sich an der zeitgenössischen expressionistischen Architektur, insbesondere an dem kurz zuvor von Clemens Holzmeister errichteten Krematorium. ${ }^{113}$ Die Zeremonienhalle, die I 938 teilweise zerstört wurde, ist zumindest im Kern erhalten geblieben; sie sollte Reisers größter Auftrag bleiben. Bis I 938 konnte er nur mehr einige bescheidenere Projekte realisieren, darunter den sogenannten "Storchentempel ( Wien I 5, Storchengasse 2 I) oder die Winterbethalle des Ottakringer Tempels. Sein häufiger Wohnungswechsel in diesen Jahren lässt auf finanzielle Schwierigkeiten schließen. Reiser, der möglicherweise auch aus diesem Grund nach dem »Anschluss« Österreichs I 938 nicht emigrierte, ist schließlich kurz vor dem Einsetzen der Judendeportationen noch im Jänner I940 im Wiener Rothschildspital einem Krebsleiden erlegen. Seine Frau wurde nach Theresienstadt deportiert und schließlich I942 im Vernichtungslager Treblinka ermordet, während seinen Kindern die Flucht ins rettende Ausland gelang. ${ }^{114}$

Neben der Zeremonienhalle am Zentralfriedhof in Simmering ist vor allem die Hietzinger Synagoge in der Eitelbergergasse als das bedeutendste Vorhaben eines jüdischen Kultbaus im Wien der Zwischenkriegszeit anzusehen. Auch dieses Projekt hatte bereits eine längere Vorgeschichte. ${ }^{115}$ Schon kurz vor dem Ersten Weltkrieg hatte der Hietzinger Tempelverein I9 I 2 einen Wettbewerb ausgeschrieben, der an keinerlei Konfession der Architekten gebunden war. Unter den drei Erstgereihten befand sich insbesondere auch der Entwurf von Hugo Gorge (I883-I934), der auch späterhin die Ausgangsbasis für das Projekt bleiben sollte. ${ }^{116}$ Das Gebäude hätte auf einem Areal in der Onno-Klopp-Gasse errichtet werden sollen, wo es im Häuserverbund

I 3 Siehe dazu Achleitner, zit. Anm. 26, S. 293; M. Eisler, Ein neuer Judenfriedhof in Wien, in: Moderne Bauformen 26.1927, S. 498ff.

I 4 Freundliche Auskunft Vivian Schiffmann-Reiser (Enkelin des Architekten).

I I 5 Siehe dazu R. Hanisch/O. Kapfinger, Der Wettbewerb um eine Synagoge in Wien Hietzing, in: Visionäre und Vertriebene, zit. Anm. Io; U. Unterweger, Die Synagoge in Wien Hietzing, in David, Sept. 2006, H. 70.

I 6 Neben dem Entwurf von Gorge wurden auch die Projekte von Rudolf Perco und Ernst Lichtblau preisgekrönt. Hugo Gorge stand damals am Anfang seiner Karriere und hatte zu diesem Zeitpunkt noch kaum etwas realisiert. Rudolf Perco (I 884-I942) war der einzige nicht jüdische Architekt. Er arbeitete ironischerweise in der NS-Zeit im innersten Zirkel der Machthaber bei Hanns Dustmann und beging 1942 Selbstmord. 


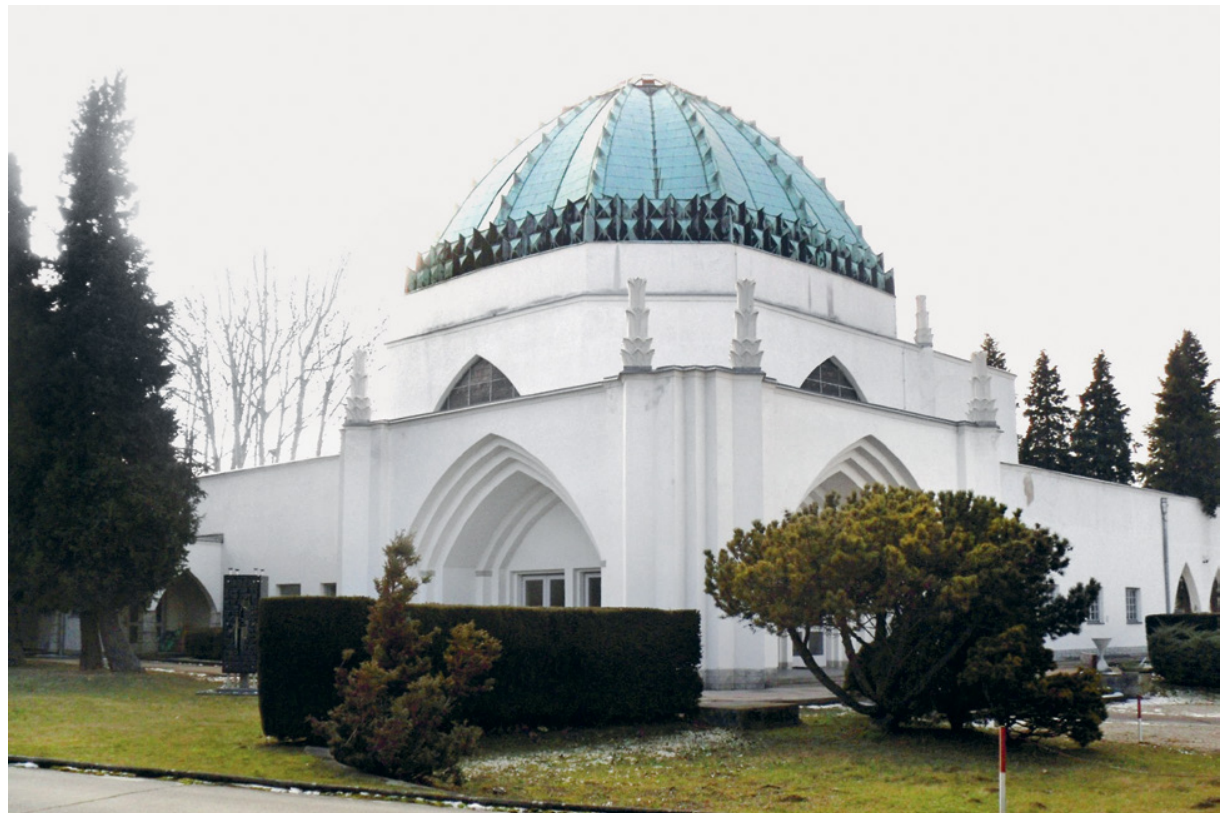

46. Ignaz Reiser, Eingangshalle d. neuen israelit. Abteilung d. Wiener Zentralfriedhofes, Wien I I, erbaut I928, (teilw. erhalten)/Prokop

situiert gewesen wäre. Gorge, der bei Friedrich Ohmann studiert hatte und späterhin als Assistent von Oskar Strnad tätig war, hatte bei seinem preisgekrönten Entwurf versucht, neue Wege zu beschreiten und jegliche historisierende Bezüge zu vermeiden. Bereits in Vorwegnahme expressionistischer Tendenzen hätte der nur sparsam dekorierte Bau eine eher wuchtige Wehrhaftigkeit vermittelt. ${ }^{117}$ Allerdings verzögerte sich das Projekt - möglicherweise infolge der Unentschlossenheit darüber, wem man den definitiven Auftrag erteilen sollte - und wurde dann infolge des Kriegsausbruchs nicht mehr realisiert. Als man 1924 einen zweiten Wettbewerb ausschrieb, kam Gorge neuerlich in die engere Wahl, erhielt den Auftrag aber nicht. Generell konnte er in der Zwischenkriegszeit nur sehr wenig bauen. Neben zwei Wohnhausanlagen für das "Rote Wien" und einem Doppelhaus in der Werkbundsiedlung musste er sich gleichfalls weitgehend auf Inneneinrichtungen spezialisieren. Seine Möbelentwürfe, die formal in großer Nähe zu Oskar Strnad standen und auf den diversen Werkbundschauen ausgestellt wurden, gehören in ihrer Eigenwilligkeit zu den originellsten der Zwi-

I 17 H. Gorge, Ein Synagogenentwurf, in: Der Architekt 22.I I9., S. I33ff. 
schenkriegszeit überhaupt. ${ }^{18}$ Gorge, der in relativ jungen Jahren erkrankte, ist nach langer Krankheit 1934 verstorben, sodass ihm ein noch tragischeres Schicksal erspart blieb. Seine Frau und Kinder mussten jedoch 1938 nach London fliehen.

Das Projekt der Hietzinger Synagoge ist erst nach Ende des Ersten Weltkrieges wieder aufgenommen worden, allerdings wurde die Situierung in der Onno-Klopp-Gasse verworfen. Nachdem sich die wirtschaftliche Lage allmählich zu stabilisieren begonnen hatte, kaufte der Tempelverein 1924 ein Grundstück an der Eitelbergergasse an, und es wurde ein zweiter Bewerb ausgeschrieben, der diesmal nur Juden vorbehalten war. ${ }^{19}$ Das Projekt hatte insofern eine besondere Bedeutung, als es sich infolge der Lage des Areals diesmal um einen rundum freistehenden Bau handelte, der in städtebaulicher Hinsicht eine spezifische architektonische Qualität erforderte. Vor allem der Architekturpublizist Max Eisler engagierte sich in diesem Kontext besonders und thematisierte in mehreren Aufsätzen, die Problematik eines genuin "jüdischen Stils", der angesichts des Aufkommens der »Neuen Sachlichkeit« eine neue Aktualität erhalten hatte und historisierende Bezugnahmen auf vergangene Stile obsolet machte. ${ }^{120}$ An diesem zweiten Bewerb nahm auch der junge Richard Neutra teil, der zu diesem Zeitpunkt bereits in den USA lebte und später eine große Karriere machte. Sein kühner, funktionalistischer Entwurf fand zwar viel Beachtung, war aber den Zeitgenossen doch etwas zu progressiv.

Die Jury entschied sich schließlich für den Beitrag von Arthur Grünberger und Adolf Jelletz, der einer sehr expressionistischen Ausrichtung verpflichtet war und durchaus auch einige Ideen Gorges übernahm (Abbildung 47). Obwohl der jeweilige Anteil nicht herauszuschälen ist, dürfte Grünberger federführend gewesen sein. Jelletz wurde manchmal als Mitprojektant, manchmal auch nur als Ausführender angegeben. Bezeichnend ist, dass beide Architekten Schüler Karl Königs an der Technischen Hochschule waren und sich als Studienkollegen von dieser Zeit her kannten.

Arthur Grünberger (1882-1935), der als Sohn eines Kaufmanns im mährischen Fulnek geboren wurde, besuchte nach dem Technikstudium noch die Meisterschule bei Friedrich Ohmann an der Akademie der bildenden Künste. Dieser Umstand erklärt möglicherweise die sehr ornamentale Ausrichtung seines Werkes, die vielen Schülern Ohmanns zu eigen war. Nach einer längeren Studienreise hatte Grünberger kurz vor dem Ersten Weltkrieg in Wien seine Tätigkeit als Architekt begonnen,

I I 8 E. Ottilinger (Hg.), Wohnen zwischen den Kriegen. Wiener Möbel I9I4-I945, Wien 2009.

I 9 Siehe dazu Unterweger, zit. Anm. I I 5.

I 20 M. Eisler, Der Wettbewerb um eine Wiener Synagoge, in: Österreichs Bau- und Werkkunst 2.1925/26, S. Iff. 


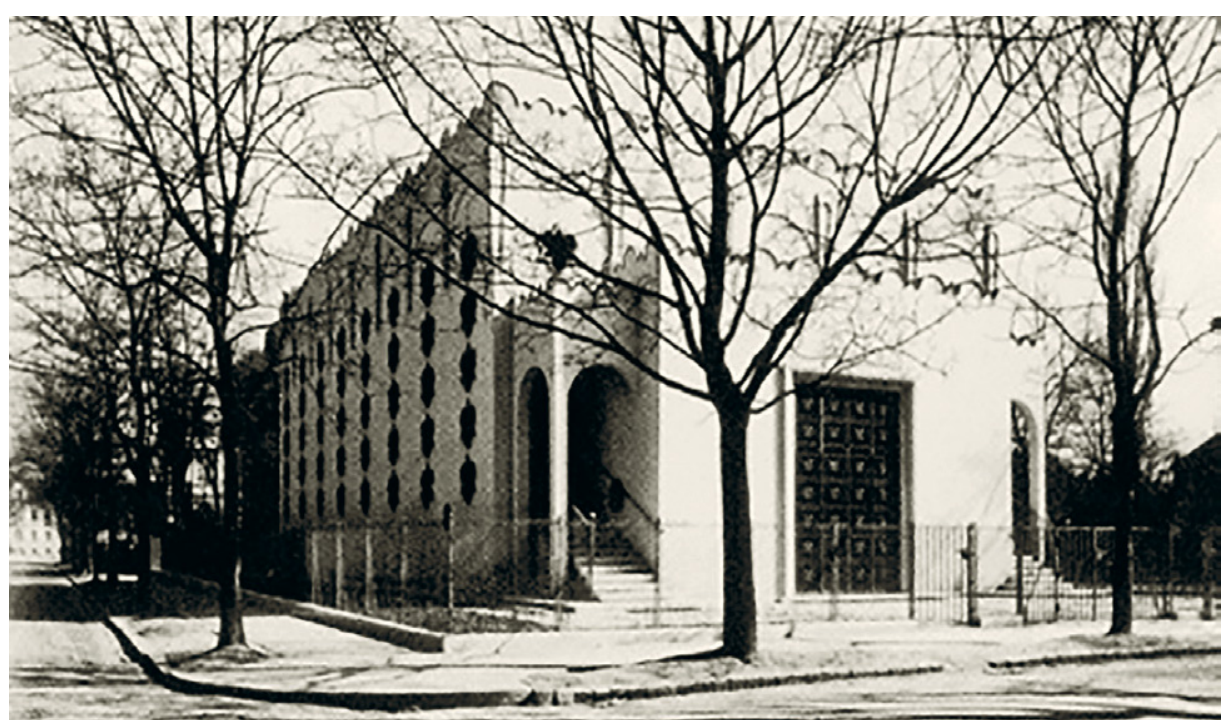

47. Arthur Grünberger, Synagoge Wien I3, Eitelbergergasse 22, erbaut um I930 (nicht erhalten)/Kata$\log$ Visionäre u. Vertriebene

zumeist mit wechselnden Partnern. ${ }^{121}$ Bereits Anfang der Zwanzigerjahre hatte er Wien - möglicherweise aufgrund der schlechten Wirtschaftslage - verlassen und war in die USA gegangen. Zum Zeitpunkt des Wettbewerbes lebte Grünberger bereits in San Francisco, während Adolf Jelletz der »Mann vor Ort« in Wien war. Inwieweit Grünberger, der später als Filmausstatter in Hollywood tätig war, bereits zu diesem Zeitpunkt für den Film arbeitete oder zumindest Kontakt hatte, ist unklar, aber höchstwahrscheinlich war er mit der Materie bereits vertraut. Neben seiner Ausbildung bei Friedrich Ohman könnte dieser Umstand eine Erklärung für den bühnenhaft-dekorativen Charakter von Grünbergers Entwurf der Hietzinger Synagoge sein, der außer den Einflüssen von Neuer Sachlichkeit und Expressionismus auch einen "Hauch von Hollywood « aufweist. Während der kubische Baukörper mit Flachdach den damals aktuellen Tendenzen entsprach, beschwor der zinnenähnliche Dachkranz eine Art von Festungscharakter. Die als Davidsterne über die Außenhaut verteilten Fenster ermöglichten im Inneren des Baus eine raffinierte Lichtführung mit nahezu filmischen Effekten.

Der Bau, dessen Errichtung schließlich 1928 in Angriff genommen wurde, konnte erst I93 I fertiggestellt werden. Die relativ lange Bauzeit erklärt sich durch den Um-

I 2 I $\mathrm{Zu}$ Grünbergers Lebenslauf siehe Visionäre und Vertriebene, zit. Anm. Io, S. 333. 
stand der einsetzenden Wirtschaftskrise und der daraus resultierenden großen ökonomischen Probleme des Tempelvereines, der weitgehend auf Spenden angewiesen war. ${ }^{122}$ Damit war diese sehr bemerkenswerte Synagoge - bis auf einige kleinere Bethäuser - das letzte größere Projekt eines jüdischen Kultbaus in Wien, um zynischerweise bereits einige Jahre später, I938, zerstört zu werden. Grünberger, der nach der Synagoge in Wien nur ein Doppelhaus in der Werkbundsiedlung errichtete, blieb in den USA, wo er es in Hollywood bis zum Art Director von Warner Brothers brachte und erst dreiundfünfzigjährig in Los Angeles verstarb.

Der nur wenige Jahre ältere Adolf Jelletz (I878-1936), der überwiegend für die Ausführung verantwortlich gewesen sein dürfte, stammte aus Wien und hatte nach seinem Technikstudium keine weiterführende Ausbildung genossen, sondern in den Jahren vor dem Ersten Weltkrieg weitgehend als Mitarbeiter in anderen Architekturbüros gearbeitet und eigenständig nur einige wenige Miethäuser realisiert, zumeist mit Partnern. I9 I 4 arbeitete er erstmals mit Arthur Grünberger zusammen, als sie sich an dem Bewerb für eine neue israelitische Abteilung auf dem Zentralfriedhof beteiligten. Weitere gemeinsame Projekte folgten, insbesondere I92 I ihr äußerst spektakulärer Konkurrenzentwurf für ein Krematorium am Zentralfriedhof, der von manchen als der beste Beitrag dieses Wettbewerbes angesehen wurde. ${ }^{123}$ Jelletz konnte neben der Hietzinger Synagoge nur eine Wohnhausanlage im Rahmen des Bauprogramms des »Roten Wien« realisieren (WHA, Wien 5, Margaretengürtel I 22). Wie fast alle Architekten in diesen Jahren hatte er mit erheblichen Schwierigkeiten zu kämpfen. Seine schlechte finanzielle Situation belegen auch seine zahlreichen Bittbriefe an den Unterstützungsfonds der bildenden Künstler Wiens. ${ }^{124}$ Auch er verstarb noch relativ jung im siebenundfünfzigsten Lebensjahr. Damit blieb beiden Architekten erspart, die Zerstörung der Synagoge mitzuerleben.

\subsection{Hartwig Fischel - ein Schüler Karl Königs im künstlerisch-intellektuellen Umfeld der Wiener Moderne}

Eine Sonderstellung unter den der König-Schülern nimmt in gewisser Weise der bereits im Vorwort erwähnte Hartwig Fischel (I86I-I942) ein. Neben seinem umfangreichen architektonischen Werk - das allerdings bis heute nur rudimentär bekannt ist - gehörte er insbesondere aufgrund seiner publizistischen Tätigkeit dem künstle-

I 22 Bericht der Kultusgemeinde Wien über die Tätigkeit in der Periode 1929-32, Wien I932, S. 22.

I 23 Der Architekt 24.I92 I/22, S. 65. Zur Ausführung kam das Projekt von Clemens Holzmeister.

I 24 M. Tscholakov, Adolf Jelletz, in: Architektenlexikon, zit. Anm. I3. 
risch-intellektuellen Umfeld der Jahrhundertwende an. I86I in Wien als Enkel des Ersten Oberrabbiners der israelitischen Kultusgemeinde geboren, kam er sozusagen aus dem Wiener jüdischen Establishment. Der Vater war ein gut situierter Börsensensal, sodass er in wohlgeordneten Verhältnissen aufwuchs. Nach dem Abschluss des Realgymnasiums studierte er an der Technischen Hochschule bei Heinrich von Ferstel und Karl König, um sich dann an der Akademie der bildenden Künste in der Meisterschule Friedrich Ohmanns künstlerisch zu vervollkommnen. Nach einer kurzfristigen Tätigkeit als Assistent an der Technischen Hochschule erhielt er I 888 die Stelle eines Inspektors und Fachreferenten der Kaiser-Ferdinands-Nordbahn, die er bis zu seiner vorzeitigen Pensionierung 19 IO innehatte. ${ }^{125}$ Wie schon im Abschnitt über Josef Unger angeführt, zeigt sich auch hier die Bedeutung des Bahnwesens für diese Zeit generell und für jüdische Techniker und Architekten im Besonderen. Hartwig Fischel hatte im Rahmen dieser Tätigkeit viele Bahnhochbauten ausgeführt und war vor allem auch mit zahlreichen Fachartikeln über das Bahnwesen publizistisch hervorgetreten. Obwohl er vereinzelt schon in diesen Jahren auch private Aufträge ausgeführt hatte, konnte er erst nach seiner Pensionierung seine Tätigkeit als freier Architekt intensivieren und sich vor allem auch seiner publizistischen Arbeit widmen.

Fischel schrieb in der Folge zahlreiche Artikel über Architektur und bildende Kunst, wobei seine Themen über die Volkskunst bis zur Malerei reichten. Unter anderem schrieb er auch Beiträge für das Prestigeprojekt des »Kronprinzenwerkes « ${ }^{126}$ und arbeitete als Mitarbeiter oder Schriftleiter für zahlreiche Fachzeitschriften in Österreich und Deutschland. Insbesondere befasste er sich auch mit Künstlern der zeitgenössischen Moderne, etwa den Architekten Otto Wagner und Max Fabiani oder den Malern Emil Schindler, Gustav Klimt und Egon Schiele.

Diese Tätigkeit, die bereits weit in das Gebiet der Kunstberichterstattung und der Kunstgeschichte reichte, führte ihn mit einem der bedeutendsten österreichischen Kunsthistoriker jener Jahre, mit dem bereits zu Anfang erwähnten Hans Tietze (I 880-1954), zusammen. Der aus einer Prager jüdischen Familie stammende Tietze, der bereits in Wien Kunstgeschichte studiert hatte, wurde bald zu einer der Schlüsselfiguren im damaligen Kunstbetrieb und hatte zu zahlreichen zeitgenössischen Künstlern Kontakt. Unter anderem hatte der junge Oskar Kokoschka ihn und seine Frau Erica, die gleichfalls Kunsthistorikerin war, in einem eindrucksvollen Doppelporträt verewigt. ${ }^{127}$ I 906 wurde Tietze in die Zentralkommission für Denkmalpflege (Vorläu-

I25 Siehe dazu Weihsmann, zit. Anm. I3.

I26 Das sogenannte "Kronprinzenwerk" war eine von Kronprinz Rudolf herausgegebene Publikationsreihe namens »Die Österreichische Monarchie in Wort und Bild«, deren 24 Bände von I 886 bis 1902 herauskamen.

I27 Das Bild hängt heute im Museum of Modern Art, New York. 
ferinstitution des heutigen Bundesdenkmalamtes) berufen, wo er in Zusammenarbeit mit Max Dvořak mit der Aufarbeitung einer "österreichischen Kunsttopographie« beauftragt wurde. Es ist naheliegend, dass Hartwig Fischel, der - ganz im Sinne seines geschichtsbewussten Lehrers Karl König - seinerseits zahlreiche Aufsätze über historische österreichische Architektur veröffentlicht hatte, Tietze dabei unterstützte. Diese Zusammenarbeit von Tietze und Fischel schlug sich auch in dem bereits erwähnten Auftrag Tietzes für ein Einfamilienhaus in Wien-Döbling (Armbrustergasse 29) nieder, das der Architekt 1907 im Geist der neuen Schlichtheit für den Kunsthistoriker errichtete (leider ist der Bau nur in einem sehr veränderten Zustand erhalten).

Ein weiterer Bau Hartwig Fischels, der gleichfalls in diesem künstlerischen Umfeld entstand, war eine Villa für Alma Mahler-Schindler in Breitenstein, NÖ. Gustav Mahler hatte I9 Io noch kurz vor seinem Tod mithilfe seines Schwiegervaters Carl Moll dieses Grundstück in den Adlitzgräben angekauft, um in seinen geliebten Bergen Erholung suchen zu können. Erst nach seinem Tod nahm seine Witwe Alma I9 I 3 dann den Bau eines Landhauses in Angriff. Es verwundert nicht, dass sie Hartwig Fischel damit beauftragte, hatte dieser doch eine Monografie über ihren Vater Emil Schindler publiziert, ebenso diverse Artikel über Arbeiten ihres Stiefvaters Carl Moll. In Zusammenarbeit mit Rudolf Bredl entstand der Bau dann kurz vor dem Ersten Weltkrieg, wobei allerdings die etwas exzentrischen Wünsche der Bauherrin, zum Beispiel eine umlaufende Säulenterrasse, den Architekten wenig Spielraum zur eigenen Entfaltung ließen (Abbildung 48). Von der Innenausstattung war insbesondere ein monumentales Fresko im Wohnzimmer über dem Kamin bemerkenswert, das von Oskar Kokoschka, der zu dieser Zeit mit Alma liiert war, geschaffen worden war womit sich der Personenkreis um Hartwig Fischel schließt. Alma Mahler bewohnte das Haus jeweils im Sommer bis zu ihrer Emigration, und es war die Stätte vieler dramatischer Ereignisse in ihrem Leben.

Nach Ausbruch des Ersten Weltkrieges befasste sich Fischel mit dem Bau von Flüchtlingslagern, die angesichts der angespannten Situation an der Ostfront und der zahlreichen Flüchtlinge - insbesondere Juden aus Österreichisch-Galizien - notwendig geworden waren. ${ }^{128}$ In der Zwischenkriegszeit beschränkte er sich infolge der schlechten wirtschaftlichen Lage und der geringen Bautätigkeit weitgehend auf seine schriftstellerische Arbeit, einzig eine relativ kleine Wohnhausanlage aus der Ära des "Roten Wien« (Wien 9, Sechsschimmelgasse I9, errichtet 1925 in Zusammenarbeit mit Josef Bayer) ist dokumentiert. Hartwig Fischel musste nach dem "Anschluss« I 938 bereits hochbetagt vor den Nazis fliehen und ging nach London, wo er 1942 verstarb.

I 28 H. Fischel, Bauanlagen der staatlichen Flüchtlingsfürsorge, in: Der Architekt 21.1916/18, S. I 5 ff. 


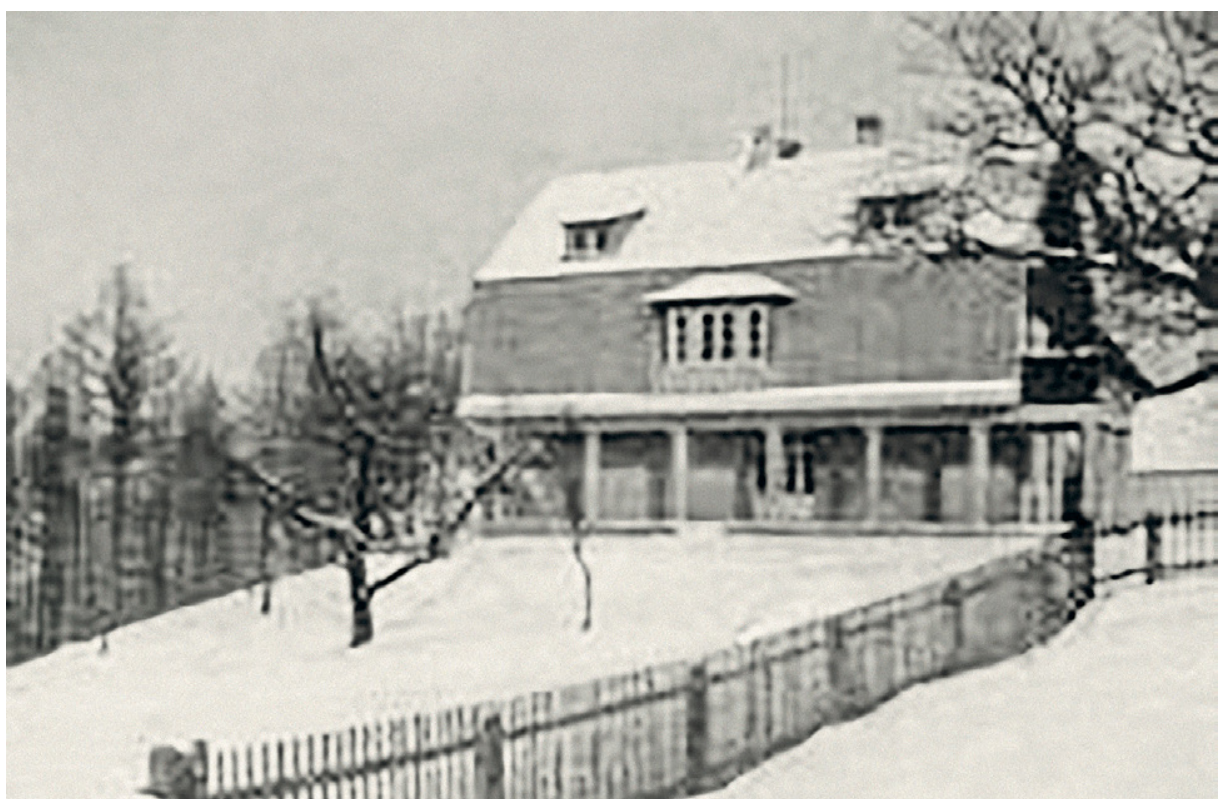

48. Hartwig Fischel, Villa Mahler, Breitenstein I02, Bez. Neunkirchen, NÖ, erbaut um I9I3/Internet (Alma Home page) 


\section{Baumeister und nicht akademische Architekten - die Hochblüte des Miethausbaus. Drei Fallstudien: Leopold Fuchs, Neumann Tropp und Ernst Epstein}

Eine Sondergruppe bilden die Baumeister und nicht akademischen Architekten, denen dieses Kapitel gewidmet ist und die insbesondere in den letzten Jahren vor dem Ersten Weltkrieg eine nicht unwesentliche Rolle im Wiener Baugeschehen spielten, darunter zunehmend auch Juden, wobei dieser Umstand in mehrfacher Hinsicht bemerkenswert ist. Nach den damaligen Usancen war es üblich, dass sogenannte "Monumentalbauten«, darunter verstand man Museen, Rathäuser etc., die in die Kategorie der "Baukunst« fielen, üblicherweise Architekten vorbehalten waren, die entweder eine akademische Ausbildung erhalten oder die technische Hochschule absolviert hatten, während es Baumeistern zumeist nur erlaubt war, als Planverfasser von Wohnbauten aufzutreten.

Der Umstand, dass nicht akademisch ausgebildete Architekten von aufwendigen, zeitraubenden Großprojekten der öffentlichen Hand ausgeschlossen waren, hatte jedoch zur Folge, dass damit in anderen Bereichen ein enormes Potenzial freigesetzt wurde, führte er doch - in Verbindung mit der guten Baukonjunktur zu Beginn des 20. Jahrhunderts - dazu, dass alle der in diesem Kapitel angeführten Persönlichkeiten eine Unzahl von Wohnbauten innerhalb kurzer Zeit realisieren konnten. Andererseits hatten die sich verändernden Anforderungen der Großstadt zur Folge, dass auch - insbesondere bei dem bereits oben beschriebenen Mischtypus des WohnGeschäftshauses - die Grenzen zunehmend fließend wurden und so manches Gebäude dieses Typus aufgrund seines repräsentativen Anspruches in die Nähe eines "Monumentalbaues" geriet und damit einige "Baumeister" durchaus in Konkurrenz zu den akademisch ausgebildeten Kollegen traten. Ein nicht unerheblicher Faktor bei dieser Entwicklung war das hohe fachliche Niveau der Staatsgewerbeschulen auf dem Gebiet der Donaumonarchie, deren duales System von Praxis und Theorie sich bestens bewährte, wobei die Ausbildung in sich sehr differenziert war. Neben einer verpflichtenden Maurerlehre hatten die Absolventen die Möglichkeit eines zweijährigen Schulbesuches, der, nach entsprechender Praxis, zur Ablegung einer Meisterprüfung und zum Erwerb einer Baumeisterkonzession berechtigte. Demgegenüber stellte die vierjährige »Höhere Staatsgewerbeschule«, die mit einer Reifeprüfung abgeschlossen wurde, die Voraussetzung für ein Studium an einer Technischen Hochschule dar. Für den Besuch der Akademie der bildenden Künste war an sich nur eine Eignungsprü- 
fung notwendig, in der Praxis hatten aber alle Studenten bereits eine Fachausbildung hinter sich. Diese sehr flexible Schulorganisation war daher eine gute Ausgangsbasis für die unterschiedlichsten Karrieren in der Baubranche und wurde auch nicht zuletzt von den sich bürgerlich assimilierenden Juden genutzt, die damit zunehmend in einem lange Zeit zünftisch organisierten Gewerbe Fuß fassen konnten. Stellvertretend für die nicht geringe Zahl sollen hier einige Persönlichkeiten genannt werden, deren Werk oder auch Biografie aus den verschiedensten Gründen besonders erwähnenswert sind.

Als Ältester dieser Gruppe ist Leopold Fuchs (oder auch Fux, I 868-I929) zu nennen, der ungeachtet dessen, dass er äußerst erfolgreich war und eine Unzahl von Miethäusern errichtete, nur sehr unzulänglich biografisch dokumentiert ist. Obwohl seine Bauten in den damaligen Fachzeitschriften umfassend publiziert wurden, finden sich keinerlei Angaben zu seiner Person in zeitgenössischen Anthologien oder Lexika. Man weiß nur, dass er der Sohn eines Gutpächters aus Koczoc/Kočovce war, das damals zu Ungarn gehörte und jetzt Teil der Westslowakei ist. Über seine Ausbildung, die möglicherweise in Ungarn erfolgte, ist gleichfalls nichts bekannt. Ab Mitte der Neunzigerjahre des I9. Jahrhunderts tauchte er in Wien als Architekt und Baumeister auf. ${ }^{129}$ In der Folge realisierte er bis zum Ausbruch des Ersten Weltkrieges eine Vielzahl von Projekten, wobei er mehrfach auch als Bauunternehmer auftrat. Seine Bautätigkeit konzentrierte sich auf die inneren Gürtelbezirke und hier wiederum vor allem auf den 3. und 7. Bezirk. Insbesondere die Neubaugasse, wo er auch selber wohnte (Neubaugasse I2) und innerhalb nur einiger Jahre mindestens sechs WohnGeschäftshäuser errichtete, ist abschnittweise von seinem Schaffen geprägt, wobei jedes Haus völlig individuell gestaltet ist (dies betrifft die beiden Eckhäuser Nr. I und 2 und die Nummern 8-I4). Generell gehören diese in den letzten Jahren vor dem Ersten Weltkrieg erbauten Miethäuser zu den originellsten Schöpfungen dieser Zeit überhaupt. Leopold Fuchs, dessen Bauten anfangs noch sehr von einem späthistoristischen, zumeist neobarocken Duktus geprägt waren, fand hier zu einer Formensprache, die traditionelle Elemente höchst eigenständig mit Ideen der zeitgenössischen Moderne verband. So machte er im Sinne der technoiden Ästhetik der Zeit die Pfeilerkonstruktion an der Fassade sichtbar, ohne jedoch auf traditionsverbundene dekorative Details zu verzichten (Neubaugasse 8, Abbildung 49), wobei insbesondere die aufwendige Ausgestaltung der Portalzone dem Repräsentationsbedürfnis diente. In-

I 29 Der früheste Bau von Leopold Fuchs ist aus dem Jahr I 894 dokumentiert, im selben Jahr hatte er auch im Wiener Stadttempel geheiratet (Trauungsmatriken der Israelitischen Kultusgemeinde/IKG). Dass er zu diesem Zeitpunkt noch recht jung war, lässt darauf schließen, dass er keine höhere akademische Ausbildung hatte. 
49. Leopold Fuchs, Miethaus

Wien 7, Neubaugasse I 2, erbaut um I908/Prokop

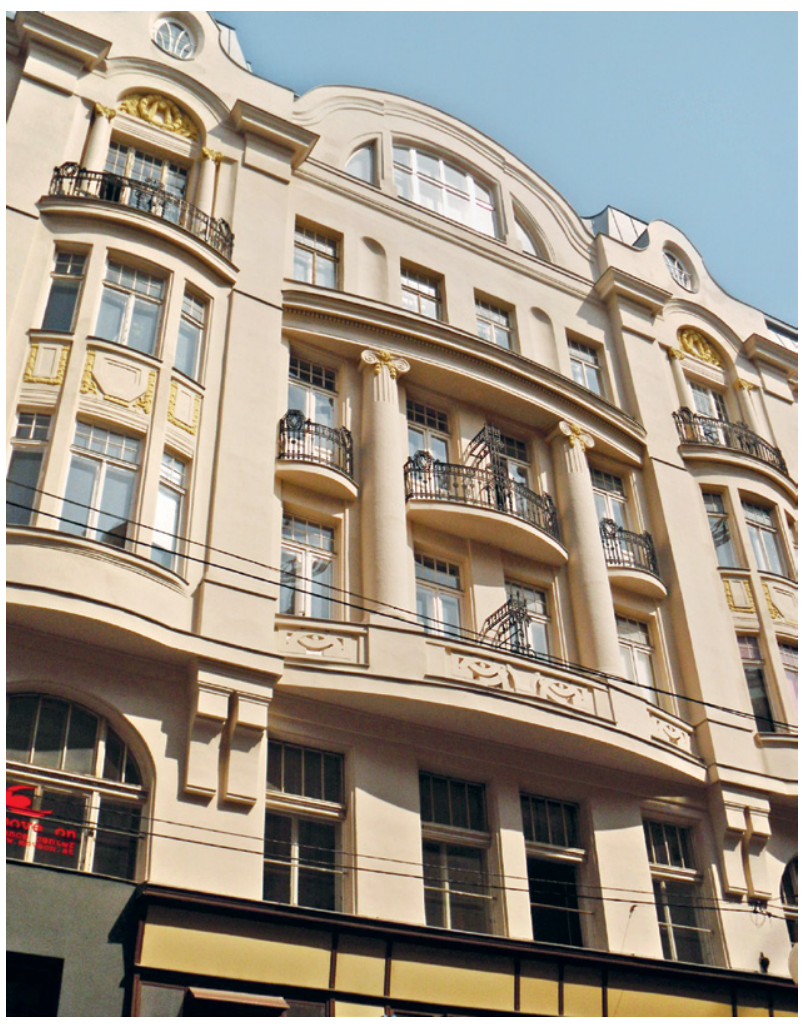

folge der hohen architektonischen Qualität der Bauten sind heute einige unter Denkmalschutz gestellt.

Der Ausbruch des Krieges I9I4 setzte seinem intensiven Schaffen jäh ein Ende. Leopold Fuchs ist schließlich verhältnismäßig jung im November I 920 an Herzversagen gestorben.

Gewisse Parallelen zeigt auch die berufliche Laufbahn von Neumann Tropp, (1873-1928, Abbildung 50), der eine äußerst schillernde Persönlichkeit war. Auch er konnte in der Zeit zwischen 1900 und dem Ausbruch des Ersten Weltkrieges eine Reihe von äußerst anspruchsvollen Miethäusern und Villen in Wien errichteten. ${ }^{130}$ Aus Czernowitz/Černovici (damals österreichische Bukowina) stammend, war er ein Angehöriger der sogenannten "Ostjuden«, für die die Anpassung an das Wiener Milieu eine besondere Herausforderung darstellte, die Tropp jedoch sehr schnell mit

I 30 Siehe dazu U. Prokop, Neumann Tropp oder die Leichtigkeit des Seins, in: David, 23.20 I I, H. 90, S. $72 \mathrm{ff}$. 


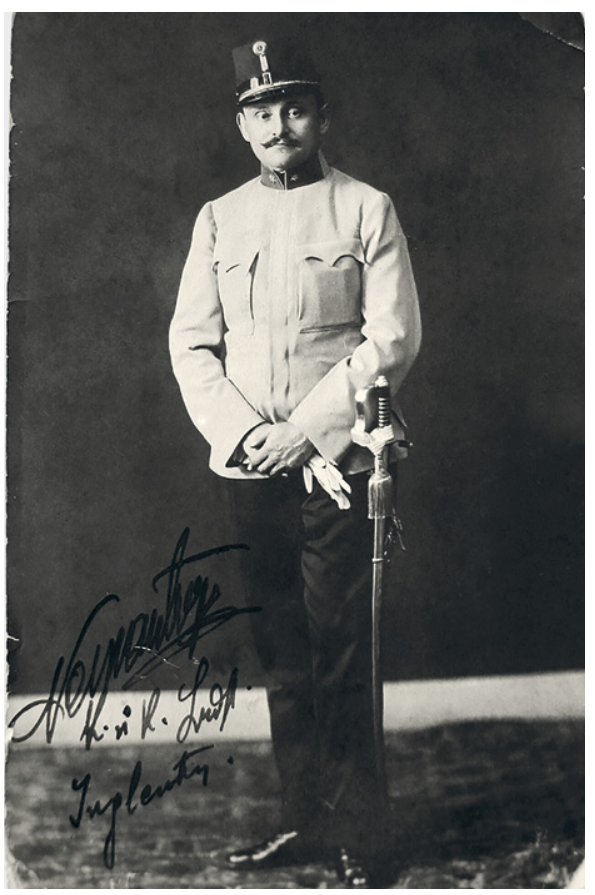

großem Ehrgeiz schaffte. Über seine Familie und seine Kindheit ist nichts bekannt. Gesichert ist nur, dass er die Höhere Staatsgewerbeschule in Czernowitz absolviert hatte und im Anschluss daran I 892 seinen Militärdienst als "Einjährig-Freiwilliger«ein Privileg, das nur Maturanten vorbehalten war - leistete und damit als Reserveoffizier bereits einen beachtlichen sozialen Status erreichte. Mitte der Neunzigerjahre tauchte Tropp im mährischen Olmütz/Olomouc als Bauunternehmer auf und realisierte die ersten Wohnhäuser der Stadt im damals höchst aktuellen "Jugendstil«. ${ }^{131}$ Anlässlich seiner Eheschließung I 898 trat er aus der Kultusgemeinde aus, änderte seinen hebräischen Namen Nachmann (oder Nahum) in Neumann und vollzog damit den Schritt zur endgültigen Assimilation. ${ }^{132}$ Zur selben Zeit übersiedelte er mit seiner Familie nach Wien, wo er als freier Architekt und Bauunternehmer auftrat, oft auch in Zusammenarbeit mit seinem jüngeren Bruder Eduard (oder auch Elias), der

I3I P. Zatloukal, Neumann Tropp - autor prvnich secesnich domů v Olomouci, in: Židovska obec Brno 20I I (www.zob.cz).

I32 IKG Wien (Matrikenstelle), der Vorname "Neumann« führte die längste Zeit zur Unklarheit über die Person Tropps und wurde manchmal als Name eines Partners interpretiert, sodass zeitweise die Bezeichnung "Neumann \& Tropp« in der Fachliteratur zu finden ist. 


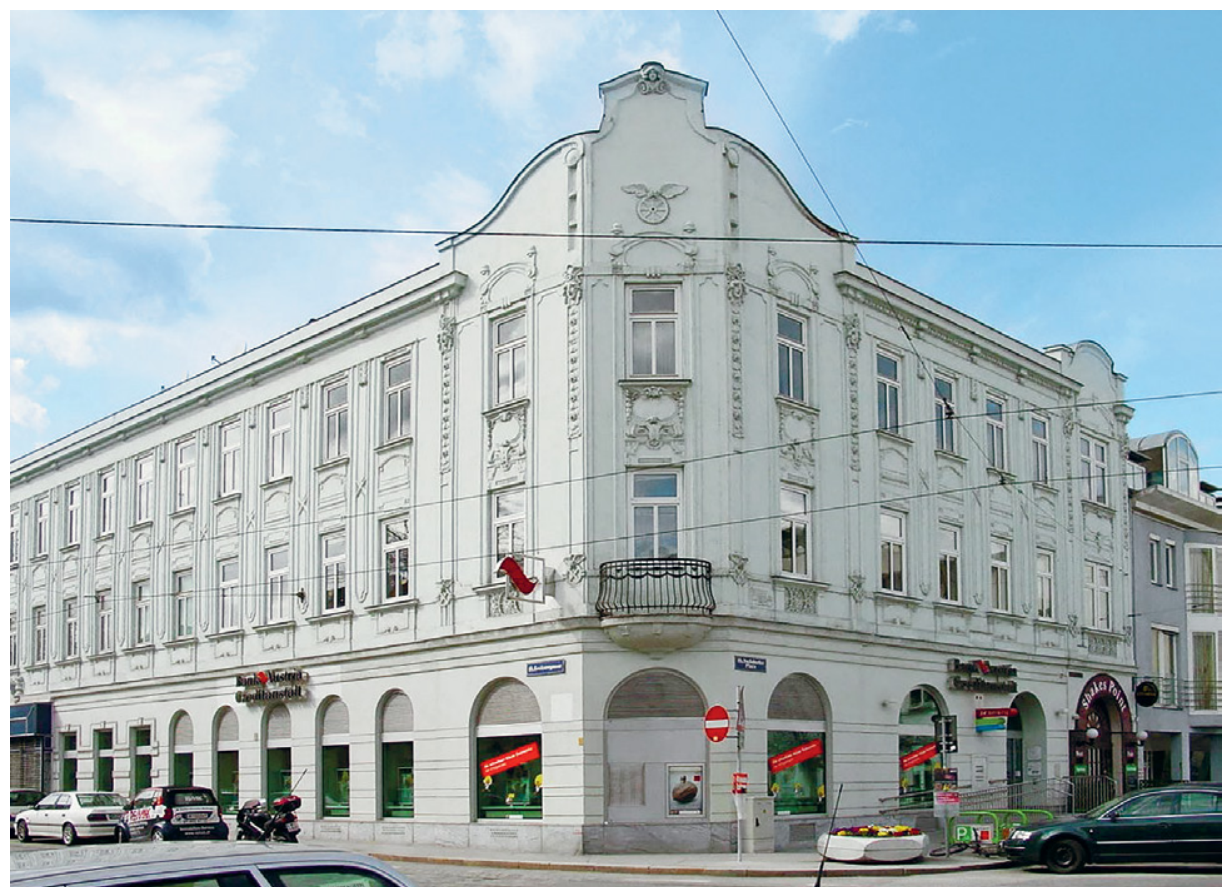

51. Neumann Tropp, Miethaus u. Amtsgebäude der Zahnradbahn, Wien I9, Nußdorfer Platz 5/Prokop

aber bald aus dem Baugeschäft austrat, um sich der glitzernden Filmwelt zu widmen. Nicht nur dass Elias Tropp den Stummfilmstar Eugenie Bernay (eigentlich Bernleutner) heiratete, er gründete zudem mit dem Regisseur Felix Dörmann die „Vindobona-Film«, die sich jedoch finanziell als wenig erfolgreich erwies.

Gleich einer der ersten Aufträge Neumann Tropps war eine hochherrschaftliche Villa in Wien-Dornbach (I898, Wien I7, Dornbacher Straße 27), wo er auch den durchaus bemerkenswerten Garten mit gestaltete. ${ }^{133}$ Die nächsten Jahre errichtete Tropp eine Reihe von sehr repräsentativen Miethäusern in den gutbürgerlichen Bezirken Wiens, vor allem auch in den damals im Ausbau begriffenen noblen Villenvierteln von Währing und Döbling, darunter 1907 das ehemalige Direktionsgebäude der Zahnradbahngesellschaft in Wien I9, Nussdorferplatz 5 (Abbildung 5I). Obwohl Tropp nicht in Wien ausgebildet worden war, orientierten sich seine Bauten in formaler Hinsicht an der damals aktuellen Wiener Moderne, das heißt, neben secessionistischen Einflüssen lassen sich späterhin im Detail auch Motive des damals gängigen

I33 Wiener Bauten im Style der Secession, Bd. 2, Wien I904, T. 59. 
Neobiedermeier beobachten. Der Sorgfalt, die Tropp zumeist auf die sehr elegant gestalteten Fassaden anwandte, entsprechen auch oftmals die sehr aufwendig gestalteten Vestibüle, wie zum Beispiel beim Wohn-Geschäftshaus "Donauhof" (Wien 2, Obere Donaustraße 79), dessen glasüberdachtes Stiegenhaus mit Fliesen im secessionistischen Dekor verkleidet ist. ${ }^{134}$ Nicht wenige der bemerkenswerten Miethäuser und Villen Tropps wurden auch immer wieder in der einschlägigen Fachpresse publiziert.

Der Ausbruch des Ersten Weltkrieges und in der Folge das weitgehende Erliegen der zivilen Bautätigkeit bedeuteten auch für Tropp einen herben Einschnitt. Als Reserveoffizier musste er sofort einrücken und diente aufgrund seiner technischen Ausbildung als Leutnant in der Luftfahrtgruppe, die damals eine elitäre Pioniereinheit darstellte. Der Zusammenbruch der Monarchie und die schlechte wirtschaftliche Lage nach dem Krieg führten dazu, dass Tropp versuchte, seine Firma auf eine breitere Basis zu stellen und auch in Brünn und Berlin tätig zu sein. Seine angespannte finanzielle Situation verschärfte sich jedoch noch durch eine gewisse Leichtlebigkeit und Spielleidenschaft, wobei er nicht selten sein Geld in Monte Carlo verspielte. Nachdem er 1928 nach Berlin gegangen war, wo er immer wieder fallweise tätig gewesen war, verstarb er an einem Gehirnschlag. Seine Familie erlebte späterhin eine wechselvolle Geschichte. Während ihn seine Witwe nur um einige Monate überlebte, mussten sein Sohn und sein jüngerer Bruder Eduard (Elias) nach dem "Anschluss« Österreichs an NS-Deutschland 1938 als Juden emigrieren, kehrten aber nach Ende des Zweiten Weltkrieges wieder zurück. ${ }^{135}$ Zwei weitere Kinder, die aus einer außerehelichen Beziehung mit einer Christin stammten, überlebten nur aufgrund des Umstandes, dass ihre jüdische Herkunft väterlicherseits den Behörden verschwiegen wurde.

$\mathrm{Zu}$ den bedeutendsten Vertretern der Gruppe von Architekten ohne akademische Ausbildung ist jedoch zweifellos Ernst Epstein (I88 I-I938) zu zählen, der auch im Gegensatz zu den beiden Vorgenannten nicht völlig vergessen ist, sondern zumindest in Fachkreisen aufgrund seiner Zusammenarbeit mit Adolf Loos einen gewissen Namen hat. ${ }^{136}$ Epstein, der in Wien geboren wurde, stammte aus der zweiten Ehe des Gewerbetreibenden Oskar Epstein, der eine - wie die zahlreichen Adressen und Firmenwechsel zeigen - offensichtlich nicht besonders gut gehende Installationsfirma

I 34 Tropp arbeitete zumeist mit der Fa. Wienerberger zusammen. Siehe dazu B. Bastl, Wiener Jugendstilvestibüle, in: Zeitreisen Syrien-Palmira-Rom (hg. v. B. Bastl u. a.), Wien 20 Io, S. $37 \mathrm{ff}$.

I35 Elias oder auch Eduard Tropp wurde 1875 in Czernowitz geboren. Nach seiner Emigration in der NS-Zeit kehrte er Ende der 5oer-Jahre nach Wien zurück, wo er 1963 verstarb. Freundliche Auskunft Roland Miksch (Enkel).

I36 Das Jüdische Museum widmete Epstein sogar eine Sonderausstellung und gab dazu einen Katalog heraus: K. Gruber u. a. (Hg.), Ernst Epstein I88 I-I938, Wien 2002. 
betrieb. Diese höchstwahrscheinlich prekäre finanzielle Situation der Familie wie auch der frühe Tod der Mutter könnten eine Erklärung dafür sein, dass Epstein nach dem Abschluss der Staatsgewerbeschule im Jahre 1900 keine der weiterführenden Institutionen - sei es die Technische Hochschule oder die Akademie - besuchte und bald ins Berufsleben eintrat. Nachdem er einige Jahre in verschiedenen Baubüros gearbeitet hatte, erwarb er 1906 die Baumeisterkonzession und machte sich selbstständig. Bereits drei Jahre zuvor war er aus der Kultusgemeinde ausgetreten, unterließ es aber, zu einer christlichen Glaubensgemeinschaft überzutreten. Es ist nicht geklärt, ob es hier um einen generellen Versuch geht, sich zu assimilieren, oder ob seine Beziehung zu seiner späteren Frau Melanie König, die Katholikin war, den Ausschlag für den Austritt gegeben hat - wie auch immer, es wird ihn später nicht davor bewahren, ein Opfer der NS-Rassenpolitik zu werden.

Bereits einer seiner ersten Aufträge, ein eher unprätentiöses Vorstadtzinshaus in Wien Ottakring (sog. »Römerhof«, Wien I6, Stöberplatz 9, 1906), brachte Epstein in Kontakt mit der Familie Goldmann, die späterhin sowohl für ihn selbst als auch für Adolf Loos von großer Bedeutung werden sollte. Denn Sigmund Goldmann, der Bauherr dieses eher unspektakulären Gebäudes und Besitzer einer Antiquariatsbuchhandlung, war der Onkel von Leopold Goldmann, der seinerseits den noblen Schneidersalon Goldmann \& Salatsch in der Innenstadt betrieb, dessen Stammkunde Adolf Loos war. Mit Sigmund Goldmann blieb Epstein insofern auch späterhin in Kontakt, als er einige weitere bemerkenswerte Bauten in seinem Auftrag ausführen sollte. Vorerst konnte Epstein neben einigen eher bescheideneren Realisationen noch im selben Jahr 1906 für den Glasereibesitzer Severin Tesar ein Zinshaus errichten, wobei es in diesem Kontext bemerkenswert ist, dass Epstein mehrmals für Severin Tesar tätig war, was für seine fachliche Kompetenz und wahrscheinlich auch eine vernünftige finanzielle Gebarung spricht. Aufgrund des Umstandes, dass das Miethaus Tesar in einer eher noblen Wohngegend in Döbling auf der Sieveringer Straße I07 errichtet wurde, konnte Epstein hier seine speziellen Qualitäten, beispielsweise eine distinguiert zurückhaltende Eleganz, einbringen. Die Akzentuierung des Baukörpers erfolgte mittels eines leicht vorschwingenden Mittelrisalites, während die Biedermeierdekoration dem gängigen Kanon der Zeit entsprach. Den repräsentativen Anspruch des Gebäudes unterstrich insbesondere der geschwungene Giebel, der mit Putti in der Art der Wiener Werkstätte dekorierte war.

Nur ein Jahr später konnte Epstein endgültig ein Zeugnis seines Könnens ablegen, als er für die Appreturfirma Krüger's Söhne ein Wohn-Bürohaus in Wien 7, Seidengasse 30 entwarf. Im konkreten Fall handelte es sich um ein Wohnhaus, in dem im unteren Bereich die Betriebsräume der Firma Krüger untergebracht waren, wo in verschiedenen Fertigungstechniken Textilien veredelt wurden. Im Grunde handelte es 
sich um den gleichen Gebäudetypus mit gemischter Funktion, wie ihn rund dreißig Jahre zuvor Wilhelm Stiassny für das Textilviertel in der Inneren Stadt entwickelt hatte. Epstein ging jedoch andere Wege bei der Grundrisslösung. Während Stiassny mit zwei Eingängen für den jeweiligen Funktionsbereich arbeitete, brachte Epstein straßenseitig nur ein Einfahrtstor an und versetzt die Zugänge zu den einzelnen Bereichen in den Innenhof. ${ }^{137}$ Hervorzuheben ist die höchst eigenwillige Durchgestaltung der Fassade, die die Trennung der verschiedenen Funktionsbereiche auch optisch vermittelt, indem Geschäfts- und Wohnbereich sich durch verschiedene Achseneinteilungen unterscheiden und auch höchst unterschiedlich dekoriert sind. Der eher unübliche Einsatz von metallener Zierart könnte von dem rund zehn Jahre früher von Max Fleischer errichteten "Eisenhof" in Margareten (Wien 4, Margaretenstraße 70) beeinflusst sein, wo Fleischer gleichfalls die Fassade mit metallenen Dekorelementen versah.

Epstein bewies mit diesem Bau, dass er mit seinem Können auf der Höhe der Zeit stand und durchaus mit akademisch ausgebildeten Architekten konkurrieren konnte. Nicht zuletzt erhielt auch er durch mehrere Veröffentlichungen in Fachzeitschriften einen gewissen Bekanntheitsgrad. ${ }^{138}$ Dieses zunehmende Renommee Epsteins war möglicherweise mit ein Grund, dass er I 909 von Leopold Goldmann, einem Neffen von Sigmund Goldmann, für den er - wie erwähnt - schon mehrmals gearbeitet hatte, zu einem internen Wettbewerb für die Errichtung eines Wohn-Geschäftshauses der Schneiderfirma Goldmann \& Salatsch eingeladen wurde, das in einer sehr prominenten Lage gegenüber der Hofburg auf dem Michaelerplatz errichtet werden sollte. Auch wenn möglicherweise Adolf Loos von Anfang an als Planverfasser dieses Baus feststand und der Wettbewerb nur veranstaltet wurde, um der Form Genüge zu tun, so war Epstein, der in der Folge mit der Bauleitung beauftragt wurde, damit in eines der bedeutendsten Bauvorhaben des frühen 20. Jahrhunderts eingebunden, denn immerhin sollte das "Haus am Michaelerplatz« Architekturgeschichte schreiben. Generell ist in diesem Kontext daran zu erinnern, dass dieses Schlüsselwerk in vieler Hinsicht mit dem Wiener jüdischen Bürgertum verbunden ist. ${ }^{139}$ Nicht nur dass Epstein und der Bauherr Leopold Goldmann, der sich ganz besonders für Loos eingesetzt hat, dieser Gruppierung angehörten, vielmehr unterstützte auch Karl Kraus diesen Meilenstein der Moderne vehement publizistisch. Kaum ein anderes Gebäude hat die Gemüter der Zeitgenossen dermaßen erregt wie dieses, dessen rigide puristische Gestaltung von Adolf Loos drastisch gegen den gängigen Zeitgeschmack verstieß.

I 37 Der Architekt I 5.1909, T. 27.

I 38 Siehe dazu Epstein, zit. Anm. I36, S. 7 I.

I 39 Siehe dazu E. Shapira, Assimilation with Style. Jewish Assimilation and Modern Architecture and Design in Vienna. Phil. Diss., Wien 2004. 


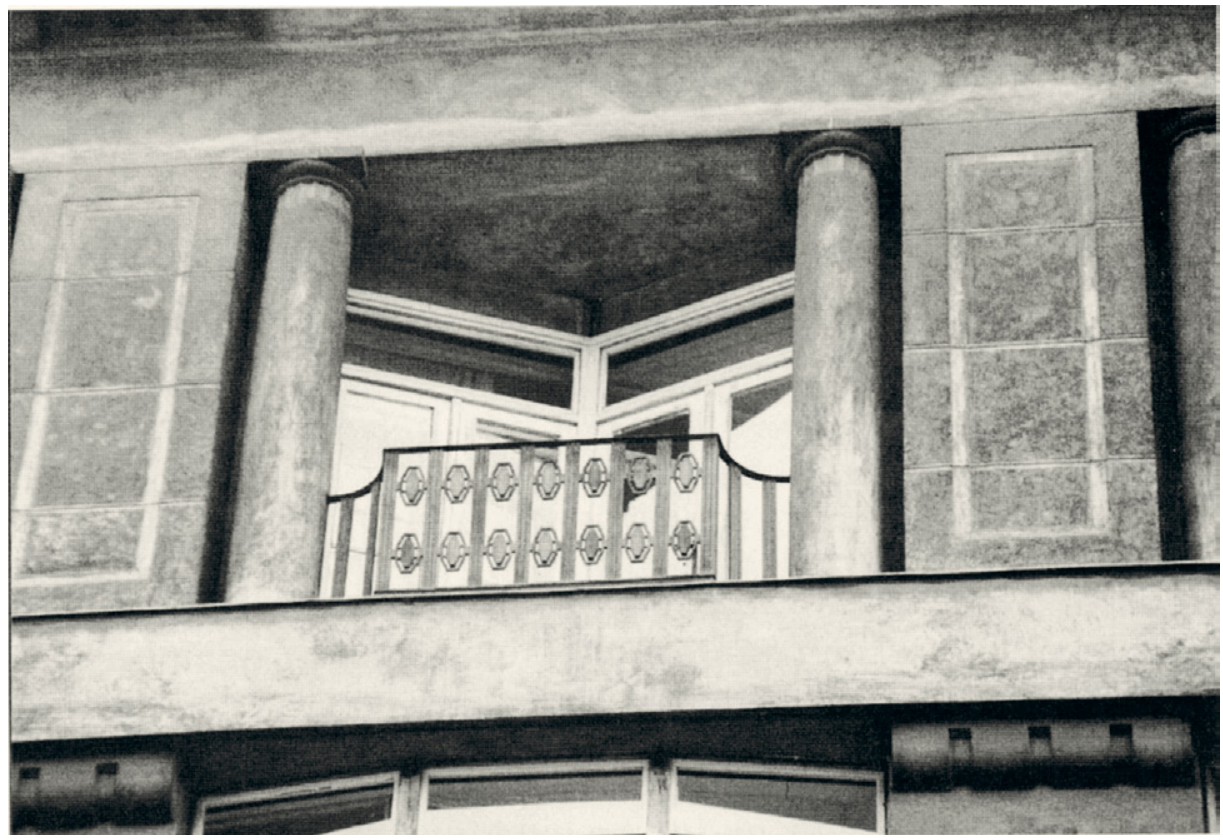

52. Ernst Epstein, Paulanerhof, Wien 4, Schleifmühlgasse 3, um I9ro/Prokop

Als Bauleiter und ausführender Baumeister (wobei die Zusammenarbeit mit Loos durchaus nicht immer ganz friktionsfrei verlief) konnte Epstein bei diesem Vorhaben allerdings kaum kreativ agieren. Zur selben Zeit war er jedoch mit einem eigenständigen Projekt befasst, das zu den qualitätvollsten und originellsten seiner Zeit zählt. Um I9I0/I I errichtete Epstein wiederum in Auftrag von Sigmund Goldmann den sogenannten "Paulanerhof" (Wien 4, Schleifmühlgasse 3), ein Wohn-Geschäftshaus der gehobenen Kategorie. ${ }^{140}$ Zur optimalen Ausnutzung des schmalen Areals konzipierte Epstein eine sehr ausgeklügelte Grundrisslösung mit gestaffelten Räumen. In der Fassadengestaltung machte sich der Einfluss von Loos bemerkbar, insofern er klassizierende Elemente einsetzte und weitgehend auf Dekor verzichtete.

Epsteins eigenständiger Erfindungsreichtum manifestierte sich insbesondere in der Gestaltung des obersten Geschoßes, wo er zwischen Säulen gesetzte Fenster in einem flachen Winkel zurückspringen ließ (Abbildung 52); dieses Motiv wurde in variierter Form auch bei der Eingangstür übernommen. Im Gegensatz zum berühmten »LoosHaus« auf dem Michaelerplatz hat dieser Bau jedoch relativ wenig Aufmerksamkeit

I40 Der Bautechniker 3I.I9I I, S. 283. 
auf sich gezogen, obwohl er es durchaus verdient hätte. Die Erklärung dafür könnte die relativ unspektakuläre Lage sein, auch war Epstein keine so prominente Persönlichkeit wie Adolf Loos.

Für die nächsten Jahre war Epstein weiterhin äußerst erfolgreich tätig und errichtete zahlreiche Miethäuser, Villen und anderes mehr, wobei er unter Mithilfe seines Cousins Dr. Siegfried Kantor nicht selten als Generalunternehmer auftrat, der Grundstücke aufkaufte und mit fertigen Bauplänen und vorliegenden Baubewilligungen gewinnbringend weiterverkaufen konnte. Bei Ausbruch des Ersten Weltkrieges wurde Epstein - obwohl seinerzeit bei der Assentierung als waffenunfähig eingestuft eingezogen und der Militärbauabteilung zugewiesen, wo er seinen Dienst in Lemberg/ Lwow und späterhin in Wien ableistete.

Auch nach dem Ende des Krieges und dem Zusammenbruch der Monarchie gelang es Epstein trotz der äußerst schlechten wirtschaftlichen Lage dieser Jahre, sein Büro erfolgreich weiterzuführen. Gesellschaftlich gut vernetzt, konnte er insbesondere für eine gut situierte Klientel anspruchsvollere Miethäuser und repräsentative Villen in Stadtrandlage realisieren. Dessen ungeachtet ist als sein bedeutendster Bau und wahrscheinlich auch sein größtes Projekt in der Zwischenkriegszeit das Ende der Zwanzigerjahre errichtete Bürohaus der Versicherungsgesellschaft "Phönix« anzusehen, für die Epstein bereits einige andere Vorhaben realisiert hatte (Wien 9, Otto WagnerPlatz 5, Abbildung 53). Aufgrund seiner städtebaulich prominenten Lage - unmittelbar neben dem I9 4 errichteten Druckereigebäude der Nationalbank und gegenüber dem Landesgericht - wurde der nach zwei Seiten frei stehende Bau nach damaligem Verständnis der Kategorie der »Monumentalarchitektur« zugeordnet. Interessanterweise hatte sich die Nationalbank, die das Bauareal an die Versicherungsgesellschaft verkauft hatte, ein Mitspracherecht bei der Ausführung vorbehalten und war bedacht, dass der Neubau in architektonischer Hinsicht nicht allzu dominant ausfallen sollte. ${ }^{141}$ Epstein meisterte diese nicht einfache Aufgabenstellung sehr geschickt, indem er einerseits die Funktionalität des Baus durch die Ablesbarkeit der Skelettbauweise nach außen unterstrich, andererseits in formaler Hinsicht den monumentalen Anspruch hervorhob, indem er traditionsverbundene Elemente, insbesondere ein wuchtig verkröpftes Gesims, zum Einsatz brachte. Sowohl die markante kubistoide Formgebung an der Außenseite als auch die transparente funktionalistische Ausgestaltung des Vestibüls und des Treppenhauses waren auf der Höhe der Zeit. Die Möblierung der Büros besorgte die renommierte Einrichtungsfirma »Haus und Garten«, die 1925 von Josef Frank und Oskar Wlach gegründet worden war und von der noch zu sprechen sein wird.

I4I Ebenda, S. I $59 f f$. 
53. Ernst Epstein, Bürohaus

Phönix, Wien 9, Otto

Wagner-Platz 5, erbaut I928 (heute Sitz der OMV)/Kristan Privatbesitz

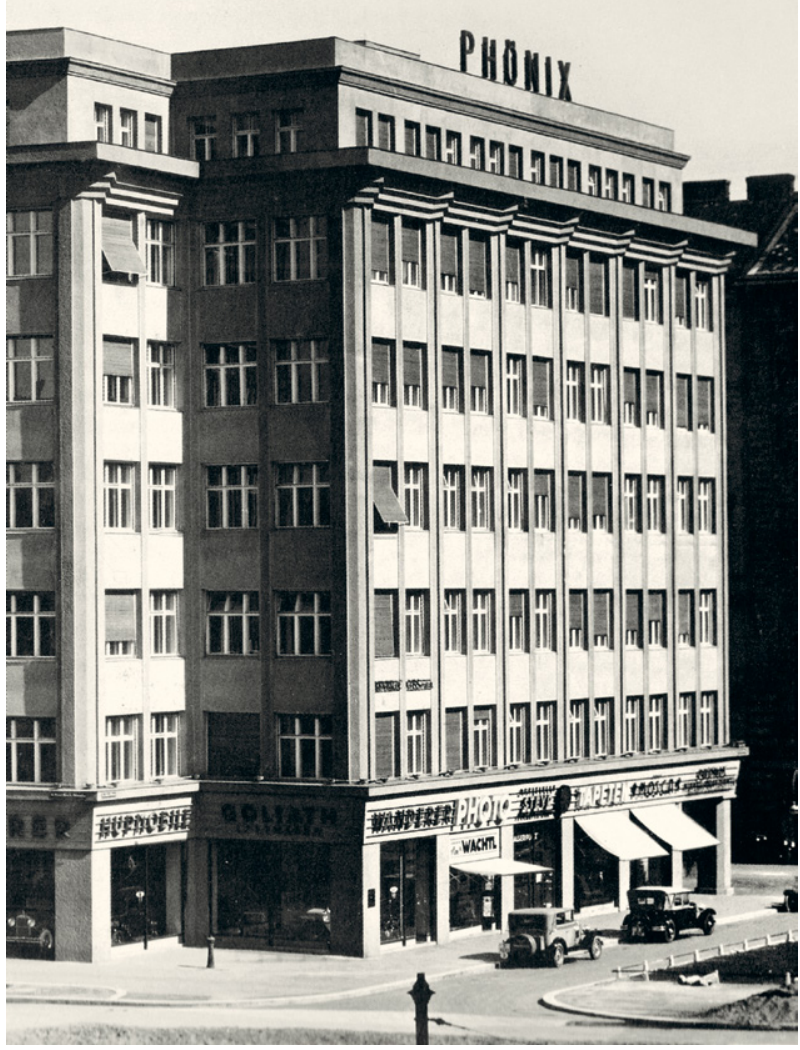

Epstein konnte sogar noch in den Dreißigerjahren trotz Wirtschaftskrise mehrere Projekte realisieren. Generell könnte man von einem geglückten, erfolgreichen Leben sprechen, wenn Epstein nicht nach dem "Anschluss« Österreichs I 938 zu einem der ersten Opfer der NS-Rassenpolitik geworden wäre: Nur einen Tag nach Einführung der NS-Rassegesetzgebung am 21. Mai, die ein Berufsverbot nach sich zog, setzte er seinem Leben mit einer Überdosis Veronal ein Ende.

Zum Abschluss dieses Kapitels lässt sich sagen, dass diese Gruppe der praxisgeschulten Baumeister-Architekten großteils ein sehr hohes Niveau vorweisen konnte, das oft durchaus mit ihren akademisch ausgebildeten Kollegen vergleichbar war. Wenn sie auch nicht schulbildend waren oder bedeutende Theorien vertreten haben, so sind sie insgesamt für das Baugeschehen in Wien in den letzten Jahren vor dem Ersten Weltkrieg von großer Bedeutung und haben das Erscheinungsbild der Stadt wesentlich mitgeprägt. 


\section{Die Schüler Karl Königs in der Zwischenkriegszeit - die "zweite Wiener Moderne«}

Das Ende der Donaumonarchie, das neben den politischen Folgen auch den praktischen Zusammenbruch der österreichischen Wirtschaft nach sich zog, die jetzt auf ein kleines Kernland beschränkt war, bedeutete für alle in der Baubranche Tätigen eine herbe Zäsur. Nicht wenige Architekten und Baumeister wechselten infolge des Ausbleibens von Aufträgen in einen anderen Beruf oder fielen der völligen Verarmung anheim. Die sich verändernden gesellschaftlichen Strukturen führten darüber hinaus auch zu einer Verlagerung der Schwerpunktsetzung bei den Bauaufgaben. Obwohl die Bevölkerung Wiens infolge der Abwanderung zahlreicher in der Verwaltung tätig gewesener Menschen in ihre ursprünglichen Heimatländer, die sogenannten "Nachfolgestaaten", erstmals seit Jahrzehnten einen Schrumpfungsprozess erfuhr, herrschte Wohnungsnot. Der Überbelag der Wohnungen der unteren sozialen Schichten blieb ein verhängnisvolles Erbe der Monarchie. Die allgemeine Verarmung und der Mangel an privatem Kapital führten jedoch dazu, dass der Wohnbau, der endlich als soziales Problem zur Kenntnis genommen wurde, nahezu völlig von der Gemeinde übernommen wurde. Nicht mehr das Miethaus für gehobenere Ansprüche stand im Vordergrund, sondern große Wohnhausanlagen, die sogenannten »Volkswohnungspaläste« für die untere Bevölkerungsschicht, die im Rahmen des soziales Bauprogramms des "Roten Wien" errichtet wurden und späterhin Geschichte schreiben sollten. Auch der Typus der repräsentativen Villa wurde obsolet und musste dem bescheideneren Einfamilienhaus Platz machen. Insgesamt schrumpfte jedoch das Bauvolumen drastisch, nachdem auch die Industrie als Auftraggeber aufgrund der schlechten Wirtschaft sehr zurückhaltend agierte. Dieser Umstand führte dazu, dass viele Architekten sich notgedrungen auf die Inneneinrichtung und das Möbeldesign verlegten, da diese Sparte weniger finanzielle Ressourcen erforderte. Der Umstand, dass zum Teil die besten Köpfe - darunter nicht wenige Architekten jüdischer Herkunft - sich diesem Bereich widmeten, führte daher zu einer Blüte der Innenarchitektur, die als »Wiener Wohnraumkultur« in die Kulturgeschichte einging und als charakteristisches Phänomen dieser Periode anzusehen ist.

\subsection{Josef Frank und die Werkbundsiedlung}

Die führende Persönlichkeit der österreichischen Architekturszene der Zwischenkriegszeit im Allgemeinen und der sogenannten "Wohnraumkultur« im Besonderen 


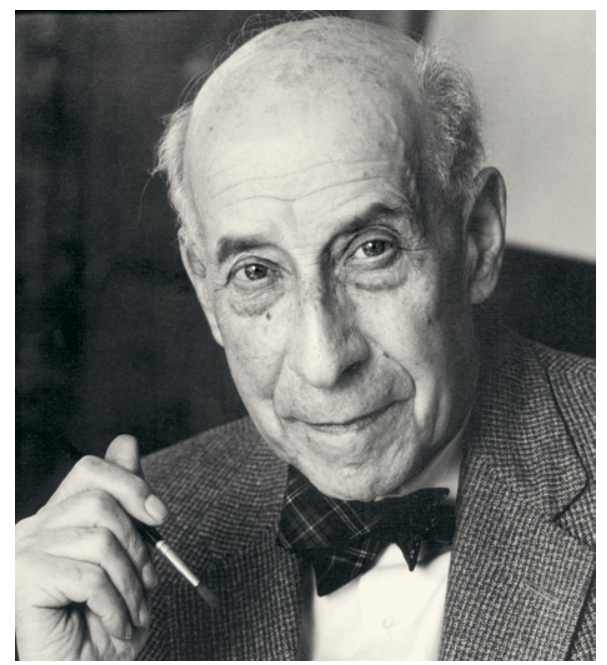

war zweifellos Josef Frank (1885-1967, Abbildung 54), der auch mit zahlreichen Publikationen als bedeutender Theoretiker hervortrat. Entsprechend seinem Stellenwert ist die Literatur über Josef Frank ziemlich umfassend. Es würde den Rahmen sprengen, in allen Details auf ihn einzugehen, es werden daher nur einzelne Aspekte, die für den Gesamtzusammenhang wesentlich sind, abgehandelt.

Obwohl Josef Frank ein "Wiener" war, wurde er im Juli 1885 in Baden in Niederösterreich geboren, als sich die Familie dort gerade zur Sommerfrische aufhielt, was durchaus symptomatisch für die jüdisch-gutbürgerlichen Verhältnisse war, aus denen er stammte. In Baden suchten die besseren Wiener Familien Zuflucht vor der sommerlichen Hitze der Großstadt, und darüber hinaus hatte eine nicht unbedeutende jüdische Gemeinde seit Längerem Anteil am lokalen Geschehen. Selbstverständlich wuchs Frank aber in Wien auf, wo er nach dem Abschluss des Oberrealgymnasiums an der Technischen Hochschule studierte und dort auch Vorlesungen bei Karl König besuchte, bei dem er schließlich, nach der Einführung des Doktoratsstudiums, als einer der ersten Doktoranden seine Dissertation über die Kirchenbauten Leon Battista Albertis schrieb. ${ }^{142}$ Generell fällt auf, dass die Themen der Doktorarbeiten vieler jüdischer Studenten sich vor allem mit der christlichen Kunstgeschichte beschäftigten und nicht, wie man annehmen könnte, der eher "neutralen" Antike, was durchaus auch als Wille zur Assimilation angesehen werden kann. So hatten kurz zuvor Franks Studienkollegen und spätere Mitarbeiter Oskar Wlach und Oskar Strnad Arbeiten

I 42 Siehe dazu Welzig, zit. Anm. I I. 
über die Florentiner Protorenaissance beziehungsweise die Dekoration in der frühchristlichen Kunst geschrieben, wobei immer Karl König als Doktorvater fungierte. ${ }^{143}$

Während Frank und seine Kollegen an der Technischen Hochschule in dieser Zeit am Beginn des 20. Jahrhunderts - eine sehr traditionsverbundene, aber auch sehr gut fundierte Ausbildung erhielten, kamen sie gleichzeitig mit dem großen Neuerer der Wiener Moderne Adolf Loos in Kontakt, der im nahe gelegenen Café Museum, das kurz zuvor nach seinen Entwürfen eingerichtet worden war, seine Diskussionsrunden und informellen »Seminare « hielt. ${ }^{144}$ Der Einfluss von Loos sollte späterhin sowohl für das Werk als auch die Theorien Franks stets von Bedeutung bleiben.

Dessen ungeachtet ging Frank nach Abschluss seines Studiums 1908 vorerst nach Berlin, um bei dem deutschen Architekten Bruno Möhring sein Praktikum zu absolvieren. Dort lernte er die um fünf Jahre ältere schwedische Musikstudentin Anna Sebenius kennen, die er auch I9I 2 heiratete. Durch diese Verbindung sollte Schweden späterhin für Frank zu einer Art zweiter Heimat werden. Auch einer seiner ersten Aufträge, die im Zusammenhang mit Arthur Baron bereits erwähnte "Schwedische Turnschule« von I9I0, erhielt Frank höchstwahrscheinlich über die Vermittlung seiner Frau. Die im obersten Stockwerk des "Residenzpalastes« (Wien I, Fleischmarkt I, heute nicht mehr erhalten) untergebrachten Räumlichkeiten waren, wie bereits erwähnt, einem folkloristischen Nationalstil in kräftiger Farbigkeit verpflichtet. Ungeachtet der sehr dekorativen Ausrichtung ist es jedoch bemerkenswert, dass Frank in der Erläuterung dieser Einrichtung sich von den einheitlich durchgestalteten Interieurs Josef Hoffmanns und der Wiener Werkstätte, die damals tonangebend waren, etwas distanzierte, in dem er streng durchkomponierte Räume ablehnte und eine "Zwanglose Wohnlichkeit« forderte. ${ }^{145}$ Mit diesen Prinzipien, die Frank hier erstmals ansatzweise ausformulierte, versuchte er die Idee einer einheitlichen formalen Durchgestaltung (im Sinne von Josef Hoffmann) insofern zu modifizieren, als er diese mit einem freien "wohnlichen" Ideal ohne dogmatischen Zwang, wie es Loos seit je gefordert hatte, in Einklang brachte. Mit dieser Synthese schuf Frank die theoretische Voraussetzung für die Wiener Wohnraumkultur der Zwischenkriegszeit.

Neben der "Schwedischen Turnschule« führte Frank in den ersten Jahren seiner Laufbahn noch verschiedene weitere Inneneinrichtungen aus und fungierte auch demgemäß I9I2 als Gründungsmitglied des "Österreichischen Werkbundes", der nach dem gleichnamigen deutschen Vorbild ins Leben gerufen wurde und sich für die

I 43 Oscar Strnad dissertierte 1904 über "Das Princip in der christlichen Kunst«, Oskar Wlach 1906 über "Die farbige Inkrustation der Florentiner Protorenaissance».

I 44 Josef Frank, Arkitekt och outsider (Kat.), Stockholm 2007, S. 35.

I45 Das Interieur 19I2, S. 4Ifff. 
"Veredelung des Gewerbes in Zusammenarbeit mit Kunst, Industrie und Handwerk" einsetzte. ${ }^{146}$ In der Folge sollte Frank in dieser Institution, insbesondere im Rahmen seiner Tätigkeit als Vizepräsident in den Jahren 1928-1933, besondere Aktivitäten entfalten und eine bedeutende Rolle spielen - es wird davon noch zu sprechen sein. I9I 3 schloss sich Frank der Ateliergemeinschaft von Oskar Wlach und Oskar Strnad an, mit denen ihn sowohl die gemeinsame jüdische Herkunft als auch die Ausbildung an der Technischen Hochschule bei Karl König verband. In den letzten Jahren vor Ausbruch des Ersten Weltkrieges konnte ihr Architekturbüro einige bedeutende Wohnbauten realisieren, wobei es üblich war, dass zumeist einer der Partner bei einem der Projekte federführend war. Für Frank traf dies insbesondere auf die beiden Einfamilienhäuser Scholl und Strauß zu, die er um I9 13/I4 in Wien-Döbling (Wien I9, Wildbrandtgasse 3 und I I, Abbildung 55) errichtete. Bezeichnend ist, dass Frank sich hier weitgehend vom zeitgenössischen Umfeld des Secessionismus löste und zu einer Lösung kam, die schon als Vorgriff auf die Architektur der Zwischenkriegszeit anzusehen ist. Neben der kubischen Geschlossenheit des Baukörpers, die sichtlich von Loos beeinflusst war, beschränkte er sich bei der Außenerscheinung auf eine minimale puristische Gestaltung von Fenster und Türen, wobei deren weiße Umrahmung und die geschlämmte Ziegelfassade ein wenig an die englische "Georgian Architecture» des späten I 8. Jahrhunderts erinnerten. Bei der Organisation der Räumlichkeiten war für Frank vor allem eine funktionelle Wegführung von Bedeutung, die das Grundkonzept bestimmte. Jahre später fanden diese Überlegungen ihren Niederschlag in seiner Publikation »Das Haus als Weg und Platz. « ${ }^{147}$ Das englische Vorbild spielte für Frank jedoch nicht nur in formaler Hinsicht, sondern auch in seinen Konzepten für den Wohnbau späterhin eine nicht zu unterschätzende Rolle.

Der Beginn des Ersten Weltkrieges bedeutete auch für Frank einen Einbruch in seiner beruflichen Laufbahn, und das gemeinsame Atelier mit Strnad und Wlach wurde aufgelöst. Dennoch blieben sie auch in späteren Jahren beruflich in engem Kontakt. Als Reserveoffizier musste Frank an der Balkanfront dienen, wo er aufgrund seiner technischen Ausbildung im Eisenbahnwesen eingesetzt wurde. Nach Kriegsende konnte er jedoch ungeachtet der Wirren, die der Zusammenbruch der Monarchie nach sich zog, bald wieder beruflich Fuß fassen. I9I9 erhielt Frank einen Lehrauftrag an der Wiener Kunstgewerbeschule, wo bereits Oskar Strnad eine Architekturklasse leitete, für das Fach »Baukonstruktionslehre«. Damit gehörten Frank und Strnad nach Karl König zu den ganz wenigen Juden, die in Wien Professorenstellen auf dem Gebiet der Architektur innehatten. Darüber hinaus arbeitete Frank

I 46 A. Gmeiner/G. Pirhofer, Der Österreichische Werkbund, Salzburg/Wien, I985, S. I I.

I 47 J. Frank, Das Haus als Weg und Platz, in: Der Baumeister 29.193 I, S. 3 I $6 f f$. 
55. Josef Frank, Haus Scholl

Wien I9, Wildbrandtgasse 3, erbaut um I9 3 /Wasmuths Monatshefte

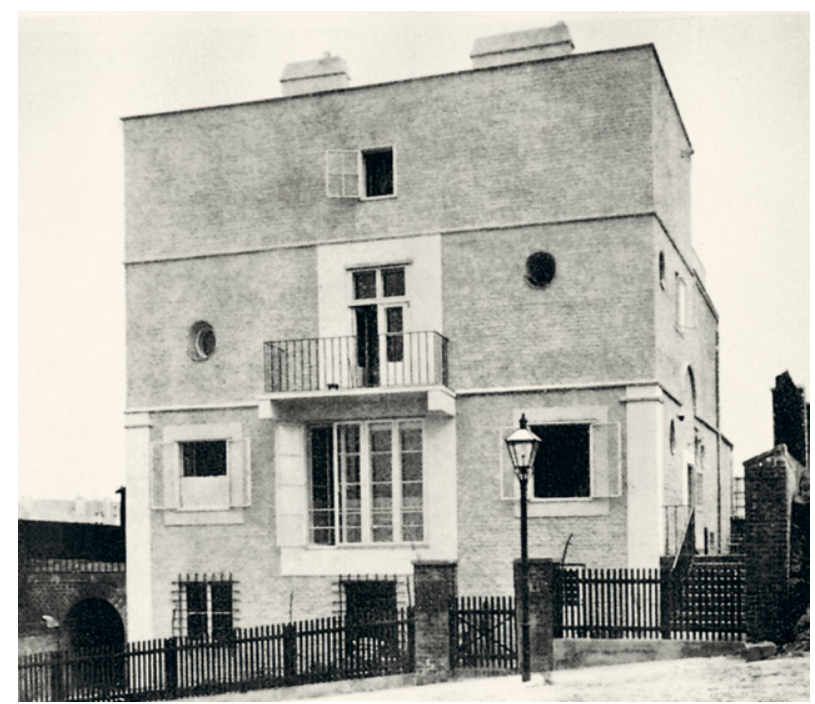

Anfang der Zwanzigerjahre auch als Architekt des "Österreichischen Verbandes für Siedlungs- und Kleingartenwesen", der die wilden Siedlungsbewegungen, die aus der Not der Zeit entstanden waren, in geordnete Bahnen lenken sollte. Im Rahmen dieser Tätigkeit konnte Frank allerdings nur eine Siedlung realisieren, da die sozialdemokratische Wiener Stadtverwaltung sich bald entschloss, der Geschoßbauweise den Vorzug zu geben, und die Siedlungsbewegung daher an Bedeutung verlor. ${ }^{148}$ Frank, obwohl selbst ein Sympathisant der Sozialdemokratie, zählte zu den heftigsten Kritikern dieser Entwicklung und verabsäumte es nicht, immer wieder gegen die monumentalen "Volkswohnungspaläste" zu polemisieren. ${ }^{149}$ Dessen ungeachtet errichtete auch er drei Wohnhausanlagen für die Gemeinde Wien, wobei offensichtlich die schlechte Baukonjunktur ihn zur Übernahme dieser Aufträge veranlasste. Bezeichnend ist jedoch, dass Frank trotz der Größe dieser Anlagen darauf bedacht war, die damals übliche pathetische Monumentalität zu vermeiden. Insbesondere die 1928 errichtete Wohnhausanlage in Wien I4, Sebastian-Kelch-Gasse I (Abbildung 56), ist aufgrund ihrer klaren Strukturierung und guten Proportionierung ein mustergültiges Beispiel für eine qualitätvolle Auseinandersetzung mit der zeitgenössischen Moderne.

I 48 Bei dem Projekt handelte es sich um die Siedlung "Hoffingergasse«, Wien I 2, Hoffingergasse (I92 II925).

I49 Siehe dazu J. Frank, Der Volkswohnungspalast, in: der aufbau 1926/27, S. Io7ff. 


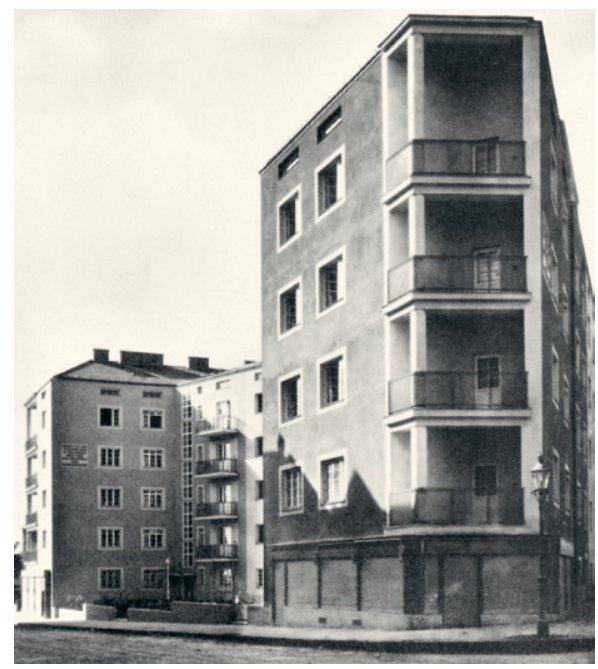

56. Josef Frank, Wohnhausanlage Wien I4, Sebastian Kelchgasse I-3, erbaut um I928/ Moderne Bauformen

Als sich die österreichische Wirtschaft nach der Währungsreform und der Einführung des Schillings Ende 1924 etwas zu konsolidieren begann, wagte es Frank, wieder eine eigene Firma zu gründen. Sozusagen als Gegenmodell zur »Wiener Werkstätte« von Josef Hoffmann eröffnete er in Zusammenschluss mit seinem alten Partner Oskar Wlach das Einrichtungsunternehmen »Haus und Garten«, wobei der Name schon als Programm diente: Zielsetzung war, nicht nur eine qualitätvolle Inneneinrichtung zu schaffen, sondern auch Architektur und umgebende Landschaft in eine Synthese zu bringen. In Gegensatz zu Josef Hoffmanns Innenräumen, die einen äußerst repräsentativen Charakter aufwiesen und einer strikt einheitlichen Ausgestaltung im Sinne der "Stilkunst« unterlagen, waren die Interieurs von »Haus und Garten« einer sehr freien, oft spielerischen Ausrichtung verpflichtet. Neben einem formal an der zeitgenössischen Moderne ausgerichtetem Mobiliar scheute man sich auch nicht, kräftige Muster oder Anlehnungen an die Formensprache des Biedermeier einzubringen. In dieser angestrebten formalen Pluralität eines Interieurs war auch Platz für bereits vorhandene Möbel oder Versatzstücke. Nicht zuletzt war es diese Offenheit, die der Einrichtungsfirma einen großen geschäftlichen Erfolg beschied. In der Folge stattete das Unternehmen nicht nur eine Reihe von Wohnungen und Häuser aus, sondern beteiligte sich auch an diversen Ausstellungen, die im Zusammenspiel mit zahlreichen Publikationen dazu führten, dass »Haus und Garten" maßgeblich den Wohnstil dieser Jahre prägte.

Einer der Höhepunkte im Rahmen von Franks Schaffen - und der österreichischen Architektur dieser Jahre generell - stellt das sogenannte »Haus Beer« dar, das Frank 


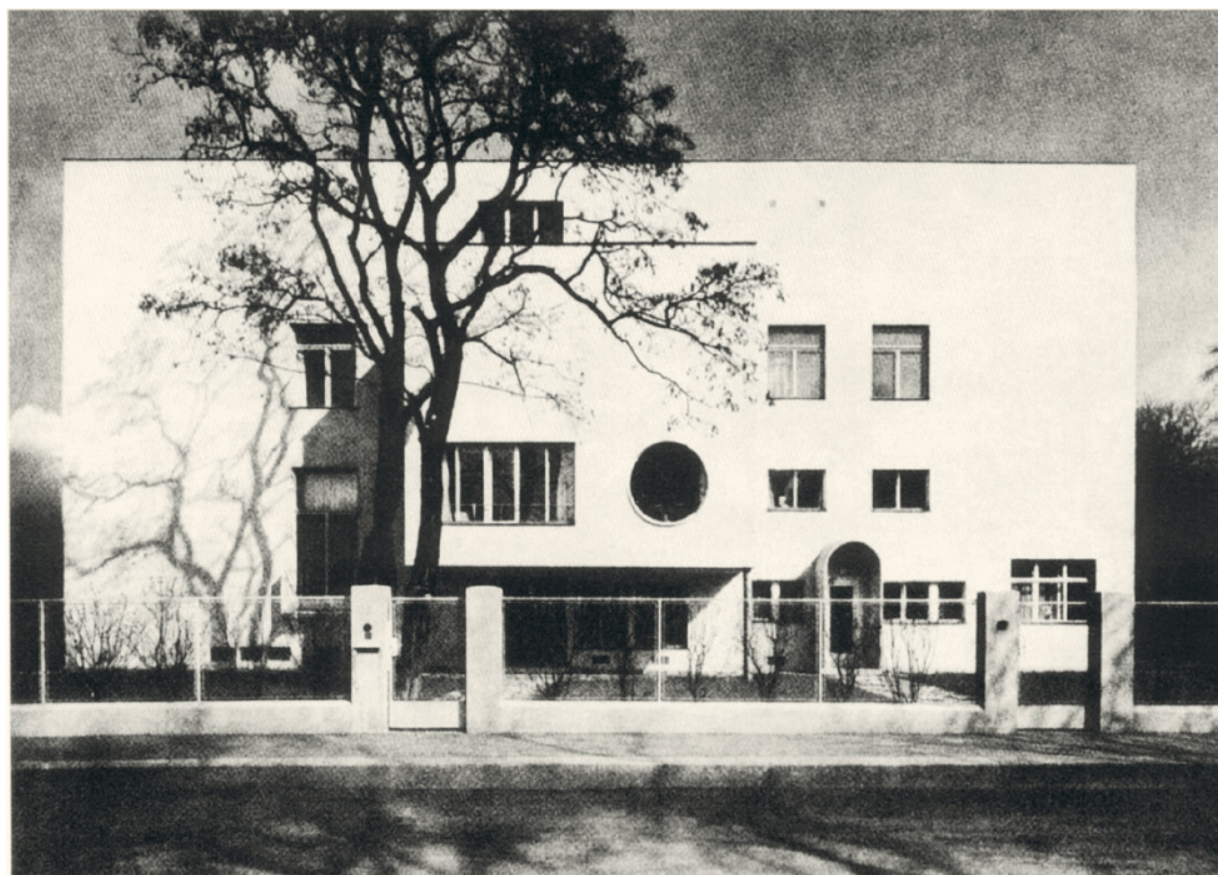

57. Josef Frank, Haus Beer, Wien I3, Wenzgasse I2, erbaut um 1930/Welzig

um I930 in Wien Hietzing (Wien I3, Wenzgasse I2, Abbildung 57) für den Kautschukfabrikanten Julius Beer errichtete. In Zusammenarbeit mit seinem Partner Oskar Wlach realisierte Frank in diesem gehobenen Villenviertel seine Idealvorstellung eines Einfamilienhauses, wobei er in der Weiterentwicklung der Theorien von Adolf Loos zu neuen Lösungen in der Raumanordnung kam. Neben der funktionell bedingten unterschiedlichen Raumhöhe waren die Räumlichkeiten insbesondere im Hinblick auf eine rationelle Wegführung im Inneren und der Einbindung des umgebenden Gartens konzipiert. Der offene Grundriss, den Frank bei der Lösung einbrachte, führte zu einer völlig unregelmäßigen Außengestaltung, die den Gesetzen im Inneren folgte. Ein markantes Rundfenster an der straßenseitigen Front gehört zum Markenzeichen des Hauses, das selbstverständlich von der Firma "Haus und Garten« auch eingerichtet wurde und somit als Paradigma der Vorstellungen Franks anzusehen ist.

Als das bedeutendste Projekt Josef Franks ist indes die Wiener Werkbundsiedlung anzusehen. Nicht nur dass er für deren Generalplanung verantwortlich war, er war auch deren Initiator und Spiritus Rector. Franks Engagement im Österreichischen 
Werkbund wurde bereits erwähnt, nicht zuletzt stimmten die Intentionen des Vereines auch mit seiner persönlichen Ausrichtung überein. Zur Lösung der aktuellen Wohnungsnot der Zwischenkriegszeit waren seitens der nationalen Werkbundsektionen bereits mehrfach Ausstellungen mit Mustersiedlungen - wie in Prag oder Breslau - organisiert worden, wo anhand verschiedener Prototypen für Einfamilienhäuser neue Wege für den sozialen Wohnbau vorgestellt wurden. Als eine der wichtigsten galt die 1926/27 errichtete Weißenhofsiedlung in Stuttgart, wo neben den bedeutendsten Architekten ihrer Zeit auch Josef Frank als Leiter der österreichischen Sektion teilgenommen hatte. Obwohl er wegen der moderaten Modernität seines dortigen Doppelhauses in der ausländischen Presse auf Skepsis gestoßen war, organisierte Frank ab I 929 in Zusammenarbeit mit Hermann Neubacher, dem Direktor der gemeindeeigenen GESIBA-Baugesellschaft, ${ }^{150}$ schließlich die letzte Ausstellung in der Reihe dieser Mustersiedlungen in Wien. In der konkreten Situation war das Vorhaben im Rahmen des Diskurses um den sozialen Wohnungsbau insbesondere auch als Gegenentwurf zu den monumentalen Wohnhausanlagen der Gemeinde Wien gedacht, die von Frank wie erwähnt - als kleinbürgerlich und undemokratisch abgelehnt wurden. Demgegenüber verkörperte für ihn der englische Siedlungsbau in Flachbauweise wahrhaft demokratische Werte. Er definierte seine - weit über die eigentliche Architektur hinausgehenden, durchaus gesellschaftspolitischen - Zielvorstellungen im Katalog zur Werkbundsiedlung folgendermaßen: "Wir wissen heute bereits, dass Bescheidenheit nicht Armut bedeutet und dass wir lieber in einem einfachen Rahmen leben, als dass wir unsere Umgebung dekorieren wollen. [...] Wir wissen, dass es ein wesentliches Ziel der modernen Zivilisation sein muss, einem jeden eine würdige Wohnstatt zu bieten. Deshalb wollen wir Einfachheit und Zweckmäßigkeit zu Schönheit vereinen. Wir wollen dazu beitragen, durch die Wohnung eine gemeinsame Art des Denkens und der gemeinsamen Kultur zu begründen, von der alleine eine höhere Entwicklung der gesamten Menschheit möglich ist. «151

Beinahe alle Architekten, die Frank in der Folge für dieses Vorhaben einlud, waren Vertreter der sogenannten "Zweiten Wiener Moderne», die sich im Umfeld von Frank, Oskar Strnad und den Veteranen Josef Hoffmann und Adolf Loos herausgeformt hatte. Unter den Eingeladenen befanden sich Persönlichkeiten wie Clemens Holzmeister, Ernst Plischke, Walter Sobotka, Hugo Gorge, Ernst Lichtblau, Jacques Groag, Hans Vetter und andere mehr. Nicht wenige davon waren Juden, es wird späterhin noch von einigen die Rede sein. Alle diese Architekten, obwohl sie keine ein-

\footnotetext{
I 50 Hermann Neubacher zählte zynischerweise nach dem "Anschluss" von 1938 zu den prominentesten österreichischen Nationalsozialisten und war für einige Jahre auch Bürgermeister von Wien.

I 5 I J. Frank, Die internationale Werkbundsiedlung, Wien 1932.
} 
heitliche Gruppe bildeten und durchaus verschiedene Positionierungen einnahmen, standen aber in einem nahezu antithetischen Verhältnis zur Gruppe der Schüler Otto Wagners, die zum Großteil für die monumentalen Volkswohnungspaläste verantwortlich waren. Um die Eingebundenheit des Vorhabens in das aktuelle europäische Architekturgeschehen zu demonstrieren, waren auch einige prominente ausländische Architekten wie Hugo Häring, Gerrit Rietveld, Andrè Lurçat, Gabriel Guevrekian und die beiden inzwischen in die USA ausgewanderten Wiener Arthur Grünberger und Richard Neutra eingeladen worden. Intention des Wiener Projektes war es vor allem, eine möglichst große Vielfalt an Einfamilienhäusern vorzustellen, die als Prototypen für spätere Siedlungsbauten dienen sollten. Daher reichte die Bandbreite von ebenerdigen Bungalows bis zu dreigeschoßigen Häusern, die maximal fünf Wohnräume umfassen sollten, die allerdings alle sehr klein gehalten waren. Auch sollte jedes Haus über einen Garten verfügen, um auch einer - zumindest eingeschränkten - Eigenversorgung zu dienen.

Von Anbeginn an hatte Frank jedoch mit einer Reihe von Schwierigkeiten zu kämpfen. Das ursprünglich ins Auge gefasste Areal an der Triester Straße, das sich in einer traditionellen Arbeiterwohngegend befand, stand nicht zur Verfügung, sodass das Konzept geändert werden musste, was zu einer erheblichen Verteuerung führte. Der Wechsel in die Nähe eines Villenviertels in Lainz und der Umstand, dass keine Miet, sondern Eigentumshäuser entstehen sollten, führte dazu, dass die ursprüngliche Intention, modellhafte Wohnungen für die Arbeiterschaft zu errichten, nur sehr eingeschränkt umgesetzt worden konnte. ${ }^{152}$ Stattdessen kamen weitgehend nur Angehörige des Mittelstandes als potenzielle Käufer infrage, für deren Ansprüche allerdings vieles zu karg und zu klein dimensioniert war. Das Schlagwort der »Villen für Zwerge«, das damals die Runde machte, bezeichnete treffend den Zwiespalt des Unternehmens. Darüber hinaus überschatteten sehr bald die Ereignisse der Wirtschaftskrise das Vorhaben. Alle diese Umstände führten letztlich dazu, dass nur vierzehn der siebzig Häuser Käufer fanden, der Großteil musste von der Gemeinde Wien angekauft und vermietet werden.

Der von Frank erstellte Generalplan für das schwierig zu verbauende, spitzwinkelige Areal zwischen Jagdschlossgasse und Veitinger Gasse war schließlich ein Kompromiss zwischen Zeilenverbauung und einigen frei stehenden Häusern, wobei notgedrungen alles sehr klein dimensioniert war, schließlich sollte auch jede Parzelle über einen eigenen Garten verfügen. Eines der Häuser wurde von Frank selbst geplant. Wie alle Objekte der Werkbundsiedlung zeichnete sich auch dieses Wohn-

I 52 Siehe dazu O. Kapfinger, Positionen einer liberalen Moderne. Die Wiener Werkbundsiedlung I932, in: Gmeiner/Pirhofer, zit. Anm. I46, S. I $55 \mathrm{ff}$. 
haus - bedingt durch das Flachdach - durch eine betont kubische Struktur aus, die mittels eines zurückgesetzten Terrassengeschoßes aufgelockert wurde (Wien I3, Woinovichgasse 32, Abbildung 58). Frank demonstrierte hier in Auseinandersetzung mit zeitgenössischen aktuellen Strömungen eine einfache praktikable Wohnform. Allerdings war er im Hinblick auf die Konzeption von Grundriss und Raumanordnung sehr eingeschränkt, sodass für architektonische Experimente kaum Entfaltungsmöglichkeiten bestanden.

Ein weiterer wichtiger Aspekt war, die Interessenten über die aktuellen Möglichkeiten einer funktionellen und ästhetisch ansprechenden Möblierung zu informieren. Aus diesem Grund wurden die Häuser auch eingerichtet. Franks Interieur des Werkbundhauses, das die Qualität der Wiener Wohnraumkultur demonstrierte wie wenige andere, orientierte sich keinesfalls an dem spröden Funktionalismus der damals gängigen "Bauhausmoderne«, sondern vermittelte den Eindruck einer durchaus bürgerlichen Wohnlichkeit. Neben Textilien in kräftiger Musterung brachte er auch Möbel zum Einsatz, deren weiche Formgebung sich manchmal an das Repertoire des Biedermeier anlehnte.

Wenn das Projekt der Wiener Werkbundsiedlung, das sich vor allem der Initiative Josef Franks verdankte, infolge zahlreicher Einschränkungen und zeitbedingter Konzessionen nicht in allen Teilaspekten zu befriedigen vermochte, gilt es dennoch bis heute als ein Meilenstein der österreichischen Architekturgeschichte und hat weltweit Anerkennung gefunden. Bereits damals wurden allerdings in den Medien diverse Unzulänglichkeiten - insbesondere die bereits angeführte kleine Dimensionierung beklagt. Darüber hinaus verhinderten die Wirtschaftskrise und die sich verändernde politische Situation den Erfolg des Projektes, insbesondere was eine Weiterführung der hier erarbeiteten Ideen betraf. Der zunehmende Einfluss der politischen Rechten führte dazu, dass das Vorhaben als »links« und aufgrund der relativ hohen Anzahl an jüdischen Architekten (rund ein Drittel der 32 Eingeladenen) als "jüdisch" diffamiert wurde. ${ }^{153}$ Insbesondere die rechtsgerichtete "Reichspost" tat sich in ihrer Kritik mit kaum verhüllten antisemitischen Klischees hervor. Generell wurde beklagt, dass zu wenig "Österreicher« - wie auch immer der Begriff zu verstehen war - teilgenommen hätten und dass einem Großteil der Teilnehmer die »Bodenständigkeit« und die »Verbundenheit mit der Landschaft" abgingen. Im Besonderen wurde Josef Frank kritisiert: Der Aufschließungsplan wurde als »unästhetisch« abgelehnt, das Wohnhaus als

I 53 Auch der ausführende Baumeister Carl Korn, der schon zur Zeit der Monarchie in Bielitz (damals Österreichisch-Schlesien) eine der größten Baufirmen betrieb, war jüdischer Herkunft. Unter anderem hatte er in Wien auch das "Wittgensteinhaus« ausgeführt. 


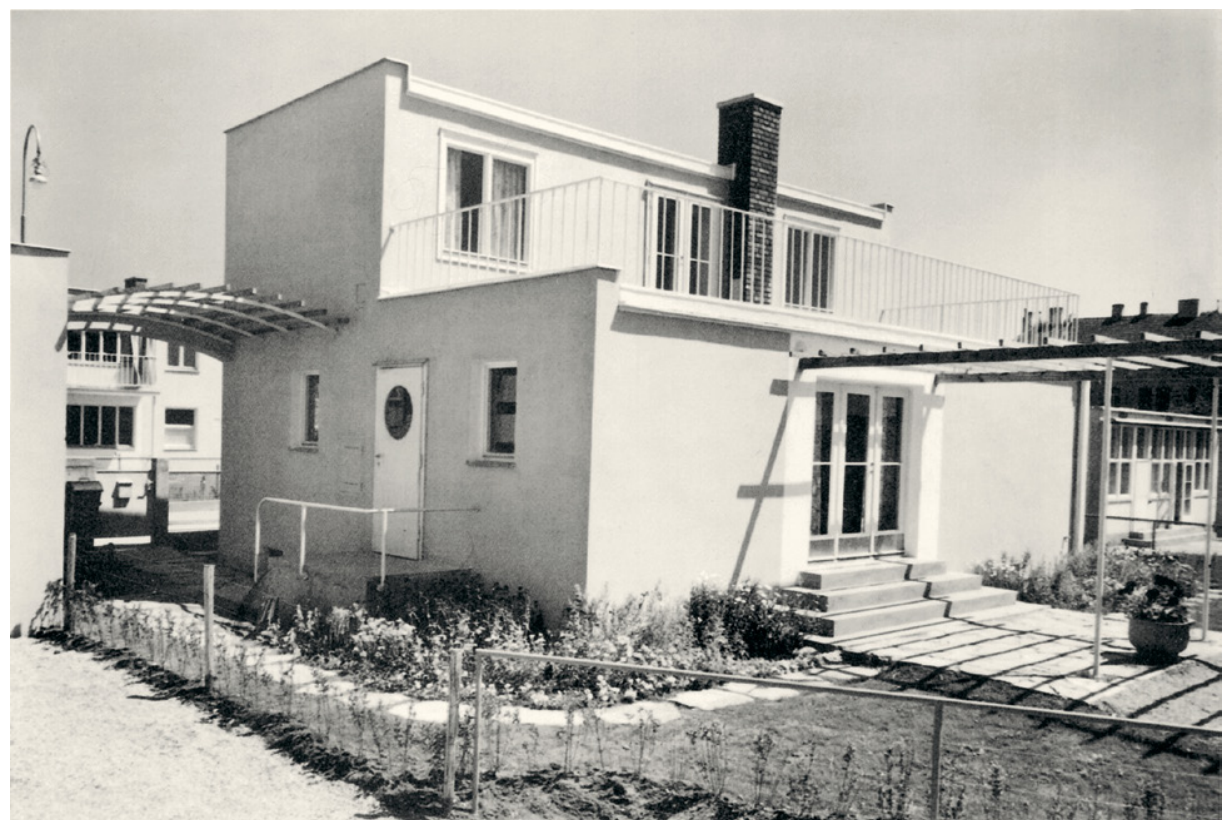

58. Josef Frank, Doppelhaus in der Werkbundsiedlung, Wien I 3 Woinovichgasse 32, erbaut 1932/Wasmuths Monatshefte

"formal völlig unbefriedigend" bezeichnet. ${ }^{154}$ Noch krasser tat sich der unmittelbar NS-affine "Kampfbund « hervor, der das Projekt sogar als "Tel Awiw [sic] in Lainz» bezeichnete und von »üdischen Bauschwindlern« sprach. ${ }^{155}$

Diese Berichterstattung reflektiert die generelle Stimmungslage dieser Zeit, die sich zunehmend verhärtete. So wie die Wiener Werkbundsiedlung ins Schussfeld konservativ-nationaler Kreise geriet, so brach in ähnlicher Weise auch der Konflikt innerhalb des Österreichischen Werkbundes aus. Die Dominanz von Josef Frank und seinem Freund und Studienkollegen Oskar Strnad ließ antisemitische Ressentiments bei anderen Mitgliedern hochkommen, die die "Verjudung des Werkbundes« beklagten. ${ }^{156}$ Vor allem Josef Hoffmann, dessen Stern zu diesem Zeitpunkt bereits etwas zu verblassen begann - so wurde er unter anderem in Insiderkreisen bereits als »Repräsentant einer eigentlich gestorbenen Dekorations-Epoche« bezeichnet - fühlte sich innerhalb

I54 Anonymus, Das Einfamilienhaus der Werkbundsiedlung, in: Die Reichspost, I9.6.1932.

I 55 Der Kampfbund, i I.6.1932, Nr. 24.

I 56 F. Achleitner, Der Österreichische Werkbund und seine Beziehung zum Deutschen Werkbund, in:

L. Burckhardt (Hg.), Der Werkbund in Deutschland, Österreich und der Schweiz, Stuttgart 1978. 
der Vereinigung an den Rand gedrängt. ${ }^{157}$ Als Strnad 1933 mit der Gestaltung der Österreichischen Abteilung der Triennale in Mailand betraut wurde, verschärften sich die Spannungen und Krisen vollends. Hoffmann, der Josef Frank unter anderem »Allerweltsinternationalismus" vorwarf, verließ den Werkbund unter Protest, um einige Monate später im Februar I934 den »Neuen österreichischen Werkbund « zu gründen. Dieser Vereinigung, in der neben Hoffmann vor allem auch Clemens Holzmeister und Peter Behrens eine wesentliche Rolle spielten - alles Persönlichkeiten, die dem "Ständestaat" oder dem NS-System nahestanden -, gehörten keine Juden und keine Sozialdemokraten mehr an. Damit war bereits eine Weichenstellung vollzogen, die nur wenige Jahre später zur völligen Ausschaltung der Juden führen sollte.

Nicht zuletzt aufgrund dieser Umstände verließ Josef Frank bereits I934 Österreich und emigrierte nach Schweden, wo er bereits zuvor einige Familienhäuser und Wohnungseinrichtungen ausgeführt hatte. Allerdings blieben seine Beziehungen zu Österreich noch für einige Zeit bestehen. Erst I938 - nach dem "Anschluss« Österreichs und der "Arisierung « der Firma »Haus und Garten« - verlegte er seinen Wohnsitz endgültig nach Stockholm, wo er Ende der Sechzigerjahre verstarb. Obwohl er sehr erfolgreich für die Möbel- und Einrichtungsfirma "Svensk Tenn« arbeitete - bis heute sind seine in kräftigen Farbmustern gehaltenen Textilien Teil der schwedischen Alltagskultur -, gelang es ihm nicht, seine Karriere als Architekt weiterzuführen. Wie weit dieser Umstand auf bürokratische Hindernisse zurückzuführen ist oder auf einen Mangel an Auftraggebern, sei dahingestellt, jedenfalls ist die Liste seiner nicht ausgeführten Projekte lange. Das Verhältnis zu seiner Heimatstadt Wien blieb mehr als zwiespältig. Nachdem er 1947 zu einem Vortrag im Forum Alpbach eingeladen worden war, erhielt er im Jahr darauf sogar eine Einladung nach Wien. Im Rahmen einer Veranstaltung des Stadtbauamtes sprach er über Städtebau in den USA und Schweden. Der Andrang war außerordentlich groß, sodass Frank auf Initiative von Stadtrat Viktor Matejka und seinem ehemaligen Mitarbeiter Oswald Haerdtl gebeten wurde, zwei weitere Vorträge zu halten. In diesem Kontext kam Frank auch explizit auf die beschämenden Ereignisse rund um die Spaltung des Werkbundes zu sprechen, wobei ein Teil seiner ehemaligen Widersacher in den vordersten Reihen saßen. Von einer ideellen Wiedergutmachung war keine Rede. Auch sein im selben Jahr im Rahmen eines Wettbewerbes ausgearbeiteter Entwurf zur Verbauung des Wiener Stephansplatzes wurde nicht weiter verfolgt. ${ }^{158}$ Diese beiden Episoden sollten ein Intermezzo bleiben, seine Heimatstadt hatte keine Verwendung mehr für ihn.

I 57 Siehe Kapfinger, zit. Anm. I 52, S. I 82.

I 58 Siehe Welzig, zit. Anm. I I, S. 2 I I. 


\subsection{Oskar Strnad - fließende Grenzen zu Theater und Film}

Die bedeutendste Persönlichkeit neben Josef Frank war zweifellos der bereits mehrmals erwähnte Oskar Strnad (1879-1935, Abbildung 59). In Wien geboren, verbrachte er infolge der Tätigkeit des Vaters als Gutsverwalter seine Kindheit auf verschiedenen Gütern in Ungarn und Österreich. Die Realschule besuchte er bereits in Wien, wo er dann auch an der Technischen Hochschule studierte und bei Karl König I 904 dissertierte. Danach praktizierte er bei dem berühmten Jugendstilarchitekten Friedrich Ohmann, der damals gerade mit dem Ausbau der Hofburg befasst war, und späterhin im Büro der Theaterfachleute Fellner und Helmer. ${ }^{159}$ Möglicherweise hat diese rund zweijährige Praxiszeit den dekorativen und bühnenhaften Charakter seines späteren Werkes geprägt. Bereits 1906 machte er sich in Zusammenarbeit mit seinem Studienkollegen Oskar Wlach als Architekt und Designer selbstständig, wobei diese frühen gemeinschaftlichen Arbeiten durchaus noch von einem späthistoristischen Kanon geprägt waren, wie beispielsweise der aus dem Jahr 1907 stammende Wettbewerbsentwurf für das Kriegsministerium in Wien, das einer Art pompösen Neobarocks verpflichtet war. ${ }^{160}$ Inwiefern der erst I9I 3 erfolgte Eintritt des einige Jahre jüngeren Josef Frank in die Bürogemeinschaft, die bis zum Ende des Ersten Weltkrieges bestand, einen Paradigmenwechsel hin zur »Moderne« auslöste, sei dahingestellt. Wie auch immer, auf den Umstand, dass innerhalb der Bürogemeinschaft jeweils einer der Architekten federführend war, wurde bereits hingewiesen.

Strnad, der bereits 1909 einen Lehrauftrag an der damaligen Kunstgewerbeschule in Wien erhielt, der einige Jahre später in eine Professur für Architektur umgewandelt wurde, war vor allem auch ein bedeutender Theoretiker, dessen Vorstellungen über Wohnkultur, die er in zahlreichen Publikationen und Vorträgen darlegte, zum Teil von englischen Vorbildern und der Schlichtheit einer vorindustriellen Gesellschaft geprägt waren, während später auch ostasiatische Lehren eine Rolle spielen sollten. Wesentlich war ihm ein Eingehen auf den Auftraggeber und eine Zurücknahme der persönlichen Handschrift; auf der Suche nach dem menschlichen Maß wollte er "formlos formen«. ${ }^{161}$

I 59 Siehe dazu I. Meder/E. Fuks, Oskar Strnad, I 879-1935, Salzburg/München 2007.

I60 Dieser Bewerb war damals einer der bedeutendsten in Wien. Nicht zuletzt hatten sich auch Otto Wagner und Adolf Loos beteiligt. Infolge der Einflussnahme des Thronfolgers Franz Ferdinand, der einen äußerst konservativen Geschmack pflegte, erhielt schließlich dessen Günstling Ludwig Baumann den Auftrag für das Kriegsministerium am Stubenring (heute sind hier verschiedene Ministerien untergebracht).

I6I Siehe dazu I. Meder, "Formlos zu formen« - Oskar Strnad und seine Schule, in: Moderat modern (hg. v. J. Eiblmayer), Salzburg 2005. 


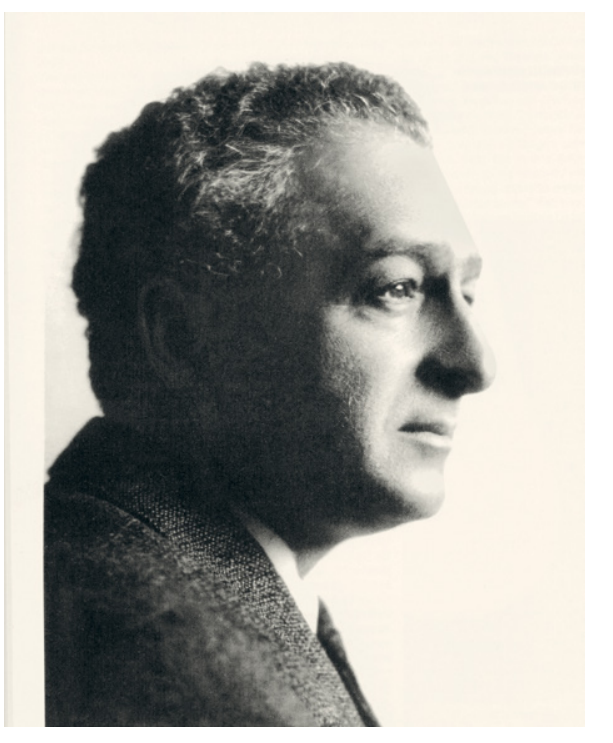

59. Oskar Strnad, Porträt/AzW

Mit diesen Theorien, die abseits jeder Architekteneitelkeit standen, schuf Strnad in Ergänzung zu Frank eine weitere wichtige Basis für die „Wiener Wohnraumkultur» der Zwischenkriegszeit. Infolge der zeitlichen Inanspruchnahme durch all diese Aktivitäten war er in seiner Tätigkeit als Architekt sicherlich etwas eingeschränkt. Dennoch gelang es ihm, mit zwei Bauten, die beide kurz vor dem Ersten Weltkrieg realisiert wurden, neue, beispielhafte Lösungen zu demonstrieren. Dabei verstand er es, von den Theorien eines Adolf Loos auszugehen, aber dennoch eine höchst eigenständige Position zu beziehen. Sowohl das Haus Hock (Wien I9, Cobenzlgasse 7I) als auch das Haus für den berühmten deutschen Schriftsteller Jakob Wassermann (Wien I9, Paul-Ehrlich-Gasse 4, Abbildung 60) zeichneten sich durch eine Zusammenfassung aller Wohnbereiche mittels einer zentralen Halle und eine ausgeklügelte Wegführung aus, die den Außenbereich mit einschloss. Dieses Raumkonzept, das zu einem betont asymmetrischen Baukörper mit frei angeordneten, unterschiedlich geformten Wandöffnungen führte, löste mit seinem unkonventionellen Charakter bei den Zeitgenossen aber auch herbe Kritik aus. Charakteristisch für Strnad war insbesondere die formale Durchgestaltung, die mit Biedermeierelementen oder klassizierenden Motiven angereichert war und den Gebäuden einen etwas manieristischen, nahezu aleatorischen Charakter verlieh. Auch die Einrichtung mit ihrer ungezwungenen Anordnung des Mobiliars oszillierte zwischen Landhausstil und Neobiedermeier.

In der Zwischenkriegszeit war Strnad aufgrund der schlechten Baukonjunktur und seiner bereits erwähnten zahlreichen Aktivitäten nur sehr eingeschränkt als Architekt 


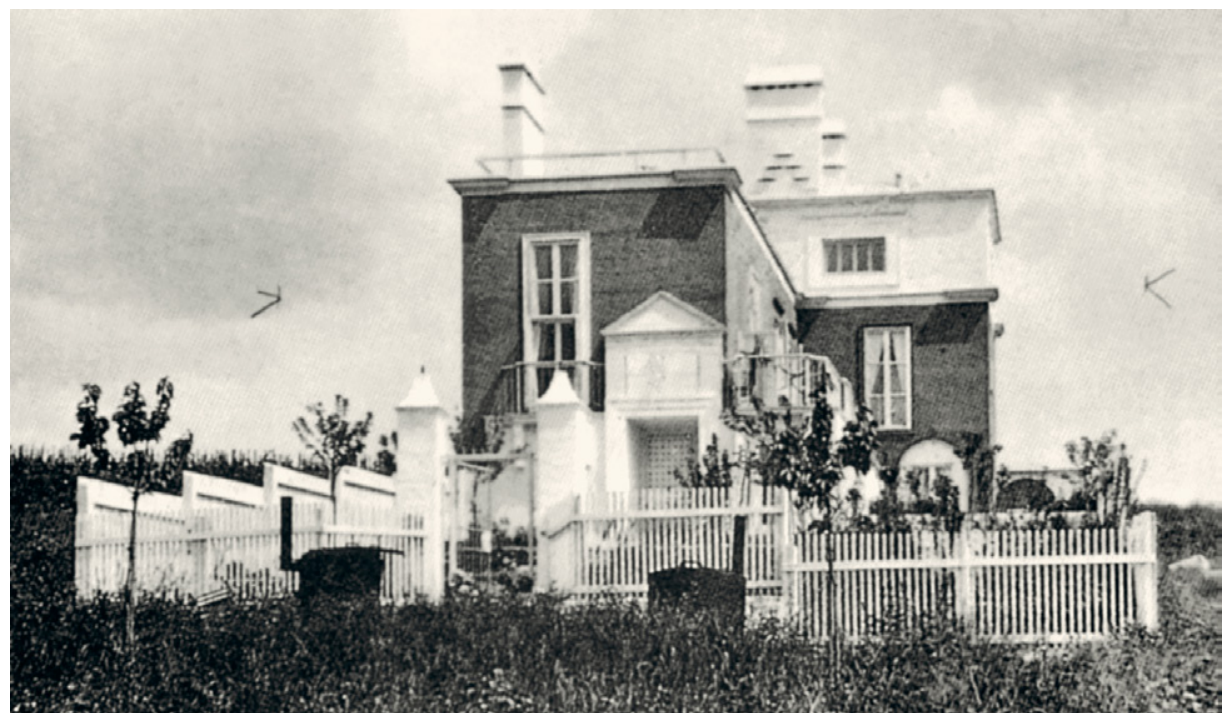

6o. Oskar Strnad, Haus Wassermann, Wien I9, Ehrlichgasse 4, erbaut I9 I4/Welzig

tätig. Neben zwei Wohnhausanlagen für die Gemeinde Wien war er mit einem Doppelhaus für die Werkbundsiedlung befasst (Wien I3, Engelbrechtweg 5-7, Abbildung 6I), wobei Letzteres sich durch besondere Leichtigkeit und Eleganz auszeichnete. Leider wurde es im Zweiten Weltkrieg zerstört, sodass sein auf uns gekommenes architektonisches Euvre sehr schmal ist. Bemerkenswert sind allerdings seine Grabdenkmäler, die in die jüdische Grabikonografie Neues und Unkonventionelles einbrachten. Infolge seiner Konzentration auf das Gebiet der Innenarchitektur leistete Strnad vor allem auch Bahnbrechendes für das Ausstellungswesen, wo er neue Maßstäbe an Transparenz und Ästhetik setzte. Insbesondere für den Österreichischen Werkbund gestaltete er eine Reihe von Werkschauen, beginnend mit der Kölner Werkbundausstellung von I9I4 bis zu der bereits erwähnten Triennale in Mailand I933. Diese Affinität zur Ausstellungsarchitektur ermöglichte es Strnad, sich auch mit dem Bühnenbild zu befassen. Aufgrund seiner Freundschaft mit Alfred Bernau, dem damaligen Direktor des Wiener Volkstheaters, entwarf er Anfang der Zwanzigerjahre zahlreiche Bühnenbilder für dessen Bühne. Da Bernau außerdem das Patent für eine drehbare Ringbühne besaß, begann Strnad sich auch mit dem Theaterbau selbst zu befassen und konzipierte zahlreiche Entwürfe für ringförmige Bühnen mit der Absicht, einen möglichst rundumsichtigen "Bühnenraum " zu gestalten und nicht im Schema der Guckkastenbühne zu verharren. Allerdings sind alle diese Projekte Papierarchitektur geblieben. Als Theaterausstatter und Bühnenbildner war Strnad hinge- 
gen äußerst erfolgreich und gehörte in der Zwischenkriegszeit international zu den gefragtesten Künstlern dieser Sparte. Seine Kontakte mit der Welt des Theaters vertieften sich insbesondere durch seine Freundschaft mit Max Reinhardt und dem Dirigenten und damaligen musikalischen Leiter der Wiener Staatsoper Bruno Walter. In der Folge entwarf Strnad unzählige Bühnenbilder (die Angaben schwanken zwischen 77 und I 22) für das Theater in der Josefstadt, die Wiener Staatsoper (u.a. für die Uraufführung des»Wozzeck«), die Salzburger Festspiele und Bühnen in aller Welt, von New York bis Moskau.

In seinen letzten Lebensjahren begann sich Strnad auch mit dem damals relativ neuen Medium des Films zu befassen. Erstmals stattete er I934 den Streifen »Maskerade« aus, der Filmgeschichte schreiben sollte, insbesondere durch die Mitwirkung der jungen Paula Wessely. Bemerkenswert ist, dass Strnad in dieser eleganten Komödie mit seinen Bauten das Konstrukt eines "Alt-Wien« mittels eines imaginativen Neobarock zum Leben brachte, damit der nostalgischen Erwartungshaltung des damaligen Publikums voll gerecht wurde und nicht unwesentlich zum Erfolg beigetragen haben dürfte. Ein Jahr später I 935 stattete er noch den Film »Episode« aus, gleichfalls mit Paula Wessely.

Neben all diesen Aktivitäten prägte Strnad aber auch als Lehrer und Theoretiker eine ganze Generation von Architekten. Rund ein Vierteljahrhundert hatte er die Leitung der Architekturklasse an der damaligen Kunstgewerbeschule inne (heute Universität für angewandte Kunst), die er mit viel Engagement betrieb. Zu Strnads erfolgreichsten Schülern gehören unter anderen Margarete Schütte-Lihotzky, Oswald Haerdtl, Erich Boltenstern, Franz Schuster und andere mehr, die ihrerseits am Architekturgeschehen in den Jahren nach dem Zweiten Weltkrieg einen großen Anteil hatten.

Strnad, bei dem sich bereits anfangs der Dreißigerjahre Herzprobleme bemerkbar machten, verstarb 1935 während eines Erholungsaufenthaltes in Bad Aussee, gerade mit den Bühnenbildern für die Oper »Die Entführung aus dem Serail« für die Salzburger Festspiel befasst, im sechsundfünfzigsten Lebensjahr. Wohl wenige Künstler seiner Generation haben im Rahmen ihres Werkes so viel zur "österreichischen Identität« der jungen Republik beigetragen wie Strnad. Seine Frau Mathilde, die sich I 938 nach dem "Anschluss" Österreichs an NS-Deutschland geweigert hatte, Wien zu verlassen, überlebte die letzten Jahre versteckt als sogenanntes »U-Boot (damalige Bezeichnung für Leute, die in die Illegalität untertauchten). Nach dem Krieg war es ihr noch vergönnt, einige der posthumen Ehrungen Strnads zu erleben.

In diesem Kontext ist auch ein kleiner Exkurs zu Viktor Lurje (I883-I944) zulässig, obwohl er bis auf einen kleinen Wohnbau aus den Dreißigerjahren kaum als Architekt hervorgetreten ist, sondern weitgehend als Kunstgewerbler tätig war. Er stand Oskar Strnad sowohl persönlich als auch in der Ausrichtung seines Werkes sehr nahe. Sie kannten einander von ihrem gemeinsamen Studium an der Techni- 


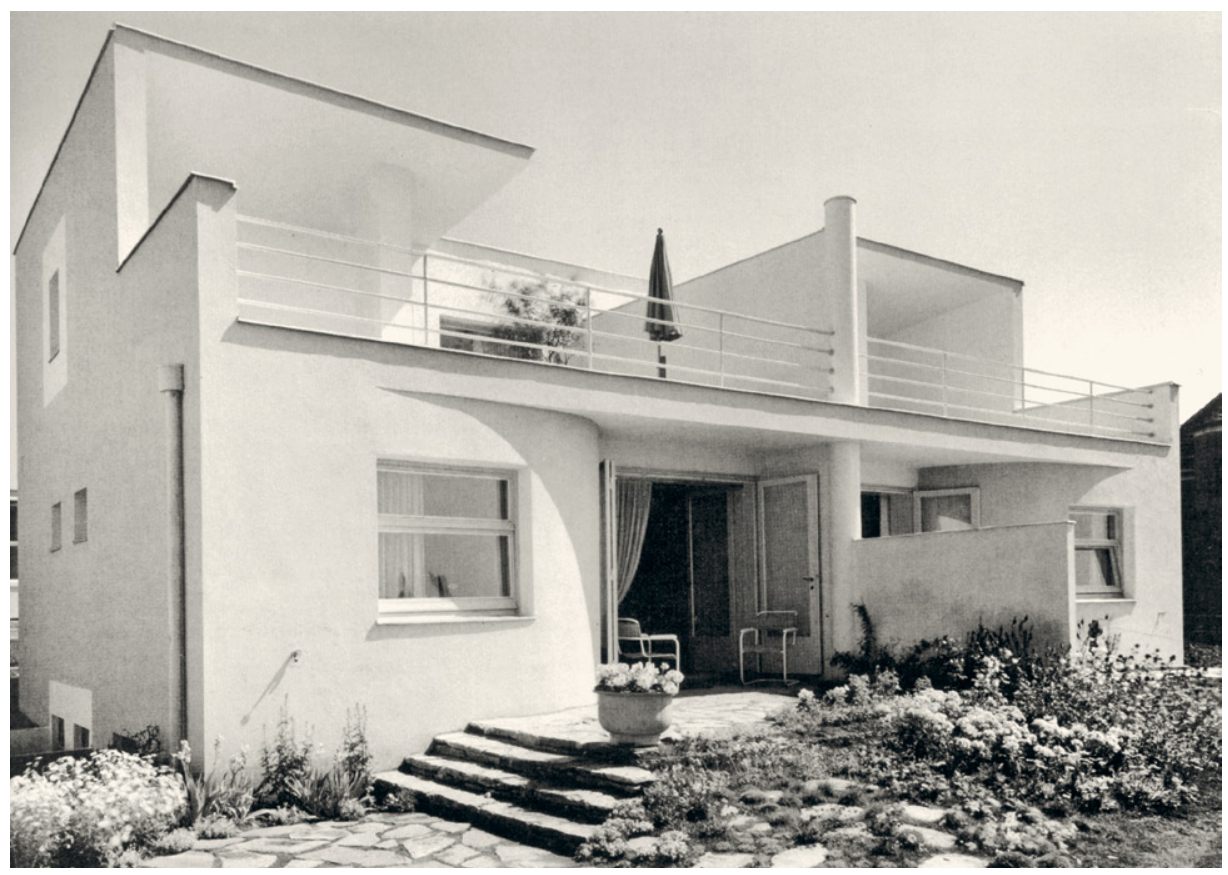

6r. Oskar Strnad, Doppelhaus in der Werkbundsiedlung, Wien I3, Engelbrechtweg 5-7, erbaut 1932 (nicht erhalten)/Meder

schen Hochschule (190I-1906), wo sie sich noch als Studenten im sogenannten "Konkurrenz-Club« engagierten. Auch nach ihrem Studium arbeiteten sie mehrmals zusammen, unter anderem bei der Winterausstellung des Museums für Kunst und Industrie I9I I/I2, wo ihr Gartensaal mit seinen kräftigen Farben und Mustern Aufsehen erregte, wie auch beim Projekt der Villa Hock, das sie gemeinsam als Vorprojekt erarbeiteten. Warum Lurje wenig später die Zusammenarbeit mit Strnad aufgab, ist nicht bekannt. In Wien als Sohn eines gut situierten Fabrikanten geboren, verlegte er sich ungeachtet seiner eher technisch ausgerichteten Ausbildung schon bald auf das Kunstgewerbe, wo sein Schaffensbereich sehr weit gesteckt war. Neben Plakatmalerei, Entwürfen für Glas, Textilien, Keramik und anderem konzentrierte sich Lurje vor allem auf die weniger gängigen Techniken der Intarsienmalerei und der Stuckdekoration, die er bei der Ausstattung von Innenräumen zum Einsatz brachte.

Nach seinem Kriegsdienst während des Ersten Weltkrieges und der kurzfristigen Tätigkeit für die Wiener Werkstätte und die Keramikfirma »Brüder Schwadron« arbeitete er vor allem auch für die Deutsche Werkstätte und stattete in dieser Funktion zahlreiche Lokale und Museen in Deutschland aus. Sein Lebensmittelpunkt blieb aber 
dennoch Wien, wo er wie erwähnt I930 für das »Rote Wien« einen Gemeindebau errichtete (Wien I 5, Pilgerimgasse 4). Als I93 I das Projekt der Werkbundsiedlung von Josef Frank in Angriff genommen wurde, gehörte er zu den Mitprojektanten der ersten Stunde. Warum er späterhin ausschied (wie schon Jahre zuvor beim Haus Hock), ist nicht geklärt. Nach dem »Anschluss« von I 938 gelang es ihm, mit seiner Frau nach Shanghai zu fliehen, das damals eine relativ großzügige Einwanderungspolitik an den Tag legte. Die näheren Umstände seiner Emigration sind nicht bekannt. Bereits I 940 ging er nach Indien (seine Reiseskizzen sind in seinem Nachlass erhalten) ${ }^{162}$, um schließlich 1944 in Jaipur an der Ausstattung des Palastes des örtlichen Maharadschas mitzuarbeiten, wo er auch verstarb. ${ }^{163}$

\subsection{Oskar Wlach - »Haus und Garten«}

Oskar Wlach (1881-I963, Abbildung 62), der dritte der Architektengemeinschaft, die in der NS-Zeit von antisemitischen Kollegen auch bösartig als »jüdisches Kleeblatt « diffamiert wurde, ${ }^{164}$ steht ein wenig zu Unrecht im Schatten von Josef Frank und Oskar Strnad. Dazu hat sicherlich der Umstand beigetragen, dass sein Anteil am Werk der beiden anderen nur schwer auszumachen ist. Wie Frank stammte auch Wlach aus einer gutbürgerlichen Wiener jüdischen Familie, die ihm ein Studium an der Technischen Hochschule ermöglichte. Es erübrigt sich beinahe darauf hinzuweisen, dass auch er bei Karl König studierte und bei diesem 1906 seine Dissertation über die italienische Frührenaissance schrieb. ${ }^{165}$ Wlach gehörte damit zu der Gruppe von Absolventen der Technischen Hochschule, die erstmals einen Doktorgrad erhielten. Schon bald nach dem Studium machte er sich in Zusammenarbeit mit Oskar Strnad selbstständig. Wie bereits erwähnt, beteiligten sie sich in den ersten Jahren ihrer Tätigkeit an verschiedenen großen Wettbewerben und realisierten einige Wohnhäuser. Bei Ausbruch des Ersten Weltkrieges musste Wlach einrücken und arbeitete in der technischen Gruppe des Militärbevollmächtigten in Konstantinopel/Istanbul, wo er bemerkenswerterweise noch über das Kriegsende hinaus blieb und einige Projekte, unter anderem diverse Wohnhäuser und ein Schlachthaus, errichtete. ${ }^{166}$ Als er nach dem

\footnotetext{
I62 Nachlass Viktor Lurje, MAK.

I63 Weihsmann, zit. Anm. I 3.

I64 F. Kaym, unpublizierter Nachruf auf Rudolf Perco, 1942 (Nachlass Perco/Wiener Stadt- und Landesarchiv).

I65 Siehe Anm. I43.

I 66 Siehe M. Welzig, Sobotka, Wlach und Frank, in: Visionäre und Vertriebene, zit. Anm. ıo, S. 20 Iff.; M. Boeckl, Oskar Wlach, in: ebenda, S. $348 \mathrm{f}$.
} 
62. Oskar Wlach, Porträt/AZW

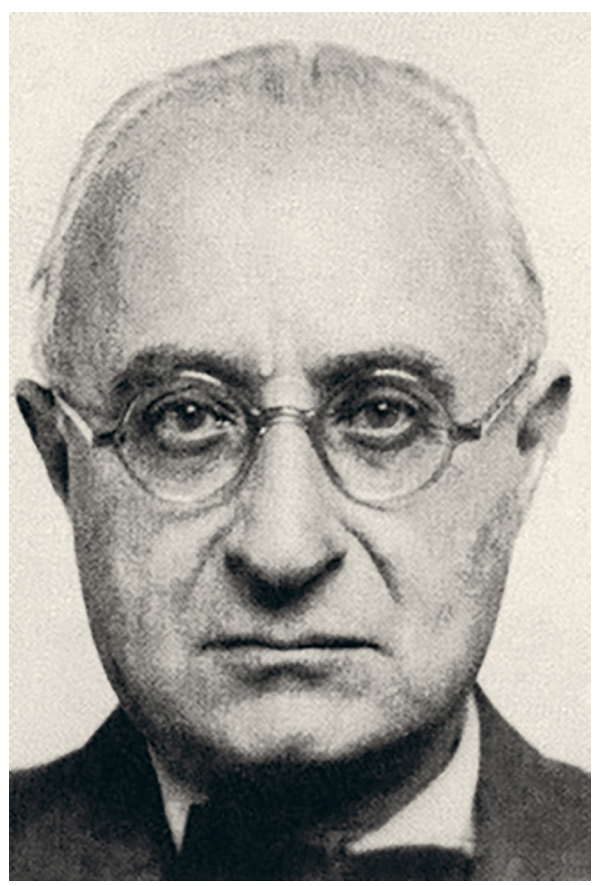

Krieg zurückkehrte, war er - obwohl die Bürogemeinschaft aufgelöst worden war weiterhin in loser Zusammenarbeit mit Oskar Strnad und Josef Frank tätig. Anfang der Zwanzigerjahre war er an einigen Siedlungen und Wohnhausanlagen beteiligt, alle weitgehend im Auftrag der Gemeinde Wien. Als sich nach der Währungsreform von I 924 die wirtschaftliche Lage etwas zu bessern begann, gründete er mit Josef Frank die Einrichtungsfirma "Haus und Garten«, wobei ein jeder zur Hälfte beteiligt war und Wlach die Funktion des Geschäftsführers innehatte. ${ }^{167}$ Die Firma war in den folgenden Jahren äußerst erfolgreich und richtete zahlreiche Wohnungen ein. Die große Akzeptanz gründete zweifellos in der Umsetzung einer gemäßigten Moderne, die sich aktuellen Trends nicht verschloss, bürgerlichen Wohnkomfort aber nicht aus den Augen verlor. "Haus und Garten" hatte nicht zuletzt großen Anteil an der Ausformung der gehobenen "Wiener Wohnraumkultur«, die sich auch eines internationalen Rufs erfreute und in zahlreichen Ausstellungen und Publikationen präsentiert wurde. Neben seiner Mitarbeit am Haus Beer in Wien Hietzing - wobei das oben bereits erwähnte Problem, den kreativen Anteil Wlachs nicht genauer bestimmen zu können, zum Tragen kommt - war er I93 I/32 auch am Projekt der Wiener Werkbundsiedlung

I67 Siehe Welzig, zit. Anm. I I. 


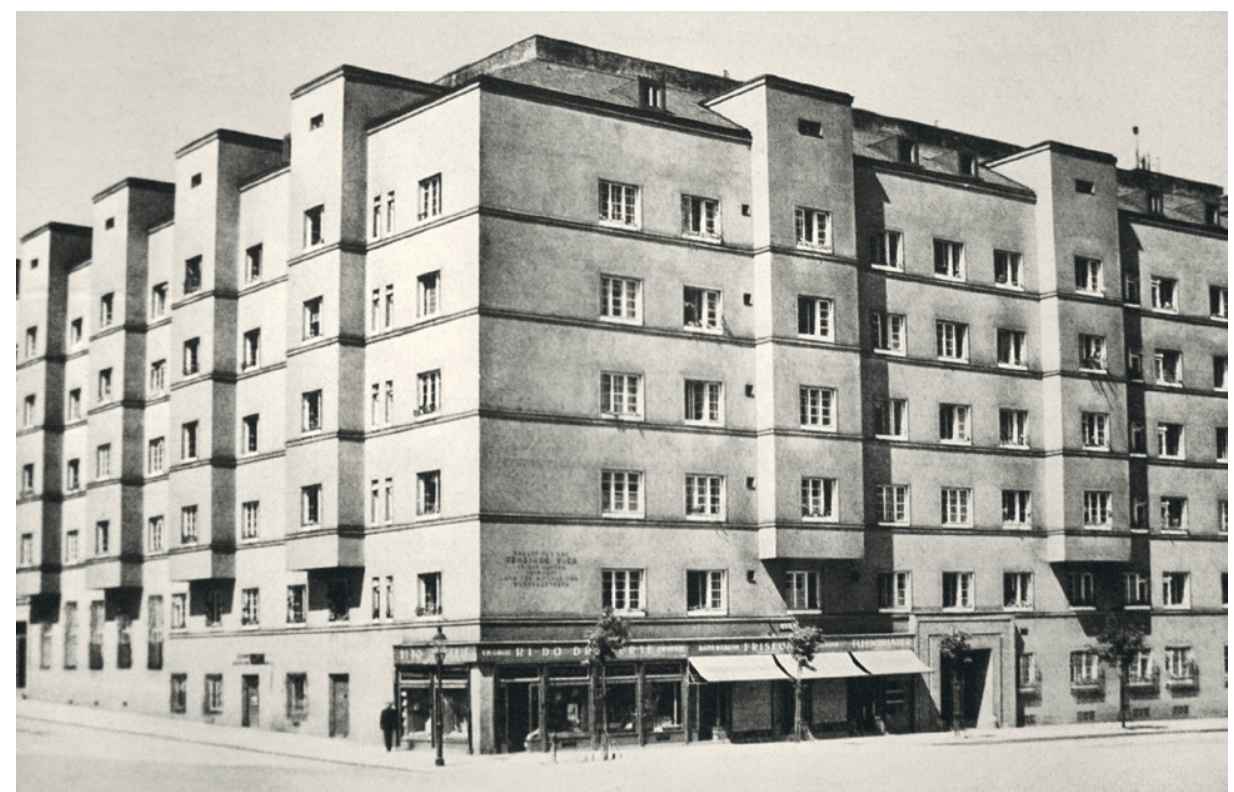

63. Oskar Wlach, Wohnhausanlage d. Gemeinde Wien, Wien Io, Laaerbergstraße 22-24, erbaut um 1933./Mod. Bauformen

beteiligt. Das von ihm errichtete Doppelhaus in der Veitingergasse 99 zeichnete sich durch eine betont unprätentiöse Schlichtheit aus, die den Intentionen des Vorhabens preiswerte Prototypen für Einfamilienhäuser zu präsentieren - in idealer Weise entsprach.

Nach der Emigration Franks 1934 hielt Wlach in Wien die Stellung und führte die Firma "Haus und Garten" weiter, wobei Frank durchaus auch weiterhin an zahlreichen Inneneinrichtungen mitarbeitete. Einer der prominentesten Auftraggeber in diesen Jahren war der Komponist Ernst Krenek, dessen Wohnung die Firma 1934 einrichtete. Wlach schaffte es, noch in der Ära des sogenannten "Ständestaates« einige Aufträge seitens der öffentlichen Hand zu erhalten, etwa die Wohnhausanlage in Wien-Favoriten (Wien ro, Laaerberg Straße 22, Abbildung 63). Auch bei den großen internationalen Ausstellungen dieser Jahre, wie 1936 in Mailand oder 1937 in Paris, konnte er im Rahmen der österreichischen Sektion seine Möbel präsentieren. Umso heftiger war Wlach, nachdem Strnad bereits verstorben und Frank emigriert war, vom sogenannten "Anschluss" Österreichs an NS-Deutschland 1938 betroffen. Die Firma »Haus und Garten" musste umgehend »arisiert" werden. ${ }^{168}$ Wlach und

I68 Die Firma "Haus und Garten" wurde von Julius Kalmar, der seinerseits eine Lampenerzeugung betrieb und in einem freundschaftlichen Verhältnis zu Wlach und Frank gestanden war, übernommen. 
seiner Frau, der Malerin Klari Haynal (geb. Krausz), gelang nur mit Mühe die Flucht in die Schweiz, wobei ihm sein Kollege Eugen Wörle (der in Arbeitsgemeinschaft mit Max Fellerer in der Nachkriegszeit zu den bedeutendsten Architekten gehörte) behilflich gewesen sein soll. Dennoch bleibt ein schaler Nachgeschmack, da Wörle nachweislich in die Wohnung von Wlach zog und damit zum Profiteur (oder auch "Ariseur«) wurde. ${ }^{169}$

Nach einer Zwischenstation in London kamen Wlach und seine Frau 1939 in die USA, wo sie sich in New York niederließen. Wie viele Emigranten konnte sich Wlach nur mit Mühe etablieren. Bereits im fortgeschrittenen Alter erwarb er die Architektenlizenz und stattetet gelegentlich Wohnungen aus. Allerdings blieb die Auftragslage ungenügend. Auch seine Frau, die die Modistenfirma "Madame Klari« betrieb, war wenig erfolgreich. Alle diese Umstände führten zu großen finanziellen Schwierigkeiten. Umso beschämender ist der Umstand, dass Wlach, als er Anfang der Fünfzigerjahre einen Antrag auf Restituierung der Firma »Haus und Garten« stellte, abgewiesen wurde. Schon hochbetagt, nahm er Ende der Fünfzigerjahre eine Stelle als Zeichner in einem Einrichtungsbüro an und lebte von einer kleinen Rente. Wlach starb schließlich in seinem dreiundachtzigsten Lebensjahr in einem New Yorker Altersheim.

\subsection{Walter Sobotka - der gute und billige Gegenstand}

Dem Freundeskreis um Josef Frank eng verbunden war auch Walter Sobotka (I 888I972), der allerdings mit Abstand der Jüngste dieser Gruppierung war und den daher bereits viel mit der im nächsten Kapitel abgehandelten Gruppe der Loos-Schüler verband, die, praktisch einer anderen Generation angehörend, eine relativ progressivere Haltung einnahmen. Da ungeachtet seiner Bedeutung bis heute keine monografische Arbeit über ihn publiziert wurde und auch sein Nachlass noch nicht aufgearbeitet wurde, ist sein Werk nur sehr lückenhaft überliefert. ${ }^{170}$

Aus einer gut situierten Wiener Industriellenfamilie stammend (die Eltern waren Inhaber der Stadlauer Malzfabriken, damals eines der führenden Unternehmen auf diesem Gebiet), ${ }^{171}$ studierte Sobotka von 1907 bis I9I 2 an der Technischen Hochschule, wo er noch zu den allerletzten Schülern Karl Königs gehörte. Der Ausbruch des Ersten Weltkrieges unterbrach schon bald sein berufliches Fortkommen, und aufgrund seines technischen Studiums rückte er bei der berittenen Artillerie ein, um

I69 Meldeauskunft Wiener Stadt- und Landesarchiv.

I70 Siehe Visionäre und Vertriebene, zit. Anm. Io.

I7 I Die 1938 "arisierte« und später in eine Aktiengesellschaft umgewandelte Firma existiert heute noch. 
schließlich I9I 8 als hochdekorierte Oberleutnant aus dem Dienst zu scheiden. Nach Kriegsende begann er seine Tätigkeit mit kleineren Arbeiten wie Umbauten und Einrichtungen. Erst gegen Mitte der Zwanzigerjahre stellten sich größere Aufträge ein, neben diversen Einfamilienhäusern insbesondere zwei Wohnhausanlagen für die Gemeinde Wien. Bemerkenswert ist, dass sich vor allem die I927 errichtete Anlage in Wien-Landstraße (Wien 3, Schrottgasse Io-I 2, Abbildung 64) in ihrer klaren Strukturierung und Schmucklosigkeit auffallend von zeitgleichen Bauten, die zumeist noch einem sehr expressiven Pathos verpflichtet waren, unterscheidet ein Charakteristikum, das den Bau mit den Wohnhausanlagen von Josef Frank verbindet.

Aufgrund seiner Freundschaft mit Frank war Sobotka auch kurzfristig an der Firma "Haus und Garten« beteiligt. Besonders fruchtbar war die Zusammenarbeit mit Frank jedoch im Rahmen des Österreichischen Werkbundes, an dessen Ausstellungen sich Sobotka mehrmals mit zahlreichen Möbelentwürfen beteiligte, deren elegante, gemäßigte Moderne viel zur Qualität der »Wiener Wohnraumkultur« beitrug. Sobotka hatte auch immer wieder diverse Fachartikel publiziert, wo er sich insbesondere mit der Problematik der Erzeugung eines »billigen, aber qualitätvollen Gebrauchsgegenstandes " auseinandersetzte. ${ }^{172}$

Als einer der maßgeblichen Protagonisten des Österreichischen Werkbundes war Sobotka auch am Projekt der Wiener Werkbundsiedlung beteiligt. Sein einstöckiges Doppelhaus (Wien I3, Veitingergasse 95-97), das neben dem von Wlach zu liegen kam, zeichnete sich durch eine funktionelle Schlichtheit aus und verfügte über keine Balkons oder Terrassen. So wie das Doppelhaus von Strnad wurde auch dieses im Krieg zerstört. Über seine Arbeit in den späten Dreißigerjahren ist nur wenig bekannt. Nach dem "Anschluss" Österreichs 1938 gelang es ihm, in die USA zu emigrieren. Vorerst ließ er sich in New York nieder, wo er Bugholzmöbel für die Firma Thonet entwarf und als Designer tätig war. Anfang der Vierzigerjahre erhielt er einen Lehrauftrag an der Carnegie University in Pittsburgh, den er bis zu seiner Emeritierung I 958 innehatte. In diesem Kontext publizierte er auch theoretische Schriften über den Wohnhausbau und das Möbeldesign. ${ }^{173}$ Ein Intermezzo ohne Folgen blieb hingegen der Versuch, wieder in seiner alten Heimat tätig zu sein, als er I952/54 in Zusammenarbeit mit Erich Boltenstern in Wien ein Bürohaus für die Veitscher Magnesitwerke (Wien I, Schubertring Io) projektierte. Mehrere widrige Umstände, insbesondere die kleinliche bürokratische Handhabung seiner Architektenbefugnis, die ihm als "Ausländer" verweigert wurde, sodass er offiziell nur eine beratende Funktion ausüben und

I72 W. Sobotka, Der gute billige Gegenstand, in: Ausstellungskatalog Wiener Werkbund, Wien 1930/3 I. I73 Unter anderem Residential furniture, Pittsburgh 1950. 
64. Walter Sobotka, Wohnhausanlage d. Gemeinde Wien,

Wien 3, Schrottgasse Io-I 2, erbaut I 927/Prokop

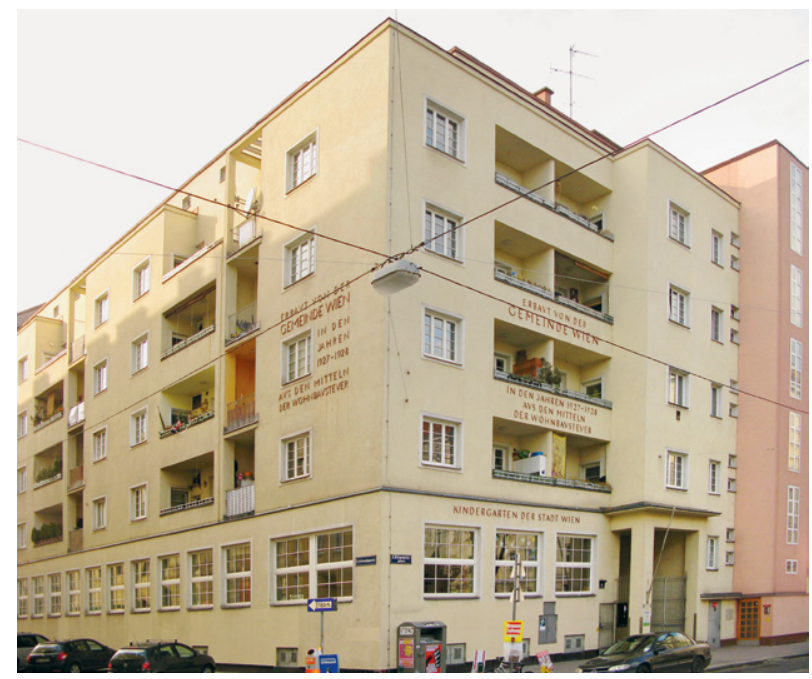

kaum Einfluss auf die Ausführung des Baus nehmen konnte, waren äußerst kränkend und haben seinen Wiedereinstieg in Österreich verhindert.

In den USA arbeitete er hingegen nach seiner Emeritierung wieder als freier Architekt und konnte in Pittsburgh einige Wohnhäuser errichten. Sobotkas späte Jahre waren darüber hinaus durch eine familiäre Tragödie belastet, als seine Tochter Ruth noch in jungen Jahren an Krebs verstarb. In der Folge widmete Sobotka seiner geliebten Tochter ein Buch. Unpubliziert blieb dagegen die Zusammenfassung seiner didaktischen Erfahrung in den als dreibändiges Werk angelegten "Principles of Design", wobei der letzte Band seine langjährige Korrespondenz mit Josef Frank als Manifest ihrer Freundschaft beinhalten sollte. Als Sobotka hochbetagt im fünfundachtzigsten Lebensjahr verstarb, war es bezeichnenderweise einzig sein gleichfalls in den USA lebender Freund Felix Augenfeld der ihm einen längeren Nachruf in der "Presse" widmete. ${ }^{174}$ Dessen ungeachtet wurde noch längere Zeit ein falsches Todesdatum kolportiert, was nicht zuletzt das Desinteresse der damaligen Zeit reflektiert.

Soweit eine Zusammenfassung der wichtigsten Schüler Karl Königs. Damit ist diese Gruppe jedoch keinesfalls umfassend behandelt. Insbesondere im Kapitel über die Opfer werden noch weitere Namen aus diesem Umfeld genannt werden.

174 F. Augenfeld, Nachruf Walter Sobotka, in: Die Presse, 24.5.I 972. 


\section{Der Kreis um Adolf Loos}

Neben der Gruppe um Josef Frank und seine Mitarbeiter gab es in Wien gleichzeitig auch einen Kreis von Architekten, die in einem Naheverhältnis zu Adolf Loos standen, wobei die Grenzen der beiden Gruppierungen durchaus fließend waren. Denn wie bereits erwähnt, waren sowohl Frank als auch seine Mitarbeiter von den Ideen Adolf Loos' beeinflusst. Im Speziellen geht es hier um unmittelbare Schüler und Mitarbeiter von Loos, die, durch dessen Bauschule geprägt, seine Ideen weiterführten. Da diese Bauschule jedoch als Institution nie genau definiert war, sondern eher als lose Diskussionsgruppe anzusehen ist, lässt sich der Personenkreis bis heute nicht genau rekonstruieren. ${ }^{175}$ Charakteristisch für diese Gruppierung war, dass man hier die Moderne etwas rigoroser vorantrieb, als es Frank und seinen Kollegen vorbehalten war. In Hinblick auf die konkrete Thematik ist zudem bemerkenswert, dass nahezu alle Schüler und Mitarbeiter von Loos jüdischer Herkunft waren. Generell bevorzugte Loos, der selbst kein Jude war, auch im privaten Kreis - sei es bei Freunden wie Karl Kraus und Peter Altenberg oder auch bei seinen Lebensgefährtinnen - Personen mit einem jüdischen Hintergrund. Möglicherweise erklärt sich dieser Umstand durch seine avantgardistische Haltung, die beim aufgeklärten und aufgeschlossenen jüdischen Bürgertum mehr Anklang fand als in einem konservativ-katholisch geprägten Milieu.

\subsection{Jacques Groag und Paul Engelmann - das Projekt des "Wittgenstein-Hauses"}

$\mathrm{Zu}$ den bemerkenswertesten Schülern von Adolf Loos gehört Jacques Groag (I8921962, Abbildung 65), ${ }^{176}$ der einen großen Anteil an der Wiener Moderne der Zwischenkriegszeit, insbesondere der damals florierenden Wohnraumkultur, hatte. Groag stammte, wie auch Adolf Loos oder Josef Hoffmann, aus dem damaligen Kronland Mähren.r 892 in Olomouc/Olmütz als jüngster Sohn einer wohlhabenden, deutsch akkulturierten jüdischen Unternehmerfamilie geboren, kam er schon als junger Student 1909 nach Wien, um hier bis zu seiner erzwungenen Emigration tätig zu sein. Neben seinem Bauingenieursstudium an der Wiener Technischen Hochschule nahm den jungen Studenten schon bald die künstlerische Avantgarde rund um Adolf Loos und Karl Kraus, die damals im Café Museum ihre Diskussionsrunden hatten,

I75 Siehe dazu B. Rukschcio/R. Schachel, Adolf Loos, Salzburg/Wien 1982.

I76 P. Plaisier, De leerlingen van Adolf Loos, Delft 1987. 


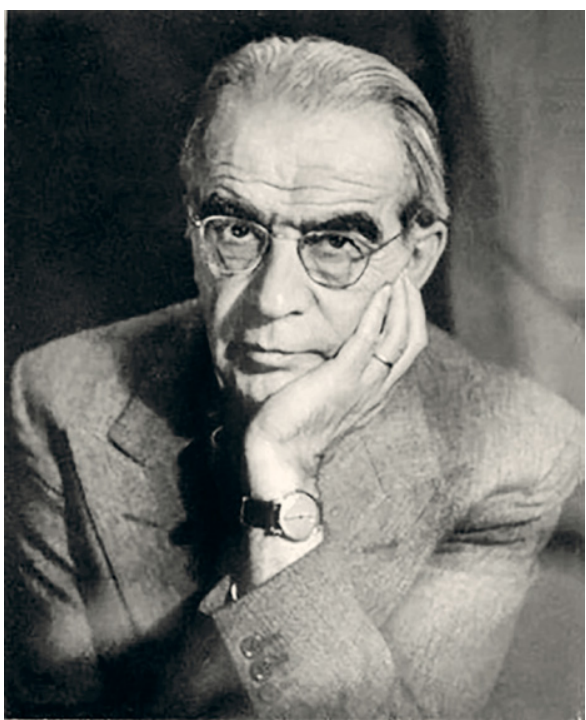

65. Jacques Groag, Foto von Trude Fleischmann, um $1950 /$ privat

gefangen. ${ }^{177}$ Gerade zu diesem Zeitpunkt tobte in Wien der Streit um das von Adolf Loos errichtete Haus am Michaelerplatz, das in seiner völligen Ornamentlosigkeit von konservativer Seite als Provokation empfunden wurde. Wahrscheinlich war Jacques Groag von Engelmann, mit dem er weitläufig verwandt und seit seiner Schulzeit in Olmütz befreundet war, in diesen intellektuellen Kreis eingeführt worden. Paul Engelmann (1891-1965, Abbildung 66), der nur wenig älter war, hatte sein Studium schon ein Jahr zuvor gleichfalls an der Technik in Wien begonnen, war aber schon bald in die Bauschule von Adolf Loos, den er ungemein bewunderte, gewechselt. Konsequenterweise war Engelmann auch ein begeisterter Anhänger von Karl Kraus, der mit Loos eng befreundet war und mit diesem für die Sache der Moderne kämpfte. Vorübergehend arbeitete Engelmann sogar als Sekretär für die von Karl Kraus herausgegebene Zeitschrift "Die Fackel« und setzte sich auch in einem von ihm verfassten Sonett vehement für das damals gerade neu errichtete und höchst umstrittene »Haus am Michaelerplatz« von Adolf Loos ein. ${ }^{178}$ Angesichts dieses Umfeldes überrascht es nicht, dass sich auch Jacques Groag bemüßigt fühlte, neben seinem Technikstudium die damals gerade ins Leben gerufene Bauschule von Adolf Loos zu besuchen. Der Ausbruch des Ersten Weltkrieges I9I4 unterbrach allerdings sein Studium und Jacques Groag wurde aufgrund seiner technischen Ausbildung als Reserveoffizier zur

I77 J. Groag, Erinnerungen (unpubliziertes Typoskript/U. Prokop).

I78 Siehe dazu P. Wijdeveld, Ludwig Wittgenstein, Architekt, Cambridge/Mass. I994, S. 48. 
66. Paul Engelmann, Porträt/Bakaczy (Edda

Wolfner)

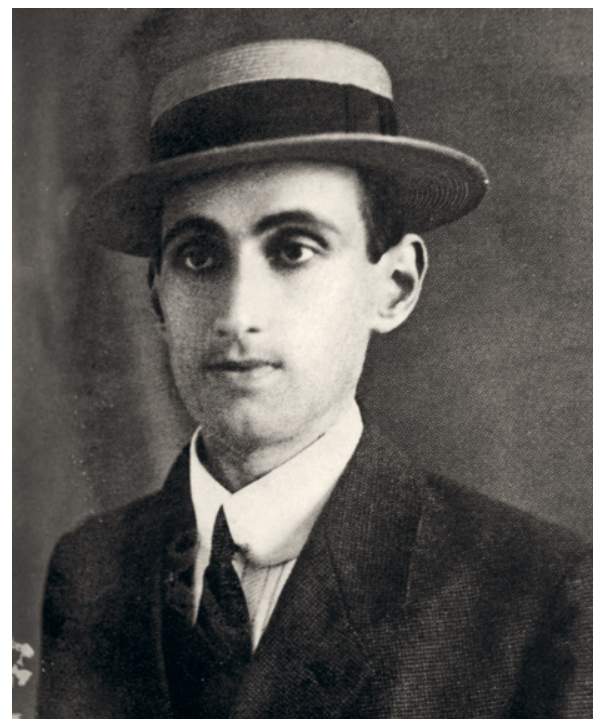

Artillerie eingezogen. Als junger Offizier diente er an vorderster Front, wo er einmal unter heftigen Artilleriebeschuss geriet. Durch das intensive Trommelfeuer erhielt er einen Schock, der bei ihm zu einem Trauma führte, das ihn zeitlebens psychisch belastete.

Erst nach Ende des Krieges konnte Groag sein Studium abschließen, danach praktizierte er in einigen Baubüros, unter anderem bei Fritz Keller, mit dem ihn neben dem deutsch-jüdischen Milieu auch die Herkunft aus den böhmischen Kronländern verband. Nachdem sich die wirtschaftliche Situation Mitte der Zwanzigerjahre in Österreich etwas stabilisiert hatte, machte sich Jacques Groag in Wien schließlich selbstständig und war gleich am Anfang seiner Tätigkeit in zwei architekturhistorisch äußerst bedeutende Projekte eingebunden. Für seinen ehemaligen Lehrer Adolf Loos, der zu diesem Zeitpunkt weitgehend in Paris lebte, übernahm er um 1927 die Bauführung der Villa Moller in Wien-Währing (Starkfriedgasse I8), wo er infolge des Umstandes, dass Loos die nötigen Pläne nur sehr unzulänglich nach Wien schickte, selbst gestalterisch Anteil nahm. ${ }^{179}$ Praktisch gleichzeitig leitete er auch den Bau des

I79 Der Bauherr Hans Moller war ein vermögender Unternehmer und Kunstmäzen, in dessen Haus unter anderen Adolf Loos und Arnold Schönberg verkehrten, während seine Frau Anny Moller, die am "Bauhaus« studiert hatte, wiederum mit Jacques Groag befreundet war. Die nach dem "Anschluss" marisierte« Villa wurde nach der Restitution an Hans Moller von diesem dem Staat Israel vermacht und dient heute als Residenz des israelischen Botschafters. Siehe dazu U. Prokop, Das Architektenund Designerehepaar Jacques und Jacqueline Groag, Wien u. a. 2005, S. 3 Iff. 
sogenannten "Wittgenstein-Hauses« (Wien 3, Kundmanngasse I9, Abbildung 67), dessen Entwurf ursprünglich von seinem Freund Paul Engelmann angefertigt worden war, der von der Bauherrin Margaret Stonborough-Wittgenstein den Auftrag erhalten hatte, eine Stadtvilla in der Art von Adolf Loos zu errichten. ${ }^{180}$ Da Engelmann jedoch kaum praktische Bauerfahrung hatte, zog er Groag als ausgebildeten Bauingenieur zurate. Verkompliziert wurde das Vorhaben insofern, als sowohl die Auftraggeberin Margaret Stonborough als auch ihr Bruder Ludwig Wittgenstein, der als einer der bedeutendsten Philosophen des 20. Jahrhunderts in die Geschichte eingehen sollte, großen Anteil an der Planung nahmen, was zu äußerst schwierigen und belastenden Situationen für den jungen Jacques Groag führte, der für die bautechnischen Belange und die Kalkulation verantwortlich war. Insbesondere die kostenaufwendigen Planungsänderungen Ludwig Wittgensteins führten mehrfach zu schweren Konflikten zwischen Groag und dem berühmten Philosophen. In der letzten Phase des Baus, Ende 1928/29, als Wittgenstein bereits einem Lehrauftrag in Cambridge nachgekommen war und Engelmann sich weitgehend zurückgezogen hatte, um sich gleichfalls philosophischen Studien zu widmen, war Groag für die Planung der Abschlussarbeiten und den Entwurf verschiedener Einbaumöbel allein verantwortlich, sodass er in gewisser Weise auch an diesem geistesgeschichtlich und architekturhistorisch maßgeblichen Bau schöpferischen Anteil hatte.

Eine allzu sehr auf Ludwig Wittgenstein und seine Philosophie ausgerichtete Geschichtsschreibung des Wittgenstein-Hauses, das in der Zwischenzeit zu einer Ikone des modernen Bauens geworden ist, hat sich bislang kaum damit befasst, inwieweit auch ein spezifisch jüdischer Hintergrund für dieses Vorhaben prägend gewesen sein könnte. Denn neben Paul Engelmann und Jacques Groag waren nicht zuletzt auch die Bauherrin Margaret Stonborough, ihr Bruder Ludwig Wittgenstein und sogar der Inhaber der ausführenden Baufirma Carl Korn weitgehend jüdischer Herkunft. ${ }^{181}$ Speziell in diesem Zusammenhang erhebt sich die Frage, inwieweit neben anderen Einflüssen auch ein gewisses $M a ß$ an jüdischer Tradition die Beteiligten gegenüber den unübersehbaren ikonoklastischen Tendenzen dieses Projektes aufgeschlossen gemacht hat.

I 80 Engelmann war Margarete Stonborough von ihrem Bruder Ludwig Wittgenstein empfohlen worden, der diesen während des Ersten Weltkrieges in Olmütz, wo er zum Offizier ausgebildet wurde, kennengelernt hatte. Engelmann, der sich gleichfalls intensiv mit philosophischen Fragen beschäftigte, war in der Folge einer der treuesten Anhänger Wittgensteins geworden, und seine Schriften sind bis heute eine wichtige Quelle für die Wittgenstein-Forschung. Siehe dazu: J. Bakaczy (Hg.), Paul Engelmann und das mitteleuropäische Erbe, Wien/Bozen o. J. [1999].

I 8 I Die Baufirma Carl Korn wurde ursprünglich in Bielitz-Biała von dem aus Galizien stammenden gleichnamigen Baumeister (1852-1906) gegründet, der späterhin ein Zweigunternehmen in Wien aufmachte. Zum Zeitpunkt des Baus des Wittgenstein-Hauses wurde die Firma, die mit namhaften Wiener Architekten zusammenarbeitete, von seinem Sohn Friedrich Korn (I890-193I) geleitet. 


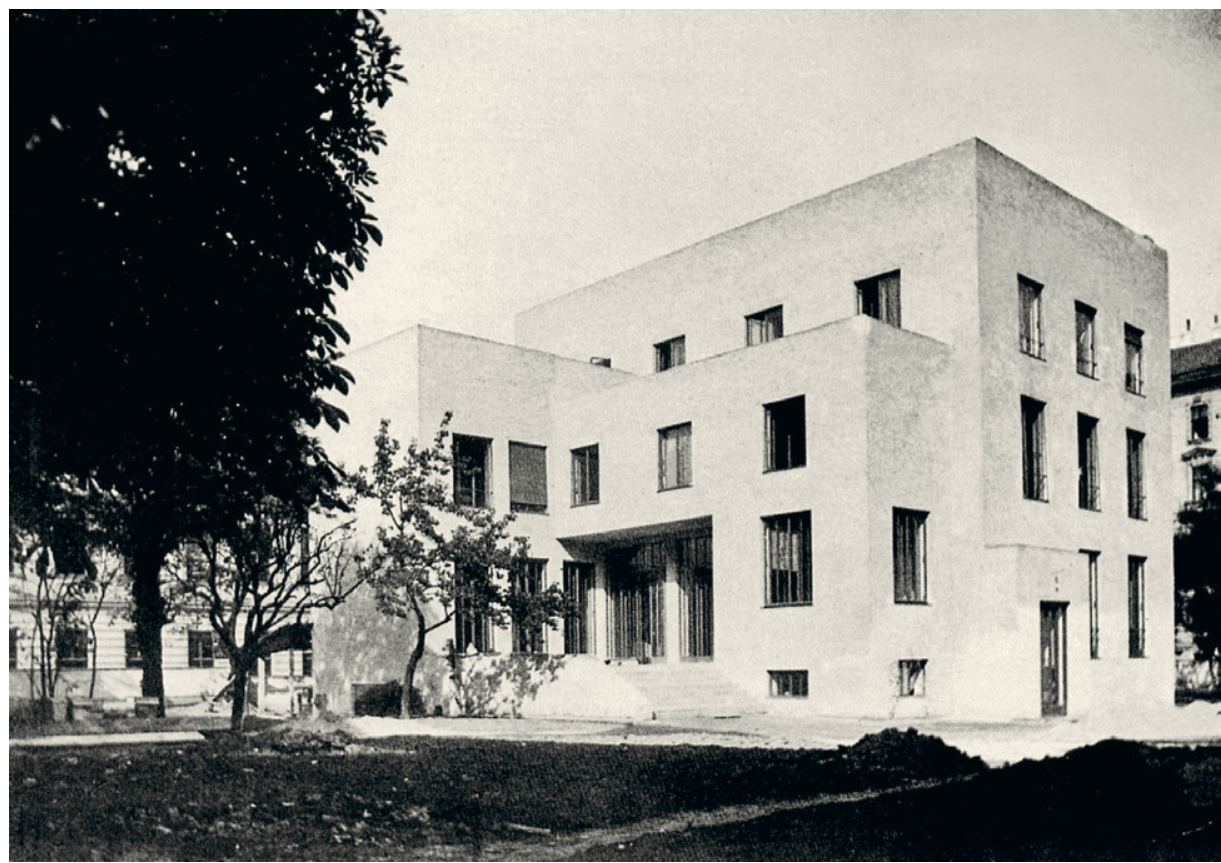

67. Paul Engelmann u. Ludwig Wittgenstein, Haus Wittgenstein (Palais Stonborough), Wien 3, Kundmanngasse I9, erbaut um I928/Wijdeveld

Nach der Fertigstellung des Baus trennten sich die Wege von Jacques Groag und Paul Engelmann weitgehend. Letzterer realisierte noch einige Villen und Siedlungsbauten in Mähren, ${ }^{182}$ um schließlich 1934 nach Palästina auszuwandern. Im Gegensatz zu den meisten anderen in Wien tätigen jüdischen Architekten war Engelmann ein überzeugter Zionist und verließ Österreich, nachdem sich das politische Klima infolge der Etablierung des sogenannten "Ständestaates« verhärtet hatte. Obwohl die Voraussetzungen in der Baubranche im damaligen Palästina angesichts einer großen Zuwanderungswelle relativ gut waren, widmete sich Engelmann jedoch lieber seinen philosophischen Studien und arbeitete nur fallweise als Architekt, wenn er gerade Geld benötigte. Dies erklärt sein relativ bescheidenes - zum Großteil auch noch nicht aufgearbeitetes - CEuvre aus diesen Jahren. Im Rahmen seiner Tätigkeit für die Einrichtungsfirma »Cultivated Home« von Arthur Wachsberger richtete er unter anderem das »King David Hotel« und den Presseclub in Jerusalem ein. Er beteiligte sich auch

I 82 Siehe dazu I. Scheidl, Paul Engelmann, in: Architektenlexikon, sowie Weihsmann, beide zit. Anm. I3. 
in Zusammenarbeit mit Kurt Unger an diversen städtebaulichen Projekten für Haifa und Akko, die jedoch nicht zur Ausführung gelangten. Einer der wenigen erhalten gebliebenen Bauten Engelmanns ist das Haus Yadlin, das 1937/38 in Haifa errichtet wurde und auf den Ideen des Loos'schen Raumplanes basiert. ${ }^{183}$ Sich weitgehend auf seine publizistische Arbeit beschränkend, die insbesondere auch biografische Studien zu Karl Kraus, Adolf Loos und Ludwig Wittgenstein umfassten, ist Engelmann ${ }_{96} 6$ in Tel Aviv gestorben.

Ganz anders verlief hingegen der weitere Lebensweg von Jacques Groag, der kurze Zeit nach der Vollendung des Wittgenstein-Hauses nahezu uneingeschränkt seine eigenen Vorstellungen beim Bau eines Wohnhauses für seinen Bruder Emo Groag in Olmütz/Olomouc umsetzen konnte. In der Folge entstand auf einem bis dahin unerschlossenen städtischen Areal im Süden der Stadt in den Jahren I927/28 ein Einfamilienhaus, das in seiner rigiden Struktur und mit seinem streng kubischen Baukörper ganz dem Geist von Adolf Loos verpflichtet war (Abbildung 68). Die konsequente Umsetzung eines radikal funktionalistischen Konzepts seitens des Architekten zur Erzielung der größten Raumökonomie und die Anwendung der puristischen Formensprache der damaligen Moderne stellte jedoch für alle Beteiligten eine große Herausforderung dar und führte nicht zuletzt zu Konflikten mit der Familie. ${ }^{184}$ Dessen ungeachtet entstand mit diesem Projekt Ende der Zwanzigerjahre eine der wegweisendsten Villenbauten in der damaligen Tschechoslowakei. Seinen Vorstellungen gemäß entwarf Jaques Groag auch die Inneneinrichtung des Einfamilienhauses, wobei raumsparende Einbaumöbel und leichte, bewegliche Versatzstücke dominierten.

Dem allgemeinen Zeittrend entsprechend musste sich Groag in diesen Jahren vor allem was seine Tätigkeit in Wien betraf - auf Einrichtungen und Umbauten konzentrieren. Von Vorteil erwies sich hier, dass er in Wiener Künstlerkreisen gut vernetzt war. Da er sich selbst auch als Maler betätigte und zeitweise sogar ausstellte, unterhielt er gute Kontakte zu Künstlerkollegen wie Sergius Pauser, Josef Dobrowsky und dem Bildhauer Georg Ehrlich. Insbesondere im Sommer traf man sich gerne in Zinkenbach am Wolfgangsee, um dort einen künstlerischen Austausch zu pflegen. Interessanterweise war diese sommerliche Malerkolonie höchst gemischt. Neben konservativen Monarchisten und späteren Nationalsozialisten waren nicht wenige der Künstler und Künstlerinnen jüdisch. ${ }^{185}$ Aber neben seinen Freundschaften zu bildenden Künstlern und Architektenkollegen wie etwa Felix Augenfeld verkehrte Jacques

I 83 J. Bakaczy, zit. Anm. I80.

I 84 Siehe Prokop, Anm. I79, S. 4off.

I 85 Neben den bereits angeführten gehörten unter anderen auch Ernst Huber, Heinrich Jungnickel, Georg Merkel, Gudrun Baudisch und Oskar Laske der Zinkenbacher Malerkolonie an. 


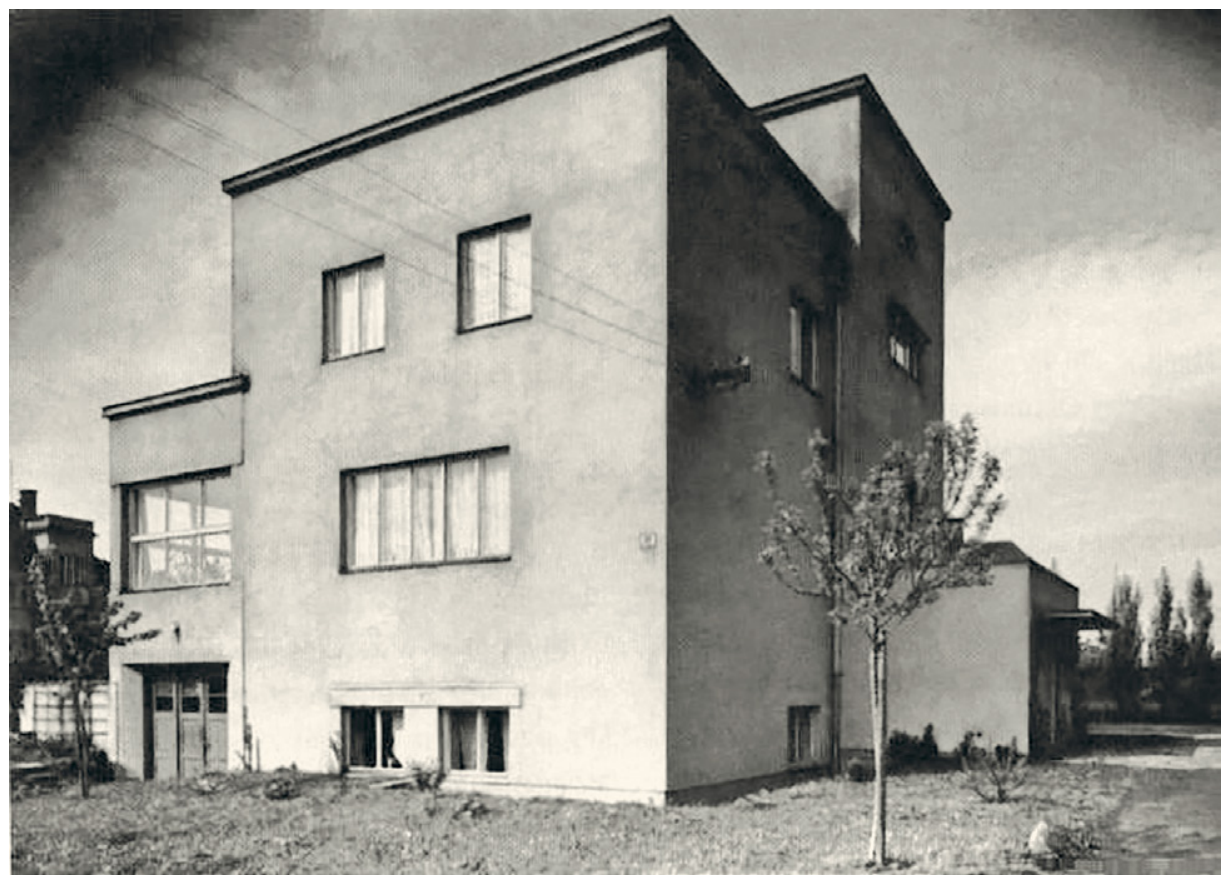

68. Jacques Groag, Villa Groag, Olmütz/Olomouc, Mozartova 36, erbaut 1927/privat

Groag auch in Schauspielerkreisen. Möglicherweise spielte in diesem Zusammenhang die bekannte Fotografin Trude Fleischmann eine Rolle, die mit Groag schon seit jeher befreundet und insbesondere auf Fotoporträts von Schauspielern spezialisiert war. Faktum ist, dass Jacques Groag in den Dreißigerjahren seitens damals sehr populärer Künstlerinnen wie Liane Haid und Paula Wessely nicht unbedeutende Aufträge für Umbauten und Inneneinrichtungen erhielt, die viel zu seiner Bekanntheit beitrugen. Zur Beliebtheit seiner Einrichtungen, die sich durch Leichtigkeit und Transparenz auszeichneten, trug sicherlich bei, dass er es sehr geschickt verstand, die Tendenzen der zeitgenössischen Moderne dem eher moderaten Wiener Geschmack anzupassen (Abbildung 69). In dieser Zeit lernte Jacques Groag auch die Textildesignerin Hilde Blumberger kennen - es wird von ihr noch im Kapitel zu den Kunstgewerblerinnen die Rede sein -, die des Öfteren an seinen Einrichtungen mitarbeitete und später auch seine Frau wurde. Ihre Vorhang- und Teppichentwürfe bildeten zumeist einen farbkräftigen Akzent im Rahmen seiner Interieurs.

Um I930 war Jacques Groag auch dem Werkbund beigetreten, wo er seine Möbel bei diversen Ausstellungen der Vereinigung einer breiteren Öffentlichkeit präsentieren konnte. Konsequenterweise gehörte er daher auch zu dem Kreis von Architekten, 


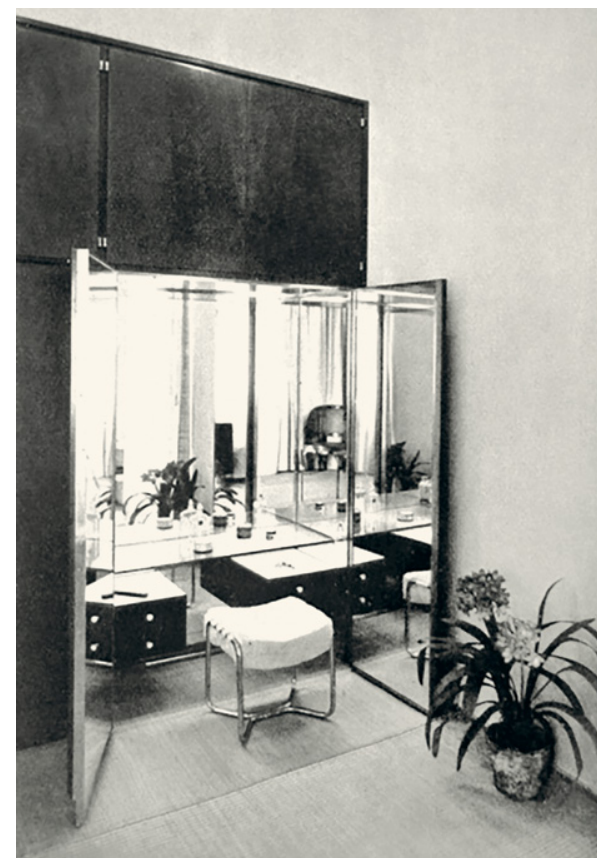

69. Jacques Groag, Interieur, um I932/Innendekoration

die eingeladen wurden, beim Projekt der Wiener Werkbundsiedlung mitzuarbeiten. Trotz seiner tschechischen Staatsbürgerschaft, die er nach Ende des Ersten Weltkrieges angenommen hatte, wurde er bei der Gruppe der "österreichischen « Architekten angeführt - offensichtlich im Hinblick darauf, dass sich sein Wohnsitz und sein Atelier in Wien befanden und die Angehörigen dieser Generation, die noch in der Monarchie groß geworden waren, sich ungeachtet ihrer formalrechtlichen Staatszugehörigkeit weiterhin als "Österreicher « empfanden. ${ }^{186}$

Da Groag von Anfang an in dieses Vorhaben eingebunden war, erfolgten die ersten Planungen bereits I929. ${ }^{187} \mathrm{Im}$ Sinne der angestrebten Typenvielfalt konzipierte

I 86 Groag hatte aufgrund seines Geburtsortes Olmütz/Olomouc nach Ende des Ersten Weltkrieges für die damalige Tschechoslowakei optiert, obwohl sich sein Hauptwohnsitz in Wien befunden hatte. Auch Adolf Loos hatte sich als gebürtiger Brünner für die tschechische Staatsbürgerschaft entschieden. Diese Fälle zeigen die nationale Problematik, der viele nach dem Auseinanderbrechen der Monarchie ausgesetzt waren.

I 87 Jacques Groag war schon bei den ersten Planungsarbeiten 1929 für das Gelände bei der "Spinnerin am Kreuz« mit einem Doppelhaus einbezogen. Möglicherweise musste er seine Entwürfe für die Lainzer Siedlung kaum umarbeiten. Die Einreichpläne des realisierten Hauses datieren vom Jänner I93 (MA 37/E. Z. IоI2). 


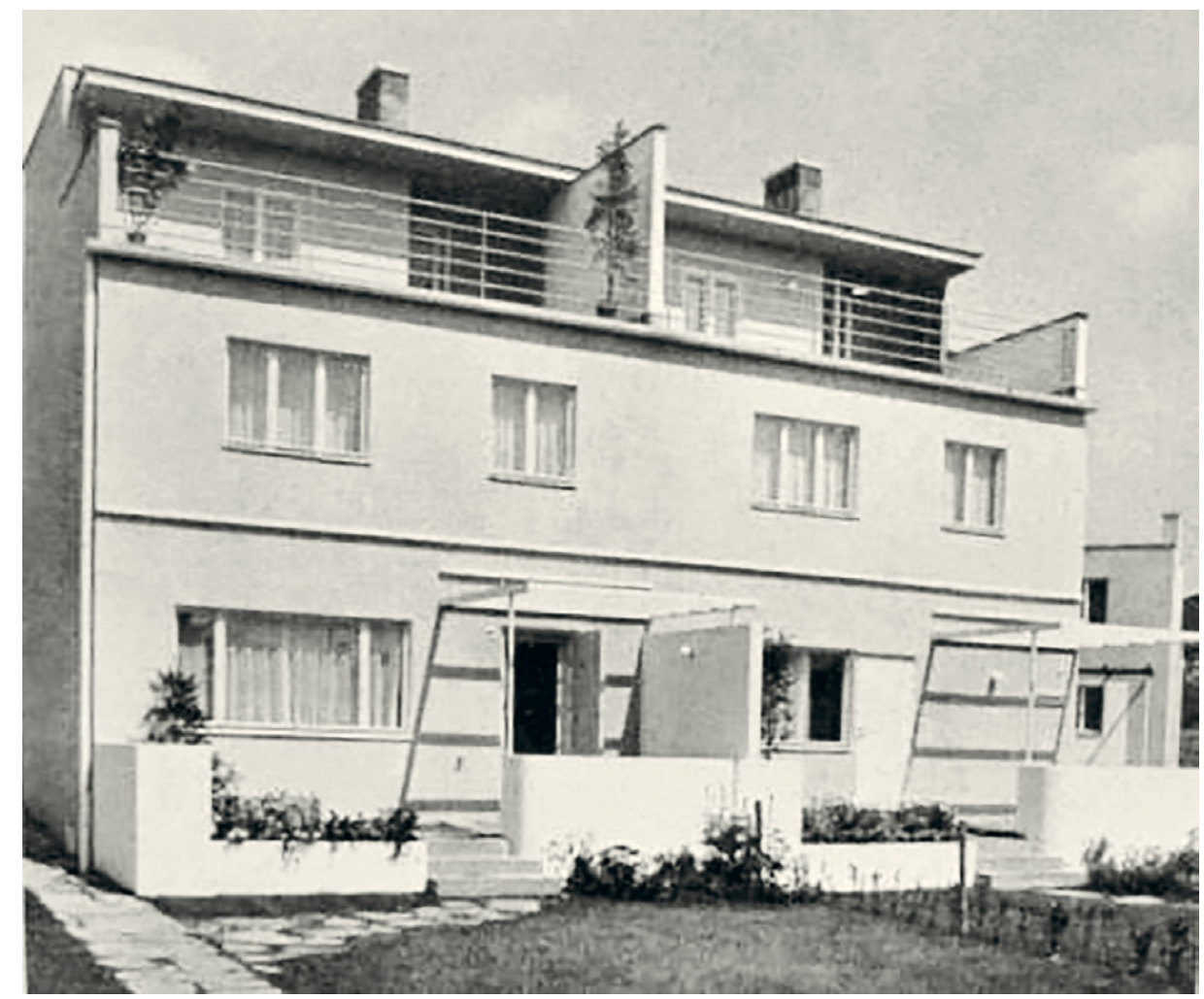

70. Jacques Groag, Doppelhaus in der Werkbundsiedlung, Wien I3, Woinovichgasse 5-7, erbaut I932/ Moderne Bauformen

Groag ein dreigeschoßiges Doppelhaus (Wojnovichgasse 5-7) für eine Hanglage mit einer betonten Nord-Süd-Ausrichtung (Abbildung 70). Obwohl in der Raumorganisation weitgehend identisch, weichen die Pläne der beiden Häuser in einigen kleineren Details voneinander ab, was sich auch seinerzeit in einem leicht unterschiedlichen Preis niederschlug. Ausgehend von einer differenzierten Geschoßhöhe - in der Art eines Loos'schen Raumplanes - gelang es Groag, trotz des Nachteils der Hanglage eine optimale Raumökonomie zu erzielen. Im rückwärtigen, höher gelegenen Teil situierte er einen Vorraum und die Küche. Über einige Stufen war der etwas tiefer gelegene Wohnraum zu erreichen, der über die größte Geschoßhöhe verfügte. Die in die Wohnräume integrierte Treppe diente zusätzlich auch als trennendes Element zwischen den unterschiedlichen Funktionen wie Ess- und Wohnbereich. Aus Kostengründen war auch nur dieser vordere Teil unterkellert. Im Obergeschoß befanden sich jeweils drei Zimmer und ein Bad. Das Dachgeschoß mit Atelier und Terrasse war im 
Hinblick auf einen eventuellen späteren Ausbau angelegt. In der Außenerscheinung zeichneten sich die beiden mit einem Flachdach abgeschlossenen Häuser durch eine klare Gliederung aus, deren Rhythmisierung mittels unterschiedlicher Fenstertypen betont wurde. Das zurückgestufte Terrassengeschoß lockerte die kubische Geschlossenheit des Baukörpers auf. Mittels einer kleinen Laube und einem vorgesetzten Gartenplatz schuf Groag eine für ihn charakteristische fließende Verbindung zum Vorgarten.

Sowohl durch die optimale Ausnutzung der relativ klein dimensionierten Häuser als auch eine dem Zeitgeist entsprechende ästhetische Form gehörte Groags Doppelhaus zu den am meisten gelobten Objekten der Werkbundsiedlung. »Die Häuser Groags mit den schönen Terrassen erfreuen durch eine klug abgewogene Wirkung, man kann auf seine nächsten Arbeiten neugierig sein«, urteilte die "Neue Freie Presse«. ${ }^{188}$ Sogar die antisemitische "Reichspost«, die sich, wie bereits angeführt, generell ablehnend gegenüber der Idee der Werkbundsiedlung und hier insbesondere gegenüber dem Konzept Josef Franks verhielt und die meisten der Häuser vernichtend kritisierte, konnte es sich nicht versagen, den "vorzüglichen Grundriss und die Raumeinteilung" zu loben. ${ }^{189}$

Auch die Musterinneneinrichtung - angedacht für den Zeitraum, in der die Werkbundsiedlung als Ausstellung zugänglich war - wurde von Groag bis ins kleinste Detail selbst gestaltet, wobei er neben den Lehren von Adolf Loos auch von den Theorien Strnads beeinflusst war, die dieser insbesondere in seinem Aufsatz "Neue Wege in der Wohnraumeinrichtung" (1922) niedergelegt hatte. Dabei werden Wände nicht als Begrenzung aufgefasst, sondern möglichst transparent gestaltet. Dementsprechend sind die meisten der Möbel tatsächlich »mobil«. Einbaumöbel dienen zumeist als Fensterbänke oder Regale und zeichnen sich durch eine minimalistische Grazilität aus (Abbildung 7I). Vorhänge sind oft auch als Trennelemente konzipiert, die mit den als Bodenbelägen dienenden Japanmatten farblich abgestimmt sind. Kräftige Farbakzente setzen hingegen die von Hilde Blumberger entworfenen Wandbehänge.

Obwohl die Baukosten der beiden Häuser mit 40.000 bzw. 4I.00o Schilling sich im oberen Bereich des vorgegebenen Rahmens bewegten, gehörten diese dennoch zu den wenigen, die einen privaten Käufer fanden. Im konkreten Fall handelte es sich um das Ehepaar Eva und Stefan Schanzer, das bereits zuvor mit Adolf Loos, der mit Eva Schanzers Schwester Claire Beck verheiratet war, wegen der Planung eines Hauses in Kontakt gestanden hatte. Das Vorhaben war aber nicht zur Ausführung gelangt, sodass die beiden schließlich Groags Haus in der Werkbundsiedlung erwarben, das

I 88 Neue Freie Presse, I 5.6.1932.

I 89 Reichspost, I9.6.1932. 


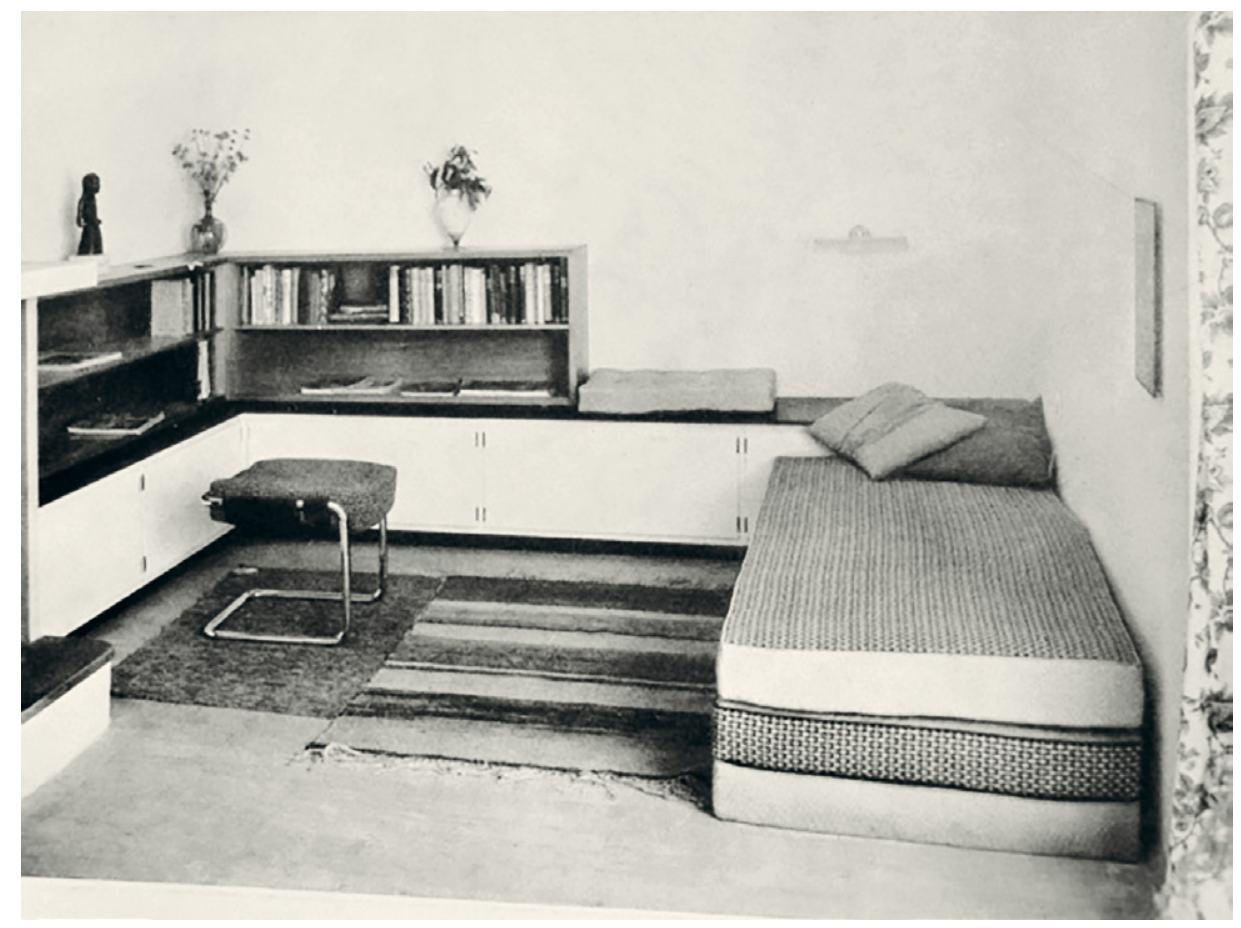

7I. Jacques Groag, Werkbundsiedlung, Einrichtung, 1932/Moderne Bauformen

dieser auch dann nach ihren Vorstellungen adaptierte. Eva Schanzer beging nach dem "Anschluss" infolge der diskriminierenden Judengesetzgebung Selbstmord, während ihrem Mann mit den beiden Kindern die Flucht in die Emigration gelang. ${ }^{190}$ Auch diese Episode zeigt, wie sehr Jacques Groag mit dem Umfeld von Adolf Loos verbunden war.

Ungeachtet des persönlichen Erfolges, den Groag im Rahmen des Projektes der Wiener Werkbundsiedlung einheimsen konnte, blieben die großen Bauaufträge dennoch aus. Außer einem kleinen Einfamilienhaus für einen Arzt in Perchtoldsdorf bei Wien musste er sich weiterhin weitgehend auf Einrichtungen und Umbauten beschränken. ${ }^{191}$ Günstiger war hingegen die Situation in seinem heimatlichen Mähren,

I90 B. Sauer, Licht, Luft, Sonne im modern eingerichteten Eigenheim, in: Werkbundsiedlung Wien 1932 (Kat.), Wien 2012, S. $260 f f$.

I 9 I Haus Dr. Gustav Stern, Perchtoldsdorf, NÖ, Franz-Josef-Straße 28, publiziert in: Moderne Bauformen I934, S. 32If. Das Gebäude, das seinen Eigentümern 1938 weggenommen und nach dem Krieg restituiert wurde, ist trotz diverser Veränderungen noch in seiner Substanz erhalten. 
wo er infolge der relativ guten Wirtschaftslage in der damaligen Tschechoslowakei eine rege Tätigkeit entfalten konnte. Neben einigen sehr qualitätvollen Villen in einer Heimatstadt Olmütz/Olomouc und im polnischen Skotschau/Skoczow (ehemals Österreichisch-Schlesien), entstanden nach seinen Plänen in den Dreißigerjahren auch größere Wohnhausanlagen, Industriebauten und anderes mehr in Brünn/Brno und Mährisch-Ostrau/Ostrava.

Eine große Resonanz erzielte Jacques Groag schließlich mit einem Landhaus, das in den Jahren 1935/36 in Ostravice errichtet wurde. Der kleine Ort in den Beskiden wurde infolge seiner reizvollen Lage damals gerade touristisch erschlossen. Auftraggeber war ein Industrieller aus Mährisch-Ostrau, der sich in dieser malerischen Region ein erholsames Refugium schaffen wollte. In einer komplexen Kombination von orthogonalen Strukturen mit organischen Formen gelang es Groag, sowohl eine optimale Raumökonomie als auch eine harmonische Einbindung des Baus in die umgebende Landschaft zu gewährleisten. Die schlanken Pilotis, auf denen das stark vorkragende Dach ruhte, und eine fein abgestimmte Farbigkeit verliehen dem kleinen Landhaus ein Höchstmaß an Luzidität und Harmonie. Dieses bemerkenswerte Projekt, das im folgenden Jahr, I937, auch in zahlreichen ausländischen Architekturzeitschriften publiziert wurde und das Interesse der internationalen Fachwelt erregte, hätte möglicherweise für Groag den Sprung in die Reihe der ganz großen europäischen Architekten bedeutet, wenn das Schicksal nicht eine andere Wendung genommen hätte. ${ }^{192}$

Nach dem sogenannten "Anschluss« Österreichs im März I938 geriet Groag als Jude in eine unmittelbar seine Existenz gefährdende Situation und er verließ mit seiner Frau Wien fluchtartig, um nach Prag zu übersiedeln. Als tschechischer Staatsbürger konnte er dies noch ohne größere bürokratische Schwierigkeiten und befand sich damit in einer glücklicheren Situation als viele seiner Wiener Kollegen, denen die Einreise in diesen dramatischen Tagen noch an der Grenze verwehrt wurde. Aufgrund dieses Umstandes konnte Groag auch einen Teil seines Hausrates und seiner fachlichen Unterlagen mitnehmen. In Prag etablierte er sich in einem Büro in der Altstadt und konnte seine Tätigkeit vorerst weiterführen. Dessen ungeachtet bedeutete diese erzwungene Emigration bereits, dass er von der Bildfläche der Fachwelt verschwand, da er ab nun seine Projekte nicht mehr publizieren konnte. In Fachzeitschriften des Deutschen Reiches unterblieb bereits seit ungefähr 1935 (das Jahr, in dem die "Nürnberger Rassegesetze« verkündet wurden), ab I938 dann auch in der "Ostmark« jegliche Berichterstattung über die Tätigkeit von jüdischen Künstlern - sie wurden von

I92 Publiziert u.a. in Innendekoration 1937, S. I2ff.; Domus 1937, S. Iff.; Architectural Review I938, S. 172 . 
nun an nicht mehr wahrgenommen und fielen damit der Damnatio Memoriae anheim. Ihre Bilder und Bücher wurden vernichtet, ihre Stücke nicht aufgeführt, ihre Bauten »arisiert « und oft bis zur Unkenntlichkeit verändert. Dies erklärt auch, warum so viele jüdische Künstler dieser Zeit in Vergessenheit geraten sind.

Rund ein Jahr konnte Groag noch in Prag arbeiten, wobei man nicht genau weiß, mit welchen Projekten er damals beschäftigt war. Möglicherweise hatte er diverse, bereits begonnene Bauvorhaben in Brünn und Mährisch-Ostrau weitergeführt. Gesichert ist für diese Zeit nur ein Einfamilienhaus in Prag-Smichov. ${ }^{193}$ Als im Frühjahr I939 die Tschechoslowakei gleichfalls von Nazi-Deutschland okkupiert wurde, sahen sich die Groags neuerlich gezwungen zu fliehen. In einer abenteuerlichen Reise gelangten sie über Paris und Holland - kurz bevor die Grenzen geschlossen wurden ohne Visum nach England. Die Zeiten dort waren hart für die Emigranten, einzig die gegenseitige Hilfe ermöglichte überhaupt ein Überleben. Neben den Bedrohungen und Nöten, die der Krieg mit sich führte - insbesondere in der schweren Zeit des "Blitzes" (des Bombardements von London) -, war es äußerst schwierig, sich eine neue Existenz aufzubauen. Obwohl tschechischer Staatsbürger und daher nicht als "feindlicher Ausländer« eingestuft, konnte Groag, der auch mit Sprachproblemen zu kämpfen hatte, nur schwer Fuß fassen. Infolge seiner hohen fachlichen Qualifikation auf dem Gebiet des Möbeldesigns wurde er jedoch gleich nach Kriegsende mit der Gestaltung mehrerer Ausstellungen, die sich mit Wohnungseinrichtungen befassten, betraut. Ebenso wurde er in das Team des staatlichen »Utility Furniture«-Projekts aufgenommen, dessen Zielsetzung es war, einfache und billig herzustellende Möbel zu entwerfen. Nach den Kriegszerstörungen galt es möglichst schnell und preiswert wieder Wohnraum zu schaffen und einzurichten. Groag war in der Folge an mehreren bedeutenden englischen Nachkriegsausstellungen beteiligt, oft in Zusammenarbeit mit seiner Frau Jacqueline.

Nachdem er die britische Staatsbürgerschaft erlangt hatte und Mitglied bei den entsprechenden Fachverbänden geworden war, war es ihm wieder möglich, sich allmählich eine Existenz aufzubauen. Während er auf dem Gebiet der Inneneinrichtung und des Möbeldesigns relativ erfolgreich war, schaffte er es jedoch nicht, auf seinem eigentlichen Fachgebiet, der Architektur, wieder tätig zu werden. Ein Lehrauftrag an einer Fachschule für Möbeldesign, in dessen Kontext er auch ein didaktisches Buch zur Geschichte des Möbels herausgab, konnte dieses Manko nicht ganz kompensieren. ${ }^{194}$

Die Einbettung in die Emigrantenszene hatte sicherlich dazu beigetragen die Härten des Exils zu mildern. So lebte das Ehepaar in einem nach eigenem Entwurf

I93 Prokop, zit. Anm. I79, S. Io2f.

I94 J. Groag/G. Russel, The story of furniture, Ipswich o. J. [um I950]. 
eingerichteten Haus in Clifton Hill, ganz in der Nähe von Ernst Freud, dem Sohn von Sigmund Freud. Dieser war gleichfalls Architekt und Schüler von Adolf Loos gewesen, allerdings war er gleich nach seinem Studium von Wien weggegangen und lebte bereits seit 1933 in England. ${ }^{195}$ Da sie gleich alt waren, kannten sie einander ziemlich sicher schon seit ihrer Studienzeit in Wien. Auch die Freundschaft mit anderen Wiener Architekten, etwa Franz Singer und den Brüdern Josef und Arthur Berger, oder dem Bildhauer Georg Ehrlich hielt über die Jahre an. Groag unternahm in den Fünfzigerjahren einige Reisen nach Israel und Europa, bei denen er auch Wien besucht haben soll. Aufträge gab es jedoch seitens seiner ehemaligen Heimat - trotz des Nachkriegsbaubooms - keine. Schließlich starb Jacques Groag völlig unerwartet im Jänner I 962 an einem plötzlichen Herzversagen. Während es in England immerhin einige Nachrufe gab, die ihn - in Unkenntnis seiner seinerzeitigen Bedeutung als Architekt - ausschließlich als Möbeldesigner würdigten, wurde sein Tod in Wien überhaupt nicht zur Kenntnis genommen.

\subsection{Felix Augenfeld und Ernst Schwadron - weitere Protagonisten der Wiener Wohnraumkultur}

Ein weiterer bedeutender Schüler von Adolf Loos und dem Freundeskreis um Jacques Groag zugehörig war Felix Augenfeld (I 893-I984, Abbildung 72). Nur ein Jahr jünger als Groag wurde er 1893 in Wien als Sohn eines gut situierten Kaufmannes geboren. Nach seiner Matura an der Realschule in der Schottenbastei begann er I 9 I o ein Studium an der Technischen Hochschule, wo er unter anderem auch Vorlesungen bei Karl König belegte, der allerdings damals schon kurz vor seiner Emeritierung stand und sicher nicht mehr ganz auf der Höhe der Zeit war. Es verwundert daher nicht, dass der junge Augenfeld, von der konservativen Ausrichtung seiner Lehrer nicht befriedigt, sich an der Bauschule von Adolf Loos weiterbildete, die allerdings, wie bereits angeführt, keinerlei offiziellen Status hatte. Aufgrund dieses Umstandes schloss er erst nach seinem Kriegsdienst im Ersten Weltkrieg sein Studium an der Technischen Hochschule I 920 korrekt mit der 2. Staatsprüfung ab. Schon bald nach seinem Praktikum machte er sich um 1922 in Arbeitsgemeinschaft mit seinem Studienkollegen Karl Hofmann (I890-I960?) selbstständig. ${ }^{196}$ Wie die meisten ihrer Berufskol-

I95 Ernst Freud (1892-1970), der Sohn von Sigmund Freud, hatte in Wien an der Technischen Hochschule und an der privaten Bauschule bei Adolf Loos studiert. Um 1920 ging er nach Berlin und emigrierte bereits 1933 nach London, wo er als Architekt tätig war. Er ist der Vater des Malers Lucian Freud.

I96 Karl Hofmann, I890 in Wien geboren, absolvierte die Technische Hochschule in Wien und arbei- 
72. Felix Augenfeld, Porträt/

Visionäre u. Vertriebene

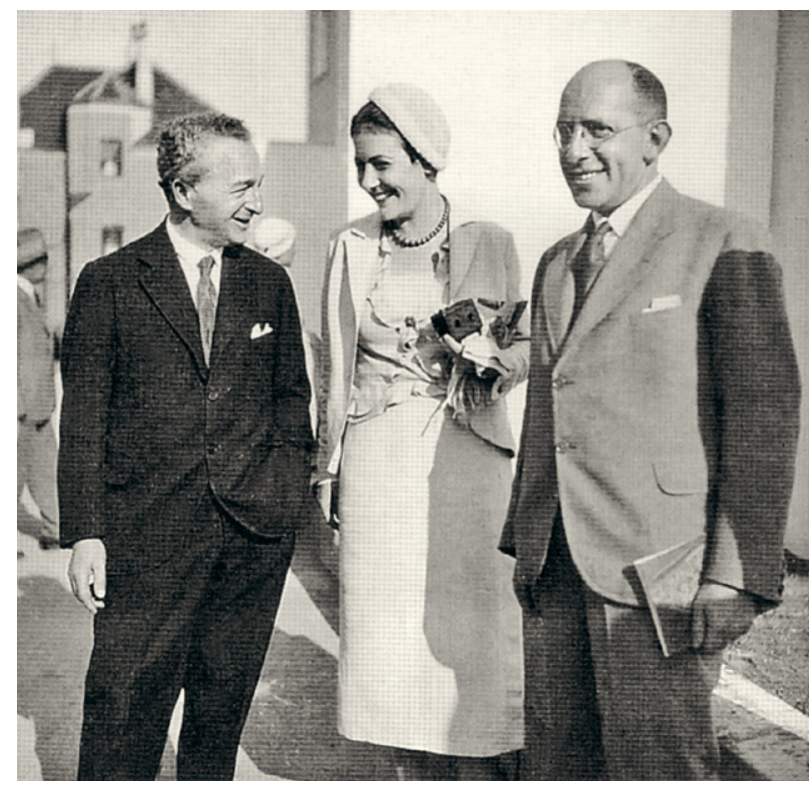

legen mussten auch sie sich vorerst zumeist mit Aufträgen für Inneneinrichtungen begnügen, wobei sie zum Teil für eine sehr prominente Klientel arbeiteten. Insbesondere durch das gemeinsame Studium mit Ernst Freud in der Bauschule von Adolf Loos wurden sie nahezu die "Hausarchitekten" der Familie Freud. Neben diversen Aufträgen für Anna Freud, etwa der Einrichtung ihrer Praxis und dem Umbau ihres Bauernhofes in Hochrotherd/NÖ, entwarfen sie vor allem auch für Sigmund Freud einen Schreibtischsessel, der sowohl den etwas unorthodoxen Sitzgewohnheiten des Wissenschaftlers angepasst war als auch durch seine anthropomorphe Gestaltung eine höchst eigenwillige Handschrift verrät. ${ }^{197}$ Darüber hinaus zählten die beiden Architekten aber auch Intellektuelle und Schriftsteller wie Gina Kaus, Dorothy Burlingham, die Freundin von Anna Freud, oder Hans Weigel zu ihren Kunden. Als Vertreter der Wiener Wohnraumkultur gehörte Augenfeld selbstverständlich auch dem Österreichischen Werkbund an, an dessen Ausstellungen er sich regelmäßig beteiligte. Insbesondere für die Werkschau von I930 entwarf Augenfeld eine "Tagesbar«, deren

tete bis zu seiner Emigration mit Augenfeld zusammen. Er flüchtete nach dem "Anschluss« Österreichs zuerst nach Brünn und ging dann höchstwahrscheinlich nach Australien. Sein Todesdatum ist unbekannt (siehe dazu M. Tscholakov, Karl Hofmann, in: Architektenlexikon, zit. Anm. I 3.

I97 R. Hanisch, Die unsichtbare Kunst des Felix Augenfeld, in: Visionäre und Vertriebene, zit. Anm. Io, S. 227f.; L. Fischer/R. Köpl, Sigmund Freud. Wiener Schauplätze der Psychoanalyse, Wien u.a. 2005 . 


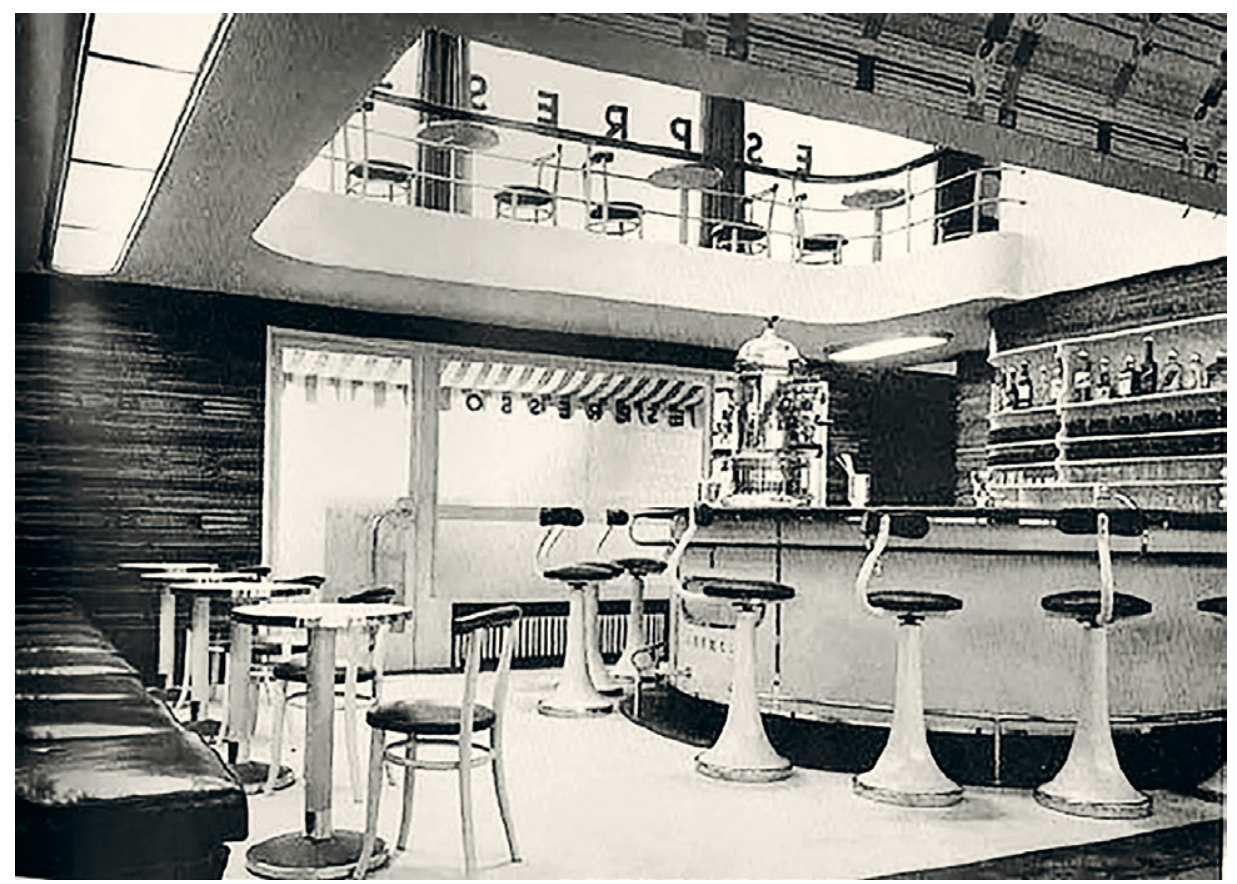

73. Felix Augenfeld, Espresso-Café »Tagesbar« der Wiener Werkbundausstellung, I930/Moderne Bauformen

kurvilineare Formgebung in Kombination mit den Materialien Chrom und Glas zu den fashionabelsten und elegantesten Inneneinrichtung der Zwischenkriegszeit gehörte (Abbildung 73).

Trotz der schwierigen Auftragslage jener Jahre konnten Hofmann und Augenfeld dennoch auch einige große und durchaus bemerkenswerte Bauprojekte ausführen. Neben diversen Industrieanlagen in der damaligen Tschechoslowakei war es ihnen vorbehalten, 1925 in Zusammenarbeit mit dem Architekten Adolf Vetter eine größere Wohnhausanlage zu realisieren, die im Rahmen des sozialen Wohnbauprogramms des "Roten Wien« entstand (Wien 2 I, Prager Straße 56-58). Der im Hinblick auf die Entstehungszeit äußerst sachliche Bau zeichnete sich durch eine relativ komplizierte topografische Situation aus, die die Architekten mittels zweier Hofanlagen sehr klug lösten.

Private Auftraggeber waren jedoch in dem verarmten Österreich weiterhin selten. Die bereits angeführte "Weekendbewegung «, in deren Kontext zahlreiche bescheidene Wochenendhäuser an der Donau zwischen Wien und Tulln entstanden, bot eine der wenigen Möglichkeiten für die Entfaltung einer - wenn auch eingeschränkten - Bautätigkeit, die unabhängig von der öffentlichen Hand war. I 928 entwarfen Augenfeld 


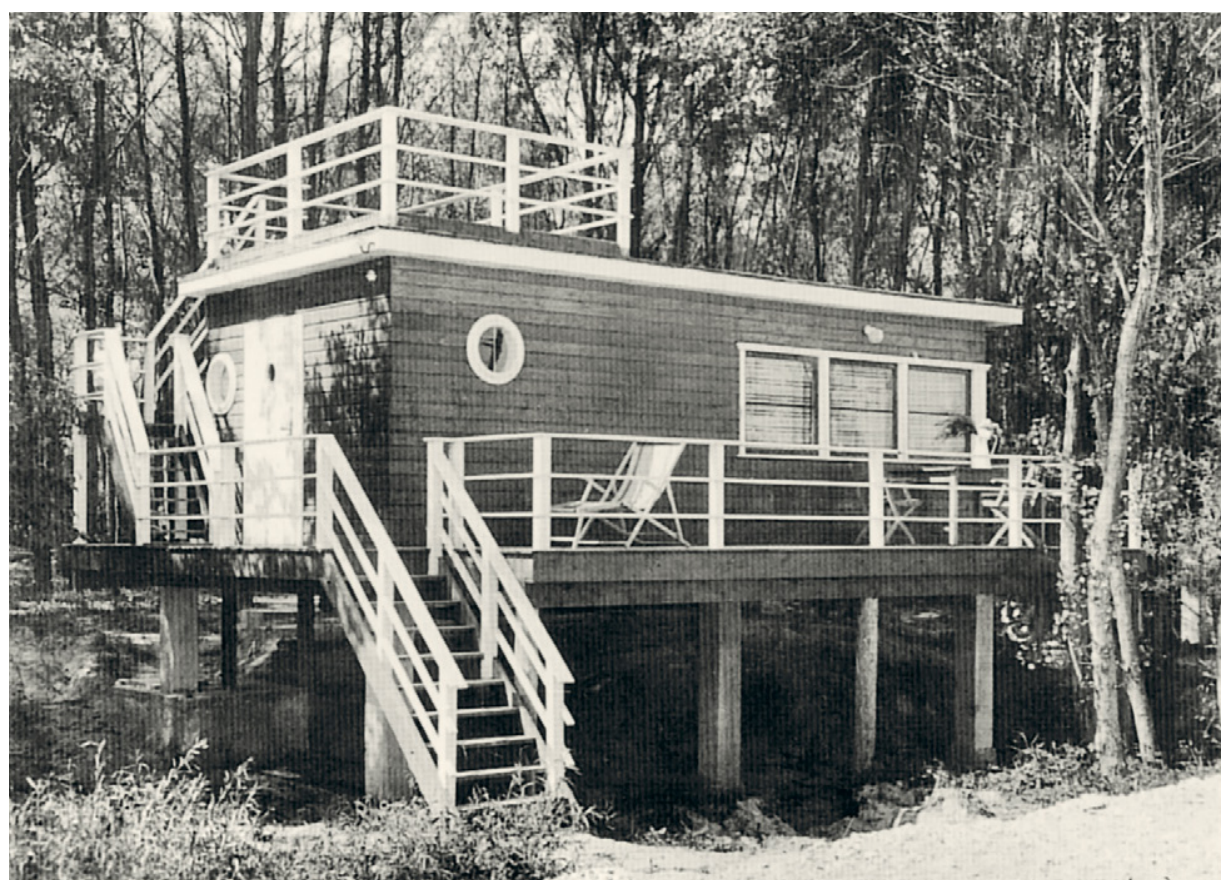

74. Felix Augenfeld, Haus Strauss- Likarz/Kritzendorf, NÖ, Donaulände, erbaut I 928 (teilw. verändert)/ Innendekoration

und Hofmann für die Kunstgewerblerin Maria Strauß-Likarz (es wird später noch von ihr die Rede sein) ein einfaches Holzhaus in Kritzendorf/NÖ, das der örtlichen Bautradition entsprechend auf Stützen gesetzt war, da die permanente Überschwemmungsgefahr groß war. Das kleine Gebäude entsprach mit seiner geschlossenen Kubatur ganz den Kriterien der "Neuen Sachlichkeit«, während das umlaufende Geländer und die kleinen Bullaugen nautische Assoziationen auslösten (Abbildung 74). ${ }^{198}$ Der Bau zeichnete sich durch eine maximale Raumökonomie aus, während die Einrichtung aus raumsparenden Einbau- und Klappmöbeln bestand, die generell von einer spartanischen Funktionalität waren.

Ihre bedeutendsten Bauaufgaben in Wien waren jedoch die Villa "Dos Santos" (Wien I 8, Sternwartestraße 57D) und das Möbelhaus Soffer (Wien I, Singerstraße 4). Die äußerst bemerkenswerte Villa, die um 1930 im Währinger Cottage gebaut wurde, stand in ihrer ästhetischen Qualität in der Tradition von Adolf Loos. Sie zeichnete

I98 Das Haus (Kritzendorf, Donaulände IO, P. 32I) existiert in etwas veränderter Form bis heute (siehe dazu auch: Klosterneuburg, Geschichte und Kultur, zit. Anm. I09, S. го4f.). 
sich jedoch durch einen stark gegliederten Baukörper aus, was es ermöglichte, den meisten Räumen eine Terrasse vorzulagern. Durch eine ausgeklügelte Raumanordnung gelang es, die verschiedenen Funktionsbereiche zu trennen und die unterschiedlichen Lebensgewohnheiten der Bewohner bestmöglich zu berücksichtigen. Ein von Albert Esch angelegter Garten erweiterte die ausgeklügelte Architektur.

Die Errichtung des Geschäfts- und Wohnhauses Soffer 1935/36 fiel demgegenüber bereits in die austrofaschistische Ära, der Auftraggeber war die gleichnamige Möbelfirma (Abbildung 75). Auch hier befleißigten sich die beiden Architekten einer sehr reduzierten, betont funktionalistischen Formensprache, die der Moderne der Dreißigerjahre entsprach. Diese Ausrichtung wurde vor allem auch durch die querrechteckigen, bündig gesetzten Fenster in Stahlverbundtechnik unterstrichen. Der Bau wurde aus Mitteln des sogenannten "Assanierungsfonds" finanziert, ${ }^{199}$ der seitens des autoritären Regimes ins Leben gerufen worden war, um die Altstadt zu »sanieren « - eine an sich nicht ganz unumstrittene Baupolitik, da in der Folge auch oftmals wertvolle historische Bausubstanz abgerissen wurde. Die Neubauten, die sich betont "modern« gaben und Wohnbedarf für eine gehobenere Klientel abdeckten, waren durchaus auch als propagandistische Antithese zu den "roten Wohnburgen« gedacht, wie man abschätzig die Wohnhausanlagen des »Roten Wien« bezeichnete. ${ }^{200}$ Es entbehrt nicht einer gewissen Ironie, dass Augenfeld, der 1934 in Kontakt zu prominenten Vertretern des sozialistischen Widerstandes wie Muriel Gardiner und Josef Buttinger gestanden war, für die er auch ein kleines Landhaus in Sulz-Stangau/NÖ errichtet hatte, das aufgrund seiner abgelegenen Lage als konspirativer Treffpunkt genutzt wurde, Gelegenheit hatte, einen sogenannten »Assanierungsbau« zu errichten - es sollte eines der letzten größeren Projekte in Wien sein, das von einem jüdischen Architekten realisiert werden konnte.

Neben der Führung seines eigenen Ateliers war Augenfeld aber auch ab I93 I als Assistent und Bühnenbildner für Oskar Strnad in Wien und London tätig, wobei nicht geklärt ist, ob er diesen Aufgabenbereich aus reinem Interesse übernahm oder weil die eher schwache Auftragslage ihn dazu nötigte. Ziemlich sicher haben sich die engeren Kontakte im Rahmen des Werkbundes ergeben, wo Strnad - wie bereits angeführt - eine bedeutende Rolle gespielt hat. Generell waren die Grenzen zwischen Inneneinrichtung, Ausstellungsarchitektur und Bühnenbild fließend. Das rege Theaterleben dieser Jahre, insbesondere der Kreis um Max Reinhardt, bot daher nicht wenigen Architekten ein weiteres Betätigungsfeld.

I99 Österreichische Kunst 1937, H. 5, S. I6.

200 St. Plischke, Der Assanierungsfond und die Wohnbaupolitik in Wien 1934-1938, in: Kunst und Diktatur (Kat.), Baden 1994, S. 216ff. 
75. Felix Augenfeld, Haus Soffer, Wien I,

Singerstraße 4, erbaut um I936/Visionäre u. Vertriebene

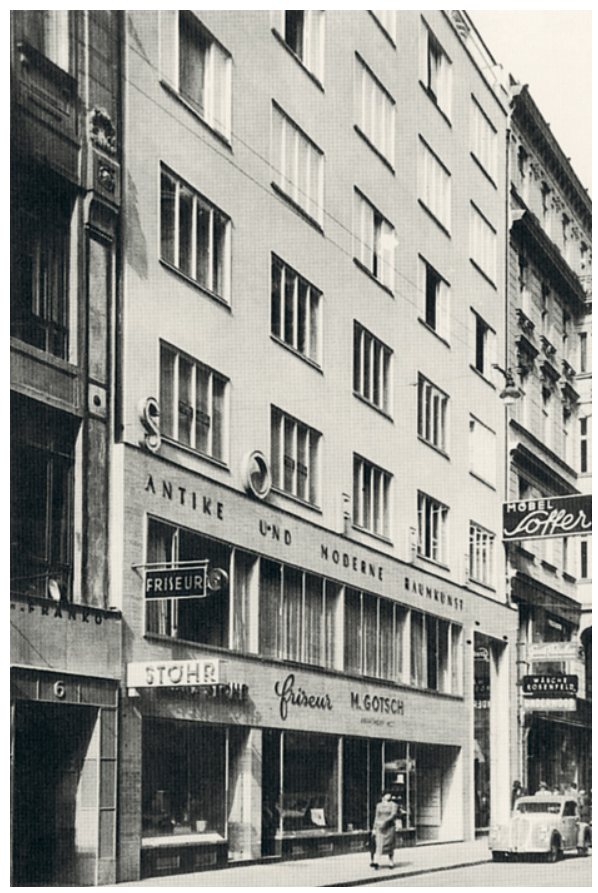

Nach dem »Anschluss« Österreichs flüchtete Augenfeld vorerst nach England und emigrierte später in die USA. Noch in seiner Londoner Zeit publizierte er einen wichtigen Artikel über die österreichische zeitgenössische Architektur. ${ }^{201}$ Dieser Aufsatz, obwohl in erster Linie als Hilfe für seine österreichischen Kollegen in der Emigration gedacht, die hier einem englischsprachigen Publikum vorgestellt werden sollten, ist heute generell eine wichtige Quelle für das österreichische Baugeschehen in der ersten Hälfte des 20. Jahrhunderts. In New York, wo sich Augenfeld schließlich niederließ, erhielt er I940 die Architekturlizenz. Allerdings war er späterhin überwiegend als Innenarchitekt und Möbeldesigner tätig. Viele seiner Auftraggeber waren gleichfalls Emigranten, die er zumeist schon aus seiner Wiener Zeit kannte.

Neben diversen Strandhäusern war Augenfelds bedeutendstes Bauvorhaben in diesen Jahren das Stadthaus und die Bibliothek Buttinger, ein Gebäude, das er 1956/57 im Auftrag von Josef Buttinger errichtete. Dieser aus Oberösterreich kommende Sozialdemokrat hatte in der Emigration Muriel Gardiner geheiratet, für die Augenfeld wie erwähnt bereits um 1930 ein Wochenendhaus im Wienerwald gebaut hatte, in das sich Buttinger zur Zeit der Bürgerkriegswirren geflüchtet hatte. Das New Yorker

20 I F. Augenfeld, Modern Austria. Personalities and Style, in: The Architectural Review 83.1938, S. I65ff. 
Gebäude, das von einer schlichten, klar strukturierten Straßenfront geprägt ist, umfasste neben einer Stadtwohnung insbesondere eine öffentlich zugängliche Bibliothek, in der die umfangreiche Buchsammlung des Ehepaares Buttinger untergebracht war. ${ }^{202}$ Um möglichst gut beleuchtete Arbeitsplätze zu gewährleisten, öffneten sich die Bibliotheksräume mittels einer Glaswand zu einem gartenähnlich ausgestalteten Hof - ein Umstand, der den Innenräumen Leichtigkeit und Transparenz verlieh.

Augenfeld heiratete I 966 bereits in fortgeschrittenem Alter von dreiundsiebzig Jahren die gleichfalls aus Wien stammende Kunstgewerblerin Anna Epstein-Gutmann und unternahm in dieser Zeit mehrere Europareisen. Seine Heimatstadt Wien besuchte er allerdings nicht mehr. Sowohl der Umstand seiner Vertreibung als auch die nach dem Krieg ausbleibenden Aufträge seitens der Republik Österreich - trotz guter Kontakte zu zahlreichen ehemaligen Landsleuten - waren für ihn eine tiefe Kränkung, die er nie verwinden konnte. Hochbetagt verstarb er schließlich mit einundneunzig Jahren in New York.

Obzwar mit großer Wahrscheinlichkeit kein Schüler von Adolf Loos, soll in diesem Kontext auch Ernst Schwadron (I 896-I979) genannt sein, da er diesem Umfeld insbesondere Felix Augenfeld und Jacques Groag - sowohl persönlich als auch in der Ausrichtung seines Werkes sehr nahestand. Eine der Schwierigkeiten im Umgang mit Schwadron besteht darin, dass sich weder sein Ausbildungsweg noch sein Werk konkreter rekonstruieren lassen. Gesichert ist nur, dass er die Wiener Staatsgewerbeschule abgeschlossen hat. Ansonsten ist er weder in den Studienbüchern der Technischen Hochschule noch der Akademie der bildenden Künste zu finden. ${ }^{203}$ Ebenso wird er wie oben angeführt - nie bei den Loos-Schülern aufgelistet. Grundsätzlich war jedoch auch die Staatsgewerbeschule bereits eine qualifizierte Ausbildungsstätte, die ihn mit entsprechendem Praktikum zur Ausbildung des Berufes eines "Architekten«, wie er sich selbst immer genannt hat, durchaus befähigte. Wie auch immer, Ernst Schwadron stammte aus einer renommierten Baumeisterfamilie und legte daher vielleicht auf eine schulische Ausbildung relativ wenig wert. Sein Vater Viktor Schwadron (I865I942), ein ursprünglich aus Galizien zugewanderter Baumeister, war Mitbegründer der »Bau- und Keramikfirma Brüder Schwadron«, die neben Hochbauten vor allem zahlreiche Tiefbauprojekte ausführte und zur Zeit der vergangenen Jahrhundertwende geschäftlich sehr erfolgreich war. ${ }^{204}$ Es verwundert nicht, dass Schwadron, da die väterliche Firma insbesondere auch auf die Verfliesung von Fassaden, Vestibülen,

202 Das Gebäude dient heute nicht mehr als Bibliothek, der Buchbestand wurde der Universität Klagenfurt vermacht.

203 Auskünfte der TU Wien (Dr. Ebner) und der Akademie der bildenden Künste, Wien (Herr Gutschi).

204 Siehe auch T. Zickler (Hg.), Brüder Schwadron. Call to mind, Wien 2014. 
Badezimmern etc. spezialisiert war, nach der Staatsgewerbeschule noch die Keramikklasse bei Michael Powolny an der Kunstgewerbeschule besuchte. Zwar war er späterhin nie in dieser Sparte tätig, arbeitete jedoch des Öfteren mit der Keramikerin Vally Wieselthier zusammen. Schwadron, der die ersten Jahre höchstwahrscheinlich im väterlichen Betrieb tätig war, machte sich gegen Ende der Zwanzigerjahre selbstständig, wobei er - wie die meisten der Architekten dieser Zeit - sich notgedrungen auf das Gebiet der Innenarchitektur spezialisierte und vor allem Lokale und Wohnungen einrichtete. ${ }^{205}$ Mit seinen raumsparenden und vielseitig zu verwendenden Möbeln, die einer moderaten Moderne verbunden waren, ist er durchaus zu den Protagonisten der "Wiener Wohnraumkultur« zu zählen. Während seine Interieurs in den diversen Fachzeitschriften publiziert worden sind, ist demgegenüber sein architektonisches Werk äußerst schmal und schlecht dokumentiert.

Dessen ungeachtet brachte ihm gleich eines seiner ersten Projekte, der Bau eines Strandhauses für das Ehepaar Lederer in Greifenstein, NÖ viel Anerkennung ein. Das kleine Strandhaus, das im Kontext der bereits mehrmals erwähnten "Kritzendorfer Wochenendhausarchitektur" zu sehen ist (das gerade im Ausbau befindliche Strandbad war nicht weit entfernt), hielt sich auch formal an den Kanon dieser Bauten. Neben einer kubischen Durchformung des Baukörpers und dem Einsatz von Fensterbändern beschwor Schwadron durch einen seitlich gesetzten turmartigen Anbau ganz bewusst - schließlich war das Gebäude an der Donau gelegen - eine Schiffsmetaphorik (Abbildung 76). ${ }^{206}$ Pikanterweise kam es im Zuge des Auftrages auch zu einer Affäre Schwadrons mit der Frau des Bauherrn, die ihren Mann verließ und mit dem Architekten eine Ehe einging, die jedoch bald wieder geschieden wurde. Wie auch immer, Schwadron scheint sich in den Dreißigerjahren durchaus als Architekt etabliert zu haben. Weitere angeblich von ihm errichtete Einfamilienhäuser in der Umgebung von Wien sowie in der damaligen Tschechoslowakei und Jugoslawien sind nur sehr vage beschrieben und lassen sich bis heute nicht genauer lokalisieren - möglicherweise wurden sie von Schwadron auch nur eingerichtet. ${ }^{207}$

Als der "Anschluss" von 1938 über ihn hereinbrach, verließ Schwadron noch im März des Jahres ohne offizielle Ausreiseerlaubnis Österreich. Wegen seiner nicht geleisteten Reichsfluchtsteuer wurde ein Steuersteckbrief herausgegeben und I94I sein Besitz beschlagnahmt. Seinem jüngeren Bruder Walter, der in der väterlichen Firma gearbeitet hatte, gelang gleichfalls die Flucht. Den hochbetagten Vater, der in Wien geblieben war, traf hingegen die NS-Judenpolitik mit voller Härte. Nachdem die

205 Siehe dazu I. Meder, Offene Welten, Phil. Diss., Stuttgart 2003.

206 Bau- und Werkkunst 5.1928/29, S. 39ff.

207 Meder, zit. Anm. 205. 


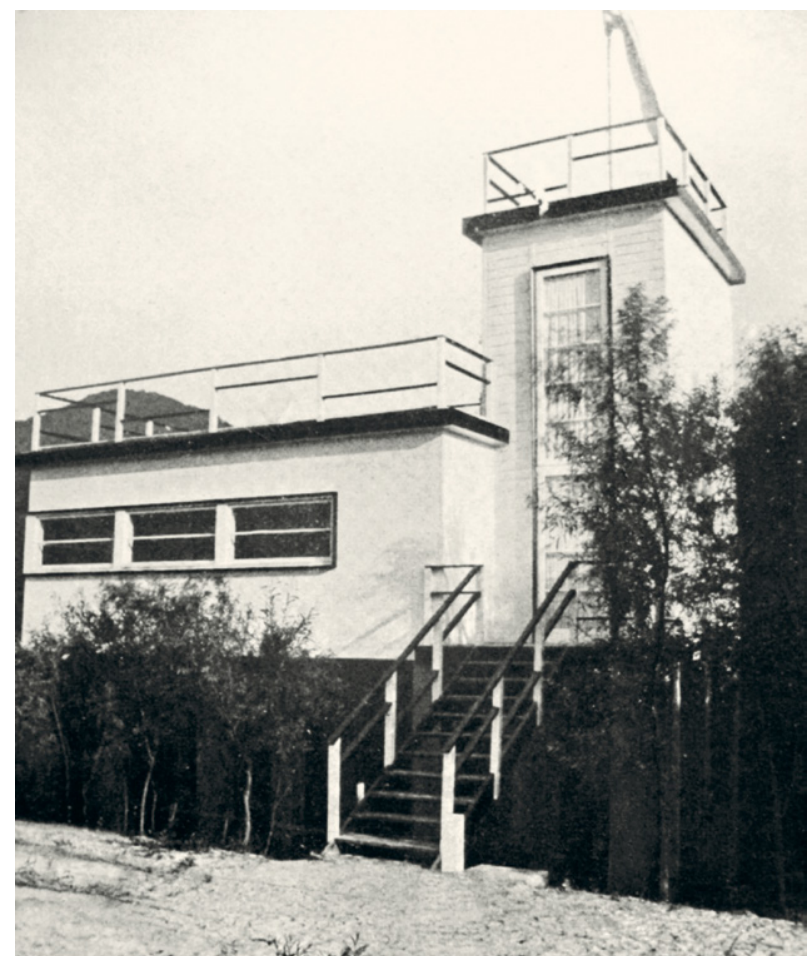

76. Ernst Schwadron, Haus Lederer in Greifenstein, NÖ, erbaut $1927 / \mathrm{Bau}$ u. Werkkunst 1928

Firma »Brüder Schwadron« »arisiert« worden war, wurde auch noch seine Wohnung ausgeraubt. Der alte Herr verstarb schließlich 1942 in Wien noch vor der Deportierung. Ernst Schwadron konnte in die USA flüchten und ließ sich in New York nieder, wo er für die Einrichtungsfirma Rena Rosenthal arbeitete. Vielseitig wie er war, beschäftigte er sich gegen Ende des Krieges sogar mit Themen wie der Adaptierung der Gastanks der US-Army für friedliche Zwecke. Einige Jahre später gründete er seine eigene Firma »Ernst Schwadron Inc.», deren Sitz in der Madison Avenue in Manhattan lag und die überwiegend Büro- und Wohnungsausstattungen ausführte. Nicht wenige seiner Arbeiten wurden in amerikanischen Fachzeitschriften publiziert. Schwadron arbeitete auch in New York weitgehend mit anderen Wiener Emigranten zusammen, etwa mit dem Architekten und Publizisten Leopold Kleiner (I 897-I985), der Keramikerin Vally Wieselthier oder der Malerin und Grafikerin Emmy Zweybrück (I890-I956). Daneben betätigte sich Schwadron auch selbst des Öfteren publizistisch und arbeitete für die deutsch-jüdische Zeitung »Aufbau«. ${ }^{208}$

208 Siehe Visionäre und Vertriebene, zit. Anm. Io. 
Die tragische Gespaltenheit vieler Emigranten in ihren Gefühlen gegenüber der "alten Heimat" wird gerade auch am Fall Ernst Schwadron deutlich. Nicht nur, dass er sich in New York fast ausschließlich in der Wiener Emigrantenszene bewegte, er legte darüber hinaus insbesondere in seinem Eigenheim, das er sich Anfang der Fünfzigerjahre errichtete, einen fast bizarren Österreichkult an den Tag. Er nannte sein Haus "Klein Österreich« und stellte es mit Österreich-Devotionalien voll. Er scheute sich auch nicht, seine "alte Heimat" nach dem Krieg wieder zu besuchen, wobei es ihn vor allem nach Bad Aussee zog. Lange Zeit bemühte er sich, eine Entschädigung für sein beschlagnahmtes Vermögen zu erhalten. Seitens der österreichischen Behörden wurde seinem Antrag jedoch nur teilweise stattgegeben. Schwadron starb schließlich hochbetagt im dreiundachtzigsten Lebensjahr in New York.

\subsection{Die Architektengemeinschaft Josef Berger und Martin Ziegler - Bauten des "Roten Wien«}

Gleichfalls aus der Schule bzw. dem Umfeld von Adolf Loos sind die Architekten Josef Berger (I 898-I989) und Martin Ziegler (I 896-I940?) hervorgegangen, die ab den frühen Zwanzigerjahren als Bürogemeinschaft in Wien arbeiteten. Ungefähr gleich alt, verband sie sowohl ein ähnliches soziales Milieu als auch das Studium an der Technischen Hochschule, das sie zur selben Zeit absolvierten. Der etwas ältere Martin Ziegler wurde in Wien als Sohn eines aus Galizien zugewanderten Kaufmannes geboren. Gleich nach Beendigung der Realschule musste er I9I4 einrücken und konnte sein Studium, das er schließlich I9 I7 begann, erst I92 I abschließen. Ganz ähnlich nahm auch der zwei Jahre jüngere Josef Berger, der aus einer Wiener mittelständischen jüdischen Familie stammte, sein Studium gegen Ende seines Kriegsdienstes I9 I 7 auf und schloss es erst I92 I ab. Zu diesem Zeitpunkt besuchte Berger zudem die Bauschule bei Adolf Loos, wie ein auf dem Dach der Schwarzwaldschule aufgenommenes Gruppenfoto dokumentiert. ${ }^{209}$ Es erstaunt, dass die beiden sich schon I92 I so früh nach ihrer Ausbildung als Partner zusammenschlossen und selbstständig machten. Anfang der Zwanzigerjahre lag die Wirtschaft in Österreich noch völlig danieder, und insbesondere Josef Berger war noch äußerst jung. In den ersten Jahren ihrer Bürogemeinschaft erhielten sie auch keinerlei Bauaufträge, sondern mussten sich mit Möbeldesign, diversen Ausstellungsbauten und Innenraumeinrichtungen zufriedengeben. Wie sehr Design und Kunsthandwerk als zweites Standbein dienen mussten, zeigt auch der Umstand, dass Josef Berger gemeinsam mit seinem älteren Bruder Arthur (I 892-

209 Rukschcio/Schachel, zit. Anm. I75, S. 25 I; siehe auch Meder, zit. Anm. 205. 
I98 I) und seinem Schwager, dem Publizisten und Kunstgewerbler Fritz Lampl ${ }^{210}$, I 923 die "Bimini-Werkstätten " gründete, die sich auf die Produktion von dekorativen Glaswaren spezialisierten und insbesondere wegen ihrer filigranen Glasfigürchen Berühmtheit erlangten. Federführend dürfte hier allerdings Arthur Berger gewesen sein, der an der Kunstgewerbeschule bei Josef Hoffmann und Oskar Strnad studiert hatte, während Josef unter anderem die Ausstellungsräume gestaltete. ${ }^{211}$

Wie viele andere Architekten in diesen schweren Zeiten erhielten auch Berger und Ziegler erst beim Anlaufen des sozialen Wohnbauprogramms des "Roten Wien" Mitte der Zwanzigerjahre ihre ersten Bauaufträge. Nachdem sie sich bereits 1923 vergeblich an einem Wettbewerb für eine Wohnhausanlage in der Lasallestraße im 2. Bezirk beteiligt hatten, konnten sie schließlich 1926 einen »Volkswohnpalast«, wie man die großen Wohnblöcke damals gerne zu nennen pflegte, im 3. Bezirk in der Schlachthausgasse realisieren - vier weitere sollten in den nächsten Jahren folgen. Damit war ihr Anteil am Bauprogramm des "Roten Wien« - gemessen an der Beteiligung jüdischer Architekten - relativ hoch. ${ }^{212}$ Signifikanterweise unterschied sich bereits ihr erstes Projekt in der Schlachthausgasse (Abbildung 77) von dem damals gängigen expressiven Pathos zeitgleicher Wohnhausanlagen, insofern sie sich einer eher sachlichen Formensprache bedienten und den Bau nur mittels treppenartig gestufter Erker und Balkone gliederten. Diese unprätentiöse Ausrichtung behielten sie bis zu ihrem letzten Projekt bei, dem »Grassinger-Hof» (Wien I5, Brünhildengasse), den sie in den Jahren $1932 / 33$ errichteten. Zu diesem Zeitpunkt kam auch das Wohnbauprogramm der sozialdemokratischen Stadtverwaltung infolge der Wirtschaftskrise und der politischen Situation zu einem Ende. In der sogenannten Ära des "Ständestaates" konnten sie noch Mitte der Dreißigerjahre in privatem Auftrag drei klein dimensionierte Wohnhäuser errichten, von denen sich das Haus Schur in der Formanekgasse 32 (Wien 19) durch besondere architektonische Qualitäten auszeichnete (Abbildung 78). Ganz der Linie von Adolf Loos verpflichtet, konzipierten sie hier einen streng kubischen Baukörper mit Flachdach, dessen Fensteranordnung sich strikt den jeweiligen Funktionen der Räume unterordnete. Nur kleine architektonische Details, etwa ein abgetrepptes Stiegenhausfenster, werden als dekorative Akzente eingesetzt.

2 Io Fritz Lampl, der als Kunstgewerbler und auch als Schriftsteller tätig war, war mit Josef Bergers Schwester Hilde verheiratet. Bezeichnend für die Verflochtenheit dieses künstlerisch-intellektuellen Kreises ist auch der Umstand, dass Fritz Lampl mehrere Artikel über Jacques Groag publiziert hat.

2I I Arthur Berger seinerseits firmierte bei einigen der architektonischen Projekte von Josef Berger und Martin Ziegler als Mitarbeiter, wie weit sein Anteil geht, ist allerdings ungeklärt.

2 I 2 Die meisten der Projektanten der Wohnhausanlagen des "Roten Wien « - seien es beamtete Architekten, seien es freiberuflich Tätige - waren Schüler Otto Wagners. 


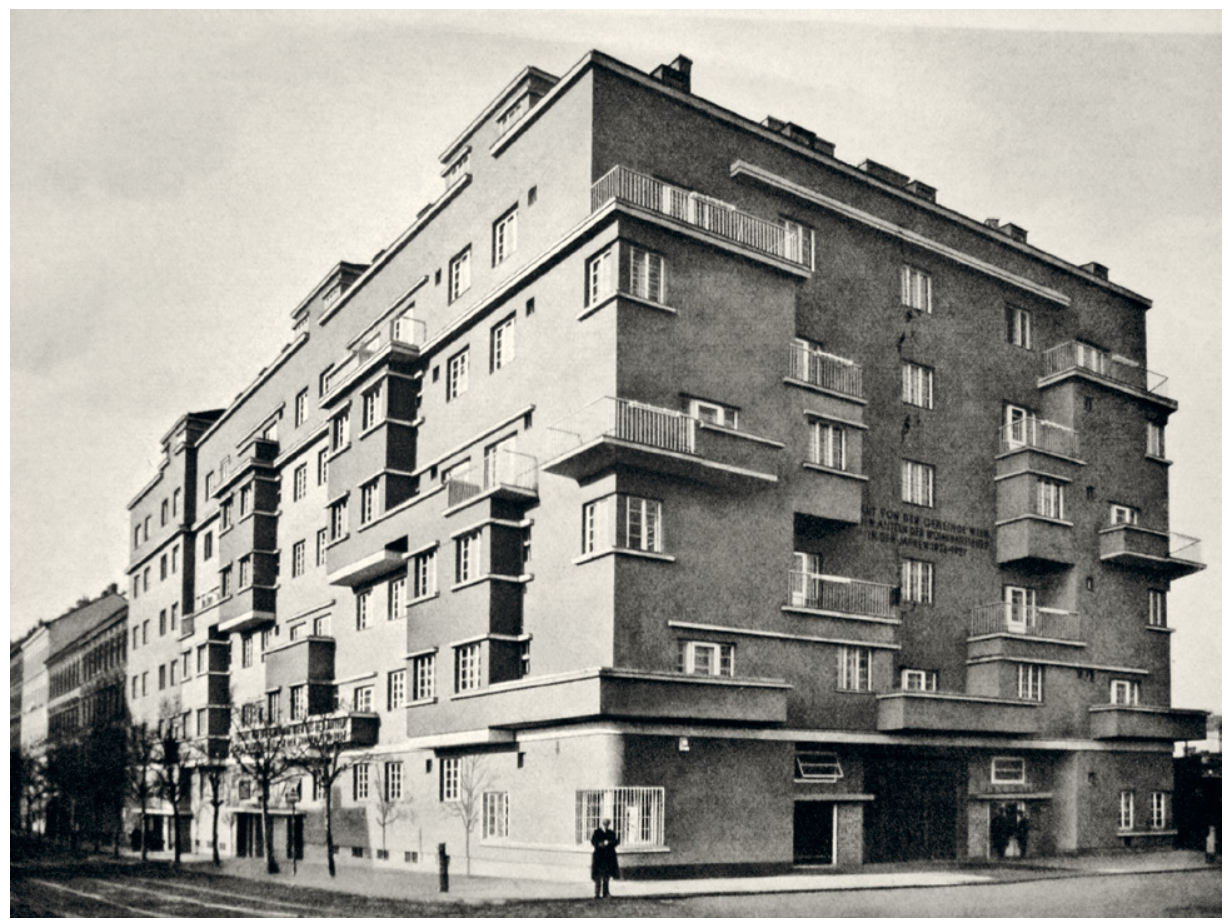

77. Josef Berger u. Martin Ziegler, Wohnhausanlage d. Gemeinde Wien, Wien 3, Schlachthausgasse 2-6, erbaut I926/Mod. Bauformen

Josef Berger verließ I934 Österreich aufgrund der zunehmend schwierigen wirtschaftlichen Situation und des veränderten politischen Klimas in der Ära des »Ständestaates«. Er emigrierte mit seiner Frau, der Kunstgewerblerin Margarete Hammerschlag, nach Palästina in der Hoffnung, einen größeren Hotelkomplex in Haifa errichten zu können. Nachdem das Projekt nicht zur Ausführung gelangte und auch diverse Entwürfe für Wohnbauten und Synagogen Papierarchitektur blieben, ging er 1936 nach London. Über seine Tätigkeit in den ersten Jahren in England ist wenig bekannt; ob er tatsächlich eine Zweigstelle des Büros Berger \& Ziegler in London errichten konnte, erscheint angesichts der restriktiven englischen Zulassungsbestimmungen für ausländische Architekten mehr als fraglich. ${ }^{213}$ Bei Kriegsausbruch wurde er als »enemy alien" auf der Isle of Man interniert. Späterhin engagierte er sich in der in London tätigen Emigrantengruppe »Deutsche Erneuerung «. ${ }^{214}$ Ungeachtet aller Widrigkeiten

2 I 3 Siehe dazu I. Scheidl, Josef Berger, in: Architektenlexikon, zit. Anm. I3.

2 I 4 Ch. Benton, A different world. Emigre architects in Britain I928-1935 (Kat.), London I995, S. I 40. 


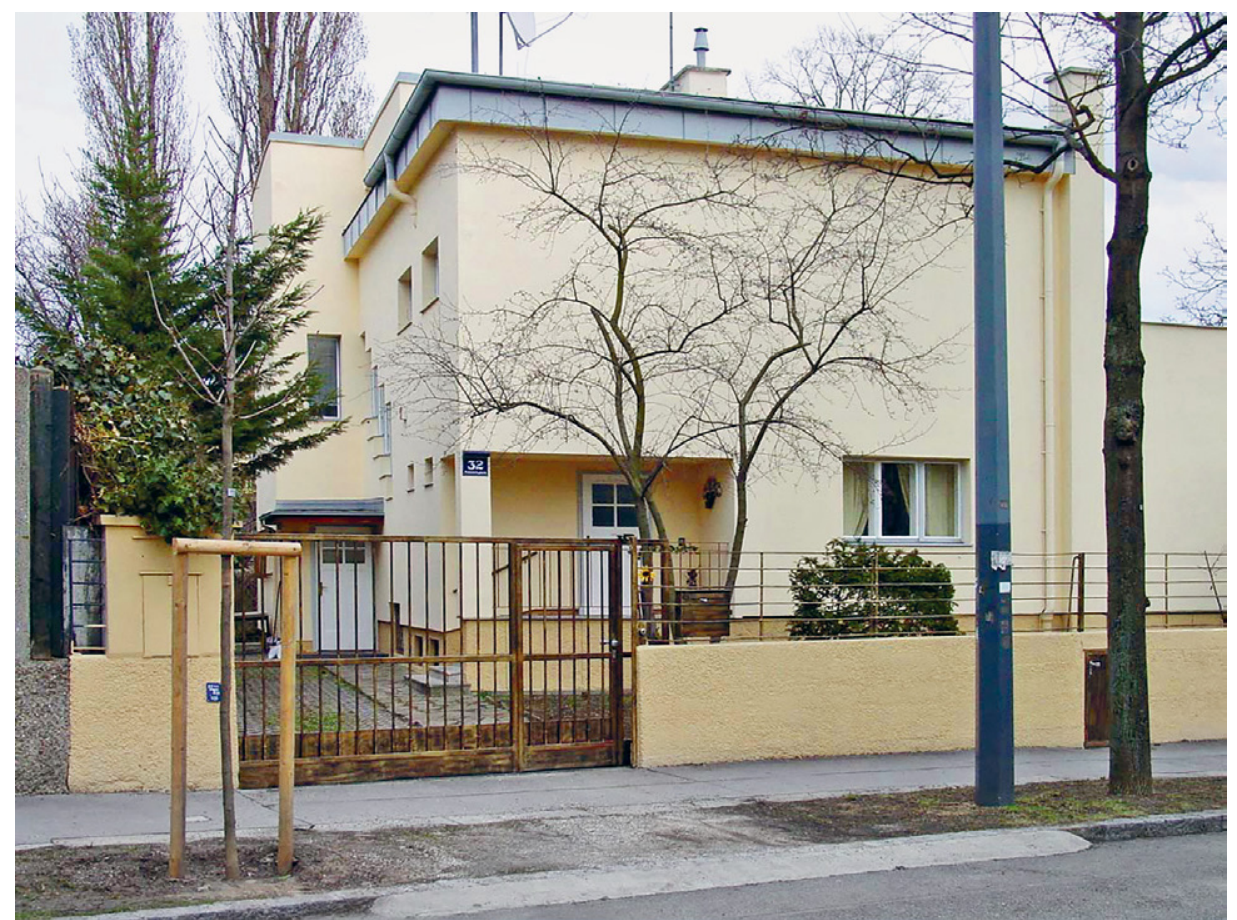

78. Josef Berger u. Martin Ziegler, Haus Schur, Wien I9, Formanekgasse 32, erbaut 1932/Prokop

gelang es ihm nach dem Krieg wieder eine berufliche Existenz aufzubauen. In Fortführung der "Bimini-Werkstätten" gründete er mit seinem gleichfalls nach London emigrierten Schwager Fritz Lampl die Firma "Orpid Glass«. Daneben arbeitete er als Mitarbeiter des "London Country Council«, wo er im Rahmen des Wiederaufbaus nach den Zerstörungen des Krieges bis zu seiner Pensionierung I963 an diversen städtebaulichen Projekten und der Errichtung von Wohn- und Schulbauten befasst war. Hochbetagt starb er schließlich im einundneunzigsten Lebensjahr in London. Sein Bruder Arthur, der noch 1933 in Wien als Mitbegründer des Instituts für Tonfilmkunst fungiert hatte, war Mitte der Dreißigerjahre in die Sowjetunion gegangen, wo er unter dem Namen Artur Semenowitsch bei den Meschrapom-Film-Studios in Moskau arbeitete und zahlreiche Filme ausstattete. Er blieb auch über den Krieg in der Sowjetunion und verstarb als hochgeehrter Staatskünstler I98 I in Moskau. ${ }^{215}$

2 I 5 Arthur Berger (I892-I98I) hatte an der Kunstgewerbeschule bei Oskar Strnad und Josef Hoffmann studiert. Weitgehend als Kunstgewerbler tätig, machte er vor allem Karriere als Filmausstatter: an- 
Martin Ziegler, der einstweilen in Wien geblieben war und das Büro in alleiniger Verantwortung weiterführte, konnte noch einige Wohnhäuser in den späten Dreißigerjahren realisieren. Der sogenannte "Anschluss« Österreichs an NS-Deutschland I 938 beendete aber auch seine Tätigkeit. Unter Berufsverbot gestellt und damit seiner Existenz beraubt, emigrierte er vorerst nach London in der Hoffnung, mit Josef Berger wieder ein Büro etablieren zu können. Nach der Internierung Bergers zerschlugen sich jedoch alle Hoffnungen, und Ziegler wanderte schließlich mit seiner Familie in die USA aus, wo sich seine Spuren verlieren.

\subsection{Heinrich Kulka und seine Verdienste um die Loos-Rezeption}

Von allen Schülern Adolf Loos' hat sich jedoch unbestreitbar Heinrich Kulka (I900I97I) am meisten um den "Meister« verdient gemacht, sowohl aufgrund seiner langjährigen Tätigkeit als Mitarbeiter als auch infolge seiner Publikationen, die sehr viel zur Loos-Rezeption beigetragen haben. Bereits etwas jünger als Jacques Groag oder Felix Augenfeld, gehörte er - ähnlich wie Josef Berger - zu der Generation von Architekten, die die Bauschule bei Loos erst nach dem Ersten Weltkrieg besuchten. ${ }^{216}$

Geboren in Littau/Litovel in Mähren als Sohn eines Kaufmannes, studierte Heinrich Kulka von I9I 8 bis 1923 an der Wiener Technischen Hochschule, allerdings ohne das Studium je korrekt abzuschließen. Zur selben Zeit besuchte er auch die Bauschule bei Loos und arbeitete in der Folge als Zeichner und Assistent in dessen Atelier. Insbesondere machte er sich aber durch seine hilfreiche Mitarbeit an Adolf Loos' Buch "Ins Leere gesprochen" (I92I) verdient. Als Loos 1926 nach Paris ging, nahm Kulka vorübergehend eine Stelle in Stuttgart im Baubüro von Ernst Otto Oswald an und fungierte daneben auch als Mitarbeiter für Josef Frank, der in dieser Zeit in Stuttgart mit einem Doppelhaus für die Mustersiedlung des Deutschen Werkbundes auf dem Weißenhof befasst war. Nur kurze Zeit später agierte Frank dann als Initiator der Wiener Werkbundsiedlung. Dieses Faktum zeigt, wie eng die Interaktion zwischen Frank, Loos und deren Mitarbeitern und Schülern damals war.

Kulka gab jedoch seine Tätigkeit in Stuttgart bald wieder auf, als ihn Loos 1928 neuerlich als Mitarbeiter zu sich rief. Allerdings fungierte er jetzt als gleichberechtigter Partner und Büroleiter. Infolge des Umstandes, dass sich der Gesundheitszustand

fangs für die Österreichische Sascha-Film, ab 1936 für die Meschrapom-Filmgesellschaft in Moskau, für die er bis in die frühen 7oer-Jahre arbeitete. Siehe dazu Ch. Dewald, Arthur Berger, in: Österreichisches biographisches Lexikon - online, 2013.

216 Meder, zit. Anm. 205; Plaisier, zit. Anm. 176. 
von Loos immer mehr verschlechterte, arbeitete Kulka nun zunehmend selbstständig. Bis zu Loos' Tod 1933 war er mit der Ausführung von dessen Projekten befasst, etwa dem Landhaus Khuner in Payerbach/NÖ (1929/33), der Villa Müller in Prag (1928/30) und dem Doppelhaus in der Wiener Werkbundsiedlung (I932). Da sich Loos weitgehend auf seinen Partner verließ und oft nur vage Vorgaben machte, Kulka darüber hinaus auch meist für die Inneneinrichtung verantwortlich war, ist sein kreativer Anteil nicht zu unterschätzen. Gleichfalls in diesen Jahren entstand in Zusammenarbeit mit Adolf Loos eine Reihe von Geschäftseinrichtungen. So waren die beiden nicht nur für die Ausstattung des renommierten Herrenmodesalons Kniže in Paris, sondern auch für die Geschäftslokale der seinerzeit bekannten Textilfirma "Matzner« (Wien I, Kohlmessergasse 8 und Rotenturmstraße 6) verantwortlich, deren elegante Geschäftsportale lange das Stadtbild von Wien prägten. Völlig eigenständig plante Heinrich Kulka in seinen Wiener Jahren hingegen nur das Haus Weiszmann in Wien-Hietzing (Küniglberggasse 55). Das zwischen 1930 und 1933 errichtete Einfamilienhaus war in seiner rigiden kubischen Struktur und den unregelmäßig gesetzten Fenstern selbstverständlich ganz den Ideen von Adolf Loos verpflichtet (Abbildung 79). Wie bei den meisten anderen Projekten war Kulka auch hier für die Einrichtung verantwortlich.

Wie bereits angeführt, machte sich Kulka jedoch vor allem durch seine Publikationen um Adolf Loos verdient. I93 I veröffentlichte er anlässlich des 60. Geburtstages von Adolf Loos eine Monografie über seinen verehrten Meister. ${ }^{217}$ Neben einer kurzen Biografie und der Präsentation der wichtigsten Werke, die von Martin Gerlach in Fotos festgehalten worden waren, fasste Kulka auch die theoretischen Überlegungen von Loos zusammen. Unter anderem schuf er hier den Begriff des »Raumplanes«, mit dem er das räumliche Denken von Adolf Loos beschrieb. Darunter verstand er "[d]as freie Denken im Raum, das Planen von Räumen, die in verschiedenen Niveaus liegen und an kein durchgehendes Stockwerk gebunden sind [...], das Komponieren zu einem raumökonomischen Gebilde«. Heinrich Kulka vermittelte damit breiteren Kreisen die Theorien von Adolf Loos und lieferte einen wichtigen Beitrag zum Verständnis eines der maßgeblichsten Architekten des 20. Jahrhunderts. Bezeichnenderweise erfuhr diese Publikation mehrere Neuauflagen und gilt bis heute als eines der Schlüsselwerke über Adolf Loos.

Ab I933, dem Jahr, in dem Loos verstarb und sich die politische Situation in Österreich durch die Etablierung des sogenannten »Ständestaates« veränderte, verlegte Kulka den Schwerpunkt seiner Tätigkeit zunehmend in die damalige Tschechoslowakei, wo er mehrere Villen und Einfamilienhäuser errichtete, wenn er auch weiterhin sein Wie-

217 H. Kulka, Adolf Loos, das Werk des Architekten, in: Neues Bauen in der Welt, Bd. 4, Wien I93 I. 
79. Heinrich Kulka, Haus

Weiszmann, Wien I3,

Küniglberggasse 55, erbaut um I930/Prokop

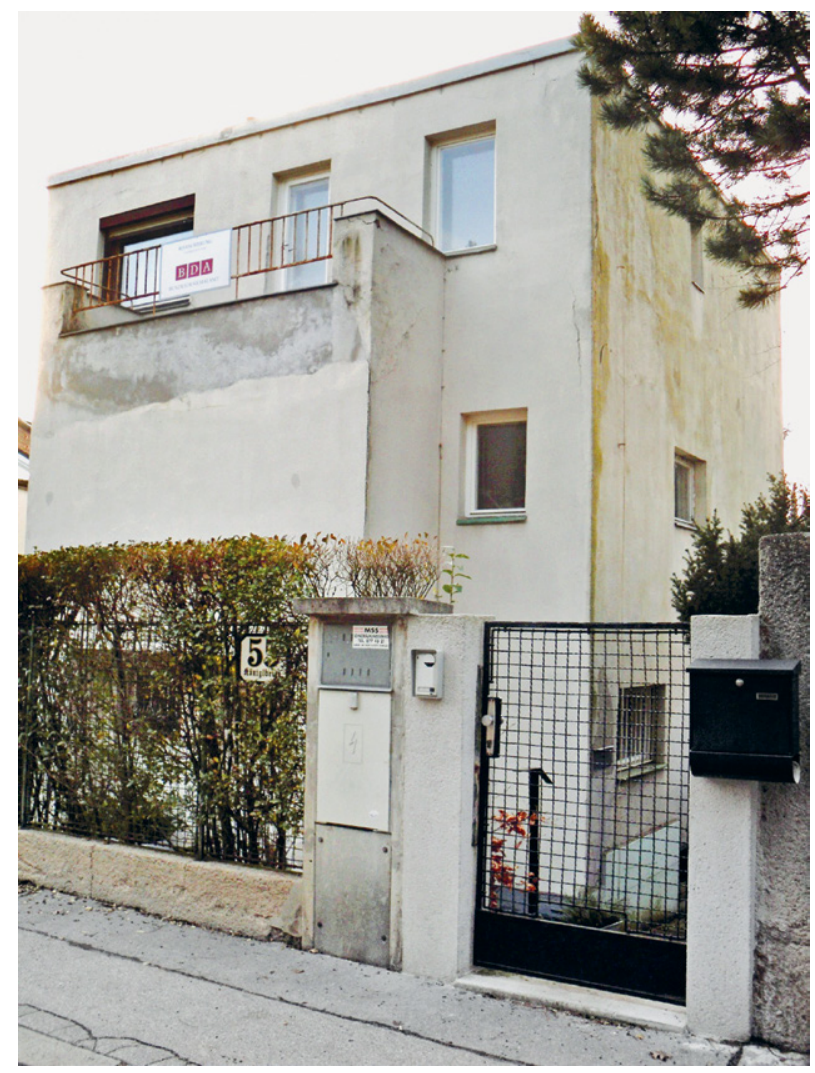

ner Büro behielt. Als nach dem »Anschluss« Österreichs I938 ein Berufsverbot über ihn verhängt wurde, ging er mit seiner Frau zunächst zu Verwandten nach Königgrätz/ Hradec Králové. Nachdem schließlich auch die »Resttschechei« ein Jahr später von den Nazis besetzt wurde, floh er nach England, um endlich 1940 mit seiner Familie nach Neuseeland auszuwandern. Kulka, der zu diesem Zeitpunkt erst vierzig Jahre alt war, schaffte es im Gegensatz zu seinen älteren Kollegen, hier wieder als Architekt tätig zu werden. Als Mitarbeiter und späterhin Chefarchitekt der großen Baufirma Fletcher Construction Ltd. in Auckland war er bis I 960 für zahlreiche große Projekte verantwortlich, neben Wohnbauten und Industrieanlagen insbesondere auch für mehrere Kirchen. ${ }^{218}$ Darüber hinaus arbeitete er bis zu seinem Tod I97 I erfolgreich als freier Architekt. Beschämenderweise ist sein Nachlass bis heute nicht aufgearbeitet.

2 I 8 Siehe dazu D. Herzner-Kaiser, Heinrich Kulka, in: Architektenlexikon, zit. Anm. I 3. 


\section{Auflösungstendenzen der jüdischen Identität - Konvertiten und Partnerschaften mit Nichtjuden}

Dieses Kapitel ist den Architekten gewidmet, die Grenzgänger im damaligen gesellschaftlichen Gefüge waren, indem sie sich entweder von ihrem Judentum lösten oder Partnerschaften mit Nichtjuden eingingen - ein Phänomen, das in größerem Umfang erst in der Zwischenkriegszeit auftrat und möglicherweise als Höhepunkt, zugleich aber auch als Krise der Assimilation anzusehen ist. Bemerkenswert ist, dass diese Loslösung aus dem jüdischen Umfeld für die Betroffenen zumeist zur Ausformung anderer sozialer Netzwerke und damit auch zu anderen Positionierungen innerhalb der Wiener Architekten geführt hat. Insofern ist es auch in architekturhistorischer Hinsicht legitim, diesen Personenkreis als eigene Gruppe zu behandeln.

\subsection{Ernst Lichtblau}

Als prominentester Architekt in diesem Umfeld ist sicherlich Ernst Lichtblau (I883I963, Abbildung 80) anzusehen, der zu den bedeutendsten Schülern Otto Wagners zählt. ${ }^{219}$ Wie bereits angeführt, galt der Kreis um Otto Wagner eher als antisemitisch der große Reformer auf dem Gebiet der Architektur hatte bezeichnenderweise auch gute Kontakte zu Bürgermeister Karl Lueger, und nicht wenige seiner Schüler waren in der NS-Zeit engagierte Parteigänger. Die Akademie der bildenden Künste wurde daher von jüdischen Studenten nur sehr eingeschränkt besucht. Wenn überhaupt, dann studierte man an den Meisterschulen von Viktor Luntz oder Friedrich Ohmann, die in dieser Hinsicht als liberaler galten. Dessen ungeachtet übte die architektonische Avantgardebewegung Otto Wagners eine große Faszination auch auf jüdische Architekten aus, die sich in ihren Arbeiten an dieser zeitgenössischen "Moderne» orientierten, wie unter anderen der bereits erwähnte Oskar Marmorek, obwohl er ein überzeugter Zionist war. Lichtblau hingegen, der es wagte, sich in den inneren Kreis der WagnerSchüler zu begeben, gehörte sichtlich zu dem Teil der jüdischen Österreicher, die bereit waren, sich angesichts des antisemitischen Drucks völlig zu assimilieren. Dafür spricht auch sein Übertritt zum Katholizismus, der bald nach seinem Studium erfolgte. ${ }^{20}$

2 I9 Siehe dazu A. Sarnitz, Ernst Lichtblau, Architekt 1883-1963, Wien u.a. I994; O. A. Graf, Die vergessene Wagnerschule, Wien I969.

220 IKG Austrittsvermerk 24.9.I909 und Taufmatrik Schottenpfarre 26.9.I909 - Lichtblau übte zu 


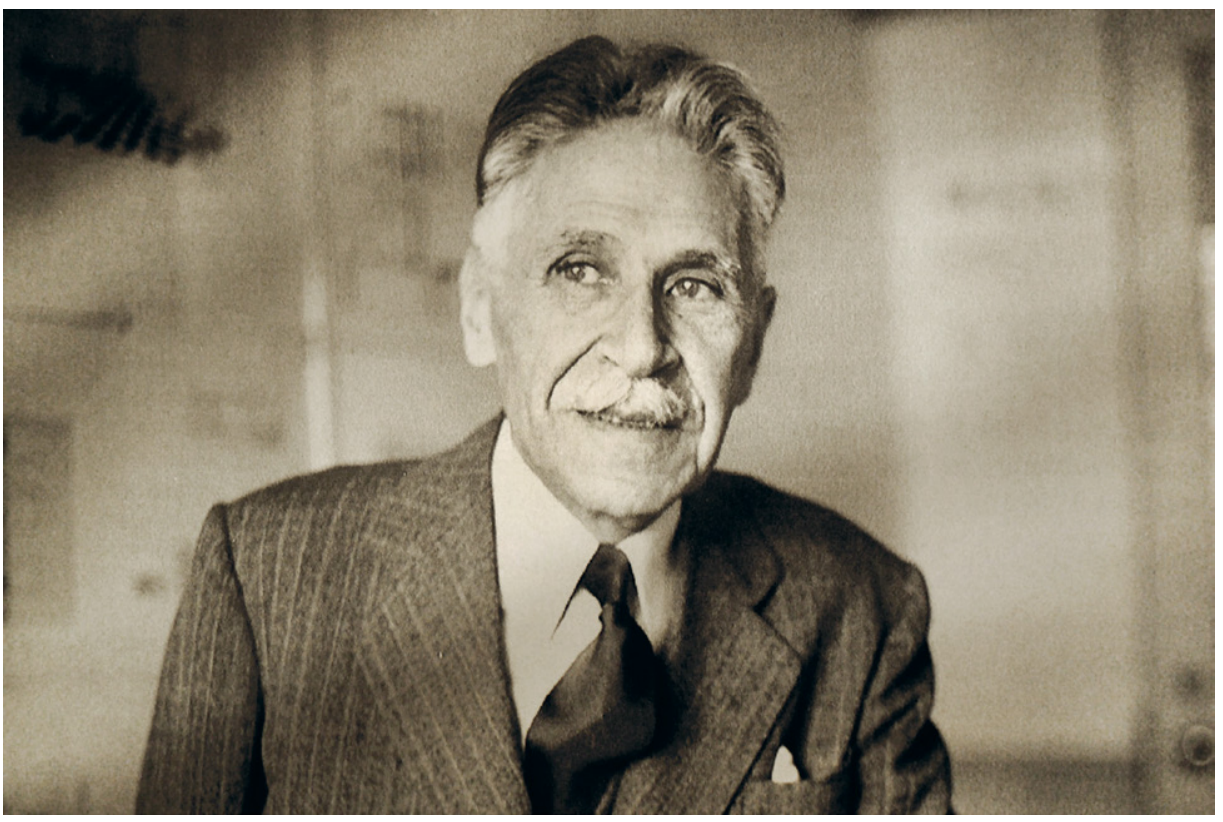

8o. Ernst Lichtblau, Porträt/Sarnitz

Ernst Lichtblau, der 1883 in Wien geboren wurde, stammte aus einer gut situierten Mittelstandsfamilie und wuchs als jüngster von drei Brüdern in bürgerlich-gehobenen Verhältnissen auf. Nach der Absolvierung der vierjährigen Staatsgewerbeschule begann er das Studium an der Akademie der bildenden Künste in der Meisterschule Otto Wagners, das er I905 abschloss. Mehrere Umstände zeigen, dass er schnell Erfolg hatte und in diesem Kreis auch geschätzt wurde. So war er von I 905 bis 1907 für die jährliche Publikation "Aus der Wagner-Schule« redaktionell verantwortlich und erhielt für seinen Akademieentwurf eines Forstamtsgebäudes den Goldenen Hofpreis I. Klasse, sodass er eine längere Studienreise unternehmen konnte. Seine in der Fachzeitschrift »Der Architekt" publizierten Skizzen von dieser Reise nach Bosnien und Dalmatien zeugen nicht nur von seiner zeichnerischen Meisterschaft, sondern verraten auch die formale Eingebundenheit des jungen Studenten in die "Wagner-Schule», von der er sich erst späterhin lösen wird. ${ }^{221}$ Bemerkenswerterweise veröffentliche

diesem Zeitpunkt seine Lehrtätigkeit an der Staatsgewerbeschule bereits seit drei Jahren aus, sodass kein unmittelbarer beruflicher Grund für die Konversion vorlag. Dass diese Handlung dennoch einen Zwiespalt bei ihm auslöste, zeigt der Umstand, dass er 1926 wieder aus der katholischen Kirche austrat, um 1936 - in der Ära des "Ständestaates" - wieder einzutreten.

22 I Der Architekt I3.1907, T. 2 I u. I4.1908, S. 82ff. 
Lichtblau jedoch nicht nur die üblichen Reiseskizzen mit Architekturstudien, sondern ergänzte seinen Bericht mit dem modernen Medium der Fotografie, wodurch dieser Reisebericht bis heute ein interessantes Zeitdokument dieser Region darstellt.

Lichtblau erhielt bald nach der Beendigung seines Studiums 1906 einen Lehrauftrag an der Staatsgewerbeschule in der Schellinggasse - allerdings nicht für Architektur, sondern für das Fach »Zeichnen für Möbeltischlerei«, womit auch schon in gewisser Weise der Schwerpunkt Möbeldesign für seine spätere Zeit vorgezeichnet war. Obwohl ihm I9I 3 in dieser Funktion sogar der Titel "Professor « verliehen wurde (was allerdings nicht dem Status eines ordentlichen Universitätsprofessors entsprach), endete seine Unterrichtstätigkeit bei Kriegsausbruch I9I4 und wurde auch später nicht mehr von ihm aufgenommen, ohne dass die Gründe dafür bekannt wären.

In diesen letzten Jahren vor dem Ersten Weltkrieg war Lichtblau neben seinem Unterricht an der Staatsgewerbeschule auch als Kunstgewerbler für die "Wiener Werkstätte« tätig, wobei er insbesondere Textilentwürfe anfertigte, die durch ihre kräftige Farbigkeit einen besonderen Reiz ausstrahlten. Eine sehr dekorative, sichtlich von Josef Hoffmann beeinflusste kunstgewerbliche Ausrichtung prägte auch sein architektonisches Werk dieser Jahre. Neben einem Gartenpavillon für die Österreichische Kunstgewerbeausstellung von I9I2 gilt dies insbesondere auch für ein Mehrfamilienhaus in der Wattmanngasse 29 (Wien I3, Abbildung 8I), das unmittelbar vor Kriegsausbruch errichtet wurde. Das Gebäude wurde zumeist als "Schokoladenhaus« bezeichnet, weil die Fassade mit großen dunkelbraunen Keramikfliesen bedeckt war. Lichtblau schuf hier ein völlig eigenständiges Werk, das sich jedem Schema entzog und in der Ausformung von Fensterbändern bereits Kriterien der Zwischenkriegszeit vorwegnahm. Die äußerst originelle Fassadengestaltung wurde auch seinerzeit mit einem Preis der Gemeinde Wien ausgezeichnet. Sogar noch während des Ersten Weltkrieges, wo es nahezu keinerlei Bautätigkeit gab, erhielt Lichtblau einen Auftrag zum Bau des Orthopädischen Spitals (Wien 5, Gassergasse 44), das offensichtlich für die Behandlung der Kriegsinvaliden benötigt wurde.

Ungeachtet dieser frühen Erfolge waren späterhin die Zwischenkriegsjahre für Lichtblau nicht einfach. In den ersten Jahren nach dem Krieg, als die Bauwirtschaft praktisch völlig daniederlag, wurden mit Spenden aus dem Ausland einige Wettbewerbe organisiert, um den Architekten zumindest mit den Preisgeldern einige wenige Einkünfte zu verschaffen. Auch Lichtblau beteiligte sich an diesen Wettbewerben, als jedoch 1923 sein Entwurf für das »Denkmal der Auslandshilfe« den I. Preis erhielt, schlug ihm die Wut der Antisemiten voll entgegen. Unter dem Vorwand der religiösen Entrüstung - das Denkmal sollte an der Fassade der Kapuzinerkirche angebracht werden, was in katholischen Kreisen als Profanierung empfunden wurde -, trat in den in der »Reichspost« publizierten Polemiken unverhüllter, gehässigster Antisemitismus 


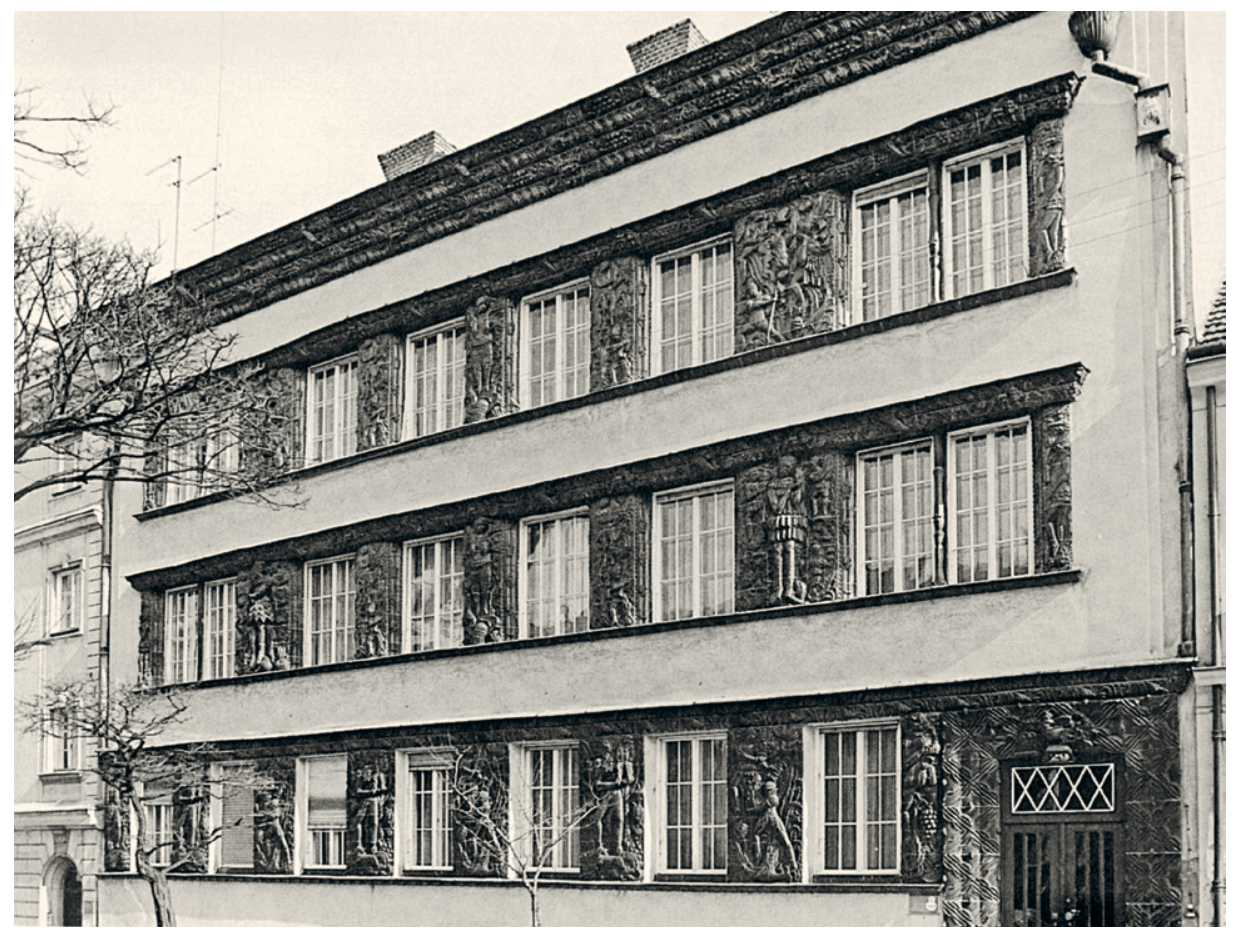

8 I. Ernst Lichtblau, Schokoladenhaus, Wien I3, Wattmanng. 29, erbaut I9I4/Sarnitz (Spiluttini)

zutage. ${ }^{222}$ Als der Denkmalentwurf Lichtblaus schließlich in einer Ausstellung im Wiener Künstlerhaus präsentiert wurde, eskalierte die Situation dermaßen, dass das als "Schande« bezeichnete Modell im Zuge von Handgreiflichkeiten sogar zerstört wurde. $^{223}$

Angesichts dieser Umstände war für Lichtblau die Situation doppelt schwierig. Auch für ihn bot der Bereich des Möbeldesigns und des Kunsthandwerkes eine Kompensation für die geringe Bautätigkeit. Ähnlich wie Josef Frank gründete er 1925 eine eigene Einrichtungswerkstätte, deren Firmenbezeichnung "Lichtblau Werkstätte Ges.m.b.H. für Gegenstände des täglichen Bedarfs in exakter Zweckbestimmtheit unter Verwendung von bescheidenen Werkmaterialien« die ökonomischen Schwierigkeiten dieser Jahre reflektiert. Es verwundert nicht, dass infolge wirtschaftlicher

222 Reichspost 16.6. und 19.6. I923.

223 Moderne Welt I923, H. 6, S. I3; F. Fellner v. Feldegg, Ein Denkmalskandal. Epilog zum Wettbewerb um das Denkmal für die Auslandshilfe in Wien, Wien/Leipzig o. J. 


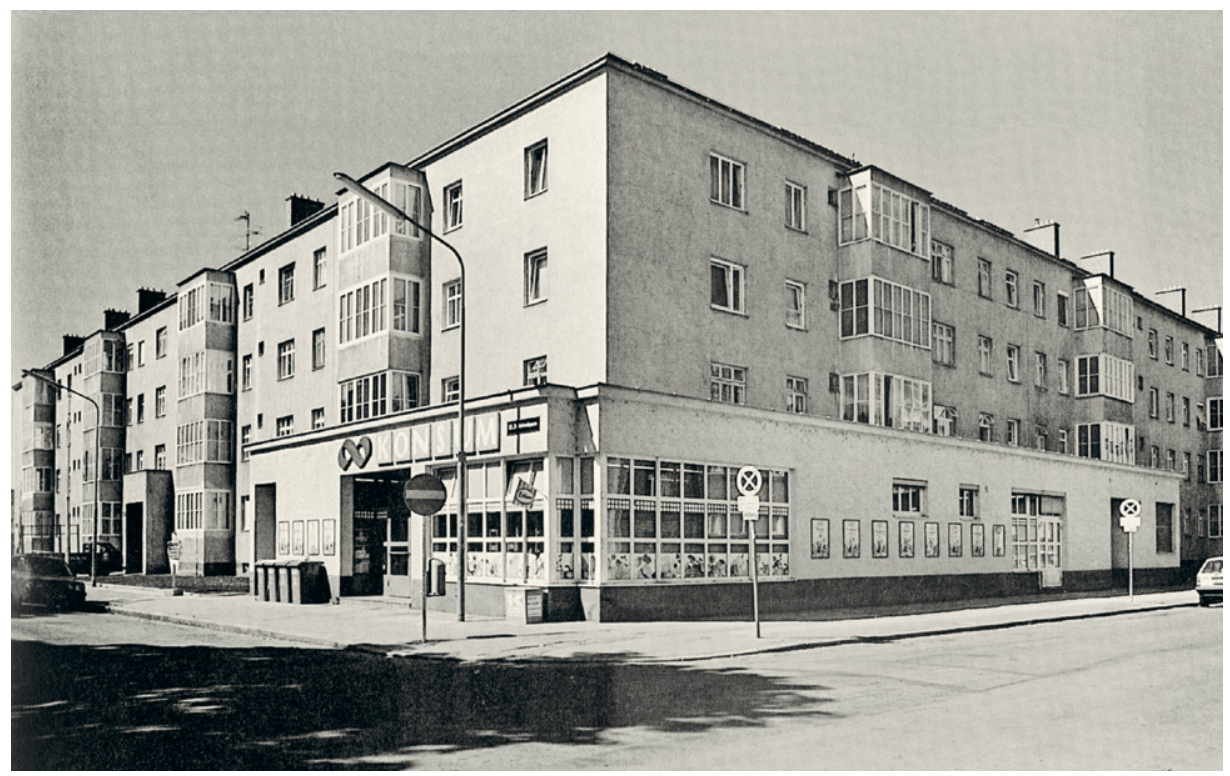

82. Ernst Lichtblau, Paul Speiser-Hof, Wien 2I, Franklinstraße 20 (Bauteil II), erbaut I929/Sarnitz (Spiluttini)

Schwierigkeiten der Betrieb nur drei Jahre bestand. Dann übernahm Lichtblau die Leitung der seitens der Kommune ins Leben gerufenen BEST, der Beratungsstelle für Inneneinrichtungen der Gemeindebauwohnungen. Die kleine Dimensionierung der Räumlichkeiten in den städtischen Wohnhausanlagen erforderte eine eigene Kultur an möglichst kleinen und handlichen Möbeln, und die Beratungsstelle, die im »KarlMarx-Hof « untergebracht war, sollte die Bewohner diesbezüglich informieren.

Während Lichtblau in diesen Jahren auch zahlreiche Geschäftslokale und Wohnungen einrichtete, konnte er hingegen nur wenige Bauten realisieren. Neben einem relativ anspruchslosen Fabrikgebäude errichtete er im Auftrag des »Roten Wien« zwei Wohnhausanlagen, die jedoch infolge ihrer architektonischen Qualitäten besonders hervorzuheben sind. Vor allem der 1929 errichtete "Paul-Speiser-Hof" (Wien 2 I, Franklinstraße 20, Abbildung 82) besticht durch seine klare Strukturierung und luzide Fassadengestaltung mittels rhythmisch gesetzter gläserner Erker, die sich vom üblichen monumentalen Pathos der sonstigen »Volkswohnungspaläste« unterscheiden.

Profilieren konnte sich Lichtblau insbesondere auch im Rahmen des »Österreichischen Werkbundes", dessen Gründungsmitglied er war. Bei der I930 veranstalteten Ausstellung, die dem Thema des Tourismus gewidmet war, konzipierte Lichtblau einen »Fremdenverkehrspavillon« auf dem Ausstellungsgelände des Museums für Kunst 
und Industrie. Der offene, weiß gestrichene Stahlskelettbau war von Leichtigkeit und Transparenz geprägt und vermittelte zeitgenössische »Moderne« auf höchstem Niveau. Während es sich hier jedoch nur um ephemere Architektur handelte, war Lichtblau auch in Josef Franks Projekt der Werkbundsiedlung von 1932 eingebunden, wo er ein Doppelwohnhaus (Wien I3, Jagdschloßgasse 88) konzipierte, das Wohnkomfort zu relativ preisgünstigen Bedingungen demonstrierte. Das Gebäude in schlichten kubischen Formen entsprach in formaler Hinsicht der unprätentiösen Ausrichtung der Werkbundsiedlung und verfügte auch über eine kleine von einer Pergola überdachte Terrasse, die das Fehlen eines richtigen Gartens kompensierte. Als Spezialist für Möbeldesign und Leiter der BEST richtete Lichtblau sowohl sein eigenes Doppelhaus als auch die Häuser einiger Kollegen in der Werkbundsiedlung mit handlichen funktionellen Möbeln ein, die auch ästhetischen Ansprüchen genügen sollten. ${ }^{224}$

Der bereits angesprochene Zerfall des Werkbundes und die Verhärtung des politischen Klimas machten auch für Lichtblau die Situation in den nächsten Jahren schwierig, sodass er bis zur Zeit des sogenannten "Anschlusses« I 938 nur mit diversen Inneneinrichtungen befasst war. Unter anderem handelte es sich dabei um die Einrichtung des renommierten »Promenaden-Cafés « am Parkring (1934), das leider nicht mehr besteht. Seine Versuche, sich an mehreren prominenten Wettbewerben zu beteiligen, waren alle ergebnislos geblieben, obwohl I933 sein Entwurf für ein Restaurant auf dem Kahlenberg einen Preis erhielt und in der Presse als das "einfallsreichste« und "großzügigste« Projekt bezeichnet wurde. ${ }^{225}$ So blieb Lichtblau weiterhin nur das Gebiet der Innenarchitektur vorbehalten, bis sich durch die Ereignisse vom März I 938 die Situation dramatisch zuspitzte. Trotz seiner Konversion war ihm als "Rassejude» der Beitritt in die Reichskammer verwehrt und damit die Berufsbefugnis entzogen. Im August 1939 floh Lichtblau vorerst nach England, wo er sich als Grafiker betätigte und sich mit der Gestaltung von Buch- und Zeitschriftencover durchschlug. Angesichts der wenig verheißungsvollen Aussichten verließ er schließlich England und emigrierte in die USA, wo er mit einigen britischen Pfund in der Tasche in New York ankam.

Nach einem kurzfristigen Intermezzo als Instructor für Textildesign an der Cooper Union in New York bekam er I947, nachdem er die amerikanische Staatsbürgerschaft erhalten hatte, einen definitiven Lehrauftrag für Innenarchitektur an der Rhode Island School of Design, den er bis zu seiner Pensionierung im Jahre I960 innehatte,

224 Die Einrichtungen, die sozusagen einen modellhaften Charakter hatten, waren allerdings nur für den Zeitpunkt der Ausstellung gedacht und wurden nach deren Beendigung entfernt.

225 Zur Realisation gelangte der Entwurf von Erich Boltenstern, wobei der Bau - wenn auch in verstümmelter Weise - bis heute existiert. 


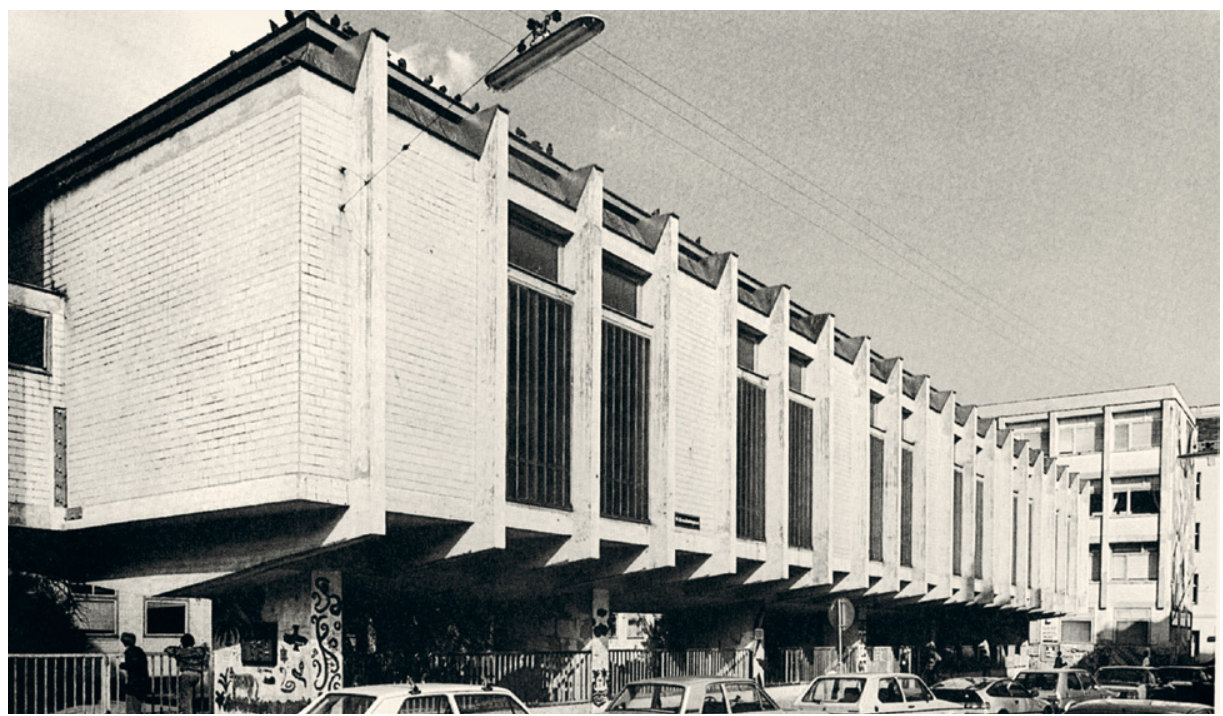

83. Ernst Lichtblau, Schule, Wien I6, Grundsteingasse 48, erbaut 1962/63/Sarnitz (Spiluttini)

wobei er vorübergehend auch die Funktion des Dekans der Fakultät für Architektur ausübte. Diese Jahre erwiesen sich als sehr fruchtbar für Lichtblau, insofern er sehr erfolgreich als Lehrer tätig war und eine ganz Schülergeneration prägte, darüber hinaus auch mehrere Preise für diverse Ausstellungsbauten erhielt. Bis auf einige Umbauten konnte er auch in den USA allerdings kaum nennenswerte Bauprojekte realisieren.

Es verwundert daher nicht, dass Lichtblau 1957 im Rahmen seines ersten WienBesuches, bei dem er einen Antrag auf Rückstellung des »arisierten« Familienbesitzes stellte, auch interessiert war, den Auftrag zum Bau einer Volksschule im I6. Bezirk in der Grundsteingasse zu erhalten. Die Angelegenheit zog sich noch einige Jahre hin, bis er schließlich I962 den definitiven Auftrag erhielt. Da sich ähnlich wie im Fall Walter Sobotka die Behörden schikanös verhielten und ihm nicht die österreichische Architektenbefugnis zurückgaben, musste er zwangsläufig einen in Österreich konzessionierten Architekten - im konkreten Fall Norbert Schlesinger - in das Projekt einbeziehen, um der Form Genüge zu tun. ${ }^{226}$ Demgemäß ist es auch relativ schwierig festzustellen, inwieweit der realisierte Bau die Handschrift Lichtblaus trägt. Ungeachtet dessen war die um einen begrünten Innenhof gruppierte Gebäudegruppe

226 Der Einbezug von Norbert Schlesinger (1908-1980) erfolgte wahrscheinlich auf Empfehlung Rudolf Baumfelds, der in der Zwischenkriegszeit für einige Jahre Schlesingers Partner war und auch mehrmals mit Lichtblau zusammengearbeitet hatte. 
in ihrer transparenten Leichtigkeit einer der innovativsten Schulbauten dieser Jahre (Abbildung 83). Für Ernst Lichtblau, der sich damals bereits in seinen Achtzigern befand, waren jedoch die offenbar emotional sehr belastenden Ereignisse rund um das Baugeschehen zu viel. Nur kurz vor Fertigstellung - die feierliche Eröffnung sollte im April I96 I erfolgen - verstarb er im Jänner des Jahres im Parkhotel Hietzing an einem Herzinfarkt, wobei die Aufregung über einen Brand im Hotel, bei dem allerdings niemand ernstlich zu Schaden kam, zu viel für das Herz des alten Herrn gewesen sein dürfte.

\subsection{Die Grenzfälle - Karl Jaray, Siegfried Drach, Felix Angelo Pollak und Gustav Schläfrig}

Obwohl alle diese Architekten an der Wiener Technischen Hochschule bei Karl König studiert haben, nehmen sie sowohl in ihrer architektonischen Positionierung als auch im Hinblick auf ihre jüdische Herkunft in der Wiener Architekturszene der Zwischenkriegszeit eine Sonderstellung ein. Insbesondere Karl Jaray (I 878-I947, Abbildung 84) ist neben seiner Bedeutung als Architekt und Techniker vor allem in kulturhistorischer Hinsicht von Interesse, da er auch in Literatenkreisen verkehrte und Karl Kraus sehr nahestand. Geboren in Wien, stammte Jaray aus der alten jüdischen Familie Jeiteles, deren Ursprünge bis ins Mittelalter zurückreichen. Erst im I9. Jahrhundert magyarisierte die damals in Ungarn lebende Familie den Namen in Jaray. Um I 870 kam eine Linie der Jarays nach Wien und gründeten die äußerst erfolgreiche Inneneinrichtungsfirma "Sandor Jaray«, die insbesondere auch für den kaiserlichen Hof arbeitete. ${ }^{227}$ Karl Jarays Vater hingegen war Chemiker und unternehmerisch als Presshefeerzeuger und Weinhändler tätig. Auch er dürfte in den Siebzigerjahren von Budapest nach Wien gezogen sein, da Karl bereits in Wien geboren wurde und hier seine Ausbildung erhielt. Nach Abschluss der Realschule studierte er von i 895-I90 I an der Technischen Hochschule, um dann eine Stelle als Bauassistent bei der Staatsbahn in Villach anzunehmen, die er jedoch bald zugunsten eines Lehrauftrages an der Prager Technischen Hochschule aufgab. An dieser Institution schrieb er auch seine Dissertation und konnte sich aufgrund seiner außerordentlichen Begabung bereits zwei Jahre später habilitieren. Als Dozent befasste er sich insbesondere mit dem Fachgebiet des Eisenbetonhochbaus und war auch einige Zeit in der Chefredaktion der Zeitschrift »Technische Blätter« tätig. In

227 Siehe dazu www.jarayfamily.net und G. Gaugusch, Wer einmal war, Wien 20 I I,S. I $260 f f$. Karl Jaray wird auch des Öfteren mit seinem gleichnamigen, etwas älteren Cousin Karl Hans Jaray (I 844I944), dem Sohn von Sandor Jaray, verwechselt, der aber nur als Innenausstatter tätig war. 


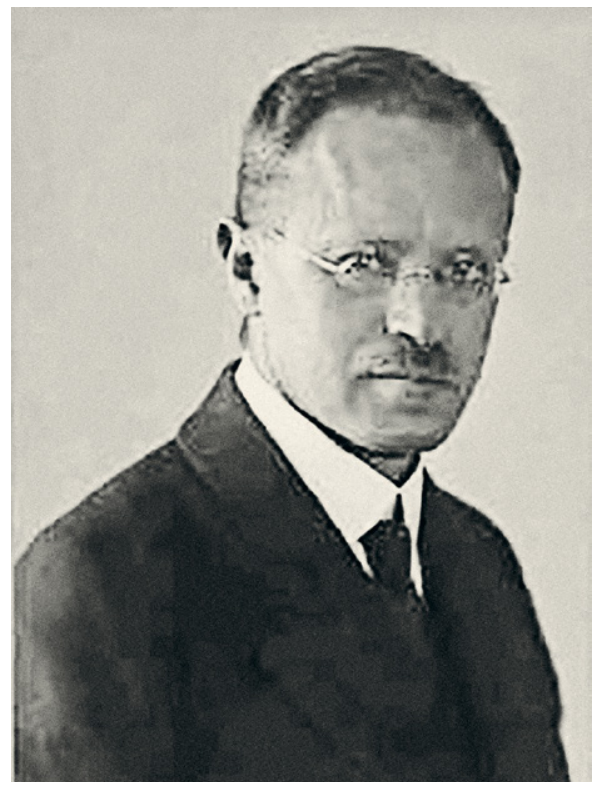

diesen Jahren heiratete er Margit Hirsch, eine Wienerin jüdischer Herkunft, und konvertierte anlässlich der Eheschließung gemeinsam mit seiner Frau zum Katholizismus. Neben seiner Lehrtätigkeit an der Prager Technischen Hochschule war er auch als freiberuflicher Architekt tätig und realisierte mehrere Bankgebäude, Fabrikanlagen, Sanatorien und Miethäuser in Prag und der böhmischen Provinz. Obwohl er I9I8 noch kurz vor dem Zusammenbruch der Monarchie zum ordentlichen Professor ernannt wurde, ließ er sich bereits Mitte der Zwanziger pensionieren und kehrte nach Wien zurück. Zweifellos dürften ihn die zweifachen Schwierigkeiten als »Deutscher« in der jungen tschechischen Republik und als Jude - trotz Konversion - an der als extrem national und antisemitisch geltenden Prager Deutschen Hochschule zu diesem Schritt veranlasst haben. Dessen ungeachtet war er auch noch späterhin an einigen bedeutenden Bauvorhaben, insbesondere einigen sehr repräsentativen Bankgebäuden, in der damaligen Tschechoslowakei beteiligt. ${ }^{228}$

In Wien arbeitete Karl Jaray wieder als freier Architekt und war unter anderem mit der Errichtung von Industrieanlagen in Wien und Pernitz/NÖ für seinen Freund, den Papierfabrikanten Hugo Bunzl, und der Planung mehrerer Villen für sich und seinen Bekanntenkreis befasst, wobei alle Bauten in formaler Hinsicht eine große Eigenständigkeit abseits aller zeitgenössischen Tendenzen aufweisen. Insbesondere

228 Der bedeutendste Bau aus dieser Zeit war die Böhmische Escompte-Bank in Prag, die er um 1932 gemeinsam mit den Wiener Spezialisten für Bankgebäude Gotthilf \& Neumann errichtete. 
seine eigene Villa, die er sich in Grinzing in der Langackergasse 22 (Abbildung 85) errichtete, zeichnete ein höchst eigenwilliger Charakter aus: Sie hatte eine holzverkleidete Fassade, vor allem aber prägte ein hochgezogenes Fußwalmdach den nostalgischen Charme des Gebäudes. Neben seiner Tätigkeit als Architekt widmete sich Jaray in seinen Wiener Jahren vor allem seinen Interessen und beschäftigte sich intensiv mit Literatur. Dem Intellektuellenkreis um Adolf Loos und Karl Kraus angehörend, führte er insbesondere mit Letzterem einen intensiven Schriftverkehr und agierte als dessen Vermittler und Propagandist. Gemeinsam mit Hugo Bunzl finanzierte er I930 den Rückkauf des Brenner-Verlages in Innsbruck an Ludwig Ficker, damit dieser die Schriften von Adolf Loos herausgeben sollte. Daneben arbeitete er intensivst daran, ein Register der »Fackel « herauszugeben, und war maßgeblich an der Gestaltung des sechzigsten Geburtstages von Karl Kraus beteiligt. Nicht zuletzt wurde er von Kraus in dessen Testament zu einem seiner Nachlassverwalter bestimmt. Als nach dem sogenannten "Anschluss« Österreichs I 938 Jarays Grinzinger Villa von der Gestapo beschlagnahmet wurde, fielen daher zahlreiche Materialien und Unterlagen von Karl Kraus in deren Hände. ${ }^{229}$ Jaray selbst konnte noch rechtzeitig mit seiner Frau nach Prag fliehen und erlebte in seinen letzten Jahren ein sehr wechselvolles Schicksal. Nach der deutschen Besetzung der Tschechoslowakei emigrierte er nach London, wo seine Frau verstarb. Noch während des Krieges verließ Jaray England und ging nach Argentinien; dort heiratete er ein zweites Mal und war auch kurzfristig wieder als Architekt tätig. Allerdings verstarb er bereits 1947 in Buenos Aires nach einer langwierigen Infektionskrankheit.

Als zweite Persönlichkeit in diesem Kontext ist Siegfried Drach (I88I-I943) zu nennen, der - ähnlich wie Karl Jaray - heute weitgehend unbekannt ist, aber zu den bemerkenswertesten Architekten der Zwischenkriegszeit gezählt werden muss. Drach wurde I88I als Sohn eines jüdischen Kaufmannes in Wien geboren, hatte allerdings eine katholische Mutter, die anlässlich ihrer Eheschließung zum Judentum konvertierte. Dieser Umstand wird in seinem späteren Leben noch eine wichtige Rolle spielen. Wie üblich besuchte Drach die Technische Hochschule, die er 1904 mit der 2. Diplomprüfung abschloss. Noch im selben Jahr ließ er sich - möglicherweise um sich als Jude seine Berufsaussichten nicht zu verstellen - katholisch taufen. Schwierigkeiten hatte er allerdings mit einer von ihm vorgelegten Dissertation über Eisenbetonkonstruktionen, die aufgrund eines Berechnungsfehlers zurückgewiesen und erst I9 Iо nach einer Überarbeitung angenommen wurde. Späterhin konnte er das Resultat dieser Arbeit als »Deckensystem Dr. Drach«, das konstruktive Vereinfa-

229 Ch. Wagenknecht, Karl Jaray. Rundschreiben 1928-1934, in: Kraus-Hefte 52, Oktober 1989 und freundliche Auskunft Mag. G. Hirschmann, Kärntner Literaturarchiv. 
85. Karl Jaray, Villa Jaray, Wien I9, Langackergasse 22/Prokop

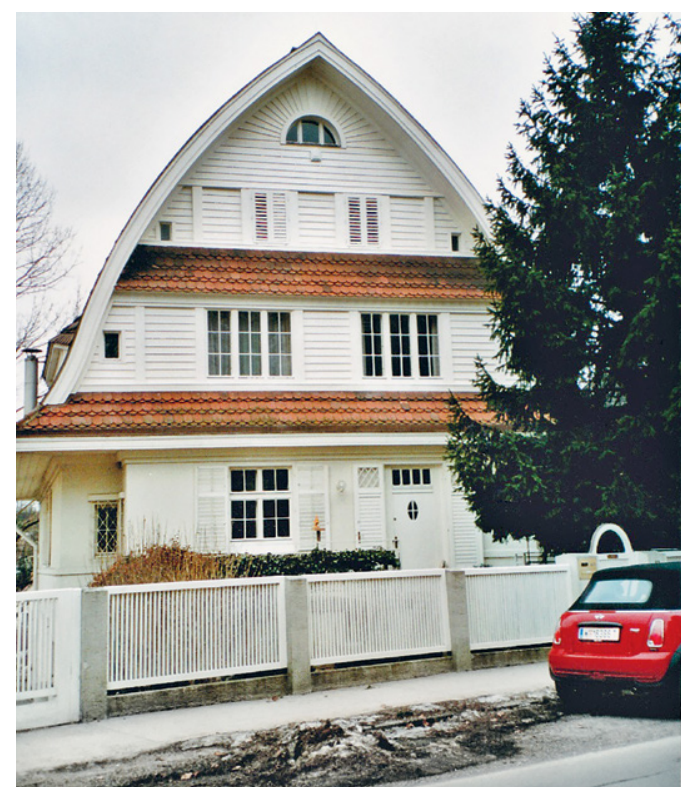

chungen und daher auch Kostenminimierungen ermöglichte, zum Patent anmelden. Dermaßen als Betonbaufachmann qualifiziert, wobei er immer wieder fachspezifische Artikel publizierte, ging er für zwei Jahre nach Hamburg, wo er als Geschäftsleiter eines Eisenbetonbauunternehmens arbeitete. Als er I9I 2 nach Wien zurückkehrte, erhielt er die Stelle eines Oberingenieurs bei der renommierten Baufirma »Rella«. Ein Jahr später wurde er auch deren Gesellschafter.

Erst um I930 scheint er aus der Firma ausgeschieden zu sein, um als selbstständiger Architekt und Bauunternehmer aufzutreten. Die näheren Umstände oder Beweggründe für diese Entscheidung sind unbekannt. Ein möglicher Grund könnte jedoch der Auftrag seitens der Allgemeinen Unfallversicherung zur Verbauung der sogenannten »Malfatti-Gründe« in Wien-Hietzing gewesen sein, den er im Herbst I 929 erhalten hatte. Die Versicherungsgesellschaft plante, hier eine umfangreiche Siedlung mit rund 74 Einfamilienhäusern zu errichten. ${ }^{230}$ Drach erstellte für dieses Vorhaben einen Flächenwidmungsplan und entwarf verschiedene Villentypen, die mit steilen Walmdächern und portikusartigen Vorbauten sehr traditionsverbunden waren. Seitens des Wohnbauförderungskuratoriums wurde dieses Konzept jedoch als nicht zeitgemäß abgelehnt und die Errichtung von einfachen Einfamilienhäusern

230 Siehe dazu E. Bernard/B. Feller, Unbekannte Wiener Moderne. Die Malfatti-Siedlung von Siegfried Drach, in architektur aktuell, H. I80, Juni 1995, S. $74 \mathrm{ff}$. 


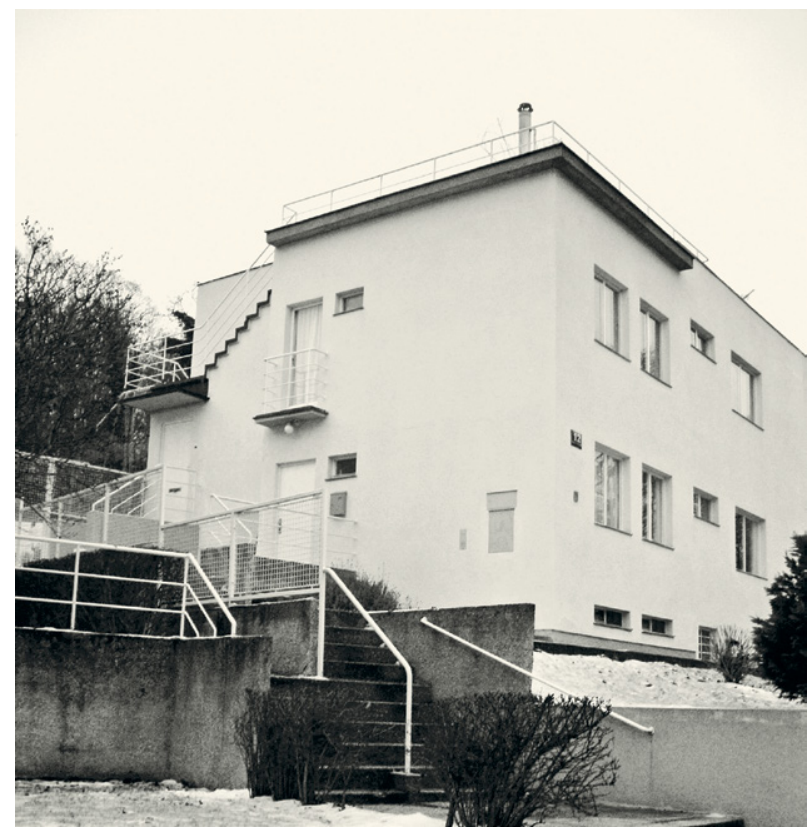

86. Siegfried Drach, Malfattisiedlung, Wien I3, Fanz Schalk-Platz I-I 5 , erbaut 1930/32/Prokop

gefordert. Siegfried Drach hat dann in der Folge das Konzept sehr schnell überarbeitet und ein inhaltlich wie ästhetisch völlig neues Projekt ausgearbeitet, das nun als erste Ausbauphase ein Einfamilienhaus und vierzehn freistehende Zweifamilienhäuser in gekuppelter Bauweise vorsah, die auch formal einem sachlich-modernen Stil verpflichtet waren. Da dieses neue Projekt im April 1932 seitens der Wohnbauförderung genehmigt wurde, ist anzunehmen, dass die Planungsphase zeitgleich mit der Errichtung der Werkbundsiedlung in Lainz zusammenfiel und Drach die schnelle Änderung der Pläne in Kenntnis des Konkurrenzprojektes vornahm. Wie auch immer, die in Zeilenverbauung angeordneten einstöckigen Einfamilienhäuser waren auf dem letzten Stand der damaligen Moderne. Neben einer kubischen Geschlossenheit waren die Häuser in ihrer Außenerscheinung von einem benutzbaren Flachdach und querrechteckigen Fenstern geprägt, während Balkons und Terrassen die Verbindung zum umliegenden Grünland herstellten. Die einzelnen Doppelhäuser umfassten pro Geschoß knapp $60 \mathrm{~m}^{2}$ Wohnfläche, wobei sie durch den Einsatz von Leichtwänden sehr flexibel gestaltet werden konnten. Die nach dem »System Drach« verwendeten Eisenbetondecken ermöglichten außerdem eine rationalisierte und daher auch verbilligte Bauweise. Im Gegensatz zu den Schwierigkeiten der Werkbundsiedlung, Käufer oder Mieter zu finden, waren bei der sogenannten "Malfatti-Siedlung«(Wien I3, FranzSchalk-Platz I-I 5, Abbildung 86) bereits im Jahr der Fertigstellung 1933 über 
87. Siegfried Drach, Miethaus

Wien 3, Neulinggasse 52, erbaut $1933 / 35 /$ Österr. Kunst 1936

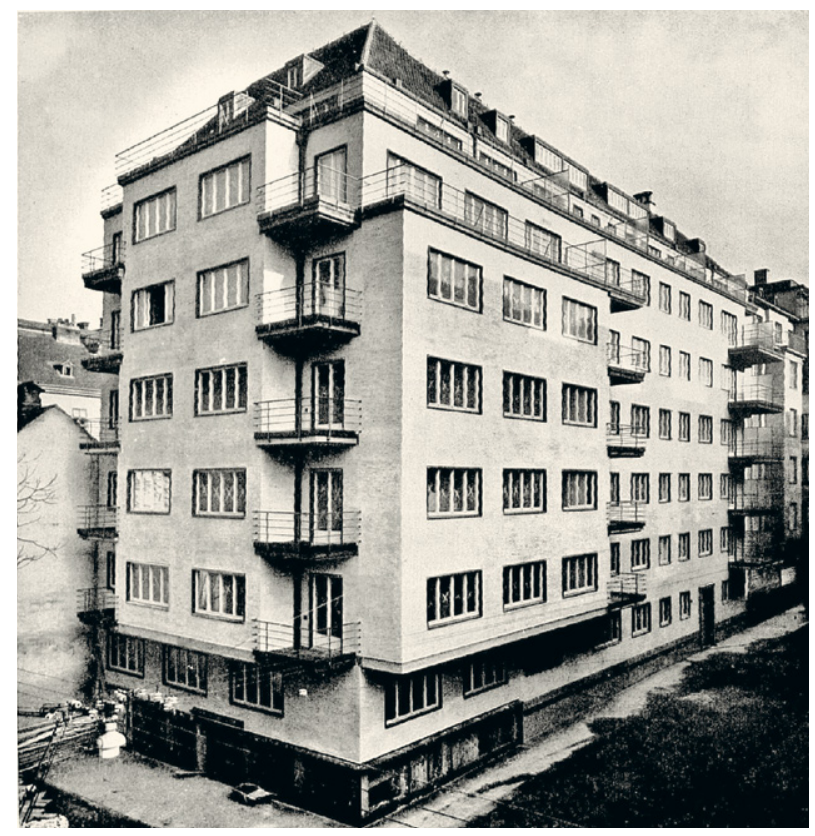

8o Prozent der Wohnungen vermietet. Trotz dieses Erfolges konnte die Siedlung jedoch infolge der Wirtschaftskrise nicht wie ursprünglich geplant weiter ausgebaut werden. Dessen ungeachtet zählen beide Projekte, Werkbundsiedlung und MalfattiSiedlung, bis heute zu den innovativsten Bauvorhaben dieser Jahre, wobei letztere zu Unrecht in der Architekturgeschichte relativ wenig Beachtung fand.

Für Siegfried Drach war dieses Projekt jedenfalls ein großer persönlicher und auch finanzieller Erfolg, der ihm trotz der schwierigen Zeiten ermöglichte, als Bauunternehmer tätig zu werden. Gemeinsam mit seinem Geschäftspartner Alexander Osterberger erwarb er in der Folge zwei Bauareale im 3. Bezirk beim sogenannten Modenapark, einer sehr gehobenen Wohngegend, die nach der Auflassung der alten, zum Palais Modena gehörenden Gründe 1926 teils in einen öffentlichen Park umgewidmet, teils zur Verbauung freigegeben wurde. In den nächsten Jahren entstand hier ein kleines Wohnviertel des gehobenen Standards, das auch formal auf der Höhe der Zeit war. Dieser Ausrichtung folgten auch die beiden in den Jahren I93 I bis 1937 errichteten Wohnhäuser von Siegfried Drach (Wien 3, Neulinggasse 50-52, Abbildung 87), deren differenziert gestaltete Fassaden mit französischen Fenstern bereits nach außen einen gehobeneren Wohnkomfort verrieten. Bis zum Schicksalsjahr 1938 konnte Drach noch einige Villen realisieren, dann veränderte die Machtergreifung der Nationalsozialisten seine Situation. Als getaufter »Halbjude«, der wiederum mit einer "Arierin« 
verheiratet war, ${ }^{231}$ blieb er zwar relativ unbehelligt, insofern er keinen Judenstern tragen musste und nicht deportiert wurde - im Gegensatz zu seinen Schwestern, die weiterhin der jüdischen Religionsgemeinschaft angehörten. Allerdings war ihm aufgrund seiner teilweise jüdischen Herkunft die Mitgliedschaft in der Architektenkammer verwehrt, womit er de facto einem Berufsverbot unterlag. Siegfried Drach verstarb I943 in Wien an einem Krebsleiden. Gerade an diesem Fall wird deutlich, wie schwierig es ist, den Begriff "Jude« zu definieren. Drach ist nach jüdischer Auffassung infolge des Umstandes, dass er eine christliche Mutter hatte und zum Katholizismus konvertierte, kein Jude. Für die Nazis, die mit höchst problematischen Begriffen wie »Halbjude» arbeiteten, blieb er dennoch ein »rassisch minderwertiger« Außenseiter.

Von Konversion und Assimilierung ist auch die Biografie von Felix Angelo Pollak (1882-1936) geprägt, dessen architektonisches Euvre in Wien allerdings relativ klein ist. Kurioserweise erhielt er aufgrund seiner engen Beziehungen zu einem katholischen Orden sogar den Spitznamen »Herz-Jesu-Pollak». Geboren in Baden bei Wien, erhielt er seine Ausbildung, die er I9 I a abschloss, an den Technischen Hochschulen in Wien und Graz. Als Reserveoffizier während des Ersten Weltkrieges eingerückt, war er neben seinem Dienst an der Front auch als Lehrer an der renommierten Militärakademie in Wiener Neustadt/NÖ tätig und wurde mehrfach dekoriert. Nach Kriegsende war er als freier Architekt mit dem Bau mehrerer Wohnhäuser befasst. Ende der Zwanzigerjahre konvertierte er zum Katholizismus und engagierte sich in verschiedenen karitativen christlichen Vereinen. Diese Tätigkeit brachte ihn in engen Kontakt zum Orden vom Herzen Jesu, für den er in der Folge sowohl ein Spital in Berlin als auch eine Schule und ein Schwesternheim in Wien-Landstraße errichtete. Insbesondere Letzteres ist durch seine prägnante Ecklage bis heute ein architektonischer Blickpunkt dieser Gegend (Abbildung 88). Pollak, der sich darüber hinaus zunehmend auf den Bau von Betonstraßen (insbesondere im Ausland) spezialisiert hatte, realisierte noch Mitte der Dreißigerjahre in Arbeitsgemeinschaft mit Leo Kammel einen der ersten, sehr progressiven Hochhausbauten in Wien (Wien I, Laurenzerberg 3). ${ }^{232}$ Bereits kurz danach verstarb er I 936 an den Folgen eines Schlaganfalles.

Ein Sonderfall stellt auch das Schicksal von Gustav Schläfrig dar (I 88 I-I950, Abbildung 89), der wahrscheinlich der einzige jüdische Architekt war, der während der NS-Zeit in Wien blieb und überlebte. Dem gleichen Jahrgang wie Siegfried Drach angehörend, studierte er auch zur selben Zeit an der Technischen Hochschule. Es ist

23 I Siegfried Drach war seit 1907 mit Hermine Maria Hafkesbring verheiratet.

232 Österreichische Kunst 7.1936, H. 7/8, S. 30. Auch dieser Bau wurde seitens des Assanierungsfonds finanziert. 
88. Felix Angelo Pollak, Herz Jesu-Schwesternschule, Wien 3, Landstr. Hauptstraße I37A, erbaut I930/3 I/Prokop

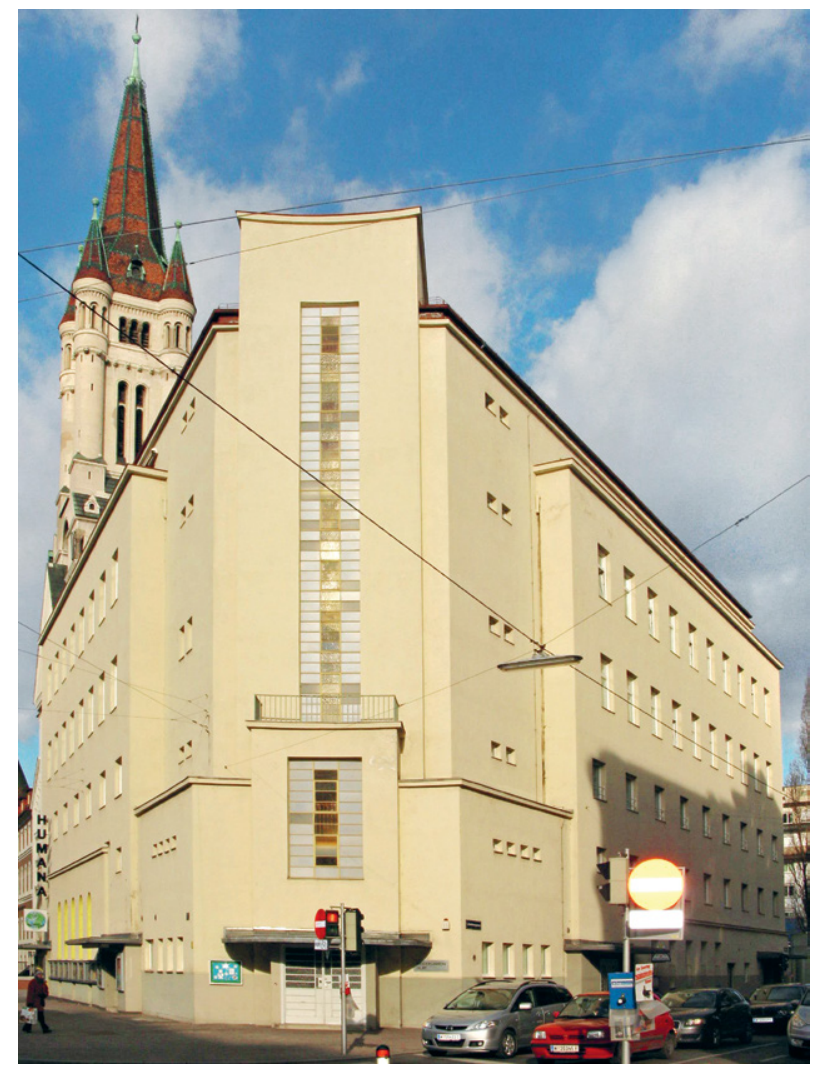

anzunehmen, dass die beiden einander kannten. Im Gegensatz zu Drach stammte Schläfrig allerdings aus einem betont jüdischen Milieu. Sein Vater Dr. Jonas Schläfrig gehörte als Vorsteher der jüdischen Gemeinde in Mistelbach/NÖ und Amtsarzt zu den der Honoratioren des Ortes. Dementsprechend durften auch alle drei Söhne studieren. Während der älteste, Albert in die Fußstapfen des Vaters trat und Arzt wurde, absolvierten die beiden anderen, Friedrich (I 875-1953) und Gustav, ein Architekturstudium. Friedrich Schläfrig fand nach seinem Studium eine Anstellung bei den österreichischen Staatsbahnen, wo er für die Errichtung zahlreicher Hochbauten verantwortlich war und bis zum Ministerialrat aufstieg. Gustav hingegen arbeitete nur kurzfristig bei der Bahn, um sich um I 9 I 2 selbstständig zu machen. Nach dem Ersten Weltkrieg, in dem er als Reserveoffizier Kriegsdienst geleistet hatte, gelang es ihm, bei der Wohnbaugenossenschaft der Eisenbahner (EBG) Fuß zu fassen. ${ }^{233}$ In dieser

233 Weihsmann, zit. Anm. I 3 und Auskunft Mag. Helga Schläfrig (Tochter von Gustaf Schläfrig). 


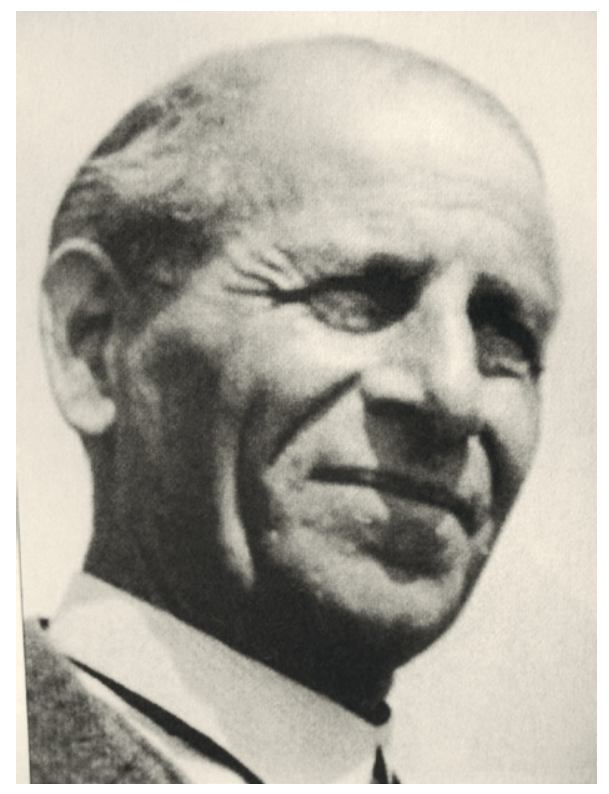

Zeit - Anfang der Zwanzigerjahre - konvertierte er aus Anlass seiner Eheschließung mit einer Christin zum Katholizismus und ließ auch seine Tochter taufen.

Als Chefarchitekt der Genossenschaft war er in der Folge für die Planung zahlreicher Wohnhausanlagen in Wien und in den Bundesländern verantwortlich (Abbildung 90, WHA Wien 5, Gassergasse). Auch seitens des "Roten Wien« erhielt er als Spezialist für den sozialen Wohnbau einige Aufträge und errichtete mit seinem Partner Hans Reiser einige "Gemeindebauten", die sich zumeist durch die Absenz von Monumentalität und Pathetik auszeichneten und eher dem Schema von Arbeitersiedlungen folgten, wie die Mitte der Zwanzigerjahre errichtete Wohnhausanlage "Brettschneiderhof" im 21. Bezirk. Erst Ende der Dreißigerjahre traf die Wirtschaftskrise auch das gut ausgelastete Architekturbüro.

Nach dem »Anschluss« Österreichs wurde Gustav Schläfrig infolge seiner jüdischen Herkunft die Berufsbefugnis entzogen, er war jedoch durch seine "Mischehe« und seine katholisch getaufte Tochter geschützt und blieb von der Deportation verschont. Halb im Untergrund lebend und unter der Hand für andere Baubüros arbeitend, konnte er zumindest seinen nach Theresienstadt deportierten Verwandten Lebensmittelpakete zukommen lassen und ihnen damit das Überleben ermöglichen. Nach dem Krieg erhielt er seine Berufsbefugnis zurück und konnte noch einige Jahre als freiberuflicher Architekt arbeiten. Allerdings erhielt er trotz des großen Nachkriegsbaubooms nur Aufträge für kleinere Umbauarbeiten und musste mit seiner Familie 
90. Gustav Schläfrig, Wohnhausanlage d. Eisenbahnergenossenschaft, 5, Gassergasse 33-35, erbaut I929/32/Prokop

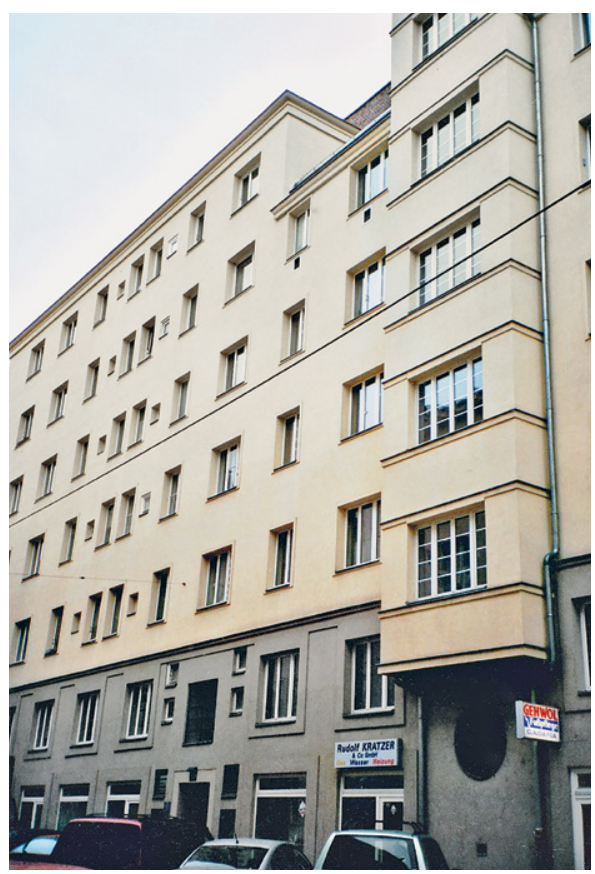

ein äußerst bescheidenes Leben fristen. Schläfrig verstarb schließlich im neunundsechzigsten Lebensjahr in Wien.

\subsection{Partnerschaften mit Nichtjuden}

Ein weiteres Phänomen der gesellschaftlichen Entwicklung dieser Jahre war, dass jüdische Architekten eine Bürogemeinschaft mit Nichtjuden eingingen - ein Arrangement, das bis zum Ersten Weltkrieg kaum üblich war. Dabei standen nicht selten ökonomische Überlegungen und die Herstellung sozialer Kontakte zu unterschiedlichen gesellschaftlichen Gruppierungen im Vordergrund. In diesem Kontext werden einige dieser Partnerschaften beschrieben, keineswegs können jedoch alle Fälle angeführt werden.

\subsection{Paul Fischel und Heinz Siller - traditionelle Tendenzen im Wohnbau}

Als Paradefall ist in dieser Hinsicht die Ateliergemeinschaft von Paul Fischel (I $885-$ I942, Abbildung 91) und Heinz Siller (I884-I946) zu nennen, die beide aus einem sehr gut situierten bürgerlichen Milieu stammten. Während Fischel (in dem Fall der 


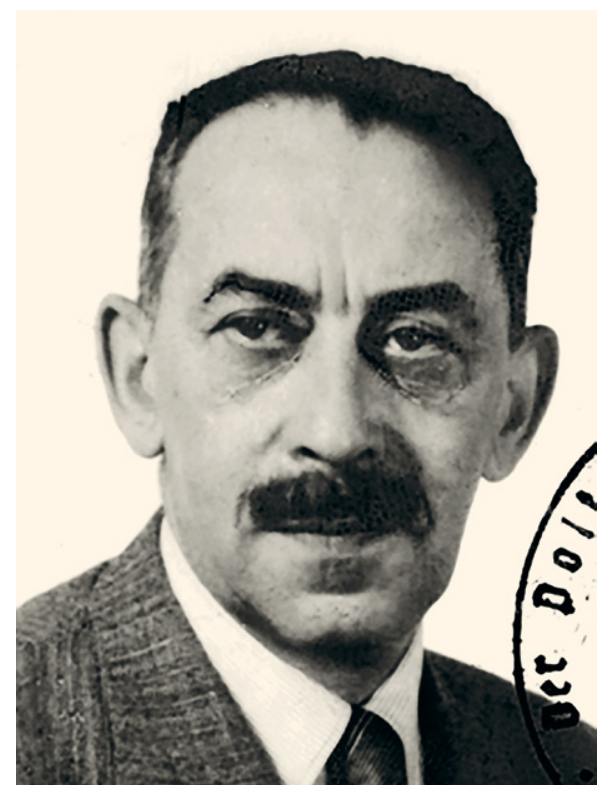

jüdische Partner) durch seine Verwandtschaft mit dem Eigentümer der Spiritusfabrik M. Fischel's Söhne in Industriellenkreisen gut vernetzt war, war wiederum Heinz Sillers Vater Gesellschafter einer großen Baufirma, sodass aufgrund dieser Konstellation ihre Klientel breit gestreut war und sie auch in diesen wirtschaftlich schwierigen Jahren volle Auftragsbücher hatten und zu den meist beschäftigten Architekten dieser Periode gehörten. Die beiden, die nahezu gleich alt waren, kannten einander von ihrem Studium an der Wiener Technischen Hochschule, das sie in den Jahren I904I9 I I absolviert hatten und wo sie noch zu den letzten Schülern Karl Königs vor seiner Emeritierung gehört hatten. Auch Fischel ließ nach seinem Studium seine jüdischen Wurzeln hinter sich und wurde 1906 protestantisch. ${ }^{234}$ Beide Architekten, Fischel und Siller, leisteten vorerst ihren Militärdienst $\mathrm{ab}$, und nachdem sie diverse Praktika absolviert hatten, mussten sie während des Ersten Weltkrieges einrücken, sodass sie sich erst wieder Anfang der Zwanzigerjahre ihrem beruflichen Fortkommen widmen und eine Ateliergemeinschaft gründen konnten.

In der Folge errichteten sie eine Reihe von Villen, Fabrikanlagen, Geschäftslokalen und anderes mehr im Raum von Wien und insbesondere auch in den Nachfolgestaaten der Donaumonarchie, wobei ihre Kundschaft neben der Familie Fischel selbst so große

234 Siehe I. Scheidl, Paul Fischel, in: Architektenlexikon, zit. Anm. I 3 ; die Schreibweise divergiert zwischen Fischel und Fischl. 


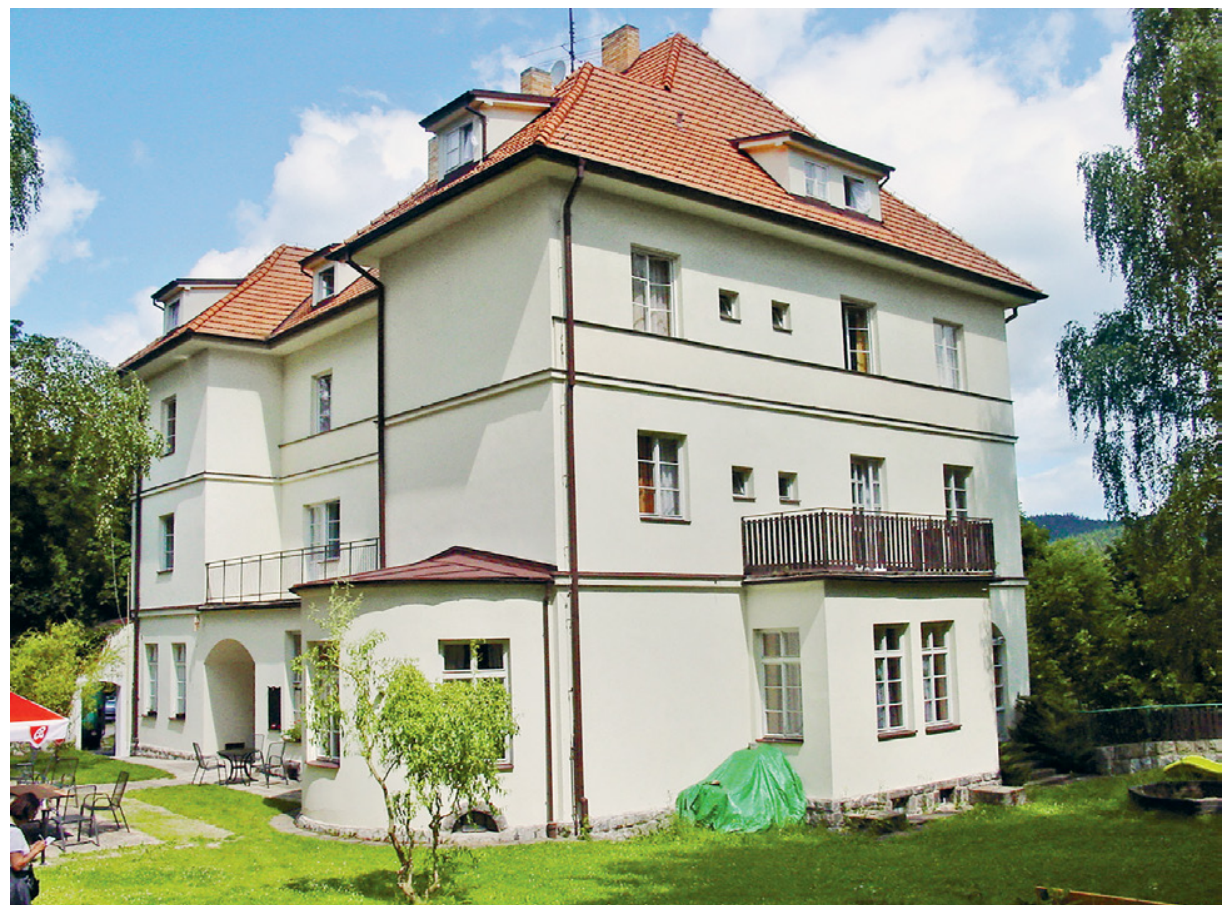

92. Paul Fischel u. Heinz Siller, Haus Spiro, Krumau/Česky Krumlov, CZ, erbaut 1922/24/Prokop

Namen wie das Mineralwasserunternehmen Mattoni, die Papierindustriellen Spiro, die Familie Lederer und andere mehr umfasste. Ihre eher traditionsverbundene Ausrichtung hat wahrscheinlich noch zusätzlich zur Akzeptanz der Ateliergemeinschaft beigetragen. Einer ihrer ersten Aufträge, ein Landhaus für den Papierindustriellen Hans Spiro in Krumau/Česky Krumlov, um 1924 errichtet, war in einem geschickt modernisierten Heimatstil gehalten, der sich sensibel der ländlichen Umgebung anpasste (Abbildung 92). Die Innenausstattung wies dem repräsentativen Anspruch gemäß neobarocke Anklänge wie beispielsweise dekorierte Stuckdecken auf. ${ }^{235}$ Es verwundert nicht, dass diese gekonnt modernisierte Adaption in einer eher konventionellen Formensprache sich höchster Beliebtheit erfreute und noch viele weitere Landhäuser für betuchte Auftraggeber folgten. Auch in Wien errichteten sie in den nobleren Außenbezirken eine Reihe von Villen, die jedoch fast alle weitgehend verändert oder nicht erhalten sind. ${ }^{236}$

235 Siehe dazu E. Erbanova u. a., Slavné vily, jihočesko kraje, Praha 2007, S. I03f.

236 Siehe H. Siller, Wiener Architekten - Paul Fischl, Heinz Siller, Wien/Leipzig I93 I ; I. Meder, Sachen wie sie eben geworden sind. Der Architekt Paul Fischl, in: David 21.2009, H. 83, S. $48 \mathrm{ff}$. 
Einer der Schwerpunkte des Büros war jedoch - ungeachtet der wirtschaftlich schwierigen Zeiten - die Errichtung von Fabrikanlagen, insbesondere für die Lebensmittelund Textilindustrie. Trotz dieser zahlreichen großen Aufträge widmeten sie sich aber auch der Innenarchitektur, entwarfen Möbel und Lampen und richteten Geschäftslokale und Wohnungen ein, unter anderem für prominente zeitgenössische Künstler wie den deutschen Maler Christian Schad und die Modefotografin Kitty Hoffmann.

Es verwundert daher nicht, dass im Kontext dieser umfangreichen architektonischen Tätigkeit ihr Anteil an den Bauten des »Roten Wien« eher gering war. Nur eine einzige, relativ kleine Wohnhausanlage im I8. Bezirk in der Köhlergasse I-3 wurde um 1930 von ihnen errichtet, wobei sie sich in diesem Fall an die zeitgenössische Moderne anlehnten und bei dem durch Gesimsleisten horizontal strukturierten Gebäude die Formensprache der »Neuen Sachlichkeit« zum Einsatz brachten. Obwohl der soziale Wohnbau nicht eines ihrer Hauptbetätigungsfelder war, beschäftigten sie sich dennoch mit einem bemerkenswerten Projekt, das auch weniger begüterten Kreisen die Möglichkeit des Erwerbes eines erschwinglichen Wochenendhauses bot. Im Rahmen der Weekend-Bewegung, die dazu führte, dass umfassende DonaustrandKolonien in der Umgebung von Kritzendorf und Klosterneuburg/NÖ entstanden, erhielten sie seitens der Klosterneuburger Wagenfabrik Kawafag den Auftrag, standardisierte Typenhäuser in Holzbauweise zu entwerfen. Die Bandbreite reichte vom Zwei-Personen-Badehaus bis zum Dauerwohnhaus. Die vorgefertigten und vor allem preisgünstigen Holzhäuser erfreuten sich großer Beliebtheit und ermöglichten erstmals breiteren Bevölkerungsschichten, sich ein Wochenendhaus zu leisten. Einige dieser von Fischel und Siller entworfenen Typenhäuser, die wegen der Hochwassergefahr auf Stützen errichtet waren, sind bis heute bewohnt (Abbildung 93). Bemerkenswert an diesem Auftrag ist der Umstand, dass insbesondere in Kritzendorf der Anteil jüdischer Wochenendhausbesitzer sehr groß war, was vermuten lässt, dass eher die Kontakte von Fischel für diesen Auftrag maßgeblich waren. ${ }^{237}$

Insgesamt waren die dreißiger Jahre äußerst fruchtbar für die Bürogemeinschaft, wobei der jeweilige Anteil der beiden Partner an ihren Projekten kaum zu eruieren ist. Schon in etwas fortgeschrittenen Jahren, heiratete Paul Fischel 1935 die mehr als zwanzig Jahre jüngere Maria Lacerta Kammerer, die Tochter des bekannten Reptilienforschers Paul Kammerer, der nach der Aufdeckung angeblicher Manipulationen bei seinen Kröten-Experimenten Selbstmord begangen hatte. Als schließlich 1938 infolge des "Anschlusses" Österreichs an NS-Deutschland die Bürogemeinschaft aufgelöst wurde, floh Fischel mit seiner Frau nach Australien, wo er den Namen Finton annahm und als Maler und Fotograf tätig war, allerdings bereits 1942 verstarb.

237 Siehe dazu L. Fischer, zit. Anm. I07; Klosterneuburg, Sonderband, zit. Anm. Io9. 


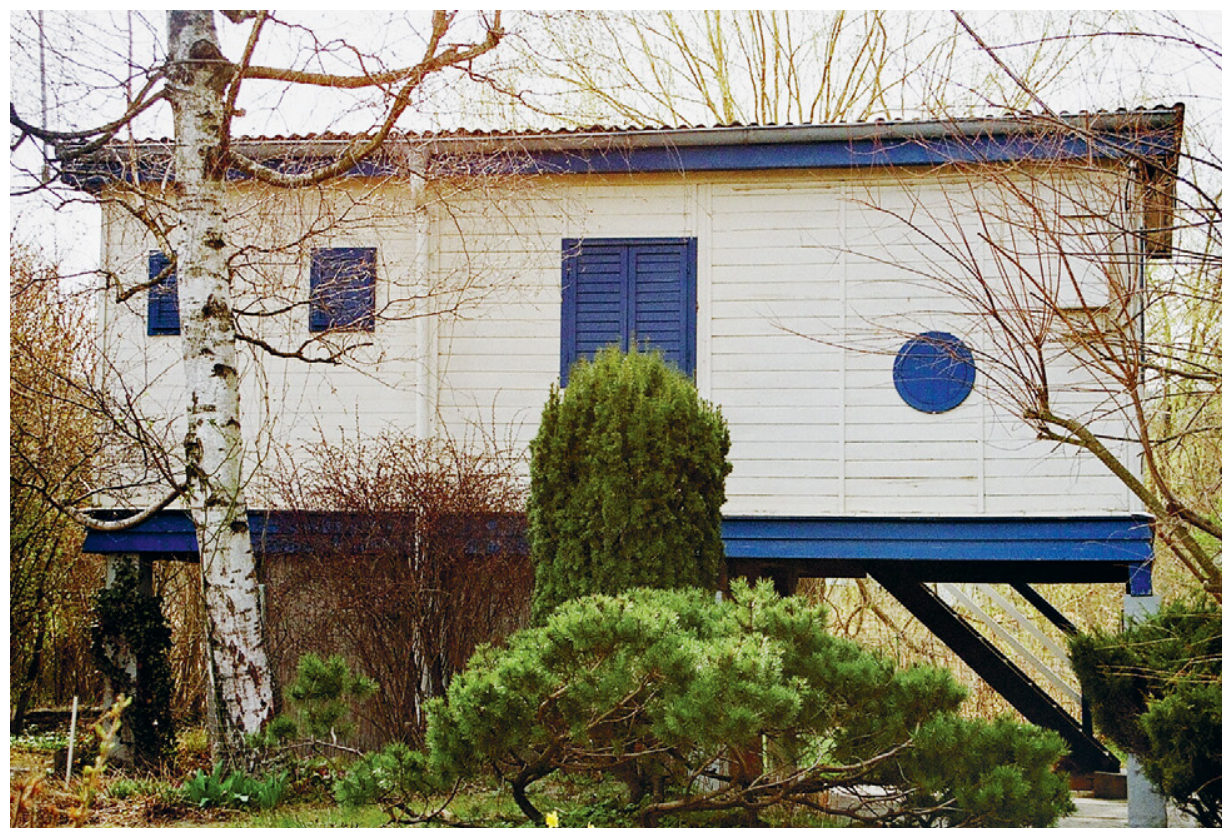

93. Paul Fischel u. Heinz Siller, Kritzendorf, NÖ Kawafag Typenhaus, um I928/30/Prokop

Der in Wien zurückgebliebene Heinz Siller arrangierte sich bestens mit den Nazis, indem er in dem für die Architektenkammer angefertigten Werkverzeichnis seinen jüdischen Partner verleugnete. Mit wechselnden Mitarbeitern konnte er in den nächsten Jahren eine Reihe von Industriebauten errichten und wurde noch I 944 zu seinem 6o. Geburtstag entsprechend gefeiert. Nachdem er sich schon für einige Zeit ins Privatleben zurückgezogen hatte, starb Siller kurz nach Kriegsende I 946.

\subsubsection{Fritz Judtmann und Egon Riss - die zeitgenössische Moderne}

Eine weitere "gemischte« Architektengemeinschaft war die von Fritz Judtmann und Egon Riss, die zwar nicht so erfolgreich war und erheblich weniger Bauten realisiert hat, deren architektonische Qualität aber wahrscheinlich höher zu veranschlagen ist. Insbesondere Egon Riss, der heute praktisch unbekannt ist, ist als einer der innovativsten Architekten der Zwischenkriegszeit anzusehen. Auch in diesem Fall kannten die beiden einander von ihrem Studium an der Technischen Hochschule, das sie allerdings erst nach dem Krieg absolviert hatten, sie kamen jedoch aus sehr unterschiedlichen gesellschaftlichen Milieus. Fritz Judtmann (I 899-I968) war der Sohn eines höheren Beam- 
ten und stammte mütterlicherseits aus einer Wiener Baumeisterfamilie. ${ }^{238}$ Ganz anders hingegen Egon Riss (I90I-I964), der als Sohn eines Kaufmannes in Lipnik bei Biała (damals Galizien) zur Welt kam und sozusagen ostjüdische Wurzeln hatte. Als sie sich I 924 zu einer Ateliergemeinschaft zusammenschlossen, war Judtmann durch seine Assistentenstelle an der Technischen Hochschule zumindest rudimentär sozial abgesichert, während Riss gerade die notwendigen Praktika in Wien und Bielitz absolviert hatte.

Gleich eines ihrer ersten Projekte sollte zu den »interessantesten Beispielen der Zwischenkriegsarchitektur in Wien « werden. ${ }^{239}$ Es ist nicht geklärt, wie das junge, noch völlig unerfahrene Team zu dem beachtlichen Auftrag für den Bau des Ambulatoriums der Arbeiterkrankenkassa gelangte, das im Zuge des Ausbaus der Infrastruktur einer besseren medizinischen Versorgung der Wiener Arbeiterschaft geplant wurde. Das in den Jahren I926/27 im 3. Bezirk in der Strohgasse 28 errichtete Gebäude (Abbildung 94) gehört jedenfalls mit seiner eigenwilligen Formgebung zu den bemerkenswertesten Projekten dieser Jahre. Neben den höchst avantgardistischen horizontalen Fensterbändern vermittelt insbesondere der halbzylindrisch vorkragende Eckrisalit in seiner dynamischen Linienführung Assoziationen an die internationale Moderne, insbesondere mit den zeitgleichen Bauten Erich Mendelsohns. Es ist nicht auszuschließen, dass der junge Egon Riss während seines Praktikums in Bielitz anfangs der Zwanzigerjahre mit dem großen Berliner Architekten, der damals in dieser Region einige Projekte ausgeführt hat (unter anderem in Gleiwitz), zusammengearbeitet hat oder zumindest in Kontakt gekommen ist. Das Krankenkassengebäude in der Strohgasse zeichnete sich durch hohe Funktionalität aus, die auch an der Außenerscheinung ablesbar war. Im unteren, zurückgesetzten Teil befanden sich die Ambulatorien und medizinischen Bereiche, die sich vor allem durch helle, glasüberdachte Warteräume auszeichneten, während in den oberen, optisch deutlich abgesetzten vorkragenden Etagen die Büro- und Verwaltungsräume untergebracht waren. ${ }^{240}$

Das Gebäude scheint auch zur Zufriedenheit der Auftraggeber ausgefallen zu sein, denn die Architektengemeinschaft erhielt in den folgenden Jahren weitere Aufträge für eine Reihe von Projekten im Spitals- und Gesundheitsbereich. Neben einigen kleineren Spitälern für die Arbeiter diverser Gewerbezweige gelang ihnen insbesondere mit dem sogenannten »Tuberkulosepavillon« im Rahmen des Ausbaus des Lainzer Krankenhauses (jetzt Krankenhaus Hietzing) die Realisation eines der - nach Achleitner - »besten Spitalbauten der Stadt «. ${ }^{241}$ Wiederum besticht der in den Jahren

238 Siehe B. Sauer, Fritz Judtmann u. P. Schumann, Egon Riss, in: Architektenlexikon, zit. Anm. I 3.

239 WEB - Lexikon der Sozialdemokratie, www.dasrotewien.at, Arbeiterkrankenkassa Wien 3, Strohgasse 28 .

240 Österreichische Bau und Werkkunst 5.1927/28, S. $277 \mathrm{ff}$.

24I F. Achleitner, Österreichische Architektur, Bd. III/2, Wien/Salzburg 1995, S. I 9. 


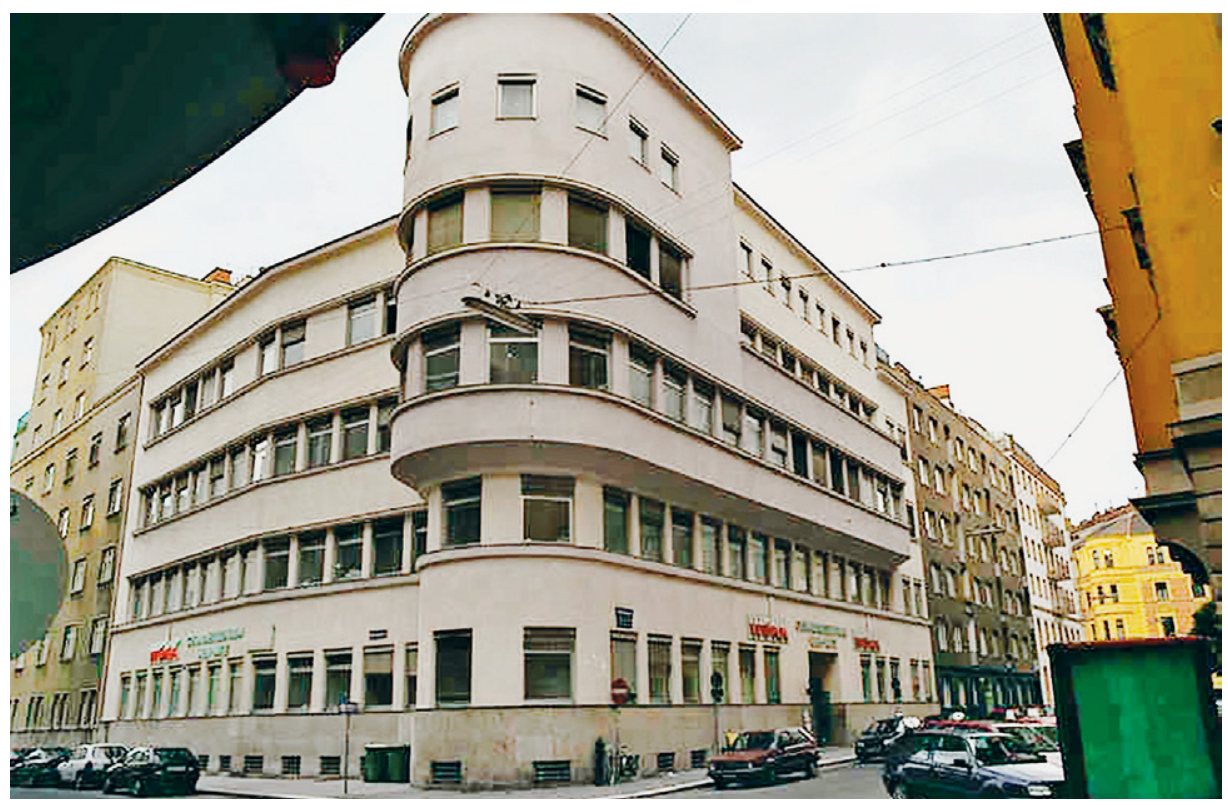

94. Fritz Judtmann u. Egon Riss, Ambulatorium d. Arbeiterkrankenkassa, Wien 3, Strohgasse 28, erbaut I926/27/Kulturgut

I 929/30 errichtete Bau durch die klare, rhythmische Gliederung des Baukörpers, dessen Fassade durch groß dimensionierte Fenster und Liegeterrassen eine transparente Leichtigkeit erhält. Judtmann und Riss konnten in diesen Jahren noch einige Wohnbauten, darunter eine kleinere kommunale Wohnhausanlage im 5. Bezirk (Diehlgasse 20), und Bürogebäude für diverse Berufsvertretungen realisieren. 1934 wurde die Arbeitsgemeinschaft jedoch aufgelöst, angeblich wegen der schlechten wirtschaftlichen Gegebenheiten, was jedoch nicht ganz glaubwürdig ist, da beide noch in den folgenden Jahren einige Projekte - jeweils in alleiniger Verantwortung - realisieren konnten. Möglicherweise spielten auch in diesem Fall die sich verhärtenden politischen Verhältnisse dieser Jahre eine Rolle. Judtmann widmete sich in der Folge überwiegend dem Gebiet der Bühnenbildnerei, wo er insbesondere für das Wiener Burgtheater umfassend tätig war, und arbeitete nur mehr vereinzelt als Architekt. Bis in die Sechzigerjahre galt er als einer der bedeutendsten Bühnenbildner in Österreich. Egon Riss dahingegen, der sich auch theoretisch mit städtebaulichen Problemen befasste, ${ }^{242}$ war weiterhin mit verschiedensten Wohnbauprojekten befasst. Neben einer Reihe von Einfamilienhäusern, deren Standort infolge der nur sehr ungenauen

242 E. Riss, Die Raumverteilung - Die neue Stadt Wien, Wien 1936. 


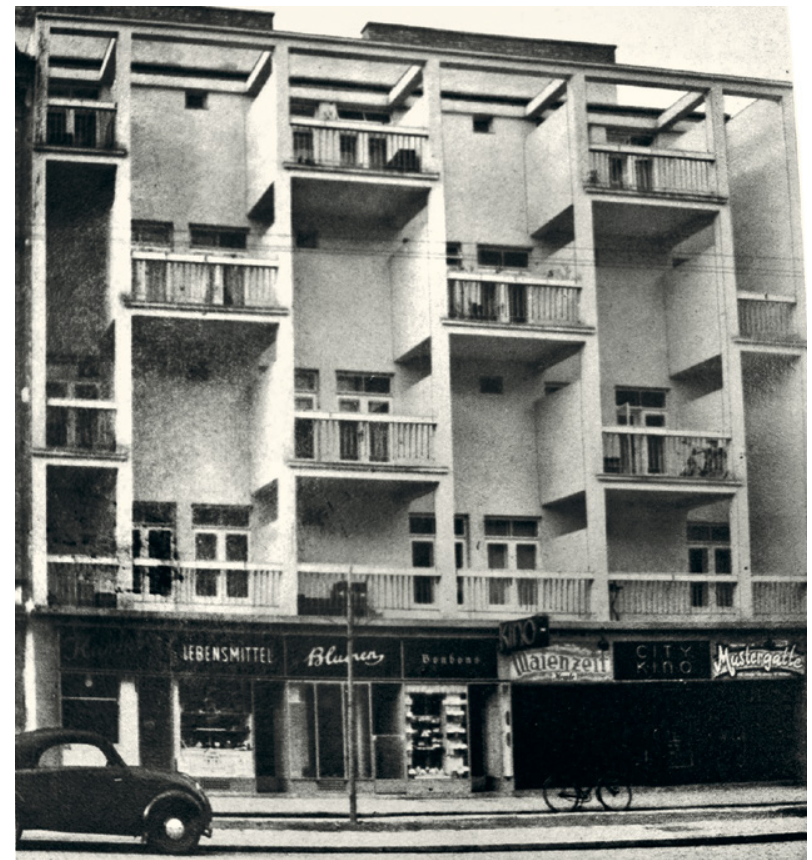

95. Egon Riss, Miethaus Wien 19, Heiligenstädterstr. 95, erbaut 1936/Österr. Kunst 1938

Kenntnis des Werkes von Riss leider unbekannt ist (angegeben wird sehr vage Wien und Schlesien), ${ }^{243}$ war er vor allem mit dem Bau eines damals höchst progressiven Miethauses in Wien-Döbling befasst. Das in den Jahren 1935/36 errichtete Gebäude an der Heiligenstädterstraße Straße 95 erstaunte die Zeitgenossen insbesondere in seiner eigenwilligen Fassadengestaltung, die sich durch eine schachbrettmusterartige Anordnung der Loggien auszeichnete (Abbildung 95), um Belichtungsproblem zu vermeiden. Dem entsprach auch die eigenwillige versetzte Situierung der Wohnungen, die wahrscheinlich von dem von Le Corbusier entwickelten Reißverschlusssystem zur Verbesserung der Raumökonomie inspiriert war. Im Hof dieses höchst innovativen Neubaus war zudem ein Kino untergebracht. Der Bauherr, der dieses eigenwillige Projekt ermöglichte, war Schmuel Pasternak, der seinerseits auch Jude war und als Beispiel dafür dienen kann, dass die Rolle des Auftraggebers bzw. dessen Aufgeschlossenheit Neuem gegenüber gleichfalls ein nicht zu unterschätzender Faktor war.

Ironischerweise wurde dieses Gebäude noch im März 1938 in einer österreichischen Fachzeitschrift publiziert, ${ }^{244}$ während Riss kurz danach infolge des sogenannten

243 H. Weihsmann, zit. Anm. I 3.

244 Österreichische Kunst 1938, H. 3, S. I6. 
"Anschlusses« zu emigrieren gezwungen war. Über die damalige Tschechoslowakei gelangte er schließlich nach England. Da er möglicherweise aufgrund seines Geburtsortes die tschechische oder die polnische Staatsbürgerschaft hatte, wurde er dort während des Krieges nicht als »enemy alien" eingestuft, sondern diente als Offizier in der Royal Navy. Bezeichnend für die emotionale Bindung an die alte Heimat - trotz aller bösartigen Geschehnisse - ist ein Brief von Egon Riss, den er als altes Mitglied der Künstlerhausvereinigung 1946 an dessen Präsidenten richtete. ${ }^{245}$ In dem Schreiben schildert er nicht nur seine Situation als Emigrant, sondern ersucht den Präsidenten auch um Auskunft über alte Kollegen, insbesondere seinen ehemaligen Partner Fritz Judtmann. Wie auch immer, Egon Riss war glücklicherweise noch jung genug, sich in der neuen Heimat eine Existenz aufzubauen. Schon bald nach Kriegsende erhielt er die englische Staatsbürgerschaft und übersiedelte nach Schottland, wo er bis zu seinem Tod 1964 als leitender Architekt des Scottish Coal Board tätig war. In dieser Funktion war er an der Errichtung zahlreicher Ingenieurs- und Bergwerksbauten beteiligt.

\subsubsection{Wilhelm Baumgarten und Josef Hofbauer - der innovative Schulbau}

Etwas ähnlich gelagert war auch die Partnerschaft von Wilhelm Baumgarten (I885I959) und Josef Hofbauer (I875-I936), die gleichfalls Bedeutendes zum Ausbau der städtischen Infrastruktur auf hohem architektonischem Niveau leisteten. Wie schon bei Siegfried Drach, so wird auch am Fall Wilhelm Baumgarten deutlich, wie schwierig es ist, eine "jüdische Identität« zu definieren. Baumgarten war ebenfalls getauft und möglicherweise nur teilweise jüdischer Herkunft, dennoch erhielt er 1938 Berufsverbot und musste emigrieren. Ursprünglich aus Mährisch-Schönberg/Šumperk stammend, absolvierte er die Staatsgewerbeschule in Wien. ${ }^{246}$ Nach seinem Dienst als Einjährig-Freiwilliger studierte er an der Akademie der bildenden Künste bei Friedrich Ohmann und machte sich dann einige Jahre bis zum Ausbruch des Ersten Weltkrieges selbstständig. Nach Kriegsende nahm er eine Assistentenstelle an der Akademie bei Peter Behrens an. Gemeinsam mit Josef Hofbauer, der zu diesem Zeitpunkt gleichfalls als Assistent tätig war, allerdings bei Friedrich Ohmann, dessen Bauschule er später vertretungsweise leitete, begann Baumgarten sich an einigen Wettbewerben zu beteiligen. Insbesondere ihr Erfolg I919 beim Bewerb für ein Medizinisches Zentrum in Wien, für dessen Entwurf sie den I. Preis erhielten (der allerdings nicht realisiert wurde), dürfte sie darin bestärkt haben, die Bürogemeinschaft Hofbauer \& Baumgarten zu gründen. Hofbauer seinerseits war zehn Jahre älter und stammte aus einer alten

245 W. Aichelburg, Das Wiener Künstlerhaus, I 50 Jahre, I86I-200 I, 2. Bd., S. 65.

246 Siehe dazu, Visionäre und Vertriebene, zit. Anm. Io. 


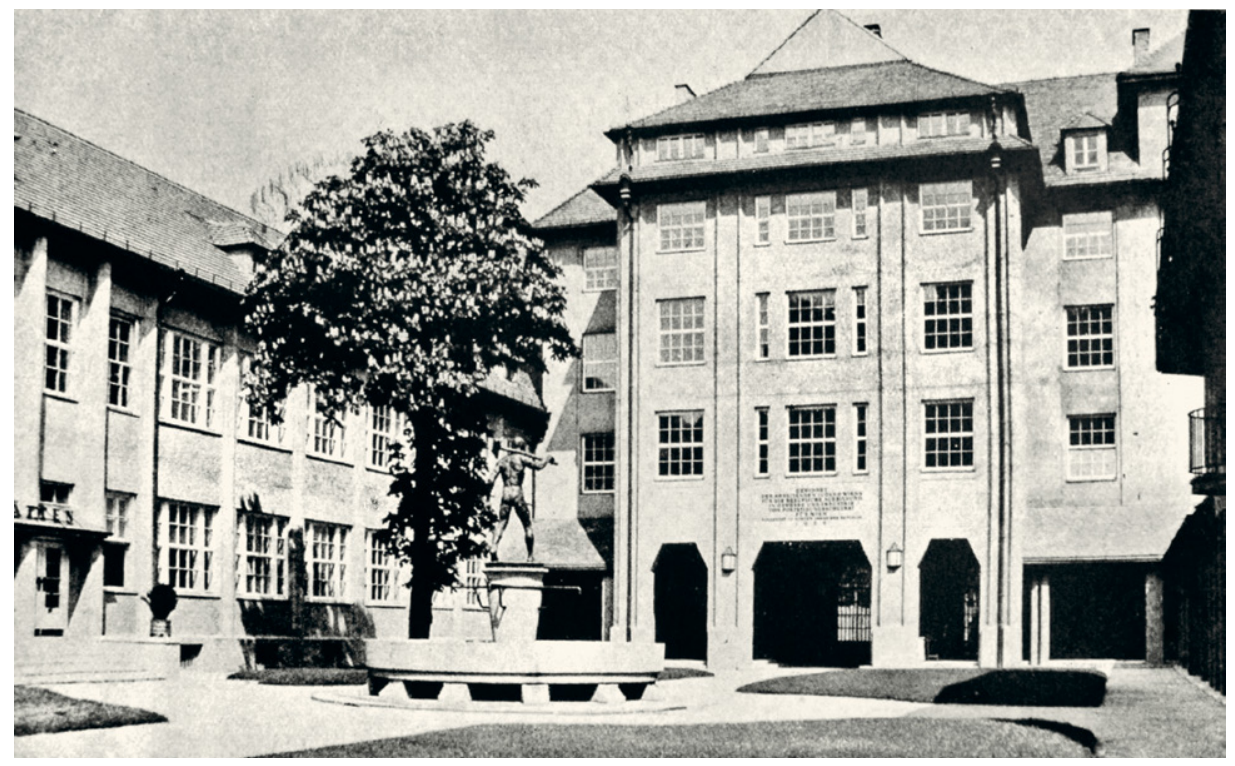

96. Wilhelm Baumgarten u. Josef Hofbauer, Gewerbliche Fortbildungsschule Wien I 5 , Hütteldorfer Straße. 7-17, erbaut $1925 / 26 /$ Österr. Bau und Werkkunst 1926

Wiener Baumeisterfamilie, sodass das soziale Netzwerk relativ breit gestreut war. Auch in fachlicher Hinsicht scheinen sich die beiden gut ergänzt zu haben. Hofbauer dürfte mehr für den technisch konstruktiven Teil zuständig gewesen sein, während der jüngere Baumgarten für die- wahrscheinlich von Peter Behrens beeinflusste - moderne Note in der formalen Ausarbeitung ihrer Projekte verantwortlich war. ${ }^{247}$

Tatsächlich konnten die beiden trotz der schlechten Wirtschaftslage in den nächsten Jahren eine Reihe von relativ großen Projekten ausführen. Neben Siedlungen und Wohnhausanlagen für die Gemeinde Wien arbeiteten sie insbesondere auf dem Gebiet des Schulbaus, wobei sie neben der Planung nicht nur die Bauleitung innehatten, sondern auch für die Innenausstattung verantwortlich waren und somit den Projekten zur Gänze ihren persönlichen Stempel aufdrückten. Nachdem sie Mitte der Zwanzigerjahre den großen Komplex der Gewerblichen Fortbildungsschule an der Hütteldorfer Straße 7 im I 5 . Bezirk errichtet hatten, der vor allem durch seine höchst funktionellen Arbeitsräume wegweisend war (Abbildung 96), dürfte sich ihr Ruf auf diesem Gebiet dermaßen gefestigt haben, dass sie durch zahlreiche Aufträge insbesondere zu den Hausarchitekten des tschechischen Schulvereines "Komensky« wurden.

247 Siehe dazu J. Hofbauer/W. Baumgarten, Projekte und ausgeführte Bauten, Wien I93 I. 
97. Wilhelm Baumgarten u. Josef Hofbauer,

Komensky-Schule, Wien I2, Erlgasse 32-34, erbaut $1930 / 3$ I/Österr. Kunst 1933

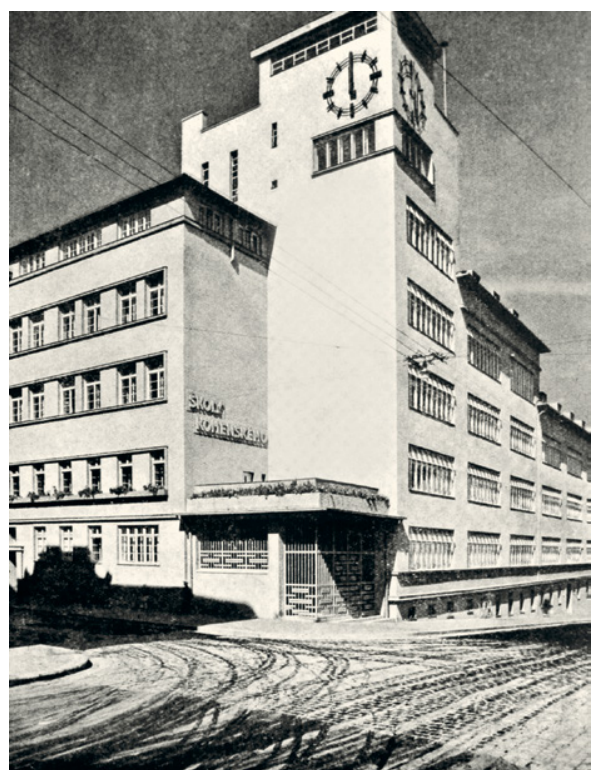

Der Verein war bereits ab den Siebzigerjahren des I9. Jahrhunderts in Wien aktiv, die tschechischen Schulen mussten jedoch die längste Zeit privat geführt werden. Erst infolge der »Brünner Verträge« von I 920 wurde den Schulen des Vereines Öffentlichkeitsrecht zugestanden, sodass in der Folge die Nachfrage unter der Wiener tschechischen Bevölkerung enorm anstieg. Dieser neue Umstand führte für einige Jahre geradezu zu einem kleinen Bauboom an tschechischen Schulen in Wien. Wie genau es im konkreten Fall zur Auftragsvergabe kam, ist allerdings nicht geklärt. Zweifellos kam den beiden zugute, dass Baumgarten, wie zum Beispiel auch Adolf Loos oder Jacques Groag, nach dem Auseinanderfallen der Monarchie aufgrund seines Geburtsortes Mährisch-Schönberg für die Tschechoslowakei optierte und daher tschechischer Staatsbürger war.

In der Folge errichteten Hofbauer \& Baumgarten in den nächsten Jahren eine Reihe von Schulen und Kindergärten für den »Komensky-Verein", die in architektonischer Hinsicht im Wiener Umfeld nahezu avantgardistisch zu nennen sind. Insbesondere die beiden um 1930 errichteten Gebäude des tschechischen Kindergartens in Wien I6, Arltgasse, und der Schule in Wien I 2, Erlgasse (Abbildung 97), waren auf der Höhe der damaligen europäischen Moderne. Dem entsprach insbesondere der kubische Baukörper mit Flachdach, der durch Vor- und Rücksprünge gegliedert und nur durch schmale Gesimse und Fensterbänder strukturiert wurde. Die große Resonanz in diversen Fachzeitschriften reflektiert die Anerkennung, die den beiden 
damals zuteilwurde. ${ }^{248}$ Die Bürogemeinschaft wurde allerdings bereits 1933 aufgelöst. Möglicherweise war eine Erkrankung Hofbauers, der Ende 1936 verstarb, die Grund. Jedenfalls wurde die letzte in der Serie der Schulen des "Komensky-Vereines« in Wien 3, Sebastianplatz 3, von Baumgarten 1934/35 in alleiniger Verantwortung errichtet. ${ }^{249}$ Es sollte generell sein letztes Projekt - soweit dokumentiert - in Wien bleiben. Ein geplanter Umbau des Warenhauses Herzmansky, der sehr bemerkenswert gewesen wäre, wurde nicht mehr ausgeführt.

Baumgarten, dessen jüdische Herkunft bis dahin offensichtlich keine Rolle gespielt hatte, traf die Konsequenz des sogenannten "Anschlusses« von 1938 mit voller Härte. Nicht nur dass er aufgrund der Nichterbringung eines Ariernachweises nicht in die Reichskunstkammer aufgenommen und damit seine berufliche Existenz verunmöglicht wurde, es erfolgte auch ein umgehender Ausschluss aus der Genossenschaft bildender Künstler. Dies war umso perfider, als er der Genossenschaft seit I 920 angehörte und sich durch zahlreiche Aktivitäten engagiert hatte. Neben seiner Tätigkeit in mehreren Komitees war er zeitweise auch Hausarchitekt und ab 1936 sogar Vizepräsident gewesen, im selben Jahr hatte er auch die Goldene Jubiläumsmedaille der Genossenschaft erhalten. ${ }^{250}$ Diese Vorfälle veranlassten Baumgarten, sich umgehend um eine Anstellung im Ausland zu bemühen. Obwohl er infolge seiner internationalen Kontakte ziemlich bald eine Berufung an das State College von North Carolina erhalten und im August des Jahres um eine Ausreisegenehmigung angesucht hatte, wurde er jedoch vorerst auf die Warteliste für tschechoslowakische Staatsbürger gesetzt und konnte daher erst im März I940 über Italien in die USA ausreisen. In North Carolina nahm Baumgarten dann schon I94 I seine Lehrtätigkeit am dortigen College auf, wo er vorerst Architekturgeschichte und Perspektivzeichnen unterrichtete. Nach Kriegsende erhielt er die amerikanische Staatsbürgerschaft und die Architektenlizenz. Baumgarten, der 1953 Professor geworden war, unterrichtete in der Folge bis zu seiner Emeritierung 1958 und verstarb ein Jahr später. Neben seiner Lehrtätigkeit publizierte er eine Reihe von Fachartikeln. Wie bei den meisten Emigranten war aber seine eigentliche Tätigkeit als Architekt mehr oder minder zum Erliegen gekommen. Er konnte nur einen einzigen Schulbau I950 im Robeson County errichten. ${ }^{251}$

248 Österreichische Baukunst 4.1933, S. I9f.

249 Der Bau dient heute noch als Schule des Komensky-Vereines, wurde allerdings später stark verändert.

250 Aichelburg, zit. Anm. 245, Bd. 2, Mitgliederverzeichnis.

25 I Visionäre und Vertriebene, zit. Anm. Io, S. 329. 
98. Rudolf Baumfeld \& Norbert Schlesinger, Geschäftsportal Trachtenmoden Lanz, Wien I, Kärntner Straße Io, erbaut I936 (Zustand 20I4)/Prokop

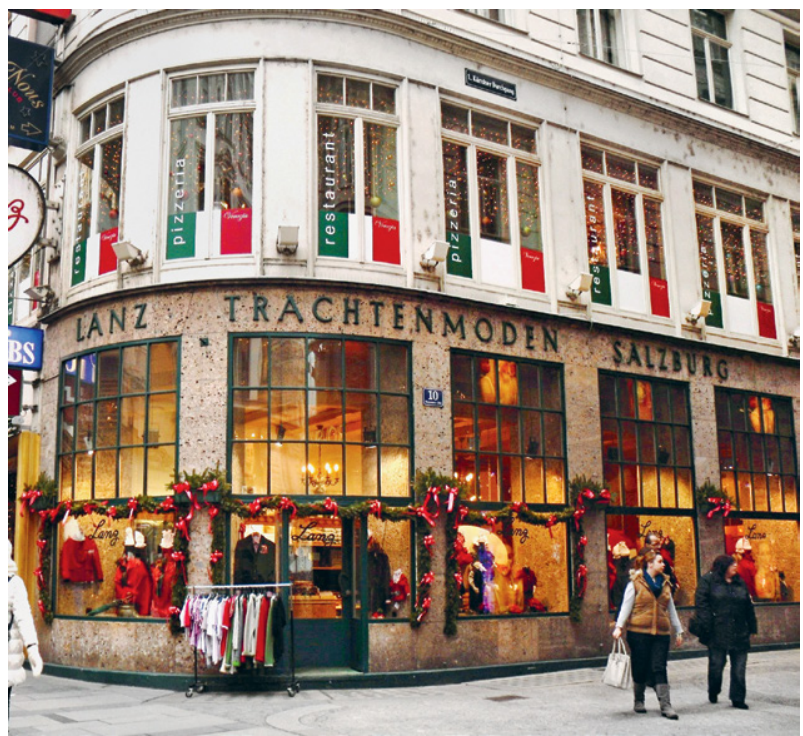

\subsubsection{Rudolf Baumfeld und Norbert Schlesinger - Geschäftslokale prägen das Stadtbild}

Eine weitere Partnerschaft, die in diesem Kontext abschließend erwähnt werden soll, ist die von Rudolf Baumfeld (I903-I988) und Norbert Schlesinger (1908-1980), die allerdings nur rund fünf Jahre von $\mathrm{I} 932$ bis 1937 währen sollte und sich weitgehend auf Inneneinrichtungen und Geschäftslokale spezialisierte. Auch in diesem Fall handelte es sich um Studienkollegen, die einander während ihrer Ausbildung an der Akademie der bildenden Künste in der Meisterschule bei Clemens Holzmeister kennengelernt hatten, und auch hier war das soziale Milieu höchst unterschiedlich. Während Norbert Schlesinger aus einer nordböhmischen Baumeisterfamilie stammte, kam Baumfeld aus einem bürgerlichen Wiener jüdischen Milieu. Als sie Anfang der Dreißigerjahre eine Bürogemeinschaft bildeten, hatte der einige Jahre ältere Rudolf Baumfeld bereits eine längere Praxiszeit - insbesondere bei Ernst Lichtblau und dessen Einrichtungsberatungsstelle BEST - hinter sich, sodass er auf dem Gebiet der Inneneinrichtung schon einige Erfahrung sammeln konnte. In der Folge richteten sie eine Reihe von renommierten Innenstadtgeschäften ein, deren Portale bis in die Sechziger/ Siebzigerjahre des 20. Jahrhunderts das Wiener Stadtbild prägten. Einzig das 1936 errichtete Sport- und Trachtenmodengeschäft »Lanz« auf der Wiener Kärntner Straße hat sich bis heute (wenn auch etwas verändert) erhalten und kann als nicht unbedeutendes Zeugnis der Zwischenkriegsarchitektur (Abbildung 98) angesehen werden. 
Dies betrifft nicht nur die formale Gestaltung, sondern ist auch unter dem Aspekt zu sehen, dass die Trachtenmode im Kontext einer österreichischen Identifikation und eines zu fördernden Tourismus zur Zeit des sogenannten "Ständestaates« einen hohen Stellenwert hatte. Eine affirmative Haltung zu den Machthabern dieser Jahre verrät auch das von der Bürogemeinschaft 1935 konzipierte Denkmal für die Gefallenen der Exekutive auf dem Wiener Zentralfriedhof. I936 wurde die Bürogemeinschaft aufgelöst, wobei der sich verstärkende politische Druck seitens NS-Deutschlands auf Österreich eine Rolle gespielt haben könnte.

Rudolf Baumfeld arbeitete noch in alleiniger Verantwortung als Konsulent der Firma "Julius Meinl" und baute in den Jahren 1933/36 eine Reihe von Geschäftslokalen für die Lebensmittelhandelskette um, deren charakteristische Formgebung in gewisser Weise gleichfalls ein Teil österreichischer Identität war. ${ }^{252}$ Nach dem sogenannten "Anschluss" Österreichs musste Baumfeld umgehend sein Atelier schließen und floh über die damalige Tschechoslowakei nach Italien, wo er vorübergehend interniert wurde. Nachdem es ihm gelungen war, dem Lager zu entkommen, gelangte er schließlich im Herbst 1940 in die USA, wo er vorerst eine Stelle als Zeichner bei der US Navy erhielt. Nach mehreren anderen Anstellungen gelangte er I943 in Los Angeles ins Baubüro von Victor Gruen, der gleichfalls aus Wien stammte und den Baumfeld noch von seiner Schulzeit her kannte. Das ursprünglich kleine Büro expandierte bald mit der Entwicklung von Geschäftsbauten und insbesondere den wegweisenden Shopping Malls. Baumfeld, der I950 Partner von Gruen wurde, arbeitete bis kurz vor seinem Tod sehr erfolgreich in der Firma und gehört damit zu der kleinen Gruppe von Architekten, die in der Emigration Karriere machen konnten. Sein Partner Norbert Schlesinger hingegen arbeitete in der NS-Zeit am Ausbau zahlreicher prestigeträchtiger Großunternehmen mit, unter anderem an der Planung der Volkswagenwerke in Wolfsburg. Nach dem Krieg gehörte er zu einem der vielbeschäftigten Architekten dieser Jahre und hatte eine Professur an der damaligen Hochschule für angewandte Kunst in Wien inne. Zweifellos auf Vermittlung seines ehemaligen Partners Baumfeld war er auch der Mitautor beim bereits angeführten Schulprojekt von Ernst Lichtblau.

252 Die Lebensmittelkette »Julius Meinl« existiert nicht mehr. 


\section{Frauen als Pioniere auf dem Gebiet der Architektur}

Dieses Kapitel widmet sich den jüdischen Frauen, die als Architektinnen oder Designerinnen tätig waren. Die Behandlung in einem eigenen Abschnitt ist grundsätzlich nicht unter einem geschlechtsspezifischen Blickwinkel zu verstehen (bei heutigen Architektinnen würde man eine solche Einteilung keinesfalls vornehmen), sondern erfolgt schlichtweg deshalb, weil Frauen damals auf diesem Gebiet noch eine Sonderstellung einnahmen und vor allem auch ihre Ausbildung weitgehend abseits der in jenen Jahren üblichen Institutionen erfolgte, weshalb sie außerhalb der oben angeführten Gruppierungen standen. Ungeachtet dieser Schwierigkeiten sind dennoch ein paar dieser Architektinnen schon seit einiger Zeit in unser Bewusstsein gerückt. Dieser Umstand verdankt sich nicht zuletzt Sabine Plakolm-Forsthuber, die mit mehreren Publikationen auf diesem Gebiet Pionierarbeit geleistet hat. ${ }^{253}$

Generell ist zu sagen, dass erst gegen Ende des I9. Jahrhunderts Frauen in qualifiziertere Berufe drängten, während sie bis dahin weitgehend nur als einfache Arbeiterinnen oder in der Landwirtschaft tätig gewesen waren. Da der Zugang zu Hochschulen oder Akademien Frauen verwehrt war (unter anderem galt das Aktzeichnen nach lebenden Modellen als unschicklich), konnten sie lange Zeit keinen Beruf mit akademischer Ausbildung ausüben, wobei manche Bereiche, darunter auch das Bauwesen, ganz besonders männlich dominiert waren. In diesem Kontext spielte die "Kunstgewerbeschule» am Stubenring (heute Universität für angewandte Kunst) eine bedeutende Rolle, insofern sie ab 1900 nach langen Kämpfen die einzige öffentliche Ausbildungsstätte war, wo auch Frauen studieren konnten (allgemeinen Zugang zu den Hochschulen erhielten die Frauen erst nach dem Ersten Weltkrieg). Deshalb haben auch nahezu alle der hier erwähnten Künstlerinnen irgendwann diese Institution besucht. Allerdings war diese Möglichkeit durchaus etwas zwiespältig, da die Ausbildung vor allem auf die »angewandte Kunst", also Kunsthandwerk oder nach heutigem Begriff Design, ausgerichtet war und damit gewissermaßen geschlechtsspezifische Klischees weitergeführt wurden.

Innerhalb dieser Problematik - des Eindringens von Frauen in bis dahin "männliche Berufe« - spielten vor allem Jüdinnen aus bürgerlichem Umfeld eine besondere Rolle, die möglicherweise auch infolge ihrer doppelten Sonderstellung risikofreudiger waren. Zumeist waren sie es, die früher als ihre nicht jüdischen Geschlechtsgenossinnen in diese Bereiche drängten und damit eine Pionierrolle einnahmen. Ungeachtet ihres Mutes gelang es jedoch den meisten der Frauen nicht, in dem hier abgehandel-

253 Insbesondere Plakolm-Forsthuber, zit. Anm. I 2. 
ten Zeitrahmen bis zum Zweiten Weltkrieg eine völlige Gleichstellung durchzusetzen. Überwiegend wurden sie - wie bereits erwähnt - in den Bereich der Innenarchitektur oder des Designs abgedrängt. Zumeist wurde den Frauen nur eine Begabung für die "innere Häuslichkeit» zubilligt. Diesen Umstand reflektiert auch ein im Februar I933 erschienener Artikel in der "Neuen Freien Presse« mit dem Titel »Wie schaffen Wiener Architektinnen? « ${ }^{254}$ Nahezu alle der hier aufgelisteten Frauen mussten sich auf Innenraumgestaltung beschränken oder waren als Assistentinnen von männlichen Kollegen tätig. Einige, wie die hier erwähnte Lilia Pollak-Soffer, wechselten überhaupt bald in eine andere Branche. ${ }^{255}$ Soweit zu der äußerst schwierigen Situation in dieser Zeit, in der sich nur ganz wenige Ausnahmen durchsetzen konnten. Angesichts dieser doppelten Diskriminierung, sowohl als Frauen als auch als Jüdinnen, die sich späterhin in der Emigration durchsetzen mussten, ist die Zähigkeit und Durchhaltekraft mancher dieser Künstlerinnen nahezu unglaublich. Demgemäß ist es auch nicht verwunderlich, dass die Laufbahn der meisten dieser Frauen auch mit einem ausgeprägten feministischen Engagement verbunden war.

\subsection{Ella Briggs und das Rote Wien}

Zu den oben angeführten Ausnahmen gehörte vor allem Ella Briggs ( I 880-I977), die in mehrfacher Hinsicht eine ganz besondere Stellung einnahm. Zum einen war sie die erste österreichische Architektin überhaupt (im Gegensatz zu der gängigen Meinung, dieses Verdienst komme Margarete Schütte-Lihotzky zu, die jedoch noch studierte, als Ella Briggs bereits ihre ersten Werke präsentierte), zum anderen war sie eine der wenigen Frauen, die nicht auf das Gebiet der Innenarchitektur beschränkt blieb, sondern tatsächlich »baute«. Als Tochter des Advokaten Josef Baumfeld in Wien geboren, entstammte sie einem gutbürgerlichen jüdischen Milieu, das intellektuell und künstlerisch sehr aufgeschlossen war. Dementsprechend versuchte die junge Ella Baumfeld sich - soweit es damals für Frauen überhaupt möglich war - fachlich ausbilden zu lassen, wobei sie jedoch weitgehend auf „Ersatzinstitutionen « zurückgreifen musste, so auf die private Malschule von Prof. Adalbert Seligmann und späterhin eben die Wiener Kunstgewerbeschule, wo sie jedoch in ihrer Ausbildung wahrscheinlich weitgehend auf das Kunsthandwerk beschränkt blieb. ${ }^{256}$

254 G. Urban, Wie schaffen Wiener Architektinnen?, in: Neue Freie Presse, I 5.2.1933 (Abendausgabe, S. 6).

255 Ebenda. Obwohl Pollak-Soffer sogar den Diplom-Ingenieur-Titel erworben hatte, gab sie ihren Beruf bald auf und wurde Schauspielerin.

256 Weihsmann und I. Scheidl, Ella Briggs, in: Architektenlexikon, beide zit. Anm. I3. Gesichert ist 
Nach Abschluss der Schule um 1906 ging die junge Ella erstmals nach New York, wo zu diesem Zeitpunkt ihr Bruder lebte. Dort schloss sie auch die Ehe mit dem aus Wien stammenden Journalisten Walter Briggs, die jedoch bald scheiterte, sodass sie bereits gegen I 9 I 2 nach Wien zurückkehrte. Hier präsentierte sie erstmals diverse Inneneinrichtung in einer vom sogenannten "Frauenclub (einer der vielen Frauenvereine, die sich damals konstituierten und von engagierten Feministinnen betrieben wurden, die versuchten, sich ihre eigene Plattform zu schaffen) veranstalteten Ausstellung. Generell bot der 1900 ins Leben gerufen »Frauenclub«, der bereits im Kontext mit Ludwig Schmidls Schulbauten erwähnt wurde, im Rahmen seiner Diskussionsabende, Vortragsreihen, Kurse, Ausstellungen und anderem mehr Frauen eine Chance der Weiterbildung, der Aufnahme sozialer Kontakte und der Präsentation in der Öffentlichkeit. ${ }^{257}$ Die Räumlichkeiten, die sich im alten Trattnerhof am Graben befanden, waren ursprünglich von Adolf Loos eingerichtet - ein Indiz dafür, wie sehr der Verein im Fokus der damaligen Moderne stand. ${ }^{258}$ Es erübrigt sich darauf hinzuweisen, dass insbesondere Frauen aus jüdisch-großbürgerlichem Milieu hier eine führende Rolle spielten, so unter anderen Editha von Mauthner-Markhof oder Clara Wittgenstein (eine Tante Ludwig Wittgensteins), die zu den Mitbegründerinnen gehörten.

Ella Briggs gab sich jedoch mit ihrer Situation nicht zufrieden und wusste, dass ihre Chance nur in der Weiterbildung bestand. Neben einem Praktikum in einem Baubüro besuchte sie daher die Staatsgewerbeschule in Salzburg und schließlich, nachdem Frauen nach Ende des Ersten Weltkrieges endlich zugelassen wurden, auch die Technische Hochschule in München, wo sie I920 das Abschlussdiplom erwarb und damit berechtigt war, den Titel »Diplom-Ingenieur« zu führen. Damit setzte die damals bereits Vierzigjährige neue Maßstäbe. In der Folge wurde sie I92 I auch das erste weibliche Mitglied des elitären "Österreichischen Ingenieur- und Architektenvereines«. ${ }^{259}$ Aufgrund der sehr schlechten wirtschaftlichen Situation in Österreich Anfang der Zwanzigerjahre ging sie jedoch neuerlich in die USA und arbeitete kurzfristig für das Baubüro Kahn \& Gregory. Um I923/24 kehrte sie in ihre Heimat zurück, wo sie insbesondere publizistisch tätig war und endlich im Rahmen des sozialen Wohnbauprogramms des "Roten Wien" zwei Aufträge erhielt. Praktisch gleichzeitig und auch räumlich in großer Nähe errichtete sie dann $1925 / 26$ einen Wohnhausblock mit Kindergarten und ein Ledigenheim in Wien-Döbling. Während zu diesem Zeitpunkt -

nur, dass sie die Malklasse von Kolo Moser besuchte, ob sie auch Architektur bei Josef Hoffmann studierte, ist nicht gesichert, scheint aber sehr wahrscheinlich.

257 Siehe dazu www.2onb.ac.at/ariadne.

258 Rukschcio/Schachel, zit. Anm. I75, S. 42 I. Der alte Trattnerhof am Wiener Graben wurde um I 9 Io abgerissen.

259 Aufnahmeformular des Österreichischen Ingenieur- und Architektenvereines von I92I. 
Mitte der Zwanzigerjahre - die meisten Bauten des Roten Wien noch von einem expressionistischen Pathos geprägt waren, zeichneten sich ihre beiden Projekte durch eine große Klarheit der Formen aus und widerlegen damit das übliche Klischee von der "weiblichen Verspieltheit« ${ }^{260}$ Hell und freundlich präsentiert sich insbesondere die Wohnhausanlage des »Pestalozzi-Hofes" (Wien I9, Philippovichgasse 2-4), deren Hauptfront sich dem gegenüberliegenden Währinger-Park hin öffnet (Abbildung 99). Mit der betont zentralen Situierung des Kindergartens im zurückgesetzten Mittelteil wird auch optisch die Zukunftshoffnung der Arbeiterschaft symbolisiert. ${ }^{261}$

Gleichfalls ohne dekorative Elemente und in schlichten Formen, die teilweise von der Bauhausästhetik beeinflusst waren, plante Ella Briggs auch das sogenannte "Ledigenheim« an der Billrothstraße 9. Im Gegensatz zu den üblichen Sozialwohnungen, die für Familien gedacht waren, wurden hier kleine Wohneinheiten für Unverheiratete geschaffen und damit ein für die Zeit höchst progressives Unternehmen gewagt. Auch hier besticht die durch Vor- und Rücksprünge gegliederte Fassade durch ihre ausgewogenen Proportionen. Trotz der hohen Qualität dieser beiden Objekte konnte Ella Briggs ihre Tätigkeit in Wien jedoch nicht fortsetzen. Aufgrund der Wirtschaftskrise, die Ende der Zanzigerjahre einsetzte, verließ sie Wien erneut und ging nach Berlin, wo die Verhältnisse etwas besser waren. Auch hier arbeitete sie auf dem Gebiet des sozialen Wohnungsbaus und veröffentlichte einige Fachartikel. Die Machtergreifung der Nazis zwang sie dann aber I936 Deutschland zu verlassen und nach England zu gehen, wo sie sich in London niederließ. Obwohl zu diesem Zeitpunkt noch Frieden herrschte und sie im Gegensatz zu vielen anderen Emigranten über gute Sprachkenntnisse verfügte, stieß sie dennoch anfangs auf große Schwierigkeiten, insofern ihr Ansuchen um eine Architektenbefugnis vorerst zurückgewiesen wurde. ${ }^{262}$ Wann genau sie wieder als Architektin tätig sein konnte, ist ungewiss. Jedenfalls erhielt sie die britische Staatsbürgerschaft erst nach Ende des Zweiten Weltkrieges und konnte damit auch Mitglied des Royal Institute for British Architects (RIBA) werden - eine Voraussetzung, um in England als freie Architektin bzw. freier Architekt tätig zu sein. Unmittelbar nach dem Krieg war sie dann auch an einem Wiederaufbauprojekt beteiligt, wo sie im Komitee für »Housing and Planing « tätig war und in dieser Funktion eine Wohnsiedlung in Bilston realisieren konnte. ${ }^{263}$ Nach dem Tod ihres Bruders

260 Siehe dazu U. Prokop, Jüdinnen als Pionierinnen der Frauenemanzipation, in: David, 23.20I I, H. 89 , S. $22 \mathrm{ff}$.

26I Zum Pestalozzi-Hof siehe H. Hautmann/R. Hautmann, Die Gemeindebauten des Roten Wien I919-I934, Wien 1980. Korrekt: Festschrift zum Pestalozzi-Hof, Wohnhausanlage der Gemeinde Wien. Wien o. J.

262 Benton, zit. Anm. 214, S. I 46.

263 Architects Journal, 2.1.1947, S. I $5 \mathrm{ff}$. 


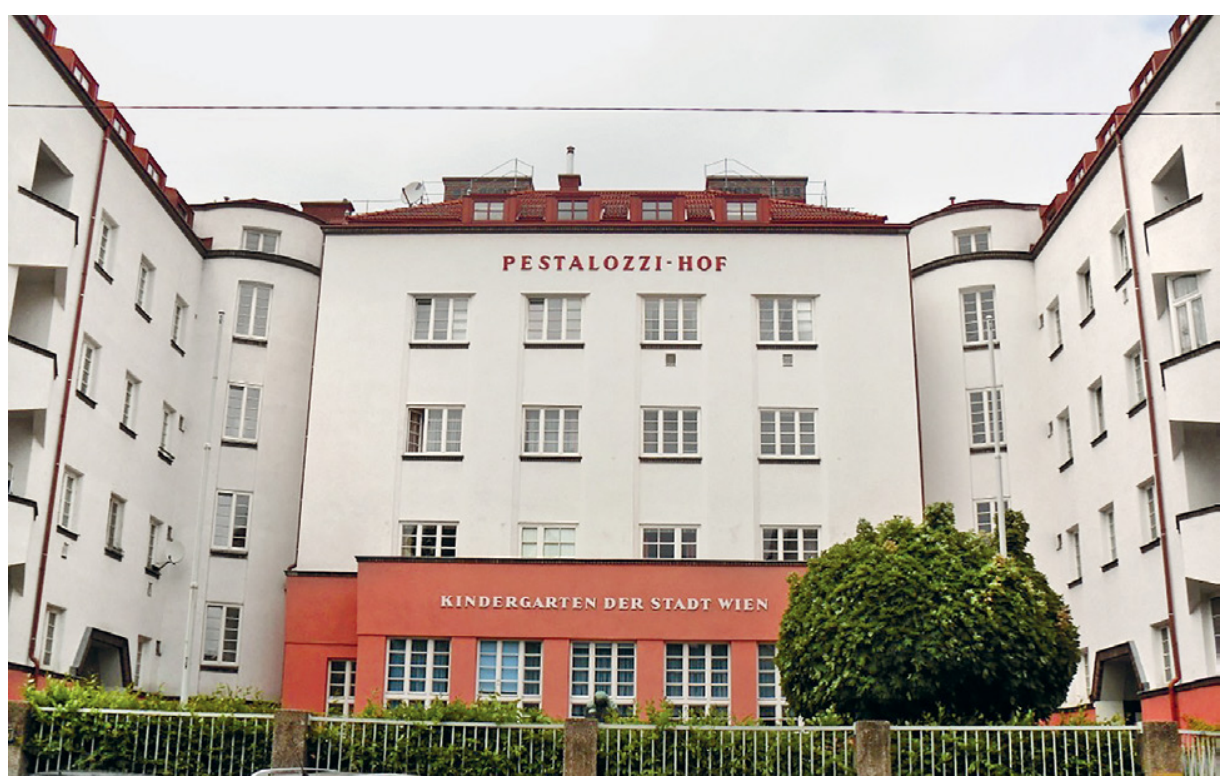

99. Ella Briggs, Pestalozzi-Hof, Wien I9, Philippovichgasse 2-4, erbaut I925/26/Prokop

Fritz, mit dem sie in einem gemeinsamen Haushalt in London gelebt hatte, zog sie sich nach Ensfield (heute ein Teil von London) in Middlesex zurück, wo sie siebenundneunzigjährig an Leukämie verstarb. ${ }^{264}$

\subsection{Liane Zimbler - Einrichtungen für die gehobene Mittelschicht}

In vielen Details nicht unähnlich - auch im Hinblick auf manche Lückenhaftigkeit ist die Biografie von Liane Zimbler (1892-1987, Abbildung Ioo), die allerdings für eine andere Klientel arbeitete. Mehr als zehn Jahre jünger als Ella Briggs, gehörte sie auch schon beinahe einer anderen Generation an. Im mährischen Prerau/Prerov als Tochter des höheren Bahnbeamten Otto Fischer geboren, kam sie infolge der Versetzung ihres Vaters bereits als kleines Kind nach Wien. Auch bei ihr ist die fachliche Ausbildung nicht mehr genau rekonstruierbar - nicht zuletzt infolge der Schwierigkeiten, auf die Frauen stießen und die sie zwangen, unorthodoxe Wege zu beschreiten. ${ }^{265}$

264 Freundliche Auskunft Cecilia Male (Großnichte).

265 Siehe dazu S. Plakolm-Forsthuber, Ein Leben, zwei Karrieren, in: Visionäre und Vertriebene, zit. Anm. ıо, S. 295; Ch. Gräwe, Liane Zimbler, Dipl.-Arb., TU Berlin 2003. 


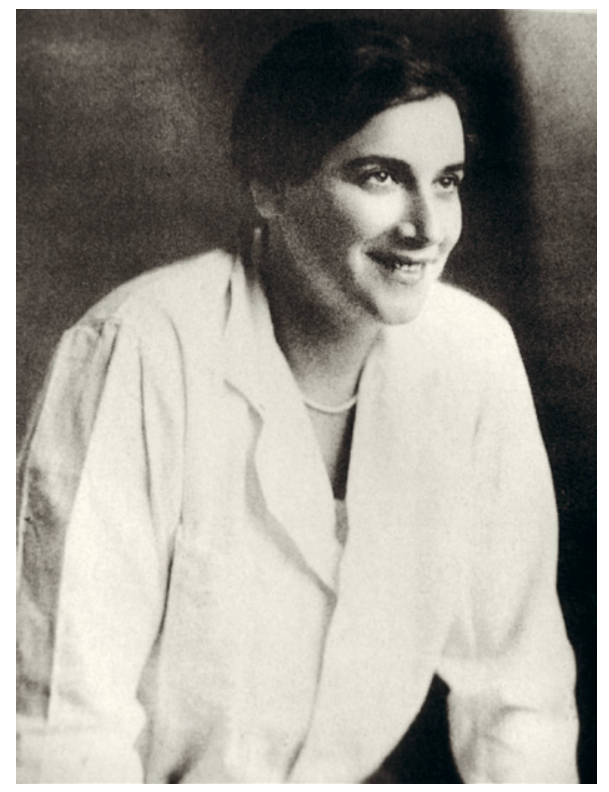

ıоo. Liane Zimbler, Porträt/Vertriebene

Wahrscheinlich um I9I2 ging sie an die Kunstgewerbeschule, wobei infolge der unzulänglichen Quellenlage nicht genau geklärt ist, wann genau und bei wem sie studierte. Vielfach wird angenommen, dass sie die Klasse von Oskar Strnad besuchte. Daneben arbeitete sie als Illustratorin und Modedesignerin für den renommierten Salon von Emilie Flöge. ${ }^{266}$ Noch während des Ersten Weltkrieges I9I 6 heiratete sie den Rechtsanwalt Otto Zimbler, aus dieser Ehe stammte auch ihr einziges Kind Eva. Zur selben Zeit nahm sie eine Stelle in einer Möbelfabrik an, was darauf schließen lässt, dass sie damals ihre Ausbildung bereits abgeschlossen hatte. Gegen Ende des Ersten Weltkrieges arbeitete sie nachweislich in einem Architekturbüro, um sich aber schon bald selbstständig zu machen. Einer ihren ersten Aufträge war I9I 8 die Errichtung eines Landhauses in Bad Aussee/OÖ. Dennoch war sie späterhin infolge der schlechten wirtschaftlichen Situation gezwungen, sich auf Umbauten und Einrichtungen zu spezialisieren. Das oben erwähnte Landhaus und das von ihr eher in konventionellen Formen 1924 geplante Einfamilienhaus Wetzler in Wien-Grinzing (Silbergasse 2) sollten daher die Ausnahmen bleiben.

Eines ihrer - wahrscheinlich auch in ökonomischer Hinsicht - bedeutendsten Projekte dieser Jahre war der Umbau des Bankhauses Ephrussi in Wien 9, Wasagasse, mit

266 Emilie Flöge war die lang)ährige Lebensgefährtin von Gustav Klimt, der sie auch porträtierte. Ihr legendärer Schneidersalon wurde von Josef Hoffmann und der Wiener Werkstätte eingerichtet. 


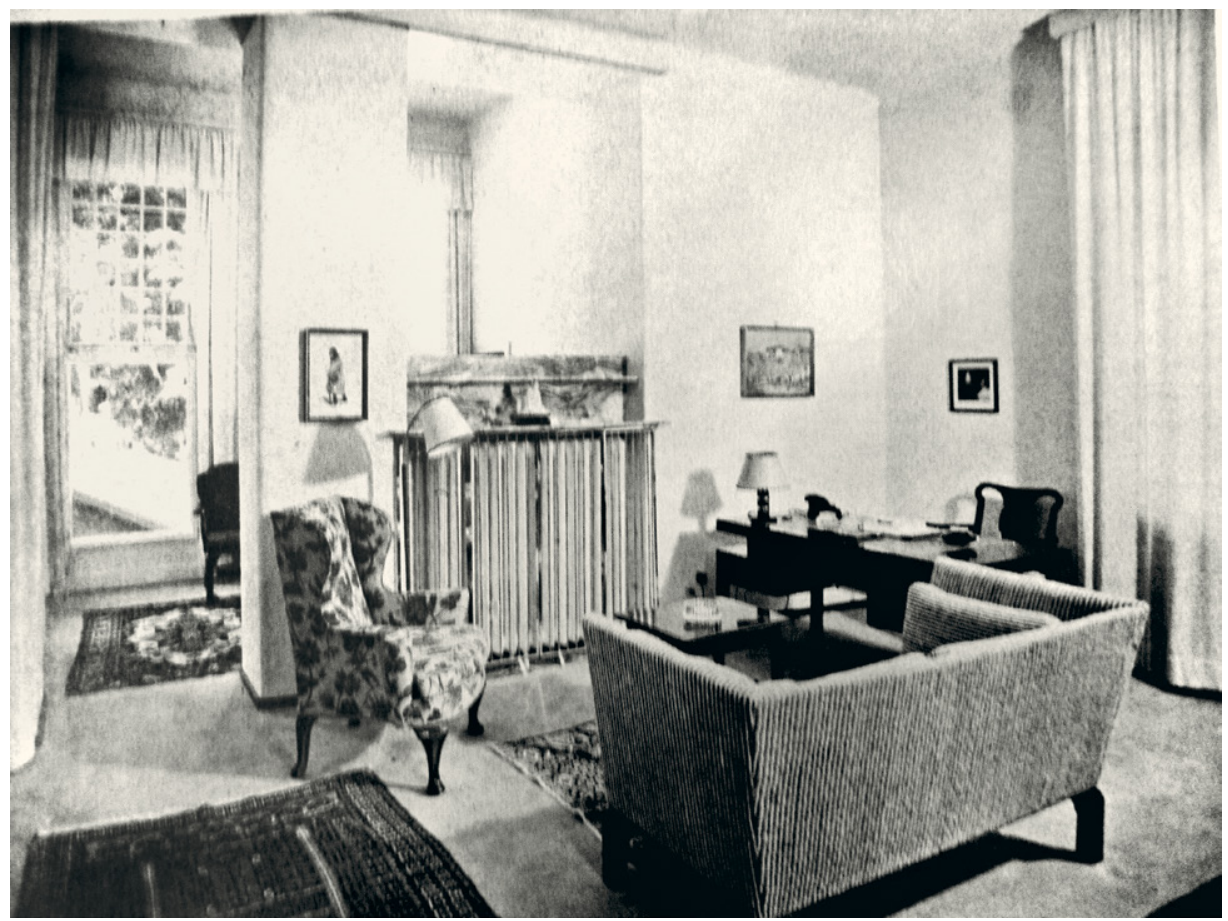

I о . Liane Zimbler, Herrenzimmer, um I935/Österr. Kunst

dem sie rund drei Jahre befasst war. Generell erfreute sich ihr Atelier bald einer so guten Auftragslage, dass sie Ende der Zwanzigerjahre bereits eine Außenstelle in Prag errichten konnte, die Annie Herrnheiser leitete, mit der sie bereits zuvor zusammengearbeitet hatte. Ihre Auftraggeber rekrutierten sich weitgehend aus gutbürgerlichen Kreisen, die jedoch gezwungen waren, einen Haushalt möglichst ökonomisch und ohne das damals zumeist noch übliche Personal zu führen. Liane Zimbler nutzte diese Marktnische sehr geschickt, sodass sie durchaus als eine der wesentlichen Protagonistinnen der »Wiener Wohnraumkultur«, wie sie von Josef Frank, Felix Augenfeld, Walter Sobotka und anderen geprägt worden war, anzusehen ist. Das Erfolgsrezept ihrer Einrichtungen waren helle, freundliche Möbel, die funktionell und modern waren, ohne jedoch von einer allzu nüchternen Bauhausästhetik geprägt zu sein (Abbildung IOI). Die Raumeinteilung war zumeist fließend und wurde mittels beweglicher Wände oder Vorhänge erzielt. Entsprechend ihrer Konzentration auf die Innenarchitektur hat sich Liane Zimbler auch immer wieder an einschlägigen Ausstellungen beteiligt. 
Eine weitere nicht unwesentliche Strategie Liane Zimblers, die eine bewusste Feministin war, war die Bevorzugung von Frauen als Mitarbeiterinnen, da sie "weiblichen Angestellten die Gelegenheit geben wollte, eine gute Stellung zu bekommen, was damals nicht so leicht war «. ${ }^{267}$ In diesem Sinn suchte sie die Zusammenarbeit mit renommierten Kunsthandwerkerinnen wie Maria Strauß-Likarz, Herta Bucher und anderen, die für viele Details ihrer Interieurs verantwortlich waren. Darüber hinaus wurde sie publizistisch von Dr. Else Hoffmann unterstützt, die fallweise auch als Innenarchitektin arbeitete, jedoch im Rahmen ihrer umfassenden journalistischen Tätigkeit laufend die Einrichtungen Zimblers veröffentlichte. ${ }^{268}$ In diesem Kontext wird auch deutlich, wie eng die künstlerischen und personellen Verflechtungen dieses Kreises waren: Nicht zuletzt hat Felix Augenfeld, wie bereits erwähnt, für Maria Strauß-Likarz ein Wochenendhaus in Kritzendorf errichtet.

Im Rahmen ihres feministischen Engagements entfaltete Juliane Zimbler, die auch mehreren einschlägigen Vereinen angehörte, so der »Wiener Frauenkunst«, dem »Soroptimist Club« (eine weibliche Variante des Rotary Clubs) und dem »Verband berufstätiger Frauen«, eine rege Vortrags- und Publikationstätigkeit und unterrichtete an der Wiener Volkshochschule. ${ }^{269}$ Noch im Februar 1938 erhielt sie als erste Frau in Österreich die Befugnis zum Zivilarchitekten, um sich allerdings kurz danach gezwungen zu sehen, ihre Heimat fluchtartig zu verlassen. Gleich in den ersten Wochen nach dem "Anschluss « verließ sie mit ihrer Familie Österreich und gelangte über Holland nach England, von wo sie um ein Einreisevisum in die USA ansuchte, die zu diesem Zeitpunkt ja noch neutral waren und österreichischen Emigranten - zumindest beschränkt - offenstanden. In der Folge gelangte die Familie noch im Herbst des Jahres nach New York. Über die Vermittlung von Ada Gomperz, der Frau des Philosophen Heinrich Gomperz, die ihrerseits auch als Innenarchitektin tätig gewesen war und dem weiblichen Netzwerk um Liane Zimbler angehört hatte, konnte sie sich schließlich in Los Angeles niederlassen.

In der Folge schaffte es Liane Zimbler mit großer Zähigkeit sich auch hier wieder eine Existenz aufzubauen. Nachdem sie kurzfristig künstlerische Entwürfe für eine

267 Zitiert nach Plakolm-Forsthuber, zit. Anm. I2, S. 254.

268 Dr. Else Hoffmann (1893 Wien - I960 New York) war promovierte Kunsthistorikerin und machte sich vor allem durch ihre umfassende publizistische Tätigkeit einen Namen. Sie arbeitete unter anderem für die Zeitschriften "Wiener Tagblatt«, »Innendekoration«, "Kunst und Dekoration« und "Österreichische Kunst«. Ihre Arbeit als Innenarchitektin ist dahingegen praktisch unbekannt. 1928 wurde ihre Einrichtung eines Wochenendhauses in einer Ausstellung im Warenhaus Zwieback gezeigt (Moderne Welt, 1928, H. 28, S. 42). Unter anderem publizierte sie über Liane Zimbler den Aufsatz Die Arbeiten einer Innenarchitektin, in: Innendekoration 42.193 I, S. $290 \mathrm{off}$.

269 Insbesondere die Wohnsituation der modernen Frau war Thema von Zimblers Artikeln (siehe Bibliografie). 
Packpapierfirma angefertigt hatte, nahm sie um 1940 - im selben Jahr verunfallte ihr Mann tödlich - eine Stellung in der Einrichtungsfirma Anita Toor an. Als auch Anita Toor bald verstarb, leitete Zimbler das Atelier, das in den nächsten Jahren zahlreiche Umbauten und Einrichtungen durchführte, alleine weiter. Auch hier verstand sie es, sehr pragmatisch Kriterien der zeitgenössischen Moderne moderat umzusetzen und mit bürgerlichen Komfortansprüchen zu vereinen. Darüber hinaus war sie auch mit der Planung einiger Neubauten befasst, die allerdings immer in Zusammenarbeit mit anderen Architekten entstanden. Eine Erklärung dafür könnte der Umstand sein, dass sie möglicherweise für die USA keine Architektenbefugnis hatte. Ab den Sechzigerjahren arbeitete auch ihre Tochter Eva Huebscher, deren Informationen eine wichtige Quelle sind, in dem florierenden Unternehmen. Liane Zimbler ist schließlich nach einem trotz aller Widrigkeiten erfolgreichen Leben fünfundneunzigjährig in Los Angeles gestorben.

\subsection{Friedl Dicker und Franz Singer - die Einfachheit des Wohnens}

Das tragischste Schicksal ereilte Friedl Dicker (I 898-I944), die jüngste der drei hier abgehandelten Architektinnen. Auch ihrem architektonischen Werk war kein Glück beschieden, und es wurde, so bemerkenswert es auch war, späterhin nahezu vollständig zerstört. Möglicherweise erklärt sich das auch aus dem Umstand, dass sie als Jüdin und Kommunistin der Verfolgung doppelt ausgesetzt war. Da sie, was ihre architektonische Tätigkeit betrifft (in ihren letzten Jahren hatte sie sich vor allem der Malerei gewidmet), immer mit ihrem Kollegen Franz Singer zusammengearbeitet hat, wird auch er in dieses "Frauenkapitel « einbezogen.

Als Tochter eines Verkäufers I 898 in Wien geboren, stammte Friedl Dicker aus eher bescheidenen Verhältnissen (Abbildung I02). Ihre Ausbildung begann sie an der Graphischen Lehr- und Versuchsanstalt, wo sie Fotografie und Reproduktionstechnik lernte. ${ }^{270}$ Danach besuchte sie kurzfristig die Textilklasse der Kunstgewerbeschule. Bedeutend war für sie jedoch die Begegnung mit dem charismatischen, esoterisch angehauchten Schweizer Kunsttheoretiker Johannes Itten, der während des Ersten Weltkrieges in Wien eine Privatschule führte. Trotz widrigster ökonomischer Umstände fand sie hier Eingang in eine Gruppe allem Neuen aufgeschlossener Studenten. Neben Anny Wottitz, die späterhin Hans Moller (den Bauherrn der gleichnamigen Villa von Adolf Loos) heiratete, freundete sich Friedl Dicker insbesondere mit Franz Singer an, der über Jahre ihr Lebenspartner werden sollte. Singer

270 E. Makarova, Friedl Dicker-Brandeis (Kat.), Wien I999. 


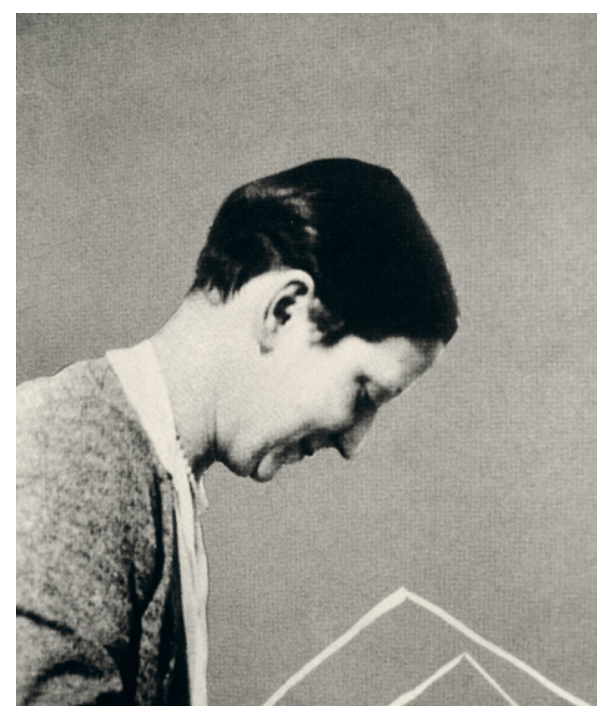

I02. Friedl Dicker, Porträt/AzW

seinerseits (I899-1954) kam aus einem gutbürgerlichen Milieu und hatte, bevor er zu Johannes Itten gekommen war, eher untypischerweise Malerei und Philosophie studiert. Nach Ende des Krieges ging die ganze Gruppe I9I9 gemeinsam mit ihrem Lehrer Johannes Itten an das neu gegründete Bauhaus in Weimar. In dieser Experimentierstätte der damaligen Moderne kam Friedl Dicker in Kontakt mit den bedeutendsten Künstlern ihrer Zeit, wie Paul Klee, Oskar Schlemmer, Lyonel Feininger, Walter Gropius und anderen mehr, die auch Einfluss auf ihr Werk haben sollten. Insbesondere die Einheit von Architektur, Malerei, Bildhauerei und anderen Techniken war für die "Bauhäusler«, die aufgrund ihrer avantgardistischen Haltung von der Weimarer Bevölkerung häufig auch als »Juden und Bolschewiken" diffamiert wurden, prägend. Noch während ihrer Ausbildung am Bauhaus arbeitete sie gemeinsam mit Franz Singer als Bühnenausstatterin. Obwohl dieser damals eine Ehe mit der Sängerin Emmy Heim eingegangen war, hielt er die Beziehung zu Friedl Dicker aufrecht, die unter dieser "menage à trois« trotz der in diesen Kreisen betonten Freizügigkeit sehr litt.

Nach Beendigung des Studiums 1923 gingen Dicker und Singer nach Berlin und betrieben die »Werkstätten Bildender Kunst«, die Inneneinrichtungen und kunsthandwerkliche Objekte, aber auch Bühnenausstattungen entwarfen. 1925 kehrten sie wieder nach Wien zurück und gründeten das Architekturbüro Dicker \& Singer. In der Folge fertigte das Atelier, das sehr erfolgreich war, für zahlreiche Wohnungs- und Geschäftseinrichtungen, den Entwurf von Möbeln und Textilien an, war aber auch für 


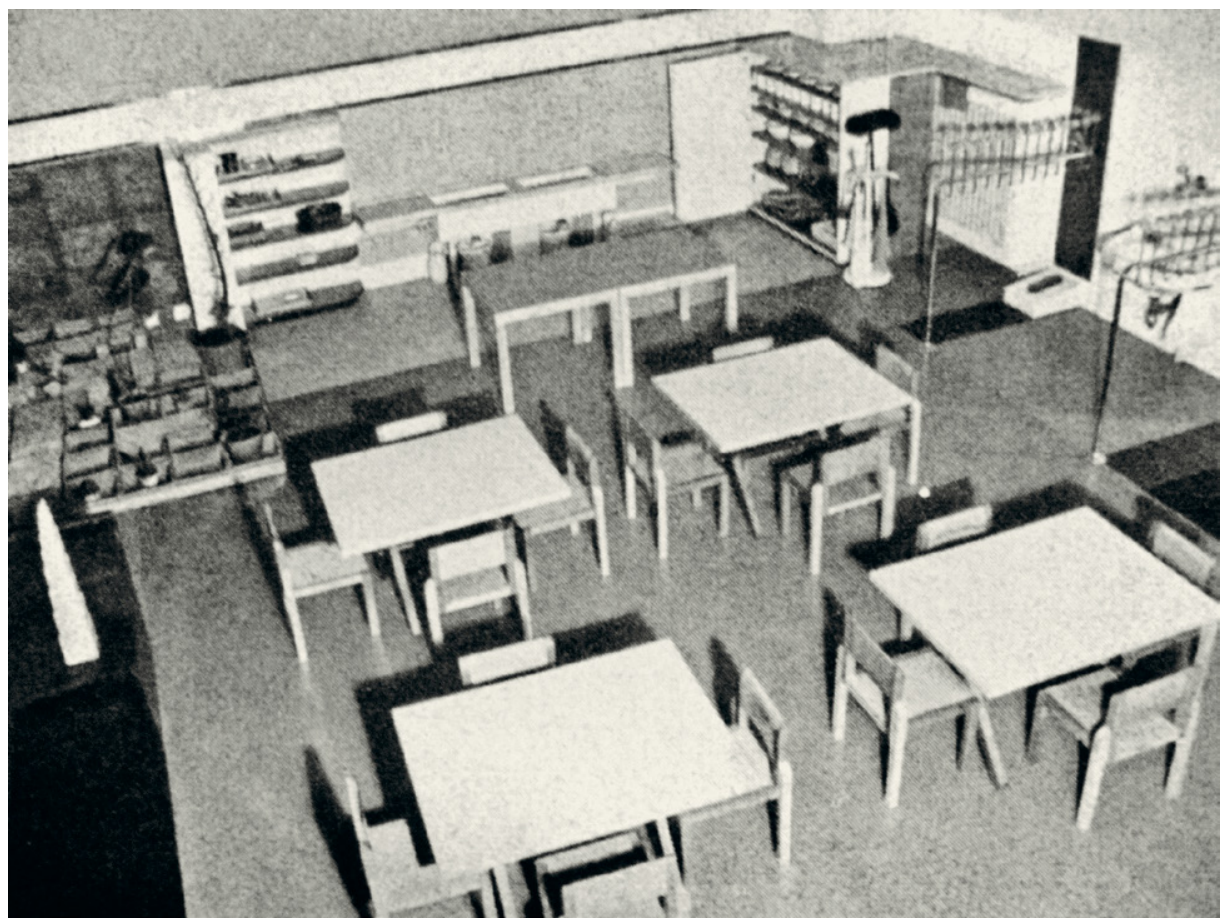

I03. Friedl Dicker u. Franz Singer, Montessorikindergarten in der Wohnanlage des Goethehofes, Wien 22, Schüttaustraße I-39, I930 (nicht erhalten)/Österr. Bau u. Werkkunst I 934

einige bemerkenswerte Bauten verantwortlich. Generell gehörten sie im Wiener Umfeld zu den ganz wenigen direkt am Bauhaus ausgebildeten Künstlern. Hilfreich in dieser Partnerschaft war sicherlich der Umstand, dass sie sich offenbar kongenial ergänzten, indem Friedl Dicker insbesondere mit Farben, Mustern und Texturen experimentierte. Ob jedoch die Arbeitsteilung wirklich so gelaufen ist, dass Franz Singer für den konstruktiven Bereich zuständig war, wie in der Literatur angeführt wird, sei dahingestellt. Tatsächlich hatten beide die gleiche Ausbildung, und möglicherweise folgt diese Interpretation doch zu sehr den gängigen Klischees. Die Spezialität des Unternehmens bestand vor allem darin, billig herzustellende, möglichst raumsparende Einrichtungsgegenstände wie Klappmöbel oder stapelbare Stühle zu entwerfen, die dem Zeittrend der Ökonomie des Raumes und des Geldes entsprachen. Ihrer politischen Gesinnung und ihrem sozialen Engagement entsprechend erhielten sie auch mehrmals Aufträge im Rahmen des Sozialprogramms des "Roten Wien«. Neben dem Projekt "Jugend am Werk", das sich der Resozialisierung Jugendlicher widmete, statteten sie vor allem diverse Kindergärten aus, wobei Friedl Dickers intensive Beschäftigung mit 


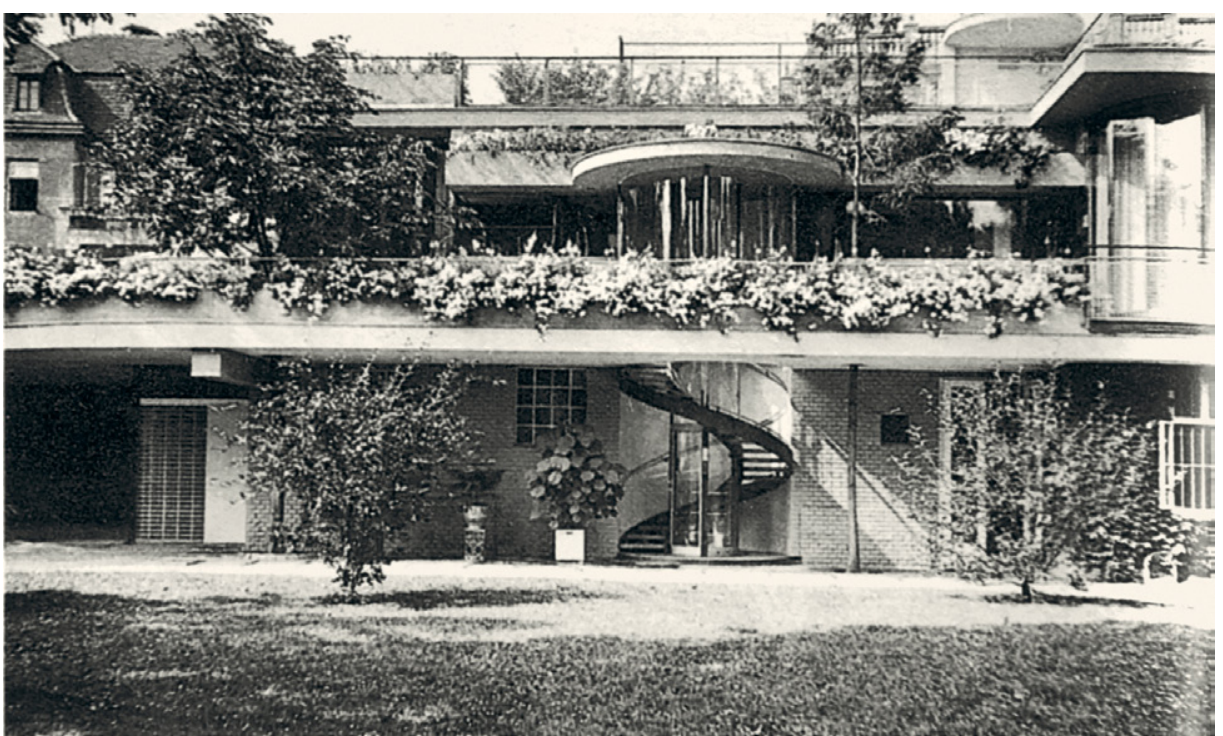

I 04. Friedl Dicker u. Franz Singer, Gästehaus Hériot, Wien 2, Rustenschacherallee, erbaut 1932/34 (nicht erhalten)/Dicker Kat.

Kindermöbel und Spielzeug sie dafür prädestinierte. ${ }^{271} 1930$ erhielten sie den Auftrag zur Einrichtung des in der städtischen Wohnhausanlage »Goethe- Hof« untergebrachten Montessori-Kindergartens. Mit seinen kindgerechten Möbeln und diversen pädagogischen Einrichtungen galt diese Institution als ein Meilenstein in der fortschrittlichen Erziehung (Abbildung 103). ${ }^{272}$ Als 1934 während des Bürgerkrieges der Goethe-Hof unter Beschuss geriet, wurde auch die Einrichtung des Kindergartens, die für die verhasste fortschrittliche Erziehung der "Roten« stand, vernichtet.

Ungeachtet ihres Schwerpunktes auf dem Gebiet der Innenarchitektur konnte das Atelier Dicker-Singer aber auch zwei äußerst bemerkenswerte Bauten realisieren. I 928 errichteten sie in Hietzing den Tennis-Club Heller, wobei die formale Durchgestaltung des Clubgebäudes höchst avantgardistisch war: ein kühn geschwungener Baukörper mit einem eingeschobenen Zylinder, dessen Dach auf schlanken Pilotis ruhte. Interessanterweise hatte der junge Jacques Groag, der sich damals gerade selbstständig gemacht hatte, die Bauleitung inne. Damit wird die soziale Vernetzung dieser Wiener Intellektuellen- und Künstlerkreise deutlich, dem auch Adolf Loos, der Publizist Max Ermers, der Kunsthistoriker Ludwig Münz, die Famile Moller und viele

27I Unter anderem entwarf sie einen Spielzeug-Baukasten namens "Phantasius«.

272 Österreichische Bau und Werkkunst 8.1932, S. 65 f. 
I05. Franz Singer Porträt/AzW

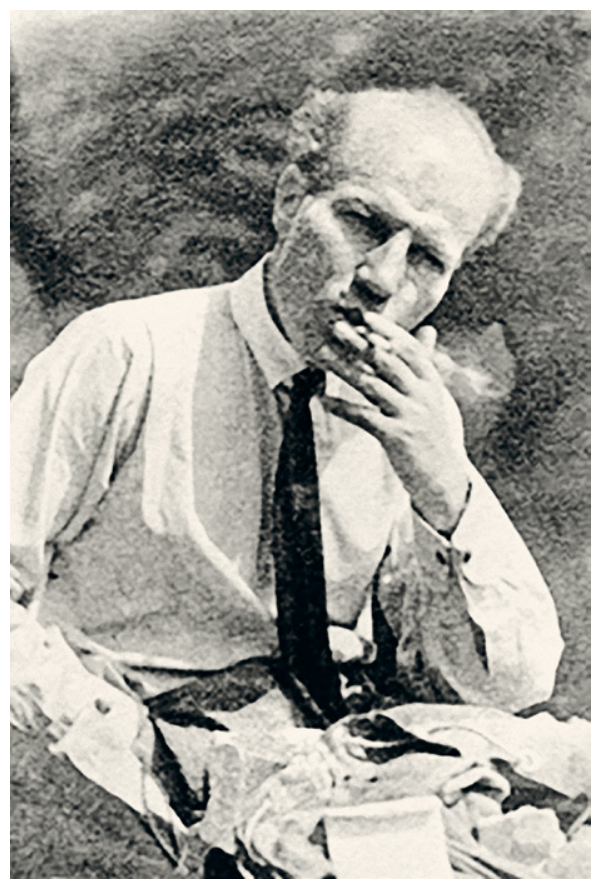

andere angehörten. Ähnliche avantgardistische Kriterien brachte das Atelier DickerSinger auch beim Gästehaus Hériot zum Einsatz, das sie einige Jahre später I 932 in der Rustenschacheralle beim Wiener Prater realisierten, wobei in diesem Fall die verglaste Vorderfront dem Gebäude eine besondere Transparenz verlieh (Abbildung I04). Bedauerlicherweise wurden beide Bauten, die unter den damals in Wien errichteten Gebäuden zu den fortschrittlichsten gehörten, späterhin zerstört.

Anfang der Dreißigerjahre wurde infolge zunehmender privater Spannungen der beiden Partner die Ateliergemeinschaft aufgelöst. Friedl Dicker widmete sich nun überwiegend der Malerei und dem Kunstunterricht. I93 I war sie der kommunistischen Partei beigetreten und wurde deshalb wegen ihrer politischen Aktivitäten nach der Etablierung des »Ständestaates« I 934 festgenommen. Das unter dem Eindruck dieser Ereignisse entstandene Gemälde »Das Verhör« zählt zu den düsteren Zeitzeugnissen jener Jahre. Nach ihrer Freilassung emigrierte sie nach Prag, wo sie 1936 mit Pavel Brandeis, einem entfernten Verwandten, eine Ehe einging. In Prag nahm sie auch wieder ihre Arbeit auf dem Gebiet der Innenarchitektur auf. Neben der Führung eines eigenen Ateliers war sie außerdem wieder bereit, in loser Zusammenarbeit mit Franz Singer zu kooperieren. Nach der Machtergreifung der Nazis zog sie sich aufs Land zurück und arbeitete für eine Textilfabrik. 1942 wurde sie mit ihrem Mann in 
das KZ Theresienstadt/Terezin deportiert, wo sich wieder in schicksalhafter Weise ihre Wege mit einem Mitglied der Familie Groag kreuzten: In Zusammenarbeit mit Willi Groag, einem Neffen von Jacques Groag, hielt sie dort Kinderzeichenkurse ab. ${ }^{273}$ Die Kinderzeichnungen von Theresienstadt, die schließlich von Willi Groag gerettet werden konnten, sind bis heute eines der bedeutendsten und erschütterndsten Zeugnisse des Lagerlebens. Im Zuge der Auflösung des Ghettos im Oktober I944 wurde Friedl Dicker nach Auschwitz deportiert und umgehend ermordet.

Franz Singer (Abbildung ro5), der bereits seit I934 für diverse Firmen in London gearbeitet hatte, wo er auf dem Gebiet der Fertigteilbauweise und des sozialen Wohnungsbaus tätig gewesen war, konnte nach dem »Anschluss« Österreichs nach England fliehen. Nach dem Kriegseintritt Großbritanniens vorübergehend als »enemy alien« interniert, gelang es ihm, nach Kriegsende wieder seine Tätigkeit als Architekt und Designer aufzunehmen. Die Beschäftigung mit kindgerechten Möbeln und pädagogischem Spielzeug blieb auch weiterhin einer seiner Schwerpunkte. Franz Singer, der Anfang der 5oer-Jahre vorübergehend nach Österreich zurückkehrte, ist schließlich 1954 in Berlin verstorben.

Gerade am Beispiel Friedl Dickers wird deutlich, wie schwierig die Abgrenzung der Architektur zur »reinen " Innenarchitektur und zum Design ist. Denn wie bereits oben angeführt, ist nicht geklärt, wie groß ihr ideeller Anteil auch an den Bauprojekten des Ateliers ist. Franz Singer, den man im Allgemeinen eher für den architektonischen Bereich verantwortlich angesehen hat, hat sich andererseits in der Zeit nach Kriegsende auch mit Kindermöbeln und Spielzeug befasst. Dies könnte durchaus als Indiz für die wechselweise Zuständigkeit der beiden gedeutet werden.

\subsection{Kunstgewerblerinnen als Innenarchitektinnen}

Mit den drei oben angeführten Persönlichkeiten ist das Feld der "Architektinnen ", die in diesen Rahmen passen, annähernd abgesteckt. Darüber hinaus gab es jedoch noch eine Reihe von Künstlerinnen, die nicht "gebaut«, sondern praktisch ausschließlich als Innenarchitektinnen gearbeitet haben und daher hier zumindest kursorisch erwähnt werden sollen.

In Wien spielten im Rahmen der Ausbildung der Frauen zwei Persönlichkeiten an der Kunstgewerbeschule eine besondere Rolle. Zum einen war dies Josef Hoffmann, aus dessen Klasse Künstlerinnen wie Maria Strauss-Likarz oder Jacqueline Groag (alias Hilde Blumberger) hervorgegangen sind, die fallweise auch Möbelentwürfe anfertig-

273 Freundliche Auskunft Willi Groag †. 
ten. Die in Przemysl geborene Maria Strauss-Likarz (I893-I971), die die die Kunstgewerbeschule bis I9 Iо Josef Hoffmann besucht hatte, war weitgehend als Grafikerin tätig, hatte aber unter anderem auch die Einrichtung eines Modesalons in der Ausstellung "Wiener Frauenkunst « 933 präsentiert. Insbesondere hatte sie auch bis I93 I jahrelang für die Wiener Werkstätte gearbeitet und des Öfteren, wie schon erwähnt, für Liane Zimbler Möbel entworfen. Auf ihre Kontakte zu Felix Augenfeld, der ihr Kritzendorfer Wochenendhaus geplant hatte, wurde bereits hingewiesen. Zwischendurch selbst an der Kunstgewerbeschule Giebichenstein (Deutschland) unterrichtend, musste sie mit ihrem Mann Wien 1938 fluchtartig verlassen und gelangte schließlich über Jugoslawien nach Rom, wo sie überwiegend als Keramikerin tätig war. ${ }^{274}$

Vergleichbar sind auch die Tätigkeit und der Lebenslauf Jacqueline Groags (1903I986), die sich in ihren Wiener Tagen noch Hilde Blumberger nannte und ihren Namen erst in der englischen Emigration änderte. Weitgehend als Textildesignerin tätig, hatte sie noch in ihrer Wiener Zeit ihre eigene Wohnung eingerichtet und später in ihren Emigrationsjahren bei den Möbelentwürfen ihres Mannes Jacques Groag mitgearbeitet. Ursprünglich aus Prag stammend, hatte sie, früh verwitwet, von I 926 bis I 929 die Kunstgewerbeschule besucht und war bei Franz Čižek und Josef Hoffmann ausgebildet worden. Obwohl auch sie für die Wiener Werkstätte arbeitete, hatte sie jedoch darüber hinaus schon sehr bald in der internationalen Branche Fuß gefasst und für allererste Salons wie Chanel und Schiaparelli gearbeitet. Gemeinsam mit ihrem Mann war sie in Wiener Künstlerkreisen äußerst gut vernetzt. Die zarte dunkelhaarige Frau mit den grünen Augen wurde vor allem auch von vielen Künstlern als Modell geschätzt. Die Fotografien Trude Fleischmann hat einige Fotoserien von ihr angefertigt (Abbildung I06) ${ }^{275}$ und die Maler Sergius Pauser und Josef Dobrowsky haben sie mehrmals porträtiert. Ihre originellen Textil- und Teppichentwürfe wurden auch gerne von ihrem späteren Mann Jacques Groag, den sie I937 heiratete, in seinen Interieurs integriert (Abbildung 107), so auch bei einer seiner Wohnungseinrichtungen in der Wiener Werkbundsiedlung. Nach ihrer Emigration nach England 939 wurde sie zu einer der bedeutendsten Textildesignerinnen der Nachkriegszeit, die maßgeblich die englische Wohnkultur dieser Jahre mitprägte. Sie verstarb 1986 in London. ${ }^{276}$ Diese beiden Künstlerinnen - Maria Strauss-Likarz und Jacqueline Groag - seien hier nur stellvertretend für die zahlreichen bei Josef Hoffmann ausgebildeten Kunstgewerblerinnen angeführt, deren Werk

274 Plakolm-Forsthuber, zit. Anm. I 2.

275 Publiziert u.a. in: Der Wiener Tag, 2.8.1936, Beilage »Der Sonntag«.

276 Siehe zur Biografie G. Rayner/R. Chamberlain/A. Stapleton, Jacqueline Groag (Kat.), Woodbridge 2009. 


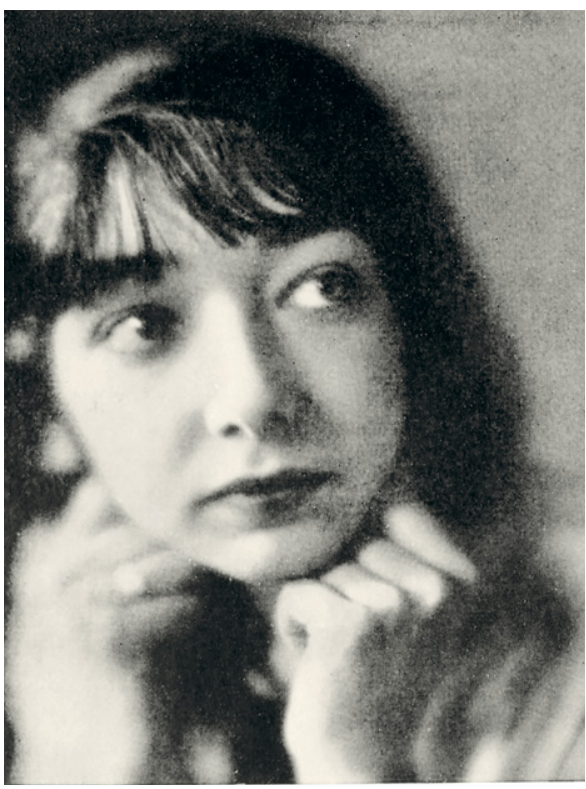

I06. Jacqueline Groag, Porträt/Deutsche Kunst u. Dekoration 1930

in einem fließenden Übergang zur Innenarchitektur steht. Interessanterweise wurde in diesem Kontext Josef Hoffmann aus rechtskonservativen Kreisen - durchaus negativ zu verstehen - eine »Pupperlwirtschaft« vorgeworfen.

Eine weitere wichtige Persönlichkeit im Rahmen der Frauenausbildung an der Kunstgewerbeschule war Oskar Strnad. Zwei seiner Schülerinnen, die zeitweise auch seine Mitarbeiterinnen waren, sollen hier stellvertretend genannt werden: Ada Gomperz und Ilse Bernheimer. Man weiß nur sehr wenig über ihr Leben und ihr Werk, aber insbesondere im Rahmen des Projektes der Wiener Werkbundsiedlung, dessen Bedeutung in vielfacher Hinsicht nicht hoch genug zu veranschlagen ist, lassen sie sich als Innenarchitektinnen festmachen. Gesichert ist, dass Ada Gomperz (I 884I954) als Mitarbeiterin von Erich Bolternstern in der Werkbundsiedlung das Haus Nr. 5 (Engelbrechtsweg Io), das vom deutschen Architekten Hugo Häring entworfen wurde, eingerichtet hat (Abbildung I 08). ${ }^{277}$ Wie weit die in einer Art von gemäßigter Moderne gestaltete Inneneinrichtung im »Wiener Stil« auf Ada Gomperz bzw. Erich Boltenstern selbst zurückgeht, ist ungeklärt. Die in Wien ursprünglich als Adele Stepnitz geboren Architektin, die bereits in einem etwas fortgeschritteneren Alter I928I932 an der Kunstgewerbeschule studiert hatte, ${ }^{278}$ war eigentlich eine Küchenspe-

277 Werkbundsiedlung Wien 1932 (Kat., hg. v. Wien Museum), Wien 2012, S. I Io.

278 Siehe Plakolm, zit. Anm. I2, und Gaugusch, zit. Anm. 227. Ada Gomperz (I 884 Wien - I954 Los 


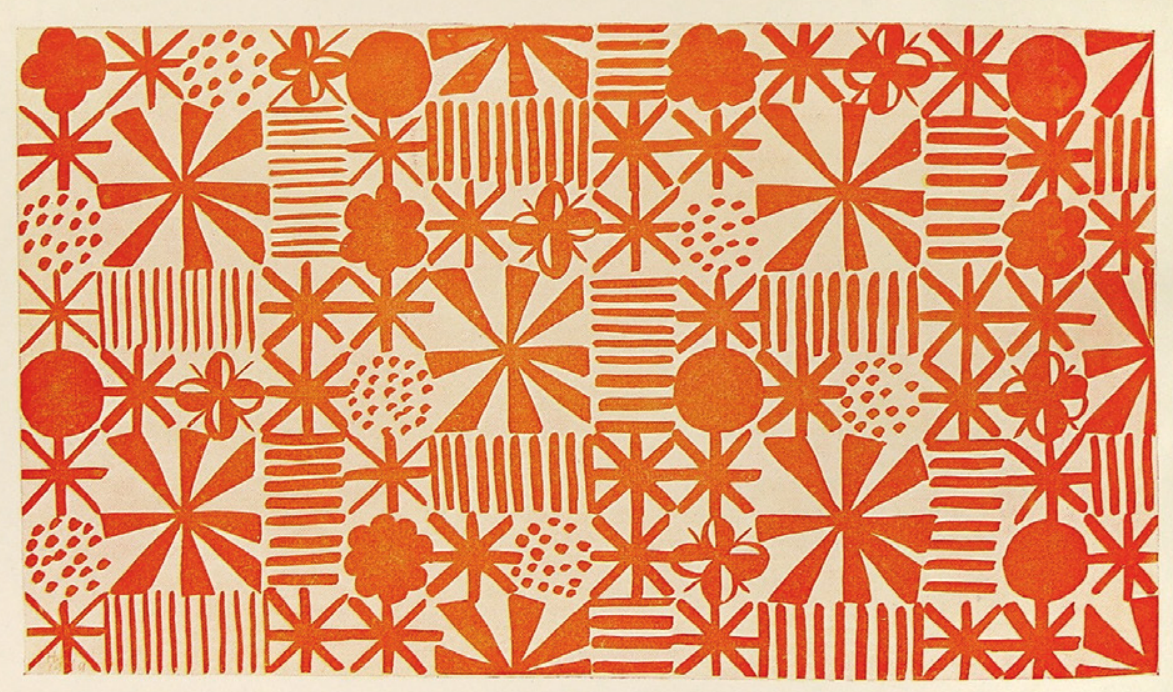

I07. Jacqueline Groag, Textilentwurf/Deutsche Kunst u. Dekoration 1930

zialistin«, die Hotels, Restaurants und Großbetriebe einrichtete. Ihre theoretischen Überlegungen umfassten aber auch die Ausstattung von Privatwohnungen, wo sie die »Idealküche« zwar räumlich getrennt, aber mit Blickkontakt zum Wohnbereich situiert sehen wollte. ${ }^{279}$ Zweifellos richteten sich diese Forderungen eher an eine gehobenere Klientel, die sich solche großzügigen Wohnungen leisten konnte. Auch ihre Karriere fand nur allzu bald ein Ende, insofern sie bereits 1935 mit ihrem Mann, dem Philosophen Heinrich Gomperz, in die USA emigrierte, wo sie sich in Los Angeles niederließ und für einige Zeit wieder mit Liane Zimbler zusammenarbeitete. I954 verstarb sie ebendort.

Eine schon etwas längere Karriere hatte Ilse Bernheimer (I 892-I984) hinter sich, als sie gleichfalls 1932 eines der Werkbundhäuser einrichtete. Im konkreten Fall handelte es sich um Haus Nr. I 5 (Engelbrechtsweg 9), das nach einem Entwurf von Anton Brenner errichtet wurde. Ilse Bernheimer, die zu diesem Zeitpunkt als Assistentin von Oskar Strnad tätig war, verwendete bei der Einrichtung Metallmöbel, deren kühne Formgebung in großer Nähe zur Bauhausästhetik stand, und rundete

Angeles) war beim Besuch der Kunstgewerbeschule immerhin bereits vierundvierzig und seit mehr als zehn Jahren mit dem Philosophen Heinrich Gomperz verheiratet. Möglicherweise hat sie bereits vor ihrem Studium in einem gewerblichen Betrieb gearbeitet.

279 A. Gomperz, Die Dame kocht, in: profil, Bd. 2, 1934, H. 2, S. 43 f. 


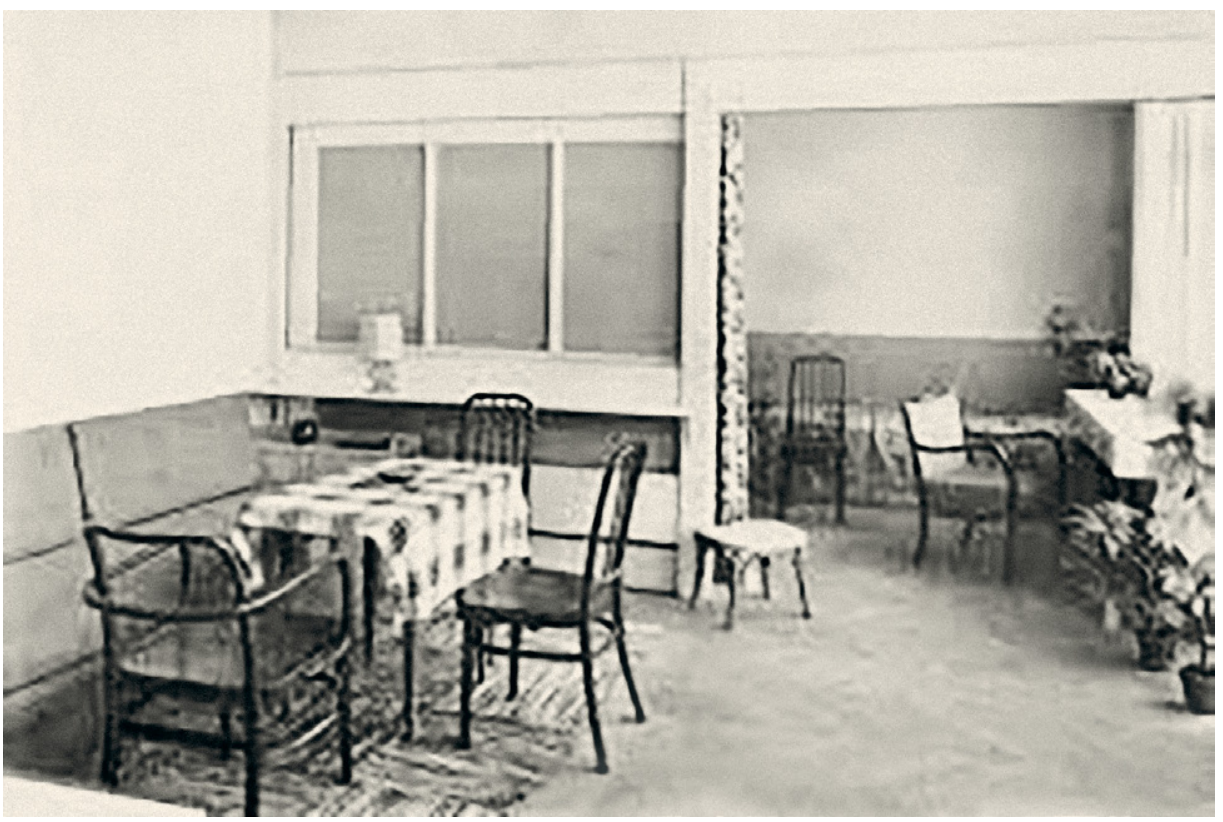

I08. Ada Gomperz mit Erich Boltenstern, Inneneinrichtung des Werkbundsiedlungshauses von Hugo Häring, Wien I3, Engelbrechtweg I0, I932/profil

das Ensemble mit einem dekorativen Wandverbau ab. ${ }^{280}$ In Wien geboren, hatte Ilse Bernheimer die Kunstgewerbeschule bereits vor dem Ersten Weltkrieg besucht, war allerdings weitgehend in Malklassen ausgebildet worden und schon über mehrere Jahre in Zürich und Paris tätig gewesen. Mitte der Zwanzigerjahre hatte sie an der Wiener Frauenakademie unterrichtet, ehe sie Assistentin bei Strnad wurde. Auch ihre Karriere in Österreich fand bald danach ein Ende. Wahrscheinlich infolge des sehr restriktiven politischen Kurses des "Ständestaates" ging sie bereits 1936 nach Italien, wo sie sich schließlich in Venedig niederließ und an der Glasschule "Zanetti« in Murano unterrichtete. Hochbetagt verstarb sie 1984 in Venedig. ${ }^{281}$

Außerdem soll hier noch die völlig vergessene Regina Renata Wiener (I 87I-I94I) erwähnt werden, über die man nahezu gar nichts weiß, deren exotische Ausstattung des Café "Tirolerhof" jedoch bis heute zumindest rudimentär erhalten ist - bei Interieurs, die besonders vergänglich sind, eine äußerste Seltenheit. Jahrgangsmäßig ist sie die älteste der Künstlerinnen, aber wir wissen nichts über ihre Ausbildung; bekannt

280 Siehe Werkbundsiedlung (Kat.), zit. Anm. 277, S. I 37.

28 I Plakolm, zit. Anm. I2; Meder, zit. Anm. I59, S. 93 f. 
ı09. Renate Wiener, Café Tirolerhof, Wien I, Führichgasse 8, errichtet um I928 (teilw. erhalten)/Moderne Welt 1929

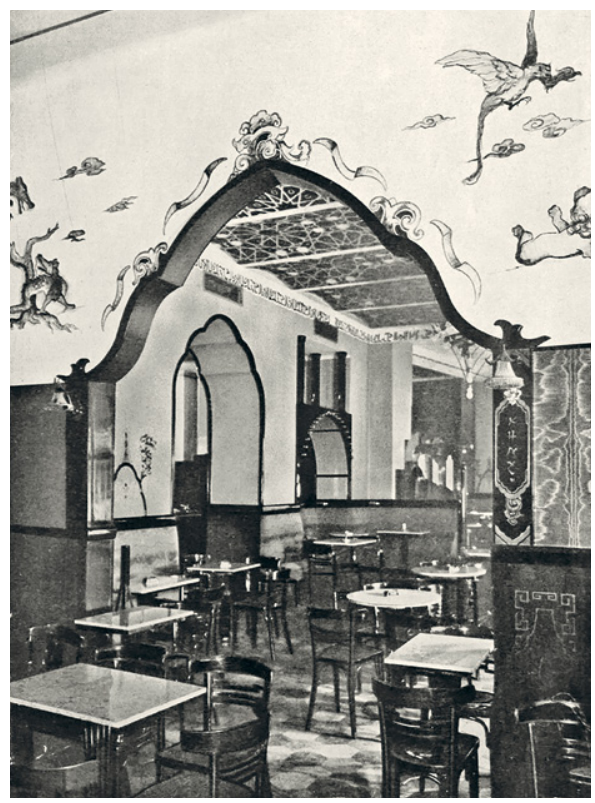

ist nur, dass sie an der guten Adresse Wien I, Parkring 20 ihr nobles Atelier betrieben hat und als Spezialistin für Einrichtungen »im Stile« galt - daher eher einer traditionsverbundenen Ausrichtung verpflichtet war. ${ }^{282}$ I 924 übernahm sie die Inneneinrichtung des "Tirolerhofs", wobei sie verwirrenderweise nicht zum Begriff »Tirol " Bezug nahm, sondern einen "arabischen" und einen "chinesischen " Raum einrichtete, die beide von hohem ästhetischem Reiz waren (Abbildung I09). Bemerkenswerterweise erfolgte die Ausgestaltung zum Teil unter Verwendung von originalen Dekorteilen. ${ }^{283}$ Regina Wiener musste wie alle Juden ihre Tätigkeit I938 einstellen und ist im November I94I noch kurz vor ihrer Deportation in Wien siebzigjährig verstorben. ${ }^{284}$

Diese Übersicht über die Gruppe der jüdischen Innenarchitektinnen in Wien erhebt mit den hier genannten Persönlichkeiten keinesfalls Anspruch auf Vollständigkeit, sondern soll nur zur Veranschaulichung der damaligen Situation dienen. Zweifellos ließe sich hier noch eine Reihe weiterer Namen nennen. Gerade bei Frauen ist

282 Brücke von einst zum Heute. Zu den Arbeiten Regina Renata Wieners, in: Moderne Welt, I93 I, H. 3, S. 566 .

283 Moderne Welt 1929, H. 8, S. 34f. In der Literatur (Dehio, Wien I, 2003) wird der Baumeister Micheroli angeführt, der allerdings nur die Bauarbeiten durchführte, während für die Ausstattung Regina Wiener zuständig war.

284 Dokumentationsarchiv des Österreichischen Widerstandes (hinfort als DÖW zitiert), Datenbank der Shoa-Opfer. 
die Recherche zumeist jedoch infolge eines Namens- oder Berufswechsel besonders schwierig. Das Kapitel soll insofern nur aufzeigen, dass auch Frauen - insbesondere jüdischer Herkunft - schon damals in diese Berufssparte drängten und zumeist infolge von wirtschaftlicher Konkurrenz in diesen schwierigen Zeiten abgedrängt wurden. 


\section{Die Opfer}

Generell zog der »Anschluss« im März 1938 für alle Juden, ungeachtet ihres weiteren Schicksals, ein unmittelbares Berufsverbot nach sich, wie es bei den vorangegangenen Biografien bereits mehrfach erwähnt wurde. Nach Inkrafttreten der NS-Reichsgesetzgebung in Österreich musste man einer der fachspezifischen Reichskammern angehören, um seinen Beruf weiter ausüben zu können. Für die Mitgliedschaft war allerdings ein »Ariernachweis« erforderlich, sodass praktisch (ohne dass eine spezielle Gesetzgebung erforderlich gewesen wäre) die jüdischen Architekten sofort aus dem Berufsleben ausgeschlossen waren. Sukzessive folgten dann Enteignung, Vertreibung und schließlich Ermordung.

Dieses Kapitel ist den Opfern gewidmet, wobei hier der Begriff des "Opfers« sehr eng aufgefasst wird, insofern nur von Persönlichkeiten die Rede sein soll, die im Rahmen des Holocaust ermordet wurden. "Opfer" im weitesten Sinn waren alle Juden, die zum Zeitpunkt des "Anschlusses" in Österreich tätig waren, auch wenn sie überlebt haben, bedeutete doch die Vertreibung - euphemistisch zumeist "Emigration" genannt - auf jeden Fall den Verlust der Heimat, der Familie und zumeist auch einen massiven Einbruch in der Karriere. Im Gegensatz zu den vorangegangenen Kapiteln lassen sich jedoch die hier genannten Architekten nicht, wie bisher gehandhabt, in Architekturschulen, im Hinblick auf einen bestimmten Personenkreis oder auf eine architektonische Thematik zusammenfassen, vielmehr ist der einzige gemeinsame Bezugspunkt ihr tragischer Tod. Einige, wie Theodor Schreier oder Friedl Dicker, wurden dabei bereits in den vorangegangenen Kapiteln in einem anderen Kontext angeführt.

\subsection{Der direkte Transport in den Tod - Friedrich Schön, Stefan Fayans und Josef Sinnenberg}

An erster Stelle soll hier Friedrich Schön (I857-I94I) genannt werden, da er der Älteste und infolge der Relevanz seines architektonischen Werkes wahrscheinlich auch der Bedeutendste dieser Gruppe ist (Abbildung I го). Obwohl in formaler Hinsicht noch ein typischer "Späthistorist", war er technischen Neuerungen gegenüber äußerst aufgeschlossen. Über die Herkunft Schöns ist relativ wenig bekannt. I 857 in Lovasbereny in Ungarn geboren, stammte er aus ärmlichen Verhältnissen und wurde bereits mit zwölf Jahren Waise. Dessen ungeachtet erhielt er seine Ausbildung 
(wahrscheinlich ermöglicht durch ein großzügiges Stipendium) bei den führenden Architekten seiner Zeit: Nach Abschluss des Polytechnikums in Budapest studierte er kurzfristig in Wien an der Technischen Hochschule bei Karl König und späterhin an der Akademie der bildenden Künste bei Theophil Hansen - einem der bedeutendsten Ringstraßenarchitekten -, den er zeitlebens sehr verehrte. Nicht nur dass er ein Gründungsmitglied des renommierten "Hansen-Klubs« war, darüber hinaus stand in seinem Haus an prominenter Stelle eine Büste des geschätzten Lehrers. Schön und sein gleichfalls aus Ungarn stammender Jahrgangskollege Moses Löw (I 8 57-?) gehörten zu den ganz wenigen jüdischen Schülern Hansens, der parallel zu Friedrich von Schmidt die zweite Architekturschulean der Akademie leitete. ${ }^{285}$ Etwas erstaunlich ist, dass Hansen - im Gegensatz zu Friedrich von Schmidt - ungeachtet vieler Aufträge für die großen Wiener jüdischen Familien, wie die Epsteins, Todescos, Ephrussis und andere, von jüdischen Studenten eher gemieden wurde. Der Grund dafür könnte darin liegen, dass Hansen, der generell etwas abgehoben agierte, als Däne und Protestant möglicherweise eher deutsch-nationalen Kreisen nahestand.

Wie auch immer, Friedrich Schön ließ sich nach einem zweijährigen Praktikum in Budapest bei Miklos Ybl und Alajos Haussmann (damals die führenden ungarischen Architekten) gegen I 885 endgültig in Wien nieder, um hier als freischaffender Architekt zu arbeiten. In der Folge führte er bald ein großes Atelier, das zahlreiche Mitarbeiter beschäftigte und bis zum Ausbruch des Ersten Weltkrieges eine Reihe von bedeutenden Projekten, vorzugsweise in Wien, aber auch in Ungarn und anderen Ländern errichtete. Friedrich Schöns umfangreiches Werk umfasste neben Miethäusern und Villen insbesondere Warenhäuser, aber auch Industrieanlagen, Schulen und anderes mehr. Da er zeit seines Lebens ein frommer Jude geblieben war, realisierte er auch mehrere Projekte für diverse Kultusgemeinden, so etwa ein Schulgebäude in Stuhlweißenburg/Szekesfejervar (H) oder die Synagoge in Mistelbach/NÖ, die die NS-Verwüstungen weitgehend überstand und beschämenderweise dennoch Mitte der Siebzigerjahre des 20. Jahrhunderts abgerissen wurde. ${ }^{286}$ Eine Reihe von Wettbewerbsentwürfen für weitere jüdische Sakralbauten gelangte hingegen nicht zur Realisation. Wie bereits angeführt, galt Schön vor allem als Spezialist auf dem Gebiet des Warenhauses, das in Wien erst relativ spät eine Blüte erlebte. Insbesondere mit dem I 895 auf der Wiener Kärntner Straße errichteten »Warenhaus Zwieback« brachte er

285 Moses Löw, geboren I 857 in Szeged, Sohn des dortigen Oberrabiners Leopold (Lipot) Löw, studierte gleichfalls an der Technischen Hochschule und an der Akademie bei Theophil Hansen. Seine Tätigkeit in Wien erstreckt sich ca. auf den Zeitraum von I880 bis I9I4. Er errichtete unter anderem das "Jubiläumsspital des Franz-Josefs-Ambulatoriums«. Aus der Zwischenkriegszeit sind keinerlei Bauten dokumentiert. Im Herbst 1938 verließ er Wien Richtung Szeged, wo sich seine Spuren verlieren.

286 U. Prokop, Friedrich Schön und die Synagoge von Mistelbach, in: David 22.201o, Nr. 84. 
I Io. Friedrich Schön, Porträt/Bezirksmuseum Landstr.

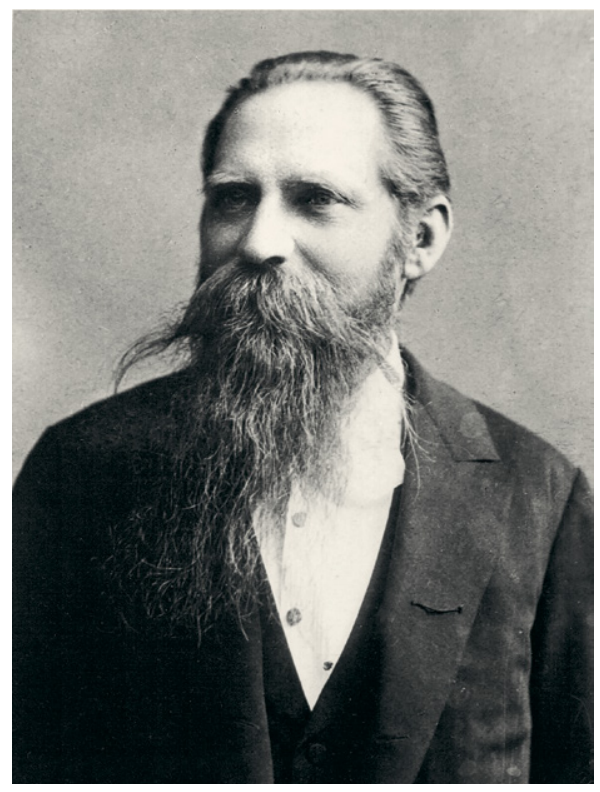

neuste Technologien auf dem Gebiet der Eisenkonstruktion ein, die damals als beispielgebend angesehen wurde. Auch die Fassadengestaltung, obzwar noch ganz der Ästhetik des Historismus verpflichtet, war von großer Originalität. ${ }^{287}$

Während das Warenhaus Zwieback nur sehr verändert auf uns gekommen ist, ist einer der bemerkenswertesten Bauten Schöns, das sogenannte "Warenhaus Pollak" (gleichfalls eine Textilhandlung), zumindest in der Außengestaltung weitgehend unverändert erhalten. I909 auf dem Wiener Kohlmarkt Nr. 2 errichtet, konnte trotz einer höchst ungünstigen Situierung auf einem äußerst schmalen Grundstück der Bau mit nur drei Fensterachsen durch den Einsatz einer ausgeklügelten Betonständerkonstruktion zehn Stockwerke hochgezogen werden. ${ }^{288}$ In der für Friedrich Schön typischen Synthese von Tradition und Moderne bilden die weit geöffnete Glasfront und der höchst sparsam eingesetzte Dekor an der mit dunklen Steinplatten verkleideten Fassade eine harmonische Einheit (Abbildung I I I). Bis heute setzt der Bau einen eigenwilligen Akzent in der Fassadenfront des Kohlmarktes. Eine Reihe weiterer Geschäftshäuser sowohl in Wien als auch im Ausland - sogar in Kairo - plante Schön

287 Das Gebäude auf der Kärntner Straße I I, das heute noch existiert, wurde insbesondere in der unteren Zone stark verändert. Die renommierte Modefirma Ludwig Zwieback \& Bruder wurde 1938 "arisiert«. Siehe dazu Walzer, zit. Anm. 74, S. I 57.

288 Der Bautechniker 30.19ro, S. 402, T. 2 I. 


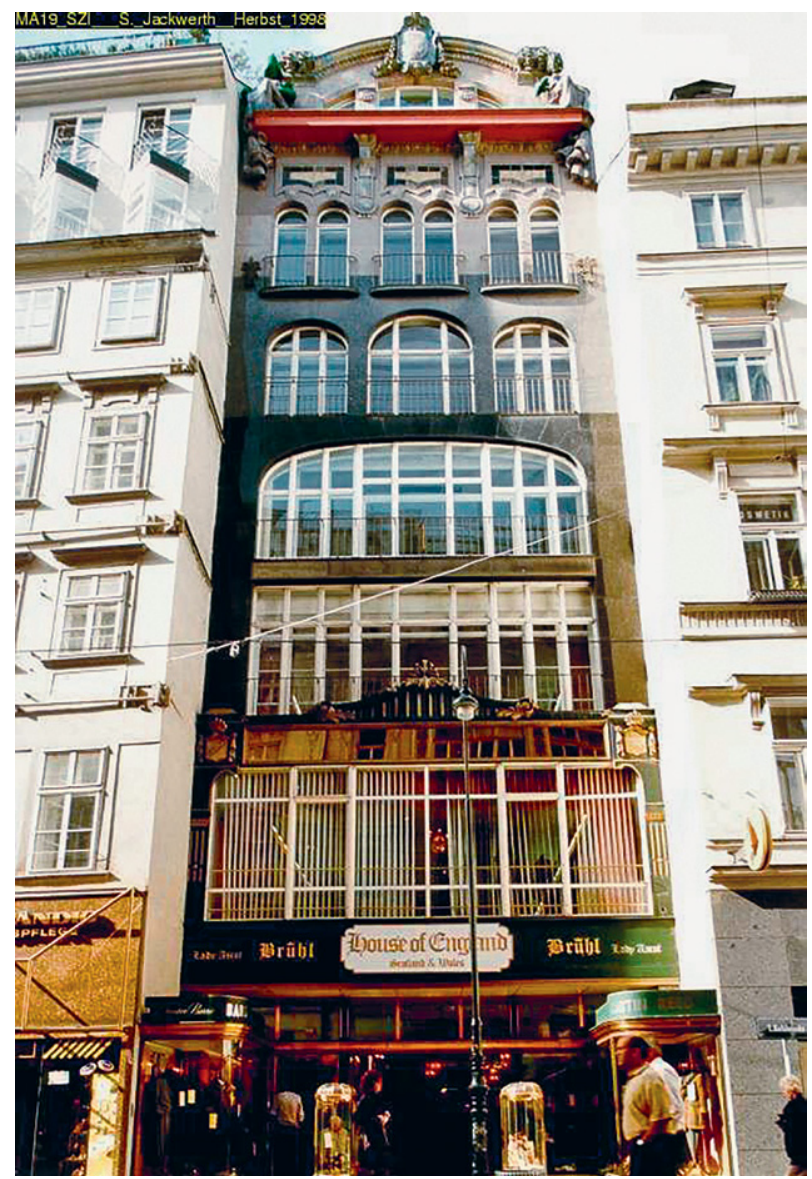

I I I. Friedrich Schön,

Warenhaus Pollak, Wien I, Kohlmarkt 2, erbaut I909/ Kulturgut

insbesondere auch für die Firma Siegfried Stein's Söhne. ${ }^{289}$ Alle diese Unternehmen befanden sich in jüdischem Besitz und wurden später »arisiert«. Generell reflektiert in der Rückschau das Werk Friedrich Schöns auch die Bandbreite jüdischen Unternehmertums der vorigen Jahrhundertwende. In diesem Kontext waren möglicherweise die größten Auftraggeber Schöns die Brüder Heinrich und Fritz Mendel, die I 89 I die "Wiener Brot- und Gebäckfabrik" gegründet hatten. Das Unternehmen in Wien-Favoriten ist bis heute unter dem Namen »Ankerbrotfabrik» in die Annalen eingegan-

289 Die Firmeneigner, die Brüder Isidor und Siegfried Stein, wurden ebenfalls Opfer des Holocaust. Isidor (geb. I 869) starb I 940 kurz vor seiner Deportierung in Wien. Siegfried jun. (geb. I883) kam 1942 im KZ Maly Trostinec um. Siehe Gaugusch, zit. Anm. 227. 
gen. Nach dem Bau des Stammhauses in Wien-Favoriten, das nach damaligen Kriterien höchst funktionalistisch in Sichtziegelbauweise ohne Dekor ausgeführt worden war, war Schön - da die Bäckerei sehr erfolgreich war und rasch expandierte - über Jahre mit weiteren Ausbauten für das Unternehmen befasst. ${ }^{290}$ Obwohl die Marke "Ankerbrot« bis heute existiert, wurde auch dieser Betrieb 1938 "arisiert«.

Seiner erfolgreichen architektonischen Tätigkeit entsprach auch Schöns Aufstieg in die Wiener Gesellschaft, der insbesondere durch seine Ehe mit Eugenie Cahn (I 862-1927), die aus einer arrivierten jüdisch-französischen Familie stammte, manifest wurde. In seiner eleganten Villa im Währinger Cottage (Wien I 8, Türkenschanzstraße 44), die in nahezu aristokratischer Manier im Giebel von einer Kartusche mit seinen Initialen geziert war, konnte er über die Jahre eine veritable Kunst- und Antiquitätensammlung anlegen. Dieses Kunstverständnis gab er schließlich auch an seine beiden Töchter weiter. Seine ältere Tochter Clara (I894-I94I), die ihre Ausbildung bei Tina Blau erhalten hatte, wurde Malerin, die jüngere, Margit (I888-1937), heiratete den italienischen Kunsthistoriker Leandro Ozzola. Das sehr produktive Schaffen Schöns wurde durch den Ausbruch des Ersten Weltkrieges jäh unterbrochen. Aus der Zwischenkriegszeit sind keinerlei Bauten von ihm dokumentiert, und er scheint sich infolge der schlechten Wirtschaftslage und seines fortgeschrittenen Alters weitgehend ins Privatleben zurückgezogen zu haben, nahm aber weiterhin am Wiener Kulturleben teil. Noch 1937 wurden ihm anlässlich seines 80. Geburtstages zahlreiche Ehrungen zuteil und seine Verdienste wurden in mehreren Würdigungsartikeln hervorgehoben. ${ }^{291}$

Nach dem "Anschluss" 1938 verabsäumte es Friedrich Schön - wahrscheinlich infolge seines fortgeschrittenen Alters -, Österreich zu verlassen, und blieb in Wien. Als im Herbst I94I die Judendeportationen begannen, gehörte er mit seiner Tochter Klara, die bei ihm lebte, zu den ersten, die verschickt wurden. Eine Erklärung dafür könnte der Umstand sein, dass Schön möglicherweise nach Kriegsende für sein Heimatland Ungarn optiert hat und als "nicht reichsangehöriger Jude» besonders früh erfasst wurde - was allerdings nur eine Hypothese ist. Auch seine elegante Villa dürfte so manche Begehrlichkeit geweckt haben. Die Geschehnisse rund um den Deportationstransport, in dem sich der damals vierundachtzigjährige Friedrich Schön und seine Tochter befanden, sind relativ gut dokumentiert. Am 23. November 194I ging der Transport, der I.000 jüdische Männer, Frauen und Kinder umfasste, vom Wiener Aspangbahnhof ab. Aus heute nicht mehr bekannten Gründen wurde der Zug, der ursprünglich nach Riga hätte fahren sollen, nach Kowno (auch Kaunas oder Kauen,

290 Siehe dazu K. Dorn (Hg.), Favoriten, ein Heimatbuch, Wien 1928.

29I Volkszeitung, 25.8.1937; Neue Freie Presse, 28.8.1937. 
heute Litauen) umgeleitet, wo die Verschleppten nach ihrer Ankunft im Fort IX, einer alten zaristischen Befestigungsanlage, unter Mithilfe einheimischer Kräfte sofort ermordet wurden. Keiner der Wiener Deportierten überlebte. ${ }^{292}$

Ähnlich tragisch verlief auch das Schicksal von Stefan Fayans (I 879-I942), dessen architektonische Hinterlassenschaft zwar recht schmal ist, der aber seinerzeit vor allem aufgrund seiner zahlreichen theoretischen Schriften einen nicht unbedeutenden Stellenwert in der Wiener Architekturszene hatte. Geboren in Warschau, das damals noch zum Zarenreich gehörte, begann er sein Studium an der Akademie für Civilarchitekten in St. Petersburg, um es an der Wiener Technischen Hochschule abzuschließen. I904 promovierte er bei Karl König und erhielt damit die Berechtigung, den Titel Dr. zu führen. Danach praktizierte er in den Ateliers von Fellner \& Helmer und Ludwig Baumann in Wien und arbeitete kurzfristig sogar bei Alfred Messel in Berlin.

Um 1907 macht er sich selbstständig und errichtet zumeist in Partnerschaft mit Fritz Brettschneider einige äußerst dekorative Wohnbauten. Darüber hinaus befasste er sich in diesen Jahren in mehreren Aufsätzen mit Friedhofsanlagen und dem Totenkult. ${ }^{293}$ Die Beschäftigung mit dieser Thematik fand schließlich I 9 I o im Mausoleum für Menachem Elias in der alten jüdischen Abteilung des Wiener Zentralfriedhofes ihren Niederschlag (Abbildung I I2). Da die Familie Elias sephardischer Herkunft war, errichtete Fayans die prachtvolle kleine Anlage in einem »maurischen Stil« und überhöhte sie mit einer Kuppel. Generell verteidigte Fayans auch in seinen Schriften den Einsatz des Ornamentes - soweit es ein "untergeordnetes Architekturelement« bleibe - und wandte sich gegen eine nüchterne Ingenieursarchitektur. ${ }^{294}$ Diesen Hang zu einem üppigen Dekorativismus und Farbenreichtum setzte Fayans dann auch bei seinen zahlreichen Inneneinrichtungen ein, die er in den folgenden Jahren zur Ausführung brachte, wobei insbesondere die Ausstattung von Kinos, Hotels und Restaurants einer seiner Schwerpunkte war. Neben dem Schwarzenberg-Kino (I9I6), dem Wiener Rathauskeller (I924) und dem Schlosshotel Kobenzl (1928) war insbesondere die neue Ausstattung des Kursalons im Wiener Stadtpark I930 ein gesellschaftliches Ereignis. Die letzten dokumentierten Arbeiten von Stefan Fayans waren die Einrichtung der »Roxy-Bar» und seine Beteiligung an dem großen Wettbewerb zur Erschließung des Kahlenberges in der Mitte der Dreißigerjahre. Nach dem »Anschluss« traf ihn vorerst das Berufsverbot. Späterhin musste er seine Wohnung in der

292 DÖW/Deportiertenliste.

293 St. Fayans, Bestattungsanlagen, in: Handbuch der Architektur, IV. Teil, 8. Halbband, H. 3, Stuttgart I907; ders., Kunst und Architektur im Dienste des Totenkultes, in: Zeitschrift des Österreichischen Ingenieur- und Architektenvereines 60.1908, S. $593 \mathrm{ff}$.

294 St. Fayans, Betrachtungen über die moderne Baukunst, in: Zeitschrift des Österreichischen Ingenieur- und Architektenvereines 4.I9I I, Nr. 6, S. 3 ff. 


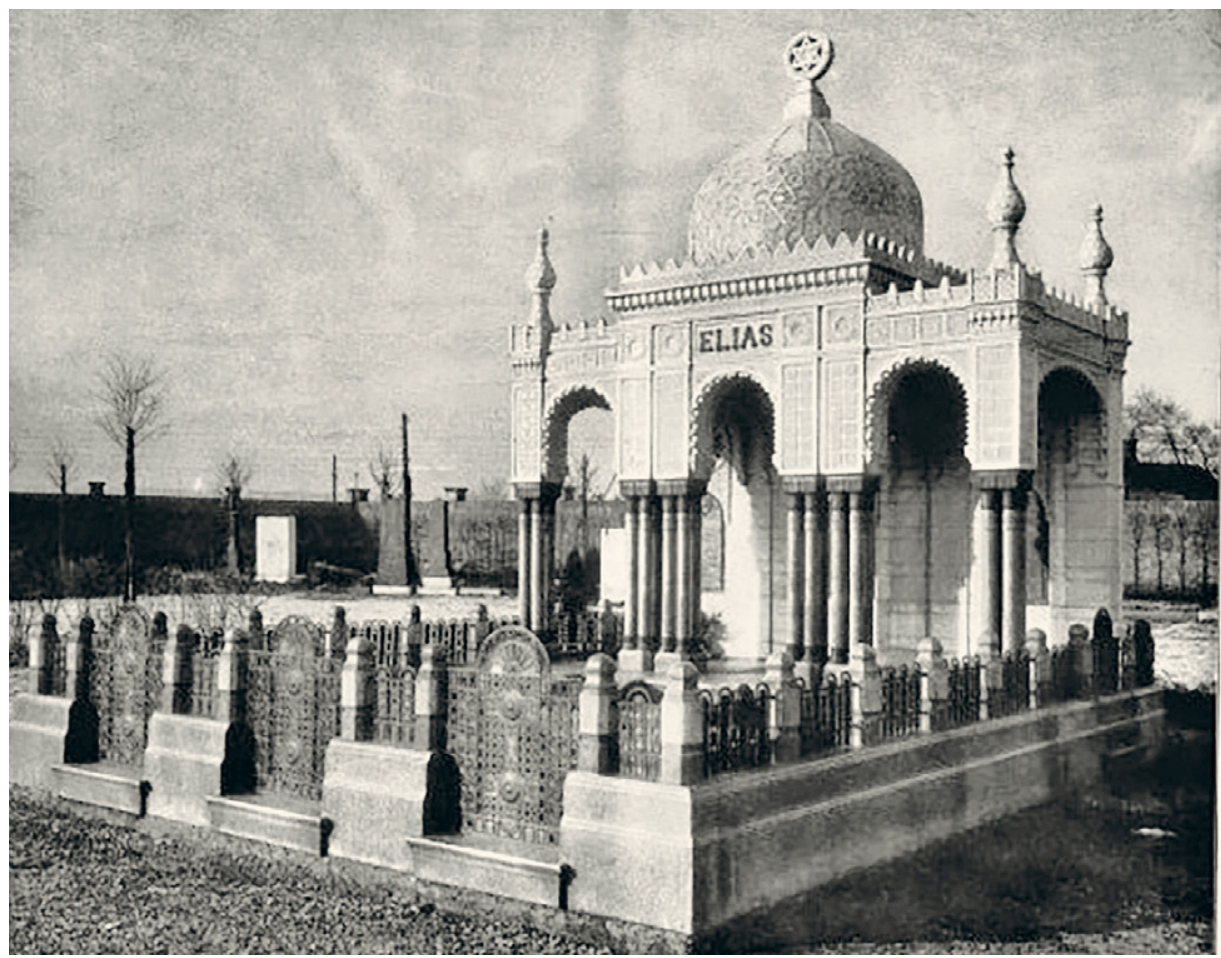

I I 2. Stefan Fayans, Grabmal Elias, Wiener Zentralfriedhof, alte israelit. Abteilung, um I9 I /Wr. Bauindustrieztg. I9I 2

Josefstadt verlassen und in ein sogenanntes "Judenhaus« (Bezeichnung für Sammelwohnungen in denen Juden vor ihrer Deportation zusammengezogen wurden) in die Leopoldstadt umziehen. Im September 1942 wurde er gemeinsam mit seiner Frau in das Vernichtungslager Maly Trostinec deportiert, wo sie nach ihrer Ankunft sofort umgebracht wurden. ${ }^{295}$

In ähnlicher Weise erging es auch Josef Sinnenberg (I88I-1942), dessen Berufslaufbahn einige Parallelen mit dem bereits angeführten Neumann Tropp aufweist. Sinnenberg kam gleichfalls aus einer ostjüdischen Familie, die aus Galizien stammte, er selbst wurde allerdings bereits in Wien geboren. ${ }^{296}$ Der Vater Herschel, ein kleiner Kaufmann, dürfte in den Sechziger/Siebzigerjahren des 19. Jahrhunderts in die

295 Die Abreise von Wien erfolgte am I4. September 1942, vier Tage später, am I8. des Monats (offensichtlich gleich bei der Ankunft), wurden beide umgebracht (DÖW, Deportiertenliste).

296 IKG Wien (Matrikenstelle). 


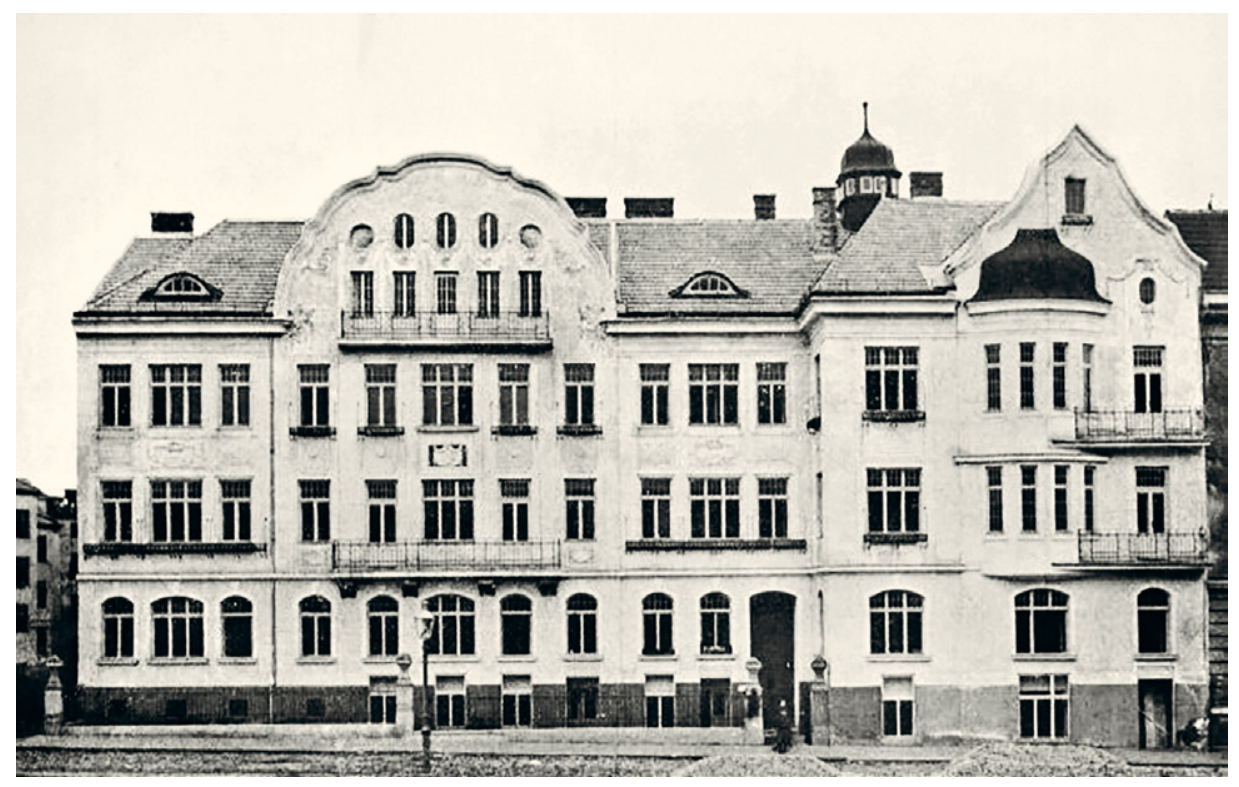

I I 3. Josef Sinnenberg, Miethaus Wien I4, Weinzierlgasse 9-I I, erbaut I9I2/I3/Wiener Bauindustriezeitung

Reichshauptstadt gekommen sein. Generell weiß man sehr wenig über die familiären Verhältnisse, sie scheinen aber eher bescheiden gewesen zu sein. Möglicherweise war es auch deswegen Sinnenberg verwehrt, nach dem Abschluss der Höheren (vierjährigen) Staatsgewerbeschule an der Technischen Hochschule oder an der Akademie weiter zu studieren. Nach einigen Praxisjahren erwarb er die Baumeisterkonzession, und ungefähr ab 1906 war er in Wien als Architekt und Baumeister tätig. Ähnlich wie Tropp konnte er vor allem in den letzten Jahren vor dem Ersten Weltkrieg eine Reihe von Wohnhäusern errichten. Die Bandbreite seiner Bauten reichte von eher anspruchslosen Miethäusern bis hin zu luxuriösen Ansitzen am Stadtrand, wobei großzügige Mietvillen für eine gehobenere Klientel zu seinem speziellen Aufgabengebiet gehörten. In formaler Hinsicht an der zeitgenössischen Moderne orientiert, zeichneten sich Sinnenbergs Bauten häufig durch aufwendig ausgestaltete Giebel und elegant vorschwingende "Bay Windows" aus (Abbildung I I 3, Miethaus, Wien I 3, Weinzierlgasse 9). Nicht zuletzt hatte er viele seiner Bauten in Fachzeitschriften veröffentlicht und dadurch eine gewisse Bekanntheit erlangt.

Der Ausbruch des Ersten Weltkrieges bedeutete auch für Sinnenberg ein Ende seiner erfolgreichen Tätigkeit. In der Zwischenkriegszeit blieben aufgrund der schlechten wirtschaftlichen Lage die Aufträge aus, und es sind keinerlei Bauten aus diesen 
Jahren dokumentiert. Es ist anzunehmen, dass er sich mit kleineren Bauaufgaben mehr schlecht als recht durchgeschlagen hat. Als ihm 1938 nach dem "Anschluss" Österreichs an NS-Deutschland die Berufsbefugnis entzogen wurde, wurde er damit jeglicher ökonomischer Basis beraubt. Diese schlechte finanzielle Lage war möglicherweise mit ein Grund, dass er trotz des starken Drucks, der auf die jüdische Bevölkerung ausgeübt wurde, nicht emigrieren konnte, da ihm dazu die erforderlichen Mittel fehlten. Wie alle Juden, die in Wien verblieben, hatte auch Sinnenberg keine Chance: I 942 wurde er in das Vernichtungslager Sobibor deportiert, wo er umgehend ermordet wurde. ${ }^{297}$

\subsection{Außergewöhnliche Schicksale im Inferno der NS-Zeit - Erich Ziffer, Jakob Reitzer, Leopold Schulz und Fritz Keller}

Dieser Abschnitt widmet sich einigen Männern, deren Schicksal in ihrer Tragik und Verworrenheit in gewisser Weise typisch war für die Geschehnisse der NS-Zeit. Die Reihe beginnt mit Erich Ziffer (I883-I942?), der infolge der Schmalheit seines Werkes als Architekt nur schwer zu erfassen ist. Geboren in Petrwald bei Ostrau/Ostrava im damaligen österreichischen Teil von Schlesien, kam er aus eher bescheidenen Verhältnissen und war schon früh verwaist, sodass er von seinem Vormund, einem wohlhabenden Großhändler, unterstützt werden musste. Ziffer kam nach dem Abschluss der Realschule nach Wien, um hier an der Technischen Hochschule zu studieren, wo Karl König einer seiner Lehrer war. Nach einigen Jahren des Praktikums im Ausland machte er sich um I9I 2 in Wien selbstständig, wobei er zumeist mit seinem Studienkollegen Arthur Grünberger zusammenarbeitete, über den schon im Abschnitt über den Synagogenbau berichtet wurde. Gemeinsam errichteten sie einige noble Miethäuser in den Villenvierteln von Hietzing und Döbling. Während über Ziffers Tätigkeit während des Ersten Weltkrieges nichts bekannt ist, kann als gesichert gelten, dass er um 1920 die Bauschule von Adolf Loos besuchte, deren Kurse damals in den Räumlichkeiten der von Eugenie Schwarzwald gegründeten Schule stattfanden. Ziffer ist auf einem Gruppenfoto aus dieser Zeit namentlich angeführt. ${ }^{298}$ Er bewegte sich also in dem damals für jüdische Architekturstudenten typischen Umfeld um Karl König und Adolf Loos.

Dieser Antagonismus zwischen Tradition und Moderne, für die einerseits Karl König und anderseits Adolf Loos standen, prägte auch das Werk von Ziffer. Während

297 DÖW/Deportiertenliste.

298 Meder, zit. Anm. 205. 
seine frühen Villen noch einer sehr dekorativen Ausrichtung verpflichtet waren, ist das von ihm in der Mitte der Zwanzigerjahre errichtete Wohnhaus in Wien-Währing, Hockegasse 88 (Abbildung I I4), von einem äußerst puristischen, etwas klassizierenden Charakter geprägt, wie er für Loos und dessen Umfeld typisch war. Dies ist der einzige dokumentierte Bau Ziffers in Wien aus der Zwischenkriegszeit. Es ist anzunehmen, dass Ziffer aufgrund der schlechten wirtschaftlichen Lage in einem größeren Baubüro angestellt war. Nach dem "Anschluss« im März 1938 emigrierte Ziffer mit seiner Frau in die damalige Tschechoslowakei, wo er kurzfristig in seinem heimatlichen Schlesien untertauchte. In der Folge nahm das Schicksal in einer unglaublichen Odyssee, die nicht eindeutig zu rekonstruieren ist, seinen Lauf. Als im Frühjahr des folgenden Jahres NS-Deutschland auch die »Resttschechei« besetzte, wurde Ziffer vorerst in ein Sammellager nach Mährisch-Ostrau verbracht. Von dort wurde er nach Nisko am San geschickt, wo Adolf Eichmann, einer der wichtigsten Mittäter des Holocaust, kurzfristig ein Sammellager hatte einrichten lassen. Um I 942 sah sich Ziffer schließlich nach Theresienstadt deportiert, um kurze Zeit später in das Vernichtungslager Treblinka verbracht zu werden, wo er mit großer Wahrscheinlichkeit umgebracht wurde. ${ }^{299}$ Die näheren Umstände und ein genaueres Todesdatum sind bis heute nicht bekannt. Seine Witwe ließ ihn jedenfalls I948 für tot erklären.

Ein gleichfalls wirres, bis heute nicht genau zu rekonstruierendes Schicksal erlitt auch Jakob Reitzer ( $1880-$ I945?), der, nur wenig älter als Ziffer, ebenfalls einer der vielen Architekten in Wien war, die der Bauboom der letzten Friedensjahre vor dem Ersten Weltkrieg in die Reichshauptstadt gezogen hatte. Bekannt ist, dass er im ungarischen Szeged geboren wurde, wir wissen aber fast nichts über seine Familie und seine Ausbildung. Da er jedoch während des Ersten Weltkrieges als Landsturmoberleutnant eingerückt war, was einen Militärdienst als Einjährig-Freiwilliger voraussetzte, der nur Maturanten vorbehalten war, ist anzunehmen, dass er zumindest eine höhere Staatsgewerbeschule absolviert hatte. Jedenfalls trat er ab ca. 1906 in Wien als freier Architekt in Erscheinung. Sein Schwerpunkt - soweit dokumentiert - waren weitgehend Wohnhäuser und Villen des gehobenen Bedarfs. Dabei orientierte er sich auch in der formalen Gestaltung an dem Geschmack und Repräsentationsbedürfnis des aufstrebenden Bürgertums, indem er seine Projekte in einer Mischform von Neobarock und Secessionismus ausgestaltete - der oft überbordende Dekor (heute oftmals nicht mehr erhalten) war allerdings eher untypisch für das Wiener Umfeld und könnte auf seine ungarische Ausbildung hinweisen (Abbildung I I 5 , Miethaus, Wien I9, Vegagasse 2 I). Während des Ersten Weltkrieges dürfte er in einer der vielen militärischen Bauabteilungen gearbeitet haben, da er sich unter anderem mit dem

299 DÖW/Deportiertenliste. 


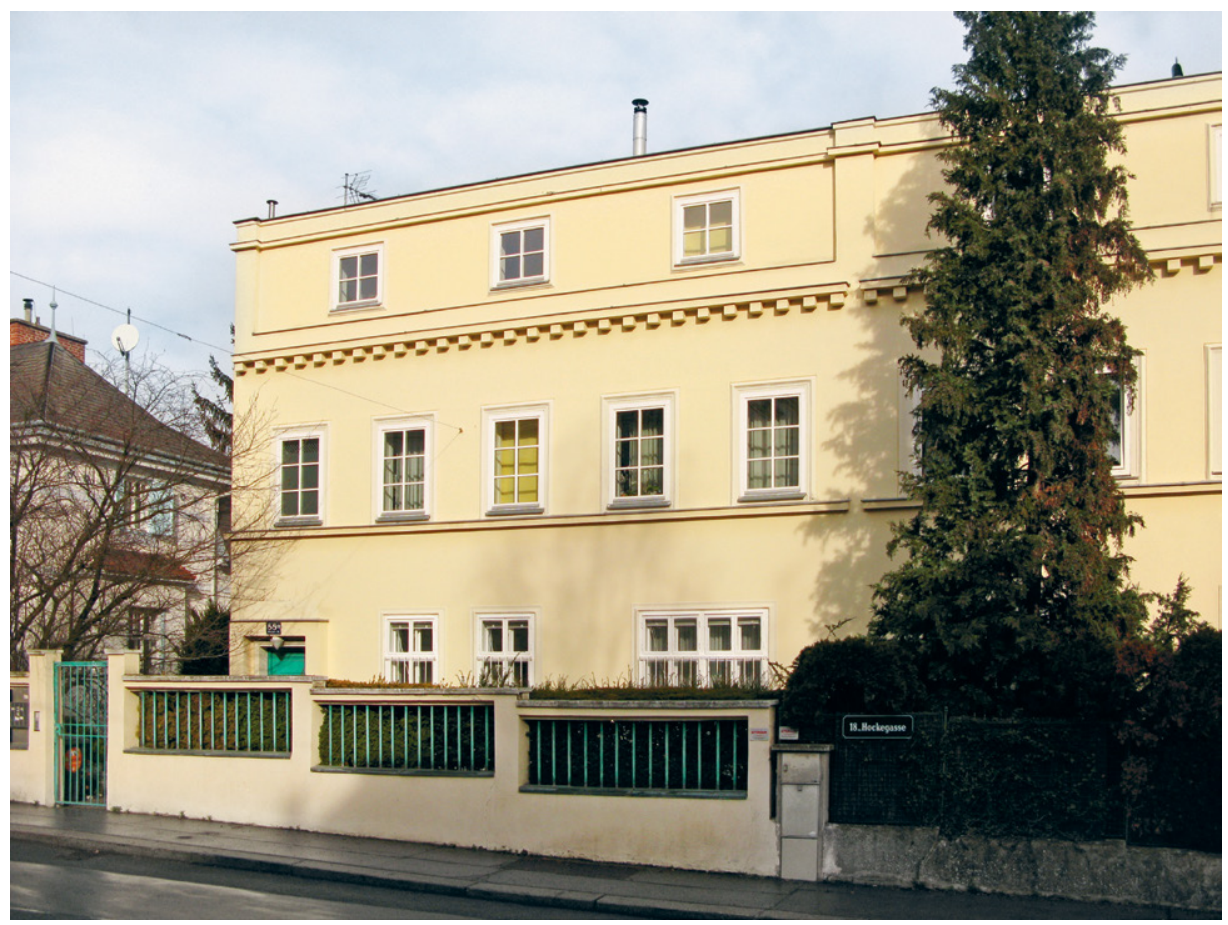

I I 4. Erich Ziffer, Doppelhaus Wien I 8, Hockegasse 88, erbaut I924/Prokop

Plan eines Militärfriedhofes in Arad befasst hatte. Obwohl nur ganz wenige Bauten dokumentiert sind, arbeitete er auch in der Zwischenkriegszeit weiterhin für eine gut situierte Klientel. Nach dem »Anschluss« 1938 flüchtete er mit seiner Frau - da er offensichtlich die ungarische Staatsbürgerschaft behalten hatte - nach Budapest. Während seine beiden Söhne emigrieren konnten, verblieb er in der ungarischen Hauptstadt, wo er - als im Sommer I944 die Judendeportationen begannen - unter nicht geklärten Umständen ums Leben kam. Seine Frau, der es zu flüchten gelang, kehrte nach dem Krieg nach Wien zurück und führte hier kurzfristig ein Geschäft. Schließlich übersiedelte sie mit ihrem Sohn nach Innsbruck, wo bis heute Nachkommen leben. ${ }^{300}$

Ein weiterer tragischer Fall, der in diesem Kontext zu nennen ist, ist das Schicksal von Leopold Schulz (1883-1945), dessen architektonisches Werk kaum zu rekonstruieren ist. In Wien als Sohn eines aus Pressburg zugezogenen Handelsagenten geboren, stammte er aus ärmlicheren Verhältnissen, sodass ihm ein Studium verwehrt war und

300 P. Schumann, J. Reitzer, in: Architektenlexikon, zit. Anm. I3; www.centropa.org. 


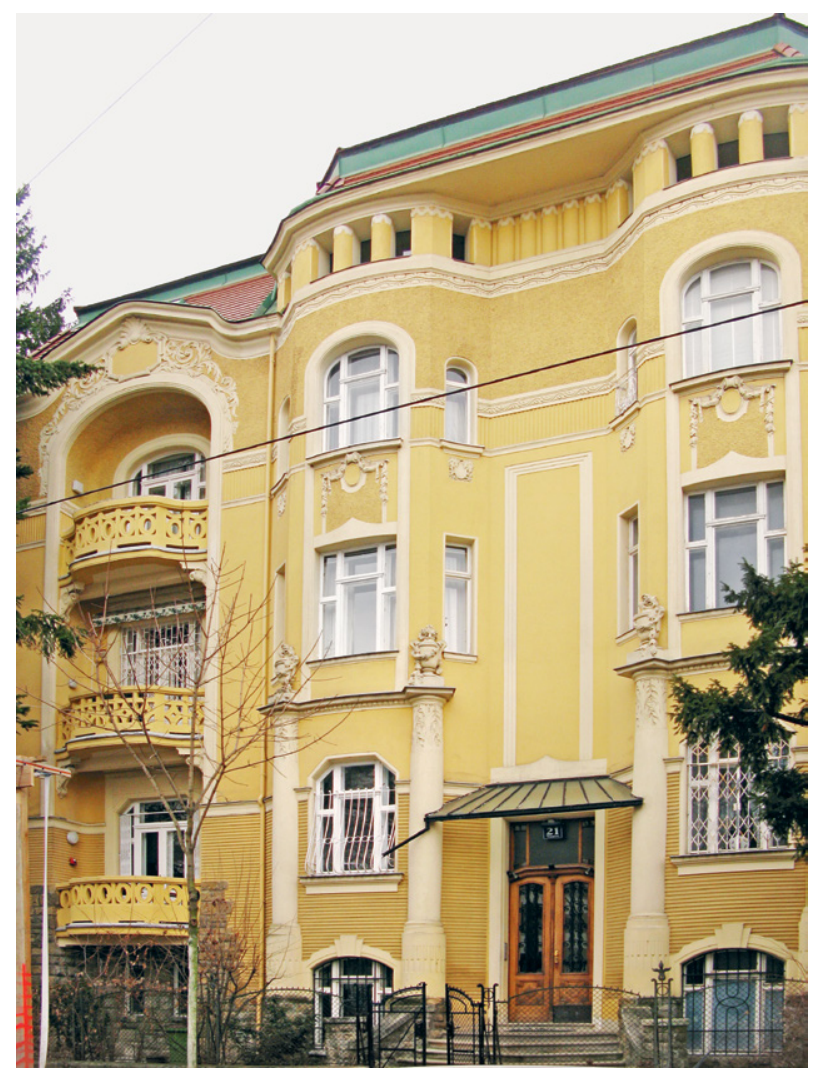

I I 5. Jakob Reitzer, Miethaus I9, Vegagasse 2I, erbaut I907/Prokop

er nur die Höhere Staatsgewerbeschule besuchen konnte. Erst kurz vor dem Ersten Weltkrieg machte er sich als Architekt und Baumeister selbstständig. Es ist anzunehmen, dass er bei Kriegsausbruch einrücken musste, da seine Tätigkeit erst wieder Mitte der Zwanzigerjahre nachzuweisen ist. Allerdings agierte er weitgehend nur als ausführender Baumeister. Nur bei zwei Wohnhausanlagen des »Roten Wien« ist er als Planverfasser nachweisbar. Dabei zeichnet sich insbesondere ein 1926 erbauter Wohnblock in Wien 2, Taborstraße 94 durch eine bemerkenswerte architektonische Qualität auszeichnet (Abbildung I I6). Errichtet auf einem Eckgrundstück, setzt das Gebäude, das von einer farbigen Akzentuierung in der Art des romantischen Expressionismus geprägt ist, durch seine eleganten Proportionen einen markanten städtebaulichen Akzent. Wie für viele Baumeister und Architekten in diesen Jahren stellten die Bauten des »Roten Wien« einige der wenigen Aufträge für Leopold Schulz dar.

Nachdem ihm nach dem "Anschluss" I 938 die Berufsbefugnis entzogen wurde, verabsäumte er es zu emigrieren und blieb in Wien. Möglicherweise verfügte er nicht 
I I6. Leopold Schulz, Wohnhausanlage d. Gemeinde Wien, Wien 2 Taborstraße 94, erbaut I926/Prokop

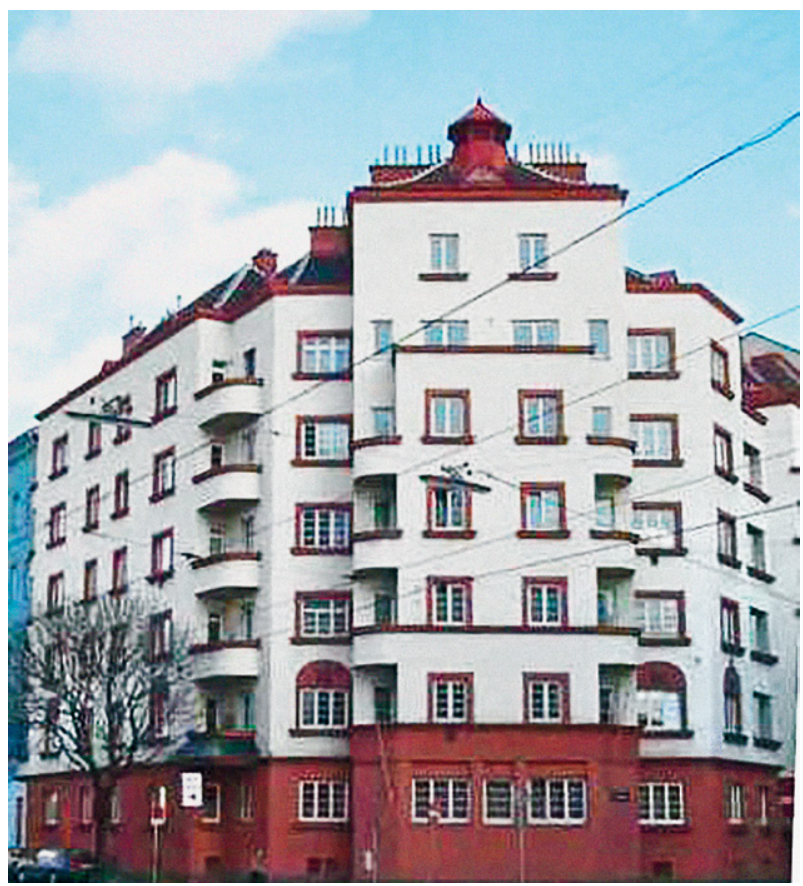

über genügend finanzielle Mittel, um ein Visum zu erlangen. Als I94I die ersten Judendeportationen einsetzten, versteckte er sich in der Wohnung seiner "arischen" Lebensgefährtin Lilly Hladisch und lebte fortan als sogenanntes "U-Boot» (damalige Bezeichnung für Menschen die in die Illegalität untergetaucht waren). Im Herbst I 944 wurde das Haus im 8. Bezirk in der Lederergasse 32, in dem sich die Wohnung befand, ausgebombt und sein Versteck flog auf. Nachdem er denunziert worden war, verhaftete ihn die Gestapo und verhörte ihn unter Folter im Hauptquartier am Morzinplatz. Im Februar 1945 wurde er in das KZ Mauthausen überstellt, wo er Ende April an den Folgen des Verhörs und der Entkräftung verstarb - tragischerweise nur eine Woche vor der Befreiung des Lagers durch die Alliierten. ${ }^{301}$

Gleichfalls im Dunklen liegt das Ende des Architekten Fritz Keller (I 878-1938). Aus der Gegend um Karlsbad stammend, ging er Ende der 9oer-Jahre nach Wien, um an der Technischen Hochschule Architektur zu studieren. Noch während seines Studiums änderte er seinen ursprünglichen Namen Kohn, den er möglicherweise als zu ausgeprägt jüdisch empfand, in »Keller ${ }^{302}$ An sich eine kleine Episode, die aber

30 I Siehe dazu H. Weihsmann, zit. Anm. I 3 ; Archiv des DÖW (Akt Hladisch Zl. 200o/H 437). 302 Studienbuch der TH Wien, I90I. 
doch zeigt, wie sehr sich nicht wenige der Juden unter dem antisemitischen Druck bemüht haben, ihre Identität zu verbergen. Fritz Keller praktizierte späterhin bei Karl Mayreder und arbeitete auch als dessen Assistent an der Hochschule, bis er I 905 zum Dr. tech. promovierte und damit zum frühen Kreis derer gehörte, die ihr Studium erstmals mit einer Dissertation abschlossen. ${ }^{303}$ Als er sich nach seiner Ausbildung selbstständig machte, ging er vorübergehend mit seinem Studienkollegen Fritz Herzmanovsky-Orlando eine Ateliergemeinschaft ein. Herzmanovsky-Orlando gab späterhin seine Architektenlaufbahn auf, um schließlich als Schriftsteller und Grafiker berühmt zu werden. Auch Keller \& Herzmanovsky verlegten sich dem Zeittrend entsprechend weitgehend auf den Miethausbau, wobei ihre Projekte von der zeitgenössischen Moderne, insbesondere dem Formenapparat der Wiener Werkstätte, geprägt waren. Wie alle anderen auch hatte Fritz Keller nach dem Krieg große berufliche Probleme und konnte nur mehr einige wenige Projekte realisieren. Interessanterweise hat in den frühen 2oer-Jahren - wie oben angeführt - der junge Jacques Groag in seinem Büro praktiziert. ${ }^{304}$ Das letzte dokumentierte Projekt Kellers ist ein Strandhaus in Kritzendorf, das er 1929 errichtete. Wie er über die Jahre der Wirtschaftskrise kam, ist nicht bekannt. Man weiß nur, dass Keller im Dezember I938 - also einige Monate nach dem Anschluss und nachdem es seiner Familie bereits gelungen war, nach London zu fliehen - unter ungeklärten Umständen in Wien verstarb. ${ }^{305}$

\subsection{Die Opfer von Theresienstadt - Heinrich Kestel und Leopold Steinitz}

Zynischer weise galt aus dem Blickwinkel der Nazis eine Verschickung nach Theresienstadt/Terezin als »Privileg«, das vor allem Juden vorbehalten war, die aus dem »Reichsgebiet"stammten. Propagandistisch in dem Film »Der Führer schenkt den Juden eine Stadt» nahezu als Idylle vorgestellt, wurden nach Theresienstadt (ursprünglich eine alte Festungsstadt aus Josephinischer Zeit, die von den Nazis zu einem Ghetto umfunktioniert wurde) insbesondere viele ältere Menschen verschickt. Dieser Umstand betraf auch die in Wien lebenden Architekten. Während viele jüngere emigrieren konnten, waren es letztlich die betagteren, die blieben - oftmals in dem trügerischen Glauben, dass man Leuten im Ruhestand nichts mehr anhaben würde oder dass man als »Kriegsteilnehmer« aus der Zeit des Ersten Weltkrieges geschützt wäre. Während

303 Kellers Dissertation behandelte »Die römische Villenanlage von Val Catena auf der Insel Brioni«, 1905.

304 Brief Jacques Groags (um 1925) an seinen Bruder Emo: „Es geht mir sehr gut bei Dr. Keller, aber leider lässt er niemand selbständig arbeiten" (Dr. Willi Groag $\dagger$ ).

305 I. Scheidl, Fritz Keller, in: Architektenlexikon und Weihsmann, beide zit. Anm. I3. 
einige Opfer von Theresienstadt bereits in den vorangegangenen Kapiteln besprochen wurden, ist dieser Abschnitt zwei in Theresienstadt umgekommenen Architekten gewidmet, deren Werk im Rahmen des Üblichen bleibt, deren Lebenslauf allerdings fast prototypisch für das Schicksal der älteren Generation der Juden in Wien ist.

So ist es bezeichnend, dass beide der hier besprochenen Personen in Wien geboren und zum Zeitpunkt der Deportation schon weit über sechzig waren. Entgegen aller Propaganda war Theresienstadt die Hölle für die Betroffenen. Auch wenn es kein unmittelbares Vernichtungslager war, kamen die meisten der Verschickten infolge von Unterernährung, völlig unzulänglichen hygienischen Verhältnissen, die schnell zu Seuchen führten, und mangelnder ärztlicher Versorgung binnen Kürze elend ums Leben. Die Daten der Opfer sprechen für sich. Außerdem wurden nicht wenige von Theresienstadt aus in die Vernichtungslager geschickt, wie dies auch im Fall von Friedl Dicker geschah.

Der ältere der beiden Architekten ist Heinrich Kestel (I 864-I 942), der als Sohn eines Kaufmanns die für Wien typische Ausbildung an der Technischen Hochschule (unter anderen bei Karl König) durchlief, an der er auch späterhin kurzfristig als Assistent tätig war. Danach arbeitete er vorübergehend im Planungsbüro des Wiener Stadtbauamtes und agierte als Chefredakteur in der renommierten Fachzeitschrift "Wiener Bauindustriezeitung«. Damit war er über Jahre weitgehend nur theoretisch tätig, sodass er kaum als Architekt in Erscheinung treten konnte. Erst nach rund zehn Jahren Praxis wagte er um I900 den Sprung in die Selbstständigkeit, wobei ihm die damalige Baukonjunktur zugutekam. Wie die meisten der um diese Zeit in Wien tätigen Architekten lag sein Schwerpunkt auf dem Gebiet des Wohnbaus. Einige von ihm errichtete Industrieanlagen in den damaligen Kronländern der Monarchie sind hingegen nur schlecht dokumentiert. Die von Heinrich Kestel bis zum Ersten Weltkrieg in Wien geplanten Villen und Miethäuser entsprechen weitgehend dem formalen Kanon dieser Jahre, indem sie sich moderat an die damalige Moderne, wie sie seitens der Secession oder der Wiener Werkstätte ausformuliert worden war, anlehnen. Ein schönes Beispiel dafür ist der um I9 Io errichtet "Rochushof « in der Hintzerstraße im 3. Bezirk, dessen gekonnte Proportionierung und elegant zurückhaltend eingesetzter Dekor das Repräsentationsbedürfnis des gehobenen Bürgertums abdeckten (Abbildung I I7). Wie bei vielen anderen Architekten auch sind aus der Zwischenkriegszeit keinerlei Bauten Kestels dokumentiert. Ob er möglicherweise bei einer großen Baufirma unterkam oder sich bald ins Privatleben zurückzog, ist nicht bekannt.

Als es 1938 zum "Anschluss" kam, verließ er das Land wahrscheinlich aufgrund seines fortgeschrittenen Alters nicht und blieb mit seiner aus Ungarn stammenden Frau, der Malerin Malvine Bauer, in Wien. Hier ereilte ihn das unausweichliche Schicksal: Zunächst musste er seine Wohnung im 9. Bezirk aufgeben und in eine 


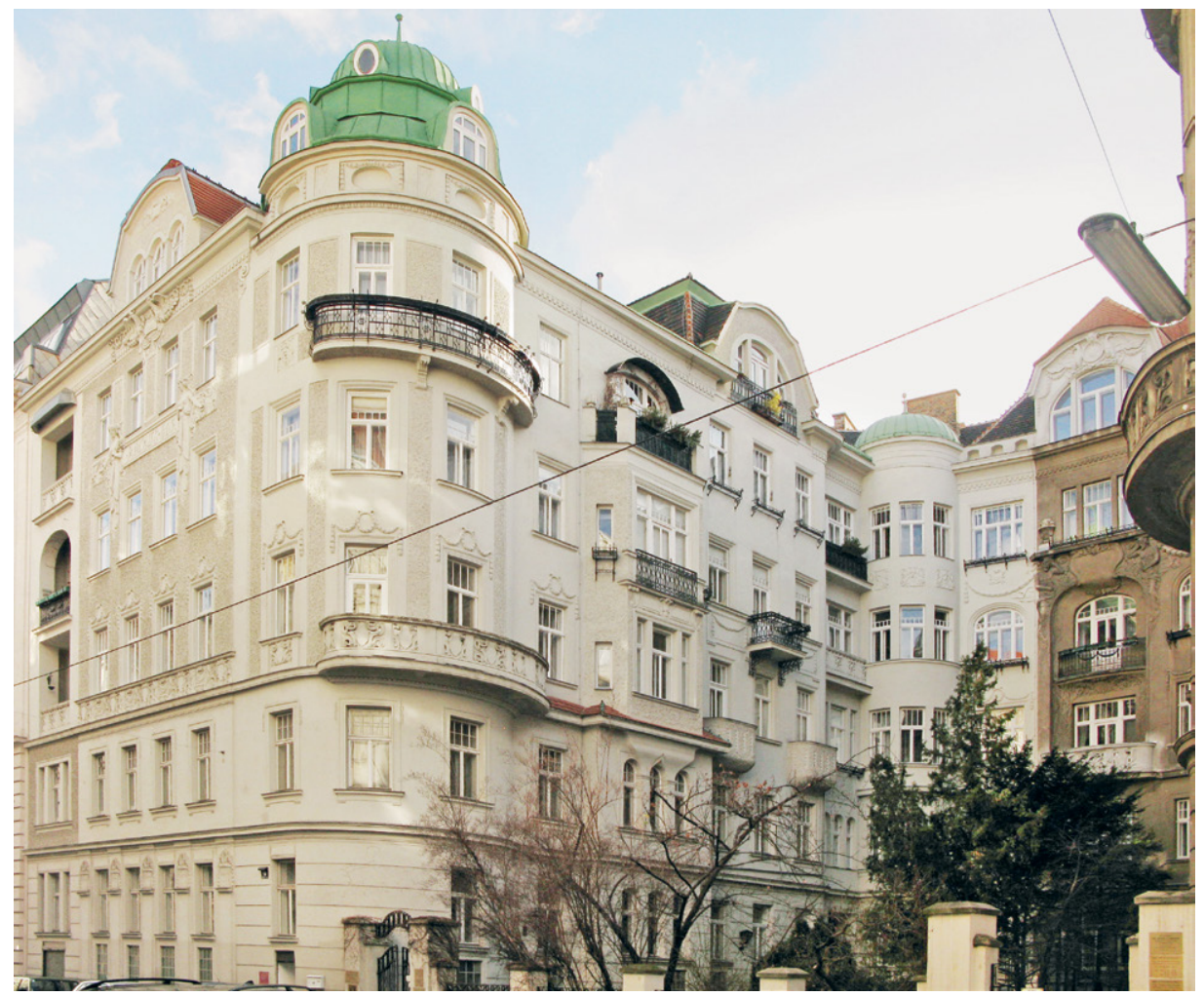

I 17. Heinrich Kestel, Rochushof, Wien 3, Hintzerstraße 9-I I, erbaut I9ı/Prokop

Sammelwohnung in die Novaragasse übersiedeln, um im April I 942 - bereits weit in den Siebzigern - mit seiner Frau nach Theresienstadt deportiert zu werden. Bereits im September desselben Jahres verstarb er dort. Seine Frau überlebte ihn nur um einige Monate. ${ }^{306}$

Ähnlich gestaltete sich auch der Lebenslauf des um einige Jahre jüngeren Leopold Steinitz ( I 868-I 942), der, gleichfalls aus der jüdischen Mittelschicht stammend, seine Ausbildung an der Technischen Hochschule erhalten hatte. ${ }^{307}$ Seine ersten Praxisjahre verbrachte er im Atelier von Fellner \& Helmer, damals das führende Büro auf dem Gebiet des Theaterbaus. Auch er machte sich um I 900 selbstständig und verlegte sich vor allem auf den Wohnbau. Gemeinsam mit seiner Frau konvertierte er kurz vor der Geburt seines ersten Sohnes zum Protestantismus und ließ auch seine

306 DÖW/Deportiertenliste.

307 Leopold Steinitz in: Architektenlexikon und Weihsmann, beide zit. Anm. I 3. 
Kinder taufen. ${ }^{308}$ Im Gegensatz zu vielen anderen Architekten gelang es ihm jedoch, seine Karriere auch nach dem Ende des Ersten Weltkrieges fortzusetzen, indem er sich vor allem auf die Errichtung von Gewerbe- und Industriebauten verlegte, für die er auch als Sachverständiger fungierte. Während ein Großteil dieser Anlagen nur mehr rudimentär erhalten ist, ist das Mitte der Zwanzigerjahre in der kraftvollen Formensprache des Art Deco errichtete Umspannwerk der Steirischen Wasserkraftwerke in Knittelfeld heute als bedeutendes Industriedenkmal unter Schutz gestellt. ${ }^{309} \mathrm{Nach}$ dem "Anschluss" fiel Steinitz ungeachtet seiner Konversion in die Kategorie »Geltungsjude" und wurde als solcher im August 1942 mit seiner Frau nach Theresienstadt deportiert, wo er nur kurze Zeit später im November des gleichen Jahres verstarb. ${ }^{310}$ Auch in diesem Fall folgte ihm seine Frau einige Monate später.

308 A. Staudacher, Jüdisch-protestantische Konvertiten in Wien I782-1914, Teil 2, Wien 2004.

309 M. Wehdorn/U. Georgeacopol-Winischhofer, Baudenkmäler der Technik und Industrie in Österreich, Bd. 2, Wien u. a. I99I.

3 Iо DÖW/Deportiertenliste. 


\section{0 »Emigranten« mit Erfolgsgeschichte}

Das Schicksal derer, die entkommen konnten, zumeist verschämt als "Emigranten" bezeichnet (da sich dieser Terminus jedoch durchgesetzt hat, wird er auch hier verwendet), war im überwiegenden Fall höchst tragisch. Für viele bedeutete die Vertreibung einen Einbruch in ihrer Karriere. Sprachprobleme und die Schwierigkeit, die jeweilige Befugnis zur Ausübung des Berufes zu erhalten, veranlassten nicht wenige, auf das Gebiet der Innenarchitektur oder des Möbeldesigns auszuweichen. Nicht selten waren es die zumeist jüngeren Frauen, die sich in der neuen Situation besser zurechtfanden und damit auch die Hauptlast der ökonomischen Versorgung trugen. Als Paradebeispiel mag hier das Ehepaar Groag dienen, wo - wie bereits angeführt die Ehefrau im englischen Exil Karriere machte. Insbesondere für die Älteren war der Berufseinstieg oft äußerst schwierig, sodass sie in die Armut stürzten und oftmals von Verwandten oder Freunden unterstützt werden mussten, wie z. B. im Fall von Oskar Wlach oder Erich Lindner. Bezeichnenderweise ist die Anzahl derjenigen, denen es gelang, in der Emigration ihren Beruf erfolgreich weiterzuführen, sehr gering. Wenn überhaupt, dann gelang es nur denjenigen, die relativ früh - also bereits einige Zeit vor Kriegsausbruch - emigrierten oder noch sehr jung waren. Sie konnten die großzügigen Möglichkeiten nutzen, die sich ihnen in Wien nie geboten hätten. Einige dieser Architekten gelangten zu großem internationalem Renommee, sodass ihre Biografien in einer umfassenden Literatur ohnedies ausgiebig dokumentiert sind. Deshalb werden sie hier nur der Vollständigkeit halber angeführt und auch eher kursorisch behandelt. Ihre Karriere nach der Flucht eingehender nachzuzeichnen, würde über die Thematik dieser Studie, die sich vor allem auf die Wiener Geschehnisse konzentriert, weit hinausgehen. Einigende Klammer der drei folgenden Biografien ist daher auch der Umstand, dass jeder der vorgestellten Architekten in ihrer Frühzeit noch Projekte in Wien realisiert haben. Generell sollten diese Erfolgsgeschichten jedoch nicht dazu benutzt werden, das tragische Schicksal der anderen herunterzuspielen.

\subsection{Friedrich Kiesler}

Der Älteste dieser Gruppe ist Friedrich Kiesler (1890-I965), der aus Czernowitz aus der damaligen österreichischen Bukowina stammte. 1908 inskribierte er in Wien an der Technischen Hochschule, um bereits ein Jahr später an die Akademie der bildenden Künste zu wechseln, wo er jedoch keineswegs eine Architekturklasse belegte, 


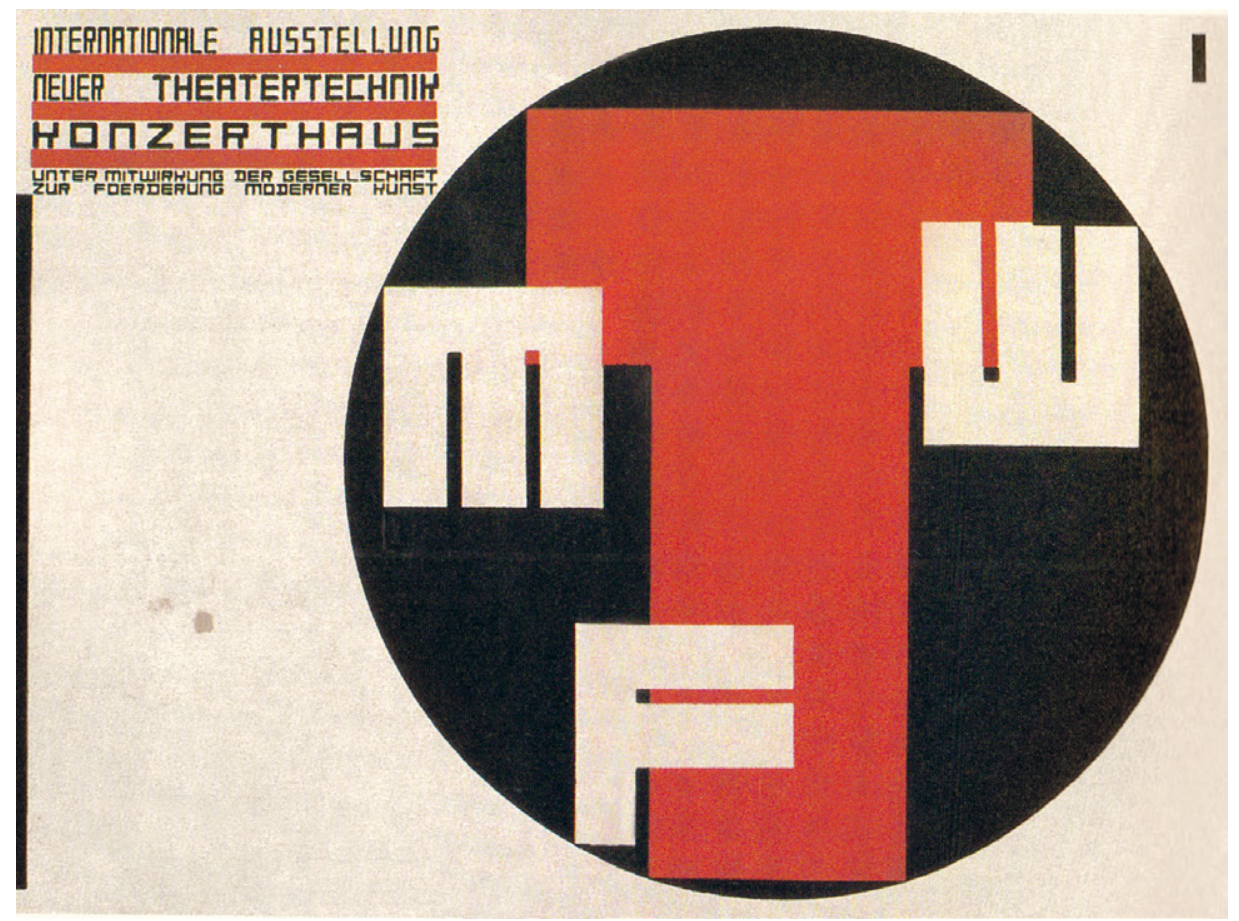

I 18. Friedrich Kiesler, Plakat der Theaterausstellung I925/Kat. Kiesler

sondern Malerei und Grafik bei Rudolf Bacher und Ferdinand Schmutzer studierte. Mit dieser Wahl entschied sich Kiesler bereits in jungen Jahren für einen Weg, der über den eigentlichen Architekturbereich weit hinausging. 19I3 brach er jedoch auch dieses Studium ohne Abschluss ab. ${ }^{311}$ Während des Ersten Weltkrieges eingerückt, war er im k. k. Pressequartier beschäftigt, in dem relativ viele Künstler arbeiteten, und in dieser Funktion unter anderem mit der Organisation von Kriegsausstellungen befasst. Auch nach Kriegsende widmete er sich dem Ausstellungswesen und vor allem der Bühnenbildnerei, wobei er zwischen Wien und Berlin pendelte und dort mit der damaligen künstlerischen Avantgarde wie Theo van Doesburg, László Moholy-Nagy und anderen in Kontakt kam. ${ }^{312}$ Bereits 1922 war er in die Vorbereitung der "Inter-

3 I I Generell war ein offizieller Abschluss damals nicht unbedingt notwendig. Man ist vor allem zu einem bestimmten Professor oder Künstler gegangen, um einige Zeit bei diesem zu lernen. Die Studienpläne waren damals noch keineswegs so kanonisiert wie heute.

3 I 2 Visionäre und Vertriebene, zit. Anm. Io, S. 335. 
I I9. Friedrich Kiesler, Shrine of the Book, Jerusalem, ISR, erbaut $1958 / 63 /$ Kat. Kiesler

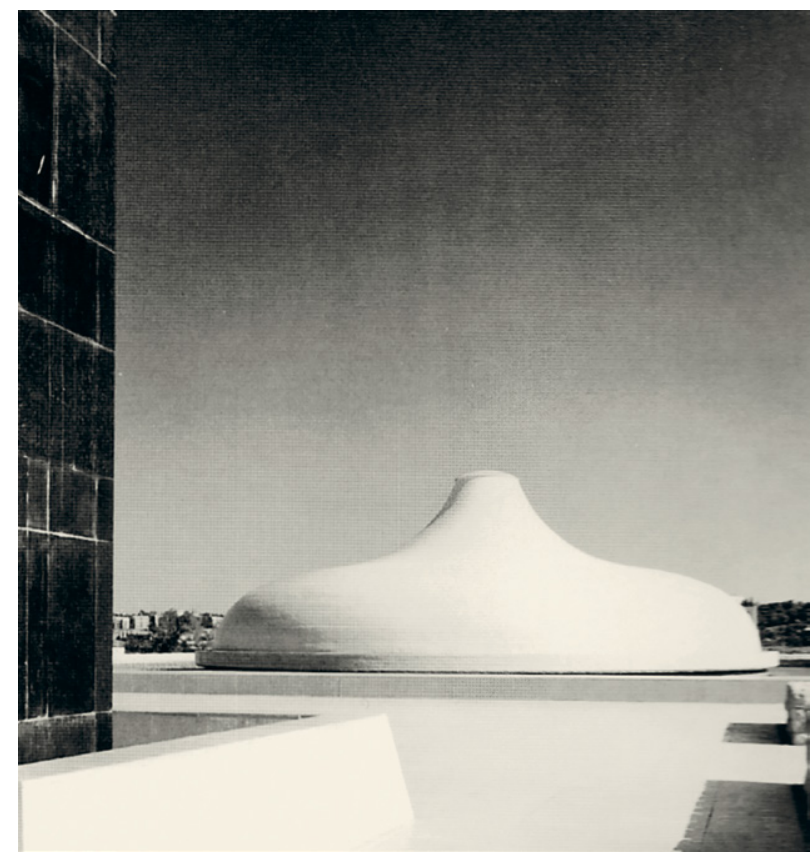

nationalen Ausstellung neuer Theatertechniken« eingebunden, die zwei Jahre später eines der innovativsten Ereignisse im Wien der Zwischenkriegszeit werden sollte. Wie kein anderer prägte dann Kiesler diese Ausstellung, indem er - neben den Entwürfen von Plakaten, Tickets und dem Katalog in einem konstruktivistisch angehauchten Stil - vor allem für die Ausstellungsarchitektur ein Trägersystem entwickelte, das freie, flexible Konstruktionen zur Präsentation der Objekte ermöglichte (Abbildung I I8). Im Rahmen der europäischen Avantgarde aus Deutschland, Russland, Frankreich und Italien - darunter Künstler wie Doesburg oder Fernand Leger -, die alle ihre neuesten Ideen präsentierten, stellte Kiesler selbst seine spiralförmige Raumbühne vor, die erstmals die Idee des endlosen Raumes thematisierte. ${ }^{313}$ Es sollte seine letzte Arbeit für Wien bleiben. Aufgrund des großen Erfolges lud ihn ein Jahr später I 925 Josef Hoffmann ein, an der »Exposition des Artes Décoratifs« in Paris teilzunehmen, wo Kiesler seine Idee des endlosen Raumes nun in einer monumentalen schwebenden Struktur der »Raumstadt« präsentierte.

Seine innovativen Ideen fanden schnell internationalen Anklang, und er folgte einem Ruf in die USA, wo er in der Folge mit unerschöpflicher Kreativität Bahnbre-

313 D. Bogner, Friedrich Kiesler, 1998. 
chendes auf dem Gebiet des Theaters und des Kinos leistete. Kieslers weit gestecktes Betätigungsfeld umfasste aber auch Ausstellungsarchitektur, Möbeldesign, Unterrichtstätigkeit und publizistisches Engagement. Auch machte ihn seine Freundschaft zu zahlreichen Künstlern in Paris und New York zu einem hochgeschätzten Katalysator der Moderne. Nach dem Krieg erneuerte er wieder seinen Kontakt mit den europäischen Surrealisten und gestaltete 1947 gemeinsam mit André Breton und Marcel Duchamp die "Exposition International du Surréalisme«. ${ }^{314}$ Die Beschäftigung mit der Idee des endlosen Raumes, die sein Leben wie ein roter Faden durchzog, setzte er schließlich in seinem Konzept des »Endless House« um. Als einer der Höhepunkte seines Werkes ist schließlich der Auftrag für den "Shrine of the Book" in Jerusalem anzusehen (Abbildung I I9), den Kiesler in jahrelanger Zusammenarbeit mit dem Architekten Armond Bartos in den frühen Sechzigerjahren realisierte. Als Aufbewahrungsort für die damals gerade entdeckten Rollen von Qumran konzipiert, schuf Kiesler hier eine grandiose Apotheose der Schriftlichkeit der jüdischen Kultur. Nur kurze Zeit nach der Eröffnungszeremonie verstarb Kiesler, der sich eigentlich jeder künstlerischen Einordnung oder Stilrichtung entzieht, an den Folgen einer Herzattacke.

\subsection{Richard Neutra}

Eine klassische Architektenkarriere durchlief hingegen der um zwei Jahre jüngere Richard Neutra (I892-I970, Abbildung I 20). Aus einer Wiener Unternehmerfamilie stammend, hatte er insbesondere über seine Schwester, die Bildhauerin Josephine Weixlgärtner, schon in seiner Jugend intensiven Kontakt mit künstlerisch-intellektuellen Kreisen in Wien. Während seines Studiums an der Technischen Hochschule, wo er unter anderen Karl Mayreder und Max Fabiani zu seinen Lehrern hatte, freundete er sich mit seinem Studienkollegen Ernst Freud, dem Sohn von Sigmund Freud, an, der späterhin in London lebte. Allem Neuen gegenüber aufgeschlossen, besuchte Neutra neben der Technischen Hochschule zudem die Bauschule von Adolf Loos, der seine Begeisterung für die Architektur der USA erweckte. Damit bewegte sich auch Neutra in dem für jüdische Architekturstudenten damals typischen Umfeld zwischen Technischer Hochschule und Adolf Loos.

Während des Ersten Weltkrieges zur Artillerie eingezogen, konnte er sein Studium erst nach dem Krieg beenden. Die folgenden Jahre sollten sich für Neutra äußerst vielfältig und lehrreich erweisen. Um eine Tuberkulose auszukurieren, ging er nach

3 I 4 Siehe dazu M. Pressler (Hg.), Breton Duchamp Kiesler - Surreal Space I947 (Kat.), Wien 20 I 3. 
I 20. Richard Neutra, Porträt/Kat. Vertriebene

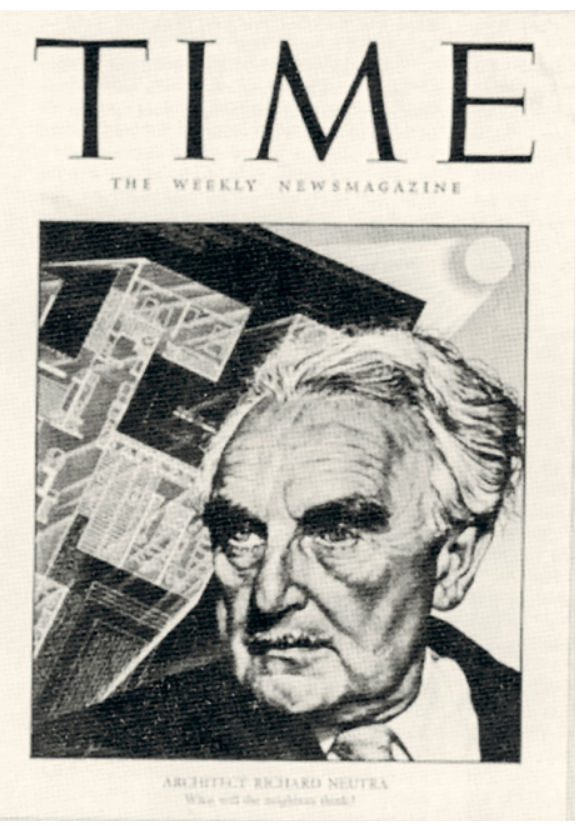

Kriegsende in die Schweiz und bildete sich dort an der ETH Zürich weiter, daneben arbeitete er als Landschaftsgärtner. Bereits 1920 wechselte er nach Berlin und erhielt über Vermittlung seines Freundes Ernst Freud eine Stelle im Büro des berühmten Architekten Erich Mendelsohn. Gemeinsame ehrgeizige Projekte für das damalige Palästina zerschlugen sich allerdings, sodass Neutra beschloss, in die USA zu gehen, wo er sich 1923 in New York niederließ. ${ }^{315}$ Hier arbeitete er vorerst in verschiedenen Baubüros, um schließlich eine Anstellung in einem der renommiertesten Ateliers von Holabird \& Roche zu erhalten, wo er Gelegenheit bekam, die hoch entwickelte industrielle Bautechnik der USA zu studieren, über die er dann später publizieren sollte. ${ }^{316}$ Während eines Besuches im Sommer 1924 bei dem von ihm hoch verehrten Frank Lloyd Wright in Taliesin entstand auch sein Wettbewerbsbeitrag für die Hietzinger Synagoge. Wie bereits im einschlägigen Kapitel angeführt, erhielt sein äußerst progressiver, funktionalistischer Entwurf zwar Anerkennung, gelangte aber nicht zur Ausführung (Abbildung I 2I). Gerade an diesem Projekt wird deutlich, wie weit sich Neutra damals bereits von der Wiener Szene, wo man noch einer spätsecessionistischen, expressionistischen Ausrichtung verpflichtet war, entfernt hatte. Im folgenden

3 I 5 Siehe dazu Visionäre und Vertriebene, zit. Anm. Io.

3 I6 R. Neutra, Wie baut Amerika, Stuttgart 1927. 


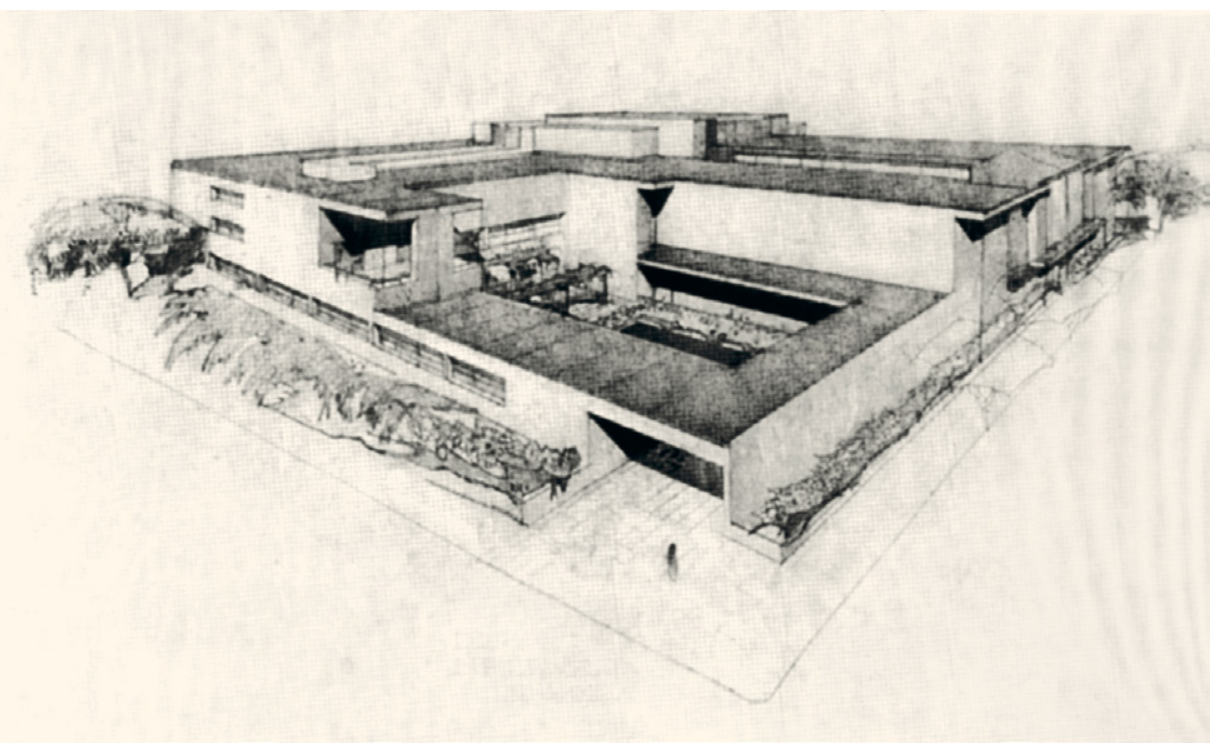

I 2 I. Richard Neutra, Entwurf Synagoge Hietzing, I924, nicht realisiert/Menorah I 929

Jahr übersiedelte Neutra nach Los Angeles und arbeitete kurzfristig im Atelier des gleichfalls aus Wien stammenden Rudolph Schindler, mit dem er seit seiner Zeit an der Bauschule von Adolf Loos befreundet war. Schindler seinerseits hatte einst an der Akademie bei Otto Wagner studiert und lebte bereits seit Beginn des Ersten Weltkrieges in den USA. I 926 erhielt Richard Neutra schließlich die Architektenlizenz für die USA und machte sich selbstständig. Einer seiner bedeutendsten Aufträge wurde das "Lovell Health House«, das den vom Reformarzt Dr. Lovell entwickelten Ideen einer modernen Lebensführung entsprechen sollte. In der unglaublich kurzen Zeit von vierzig Stunden in Stahlkonstruktion mittels vorgefertigter Teile errichtet, erzielte dieser Bau höchste Publizität und verhalf Neutra zu internationalem Ruhm.

Aufgrund des großen Interesses trat Neutra diverse Vortragsreisen an und betätigte sich publizistisch. 1932 beteiligte er sich an der von Henry Russell-Hitchcock und Philipp Johnson gestalteten legendären Ausstellung "Modern Architecture - International Exhibition", und im selben Jahr erhielt er eine Einladung aus Wien zur Mitarbeit an der Wiener Werkbundsiedlung. Gemeinsam mit seinem damals gleichfalls bereits in den USA lebenden Kollegen Arthur Grünberger stellte er sozusagen das US-amerikanische Kontingent der Werkbundsiedlung. Neutra, der damals bereits ein internationales Renommee hatte, errichtete in der Folge ein schlichtes Einfamilienhaus in der Woinovichgasse 9 mit einem begehbaren Flachdach und einer mediterran 
anmutenden Außentreppe, das sich weitgehend den Vorgaben des Siedlungsprojektes unterordnete. Nach diesem eher bescheidenen Wiener Intermezzo arbeitete Neutra weiterhin äußerst erfolgreich in den USA und konnte zahlreiche Großprojekte wie Siedlungen, Schulen, Krankenhäuser und anderes realisieren. Daneben setzte er auch seine intensive Vortragstätigkeit und sein publizistisches Engagement fort, wobei er obwohl er als ein bedeutender Vertreter des "international style« galt - seiner Zeit weit voraus war, die Natur als Basis der menschlichen Lebensweise propagierte und jeglichen dogmatischen Funktionalismus ablehnte. Neutra, der eine Unzahl von Ehrungen und Auszeichnungen erhielt, verbrachte einen Teil seines Lebensabends in den Sechzigerjahren in Wien, um schließlich auf einer Vortragsreise in Wuppertal I970 einem Herzversagen zu erliegen.

\subsection{Victor Gruen}

Die größte internationale Karriere machte jedoch Victor Gruen (1903-I980, Abbildung I22), der gleichfalls ungeachtet aller Widrigkeiten Wien nie ganz aus den Augen verlor. 1903 in Wien als Victor David Grünbaum geboren, ${ }^{317}$ gehört er zu den Jüngsten, die im Rahmen dieser Arbeit besprochen werden. Wie üblich besuchte Gruen zu seiner Ausbildung die Staatsgewerbeschule, wo er Rudolf Baumfeld kennenlernte, mit dem er sich anfreundete und der einen Großteil seines Lebensweges begleiten sollte. An der Schule wurde er allerdings auch mit dem aggressiven Antisemitismus deutschnationaler Schulkollegen konfrontiert. ${ }^{318}$ Auf eine ähnliche Situation dürfte er dann auch in der Meisterschule von Peter Behrens an der Akademie der bildenden Künste gestoßen sein, die er anfangs der Zwanzigerjahre besuchte. Immerhin hatte Behrens nur einige Jahre später an der Akademie eine illegale NS-Zelle ins Leben gerufen und arbeitete nach seinem Abgang nach Berlin mit Albert Speer zusammen. Es verwundert daher nicht, dass Gruen die Akademie bereits nach einem Jahr verließ. Viel wesentlicher war für ihn die Praxis in der Baufirma seines Vormundes. Vielseitig, wie er war, betätigte er sich auch als Mitbegründer des »Politischen Kabaretts", das von I926-I934 existierte und ihm zu einer gewissen Bekanntheit verhalf. Hier lernte er auch den jungen Kollegen Felix Slavik kennen, der späterhin als Bürgermeister für Gruens Wiener Planungstätigkeit eine Rolle spielen sollte. Im

3 I 7 Erst im Zuge der Erlangung der US-amerikanischen Staatsbürgerschaft änderte er seinen Namen in Gruen).

3 I 8 Victor Gruen, Biografischen Notizen, unpubliziertes Typoskript, angeführt bei O. Kapfinger, Victor Gruen und Rudolf Baumfeld, in: Visionäre und Vertriebene, zit. Anm. Io, S. 255. 


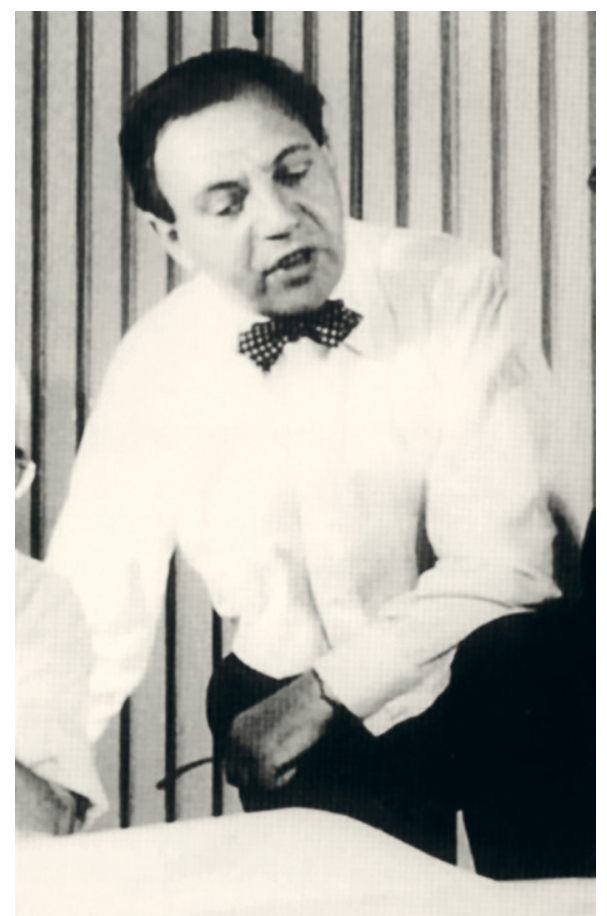

I22. Viktor Gruen, Porträt/Kat. Vertriebene

Umfeld des Kabaretts und dessen Klientel erhielt er auch seine ersten Aufträge, die sich jedoch - wie damals üblich - weitgehend auf Wohnungseinrichtungen und Geschäftsumbauten beschränkten, mit denen sich Gruen gerade so über Wasser halten konnte. Wie die meisten jungen Architekten dieser Zeit war auch er weitgehend von Adolf Loos beeinflusst. Als er das winzige Geschäftslokal der "Bristol Parfümerie« in der Kärntner Straße ausgestaltete, setzte er in der Art von Loos Spiegelfächen zur optischen Vergrößerung ein.

Nach dem "Anschluss" von 1938 gelang es ihm, nach Zürich zu fliehen, von wo er über Paris und London schließlich nach New York gelangte. Auch dort engagierte er sich für das Theater und gründete die "Refugee Artists Group", die insbesondere österreichische Literatur oder Themen aufgriff und innerhalb der Emigrantenszene Erfolge feierte. Als Architekt erhielt er ähnlich wie in Wien anfangs Aufträge für Geschäftseinrichtungen, die aufgrund ihrer Originalität schnell Furore machten und ihm schon bald zu größeren Aufgaben, etwa der Errichtung einer Kette von Läden für eine Damenkonfektionsfirma, verhalfen. Insbesondere nach seiner Übersiedlung nach Los Angeles 1942, wo er wieder auf Rudolf Baumfeld stieß, der sein Partner werden sollte, erfolgte sein atemberaubender Aufstieg. Neben Kaufhausketten und 
Department Stores errichtete er Mitte der Fünfzigerjahre mit dem »Milliron’s Department Store« das erste Shopping Center und schuf damit einen völlig neuen Bautypus - zahlreiche weitere Einkaufszentren sollten folgen. Gruen, der als Erfinder der Shopping Malls gilt, war jedoch späterhin, als diese Bauaufgabe unter ökonomischem Druck eine eigene Dynamik entwickelte, mit deren Entwicklung wenig zufrieden, hatte er sie doch ursprünglich nach dem Vorbild europäischer Stadtzentren als multikulturelle Begegnungsstätten angedacht. Von diesem kritischen Ansatz aus geriet Gruen auf das Gebiet der Stadtplanung und wurde zu einem Spezialisten für »City Revitalisation«, wobei die Idee einer autofreien Innenstadt sich zunehmend herauskristallisierte. Um der weltweiten Nachfrage nach seiner Planungstätigkeit zu genügen, gründete er 1965 die „Victor Gruen International«, die vor allem auch Projekte für europäische und asiatische Städte ausarbeitete. 1968 zog er sich allerdings bereits von dem Unternehmen zurück.

Offenbar um eine Studie zur Errichtung eines neuen Stadtteiles am Wienerberg zu erstellen, eröffnete er 1967 wieder ein Büro in Wien. Kurz darauf, 1969, erhielt er den Auftrag zur Ausarbeitung eines Konzeptes zur Revitalisierung der Wiener City, die im Zuge des U-Bahn-Ausbaus notwendig geworden war. Von seinen in den Stadtkern tief eingreifenden Plänen wurde aber schließlich nur ein Bruchteil, so etwa die Fußgängerzone Kärntner Straße/Graben, umgesetzt. Nicht nur, dass seine Pläne für die Innenstadt weitgehend nicht zur Ausführung gelangten, Gruen stieß - ungeachtet seiner internationalen Erfolge - auch sonst in Wien auf die üblichen Widerstände. Sein Vorentwurf für die UNO-City wurde, obwohl mit einem I. Preis ausgezeichnet, schon bald ausgeschieden, und die Wiener Architektenkammer wollte ihm aufgrund kleinlicher formalrechtlicher Gründe sogar die Architektenlizenz absprechen. Auch wenn Gruen 1971 den Preis der Stadt Wien für Architektur und 1978 das "Goldene Verdienstzeichen der Republik« für sein Lebenswerk erhielt, bleibt ein bitterer Nachgeschmack. Nur zwei Jahre später verstarb Gruen in seiner Geburtsstadt. 


\section{Die endgültige Auslöschung}

Fast nirgendwo wurde auf "Reichsgebiet" die Judenpolitik des NS-Regimes mit so großer Vehemenz betrieben wie in Wien. Bereits 1943 konnte Reichsstatthalter Baldur von Schirach stolz melden, dass Wien »judenrein « sei. In der Folge brachen Adolf Eichmann und sein Team, die die Deportationen durchgeführt hatten, ihr Wiener Büro ab und übersiedelten nach Berlin, um dort ihre grausame Tätigkeit fortzusetzen. Schließlich haben in Wien von rund I 80.000 nur ein paar Hundert Juden überlebt, neben einigen wenigen Mitarbeitern der IKG und einigen "U-Booten (landläufige Bezeichnung für Personen die in die Illegalität abgetaucht sind) « vor allem Personen, die aufgrund einer "Mischehe" (NS- Bezeichnung für eine Ehe zwischen Juden und Nichtjuden) geschützt waren. Dessen ungeachtet erfolgte auch nach dem Zusammenbruch des "Dritten Reiches" und der Beendigung des Krieges keineswegs ein Neuanfang - ganz im Gegenteil ging die Diskriminierung ungebrochen weiter. Als sich nach den ersten chaotischen Nachkriegsjahren die Verhältnisse allmählich zu stabilisieren begannen und im Dezember 1947 im Zuge einer Währungsreform die Reichsmark abgeschafft und der Schilling wieder eingeführt wurde, konnten auch die Hilfsgelder aus dem Marshall-Plan nach Österreich fließen, und es setzte schon relativ bald ein großer Bauboom ein. In Wien galt es in erster Linie die durch Bombardements zerstörten Gebäude wieder aufzubauen und vor allem auch das alte Übel der Wohnungsnot durch intensiven Wohnbau zu lindern. Infolge des Umstandes, dass nicht wenige der Architekten gefallen waren, kriegsbedingt mehrere Jahrgänge von Absolventen fehlten und insbesondere die jüdischen Kollegen vertrieben worden waren, herrschte großer Mangel an Fachkräften. Dies führte dazu, dass nicht wenige rüstige Pensionisten sich wieder ins Berufsleben stürzten. Auch die durch ihre Tätigkeit in der NS-Zeit belasteten Architekten konnten äußerst schnell und leicht ihre Entnazifizierung durchsetzen; oftmals wurde eine Parteimitgliedschaft mit fadenscheinigen Argumenten überhaupt abgestritten. So kam es, dass Leute, die intensiv für die diversen NS-Organisationen, etwa den Reichsnährstand, die Organisation Todt und andere mehr, gearbeitet, ja sogar KZs geplant oder Professuren innegehabt hatten, schon bald wieder an den wichtigen Schaltstellen saßen und sich die großen Projekte zuschoben. So manches Architektenbüro war in den Fünfzigerjahren mit Aufträgen überhäuft, wie es seit Jahrzehnten in Wien nicht mehr der Fall gewesen war.

Angesichts dieser personellen Kontinuität verwundert es nicht, dass man trotz Fachkräftemangel keineswegs daran dachte, die aus Wien vertriebenen Architekten zurückzuholen. Ganz im Gegenteil machte man den wenigen, die versuchten, wieder Fuß zu 
fassen, die größten Schwierigkeiten. Obwohl in den einzelnen Biografien bereits angeführt, ist es doch notwendig, einige dieser beschämenden Vorkommnisse hier nochmals kurz zusammenzufassen. Der Erste, der diese betrübliche Erfahrung machen musste, war Josef Frank. Als man Ende 1948 im Rahmen des Wiederaufbauprogramms eine Neustrukturierung des stark zerstörten Stephansplatzes in Angriff nahm, wurde er seitens der liberalen österreichischen CIAM-Gruppe eingeladen, seine Ideen einzubringen, da er sich bereits im Frühjahr in einem Zeitungsartikel mit dieser Problematik auseinandergesetzt hatte - was nicht zuletzt von seiner Verbundenheit mit seiner Heimatstadt zeugt. Frank unterbreitete in der Folge drei alternative Vorschläge, von denen jedoch keiner weiter verfolgt wurde. ${ }^{319}$ Noch vor rund fünfzehn Jahren einer der führenden Architekten in Wien, wurde Frank jetzt still und leise zur Seite geschoben. Gerne versteckte man sich hinter formalrechtlichen Argumenten und gab vor, dass die Emigranten jetzt keine österreichischen Staatsbürger mehr seien und ihnen daher auch keine Architektenbefugnis zustehe. Ein Unrechtsbewusstsein gab es nicht, noch weniger die Vorstellung einer ideellen Wiedergutmachung. Auch Walter Sobotka, der in ständigem Briefwechsel mit Josef Frank stand und sich gleichfalls bemühte, den Kontakt mit seiner Heimatstadt wieder herzustellen, musste diese Erfahrung machen. Als er Anfang der Fünfzigerjahre für einige Monate nach Wien kam, übernahm er die Planung für das Bürogebäude der Veitscher Magnesitwerke auf dem Schubertring. Allerdings hatte er auf dessen Ausführung aus oben genannten Gründen keinerlei Einfluss, und sein Name schien auch nicht in den Bauakten auf. ${ }^{320}$ Das Unternehmen blieb daher ein Intermezzo und Sobotka kehrte unverrichteter Dinge in die USA zurück. Ähnlich erging es auch Ernst Lichtblau, der um 1960 mit einem Schulprojekt beauftragt wurde. Auch er musste einen österreichischen Partner hinzuziehen. Da Lichtblau, der bereits hochbetagt war, tragischerweise in seinem Hotel kurz vor der Fertigstellung des Baus einem Herzschlag erlag, blieb auch dieses Unterfangen ohne Folgen. Als völlig lächerlich und beschämend erwies sich schließlich die Haltung der Architektenkammer, als sie I970 (!) dem internationalen Stararchitekten Viktor Gruen die Lizenz absprechen wollte. Konsequenterweise wurden auch Restitutionen von in Österreich verbliebenem Besitz der Vertriebenen nur sehr zögerlich - wenn überhaupt - gehandhabt. Als Beispiel sei hier nur der Fall Oskar Wlach erwähnt. Als er Anfang der Fünfzigerjahre einen Antrag auf Restituierung der Firma "Haus \& Garten« stellte, die er bis 1938 betrieben hatte, wurde er abgewiesen. In einigen Fällen saßen sogar einige Wiener Architekten in den »arisierten « Wohnungen ihrer ehemaligen Kollegen. ${ }^{321}$

3 i9 Siehe Welzig, zit. Anm. I I, S. 229.

320 Offiziell firmierte Erich Boltenstern als Planverfasser.

32 I Siehe dazu Walzer, zit. Anm. 74. 
Nachdem man die Menschen vertrieben, beraubt und ermordet hatte, ging man schließlich auch daran, jegliche Erinnerung an das jüdische Leben in Wien auszutilgen und das noch verbliebene Kulturgut zu zerstören. Wie weit hier ein konsequenter Antisemitismus am Werk war oder es sich nur um Gedankenlosigkeit handelte, sei dahingestellt. Von den Synagogen und anderen Kulteinrichtungen, die nahezu alle bereits im großen Novemberpogrom von 1938 zerstört worden waren, wurden nach dem Krieg noch akribisch die letzten Reste beseitigt. Auch wenn von einigen durchaus noch eine gewisse Bausubstanz erhalten war, dachte man keineswegs daran, diese eventuell als Mahnmal zu erhalten, wie man es mit christlichen Kirchen, zum Beispiel in Coventry oder Dresden, gehandhabt hatte. In diesem Sinne wurden auch darüber hinaus weiterhin Bauten mit jüdischer Konnotation im großen Stile demoliert, wobei die verschiedensten Faktoren hineinspielten. Oftmals waren die Gebäude kriegsbedingt beschädigt, die Eigner vertrieben, die Funktion durch die Nichtexistenz einer jüdischen Gemeinde obsolet geworden und anderes mehr. Nicht selten dürfte jedoch auch schlichtweg die Motivation mitgespielt haben, unangenehme Erinnerungen auszulöschen. Auf den Gedanken, dass man hier einen Teil der Wiener Kulturgeschichte auslöschte und so manches Gebäude schon allein aus ideellen Gründen erhalten werden sollte, kam offenbar niemand. In erster Linie betraf dies den Namen Rothschild, der ganz besonders mit der Geschichte der Juden in Wien verknüpft war und für die Antisemiten eine hohe symbolische Bedeutung hatte. Beide der zwei Wiener Rothschild-Palais, die sich im noblen Viertel in der Nähe des Schlosses Belvedere befanden, wurden abgerissen, obwohl insbesondere das Palais Albert Rothschild in der PrinzEugen-Straße 20 zwar devastiert, aber keineswegs zerstört war. Gerade diesem Bau verhalfen die Nazis nach dessen »Arisierung" von 1938 zynischerweise zu einer besonders negativen Symbolik, indem sie während des Krieges hier neben anderen NSEinrichtungen die Zentralstelle für jüdische Auswanderung, die von Adolf Eichmann geleitet wurde, unterbrachten (Abbildung I23). Das verwahrloste Gebäude wurde nach dem Krieg an die Rothschilds restituiert, die es jedoch schnell wieder abstießen. Als das Palais 1954 abgerissen wurde, gab es - ungeachtet des Umstandes, dass der Bau um I 880 von dem Pariser Nobelarchitekten Hyppolite Destailleur im Stil eines französischen Schlosses errichtet worden war und damit auch in architekturhistorischer Hinsicht durchaus große Bedeutung hatte - offenbar keinerlei denkmalschützerische Einwendungen. ${ }^{322}$ Jetzt befindet sich an dessen Stelle das Gebäude der Arbeiterkammer (I957 von Franz Mörth sowie Heinrich und Kurt Vana errichtet). Das andere Palais, das im Besitz von Nathaniel Rothschild gewesen war (I87I

322 Hyppolite Destailleur (I 822-I 893) plante für die Rothschilds auch Waddesdon Manor in England, das bis heute existiert. 


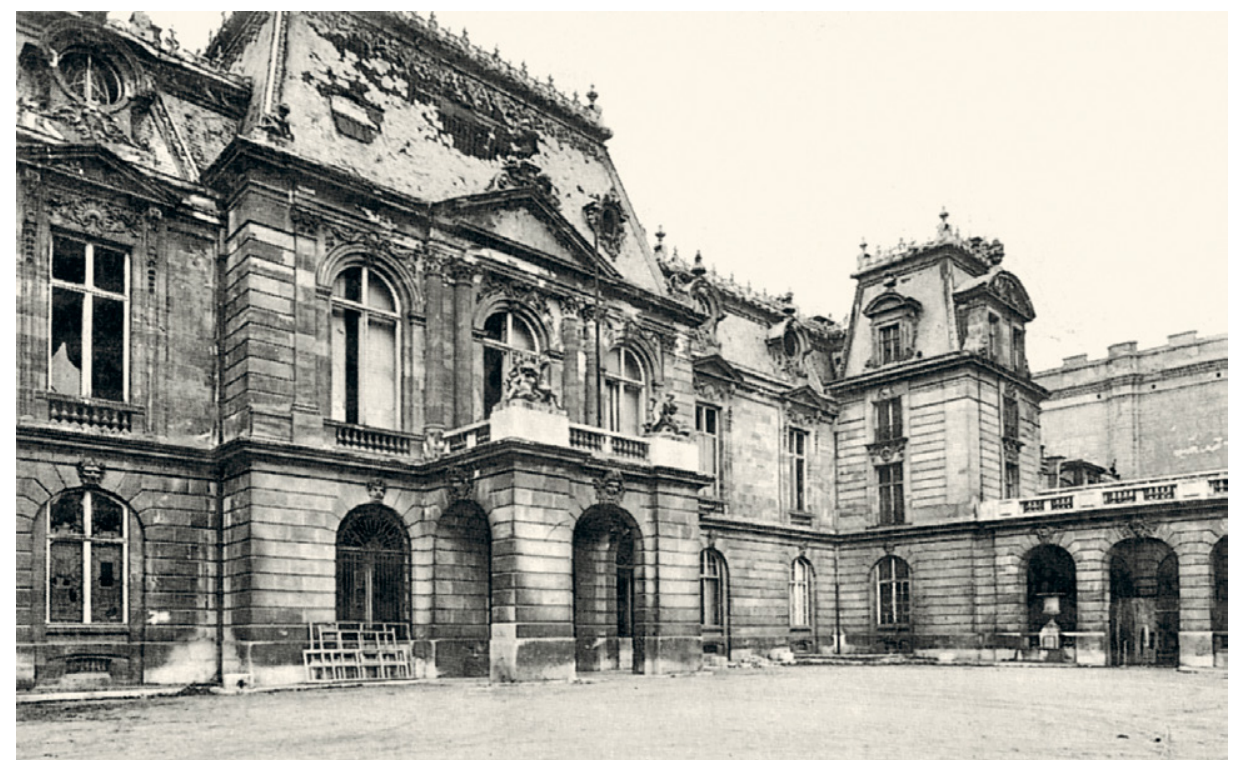

I23. Palais Albert Rothschild, Architekt Hyppolite Destailleur, erbaut um I880, Zustand I954 (nicht erhalten)/Internet

von Jean Girette erbaut) und sich in der Theresianumgasse 16 befand, war durch Bombenschäden massiv zerstört worden. Nach der Restitution und dem Verkauf der Immobilie an den Gewerkschaftsbund wurde hier I95 I von Roland Rainer das FranzDomes-Lehrlingsheim errichtet, das inzwischen nicht mehr existiert. Heute befindet sich hier das Adolf-Czettel-Bildungsheim (I986 nach Plänen von Rudolf Jarosch erbaut). Ähnlich erging es auch den Gebäuden der diversen sozialen Einrichtungen der Rothschilds, darunter das berühmte Rothschild-Spital am Währinger Gürtel, in dem Medizingeschichte geschrieben wurde. Das Spital wurde I870/7I nach Plänen von Wilhelm Stiassny errichtet und späterhin mehrmals ausgebaut, sodass es medizinisch immer auf der Höhe der Zeit war. Unter anderen waren hier Kapazitäten wie der Choleraspezialist Leopold Oser, der Urologe Otto Zuckerkandl und der junge Viktor Frankl tätig. Der Spitalsbetrieb wurde auch nach dem »Anschluss« trotz massiver Einschränkungen bis 1942 aufrechterhalten. Nach dem Krieg diente das Gebäude einige Jahre als Durchgangslager für jüdische Auswanderer und wurde schließlich in den Fünfzigerjahren abgerissen. Jetzt befindet sich der große Komplex des Wirtschaftsförderungsinstituts an dessen Stelle.

Im Belvedere-Viertel wurden noch weitere noble Palais, die ehemals jüdische Eigentümer hatten, ohne weitere Bedenken abgerissen, wie das Palais Wittgenstein in 


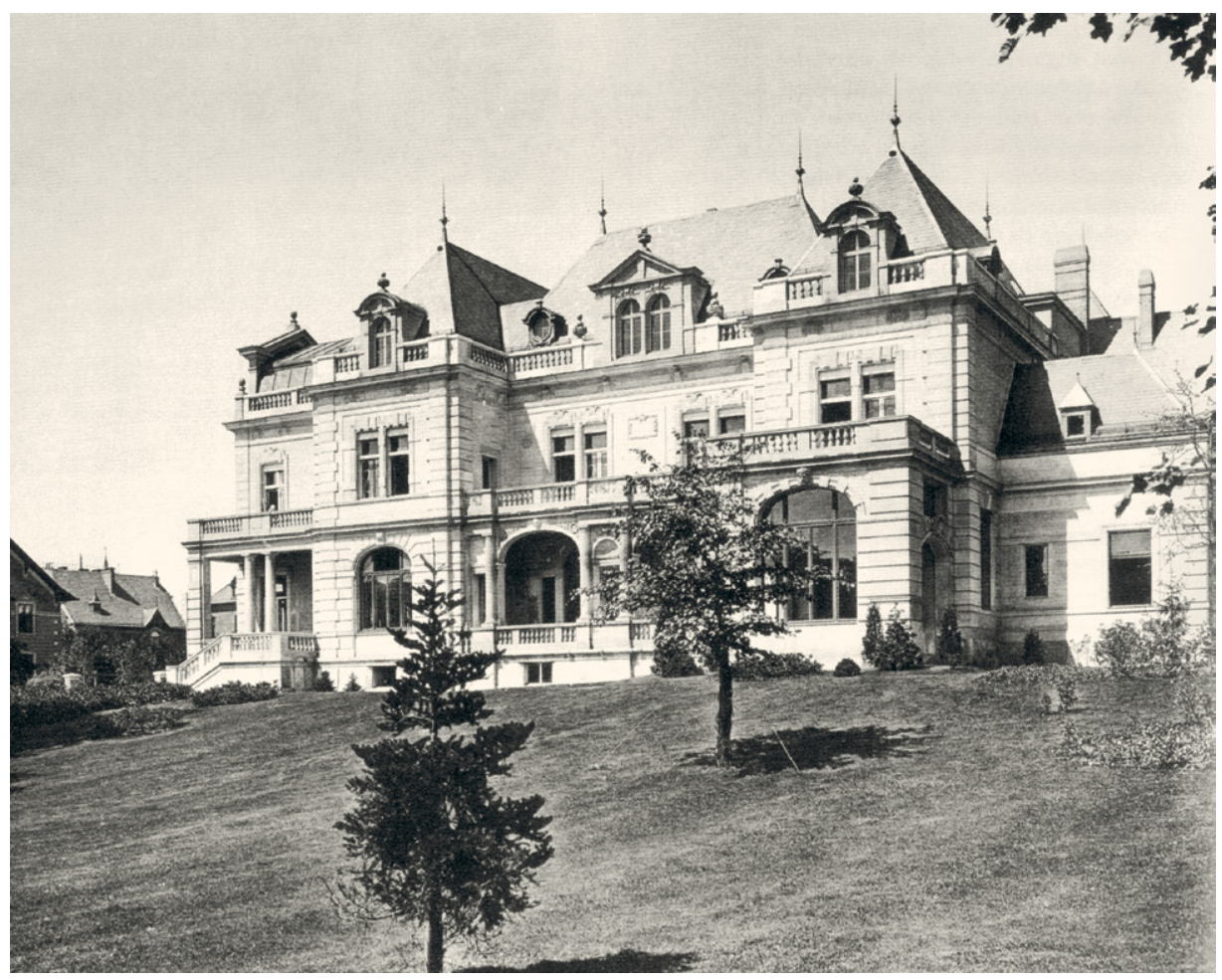

I 24. Karl König, Villa Kuffner, Wien I9, Gymnasiumstraße 85, erbaut I 905/8 (nicht erhalten)/Internet

der Alleegasse, wo der junge Ludwig Wittgenstein aufgewachsen war, oder das ehemalige Palais Castiglioni in der Prinz-Eugen-Straße. ${ }^{323}$ Während man hier noch argumentieren kann, dass diese Gegend gegen Kriegsende durch ihre Nähe zum Südbahnhof besonders intensiv der Bombardierung ausgesetzt und dadurch viele Bauten beschädigt waren, so lässt sich das jedoch für Objekte, die sich in vom Krieg kaum betroffenen Villengegenden, wie Währing und Döbling, befanden, keineswegs behaupten. Dies trifft insbesondere auf das Palais Kuffner (Wien I9, Peter-JordanStraße I) zu, das den Krieg praktisch unbeschädigt überstanden hatte (Abbildung I 24). Wie bereits angeführt, wurde der Bau I905 von Karl König im Stil der französischen

323 Das Palais Wittgenstein (ehemals Alleegasse, jetzt Argentinierstraße I6) wurde I 872 für den Grafen Nako von Friedrich Schachner errichtet, jetzt befindet sich dort ein moderner Wohnbau. Das Palais Castiglioni (ursprünglich Miller-Aichholz, Prinz-Eugen-Straße 36) wurde I 877 nach Plänen von Andreas Streit erbaut. 


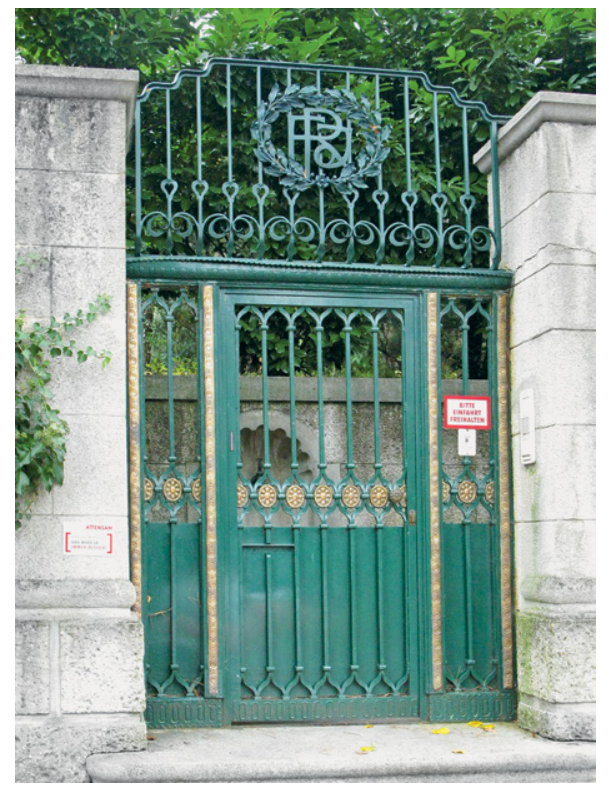

I25. Villa Regenstreif, Architekt Friedrich Ohmann, Wien I 8, Starkfriedgasse I4, erbaut I91 5/16 (nicht erhalten), Detail des Tores mit Initialen/Prokop

Renaissance errichtet und ist als einer der Höhepunkte in seinem Schaffen anzusehen. ${ }^{324}$ Der Bauherr Wilhelm Kuffner gehörte der berühmten Braudynastie an, die die Ottakringer Brauerei fast hundert Jahre äußerst erfolgreich betrieben hatte. Sein Vater Ignaz, einer der Mitbegründer des Unternehmens, war sogar in den Siebzigerjahren des I9. Jahrhunderts - vor der Eingemeindung des Vorortes - Bürgermeister von Ottakring gewesen und hatte sich als Wohltäter um die Gemeinde verdient gemacht. Wilhelms älterer Bruder Moritz, der das Unternehmen bis zur »Arisierung" leitete, hatte seinerzeit als begeisterter Hobbyastronom die "Kuffner-Sternwarte« finanziert - eine der letzten architektonischen Erinnerungen an die berühmte Familie. ${ }^{325}$ Die Brauerei wurde I938 um damalige I4 Millionen Schilling verschleudert und die Familie emigrierte in die Schweiz und die USA. Nach der Restituierung der Villa an die Erben wurde die Immobilie an die Gemeinde Wien verkauft, die das elegante Palais 960 abreißen ließ und an seiner Stelle ein Studentenheim errichtete.

Ein weiteres architektonisches Juwel aus ehemals jüdischem Besitz, das der Spitzhacke zum Opfer fiel, war die Villa Regenstreif (ehemals Wien I9, Starkfriedgasse I 5),

324 Auch Karl Königs Hauptwerk, der Philipp-Hof am Albertina-Platz, der im März 1945 durch einen Bombenangriff weitgehend zerstört wurde, ist heute nicht mehr existent.

325 Siehe dazu P. Habison, Der Brauherr als Bauherr - Moriz von Kuffner und seine Sternwarte, in: Astronomisches Mäzenatentum (hg. v. G. Wolfschmidt), Norderstedt 2008, S. I 3 Iff. 
I 26. Villa Beer-Hofmann, Architekt Josef Hoffmann, Wien i 8, Hasenauer Straße. 56, erbaut I $905 / 6$ (nicht erhalten)/Sekler

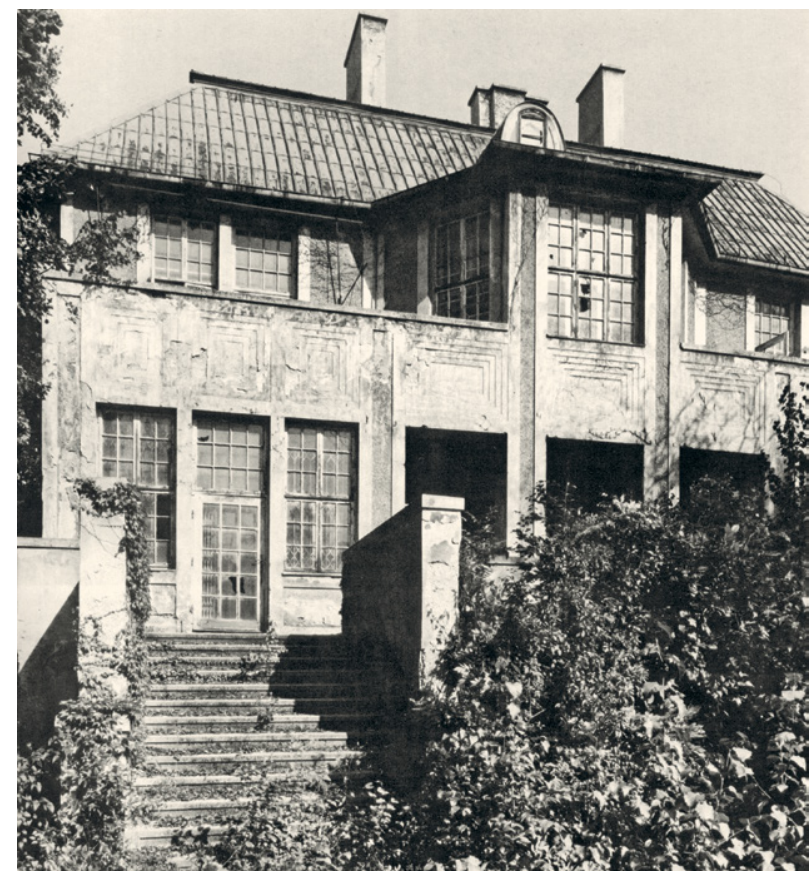

die der Jugendstilarchitekt Friedrich Ohmann (I 8 58-1927) für den Holzindustriellen Fritz Regenstreif um I9I 4 erbaut hatte. ${ }^{326}$ Ohmann, der insbesondere in Prag für eine Reihe von spektakulären Jugendstilbauten verantwortlich war und zeitweise auch den Ausbau der Wiener Hofburg leitete, war einer der Spitzenarchitekten seine Zeit. Die Villa Regenstreif, die auch eine durchgestaltete Gartenanlage mit einschloss, galt als einer der Höhepunkte in seinem Schaffen. Trotzdem nahm man einen bei Renovierungsarbeiten ausgebrochenen Dachstuhlbrand zum Vorwand, um die Liegenschaft abzureißen. Vereinzelte Relikte, wie das Eingangstor (Abbildung I25) oder das kleine Pförtnerhaus an der Pötzleinsdorfer Straße, zeugen noch von der vergangenen Pracht.

Im Hinblick auf ihre architektonische und kulturgeschichtliche Bedeutung ist auch die Villa Beer-Hofmann (Wien I 8, Hasenauer Straße 85) als Schlüsselwerk anzusehen. Nach ihrer "Arisierung« und in der Folge mehreren Besitzerwechseln wurde

326 Friedrich Ohmann, der des Öfteren für jüdische Auftraggeber arbeitete und auch etliche jüdische Schüler hatte (darunter Oskar Strnad), war selbst jedoch - ungeachtet seiner Herkunft aus Galizien kein Jude, wie manchmal in der Literatur behauptet wird. 
sie zunehmend dem Verfall überlassen und I 970 abgerissen. ${ }^{327}$ I $905 / 06$ von Josef Hoffmann für den Dichter Richard Beer-Hofmann (I 866-I945) errichtet, war sie seinerzeit eines der Zentren der Wiener Fin-de-Siècle-Kultur, wo unter anderen die mit Beer-Hofmann befreundeten Künstler Hugo von Hofmannsthal, Arthur Schnitzler und Herman Bahr ein und aus gegangen waren (Abbildung I 26). ${ }^{328}$ Die Villa, deren Errichtung in die fruchtbarste Zeit Josef Hoffmanns fällt, der damals auf dem Höhepunkt seines Schaffens stand, wäre als wichtiges architekturhistorisches Zeugnis unbedingt erhaltenswert gewesen. Obwohl sich in diesem Fall Widerstand regte, obsiegten letztlich die Bagger.

Aber nicht nur bedeutende Objekte aus der Zeit des Historismus und des Jugendstils wurden aus dem Stadtbild ausgelöscht, auch Zeugnisse der klassischen Moderne, wie das Gästehaus Heriot an der Rustenschacherallee - eines der progressivsten Projekte der Zwischenkriegszeit in Wien und Hauptwerk der Ateliergemeinschaft Dicker \& Singer -, existieren nicht mehr. Der gedankenlose Abriss jüdisch konnotierter Bauten setzte sich sogar - trotz eines allmählichen Wandels des gesellschaftlichen Bewusstseins - bis in die jüngste Zeit fort. Noch im Jahr 2000 wurde der sogenannte "Kai-Palast« abgerissen. Als architektonisches Wahrzeichen des jüdischen Textilviertels I 9 I I von Ignaz Reiser am Franz-Josef-Kai errichtet, war der Bau aufgrund seiner Ständerbauweise in Stahlbeton und seiner äußerst funktionalistischen Außenerscheinung damals ein bahnbrechendes Werk auf dem Weg zur Moderne der Zwischenkriegszeit. ${ }^{329}$ Obwohl sich eine Bürgerinitiative für die Erhaltung engagiert hatte und auch in den Medien heftig gegen den Abriss Stellung genommen worden war, wurde das angeblich baufällige Gebäude abgerissen und musste einem Neubau weichen. Im weitesten Sinn gehört auch die bis heute ungelöste Frage der Betreuung der jüdischen Friedhöfe in Wien in diesen Themenbereich.

327 Siehe dazu E. F. Sekler, Josef Hoffmann, Wien/Salzburg I982, S. $298 \mathrm{f}$.

328 I 999 widmete das Wiener Jüdische Museum diesem Thema eine Ausstellung mit dem Titel „Zu Gast bei Beer-Hoffmann".

329 U. Prokop, Zur architekturhistorischen Bedeutung des Kai-Palastes, in: Steine sprechen, Jg. XX$\mathrm{XIX/3}$, Juni 2000, Nr. II 8 . 


\section{Schlussbetrachtung}

Wenn man aus heutiger Sicht auf diese Periode der Beteiligung jüdischer ArchitektInnen am Wiener Baugeschehen blickt, so ist diese Zeitspanne, die rund siebzig Jahre umfasst, relativ kurz. Sie reicht von der frühen "Ringstraßenära" der Sechzigerjahre des 19. Jahrhunderts bis zum sogenannten "Anschluss" von 1938. Allerdings waren gerade diese Jahre prägend für das Stadtbild von Wien. Noch immer stammt ein Großteil aller Bauten aus dieser Zeit. Rund drei Generationen waren in diesem Zeitabschnitt tätig. Charakteristisch ist der Umstand, dass sich die erste Generation weitgehend aus Zuwanderern rekrutierte, die allerdings zumeist aus dem Raum um Pressburg oder den Kronländern Böhmen, Mähren und Galizien stammten und damit als Untertanen der »Donaumonarchie« Binnenmigranten waren. ${ }^{330}$ Die Integration erfolgte häufig sehr rasch, die folgende Generation war zumeist schon aus Wien gebürtig. Allerdings ist dies keinesfalls ein spezifisch jüdisches Phänomen, sondern traf - wenn auch in etwas geringerem Maß - auch auf nicht jüdische Architekten und Baumeister zu, die alle vom Sog der Wirtschaftskraft der Reichshauptstadt angezogen wurden.

Die sich relativ schnell wandelnde Stellung in der Wiener Architekturszene reflektiert in gewisser Weise auch die Situation der Wiener Juden generell - beginnend mit einigen Einzelgängern, wie dem aus Berlin zugewanderten Wilhelm Fraenkel, über die Etablierung der Gruppe der König-Schüler, die bereits ihren Anteil zur Ausformung der damaligen Moderne beitrug, bis zu maßgeblichen Persönlichkeiten - allen voran Josef Frank und Oskar Strnad -, deren Bedeutung zuletzt weit über die jüdische Gemeinschaft hinausging. Für diese Entwicklung ist auch der Einfluss von Persönlichkeiten wie Friedrich von Schmidt und Adolf Loos hervorzuheben, die beide als Nichtjuden in einer überwiegend antisemitischen Gesellschaft eine Art von Mittlerfunktion ausübten, indem sie vorurteilsfrei als Lehrer und geistige Väter wirkten und damit in der Wiener Architekturszene eine Art Katalysatorfunktion ausübten.

Von großem Interesse wäre es auch, mehr darüber zu wissen, welchen Schwierigkeiten und Animositäten die in einer eher feindlich eingestellten Umwelt lebenden und arbeitenden jüdischen Architekten ausgesetzt waren. Erstaunlicherweise geben die Quellen darüber relativ wenig Auskunft. Auf den ersten Blick scheint so manche

330 Obwohl damals wie heute landläufig im Gebrauch, gab es den Staat "Österreich" seinerzeit im eigentlichen Sinne nicht. Im Gegensatz zu Ungarn existierten nach dem Ausgleich von I 868 staatsrechtlich nur »die im Reichsrat vertretenen Kronländer« - oftmals auch als Cisleithanien apostrophiert. 
Biografie relativ "normal« verlaufen zu sein. In den zeitgenössischen Publikationen werden Arbeiten von Juden und Nichtjuden neben- und miteinander veröffentlicht. In manchen Anthologien schreiben - anscheinend vorurteilsfrei - Christen über Synagogen und vice versa Juden über Kirchen. ${ }^{331}$ Oberflächlich gesehen scheint es ein kollegiales Nebeneinander gegeben zu haben. Nur bei genauerer Analyse werden die Probleme und Konflikte sichtbar. So war es jüdischen Architekten praktisch verwehrt, in die Beamtenschaft aufgenommen zu werden, sei es in staatlichen Behörden, sei es in kommunalen Institutionen. ${ }^{332}$ In gleicher Weise gab es Schwierigkeiten, eine Professur zu erlangen. Auf die lange Wartezeit und die Vorbedingung des Austrittes aus der Kultusgemeinde wurde im Kapitel über Karl König bereits hingewiesen. Zweifellos haben diese Umstände dazu geführt, dass die meisten der jüdischen Architekten eher unter sich geblieben sind und auch überwiegend für jüdische Bauherren gearbeitet haben.

$\mathrm{Ob}$ und inwieweit sich diese Situation in der Zwischenkriegszeit entspannt hat, muss dahingestellt bleiben. Die Indizien sind sehr widersprüchlich. Oskar Strnad und Josef Frank erhielten zwar Professuren an der Kunstgewerbeschule, die jedoch als Institution in der Hierarchie der Unterrichtsstätten damals unter der Akademie der bildenden Künste und der Technischen Hochschule rangierte. ${ }^{333}$ Die Assimilation ging in diesen Jahren bereits so weit, dass es schließlich auch zu einigen Partnerschaften von Juden mit Nichtjuden kam, von den zahlreichen Konversionen und sogenannten "Mischehen" gar nicht zu sprechen. Andererseits zeigen einzelne Vorfälle, welche Feindseligkeiten den Juden - insbesondere auch seitens ihrer Kollegen entgegenschlugen. Dies insbesondere vor dem Hintergrund einer äußerst prekären wirtschaftlichen Situation. So beschreibt Viktor Gruen in seinen Erinnerungen die Ausfälle seiner antisemitischen Mitschüler an der Staatsgewerbeschule anfangs der Zwanzigerjahre. Auch der hässliche Streit im Rahmen des Wettbewerbs für ein Denkmal der Auslandshilfe I923, in dem Ernst Lichtblau heftigst angegriffen und sein in einer Ausstellung präsentiertes Modell schließlich zerstört wurde, spiegelt die Atmosphäre jener Jahre wider. Ihren Höhepunkt erreichten diese fachinternen Rivalitäten und Auseinandersetzungen schließlich I932, als es zum Zerfall des Österreichischen Werkbundes kam, der von einigen - insbesondere von Josef Hoffmann - offenbar als jüdisch dominiert empfunden wurde. Die Gründung des Neuen Werkbundes, in

33 I M. Paul, Technischer Führer durch Wien, Wien I9ro.

332 Im Wiener Stadtbauamt waren auch in den Zeiten des »Roten Wien« kaum jüdische Architekten tätig, und wenn überhaupt, dann vorübergehend als Praktikanten.

333 Anfang der Dreißigerjahre wurde der Kunstgewerbeschule sogar die Berechtigung für die Architektenausbildung entzogen und Strnads Studenten mussten ihren Abschluss an der Akademie machen ein Umstand, der ihn sehr kränkte. 
dem keine jüdischen Architekten mehr vertreten waren, bedeutete dann bereits den Anfang vom Ende, das dann nur einige Jahre später mit dem »Anschluss« definitiv eintrat.

Eine weitere Problematik ist die Frage nach einer spezifisch »jüdischen Architektur". Wie sehr dieses Thema auch unter den jüdischen Architekten diskutiert wurde und welch divergierende Meinungen es dazu gab, zeigte nicht zuletzt die Diskussion um einen genuin »jüdischen Stil« im Kontext des Synagogenbaus. Auch wenn wir heute längst nicht mehr in Kategorien des "Stiles« denken, so wäre es grundsätzlich von Interesse, ob sich bestimmte Tendenzen oder Positionierungen feststellen lassen, die von der Mehrheit der nicht jüdischen Kollegen abwichen. Auch diese Frage lässt sich aber kaum beantworten. Im Kontext der Ausformung der Moderne kann man nur feststellen, dass es unter Juden sowohl Vertreter einer konservativen Ausrichtung als auch zahlreiche Verfechter der Moderne gab (paradoxerweise setzten sich oft beide Gruppen aus Schülern Karl Königs zusammen), wobei sich die Waagschale aber zunehmend den neuen Tendenzen zuneigte. Insbesondere in der Zwischenkriegszeit gehörten Josef Frank und sein Umfeld im österreichischen Kontext zu den Vorreitern der Moderne. Frank war einer der wenigen, der sich auch den internationalen Bewegungen gegenüber öffnete (was ihm auch prompt Kritik einbrachte). Gesamteuropäisch gesehen, war Frank jedoch eher ein Konservativer, dessen Einrichtung im Rahmen der Stuttgarter Weißenhofsiedlung als typisch "Wienerisch" angesehen wurde. Dies zeigt, wie komplex und schwierig sich die Situation darstellt. Eventuell lässt sich im Rahmen der Bauten des "Roten Wien" eine gewisse Zurückhaltung bei den von jüdischen Architekten errichteten Wohnhausanlagen bemerken - im Gegensatz zu dem zu Pathos neigenden Monumentalismus der Schüler Otto Wagners, die nahezu alle nicht jüdischer Herkunft waren. Die Anlagen von Frank, Wlach, Strnad, Ella Briggs, Leopold Schulz, Berger \& Ziegler und anderen eint das Charakteristikum einer funktionellen Schlichtheit abseits jeglicher demonstrativer Gestik. Dies trifft nicht zuletzt auch auf das Werk von Ernst Lichtblau zu, ungeachtet dessen, dass er - ausnahmsweise - ein Schüler Otto Wagners war! Der Umstand, dass diese Architekten die verschiedensten Ausbildungsstätten absolviert hatten, lässt insofern den Versuch, diese Tendenz mit der Prägung durch eine bestimmte Schule zu erklären, etwas fragwürdig erscheinen. Aber auch aus dem Umstand der jüdischen Herkunft kulturell bedingte ikonoklastische Tendenzen abzuleiten, bleibt problematisch, wenn man sich die Bandbreite von den prächtig dekorierten Synagogen Stiassnys bis zur Hermetik des Wittgenstein-Hauses vor Augen führt. Jede Schlussfolgerung ist letztlich widerlegbar und kann immer nur Hypothese bleiben.

Wie auch immer, Wien verdankt diesen Persönlichkeiten eine Reihe von äußerst bemerkenswerten Bauten, von denen ungeachtet aller Zerstörungen noch immer ein 
großes Quantum vorhanden ist, das uns täglich umgibt und das wir zumeist unreflektiert wahrnehmen. Sie verdienen es, dass ihre Namen nicht der Vergessenheit anheimfallen. 


\section{Bibliografie}

\section{Quellenliteratur}

Anonymus, Das Judentum in der Baukunst, in: Zeitschrift für praktische Baukunst 38.1878, S. 3 If.

Augenfeld, Felix, Modern Austria. Personalities and Style. In: The Architectural Review 83.1938, S. I65ff.

Augenfeld, Felix, Nachruf Walter Sobotka, in: Die Presse 24.5.1972.

Dorn, Klemens (Hg.), Favoriten, ein Heimatbuch, Wien 1928.

Eisenberg, Ludwig, Das geistige Wien, Wien I 893.

Eisler, Max, Der Wettbewerb um eine Wiener Synagoge, in: Österreichs Bau- und Werkkunst 2.1925/26, S. Iff.

Eisler, Max, Ein neuer Judenfriedhof in Wien, in: Moderne Bauformen 26.1927, S. $498 \mathrm{ff}$.

Fayans, Stefan, Kunst und Architektur im Dienste des Totenkultes, in: Zeitschrift des Österreichischen Ingenieur- und Architektenvereines 60.1908, S. 593ff.

Fayans, Stefan, Betrachtungen über die moderne Baukunst, in: Zeitschrift des Österreichischen Ingenieur- und Architektenvereines 4.I 9 I I , Nr. 6, S. $3 \mathrm{ff}$.

Fellner von Feldegg, Ferdinand, Ein Denkmalskandal. Epilog zum Wettbewerb um das Denkmal für die Auslandshilfe in Wien, Wien/Leipzig o. J.

Wiener Architekten, Stefan Fayans, Wien/Leipzig 1930.

Festschrift zur 50 Jahr Feier der Technisch-gewerblichen Bundeslehranstalt Wien I, I880-I930, Wien I930.

Fischel, Hartwig, Bauanlagen der staatlichen Flüchtlingsfürsorge, in: Der Architekt 21.1916/I8, S. I 5 ff.

Fleischer, Max, Friedrich Freiherr v. Schmidt, Wien I 89I.

Fleischer, Max, Über Synagogen-Bauten, in: Zeitschrift des Österreichischen Ingenieur- und Architektenvereines 46.1894, H. I8, S. Iff.

Frank, Josef, Der Volkswohnungspalast, in: der aufbau I 926/27, S. Io7ff.

Frank, Josef, Das Haus als Weg und Platz, in: Der Baumeister 29.193 I, S. 3 I $6 f f$.

Frank, Josef, Die internationale Werkbundsiedlung, Wien 1932.

Gomperz, Ada, Die Dame kocht, in: profil, Bd. 2, I934, H. 2, S. 43 f.

Groag, Jacques/Russel, Gordon, The story of furniture, Ipswich o. J.

Halfon, Marcel, Das Wochenendhaus, Wien 1928.

Hofbauer, Josef/Baumgarten, Wilhelm, Projekte und ausgeführte Bauten, Wien I93 I. 
Hoffmann, Else, Eine moderne Zweizimmerwohnung von Liane Zimbler, in: Innendekoration 40.1929, S. $38 \mathrm{ff}$.

Hoffmann, Else, Die Arbeiten einer Innenarchitektin, in: Innendekoration 42.I93 I, S. $290 f f$.

Husserl, Sigmund, Gründungsgeschichte des Stadttempels, Wien I 906.

Ilg, Albert, Die Zukunft des Barockstiles, Wien I88o.

Israelitische Kultusgemeinde (Hg.), Bericht der Kultusgemeinde Wien über die Tätigkeit in der Periode I929-32, Wien I932.

Karplus, Arnold, Neue Landhäuser und Villen in Österreich, Wien I9ı o.

Kohut, Adolph, Berühmte israelitische Männer und Frauen in d. Kulturgeschichte der Menschheit, I. Bd., Leipzig o. J.

Kulka, Heinrich, Adolf Loos, das Werk des Architekten, in: Neues Bauen in der Welt, Bd. 4, Wien I93 I.

Loos, Adolf, Heimatkunst I9 I4, in: Trotzdem, Wien 1982.

Loos, Adolf, Ins Leere gesprochen, Wien I 92 I.

Neutra, Richard, Wie baut Amerika, Stuttgart 1927.

Paul, Martin, Technischer Führer durch Wien, Wien I9ıo.

Riss, Egon, Die Raumverteilung - Die neue Stadt Wien, Wien I936.

Siller, Heinz, Wiener Architekten - Paul Fischl, Heinz Siller, Wien/Leipzig I 93 I.

Sobotka, Walter, Der gute billige Gegenstand, in: Ausstellungskatalog des Wiener Werkbundes, Wien I930/3 I.

Stiassny, Wilhelm, Freiherr v. Schmidt als Künstler und Lehrer, Wien I 89i.

Tietze, Hans, Die Juden Wiens, Wien I930.

Unger, Joseph, Die Arbeiterwohnhäuser in Wien Favoriten, in: Wochenschrift des Österreichischen Ingenieur- und Architektenvereines I I.I 886, S. $329 \mathrm{ff}$.

Urban, Gisela, Wie schaffen Wiener Architektinnen?, in: Neue Freie Presse I 5.2.1933 (Abendausgabe, S. 6).

Wagner, Otto, Moderne Architektur, Wien I 896.

Wagner, Richard, Das Judenthum in der Musik, in: Neue Zeitschrift für Musik, 3. u. 8. Sept. I 850.

Wiener Bauten im Style der Secession, 4 Bde., I902 I 908-2008.

Zimbler, Liane, Die rechte Lebensform, in: Innendekoration 36.1925, S. 260 of.

Zimbler, Liane, Die elegante Frau und die bescheidene Wohnung, in: Österreichische Kunst, 5.I934, H. i i, S. I 5 f.

Zimbler, Liane, Wohnung und Berufsstätte, in: Kunst 70.1934, S. $225 \mathrm{ff.}$ 


\section{Forschungsliteratur}

Achleitner, Friedrich, Der Österreichische Werkbund und seine Beziehungen zum Deutschen Werkbund, in: L. Burckhardt (Hg.), Der Werkbund in Deutschland, Österreich und der Schweiz, Stuttgart 1978.

Achleitner, Friedrich, Die geköpfte Architektur, in: Die Vertreibung des Geistigen (Kat.), Wien 1985.

Achleitner, Friedrich, Österreichische Architektur im 20. Jahrhundert, Bd. Wien III/ I3, Wien/Salzburg I990-20I0.

Aichelburg, Wladimir, Das Wiener Künstlerhaus, I 50 Jahre, I 86I-200 I, I. Bd., 2003. Bakaczy, Judith (Hg.), Paul Engelmann und das mitteleuropäische Erbe, Wien/Bozen o. J. [1999].

Bastl, Beatrix, Wiener Jugendstilvestibüle, in: Zeitreisen Syrien-Palmira-Rom (hg. v. B. Bastl u. a.), Wien 2010, S. $37 \mathrm{ff}$.

Benton, Charlotte, A different world. Emigre architects in Britain I928-1958 (Kat.), London 1995 .

Bernard, Erich/Feller, Barbara, Unbekannte Wiener Moderne. Die Malfatti-Siedlung von Siegfried Drach, in: architektur aktuell, H. I 80, Juni 1995, S. $74 \mathrm{ff}$.

Bedoire, Fredric, The Jewish contribution to modern architecture 1830-1930, Stockholm 2004.

Boeckl, Matthias (Hg.), Visionäre und Vertriebene (Kat.), Wien I995.

Bogner, Dieter, Friedrich Kiesler, Wien 1998.

Bolbecker, Siglinde (Hg.), Frauen im Exil, Klagenfurt 2007.

Bösel, Richard, (Hg.), Der Michaelerplatz in Wien (Kat.), Wien I99 I.

Botstein, Leon, Judentum und Modernität, Wien/Köln I99I.

Brandstetter, Jutta, Karl König I84I-I9I 5. Das architektonische Werk, Dipl.-Arb., Wien 1996.

Erbanova, Eva u. a. (Hg.), Slavné vily, jihočesko kraje, Praha 2007.

Faber, Elfriede, Max Fleischer und die Synagoge in der Neudeggergasse, in: Verlorene Nachbarschaft (hg. v. Käthe Kratz), Wien I 999.

Fischer, Lisa, Die Riviera an der Donau, Wien u. a. 2004.

Fischer, Lisa/Köpl, Regina, Sigmund Freud. Wiener Schauplätze der Psychoanalyse, Wien u. a. 2005.

Gaugusch, Georg, Wer einmal war, Wien 20 I I.

Genée, Pierre, Synagogen in Wien I825-I938, Wien 1987.

Genée, Pierre, Synagogen in Österreich, Wien 1992.

Gmeiner, Astrid/Pirhofer, Gottfried, Der Österreichische Werkbund, Salzburg/Wien 1985. 
Gold, Hugo, Die Geschichte der Juden in Wien, Tel Aviv 1966.

Gombrich, Ernst, Jüdische Identität und jüdisches Schicksal, Wien I997.

Graf, Otto Antonia, Die vergessene Wagnerschule, Wien I969.

Gräwe, Christina, Liane Zimbler, Dipl.-Arb., TU Berlin 2003.

Gruber, Karlheinz u. a. (Hg.), Ernst Epstein I 88 I-I938, Wien 2002.

Habison, Peter, Der Brauherr als Bauherr - Moritz von Kuffner und seine Sternwarte, in: Astronomisches Mäzenatentum (hg. v. G. Wolfschmidt), Norderstedt 2008.

Haiko, Peter u.a. (Hg.), Friedrich v. Schmidt. Ein gotischer Rationalist (Kat.), Wien I99I.

Hautmann, Hans/Hautmann, Rudolf, Die Gemeindebauten des Roten Wien I919I934, Wien I980.

International Biographical Dictionary of Central European Emigres I933-I945, New York I980f., 2. Bd.

Judiska Museet i Stockholm (Hg.), Josef Frank, Architekt och outsider, Stockholm 2007.

Klemmer, Klemens, Jüdische Baumeister in Deutschland, Stuttgart, I 998.

Klosterneuburg, Sonderband 2, Klosterneuburg 2007.

Koller, Gabriele (Hg.), Die Vertreibung des Geistigen aus Österreich, Wien 1985.

Kristan, Markus, Oskar Marmorek, Architekt und Zionist. I 863-ı 909, Wien/Köln/ Weimar 1996.

Kristan, Markus, Carl König, Wien 1999.

Lehne, Andreas, Wiener Warenhäuser I 856-I9I4, Wien I 990.

Long, Christopher, An Alternative Path to Modernism: Carl König and the architectural Education at the Vienna Technische Hochschule I890-I9I3, in: Journal of Architectural Education, Sept. 200 I, S. 2 Iff.

Makarova, Elena, Friedl Dicker (Kat.), Wien I 999.

Malleier, Elisabeth, Regine Ullmann und der Mädchenunterstützungsverein in Wien, in: Ariadne (Almanach d. Archivs der deutschen Frauenbewegung), H. 35, Mai I999, S. $28 \mathrm{ff}$.

Martens, Bob, Virtuelle Rekonstruktion dreier Synagogen von Max Fleischer in Wien, in: David 9.2007, H. 74.

Martens, Bob, Die zerstörten Synagogen Wiens, Wien 2009.

Meder, Iris, Offene Welten. Die Wiener Schule im Einfamilienhausbau I9 Io-I938, Phil. Diss., Stuttgart 2003.

Meder, Iris, "Formlos zu formen" - Oskar Strnad und seine Schule, in: Moderat modern (hg. v. J. Eiblmayer), Salzburg 2005.

Meder, Iris, Sachen wie sie eben geworden sind. Der Architekt Paul Fischl, in: David 2 I.2009, H. 83, S. $48 \mathrm{ff}$. 
Meder, Iris, Lebens- und Arbeitsbedingungen jüdischer Architekten in Österreich, in: A. Senarclens de Grancy/H. Zettelbauer (Hg.), Architektur. Vergessen - Jüdische Architekten in Graz, Wien/Köln u. a. 20 I I.

Meder, Iris/Fuks, Evi (Hg.), Oskar Strnad I 879-1935 (Kat.), Salzburg/München 2007. Melichar, Peter, Neuordnung im Bankwesen, Wien 2004, S. $368 \mathrm{ff}$.

Nierhaus, Andreas, Vorbild Frankreich. Die Paläste der Rothschilds im Wiener Belvedere-Viertel, in: Österreichische Zeitschrift für Kunst und Denkmalpflege 62.2008, H. I, S. $74 \mathrm{ff}$.

Nierhaus, Andreas/Orosz, Eva-Maria (Hg.), Werkbundsiedlung Wien I932 (Kat.), Wien 2012.

Österreichisches Biographisches Lexikon, Wien I $957 \mathrm{ff}$.

Ottilinger, Eva (Hg.), Wohnen zwischen den Kriegen. Wiener Möbel I9I4-I945, Wien 2009.

Plaisier, Peter, De leerlingen van Adolf Loos, Delft 1987.

Plakolm-Forsthuber, Sabine, Künstlerinnen in Österreich I 897-I938, Wien I 994.

Pressler, Monika (Hg.), Breton Duchamp Kiesler - Surreal Space 1947 (Kat.), Wien 2013.

Prokop, Ursula, Wien. Aufbruch zur Metropole, Wien/Köln I 994.

Prokop, Ursula, Zur architekturhistorischen Bedeutung des Kai-Palastes, in: Steine sprechen, Jg. XXXIX/3, Juni 2000, Nr. I I 8.

Prokop, Ursula, Margaret Stonborough- Wittgenstein, Wien/Köln/Weimar 2003.

Prokop, Ursula, Das Architekten- und Designer-Ehepaar Jacques und Jacqueline Groag, Wien u.a. 2005.

Prokop, Ursula, Zum Anteil österreichisch-jüdischer Architekten am Aufbau Palästinas, in: Hintergrund 2008, Nr. 39, S. $35 \mathrm{ff}$.

Rayner, Geoffrey u. a., Jacqueline Groag (Kat.), Woodbridge 2009.

Rozenblit, Marsha L., Die Juden Wiens I867-I9I4, Wien/Graz I989.

Rozenblit, Marsha L., Segregation, Anpassung und Identitäten der Wiener Juden vor dem ersten Weltkrieg, in: Zerstörte Kultur (hg. v. G. Botz u. a.), Wien 2002.

Rukschcio, Bernhard/Schachel, Roland, Adolf Loos, Salzburg/Wien I 982.

Satoko, Tanaka, Wilhelm Stiassny. Synagogenbau, Orientalismus u. jüdische Identität, Phil. Diss., Wien 2009.

Sarnitz, August, Ernst Lichtblau, Architekt I883-1963, Wien u.a. I994.

Scheidl, Inge, Schöner Schein und Experiment. Katholischer Kirchenbau im Wien der Jahrhundertwende, Wien/Köln/Weimar 2003.

Schneider, Ursula (Hg.), Paul Engelmann - Architektur - Judentum, Wien/Bozen I999.

Schorske, Carl, Fin-de-siècle Vienna, Melbourne I987.

Sekler, Eduard F., Josef Hoffmann, Wien/Salzburg 1982. 
Shapira, Elana, Assimilation with Style. Jewish Assimilation and Modern Architecture and Design, Phil. Diss., Wien 2004.

Sisa, Jozsef, Neo-Gothic Architecture and Restauration of Historic Buildings in Central Europe. Friedrich Schmidt and his school, in: The Journal of the Society of Architectural Historians 6I, No. 2, June 2002, S. I7off.

Staudacher, Anna Lea, Jüdisch-protestantische Konvertiten in Wien I782-I9I4, 2 Bde., Wien 2004.

Steiner, Doris, Max Katscher, Dipl.-Arb., Wien 2004.

Stritzler -Levine, Nina (Hg.), Josef Frank, Architect and Designer, New York I996.

Tabor, Jan, Die Suche nach exakter Bestimmtheit, in: Wien aktuell, H. 3, Wien I 985 , S. 30 .

Tabor Jan (Hg.), Kunst und Diktatur, 2 Bde., Baden I994.

Unterweger, Ulrike, Die Synagoge in Hietzing, in: David, Sept. 2006, H. 70.

Wagenknecht, Christian, Karl Jaray, Rundschreiben 1928-I934, in: Karl-KrausHefte 52, Oktober I989.

Walzer, Tina/Templ, Stefan, Unser Wien. Arisierung auf Österreichisch, Berlin $200 \mathrm{I}$.

Wehdorn, Manfred/Georgeacopol-Winischhofer, Ulrike, Baudenkmäler der Technik und Industrie in Österreich, 2. Bd., Wien u. a. I99I.

Weihsmann, Helmut, Das Rote Wien, Wien 2002.

Weihsmann, Helmut, In Wien gebaut, Wien 2005.

Welzig, Maria, Josef Frank, Wien/Köln I 998.

Widtmann, Georg, Ein Blick zurück. Abriss der Geschichte des Österreichischen Ingenieur- und Architektenvereines, in: ÖIAV I 43.I 998, H. 7 (Festschrift I 50 Jahre Österreichischer Ingenieur- und Architektenverein).

Wijdeveld, Paul, Ludwig Wittgenstein, Architekt, Cambridge/Mass. I 994.

Wistrich, Robert S., Die Juden Wiens im Zeitalter Kaiser Franz Josephs, Wien/Köln/ Weimar I 999.

Zatloukal, Pavel, Neumann Tropp - autor prvnich secesnich domů v Olomouci, in: Židovska obec Brno 20 I I (www.zob.cz).

Zickler, Tina (Hg.), Brüder Schwadron. Call to mind, Wien 2014.

\section{Zeitschriften}

Allgemeine Bauzeitung

The Architectural Review

Architects Journal

Der Architekt 
Architektur aktuell

der aufbau

Der Baumeister

Der Bautechniker

Berliner Architekturwelt

David. Jüdische Kulturzeitschrift

Dr. Blochs Wochenschrift

Das Interieur

Menorah

Moderne Bauformen

Neue freie Presse

Österreichische Kunst

Die Presse

profil

Die Reichspost

Volkszeitung

Wiener Bauhütte

Wiener Bauindustriezeitung

Zeitschrift des österreichischen Ingenieur- und Architektenvereines

Zeitschrift für praktische Baukunst

\section{Internetlinks}

www.2onb.ac.at/ariadne (frauenspezifische Datenbank der Österreichischen Nationalbibliothek)

www.architektenlexikon.at (Architektenlexikon Wien I770-I945)

www.centropa.org (Datenbank zur jüdischen Geschichte)

www.dasrotewien.at (Lexikon der Sozialdemokratie)

www.doew.at (Datenbank des Dokumentationszentrums des Österreichischen Wi-

derstandes, zitiert als DÖW/Deportiertenliste)

www.jarayfamily.net (Geschichte der Familie Jaray)

\section{Archive und ihre Abkürzungen}

Archiv der Technischen Universität Wien (TUWA)

Archiv der Akademie der bildenden Künste 
Archiv der Universität für angewandte Kunst

Archiv des Österreichischen Ingenieur- und Architektenvereines (ÖIAV)

Archiv der Baumeisterinnung

Archiv der Genossenschaft der bildenden Künstler Wiens

Israelitische Kultusgemeinde Wien (IKG), Matrikenstelle

Archiv des Dokumentationszentrums des Österreichischen Widerstandes (DÖW) 


\section{Abbildungsverzeichnis}

I. Wilhelm Fraenkel, Porträt/ÖIAV

2. Wilhelm Fraenkel, Miethaus, Wien I, Schottenbastei 4, erbaut um I 870/Kulturgut

3. Wilhelm Fraenkel, Hotel Sacher, Wien I, Philharmonikerstraße 4, erbaut I 876 / Allgemeine Bauzeitung

4. Josef Unger, Arbeiterwohnhäuser, Wien Io, Kiesewettergasse 3-I 5, erbaut um I 886/Prokop

5. Max Fleischer, Büste über dem Eingang des Wiener Rathauses/Prokop

6. Max Fleischer, Synagoge, Wien 8, Neudeggergasse I2, erbaut I903 (nicht erhalten)/Der Bautechniker

7. Wilhelm Stiassny, Porträt/ÖIAV

8. Wilhelm Stiassny, Synagoge »Poln. Schul«, Wien 2, Leopoldsgasse 29, erbaut I 893 (nicht erhalten)/Allgemeine Bauzeitung

9. Wilhelm Stiassny, Jubiläumssynagoge, Prag, Nove Mesto, Jeruzalemska 7, erbaut I 906/Prokop

ı o. Wilhelm Stiassny, Miethaus, Wien I, Rudolfsplatz ı, erbaut I88 I/Wiener Bauindustriezeitung

I I. Jakob Modern, Porträt/Wiener Bauhütte I9 I 2

I2. Jakob Modern, Synagoge, Wien I 8, Schopenhauerstraße 39, erbaut I889 (nicht erhalten)/Allgemeine Bauzeitung I 892

I 3. Jakob Modern, »Servitenhof «, Wien 9, Berggasse 25, erbaut 1904/Prokop

I4. Jakob Gartner, Porträt/ÖIAV

I 5. Jakob Gartner, Synagoge, Wien ro, Humboldtgasse 27, erbaut I 896 (nicht erhalten)/Wikipedia

I6. Jakob Gartner, Miethaus, Wien I, Stubenring 2, erbaut I905/Wiener Bauindustriezeitung I 907

I7. Karl König, Porträt/Wiener Bauhütte I9 2

I 8. Karl König, Synagoge, Wien I 5, Turnergasse 22, erbaut I872 (nicht erhalten)/ Wikipedia

I9. Karl König, Philipp-Hof, Wien I, Augustinerstraße 8, erbaut um I884 (nicht erhalten)/Architektonische Rundschau

20. Karl König, Haus d. Industrie, Wien 3, Schwarzenbergplatz 4, erbaut um I906/ Prokop 
2 I. Maximilian Katscher, Warenhaus Herzmansky, Wien 7, Stiftgasse 3, erbaut um I 898/Wiener Bauindustriezeitung I 899

22. Oskar Marmorek, Porträt/Kristan, Central Zionist Archives, Jerusalem (?)

23. Oskar Marmorek, Nestroy-Hof, Wien 2, Praterstraße 34, erbaut I898/Der Architekt 1900

24. Oskar Marmorek, Rüdiger-Hof, Wien 5, Hamburgerstraße 20, erbaut I902/Der Architekt I903

25. Arthur Baron, Residenzpalast, Wien I, Fleischmarkt I, erbaut I9ı/Der Bautechniker

26. Arthur Baron, Druckereigebäude Steyrermühl, Wien I, Fleischmarkt 3, erbaut I9 $13 /$ Prokop

27. Emmerich Spielmann u. Alfred Teller, Tuchlaubenhof, Wien I, Tuchlauben 7, erbaut I9 I 2/Der Bautechniker I9 I 2

28. Arnold Karplus, Miethaus, Wien I4, Nisselgasse I, erbaut I9 I 2/Kulturgut

29. Arnold Karplus, Villa Krasny, Wien I9, Fürfanggasse 5, erbaut I928/Moderne Bauformen

30. Ludwig Schmidl, Schulhaus d. israelitischen Mädchenunterstützungsvereines, Wien 9, Seegasse I6, erbaut I 909/Prokop

3 I. Ernst Gotthilf, Krankenhaus d. Wiener Kaufmannschaft, Wien I9, Peter-JordanStraße 82, erbaut um I9 Iо (jetzt der Universität f. Bodenkultur zugehörig)/Kulturgut

32. Alexander Neumann u. Ernst Gotthilf, Wiener Bankverein, Wien I, Schottengasse 6, erbaut um i 9 Io (jetzt Bank Austria)/Der Architekt I9I9

33. Alexander Neumann u. Ernst Gotthilf, Palais Fanto, Wien 3, Schwarzenbergplatz 6, erbaut i 9 I 7/Prokop

34. Theodor Schreier u. Ernst Lindner, Entwurf Synagoge Triest, I 904 (nicht realisiert)/Wiener Bauindustriezeitung

35. Ernst Lindner, Porträtzeichnung von Hertha Karasek $1925 /$ privat

36. Theodor Schreier, Mietvilla, Wien I9, Linnéplatz 3, erbaut I9 Io/Prokop

37. Theodor Schreier u. Viktor Postelberg, Synagoge, St. Pölten, NÖ, Dr.-Karl-Renner-Promenade 22, erbaut I9 13/Prokop

38. Ernst Lindner, Doppelhaus I9, Huleschgasse 57, erbaut I9 I 2/Prokop

39. Oskar Marmorek, Entwurf einer Synagoge in Döbling, I9I 2 (nicht realisiert)/ Der Architekt

40. Julius Wohlmuth, Synagoge, Wien I9, Dollinergasse 3, erbaut I 907 (nicht erhalten)/Genée, Synagogen in Wien

4I. Julius Wohlmuth, Geschäftshaus, Wien I9, Grinzinger Allee I, erbaut I9 I3/Prokop 
42. Julius Wohlmuth (mit Heinz Rollig), Strombad, Kritzendorf, NÖ, erbaut I926/28/Prokop

43. Ignaz Reiser, Porträt/privat

44. Ignaz Reiser, Kai-Palast, Wien I, Franz-Josefs-Kai 57, erbaut I9I 2 (nicht erhalten)/Wiener Bauindustriezeitung

45. Ignaz Reiser, Synagoge, Wien 2, Pazmanitengasse 6, erbaut I9I 3 (nicht erhalten)/ Wiener Bauindustriezeitung

46. Ignaz Reiser, Eingangshalle der neuen israelitischen Abteilung des Wiener Zentralfriedhofes, Wien I I, erbaut I928 (teilw. erhalten)/Prokop

47. Arthur Grünberger, Synagoge, Wien I3, Eitelbergergasse 22, erbaut um I930 (nicht erhalten)/Katalog Visionäre und Vertriebene

48. Hartwig Fischel, Villa Mahler, Breitenstein Io2, Bez. Neunkirchen, NÖ, erbaut um i9 3 /Internet (Alma-Homepage)

49. Leopold Fuchs, Miethaus, Wien 7, Neubaugasse I 2, erbaut um I908/Prokop

50. Neumann Tropp, Porträt/privat

5 I. Neumann Tropp, Miethaus u. Amtsgebäude der Zahnradbahn, Wien I9, Nußdorfer Platz 5/Prokop

52. Ernst Epstein, Paulanerhof, Wien 4, Schleifmühlgasse 3, um I9 Io/Prokop

53. Ernst Epstein, Bürohaus Phönix, Wien 9, Otto-Wagner-Platz 5, erbaut 1928 (heute Sitz der OMV)/Kristan, Privatbesitz

54. Josef Frank, Porträt/Welzig

55. Josef Frank, Haus Scholl, Wien I9, Wildbrandtgasse 3, erbaut um I913/Wasmuths Monatshefte

56. Josef Frank, Wohnhausanlage, Wien I4, Sebastian-Kelch-Gasse I-3, erbaut um I $928 /$ Moderne Bauformen

57. Josef Frank, Haus Beer, Wien I3, Wenzgasse i 2, erbaut um I930/Welzig

58. Josef Frank, Doppelhaus in der Werkbundsiedlung, Wien I3, Woinovichgasse 32, erbaut I932/Wasmuths Monatshefte

59. Oskar Strnad, Porträt/Architekturzentrum Wien

6o. Oskar Strnad, Haus Wassermann, Wien I9, Ehrlichgasse 4, erbaut I9 I4/Welzig

61. Oskar Strnad, Doppelhaus in der Werkbundsiedlung, Wien I3, Engelbrechtweg 5-7, erbaut 1932 (nicht erhalten)/Meder

62. Oskar Wlach, Porträt/Architekturzentrum Wien

63. Oskar Wlach, Wohnhausanlage d. Gemeinde Wien, Wien ıo, Laaerbergstraße 22-24, erbaut um 1933/Moderne Bauformen

64. Walter Sobotka, Wohnhausanlage d. Gemeinde Wien, Wien 3, Schrottgasse IoI 2, erbaut I927/Prokop

65. Jacques Groag, Foto von Trude Fleischmann, um I950/privat 
66. Paul Engelmann, Porträt/Bakaczy (Edda Wolfner)

67. Paul Engelmann u. Ludwig Wittgenstein, Haus Wittgenstein (Palais Stonborough), Wien 3, Kundmanngasse I9, erbaut um I928/Wijdeveld

68. Jacques Groag, Villa Groag, Olmütz/Olomouc, Mozartova 36, erbaut 1927/privat

69. Jacques Groag, Interieur, um I932/Innendekoration

70. Jacques Groag, Doppelhaus in der Werkbundsiedlung, Wien I3, Woinovichgasse 5-7, erbaut I932/Moderne Bauformen

7I. Jacques Groag, Werkbundsiedlung, Einrichtung, I932/Moderne Bauformen

72. Felix Augenfeld, Porträt/Katalog Visionäre und Vertriebene

73. Felix Augenfeld, Espresso-Café »Tagesbar« der Wiener Werkbundausstellung, I930/Moderne Bauformen

74. Felix Augenfeld, Haus Strauss-Likarz, Kritzendorf, NÖ, Donaulände, erbaut I 928 (teilw. verändert)/Innendekoration

75. Felix Augenfeld, Haus Soffer, Wien I, Singerstraße 4, erbaut um I936/Katalog Visionäre und Vertriebene

76. Ernst Schwadron, Haus Lederer, Greifenstein, NÖ, erbaut 1927/Österreichs Bauund Werkkunst 1928

77. Josef Berger u. Martin Ziegler, Wohnhausanlage d. Gemeinde Wien, Wien 3, Schlachthausgasse 2-6, erbaut I926/Moderne Bauformen

78. Josef Berger u. Martin Ziegler, Haus Schur, Wien I9, Formanekgasse 32, erbaut I932/Prokop

79. Heinrich Kulka, Haus Weiszmann, Wien I3, Küniglberggasse 55, erbaut um I930/Prokop

8o. Ernst Lichtblau, Porträt/Sarnitz

81. Ernst Lichtblau, Schokoladenhaus, Wien I3, Wattmanng. 29, erbaut I9I4/Sarnitz (Spiluttini)

82. Ernst Lichtblau, Paul-Speiser-Hof, Wien 2 I, Franklinstraße 20 (Bauteil II), erbaut I929/Sarnitz (Spiluttini)

83. Ernst Lichtblau, Schule, Wien I6, Grundsteingasse 48, erbaut I962/63/Sarnitz (Spiluttini)

84. Karl Jaray, Porträt/Fam. Jaray

85. Karl Jaray, Villa Jaray, Wien I9, Langackergasse 22/Prokop

86. Siegfried Drach, Malfattisiedlung, Wien I3, Franz-Schalk-Platz I-I 5 , erbaut I930/32/Prokop

87. Siegfried Drach, Miethaus, Wien 3, Neulinggasse 52, erbaut 1933/35/Österreichische Kunst 1936 
88. Felix Angelo Pollak, Herz-Jesu-Schwesternschule, Wien 3, Landstr. Hauptstraße I 37A, erbaut I930/3 I/Prokop

89. Gustav Schläfrig, Porträt/privat

90. Gustav Schläfrig, Wohnhausanlage d. Eisenbahnergenossenschaft, 5, Gassergasse 33-35, erbaut 1929/32/Prokop

91. Paul Fischel, Porträt/privat

92. Paul Fischel u. Heinz Siller, Haus Spiro, Krumau/Česky Krumlov, CZ, erbaut I $922 / 24 /$ Prokop

93. Paul Fischel u. Heinz Siller, Kawafag Typenhaus, Kritzendorf, NÖ, um I 928/30/ Prokop

94. Fritz Judtmann u. Egon Riss, Ambulatorium d. Arbeiterkrankenkassa, Wien 3, Strohgasse 28, erbaut 1926/27/Kulturgut

95. Egon Riss, Miethaus, Wien I9, Heiligenstädterstr. 95, erbaut I936/Österreichische Kunst 1938

96. Wilhelm Baumgarten u. Josef Hofbauer, Gewerbliche Fortbildungsschule, Wien I5, Hütteldorfer Straße 7-I7, erbaut I925/26/Österreichs Bau- und Werkkunst I926

97. Wilhelm Baumgarten u. Josef Hofbauer, Komensky-Schule, Wien I 2, Erlgasse 32-34, erbaut 1930/3 I/Österreichische Kunst 1933

98. Rudolf Baumfeld \& Norbert Schlesinger, Geschäftsportal Trachtenmoden Lanz, Wien I, Kärntner Straße I o, erbaut I936 (Zustand 2014)/Prokop

99. Ella Briggs, Pestalozzi-Hof, Wien I9, Philippovichgasse 2-4, erbaut I 925/26/ Prokop

ıоo. Liane Zimbler, Porträt/Katalog Visionäre und Vertriebene

ıо . Liane Zimbler, Herrenzimmer, um I935/Österreichische Kunst

I02. Friedl Dicker, Porträt/Architekturzentrum Wien

I03. Friedl Dicker u. Franz Singer, Montessori-Kindergarten in der Wohnanlage des Goethehofes, Wien 22, Schüttaustraße I-39, I930 (nicht erhalten)/Österreichs Bau- und Werkkunst 1934

I 04. Friedl Dicker u. Franz Singer, Gästehaus Heriot, Wien 2, Rustenschacherallee, erbaut 1932/34 (nicht erhalten)/Dicker-Katalog

I05. Franz Singer, Porträt/Architekturzentrum Wien

I 06. Jacqueline Groag, Porträt/Deutsche Kunst und Dekoration I 930

I07. Jacqueline Groag, Textilentwurf/Deutsche Kunst und Dekoration I930

ı08. Ada Gomperz mit Erich Boltenstern, Inneneinrichtung des Werkbundsiedlungshauses von Hugo Häring, Wien I3, Engelbrechtweg Io, I932/profil

ıо9. Renate Wiener, Café Tirolerhof, Wien I, Führichgasse 8, errichtet um I928 (teilw. erhalten)/Moderne Welt I929 
I I o. Friedrich Schön, Porträt/Bezirksmuseum Landstr.

I I I. Friedrich Schön, Warenhaus Pollak, Wien I, Kohlmarkt 2, erbaut I909/Kulturgut

I I2. Stefan Fayans, Grabmal Elias, Wiener Zentralfriedhof, alte israelit. Abteilung, um I9 I I/Wiener Bauindustriezeitung I9 2

I I3. Josef Sinnenberg, Miethaus, Wien I4, Weinzierlgasse 9-I I, erbaut I9I2/I3/ Wiener Bauindustriezeitung

I I 4. Erich Ziffer, Doppelhaus, Wien I 8, Hockegasse 88, erbaut I924/Prokop

I I 5. Jakob Reitzer, Miethaus I9, Vegagasse 2 I, erbaut I907/Prokop

I 16. Leopold Schulz, Wohnhausanlage d. Gemeinde Wien, Wien 2, Taborstraße 94, erbaut I926/Prokop

I I7. Heinrich Kestel, Rochushof, Wien 3, Hintzerstraße 9-I I, erbaut I 9 Io/Prokop

I I 8. Friedrich Kiesler, Plakat der Theaterausstellung I925/Katalog Kiesler

I I9. Friedrich Kiesler, Shrine of the Book, Jerusalem, ISR, erbaut I958/63/Katalog Kiesler

I 20. Richard Neutra, Porträt/Katalog Visionäre und Vertriebene

I 2 . Richard Neutra, Entwurf Synagoge Hietzing, I924, nicht realisiert/Menorah I 929

I 22. Viktor Gruen, Porträt/Katalog Visionäre und Vertriebene

I 23. Hyppolite Destailleur, Palais Albert Rothschild, erbaut um I 880, Zustand I 954 (nicht erhalten)/Internet

I 24. Karl König, Villa Kuffner, Wien I9, Gymnasiumstraße 85, erbaut I 905/8 (nicht erhalten)/Internet

I 25. Friedrich Ohmann, Villa Regenstreif, Wien I8, Starkfriedgasse I4, erbaut I 9 I $5 /$ I 6 (nicht erhalten), Detail des Tores mit Initialen/Prokop

I 26. Josef Hoffmann, Villa Beer-Hofmann, Wien I 8, Hasenauer Straße 56, erbaut I 905/6 (nicht erhalten)/Sekler 


\section{Dankadresse}

Da sich die Arbeit und Recherche an diesem Vorhaben über Jahre und zahlreiche Länder erstreckt hat, ist kaum mehr zu rekonstruieren, wem ich allen zu Dank verpflichtet bin. An dieser Stelle sei eine Auswahl an Personen genannt, die auch stellvertretend für viele andere stehen sollen:

Mein Dank gilt unter anderen den Mitarbeitern zahlreicher Archive:

Dr. Paulus Ebner und Dr. Jukliane Mikoletzky vom Archiv der Technischen Universität Wien

Dr. Georg Widtmann vom Österreichischen Ingenieur und Architektenverein,

Ferdinand Gutschi von der Akademie der bildenden Künste Wien,

den Mitarbeitern des Archivs der Universität für Angewandte Kunst,

Dr. Wolf Erich Eckstein und Dr. Heidrun Weisz von der Matrikenstelle der Israelitischen Kultusgemeinde,

Herrn Georg Gaugusch vom Archiv Adler,

Gunther Hirschmann vom Literaturarchiv Kärnten,

Margaret Timmers vom Archiv des Victoria \& Albert Museum, in London,

Dr. Pavel Zatloukal vom Muzeum Olomouc,

den Mitarbeitern des Brighton Museum School of Art Archive.

Des Weiteren Mag. Monika Platzer und Direktor Dietmar Steiner vom Architekturzentrum Wien.

Den Mitarbeitern der Österreichischen Nationalbibliothek und der Bibliothek der TU Wien (insbesondere Herrn Alois Hartl).

Und schließlich den zahlreichen Angehörigen, die viele wichtige Informationen geliefert haben:

u. a. Roland Miksch, Monica Strauss, Doris Baum, Helga Schläfrig, Celia Male Babette Brown, Willi Groag, Jan Groag, Shmuel Groag, Oliver Bryk, Vivian Schiffmann-Reiser. 


\section{Personenregister}

Achleitner, Friedrich Iо, 24, 56, 67, 70, 88, I I 9, I $84,254 \mathrm{f}$,

Aichelburg, Wilhelm I89f, 255

Alberti, Leon Battista I Io

Altenberg, Peter I 33

Arnheim, Familie 2I

Augenfeld, Anna (geb. Epstein- Gutmann) I 52 Augenfeld, Felix I3 I, I 38, I46-I 52, I 59, I99f, 207, 253, 264,

Bach, Theodor 24

Bacher, Rudolf 232

Bahr, Hermann 248

Bakaczy, Judith I 35 f, I $38,255,264$

Baron, Arthur 59-62, I I I, 262

Baron, Kitty (geb. Kassowitz) 62

Bartos, Armand 234

Bastl, Beatrix I02, 255

Baudisch, Gudrun 138

Baum, Doris (geb. Lindner) 79, 267

Baumann, Ludwig I 2 I, 2 I8

Baumfeld, Fritz I95, 197

Baumfeld, Josef I 94

Baumfeld, Rudolf I69, I9If, 237, 239, 265

Baumgarten, Wilhelm I87-I90, 253, 265

Bayer, Josef 94

Bedoire, Fredric 9, 255

Beer, Julius I I $4 \mathrm{f}$

Beer-Hofmann, Richard $247 \mathrm{f}$

Behrens, Peter I 20, I87f, 237

Benton, Charlotte I 57, 196, 255

Berger, (alias Semenowitsch) Arthur I46, I 55 f, I $58 \mathrm{f}$

Berger, Josef I46, I 55-I 59, 25 I, 264

Berger, Margarete (geb. Hammerschlag) I 57

Bernard, Erich 173, 255

Bernau, Alfred I 23

Bernheimer, Ilse $208 \mathrm{ff}$

Bernleutner, (alias Bernay) Eugenie Io I

Blau, Tina 217

Boeckl, Mathias II, I26, 255
Bösel, Richard 48, 255

Boltenstern, Erich I24, I30, I68, 208, 2 I0, 242

Brandeis, Pavel 205

Brandstetter, Jutta 4I, 45, 7I, 255

Bredl, Rudolf 94

Brenner, Anton 209

Breton, André 234, 257

Brettschneider, Fritz 2 I 8

Briggs, Ella (geb. Baumfeld) 194-197, 251. 265

Briggs, Walter 195

Bucher, Herta 200

Bunzl,, Hugo i7 If

Burckhardt, Lucius I I 9,255

Burlingham, Dorothy I 47

Buttinger, Josef I 50 off

Chamberlain, Richard 207

Cortona, Pietro da 64

Čižek, Franz 207

Czettel, Adolf 244

Destailleur, Hyppolite 243f, 266

Dewald, Christian 159

Dicker, Friedl 20I-206, 213, 256, 265

Dobrowsky, Josef 207

Doesburg, Theo van $232 \mathrm{f}$

Dörmann, Felix Ior

Drach, Hermine Maria (geb. Hafkesbring) 176

Drach, Siegfried I70, I72-177, I87, 255, 264

Duchamp, Marcel 234, 257

Dvořak, Max 94

Ebner, Paulus 1 52, 267

Ehrlich, Georg I38, I 46

Eiblmayer, Judith I 27, 256

Eichmann, Adolf 222, 24I, 243

Eisenberg, Ludwig 37, 253

Eisler, Max 88, 90, 253

Elias, Menachem 218f, 266

Engelmann, Paul I33-I 38, 255, 257, 264 
Ephrussi, Familie 19, 49, I98, 2 I 4

Epstein, Familie I6, 49, 2 I 4,

Epstein, Ernst 97, I02-107, 256, 263

Epstein, Melanie (geb. König) I03

Epstein, Oskar IO2

Erbanova, Eva I8I, 255

Ermers, Max 204

Esch, Albert I 50

Fabiani, Max 50, 93, 234

Fanto, Daniel 73f, 262

Fayans, Stefan 213, 218f, 253, 266

Feininger, Lyonel 202

Feller, Barbara I73, 255

Fellerer, Max I 29

Fellner, Ferdinand 70, I 2 I, 2 I 8, 228

Fellner von Feldegg, Ferdinand I66, 253

Ferstel, Heinrich von 21, 44, 46, 93

Ferstel, Max 64

Ficker, Ludwig 172

Fischel, Hartwig 9, 92-95, 253, 263

Fischel, Maria Lacerta (geb. Kammerer) I 82

Fischel, Paul I79-I 83, 265

Fischer, Lisa 82, I 47, I 82, 255

Fischer von Erlach, Johann Bernhard 48

Fleischer, Max 25-37, 4If, 44, 76, I04, 253, $255 \mathrm{f}, 26 \mathrm{I}$

Fleischmann, Trude I34, I39, 207, 263

Flöge, Emilie I98

Förster, Ludwig 27, 31, 38

Fraenkel, Wilhelm I7-2 I, 249, 26I

Frank, Anna (geb. Sebenius) I I I

Frank, Josef I I, 50, 61, I06, I09-I31, I33, I42, I 59, I66, I68, I99, 242, 244, 249ff, 253, 256, 258,263

Frankl, Viktor 244

Franz Ferdinand, Erzherzog 47, I 2 I

Franz Josef I., Kaiser Io, I 5, 84, 258

Freud, Anna I47

Freud, Ernst I $45 \mathrm{ff}, 234 \mathrm{f}$

Freud, Lucian I 46

Freud, Sigmund 40, I46f, 234, 255

Fuchs, Leopold 97ff, 263

Fuks, Evi 75, I 21, 257
Gardiner, Muriel I sof

Gartner, Jakob 4I-44, 87, 26I

Gaugusch, Georg I70, 208, 216, 255, 267

Genée, Pierre Iof, 30, 80, 82, 85, 255, 262

Georgeacopol- Winischofer, Ute 229, 258

Gerlach, Martin I60

Girette, Jean 244

Gmeiner, Astrid I I 2, I I 7, 255

Goldmann, Leopold I03f

Goldmann, Salka 68

Goldmann, Sigmund I03f

Gomperz, Ada (geb. Stepnitz) 200, 208ff, 253, 265

Gomperz, Heinrich 200, 209

Gombrich, Ernst I2, 255

Gorge, Hugo 88ff, i 16

Gotthilf von Miskolczy, Alexander 37, 70-74, I 7 I, 262

Gotthilf von Miskolczy, Elisabeth (geb. Zifferer) 37

Gräwe, Christina 197, 256

Graf, Otto Antonia I63, 255

Groag, Emo I 38, 226

Groag Jacqueline/Hilde (geb. Pick, verw. Blumberger) I 35, I 45, 206-209, 257, 265

Groag, Jacques I I6, I 33-I46, I 52, I 56, I 59, I 89, 204, 206f, 226, 23 I, 253, 257, 263f

Groag, Willi 206, 226, 267

Gropius, Walter 202

Gruber, Karlheinz I02, 256

Gruen, (alias Grünbaum) Viktor I92, 237ff, 242, 250, 266

Grünberg, Dr. 83

Grünberger, Arthur 9If, II7, 22 I, 236, 263

Guevrekian, Gabriel I I 7

Gutschi, Ferdinand I 52, 267

Habison, Peter 246, 256

Haerdtl, Oswald I 20, I 24

Häring, Hugo II 7, 208, 210, 265

Haid, Liane 139

Halfon, Marcel 82f, 253

Hanisch, Ruth 88, I 47

Hansen, Theophil I7f, $38,42,214$

Hasenauer, Carl, 4I, 7 I 
Hauzsmann, Alajos 2I 4

Haynal, Klari (geb. Krausz) I 29

Helmer, Hermann 70, I21, 21 8, 228

Hernheiser, Anny 199

Herzl, Theodor 57, 59

Herzmanovsky-Orlando, Fritz 226

Herzner- Kaiser, Dagmar 64, I6I

Herzmansky, August 53, 55, 190, 262

Hirschmann, Gunther 172, 267

Hladisch, Lilly 225

Hofbauer, Josef I 87-190, 253, 265

Hoffmann, Else 200, 254

Hoffmann, Josef 64, 73, I I I, I I4, I I6, I I gf, I $33, \mathrm{I} 56, \mathrm{I} 58$. I65, I95, I98, 206ff, 233, 247f, 250, 257, 266

Hoffmann, Kitty I 82

Hofmann, Karl I 46-I 48

Hofmannsthal, Hugo von 248

Holzmeister, Clemens 88, 92, I I6, I 20, I9 I

Hrdlicka, Alfred 46

Huber, Ernst 138

Huebscher, Eva (geb. Zimbler) I98, 20 I

Husserl, Sigmund 26, 254

Ilg, Albert 47, 254

Itten, Johannes 20 If

Jaray, Adolf 170

Jaray, Karl I70-I73, 258, 264

Jaray, Karl Hans 170

Jaray, Margit (geb. Hirsch) I7If

Jaray, Sandor 170

Jarosch, Rudolf 244

Jeiteles, alias Jaray, Familie 170

Jelletz, Adolf 9 off

Johnson, Philipp 236

Joseph II., Kaiser I 5

Judtmann, Fritz I83-187, 265

Jungnickel, Heinrich 138

Kalmar, Julius I 28

Kammel, Leo 176

Kammerer, Paul I 82

Kantor, Siegfried 106

Kapfinger, Otto 88, I I7, I 20, 237
Karl, Erzherzog 26

Karplus, Arnold 64-67, 254, 262

Karplus, Gerhard 67

Katscher, Maximilian 54f, 258, 262

Kaus, Gina 147

Kaym, Franz I 26

Keller, (alias Kohn) Fritz I 35, 22 I, $225 \mathrm{f}$

Kelsen, Hans 68

Kestel, Heinrich 226ff, 266

Kestel, Malvine (geb. Bauer) 227

Kiesler, Friedrich 23I-234, 255, 257, 266

Klee, Paul 202

Kleiner, Leopold I 54

Klimt, Gustav 36, 93, I98

Kohut, Adolf ro, 254

Kokoschka, Oskar $93 \mathrm{f}$

König, Karl I I , 44-50, 53f, 56, 59, 63-80, 84f, 90, 92ff, I09-II2, I II, I 26, I 29, I 3 I, I 46, I70, I80, 2I 4, 218, 22I, 227, 245f, 249ff, $255 \mathrm{f}$, 26I, 266

Königswarter, Familie 35

Köpl, Regina I47, 255

Korn, Carl I I 8, I 36

Kornhäusel, Josef $26 \mathrm{f}$

Kratz, Käthe 27, 255

Kraus, Karl I04, I33f, I38, I70, I72, 258

Krauss, Franz von 6I

Krenek, Ernst I 28

Kristan, Markus II , 45, 49, 56f, I07, 256, $262 \mathrm{f}$

Kuffner, Ignaz 246

Kuffner, Wilhelm 48, 246

Kulka, Heinrich I $59 f f, 254,264$

Lampl, Fritz 156, I 58

Lampl, Hilde (geb. Berger) I 56

Laske, Oskar 138

Le Corbusier, (eigentlich Charles Édouard Jeanneret) 66, I 86

Lederer, Julius 80

Lederer, Familie I 53f, I 8 I, 246

Leger, Ferdinand 233

Lehne, Andreas 54, 256

Lichtblau, Ernst 50, 88, II6. I63-I70, I9If, 242, 25 of, 257, 264 
Lindner, Ernst 64, 74-80, 23I, 262

Lloyd Wright, Frank 235

Löw, Leopold/Lipot 2 I 4

Löw, Moses 2 I 4

Long, Christopher 49, 256

Loos, Adolf 43, 66, I02-I06, I I If, I I 5f, I 2 If, I 29, I 33-I 43, I 46-I 49, I 52, I 55f, I 59 f, I 72 , I 89, I95, 20I, 204, 22If, 234, 236, 238, 249, 254, 257

Loos, Claire (geb. Beck) I42

Lovell, Philip 236

Lueger, Karl 36, 50, I63

Luntz, Viktor 163

Lurçat, André II7

Lurje, Victor I $24 \mathrm{ff}$

Luzzatto, Elisabeth (geb. Grünbaum) 70

Luzzatto, Maximilian 70

Mahler, Gustav 94

Mahler, Alma (geb. Schindler) 94

Makarova, Eva 20I, 256

Male, Cecilia 197

Malleier, Elisabeth 68, 256

Mauthner-Markhof, Editha von 195

Marmorek, Alexander 56

Marmorek, Oskar II, 56- 59, 74f, 8of, 85, I63, 256,262

Marmorek, Wolfgang 56

Martens, Bob 27, 38, 85, 256

Matejka, Viktor I 20

Mayreder, Karl 64, 226, 234

Meder, Iris 5I, I 2 I, I 25, I 53, I 55, I 59, I 8 I, 210, 22I, 256f, 263

Melichar, Peter I8, 257

Mendel, Fritz 216

Mendel, Heinrich 216

Mendelsohn, Erich 67, I 84, 235

Merkel, Georg 138

Messel, Alfred 2 I 8

Micheroli, Adolf 2I I

Miksch,Roland I02, 267

Modern, Jakob 37- 40, 26I

Modern, Richard 4 of

Möhring, Bruno II I
Mörth, Franz 243

Moholy-Nagy, Laszlo 232

Moll, Carl 94

Moller, Anny (geb. Wottitz) I35, 20 I

Moller, Hans I 35, 20I, 204

Moser, Kolo I95

Münz, Ludwig 204

Nako, Graf 245

Neubacher, Hermann I I 6

Neumann, Alexander 70-74, I71, 262

Neutra, Richard 90, I I 7, 234-237, 254, 266

Nüll, Eduard van der 27

Ohmann, Friedrich 5I, 89f, 93, I2I, I63, I87, 246f, 266

Oser, Leopold 244

Oswald, Otto I 59

Ottilinger, Eva 90, 257

Ozzola, Leandro 217

Ozzola, Margit (geb. Schön) 2 I 7

Pasternak, Schmuel i 86

Paul, Martin 250, 254

Pauser, Sergius 138

Perco, Rudolf 88, I 26

Pereira, Familie 22, 27

Pirhofer, Gottfried I I 2,I I 7, 255

Plaisier, Pieter I33, I 59, 257

Plakolm,-Forsthuber Sabine II, I93, I97, 200, 207f, 2 I0, 257

Plečnik, Josef 6I

Plischke, Ernst I I 6

Plischke, Stefan 150

Pollak, Felix Angelo I70, I76f, 265

Pollak-Soffer, Lilia I 94

Postelberg, Viktor 78, 262

Powolny, Michael 6I, I53

Rainer, Roland 244

Rayner, Geoffrey, 207, 257

Regenstreif, Fritz 246f

Reinhardt, Max I24, I 50

Reiser, Hans 178 
Reiser, Ignaz 44, 84-89, 248, 263

Reitzer, Jakob 22I-224, 266

Reitzes, Freiherr von I8

Rietveld, Gerrit II 7

Riss, Egon I 83-187, 254, 265

Rösner, Karl 27

Rollig, Heinz 83f, 263

Rosenthal, Rena I 54

Rothschild, Albert $243 \mathrm{f}$

Rothschild, Familie 22, 243f, 257

Rothschild, Nathaniel 243

Rozenblit, Marsha IO, I 2, 257

Rudolf, Kronprinz 93

Rukschcio, Burkhardt I 33, I 55, I95, 257

Russel, Gordon I45, 253

Russel-Hitchcock, Henry 236

Sacher, Anna I9

Sacher, Eduard I9

Satoko, Tanka, 34, 257

Sarnitz, August I63, I66f, 257, 264

Sauer, Barbara I 43, I 84

Schachel, Roland I33, I 55, I95, 257

Schachner, Friedrich 245

Schad, Christian I82

Schanzer, Eva 142

Schanzer, Stefan 142

Scheidl, Inge I7, 26, 34, 4I, I37, I 57, I 80, I94, 226, 257

Schiele, Egon 93

Schindler, Emil $93 \mathrm{f}$

Schindler, Rudolph 236

Schirach, Baldur von 24I

Schläfrig, Albert 177

Schläfrig, Friedrich 177

Schläfrig, Gustav I70, 176-179, 265

Schläfrig, Helga 177,267

Schläfrig, Jonas 177

Schlemmer, Oskar 202

Schlesinger, Norbert I69, I9 If, 265

Schmidl, Ludwig 67-70, 195, 262

Schmidt, Friedrich von 25-28, 37, 4I, 44, 21 4, 249, 253f, 256, 258

Schmutzer, Ferdinand 232
Schnitzler, Arthur 248

Schön, Clara 217

Schön, Eugenie (geb. Cahn) 217

Schön, Friedrich 213-218, 266

Schönberg, Arnold 74, 135

Scholl, Familie I I $2 \mathrm{f}$

Schorske, Carl 9, 257

Schreier, Theodor 74-80, 21 3, 262

Schütte-Lihotzky, Margarete I 24, I 94

Schulz, Leopold 221, $223 \mathrm{ff}, 251,266$

Schumann, Petra I 84, 223

Schuster, Franz I 24

Schwadron, Erna (geb. Mendel, gesch. Lederer) I 53

Schwadron, Ernst I46-1 55, 64

Schwadron, Viktor 6I, I 25, I 52, I 54, 258

Schwadron, Walter 6I, I25, I 52, I 54, 258

Schwarzwald, Eugenie I 55,22 I

Sekler, Eduard F. 248, 257

Seligmann, Adalbert 194

Senarclens de Grancy, Antje 5 I, 256

Shapira, Elana I04, 257

Sicardsburg, August von 37

Siller, Heinz 179-183, 254, 265

Simony, Leopold 24

Singer, Emmy (geb. Heim) 202

Singer, Franz I 46, 20I-206, 248, 265

Sinnenberg, Herschel 219

Sinnenberg, Josef 213, $219 f f, 266$

Slavik, Felix 237

Sobotka, Ruth I3 I

Sobotka, Walter I16, I 26, I29ff, I69, I99, 242, 253f, 263

Speer, Albert 237

Spielmann, Emmerich 63f, 262

Spiro, Hans I8I, 265

Stapleton, Annamarie 207

Stein, Isidor 216

Stein, Siegfried 216

Steiner, Maximilian 23

Steinitz, Leopold 226, $228 \mathrm{f}$

Stern, Gustav I 43

Stiassny, Wilhelm 25, 30-37, 4I, 44, 56, 64, 76, 85, I04, 244, 25I, 254, 257, 26I 
Strauss, Familie I49, 264

Strauss-Likarz, Maria I48f, 200, 206f, 264

Streit, Andreas 245

Strnad, Mathilde I 24

Strnad, Oskar 50, 64, 75, 89, I I off, I I 6, I I 9-I 30, I 42, I 50, I 56, I 58, I 98, 208ff, 247, 249ff, $256 f, 263$

Teller, Alfred 50, 63f, 75, 262

Templ, Stephan 55, 258

Tesar, Severin I03

Tietz, Carl I7f

Tietze, Erica 93

Tietze, Hans 9, 93, 254

Todesco, Familie I 6, 27, 49, 2 I 4

Tölk, Josef 6I

Toor, Anita $20 \mathrm{I}$

Tropp, Elias/Eduard rooff

Tropp, Neumann/Nahum 97, 99-I02, 2 I 9f, 258, 263

Tscholakov, Monika 92, I47

Ullmann, Regine 68, 256

Unger, Josef I 7, 2I-24, 93, 254, 26 I

Unger, Kurt I 38

Unterweger, Ulrike 88, 90, 258

Urban, Gisela I94, 254

Vana, Heinrich 243

Vana, Kurt 243

Vetter, Hans Adolf I I 6

Wachsberger, Arthur I 37

Wagenknecht, Christian I72, 258

Wagner, Otto I I, 48ff, 57, 60, 74, 76, 93, I I 7, I 2 I, I 56, I63f, 236, 25 I, 254

Wagner, Richard I6, 254

Walter, Bruno I 24

Walzer, Tina 55, 21 5, 242, 258

Wassermann, Jakob I 22f, 263
Wehdorn, Manfred 229, 258

Weigel, Hans I47

Weihsmann, Helmut I I, 64, 67, 93, I 26, I 37 , I 77, I 86, I 94, 225f, 228, 258

Weixlgärtner, Josephine 234

Welzig, Maria I I, 6I, I Io, I 20, I 26f, 242, 258 , 263

Wessely, Paula I 24, I39

Widtmann, Georg 22, 258, 267

Wiedenfeld, Hugo von 32

Wiener, Regina Renata 2 I of, 265

Wieselthier, Vally I $53 \mathrm{f}$

Wijdeveld, Paul I 34, 258, 264

Wistrich, Robertio, 258

Wittgenstein, Ludwig I34, I36ff, I95, 245, 258, 264

Wittgenstein, Clara I95

Wittgenstein- Stonborough, Margaret I 36, 257

Wlach, Oskar 50, 67, Io6, I Io-I I 5, I 2 I, I $26-$ I 3O, 23I, 242, 25 I, 263

Wörle, Eugen I 29

Wohlmuth, Julius 8I-84, $262 \mathrm{f}$

Ybl, Miklos 2 I 4

Zatloukal, Pavel ıoo, 258, 267

Zettelbauer, Heidrun 5 I, 256

Zickler, Tina I 52, 258

Ziegler, Martin I55-I 59, 25 I, 264

Ziffer, Erich 22 Iff, 266

Zifferer, Donat $36 \mathrm{f}$

Zifferer, Paul 37

Zifferer, Rosa (geb. Schuler) 37

Zimbler, Liane (geb. Fischer) I97-201, 207, 209, $254,256,265$,

Zimbler, Otto r 98

Zuckerkandl, Otto 244

Zweybrück, Emmy I 54

Zwieback, Ludwig 200, 2 I $4 \mathrm{f}$ 


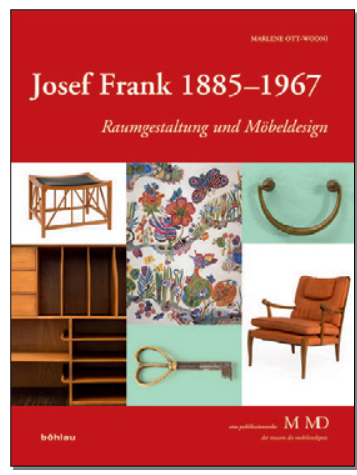

\section{MARLENE OTT-WODNI}

\section{JOSEF FRANK 1885-1967}

RAUMGESTALTUNG UND MÖBELDESIGN

(EINE PUBLIKATIONSREIHE M MD DER MUSEEN DES MOBILIENDEPOTS, BAND 33)

Der österreichische Architekt Josef Frank war in der Zwischenkriegszeit als Mitglied des Werkbundes und als teilnehmender Architekt der Stuttgarter Weißenhofsiedlung aktiv in das internationale Architekturgeschehen eingebunden. Aufbauend auf seine frühen Entwürfe der 1910er Jahre bildet seine Tätigkeit für die Einrichtungsfirma Haus \& Garten den Schwerpunkt des Buches. Das Unternehmen fungierte mit seinen flexiblen Einzelmöbeln, seinen farbenfrohen Textilien sowie seiner antidoktrinären Wohnauffassung als Gegenpol zur Wiener Werkstätte. Aufgrund seiner jüdischen Herkunft emigrierte Josef Frank in den 1930er Jahren nach Stockholm. Als Designer der Firma Svenskt Tenn knüpfte er nahtlos an sein Wiener Schaffen an. Josef Frank gilt heute gemeinhin als Begründer des modernen schwedischen Einrichtungsstils.

2015. 393 S. 722 S/W- UND 66 FARB. ABB. GB. MIT SU. $210 \times 281$ MM. ISBN 978-3-205-79647-3

BÖHLAU VERLAG, WIESINGERSTRASSE I, A-IOIO WIEN, T: + 43 I 33024 27-O INFO@BOEHLAU-VERLAG.COM, WWW.BOEHLAU-VERLAG.COM | WIEN KÖLN WEIMAR 


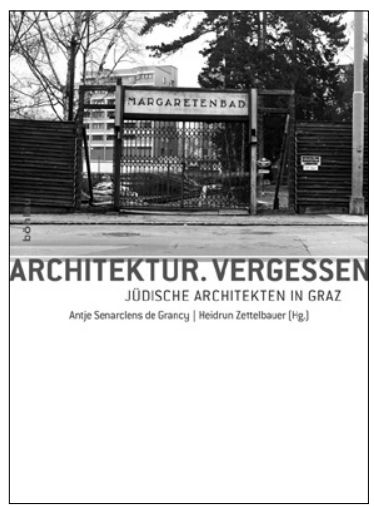

ANTJE SENARCLENS DE GRANCY UND HEIDRUN ZETTELBAUER (HG.)

ARCHITEKTUR. VERGESSEN

JÜDISCHE ARCHITEKTEN IN GRAZ

Fünf Grazer Bauten aus der Zeit von 1910 bis 1934 bilden den Ausgangspunkt für den Blick auf das Vergessen als kulturelle Praxis im Feld der Architektur. Die Autorinnen zeichnen ein Spannungsfeld zwischen alltäglichen Prozessen der Überbauung, Funktionsveränderung und räumlicher Neukonzeption sowie gewaltsamen Eingriffen wie politischer Neukodierung und Zerstörung nach.

Am Beispiel von Arbeitsamt, Freibad, Jüdischer Zeremonienhalle, Kinderheim und Stadtrandsiedlung werden vielschichtige Dimensionen des Vergessens freigelegt: Zufälliges, Intentionales, Privates, Öffentliches, Nicht-Erzähltes, Un-/Sichtbares.

Die Klammer, welche die vier Architekten und Baumeister zusammenhält, ergibt sich nicht aus ihrer jüdischen Herkunft oder Identität, sondern erst aus der nationalsozialistischen Verfolgungsgeschichte als einem Aspekt des Vergessens.

2010. BR. 300 S. 178 S/W-ABB. $170 \times 240$ MM.

ISBN 978-3-205-78472-2

BÖHLAU VERLAG, WIESINGERSTRASSE I, IOIO WIEN. T : + 43(o) I 33024 27-O BOEHLAU@BOEHLAU.AT, WWW.BOEHLAU-VERLAG.COM | WIEN KÖLN WEIMAR 
Während der Beitrag von jüdischen Künstlern und Wissenschaftlern am Wiener Kulturleben schon lange Eingang in die Geschichtsschreibung gefunden hat, wurde der Tätigkeit von jüdischen Architekten und Architektinnen bis dahin kaum ein Augenmerk geschenkt. Diese Studie versucht einen Überblick über die bedeutendsten Persönlichkeiten und deren Projekte zu geben, von den ersten Anfängen in der Ringstraßen-Ära bis zum „Anschluss“ Österreichs 1938. 